Georg Jäger

\title{
Schule
}

und literarische Kultur

Band 1: Sozialgeschichte des deutschen Unterrichts an höheren Schulen von der Spätaufklärung bis zum Vormärz

J.B. Metzlersche Verlagsbuchhandlung Stuttgart 
CIP-Kurztitelaufnahme der Deutschen Bibliothek

\section{Jäger, Georg}

Schule und literarische Kultur / Georg Jäger.

- Stuttgart: Metzler

Bd. 1. $\rightarrow$ Jäger, Georg: Sozialgeschichte des deutschen Unterrichts an höheren Schulen von der Spätaufklärung bis zum Vormärz

\section{Jäger, Georg}

Sozialgeschichte des deutschen Unterrichts an höheren Schulen von der Spätaufklärung

bis zum Vormärz / Georg Jäger.

- Stuttgart: Metzler, 1981.

(Schule und literarische Kultur / Georg Jäger; Bd. 1)

ISBN 3-476-00478-3

\section{Universitäts- Bibliothek München}

ISBN 3-476-00478-3

(C) J. B. Metzlersche Verlagsbuchhandlung und Carl Poeschel Verlag GmbH in Stuttgart 1981 Satz und Druck: Gulde-Druck, Tübingen Printed in Germany 


\section{Inhalt}

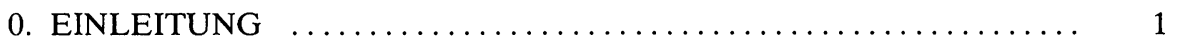

1. EPOCHEN DES DEUTSCHEN UNTERRICHTS $\ldots \ldots \ldots \ldots \ldots \ldots .6$

1.1. Grundzüge der Entwicklung vom 16. bis zum 18. Jahrhundert ........ 6

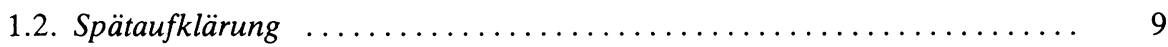

1.2.1. Die Konzeption der Universalschule und die staats- und gesellschaftspolitische Begründung des Sprach- und Literaturunterrichts ........ 9

1.2.2. Humanistische Schulorganisationsentwürfe (Heyne, Wolf, Humboldt) . 12

1.2.3. Aufklärerische Prinzipien des Sprach- und Literaturunterrichts $\ldots \ldots .13$

(a) Spracherlernung durch IInduktion und Gebrauch - (b) Textanalyse statt Rhetorik - (c) Geschmacksbildung und Lektüre - (d) Sachunterricht beim Sprachenlernen - (e) Stilübungen für Beruf, Amt und Leben

1.2.4. Die Schlüsselstellung des Braunschweiger >Collegium Carolinum in der Entwicklung des deutschen Unterrichts .................. 18

1.2.5. Querschnitt durch die Gymnasialreform 1773/83 - Zürich, Fulda,

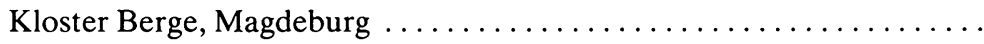

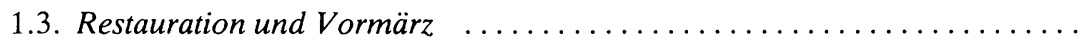

1.3.1. Sozialhistorische und schulorganisatorische Voraussetzungen der

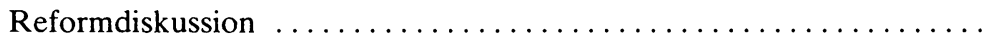

1.3.1.1. Beispiele für das Verhältnis von Studierenden und Nichtstudierenden

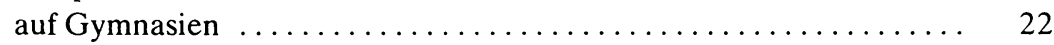

1.3.1.2. Beispiele für die Verbindung von Gymnasium und Realschule ...... 24

1.3.2. Schulorganisatorische Vorstellungen .................... 25

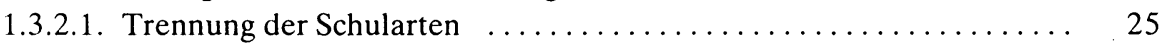

1.3.2.2. Gemeinsame Unterstufe für Gymnasien und Realschulen $\ldots \ldots \ldots .26$

1.3.2.3. Der Stufenaufbau der höheren Schule .................... 27

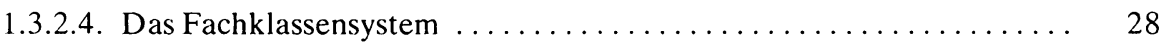

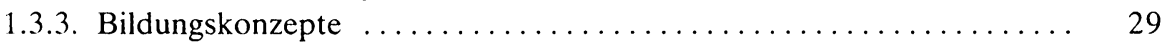

1.3.3.1. Sprachlich-formale Bildung $\ldots \ldots \ldots \ldots \ldots \ldots \ldots \ldots \ldots \ldots . \ldots . \ldots . \ldots 29$

1.3.3.2. Die Auswirkung des formalen Bildungskonzepts auf den Lehrplan und die Organisation der Gymnasien $\ldots \ldots \ldots \ldots \ldots \ldots \ldots \ldots . \ldots \ldots \ldots$

1.3.3.3. Universell-historische Bildung ...................... 33

1.3.3.3.1. Der universalistische Bildungskanon $\ldots \ldots \ldots \ldots \ldots \ldots \ldots \ldots . \ldots \ldots$

1.3.3.3.2. Die historische Interpretationsweise $\ldots \ldots \ldots \ldots \ldots \ldots \ldots \ldots . \ldots \ldots$ 
1.3.3.3.3. Der Deutschunterricht als Mittelpunkt christlich-nationaler Bildung (a) Die Aufwertung des Faches Deutsch auf Realschulen - (b) Deutsch als Mittelpunktsfach auf Gymnasien: Lektüre mit Literaturgeschichte, Aufsätze - (c) Die fach- und schulartenübergreifende Nationalbildung

2. STAATLICHE DIFFERENZIERUNGEN

2.1. Preußen

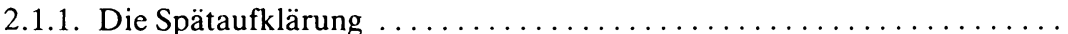

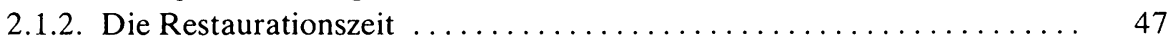

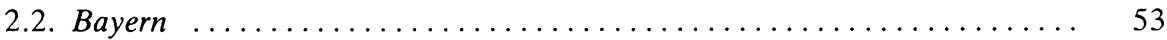

2.2.1. Die Zeit der Aufklärung von Braun bis Wismayr (1804) . . . . . . . 54

2.2.2. Neuhumanismus und rhetorische Restauration, die Zeit von 1808 (Niethammersches Normativ) bis $1829 \ldots \ldots \ldots \ldots \ldots \ldots \ldots$. . . . . . . . . . . . . . . .

2.2.3. Die altphilologische Reaktion: Der Streit um Thierschs Lehrplanent-

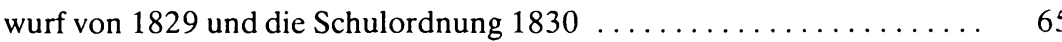

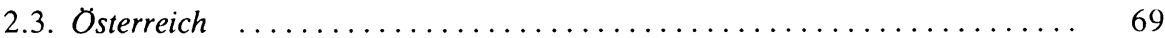

2.3.1. Schulorganisatorische und sozialhistorische Voraussetzungen ....... 69

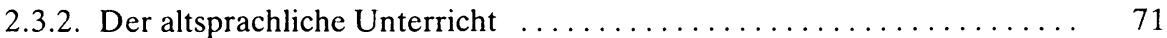

2.3.3. Der Formalismus des Rhetorikunterrichts $\ldots \ldots \ldots \ldots \ldots \ldots \ldots \ldots$

2.3.4. Die Kanonbildung im Deutschen $\ldots \ldots \ldots \ldots \ldots \ldots \ldots \ldots \ldots \ldots$

1.Institutiones ad Eloquentiam: a. »Anhang von der teutschen Dichtkunst«, b. Die Beispielsammlung, im Vergleich mit den Anthologien von Denis, Weitenauer und Mertens - 2.Institutio ad Eloquentiam 3.Sammlung deutscher Beyspiele zur Bildung des Styls - 4.Podlahas Muster deutscher Redekünste (1842), im Vergleich mit deutschen Lesebüchern

3. DIE LITERARISCHE KULTUR DER HÖHEREN SCHULE

3.1. Die Prosakultur

(a) Geschichte - (b) Naturschilderung und Reisebeschreibung - (c) Philosophisches und Theologisches - (d) Ästhetik, Kunst-, Literatur- und Sprachgeschichte - (e) Erzählprosa

3.2. Der Wandel des Literaturkanons während der Restaurationszeit: Von der rhetorischen Chrestomathie zum nationalliterarischen Lesebuch ........ Anhang zu Kap. 3.1 und 3.2: Prosa und Poesie vom Mittelalter bis zum Barock 


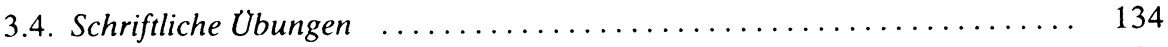

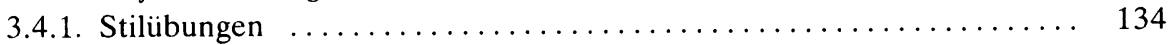

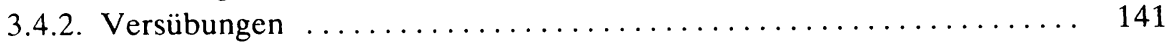

3.4.3. Schul- und Jugenddichtungen $\ldots \ldots \ldots \ldots \ldots \ldots \ldots \ldots \ldots \ldots \ldots \ldots \ldots \ldots$

4. OFFENE FRAGEN UND PROBLEME $\ldots \ldots \ldots \ldots \ldots \ldots \ldots \ldots \ldots$

5. KURZBIOGRAPHIEN $\ldots \ldots \ldots \ldots \ldots \ldots \ldots \ldots \ldots \ldots \ldots \ldots \ldots \ldots \ldots$

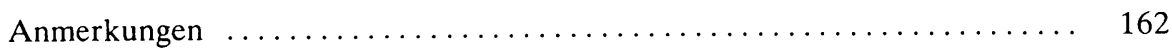

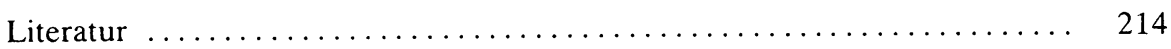

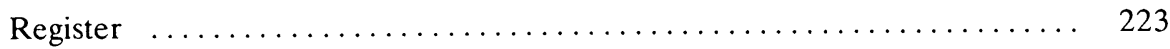




\section{Verzeichnis der Tabellen}

1 Deutschlehrpläne schlesischer Gymnasien 1830/36 ............. 49

2 Lehrplanentwicklung in Münnerstadt (Unterfranken) $1775-77 \ldots \ldots \ldots \quad 56$

3 »Deutsche Sprache« im Zweyten Triennal-Kurs in Bayern 1804 ....... 58

4 Der deutsche Lektürekanon nach dem Niethammerschen Normativ von 1808 in Bayern ................................... 59

5 Epische, idyllische und beschreibende Poesie als Schullektüre in Bayern 1809/23 ...........................................

6 Didaktische, historische und oratorische Prosa als Schullektüre in Bayern $1809 / 23$........................................ 64

7 Wochenstundenzahlen nach der bayerischen Schulordnung $1830 \ldots \ldots .67$

8 Österreichischer Lehrplan nach den Veränderungen $1818 / 19$........ 72

9 Lehrplan von Schulpforta nach dem Protokoll $1819 \ldots \ldots \ldots \ldots \ldots \ldots . . \ldots 72$

10 Lehrplan der Wiener Gymnasiallehrerversammlung $1792 \ldots \ldots \ldots \ldots \ldots \quad 81$

11 Deutsche Literatur in den Institutiones ad Eloquentiam 1778/79 ....... 90

12 Denis' Sammlung kürzerer Gedichte 1776-78 ................... 90

13 Weitenauers Sammlung kürzerer Gedichte $1768 \ldots \ldots \ldots \ldots \ldots \ldots . \ldots . \ldots 90$

14 Mertens' Auserlesene kleinere Gedichte 1772 ................... 91

15 Die Kanonbildung in außerösterreichischen Textsammlungen im Vergleich mit Podlahas Muster deutscher Redekünste 1842 ................. 94

16 Deutsche Prosa ab 1750 in Textsammlungen für Gymnasien während der

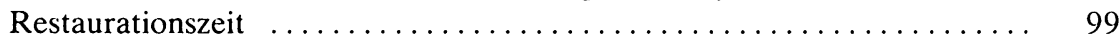

17 Die Romantik in Schwabs Prosaanthologie $1843 \ldots \ldots \ldots \ldots \ldots \ldots \ldots . \ldots \ldots$

18 Deutsche Literatur in Textsammlungen für den höheren Unterricht

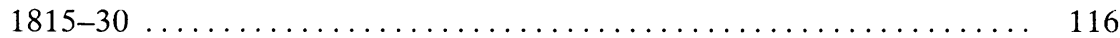

19 Deutsche Literatur in Textsammlungen für den höheren Unterricht

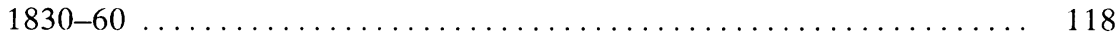

20 Philosophische Gedichte und Elegien Schillers in Textsammlungen für den höheren Unterricht in der Restaurationszeit $\ldots \ldots \ldots \ldots \ldots \ldots \ldots$.

21 Hölderlin, Romantiker und Autoren der Freiheitskriege in Textsammlungen für den höheren Unterricht in der Restaurationszeit .............

22 Auszüge und Belegstellen aus der deutschen Literatur in Rhetorik- und Poetiklehrbüchern der Restaurationszeit

23 Pischons Denkmäler der deutschen Sprache 1840-43: Auswahl für den

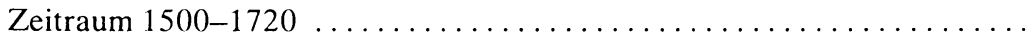




\section{Einleitung}

Das Verhältnis von Literatur und Gesellschaft, wie es sich vom späten 18. bis zur Mitte des 19. Jahrhunderts gestaltet hat, wird in dieser Studie in den durch den deutschen Unterricht gegebenen Zusammenhängen dargestellt. Dabei wird die Schule als eine zwischen den gesellschaftlichen Entwicklungen und der literarischen Kultur vermittelnde Institution angesehen, die es möglich macht, die Zusammenhänge schrittweise nach zwei Richtungen hin zu untersuchen:

1. Untersuchungsbereich

2. Untersuchungsbereich

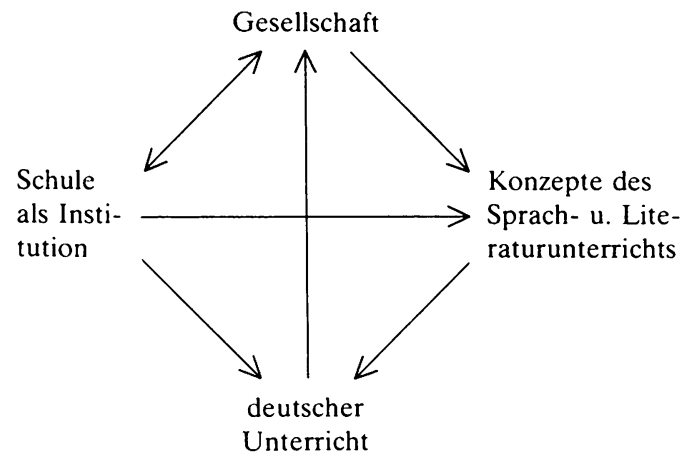

Im ersten Untersuchungsbereich (Teil 1) wird einmal den gesellschaftlichen Zielsetzungen nachgegangen, wie sie in vielen Konzepten des Sprach- und Literaturunterrichts sich direkt aussprechen, sodann den auf das Verhältnis von Schule und Gesellschaft bezogenen Diskussionszusammenhängen, denen solche Konzepte angehören. Fragen der Organisationsweise stehen dabei im Mittelpunkt, da sich im Untersuchungszeitraum, während dem das humanistische Gymnasium entsteht, eine lebhafte Kontroverse um ein ganz oder teilweise einheitliches oder gegliedertes höheres Schulwesen abspielt, in dem sich bereits die meisten heute bekannten Argumente finden. Die zeitgenössische Argumentation bindet die jeweils geforderte Art des Unterrichts vielfach unmittelbar an institutionelle Organisationsvorschläge, was für den den größten Teil der Unterrichtszeit beanspruchenden Sprach- und Literaturunterricht im besonderen Maße gilt. Somit werden die Zusammenhänge zwischen gesellschaftlichen Vorgegebenheiten und Zielvorstellungen, institutionellen Organisationsvorschlägen und Konzepten des Sprach- und Literaturunterrichts vor allem nach intentionalen Äußerungen und dem damaligen Meinungsspektrum skizziert. Wie die in diesem Rahmen plausiblen Funktionszusammenhänge realhistorisch zu bewerten sind, könnte erst eine noch ausstehende differenzierte Sozialgeschichte 
der Schule beantworten helfen. Die in dieser Arbeit mitgeteilten Angaben zur Institutionengeschichte der Schule, zur Zusammensetzung ihrer Schülerschaft etc. können immerhin die Situation verdeutlichen, in der argumentiert wird; zudem handelt es sich meist um Daten, auf die sich die Diskutanten selbst bezogen.

Die Art und Weise, wie die Schule in die literarische Kultur einübt, und der Einfluß, den sie damit auf die literarische Entwicklung nimmt, kann dagegen durch Analysen von Lehrbüchern und Textsammlungen, mit Hilfe von Lehrplänen und Angaben zum Unterricht einzelner Anstalten (in erster Linie aus den jährlichen Programmen), schließlich auch durch poetische Jugendversuche viel konkreter erfaßt werden (Teil 3). Die vor der Konkurrenz der Massenmedien im Vergleich zur Gegenwart erheblich größere kulturprägende Kraft der höheren Schule läßt sich in zweierlei Hinsicht thematisieren:

- Indem die Schule einen weiten rhetorischen Literaturbegriff tradiert, der poetische Texte, Sachprosa und Zweckformen aller Art umfaßt, und in rhetorische wie literarische Techniken praktisch einübt, kommt es noch zu keiner so weitgehenden Autonomisierung und Professionalisierung des literarischen Bereichs, wie es für die Moderne charakteristisch ist. Die »mit der Institution Kunst gesetzte Dichotomie Kunst versus Gesellschaft (im Sinne von Lebenspraxis)« [1] hat sich bis zur Mitte des 19. Jahrhunderts erst in Ansätzen entwickelt.

- Der Rhetorikunterricht war auf die künftigen Berufe der Schüler, ihre gesellschaftliche Stellung und ihre geselligen Bedürfnisse zugeschnitten. Auf diese Weise kam er der künftigen beruflichen (Predigten bei Geistlichen, Anklage- und Verteidigungsreden der Juristen, Unterricht der Professoren und Lehrer, Amtsverkehr) und öffentlichen Wirksamkeit (Stände, Parlamente, Volksfeste) und dem geselligen Leben (Zirkel und Vereine, Gelegenheitsdichtungen und -reden) zugute. So hat die zeitgenössische Kultur ihr sprachliches Kommunikationssystem noch zu wesentlichen Teilen in rhetorischen Texten beschrieben und mit Hilfe der Schule reguliert und normiert. [2]

Der mittlere Teil der Arbeit (Teil 2) trägt der regionalen Differenzierung im deutschen Kulturraum Rechnung. Zu Preußen, das die Geschichte des Bildungswesens sowohl in der Spätaufklärung wie im Neuhumanismus wesentlich bestimmt, werden Österreich als konkurrierende Großmacht und Bayern als wichtigstes süddeutsches Land im späteren kleindeutschen Reich ausgewählt. Österreich bietet einen Kontrastfall zu Preußen, so daß es möglich wird, einige auf die Entwicklung des deutschen Unterrichts wesentlich einwirkende kultur- und sozialgeschichtliche Faktoren zu isolieren. Zugleich verbinden die Länderkapitel den ersten mit dem dritten Teil der Arbeit. Durch die Analyse der Lehrpläne, Querschnitte durch die Unterrichtspraxis etc. konkretisieren sie die pädagogischen Konzepte und stellen den im folgenden detailliert behandelten literarischen Unterricht in den Rahmen dieser Entwicklung. Indem der Darstellung der literarischen Kultur der höheren Schule eine Differenzierung nach Epochen und Ländern vorangestellt wird, sind freilich Überschneidungen und Wiederholungen nicht ganz zu vermeiden.

Vorarbeiten zu den hier behandelten Fragen gibt es nur partiell, vor allem eine 
Würdigung der Schulrhetorik des späten 18. und 19. Jahrhunderts trifft noch immer auf festgewurzelte Vorurteile: Die Rhetorik werde von der konservativen Institution der Schule als totes Bildungsgut weitergegeben und, da sie keine gesellschaftliche oder literarische Funktion mehr erfülle, auf die formalen Elemente (Stilistik, Figurenlehre) reduziert. Jahre, nachdem Sengles Biedermeierzeit [3] die rhetorische Grundstruktur der Restaurationszeit detailliert erschlossen hat, heißt es in Uedings Einführung in die Rhetorik [4]: Das klassische System der Rhetorik habe »mit Beginn des 19. Jahrhunderts seine geschichtliche Bedeutung verloren « und werde »aus dem kulturellen und geistigen Leben mehr und mehr eliminiert«. Wie sehr ein solches Geschichtsbild, das eine einlinig progressive Entwicklung von der Romantik zur Moderne unterstellt, selbst die >Höhenkammliteratur`verfehlt, erhellt aus den Arbeiten Schaubs zu Büchner. [5] Vielleicht kann vorliegende Untersuchung das Postulat vom Ende der Rhetorik im 18. Jahrhundert weiter relativieren helfen. Sie setzt bewußt bei der Schule als Vermittlungsinstanz der Rhetorik an, um dann den überraschend lebhaften Beziehungen zur zeitgenössischen literarischen Kultur nachzugehen. Dieser Arbeit liegt dabei die Auffassung eines diskontinuierlichen Geschichtsganges, der zum Beispiel eine rhetorische Restauration ermöglicht, wie die Annahme einer Diskrepanz zwischen ideengeschichtlichen und realhistorischen Entwicklungen zugrunde: Konsequenzen aus geistesgeschichtlichen Problemlagen - wie Individualisierung, Historisierung versus Rhetorik als System - werden oft früh gezogen und radikal formuliert, während die kulturelle Gesamtsituation sich nur langsam umwälzt und von einer (nicht unbedingt dysfunktionalen) Verbindung traditionaler und moderner Bestände geprägt wird.

Sieht man von der Geschichte des Lesebuchs ab, so kann die Untersuchung auch nur auf wenige Arbeiten aus der Pädagogik zurückgreifen. Während die allgemeine Bildungsgeschichte als interdisziplinäre Forschungsrichtung[6] eine Renaissance erlebt - kennzeichnend dafür ist das geplante sechsbändige »Handbuch der deutschen Bildungsgeschichte « mit einem in Richtung Sozialisations-, Familien- und Medienforschung erweiterten Bildungsbegriff -, muß das Interesse an der Geschichte in der Literaturdidaktik »überhaupt erst provoziert werden «. [7] Am ehesten ist noch die Entwicklung seit der zweiten Hälfte des 19. Jahrhunderts präsent, sei es auch nur in der Kritik, die am Lesebuch und seinen Bildungsinhalten seit den fünfziger Jahren geübt worden ist. [8] Aber gerade der Rhetorik-, Poetik- und Stilistikunterricht des vorhergehenden Zeitraums könnte der aktuellen Diskussion einen historischen Erfahrungsraum bereitstellen. Wenn die Literaturdidaktik »im Anwenden von begrifflichen Kriterien, und nicht in der gemüthaften Partizipation allein « [9], den Zugang zum Text sucht, so nähert sie sich einer Literaturbetrachtung mittels definierter literaturbezogener Kriterien, wie sie die Systeme von Rhetorik und Poetik bereitstellten. Der stärker handwerkliche Angang zeigt sich da, wo man dem Lesebuch »eine Gliederung von den Formen her «, von den Gattungen und Darstellungsweisen gibt, die »einen `Lehrgang der Poetik«« möglich macht. [10] Aus der Kritik ist die Konzeption eines Lesebuchs als literarisches Arbeitsbuch entstanden. Aber auch die Reaktion auf diesen Vorgang, die Kritik an einer mit dem Anspruch auf Emanzipation durch Kompetenzverleihung auftretenden sprachlichen Schulung, die 
emotionale Lernziele wieder stärker realisiert sehen möchte, läßt sich im hier untersuchten historischen Feld studieren.

Als ein Beitrag zur Sozialgeschichte der Literatur, die in der Untersuchung der literaturvermittelnden und -prägenden Instanzen einen ihrer Schwerpunkte besitzt, ist die Arbeit interdisziplinär angelegt. Sie ist im Grenzgebiet zwischen germanistischer und bildungshistorischer Forschung angesiedelt, muß jedoch von Fall zu Fall auch den lateinischen Unterricht thematisieren. Die Notwendigkeit ergibt sich schon aus dem Übergewicht des Lateins in den Lehrplänen der Gymnasien. Ende des 18. Jahrhunderts gab es noch Anstalten, die »von 40 Stunden 28 dem lateinischen Unterricht « widmeten [11], und selbst nach den Reformen blieb das Gymnasium weithin eine `Gelehrtenschule , die in den alten Sprachen ihr Zentrum besaß. Den Verknüpfungen des deutschen mit dem altsprachlichen Unterricht muß besonders deshalb nachgegangen werden, weil der nicht nationalsprachlich begrenzte Rhetorikund Poetikunterricht die uns heute geläufigen Fächergrenzen ständig überspringt. Die Systeme der Rhetorik und Poetik knüpfen in ihrer Lehre zwar an die Antike an, benutzen jedoch >Muster aus mehreren Jahrhunderten und Sprachen und legen sogar eine direkte Parallelisierung zeitgenössischer deutscher mit fremdsprachigen und antiken Dichtungen nahe. Hier liegt bildungsgeschichtlich die Rechtfertigung für den unmittelbaren Vergleich damaliger mit antiker Literatur. Der theoretische Rhetorikund Poetikunterricht kann ebenso an die lateinische wie an die deutsche Lektüre anknüpfen. Mit Ciceros Orator und De Oratore (Buch 1 und 2) und Horaz' Ars Poetica, während des ganzen Zeitraums beliebte Unterrichtsstoffe, wird die rhetorische und poetische Lehre noch dort abgestützt, wo sie auf dem Lehrplan nicht eigens erscheint. Schließlich bildet der Lateinunterricht später vom Deutschen übernommene didaktische Verfahren zuerst aus. Dieser vom Gegenstand nahegelegten Ausweitung des Untersuchungsfeldes wirkt an anderer Stelle eine Begrenzung entgegen, die sich aus der Fragestellung ergibt. Da primär der Beitrag der höheren Schule zur literarischen Kultur interessiert, konzentriert sich die Untersuchung auf den Oberstufenunterricht und klammert die Grammatik aus.

Mit Angaben zum Vorkommen zahlreicher Autoren(gruppen) in Textsammlungen für die höhere Schule (Kap. 3.1 und 3.2) und der Diskussion von Faktoren, die hierbei zu charakteristischen Verteilungen führen, wird ein Stück Rezeptionsgeschichte bearbeitet. Daß trotz der Konjunktur rezeptionsgeschichtlicher Untersuchungen der deutsche Unterricht wenig erforscht wurde, liegt mit darin, daß es »in ganz Deutschland keine einzige planmäßige und umfangreiche Sammlung « alter Schul- und Lesebücher [12] und ebensowenig zureichende bibliographische Hilfsmittel gibt. Bd. 2 dieser Arbeit enthält neben kommentierten Programmen und Materialien zum deutschen Unterricht eine als Arbeitsinstrument angelegte Quellenbibliographie, die einige hundert Titel (davon ca. 350 zur engeren Fachgeschichte) mit Standortnachweisen verzeichnet und so als erste Grundlegung dienen kann. Eine umfassende Bibliographie der erhaltenen Bestände an älteren Schulbüchern bleibt freilich für alle auf Bildungsinhalte gerichteten bildungshistorischen Forschungen sowie alle rezeptionsgeschichtlichen Untersuchungen in den Literaturwissenschaften ein dringendes Desiderat. 
Die bisher veröffentlichten Beiträge des Verfassers zum Thema sind teils wörtlich, teils nur mit ihren Resultaten in diese zusammenfassende Arbeit - die als selbständige Schrift bei der Habilitation an der Universität München vorlag - eingegangen.

München, November 1980

G. J. 


\section{Epochen des deutschen Unterrichts}

\subsection{Grundzüge der Entwicklung vom 16. bis zum 18. Jahrhun- dert}

Da die Skizze des deutschen Unterrichts bis zum 18. Jahrhundert nur den Zweck verfolgt, die Ausgangslage der folgenden Untersuchung zu markieren, beschränkt sie sich auf die Weichenstellungen und Triebkräfte der Entwicklung im Schulbetrieb. Deutsch wird im 16. und 17. Jahrhundert, wenn überhaupt, nur aus praktischen Bedürfnissen und kaum um des eigenen Wertes deutscher Sprache und Literatur willen gelehrt. Darauf weist schon die Entstehung eines regelrechten grammatischen und stilistischen deutschen Unterrichts »im selbständigen Unterrichtsgewerbe der Schreib- und Rechenmeister in den aufblühenden Städten « des Spätmittelalters [1] hin, wo Handwerker, Kaufleute und sSchreiber (Kanzleibeamte) »die Grundlagen des für das tägliche Leben und den Verkehr im Geschäft, vor Gericht und in der Kanzlei nötigen Wissens «[2] erwarben. Da dieses Unterrichtsgewerbe, das großen Zulauf hatte und - wie Beschränkungsvorschriften zeigen - den Lateinschulen Konkurrenz zu machen begann, in der nach der Reformation eingerichteten Volksschule auf- und unterging, war die weitere Entwicklung eines an Geschäft und Beruf orientierten deutschen Unterrichts, wie er seit dem 18. Jahrhundert an Realschulen wieder eingeführt wird, zunächst abgeschnitten.

Sowohl im protestantischen wie katholischen Bereich wurde im 16. Jahrhundert die bis zur Aufklärung in ihren Grundzügen unveränderte höhere Schule geschaffen, die sich ganz am Latein als internationaler Sprache der ১Gelehrten und der Kirche ausrichtete. Durch »das philologische Bündnis zwischen Reformation und Humanismus « [3] entstand die protestantische Gelehrtenschule - mit diesem »Sammelbegriff « bezeichnet Barner die verschiedenen höheren Schulformen im übergänglichen Bereich zwischen >Trivialschule dende Kraft Luthers nur im neugeschaffenen Religionsunterricht und im Gesang (Kirchenlied) zur Geltung kam. Erstrebt wurde die aktive Beherrschung des Lateins in Wort und Schrift, weshalb "prinzipiell und vom frühest möglichen Zeitpunkt an « [4] der gesamte Unterricht in Latein erteilt und Deutschreden in und häufig sogar außerhalb der Schule untersagt wurde. Der Lateinunterricht läßt allerdings nach und nach einzelne Zweige des Deutschunterrichts »in der reihenfolge ein, in welcher sie sich dem lateinlernen dienstbar erweisen « [5]: Hinzufügung deutscher Formen beim lateinischen Deklinieren und Konjugieren, deutsche als Voraussetzung der lateinischen Grammatik, Ubbersetzung und deutsche Interpretation lateinischer Schriftsteller. Wichtiger als diese indirekte Förderung durch den lateinischen (wie den religiösen und teilweise den mathematischen) Unterricht wurde für das allmähliche Vordringen des Deutschen die Rücksicht auf ein des Lateins unkundiges Publikum, das die Schule bei den von ihr mitgestalteten Gottesdiensten und Leichenbegängnissen 
sowie durch die von ihr veranstalteten Schulactus und Theateraufführungen ansprach. In den Schulactus, einen der Repräsentation und Werbung dienenden Teil des Rhetorikunterrichts, wurden deutsche Stücke »als Konzession und Anreiz für ein größeres Publikum « [6] aufgenommen. Dem Wunsch »nach breiterer Wirkung in der Öffentlichkeit « ist es auch zuzuschreiben, daß sich »bereits während des 16 . Jahrhunderts, d. h. inmitten eines traditionell lateinisch ausgerichteten Gymnasialunterrichts, eine deutschsprachige Schultheaterpraxis « [7] herausbildete. Während im übrigen rhetorischen Unterricht die deutsche Literatur keine feste Stelle beanspruchen konnte, hat das Schultheater, indem es die Voraussetzungen für die Entwicklung des barocken Kunstdramas schuf, die deutsche Literatur entscheidend gefördert.

Im Unterschied zur protestantischen Gelehrtenschule haben die Jesuitengymnasien, die in den katholischen Territorien wie Bayern, Österreich, den Rheinlanden oder Schlesien »ein fast unbeschränktes Monopol« höherer Bildung [8] besaßen, an dem (mit der Studienordnung von 1599 festgeschriebenen) strengen Lateinbetrieb auch im Schultheater - festgehalten. Da diese Schulen einheitlich von einem Orden getragen und geleitet wurden, der sich zudem den pädagogischen Reformbewegungen des 17. Jahrhunderts (s. u.) weitgehend verschloß, kam es auch nicht zu der für den protestantischen Bereich charakteristischen lokalen Zersplitterung. Ihrem gegenreformatorischen Auftrag folgend, schufen sich die Jesuiten im Rhetorikunterricht, den sie durch ständige Wettkämpfe (»Konzertationen « in den unteren, Disputationen in den oberen Klassen) intensivierten, und dem Schultheater ein »Instrument der Glaubenspropaganda «. [9] Eventuelle Abweichungen vom Lateinbetrieb waren so "pastoraltheologisch « motiviert: »die praktische religiöse Unterweisung der ungebildeten Bürger und der Schulanfänger " machte »den Gebrauch der Muttersprache in Predigt und Gebet « erforderlich. [10] Mehr geschah im 17. Jahrhundert nicht; während das Jesuitengymnasium ein Zentrum neulateinischer Literatur war, geriet es gegenüber der deutschsprachigen literarischen Entwicklung immer mehr in die Defensive. Erst in der zweiten Hälfte des 18. Jahrhunderts, kurz vor Aufhebung des Ordens 1773, ist Deutsch »fast allgemein « [11] gelehrt worden.

Durchschlagende Veränderungen sind im höheren Schulwesen des 17. Jahrhunderts nicht auszumachen; von der aufklärerischen Schulreform her gesehen, scheint die Zeit zwischen Melanchthon und Zedlitz »nahezu stillgestanden «[12] zu haben. Aber wenn sich auch die vielfältigen Reformbewegungen (Ratke, Comenius, Weigel u. a.), deren meist verbundene Forderung nach muttersprachlichem und realems Unterricht auf die Aufklärung vorausweist (s. Kap. 1.2), nicht durchsetzen konnten, so haben sie doch stets an einigen Orten Einfluß gewonnen und somit das Schulwesen regional differenziert. Am weitesten ging Ratke, nach dessen 1612 auf dem Frankfurter Reichstag überreichten »Memorial《 »sowohl die ,Schulfächer als auch die >Wissenschaften selbst «, „also in Schule und Hochschule auf deutsch zu lehren « seien. [13] Außerhalb des Gelehrtenschulwesens werden lehrplangeschichtlich die als »Berufsoberschulen des Adels « [14] neugegründeten Ritterakademien wichtig, da sie aufgrund ihrer besonderen Funktion in bisher den traditionellen Lateinschulen verschlossene Lehrgebiete vorstoßen. Realien, d. h. Sachwissenschaften wie Geschichte oder Geographie, und neuere Sprachen stehen hier verstärkt auf dem 
Lehrplan; der rhetorische Unterricht wird auf spätere Tätigkeiten in Regierung, Militär, Diplomatie und Verwaltung hin zugeschnitten.

Einem deutschen rhetorischen Unterricht auf höheren Schulen wird erst durch Reformer um 1700, in erster Linie durch den Zittauer Gymnasialdirektor Christian Weise, Bahn gebrochen. Nachdem es durch die Erstarrung der Lateinschulen im 17. Jahrhundert zu einer »Opposition von Schulgelehrsamkeit und praktischem Nutzen « gekommen war, erfuhr die Rhetorik bei Weise eine »konsequente Instrumentalisierung in praktischer Absicht «. [15] Die »deutsche Oratorie«, für die Weise die vor Gottsched meistgebrauchten Lehrbücher schrieb, lehrt die künftigen Verwaltungsbeamten, Prediger und Lehrer, »wie vermittels rhetorischer Fertigkeiten der größtmögliche Erfolg für den Einzelnen im gesellschaftlich-beruflichen Leben erzielt werden kann «. [16] Dabei konzentriert sich die »prudentia sermonis secreti \& privati « unter Zurückdrängung der nur akademisch üblichen Reden auf »die Beratung in kleinen Gremien « (sermo secretus), z. B. der Regierungsbehörden, und »die Rede im Umgang der Menschen miteinander " (sermo privatus). [17] Der deutsche poetische Unterricht, den Weise als »Instrumental-Wesen « zum Zweck stilistischer Ausbildung behandelt, scheint sich erst unter der Ägide Gottscheds im zweiten Viertel des 18. Jahrhunderts selbständiger zu gestalten. Darauf weist die rege poetische Tätigkeit an den sächsischen Fürstenschulen. In St. Afra erscheint 1740 - ein Jahr vor Lessings Aufnahme - eine Schulanthologie mit Gedichten von Opitz und dem sächsischen Hofdichter Besser (J. G. Höre: Edle Früchte deutscher Poeten, nach gesundem Geschmack berühmter Kenner für die lehrbegierige Schul-Jugend ausgesucht), in Pforta besteht zur gleichen Zeit eine förmliche »deutsche Gesellschaft« mit Statuten und Protokollbuch, deren Mitglieder ihre rhetorischen und poetischen Arbeiten wechselseitig kritisieren. [18] Von diesen Internaten gingen wichtige Impulse für die deutsche Literatur aus: Die vier Begründer der Bremer Beiträge - Gärtner und Rabener aus St. Afra, Cramer aus Grimma, J. A. Schlegel aus Pforta - haben ihre dichterische Eigenart auf der Schule entwickelt, Klopstock hat in Pforta unter dem Einfluß der Schweizer und Miltons den Plan zum Messias gefaßt. [19]

Das Zittauer Gymnasium unter dem Direktorat von Weise und Hoffmann und die sächsischen Fürstenschulen, in Niveau und Ansehen herausragende Anstalten, bezeichnen die Spitze der Entwicklung. Wie es mit dem deutschen Unterricht im Durchschnitt ausgesehen hat, ob sich bei den starken Differenzen zwischen den verschiedenen Schultypen und Ländern ein mittleres Maß überhaupt feststellen läßt, muß nach den bisherigen Forschungen offen bleiben. Die die vorliegende Untersuchung leitende sozialgeschichtliche Frage nach dem Verhältnis des deutschen Unterrichts zur Organisationsweise höherer Schulen, zur sozialen Herkunft und dem künftigen Berufsweg der Schüler ist bislang nur für einzelne Fälle wie das Gothaer oder Zittauer Gymnasium [20] gestellt und diskutiert worden. Die in den folgenden Kapiteln über das 18. Jahrhundert hinaus konstatierte Trennung der oberen (eigentliches Gymnasium mit Vorbereitung auf die Universität) und niederen Klassen (Mehrheit von Handwerkern, Kaufleuten und sSchreibern<, die von vornherein nur einige Klassen besuchen wollen) ist in Zittau um 1700 voll ausgebildet und hat in den Lateinschulen offensichtlich eine lange Tradition. 


\subsection{Spätaufklärung}

\subsubsection{Die Konzeption der Universalschule und die staats- und gesellschafts- politische Begründung des Sprach- und Literaturunterrichts}

Die meisten Pädagogen und Bildungspolitiker der Spätaufklärung wollten die Schüler weder nach Ständen (mit Ausnahme der Bauern) noch nach Berufszielen grundsätzlich trennen. Sie erstrebten »eine Nationalerziehung, statt der pur gelehrten « [1], die alle Schichten aus sozialen Gründen in einer Anstalt versammelt. In diesem Sinne haben Steigentesch (Kurmainz), Braun und Wismayr (Bayern), Afsprung (Reichsstadt Ulm) oder Gedike (Preußen) Universal- und Einheitsschulen konzipiert, die den Handwerker, den Kaufmann, Fabrikanten, Fachbeamten und den Gelehrten in aufeinander aufbauenden Schulstufen ausbilden. [2] $\rightarrow$ Steigentesch sieht Landschulen für Bauern vor, Trivial- und Realschulen (bis zum 14./15., für Studierende bis zum 13. Lebensjahr) für »alle Kinder der Städtebewohner, [. . . ] sie mögen sodann zu den Studien bestimmt werden, oder Soldaten und Handelsleute, Handwerker und Taglöhner werden «, anschließend Gymnasien zur Vorbereitung auf die Universität. [3] Ähnlich denkt der Ulmer 〉Patriotく Afsprung an eine Einheitsschule, wobei die unteren Klassen, die alle Schüler durchlaufen, für die Bürger und Handwerker, die oberen Klassen für Studierende eingerichtet werden [4] - eine horizontale Teilung des alten Gymnasiums in eine »Bürger-« und »Gelehrtenschule «, wie sie bis 1800 in den meisten Fällen (außer in Ordens- und Klosterschulen und in deren Tradition stehenden Anstalten wie den sächsischen Fürstenschulen oder den württembergischen niederen Seminaren) durchgeführt worden sein dürfte. $\rightarrow$ Gedike, dessen Klassifikation vom Provinzial-Schulkollegium der Kurmark angenommen wurde, unterscheidet genauer »Gemeine Bürgerschulen«, »Höhere Bürgerschulen«, »Mittelschulen « und »Gelehrte Schulen«, wobei die höheren Anstalten in ihren unteren Klassen die niederen Schulen jeweils mit einschließen. [5] Die den oberen, auf das Studium vorbereitenden Klassen des Gymnasiums vorausgehende Schulstufe, wegen ihrer Ausrichtung auf SSachwissenschaften oft »Realschule « genannt, soll in diesen Plänen »das Band der bürgerlichen Gesellschaft « werden: In ihnen ist »die gelehrte und bürgerliche Erziehung miteinander auf eine solche Weise verbunden, daß die gelehrte von der bürgerlichen so viel mit bekömmt, als einem Gelehrten nöthig ist, der in einer Gesellschaft von Bürgern lebt; die bürgerliche erhält hingegen auch so viel von der gelehrten, als ihr nicht nur zur nöthigen, sondern auch zur nützlichen Besorgung ihrer Geschäfte dienen kann «. [6] Die Schulreformer haben überdies durch Fachklassen (das Beispiel der Göttinger Stadtschule s. Kap. 1.2.2), durch Kern- und Kursunterricht wie durch Dispensationsmöglichkeiten von Griechisch und Latein die höheren Schulen für verschiedene Anforderungen flexibel eingerichtet. Die ,Umschaffung der Universalklassen in Specialklassen « trug der »Verschiedenheit in Anlagen und Neigungen « und der damit einhergehenden »Verschiedenheit der Fortschritte in Sprachen und Wissenschaften« Rechnung [7]: 
Es ist hier möglich, daß der Schüler an e in e $m$ Tage in allen [in diesem Falle vier] Klassen der Schule Unterricht erhält. Er kann in Sprachen in der ersten, in der Geschichte und Geographie in der zweiten, im Rechnen in der dritten, und im Schreiben in der vierten Klasse u.s.w. sitzen; er rückt immer nur in dem einzelnen Theile höher, in welchem er es verdient, und in den übrigen bleibt er in den untern Klassen, bis er auch hierin zur Versetzung heranreift.

Mit Hilfe solcher Organisationsformen konnten selbst die vielen kleinen Schulen divergierende Ansprüche lokal befriedigen. Für einen größeren Staat realisiert wurden die Grundsätze etwa in Bayern durch den $\rightarrow$ Wismayr'schen Lehrplan von 1804: Eine gestufte Einheitsschule für alle höhere Bildung, die die aus verschiedenen Schichten kommenden und in sehr unterschiedliche Berufe übergehenden Schüler zusammen erzieht und so sozial ausgleichend und mobilisierend wirkt. Der Plan teilt die »Mittel-Schulen « in »drey Triennal-Kurse « ein, wovon der erste » für die Fortbildung des niedern Bürgerstandes; der zweyte für die des höheren Bürgerstandes, und der dritte für den zu höheren und eigentliche Gelehrsamkeit fordernden Staats- und Kirchenämtern sich vorbereitenden Jüngling berechnet ist «. [8] Nur »der eigentliche Studierende « muß »alle drey Kurse « »in allen Lehrfächern « durchlaufen, während alle Anderen die Dauer des Schulbesuchs nach ihren Mitteln und Zwecken regeln und aus dem Lehrangebot das ihnen Passende wählen können, da »nicht nach Klassen, sondern nach Fächern « unterrichtet wird. [9] Eine solche Einrichtung entsprach zweifellos dem Bedürfnis, da selbst in städtischen Zentren »kaum ein Drittheil « aller und »kaum der siebente oder achte Theil« der unteren Schüler das Universitätsstudium anstrebte. [10]

Um ihre Intentionen im Lehrbetrieb durchzusetzen, suchten die Reformer den alle höheren Schulen beherrschenden Sprachunterricht umzugestalten. Von ihm wurde eine wichtige sozialdisziplinierende und sozialausgleichende Wirkung erwartet. Wie bisher den gelehrten Studien, so sollte er künftig ebenso den bürgerlichen Geschäften (eines Handwerkers, eines Kaufmanns) wie der staatlichen Administration zugute kommen, und »zu den der menschlichen Gesellschaft zu leistenden Diensten « [11] erwies sich die Ausbildung in der deutschen Sprache als vordringlich. $\rightarrow$ Braun, der die Schulreformen der 60er und 70er Jahre in Bayern leitete, begründete die Wichtigkeit des Deutschunterrichts auf vierfache Weise [12]: (1) »Feinheit der Sprache« schafft »Höflichkeit « »in den Sitten«, und so dient der Sprachunterricht der Disziplinierung. »Je mehr wir uns von der rohen Lebensart der Barbarn entfernen, desto mehr werden in unserm Vaterlande Zucht, Ruhe, und Ordnung[,] jene Hauptgründe einer guten Policey [d.h. jene Hauptstützen einer guten inneren Verwaltung][,] anzutreffen seyn. Trägt nun nicht zu dieser Absicht eine reine Sprachkunst sehr viel wo nicht das meiste bey? «Wo es gelungen ist, »das rohe Wesen in einer Gemeinde zu tilgen «, da braucht man die Untertanen »nicht nach Art des Viehes mit Zwange und Grausamkeit [...] regieren«. Die Erhöhung sprachlicher Kompetenz schafft (2) die Grundlage für die Verbreitung von Wissen. Die Gelehrten sollen - nach einem Wort von Loëns - »kein besonderer Stand « im Staate mehr sein; die Verbesserung der Schulen macht das Wissen allgemein. „Denn wo der Weisen viel sind, da ist des Volkes Heil«. Schließlich fördert der deutsche Sprachunterricht (3) heimische Wissenschaft und Literatur und berührt damit (4) - im Sinne einer merkantilistischen 
Wirtschaftspolitik - »das Interesse des Staates dem Gelde nach «. Mußte bisher, »wer witzig und klug werden wollte «, importierte Waren kaufen, so bleiben »Gold und Silber « fortan im Lande. Die klassischen Sprachen wurden in die Argumentation gleichfalls einbezogen (vgl. $\mathrm{HeB}$ in Österreich, Kap. 2.3.2) und so kein Graben zwischen ihnen und dem deutschen und realistischen Unterricht aufgeworfen. Die Spätaufklärer versuchten vielmehr, dem Latein und Griechisch im Verein mit dem Deutschen eine lebenspraktische Bedeutung zu geben. Zur Verbesserung der `Sitten<, d. h. der Verhaltensformen und der sich in ihnen ausdrückenden Alltagsmeinung, sollte eine »Philosophie des Lebens « [13] beitragen, die man aus alten Schriftstellern vor allem aus dem platonischen Sokrates, Xenophons Denkwürdigkeiten und Ciceros Buch von den Pflichten - wie aus Gellerts moralischen Vorlesungen zog. Ein Zitat aus der Ankündigung der $\rightarrow$ Wismayr'schen Studienordnung, die eine berufsbezogene Ausbildung und die gesellschaftliche Annäherung der Schüler vorzüglich auch durch den klassischen Unterricht erreichen wollte, faßt die Zielsetzungen der Reformer am Ende der Aufklärungszeit noch einmal zusammen [14]:

Aus der ganzen Anlage des neuen Lehrplanes leuchtet unverkennbar die doppelte Absicht hervor, daß man mittelst desselben erstens brauchbares Wissen fürs wirkliche Leben erzielen, also verständige Bürger, und kluge, wohlunterrichtete Geschäfts-Männer bilden; zweytens aus den höheren Klassen allen Sekten-Geist verbannen, oder vielmehr davon entfernt halten, und dafür den aus unseren Mittelschulen lange verscheu[ch]ten Geist wahrer Lebens-Weisheit, vorzüglich auch mittelst Beförderung des Studiums der alten römischen und griechischen Klaßiker und ihrer Sprachen, wieder in dieselben zurückkehren machen wolle.

In Österreich ist $\rightarrow$ Seibt der Exponent einer Pädagogik, welche »die Ausbildung des moralischen Charakters der Bürger zur Tugend und Rechtschaffenheit « wie zu wirtschaftlichem Verhalten durch sprachlichen Unterricht und ästhetische Bildung propagiert. Für ihn bildet »der moralische Charakter « einer Nation den »Mittelpunkt«, »aus welchem alle Linien auslaufen, die den Umfang der gemeinen Wohlfahrt beschreiben «. [15] Sein Programm hat er in Moralvorträgen und in »praktischen Vorlesungen über die deutsche Schreibart « an der Universität Prag verwirklicht. Da der Schüler »in seinen Produkten das Bild seiner Seele « vorlegt, wählte er zu schriftlichen Úbungen mit Vorliebe Materien, die den Hörern Gelegenheit boten, »ihre moralischen Grundsätze, ihre Begriffe von Tugend, Laster und Thorheit, und zugleich die Gesinnungen ihres Herzens zu verrathen, und dadurch einen Beweis abzulegen, welchen Nutzen, zur Bildung ihres Verstandes und Herzens «, sie aus seinen Vorlesungen »geschöpft « hätten. [16] Eher formale Gesichtspunkte standen bei der Reform der Rhetorik im Interesse der staatlichen Bürokratie im Vordergrund - ein Vorgang, der sich in Österreich besonders klar greifen läßt. »Die Zunahme der Schriftlichkeit in den Beziehungen zwischen den Behörden und der Ansturm der Aktenfluten, der damit verbunden war, machte eine Entrümpelung des Schriftverkehrs von umständlicher Courtoisie [...] und eine Reinigung und Straffung der Kanzleisprache selbst erforderlich«. [17] Zu diesem Zwecke wurden Justi und Sonnenfels berufen. Justi wurde am Wiener Theresianum »neben den ökonomischen und Cameral-Wissenschaften das Lehramt der deutschen Beredsamkeit « aufgetragen; die Regierung wünschte, daß die jungen Leute »in dieser Staats-Schule zu allen in den 
Geschäfften vorfallenden schriftlichen Aufsätzen und Ausarbeitungen « angeführt würden, da sie nach diesem Unterricht sofort in Staatsdienste traten. [18] Sonnenfels mit einem für ihn geschaffenen Lehrstuhl für »Geschäftsstil« an der Wiener Universität avancierte zum `Staatsstilisten<, und es gab unter Joseph II. »kaum ein wichtiges Gesetz, das nicht zuvor die stilistische Feile des Professors [...] passiert hätte «. [19] Sein Lehrbuch, das für den akademischen Unterricht in den Provinzen vorgeschrieben war, erstrebte sowohl eine der amtlichen Praxis angemessene wie den "Volksklassen «, mit denen die Behörden zu tun hatten, verständliche Sprache. Die Devise, »mit dem Volke Volkssprache « zu reden [20], sollte die gesellschaftliche Wirksamkeit staatlichen Handelns erhöhen. Nach der Idealvorstellung hätte die Verwaltung gemeinsam mit der Schule an der Disziplinierung und Kultivierung der Nation zu arbeiten gehabt.

\subsubsection{Humanistische Schulorganisationsentwürfe (Heyne, Wolf, Humboldt)}

Da seit Niethammers Streit des Philanthropinismus und Humanismus in der Theorie des Erziehungs-Unterrichts (1808) Aufklärung und Neuhumanismus [21] einander oft gegenübergestellt wurden, sollen die schulorganisatorischen Vorstellungen von Heyne, Wolf und Humboldt ergänzend skizziert werden. Der in sich keineswegs einheitliche Neuhumanismus gehört von J. M. Gesner bis Heyne, was seine Pädagogik betrifft, in den Zusammenhang der Aufklärung (für die Methodik s. Kap. 1.2.3); erst die aus Humboldts Sprachtheorie, der klassischen Ästhetik und idealistischen Philosophie abgeleiteten Bildungstheorien schufen Gegensätze, die bei einer altphilologischen und klassizistischen Verengung des Neuhumanismus (vgl. Thiersch, Kap. 2.2.3) zu starren Fronten werden konnten. Gesamtdeutsch hat sich aber nicht die bayerische Reaktion, sondern der preußische Weg des mäßigenden Ausgleichs durchgesetzt.

An der Stadtschule zu Göttingen hat $\rightarrow$ Heyne 1798 das Fachklassensystem voll durchgeführt und damit ein vielbeachtetes Muster geschaffen. Neben die gelehrten Fächer traten gleichberechtigt die »gemeinnützigen Kenntnisse aus der Naturgeschichte, Naturlehre, aus den Gewerben, Professionen, Künsten, Wirthschaft «. [22] Der Lehrplan wurde für jeden Schüler »individuell und einzeln « bestimmt, indem er »nach seinen Fähigkeiten und Bedürfnissen in ganz verschiedene Lectionen und Abtheilungen « gesetzt wurde. [23] $\rightarrow$ Wolf, der »gemischte « Stadtschulen mit Fachklassen begrüßte, hat »zwischen dem älteren und dem heutigen modischen Wege«, also zwischen den lateinischen und realistischen Schulen, »eine Mittelstrasse « gesucht. [24] Er hat Französisch, Mathematik, Geographie, Naturhistorie, etwas Physik und Anthropologie in den Lehrkanon aufgenommen, vom Griechischen dispensiert und schriftliche Úbungen in dieser Sprache nur zu grammatischen Zwekken zugelassen. [25] Damit hat Wolf das universalistische oder »utraquistische « (F. Paulsen) Prinzip des Humboldtschen Gymnasiums vorweggenommen. »Fr. A. Wolfs Gymnasium ist mit allen seinen Deklamationen wider den Basedow'schen Realismus doch nur eine solche Lehranstalt, welche humanistische und realistische Elemente 
zusammen- und ineinanderschiebt «. [26] Wenn Humboldt alle höhere Bildung auf Gymnasien verweist, so setzt er voraus, daß nicht nur auf die alten Sprachen gesehen, »sondern der historische und mathematische Unterricht gleich gut und sorgfältig mit dem philologischen behandelt werde«. Die Wahl von Schwerpunktfächern soll der »Verschiedenheit der intellectuellen Richtung auf Sprachstudium, Mathematik und Erfahrungskenntnisse « Rechnung tragen, ohne die Einheitlichkeit der Schule aufzulösen. Die Schüler können auf den Gymnasien »mehr Sprachunterricht oder mehr gemeinhin realen genannten « treiben, sie können nur die unteren oder »Bürgerklassen«, die »für sehr viele Zwecke des Lebens « ausreichen, oder den gesamten Kursus besuchen. [27] Dieses universalistische Bildungskonzept wurde in Preußen, in den folgenden Jahrzehnten auch in anderen Staaten herrschend, so in Hessen-Darmstadt 1833 und in Sachsen 1835. [28] Die sprachlichen Fächer machen dabei mehr als die Hälfte, nach der Württembergischen Schulordnung von 1848 - die die obere Grenze anzeigt - »etwa zwei Drittel des Gesammtunterrichts« [29] aus.

\subsubsection{Aufklärerische Prinzipien des Sprach- und Literaturunterrichts}

Im Sinne ihrer Forderungen nach einer Ausbildung für die Praxis von Beruf, Amt und Leben, für die Bedürfnisse des Staates und der Wirtschaft haben die Reformer den Sprach- und Literaturunterricht an höheren Schulen umgestaltet. Wie sie für Schüler verschiedener Schichten, mit je nach dem angestrebten Berufsweg divergierenden Erwartungen offene Schulformen einrichteten (s. Kap. 1.2.1), so hatten sie auch jetzt die Handwerker und sSchreiber mit im Auge, die nur wenige Klassen besuchten. Die `Versittlichung und >Kultivierung der Bürger suchten sie durch eine oft intensive ästhetische Erziehung zu erreichen. Dabei sollte der Unterrichtsstoff nicht nach Maßgabe eines Lehrbuches eingepaukt, sondern im reflektierten eigenen Umgang mit der Sprache und in selbständiger Arbeit am Text angeeignet werden, so daß der Erwachsene über die im alltäglichen Leben notwendigen Ausdrucksmöglichkeiten und kritischen Urteilsmaßstäbe verfügt. Somit beschränkt sich der Unterricht keineswegs auf utilitaristische Gesichtspunkte, sondern fördert ebenso die individuelle sprachliche Entwicklung - gemäß einem spätaufklärerischen Sowohl-als-Auch, das den Einzelnen nicht aus seiner gesellschaftlichen und staatlichen Rolle entläßt.

(a) Spracherlernung durch >Induktion und Gebrauch. Die Lehrart der späteren Aufklärung fußt im wesentlichen auf dem Empirismus, der Erkenntnistheorie des Sensualismus und in ästhetischen Fragen auf dem Emotionalismus. Der verstandesmäßigen Durchdringung soll stets die anschauliche Beobachtung und die eigene Erfahrung der Sache vorausgehen. »Der Hauptgrundsatz einer jeden guten Methode ist, von dem sinnlichen anzufangen, um sich stufenweise $\mathrm{zu}$ dem intellektuellen $\mathrm{zu}$ erheben, von dem Einfachen aufs Zusammengesetzte fortzugehen, sich von Factis zu versichern, ehe man Ursachen erforscht«. [30] Diese Methode heißt "praktische«, 
»induktive« oder - im Gegensatz zur »synthetischen « bzw. »demonstrativen « »analytische « Lehrart. [31] $\rightarrow$ Resewitz hat für die »Methode des Unterrichts für den gesunden Verstand und das bürgerliche Leben « folgende Prinzipien aufgestellt [32]: - »Bringe alles, so viel möglich ist, für [vor] die Sinne; laß es oft sehen und genau betrachten «.

- „Was nicht für die Sinne gebracht werden kann, das mache durch Abbildungen, Modelle [z. B. in Naturgeschichte, Geographie, Technologie], und vornehmlich durch Beyspiele begreiflich «.

- »Zur Ueberzeugung des gesunden Verstandes führe alles auf Grundsätze zurück, welche in Empfindungen bestehen, die aus wiederholten ähnlichen Erfahrungen in der Seele entstanden sind «.

Die entscheidenden Punkte sind damit genannt: den Stoff möglichst greifbar zu machen, Lehren aus Beispielen zu entwickeln und dabei nicht nur für den Verstand aufzubereiten, sondern tiefer im Empfindungsleben zu verankern. Durch »Gewöhnung und Uebung « wird die »Bildung des Herzens « erreicht, d. h. der Heranwachsende soll »durch wiederholte Eindrücke in den Empfindungen geübet, und zu den Empfindungen gewöhnet « werden, die »nach Vernunft, Klugheit und Religion « bestimmt sind, »ihn in seinen Entschließungen und Handlungen zu regieren«. [33] Sprachen gelten nur als »Instrumentalkenntnisse «, als »Hülfs-Mittel und Vorbereitungen zu den [Sach]Wissenschaften « [34], ja in der Spätaufklärung herrscht eine ausgesprochene Skepsis gegenüber der Sprache als Erkenntnismittel.

Nach den verbreiteten Grundsätzen $\rightarrow$ Gesners - deshalb »Göttingische Lehrart « soll der sprachliche Unterricht nicht mit Grammatik und Vokabellernen, sondern mit Úbungen im Sprechen, Lesen und Schreiben seinen Anfang nehmen. Die "practische « Lehrart macht sich »die schlechte [d. h. einfache] und der Natur so geläuffige Nachahmung « [35] zunutze, mit der Kinder ihre Muttersprache und Erwachsene im geselligen Leben Fremdsprachen erlernen. In den Mainzer Schulen verfuhr man nach diesen Richtlinien. Dort war es Grundsatz, »alle Grammatiken von dem ersten Unterrichte in einer Sprache gänzlich zu entfernen, und solche erst alsdann zur Hand zu nehmen, wenn der Schüler in der neuen Sprache schon mit einiger Fertigkeit bewandert und etliche Jahre hindurch darinn geübt ist «. [36] Gesner und seine Anhänger haben diese Überzeugung selbst bei den alten toten Sprachen beibehalten. »Soll man denn also die lateinische Sprache ohne Grammatik, durch den bloßen Gebrauch lernen? Ja! im Anfange«. [37] Die Techniken, die der Unterricht dabei anwenden kann, haben Didaktiker im einzelnen entworfen. Beispielsweise prägt die »Explicirmethode « Vokabeln bei der Arbeit am Text in einem gedanklichen und sachlichen Zusammenhang ein und macht die Deklination, die Konjugation sowie »die Regeln der Wortfügung" »vermittelst einer davon gemachten Anwendung « bekannt. [38] Im Vordergrund solcher Überlegungen standen die vielen Nichtstudierenden, vor allem die Handwerker in den niederen Klassen höherer Schulen. Für sie war in der Tat »die Grammatic ein überaus unnöthiger Hausrath«. Wer »die lateinische Sprache nur als ein Werkzeug« zum Verständnis von Fachbüchern braucht, konnte »allein durch den Gebrauch « zu seinem Zweck gelangen. [39] 
(b) Textanalyse statt Rhetorik. Da die rhetorischen und poetischen Lehren an die Lektüre geknüpft werden, tritt der systematische, einem Lehrbuch folgende Vortrag ganz in den Hintergrund. Die Formalia der Lateinschule, die polemisch so genannte »Phrasenjagd, Sentenzenklauberey, Versmacherey«[40], sollen wegfallen; »man weiß wohl, was Beredsamkeit bisher in den Schulen für ein Ding gewesen ist, Tropen und Figuren - Perioden und Chrien-Fabrick nach allen Regeln einer steifen Rhetorick!« [41] Dem Lehrer muß das Lehrgebäude wohl bewußt sein, aber beim Unterricht hat er so zu verfahren, daß sich Regeln aus Bemerkungen und Beobachtungen während des Lesens allmählich entwickeln [42]:

Wenn man die Schönheiten eines Schriftstellers erklären will, so muß man unter der Hand manche Regel miteinstreuen, die man aus der Aesthetik, Rede- und Dichtkunst [...] entlehnt hat. Erleutert man nun diese Regeln, so wie es Gelegenheit giebt, wieder mit andern Beispielen, die aus [...] Schriftstellern genommen sind, welche bereits mit dem jungen Menschen gelesen worden sind, so ist es ganz natürlich, daß er nach und nach die wichtigsten Regeln der Schreibart und ihrer mancherlei Gattungen auf eine sinnliche Art aus Beispielen gleichsam spielend erlernt.

$\rightarrow$ Steigentesch spricht von »einer Art praktischer Philosophie mit Gelegenheit der Dichtkunst und Redekunst«. [43] Man lernt Rhetorik, Ästhetik, Ethik, Psychologie und Logik praktisch, wenn man die Schriftsteller »in Absicht auf die Gründlichkeit der Gedanken, Richtigkeit der Urtheile, und Stärke der Vernunftschlüsse « und »die Schönheiten des Geschmacks « durchgeht. [44] Auf diese Weise kommt es zu einer genauen Textanalyse, die sprachliche und gedankliche Feinstrukturen erfaßt, ohne sie nach einem Regelwerk zu schablonisieren (vgl. das Beispiel Zürich, Kap. 1.2.5). Der Schüler achtet dabei z. B. bei einem Geschichtsschreiber »auf die Schreibart seiner Erzälung[!]; auf das unterscheidende des schönen historischen Styls, auf die Zeichung [!] der Karaktere [...][,] auf die Gemälde, die eingestreuten Maximen und Reflexionen «, bei einem Redner »auf den Scharfsinn der Erfindung, auf die aufgewandten Kunstgriffe, zu überzeugen, zu bereden, zu rüren [!], und auf deren Grund in der Natur des menschlichen Verstandes und Herzens «. [45] Unterrichtstechnisch wird das Prinzip der Induktion durch die von $\rightarrow$ Engel, $\rightarrow$ Gedike und $\rightarrow$ Sulzer favorisierte »sokratische Lehrart «, d. h. »eine beständig neue Unterredung zwischen dem Lehrer und dem Schüler « [46], verwirklicht; der Schüler lernt »gleichsam wie durch ergötzende Selbsterfindung«. [47]

(c) Geschmacksbildung und Lektüre. Das Studium von Mustern wird nicht nur aus didaktischen Gründen betont, sondern auch weil »das Gefühl des Schönen « an ihnen "geschärft « wird. [48] Kritische Fähigkeiten und ein ästhetisches Sensorium sollen sich bei der Lektüre gemeinsam entwickeln. Auf diese Weise wird z. B. in Mainz »die Bildung eines reinen und richtigen Geschmackes, und die Erregung der Empfindsamkeit für das wahre Schöne«, die als »Endzweck« des Unterrichts in den »Schönen Wissenschaften « gelten, zu erreichen versucht [49]:

Die Bildung des Geschmackes überhaupt geschieht vorzüglich durch das fleißige, nicht forteilende, sondern anhaltende, Lesen der besten Schriftsteller in der deutschen, griechischen, lateinischen, und französischen Sprache, und die beurtheilende Aufmerksamkeit auf deren Kunstgewebe und Wendungen; auf das natürliche ungezwungene Wesen; auf den Nachdruck und das Feuer, wo es der Gegenstand fodert. 
Unterbrochen wird die Arbeit am Text durch das Vorlesen von deutschen Schriften, zumal von Neuerscheinungen. Die Reduktion des Sprachunterrichts auf unverbindliche Lektüre, wobei sich Lehrer und Schüler zu Lesezirkeln zusammenschließen, stellt dabei einen negativen, von der Reaktion polemisch aufgegriffenen Grenzfall dar (vgl. Ingolstadt 1777 und Thiersch in Kap. 2.2.1 u. 3). Hier liest bisweilen »der Lehrer seinen Zuhörern « vor, »ein andermal läßt er einen von ihnen vorlesen«; es sind Stunden, die mehr »die Art einer gesellschaftlichen Unterhaltung, als einer schulmäBigen Lection « haben. [50]

Auf empfindungsvolle Lektüre legen Pädagogen besonders dann solches Gewicht, wenn sie, ästhetisch auf dem Standpunkt des Emotionalismus [51] stehend, nicht glauben, $\mathrm{da} \beta$ sich die Produktion und Rezeption von Kunst nach Lehren und Regeln leiten läßt. Die Ausbildung des Gefühls erhält dadurch Vorrang vor Rhetorik und Poetik. »Was werden drockne [!] Lehrgebäude und Kritiken, wo man das Schöne nachahmen, wo man rühren und ergetzen soll, helfen, wenn unser Herz zu keinen zarten und lebhaften Empfindungen weich werden kann, und wenn es, wie mit einer dicken Rinde umgeben, kaum eines oberflächlichen Eindrucks fähig ist? « Das »innere Gefühl der Seele « müsse zuallererst so gestimmt werden, daß es »die gehörige Empfindlichkeit und Feinheit « für das Schöne erhalte. [52] Doch argumentieren die Reformer nicht einheitlich; neben stärker auf praktische sprachliche Ubungen und verstandesmäßige Schulung sich richtenden Forderungen gibt es Skepsis gegenüber dem »feinen Geschmack «, die sich auf Rousseaus Zivilisationskritik beruft. [53]

(d) Sachunterricht beim Sprachenlernen, nach dem Motto: "mit den Wörtern zugleich Sachen«. [54] Mit dem Rat, die (Sach)Wissenschaften nach Möglichkeit »durch die Sprachen und bey den Sprachen « [55] zu lehren, wollen die Reformer die Grammatik und Rhetorik im Unterricht zurückdrängen und zugleich die Herrschaft der Sprachen auf den Schulen unterlaufen. Dabei verknüpfen besonders die antiken Autoren die Fächer, wenn man sie so behandelt, daß sie der Sprachübung und der Realkenntnis gleicherweise dienen. Sie vermitteln zunächst die philosophische, mythologische, geographische, geschichtliche und antiquarische Kenntnis der Antike. $\rightarrow$ Engel und $\rightarrow$ Gedike wollen darüber hinaus die Elemente der Philosophie, der Psychologie, des Naturrechts und der natürlichen Theologie »durch Lesung und bey Lesung einiger philosophischen Schriften des Alterthums " [56] erläutern (ähnlich $\mathrm{HeB}$ in Österreich, s. Kap. 2.3.2). Wie ein hierfür eingerichtetes lateinisches Úbungsbuch aussieht, zeigt Büschings »Liber Latinus«, mit einem »Entwurf der Naturhistorie «, einer »Lehre von dem Daseyn Gottes« und der »Regierung der Welt" mit Pflichtenlehre und »Regeln der Diät«, d.h. Grundkenntnissen einer gesunden Lebensführung, sowie Abschnitten über »Ackerbau« und »Oeconomie «. [57] Neben Ernesti traten unter den Altphilologen besonders $\rightarrow$ Gesner, $\rightarrow$ Heyne und $\rightarrow$ Wolf für eine Verbindung des Sprach- und Sachunterrichts ein.

In der Lehrmethodik hat die Unterscheidung von statarischer und kursorischer Lektüre den Doppelcharakter des Sprachunterrichts festgesetzt. »Erstere dient hauptsächlich zur eigentlichen grammatischen, und Stylübung; der Sachenvorrath 
wird hier nur nebenher genutzt. Bey letzterer, der cursorischen aber, sind die Realien oder der Inhalt die Hauptsache, und die Sprachübung geht nebenher mit fort «. [58] Tamm hat die ssynthetische « und sanalytische ‘ Lehrart ähnlich bestimmt und dabei auf ihre verschiedene soziale Funktion bezogen. Die »synthetische Methode « sei »für diejenigen, die studiren wollen«; denn bei ihr gehe man auf wissenschaftliche Art etwa in der Sprachlehre, Rhetorik oder Logik - »vom Allgemeinen zum Besondern, von den Ursachen zu den Wirkungen, vom Vorhergehenden zum Folgenden « fort. Demgegenüber begnüge sich die »analytische Methode «, »bey der Lektüre einzelne Materien aus den Wissenschaften « herauszuheben und in die zum Verständnis nötigen Zusammenhänge zu stellen. [59]

(e) Stilübungen für Beruf, Amt und Leben. Noch mehr als bei der Lektüre und Interpretation haben sich die Reformer bemüht, bei den deutschen Stilübungen den Bedürfnissen der Nichtstudierenden und insbesondere den Handwerkern in den niederen Klassen entgegenzukommen. Die Erleichterung des Geschäftsverkehrs und die Hebung der Gewerbe, die man mit diesem Unterricht bezweckte, erfolgte unter sozialen wie wirtschaftlichen Gesichtspunkten. Man sah bei der Einrichtung des Aufsatzunterrichts zum Teil »mit Fleiß« recht einseitig auf »Schreiber und Geschäfte « [60] und nicht auf Studierende oder Literaten, von denen man zuviel zu haben glaubte. Der Mainzer Schulentwurf begründet, wie man durch eine berufspraktische Rhetorik »Pflanzschulen brauchbarer und zum Erwerbe eigener Glückseligkeit fähiger Bürger « schaffen will [61]:

Wie viele Handwerksleute findet man, die nicht einmal wissen ihre Arbeitszettel auf eine verständliche Art zu schreiben, oder Uiberschläge bestimmt und ausführlich (ohne Gefahr belacht zu werden) oder Entscheidungs-Gründe [...] in Handwerkssachen, Briefe, Wechsel, Quittungen, und dergleichen täglich vorkommende Aufsätze in Zusammenhang, Ordnung, und Richtigkeit aufzusetzen; aber eben darum auch unvermögend sind, sich selbst jedermann gefällig, ihren Stand achtbar und ihr Gewerbe, sowohl in - als außer dem Lande, geltend und nutzbar zu machen.

Weiter ist die Rede von Wirten, Krämern und »gemeinen Civil- und Militärbedienten «, die schon durch »Geschicklichkeit im Briefwechsel « und »eine ordentlichere Einrichtung ihrer Bücher « »in ihrer Nahrung « weiterkommen könnten. Neben dem Geschäftsleben hat die Reform des Stilunterrichts die bürokratischen Amtsgeschäfte und die im gesellschaftlichen Leben nützlichen Fertigkeiten (Briefe, Einladungen, Bitt- und Danksagungsschreiben, Empfehlungen etc.) im Auge. »Alle Aufgaben zu Ausarbeitungen müssen mit Absicht auf die Geschäfte des Lebens gemacht werden« [62], fordert Basedow. Die dazu nötigen Anleitungen und Lehrbücher verdanken vor allem den Anregungen von $\rightarrow$ Resewitz und seinem Ruf nach einem deutschen »Quintilian «, der die »für bürgerliche Geschäfte aufwachsende Jugend « unterrichte, ihr Entstehen. [63] 


\subsubsection{Die Schlüsselstellung des Braunschweiger >Collegium Carolinum in der Entwicklung des deutschen Unterrichts}

Das `Collegium Carolinum، (1745-1808), eine Reformanstalt des aufgeklärten Absolutismus, vereinigte Real-, Gymnasial-, Fachhochschul- und Universitätskurse. Zu seiner Gründung kam es, weil vor der Reformära (s. Kap. 1.2.1 u. 2) die höheren Schulen »nur zur unterweisung dererjenigen eingerichtet « waren, »die von der gelehrsamkeit besonders ihr geschäfte machen wollen «, und zudem mit den Universitäten »nicht genau und nahe genug verbunden « waren. [64] Das Vorlesungsverzeichnis enthält deshalb neben den Vorbereitungs- und Hilfswissenschaften zu den Fakultätsstudien ein reiches Angebot für Schüler, die sich »dem militair-stande, dem hofe, der policey [d.h. inneren Verwaltung], der kaufmanschaft, dem landleben, den forsten, bergwercken « wie auch »künsten« gewidmet haben. [65] Für Adlige nahm die Anstalt Funktionen einer Ritterakademie (mit Tanzen, Reiten, Drechseln und Glasschleifen) wahr.

Das `Carolinum weil sich hier außerhalb des institutionellen Rahmens herkömmlicher Schultypen aufklärerische Vorstellungen von einem geschmacksbildenden und gegenwartsorientierten Literaturunterricht voll entfalten konnten. Der Unterricht lag in Händen bedeutender Literaten: Gärtner war seit 1748 als Lehrer der deutschen Redekunst tätig; Ebert wurde 1748 Hofmeister und unterrichtete von 1749 an in der englischen Sprache (aus der er Youngs Nachtgedanken übertrug); Zachariä, der gleichfalls 1748 Hofmeister wurde, las über Dichtkunst; Eschenburg schließlich wurde 1767 Hofmeister und 1777 Professor der schönen Literatur und Philosophie. Im ersten Semester 1745/46 wurde den Studenten - allerdings Mittwochs und Samstags, an den traditionellen Rekreationstagen - »durch anhörung der recension [d. h. kritischen Vorstellung], auch wirkliche vorlegung der neuesten und berühmtesten deutschen bücher gelegenheit verschafft, ihre kenntniß derselben zu vermehren, auch wie solche mit nutzen zu lesen, zu gebrauchen und nachzuahmen seyn, sie treulich belehret «. An den übrigen Tagen wurde einer der besten Poeten mit ihnen gelesen, »um sie durch den reichthum, durch die pracht, vortrefflichkeit und hoheit der sprache zu einer desto größern liebe und verehrung derselben zu reizen«. Als Dichter wurden Haller und daneben Opitz, Canitz und Hagedorn zugrundegelegt. Die Beredsamkeit - »so wol in lateinischer als deutscher sprache, und so wol in gebundener als ungebundener rede « wurde mündlich wie schriftlich geübt. [66] Das Programm hat sich später kaum geändert, wenngleich der missionarische Eifer, mit dem die Lehrer anfänglich für die deutsche Aufklärungsliteratur warben, einem akademischen Unterricht wich. 1774 z. B. las Gärtner ein halbjähriges vierstündiges Kolleg über die Regeln der Oratorie. Zachariae trug in wöchentlich vier Stunden »nach des Batteux cours de belles lettres die theorie der schönen wissenschaften « vor, wobei er sich »besonders über die regeln der dichtkunst « ausbreitete und sie »mit ausgesuchten stellen aus den besten ältern und neuern dichtern « erläuterte. Dazu gab er zehn Privatstunden zur Anleitung eigener Ausarbeitungen in den verschiedenen Dichtungsarten. Eschenburg bot »encyclopädische vorlesungen nach Sulzers kurzem begrif aller wissenschaften « und 
versprach »bey den schönen wissenschaften am ausführlichsten « zu sein. [67] Sein Entwurf einer Theorie und Literatur der schönen Wissenschaften (zuerst 1783, s. Bibliographie Bd. 2, Kap. 1.3.2), eines der am weitesten verbreiteten und am längsten benutzten Lehrbücher, erwuchs aus dieser Unterrichtspraxis.

\subsubsection{Querschnitt durch die Gymnasialreform 1773/83 - Zürich, Fulda, Kloster Berge, Magdeburg}

In den $70 \mathrm{er}$ und $80 \mathrm{er}$ Jahren haben sich die höheren Schulen auf breiter Grundlage reorganisiert und legen in werbenden Prospekten, die die Lehrpläne mit Angabe der Lernziele und Unterrichtsverfahren enthalten, von ihrer neuen Einrichtung Rechenschaft ab. Die vier ausgewählten, nach Standort, Konfession und Funktion sehr unterschiedlichen Anstalten erlauben einen Querschnitt durch die Praxis des spätaufklärerischen Sprach- und Literaturunterrichts. Zwei Schulen gehören zu Preußen, darunter Kloster Berge, ein protestantisches Internat unter Leitung des engagierten Reformers $\rightarrow$ Resewitz; die Fuldaer Anstalt, aus dem Bereich der katholischen Aufklärung, hält als ১Gelehrtenschule` für den Priesternachwuchs am ehesten am alten Latein- und Rhetorikbetrieb fest.

Zürich 1773. [68] Im >Collegium Humanitatis - mit einem zweijährigen Kurs »das Mittel zwischen den niedern Schulen und der höhern, academischen Art, die Wissenschaften zu studiren «-ist der rhetorische Unterricht ganz auf die sinduktive Lehrmethode anhand von Mustern abgestellt. Die analytische Textbehandlung dringt hier bis zu rhetorischen Details vor, wie die Ausführungen zur >Periodologie $<$ d. h. dem Bau und der Verknüpfung von Sätzen, zeigen:

[Der Schüler] wird angeführt[,] eine Periode aufzulösen, den Hauptsatz sich absonderlich von den Nebensätzen vorzustellen, die mannigfaltigen nähern Bestimmungen, Erläuterungen, Beweise, die in derselben [Periode] gleichsam zusammengedrängt liegen, zu bemerken. Man läßt ihn den Versuch machen, eben diese Sätze wieder zusammen zuordnen[,] damit er sehe[,] wie ganz ungleich die Vorstellung, oder die Rührung herauskömmt, wenn man dieses manigfaltige einzeln und getrennt, oder aber in einander verwebt, vorträgt: wie ungleich es herauskömmt, wenn man eben dieselben Gedanken oder Säze [!] so, oder anderst verbindet [. . .].

Weitere Ausführungen führen ähnlich tief in sprachliche Feinstrukturen. Der Gegenstand - »die Sache selbst «, um die es sich im literarischen Werk dreht - hat nach dieser Auffassung eine zielgerichtete sprachliche Behandlung erfahren, deren Techniken es zu durchschauen und wie in einem Baukastenspiel, durch Auseinandernehmen, Neuzusammensetzen und Variieren der Vorlage sich anzueignen gilt.

Fulda 1774. [69] Die sprachlichen Lektionen finden in vier Klassen statt, doch wird Deutsch nur in den beiden unteren als Vorstufe von Rhetorik und Poetik gesondert gelehrt. Die Muttersprache macht »nicht das Hauptgeschäft « aus, sondern arbeitet insbesondere in der Grammatik - dem Latein und Griechisch vor »und bricht ihnen so zu sagen das Eis «. Die Schwerpunkte in den sprachlichen, rhetorischen und poetischen Lehrgängen sind wirkungsvoll aufeinander abgestimmt. Die dritte Klasse handelt in der Rhetorik »von der Erfindung, Anordnung, Ausarbeitung«, wobei der 
Lehrer »mehr in Mustern, als in Regeln « zeigt, »wie man alles zu Stand bringe«. In der Poetik wird zuerst Horaz' Ars Poetica ausgelegt, und dann handelt der Lehrer nochmals »von der Erfindung, Anordnung, Ausarbeitung, aber als Poet «, und macht deutlich, »wie sich Redner und Dichter in allen diesen unterscheiden «. In der vierten Klasse folgen die sbesondere Redekunst und Poetik, d. h. die prosaische und poetische Gattungslehre. Lateinische, griechische und deutsche Muster werden im rhetorischen und poetischen Unterricht durchgehend parallelisiert. Der analytische Standpunkt wird auch an dieser Stelle vertreten, doch bestimmt das tabellarisch fixierte System die Anordnung des Lehrplans.

Kloster Berge (bei Magdeburg) 1776. [70] Der Deutschunterricht, der in vier >Ordnungen (Fachklassen) stattfindet, wendet sich zunächst hauptsächlich an Schüler, die direkt in die Berufspraxis überwechseln, und differenziert erst auf der obersten Stufe durch Parallelkurse zwischen >Humanisten in der dritten und zweiten Ordnung - es wird entgegen dem damaligen Brauch von oben her gezählt - dienen demnach Briefe, Erzählungen, Beschreibungen, Berichte und Aufsätze, »welche in bürgerlichen Geschäften üblich sind «. Stilistische Urteilsfähigkeit wird beim Lesen entwickelt, indem der Lehrer »die Aufmerksamkeit auf die Kennzeichen einer guten Schreibart « lenkt. In der ersten Ordnung erhalten die Studierenden dann »eine genauere Bekanntschaft mit den Grundsätzen der Beredsamkeit «, während die übrigen weiterhin nur »im guten Geschmack und in richtiger Beurtheilung einer zweckmäßigen Schreibart « unterrichtet werden. Quintilian, Rollin, Batteux und die Principes pour la lecture des Orateurs werden für den Rhetorikunterricht herangezogen, aber: »Eine eigentliche rhetorische Kunst auf Schulen zu lehren, hält man nicht für rathsam«.

Magdeburg, Kloster Unser Lieben Frauen 1783. [71] In Rhetorik und Poetik findet hier gleichfalls »kein zusammenhangender systematischer Vortrag « mehr statt, und der Lehrer begründet die Änderung aus der Erfahrung seiner Unterrichtspraxis: Rhetorische »Schulvorlesungen « »in der Athmosphäre des Katheders verfliegen wie das Gebet für den Kaiser in der Athmosphäre der Canzel «. Jetzt, wo man "praktisch « verfahre, geben die Lektüre und die Ausarbeitungen Gelegenheit, »theils einzelne theoretische Anmerkungen einzustreuen, oder die Schüler durch sokratische Fragmethode auf die Findung derselben hinzuleiten, theils in obern Klassen über einzelne Gegenstände der Stilbildung, der Wohlredenheit, der Redekunst und Rednersprache, der poetischen Schreibart, des Versbaus, etwas ausführlichere Theorie vorzutragen «. In der Lehrart verzichtet man nach Möglichkeit auf den Frontalunterricht und aktiviert die Eigeninitiative der Schüler, etwa indem man Lebenssituationen nachstellt. So wird bei den schriftlichen Übungen auf den beiden obersten Klassen bald allen Schülern »einerlei Inhalt und Behandlung vorgeschrieben, bald einigen aufgetragen[,] sich einander ihre Briefe oder Aufsätze zu beantworten oder zu wiederlegen [!], bald jedem ein besonderer Gesichtspunkt angewiesen, aus dem er die Sache ansehn und sie behandeln sol, bald eine Geschichte im [!] Briefe, Erzählungen oder Gespräche so aufgelöset, daß jeder Schüler eine seinem sonstigen Charakter wenigstens ziemlich angemessene Person dabei agire, oder den Theil der Geschichte erzähle, diejenige Situation dialogisire, die seinem Genie am angemessensten ist «. 
Damit bietet die Anstalt das Muster eines auf modernste pädagogische Prinzipien gebrachten Sprachunterrichts.

\subsection{Restauration und Vormärz}

In Fortführung des Aufklärungskapitels werden die bildungspolitischen Diskussionen und schulorganisatorischen Entscheidungen sowie die bildungstheoretischen Begründungen für Aufbau und Einrichtung höherer Schulen zwischen den Befreiungskriegen und der Märzrevolution skizziert. Innerhalb dieses Rahmens erhalten die Inhalte und Methoden des Deutschunterrichts eine gesellschaftsgeschichtliche Interpretation. Ich stelle modellhaft in Querschnitten nacheinander dar:

- die Diskussion um die soziale Funktion und Organisation des Gymnasiums;

- die Bildungskonzepte, die den Sprach- und Literaturunterricht bestimmten;

- die Rückwirkungen des Sprach- und Literaturunterrichts auf die gesellschaftliche Funktion und Organisation des Gymnasiums.

Die Organisationsweisen des Gymnasiums, die Bildungskonzepte und der Sprachunterricht sollen dabei in ihrem Zusammenhang und ihrer sozialen Bedeutung erkannt werden.

Bei Durcharbeitung der Quellen, besonders bei den Debatten auf den Lehrer- und Schulkonferenzen, die in der Vorbereitungsphase oder im Gefolge der Märzrevolution in den meisten Staaten einberufen wurden, sowie in der aus diesem Anlaß erschienenen Kontroversliteratur fällt eine erstaunliche Kontinuität zur Aufklärung auf. Die Konferenzen diskutierten alternative Organisationsentwürfe (Verhältnis von realistischem und humanistischem Bildungsweg: Ineinander, Nacheinander, Nebeneinander) und ihre Auswirkungen auf die Lehrpläne, insbesondere auf den Sprachund Literaturunterricht (Zuordnung von Sprach- und Sachunterricht, Zahl und Reihenfolge der Fremdsprachen, Gewichtung von Latein und Griechisch). Dabei entwickelten die Reformer, die durch ihr politisches und publizistisches Engagement meist im Vordergrund standen, die von der Aufklärung erarbeiteten Problemstellungen weiter: Kann die höhere Schule zur Chancengleichheit beitragen, wenn sie in ihren niederen Klassen als Bürger- und Mittelschule eingerichtet wird? Kann eine einheitliche höhere Schule im Hinblick auf das durch Parlamente und Selbstverwaltungsorgane gemeinsam regierende Bildungs- und Wirtschaftsbürgertum eine sozialintegrative Rolle spielen? Welche gesellschaftlichen Folgen hat die Auseinanderentwicklung von sprachlich-ästhetischer und naturwissenschaftlicher Bildung (etwa eine Kluft zwischen Beamtentum und Wirtschaft)? Erst nach dem Scheitern der Revolution, mit der für Jahrzehnte definitiven Trennung eines humanistischen und realistischen höheren Bildungsweges und der im Berechtigungswesen verankerten Privilegierung des humanistischen Gymnasiums, brach die Kontinuität der Problemstellungen und Lösungsversuche ab. 


\subsubsection{Sozialhistorische und schulorganisatorische Voraussetzungen der Re- formdiskussion}

Die Forderungen nach einer gemeinsamen Schule, mindestens nach einer gemeinsamen Unterstufe, für die humanistische wie realistische höhere Bildung müssen auf die soziale Funktion und die Organisation des Gymnasiums vor 1848 bezogen werden. Die Gymnasien waren noch keineswegs - wie wohl in der zweiten Hälfte des 19. Jahrhunderts - Rekrutierungsanstalten der Akademiker und des großenteils beamteten Bildungsbürgertums. Die Nichtstudierenden machten vielmehr auf den unteren Klassen einen beträchtlichen Anteil, oft sogar die Mehrheit aus. Sie verließen das Gymnasium, das ihnen als Mittelschule diente, um in eine handwerkliche oder kaufmännische Lehre oder in niedere Beamtenstellen einzutreten. Humanistische Gymnasien und realistische Bürgerschulen waren auch organisatorisch häufig verknüpft. Wie in der Aufklärung (s. Kap. 1.2.1 u. 2), richteten auch jetzt noch zahlreiche Anstalten ihre unteren Klassen als `Bürger-८ und ihre oberen als `Gelehrtenschule ein, oder sie boten in Parallelklassen und Parallellektionen einen realbildenden Unterricht an. Die Verhältnisse sind in den verschiedenen Ländern und je nach dem Standort (und damit nach der sozialen Zusammensetzung und den Berufszielen der Schüler), dem Ansehen und der Tradition, der Finanzlage und den Rechtsverhältnissen (zwischen Staat, Kirche, Kommunen, Stiftern) unterschiedlich. Da die Sozialgeschichte des Gymnasiums im 19. Jahrhundert noch in den Anfängen steht [1], sollen die folgenden, größtenteils zeitgenössischen Angaben die Verhältnisse illustrieren.

\subsubsection{Beispiele für das Verhältnis von Studierenden und Nichtstudierenden auf Gymnasien}

In Preußen liegen Zahlen für die Rheinprovinz und die Provinz Preußen (Ost- und Westpreußen, Litauen) vor. »Von den Gymnasien der preussischen Rheinprovinz gingen in 22 Jahren, vom Jahre 1831 bis Herbst 1852, 20299 Schüler ab, von welchen nur 4029 oder ein starkes Fünftel den Gymnasial-Cursus absolvirten und die Universität bezogen «. Die große Mehrheit trat, »meist aus den mittleren Classen«, »ins gewerbliche Leben « ein oder widmete sich »der militairischen Laufbahn oder dem Subalterndienste «. [2] - In der Provinz Preußen machten die Abiturienten von 1831 bis 1847 »etwa den sechsten Theil der abgehenden Schüler «[3] aus. Viele Eltern benutzten das Gymnasium »nur als Mittelschule « und nahmen ihre Kinder aus der Quinta oder Tertia, d. h. mit Sekundareife, aus dem auf neun Jahre angelegten Kursus heraus. »Dann gehen die Schüler [...] mit dem vollendeten vierzehnten Lebensjahr aus Quarta oder Tertia zu Handwerken und andern Gewerben über. Die Befähigung in Secunda eines Gymnasiums zu sitzen, gilt gesetzlich im preußischen Staate als Beweis einer Erziehung für den höhern Bürgerstand im Sinne des allgemeinen Landrechts. Von dem Nachweise dieser Befähigung ist daher abhängig die Leistung der Militärpflicht durch einjährigen Dienst im stehenden Heere, und der Zutritt zu solchen Dienstzweigen, welche zwar eine wissenschaftliche, aber doch nicht eine 
Bildung durch Universitätsstudien erfordern. Daher die Secundaner den siebenten oder achten Theil der Frequenz der Gymnasien ausmachen, die Primaner nur den eilften [!] oder zwölften«. [4] Die Tertia ist "gleichsam die unterste Klasse der gelehrten Schulen«, während Sexta, Quinta und Quarta als Bürgerschule dienen. »Eben nun, weil die Gymnasien in ihren untern und mittlern Klassen auf den Zustand und die Bedürfnisse dieses großen Theils ihrer Schüler Rücksicht nehmen müssen, erscheinen sie sehr vielen Eltern für den frühern Unterricht ihrer zum Studiren bestimmten Söhne nicht geeignet. Sehr gewöhnlich suchen sie daher theils in Privatschulen, theils durch häuslichen Unterricht, dieselben so weit zu bringen, daß sie in die dritte [Tertia], zuweilen selbst in die zweite Klasse [Sekunda] der Gymnasien eintreten können. Darum ist namentlich Sexta, von den vier untern, die am wenigsten besuchte Klasse der Gymnasialanstalten und ihr Verhältnis zur Frequenz der ganzen Anstalt gewöhnlich nur wie 0,1547:1 «. [5]

Die Nachrichten aus Sachsen machen deutlich, wie sehr die Verhältnisse an einzelnen Gymnasien differieren. Den philologischen Kaderschmieden (Meißen, Grimma) stehen die Schulen in der Bergwerksstadt Freiberg oder in der Industrieund Gewerbestadt Plauen gegenüber. Bei der Ermittlung der Zahl der Schüler, »welche von sämmtlichen 11 Gymnasien Sachsens von Ostern 1841 bis Ostern 1842 auf die Universität oder auf andere Schulen und zu andern Berufsarten abgegangen sind «, ergab sich, daß 148 auf die Universität und 178 (mit der Leipziger Thomasschule »gegen 200«) »zu andern Bildungsanstalten oder zu andern Berufsarten « übertraten. [6] Die Zahlen im einzelnen [7]:

\begin{tabular}{|l|c|c|c|}
\hline Gymnasium & Abgänge & $\begin{array}{l}\text { Ubergang zu akademi- } \\
\text { schen Studien }\end{array}$ & $\begin{array}{l}\text { Eintritt in bürgerliche } \\
\text { Geschäfte und Wechsel } \\
\text { zu andern Schulen }\end{array}$ \\
\hline Dresden, Kreuzschule & 77 & 34 & 43 \\
Freiberg & 37 & 12 & 25 \\
Plauen & 28 & 7 & 21 \\
Grimma. Fürstenschule & 26 & 17 & $3+6$ \\
Meißen. Fürstenschule & 23 & 19 & $2+2$ \\
\hline
\end{tabular}

(Zu Freiberg: 7 Studenten bezogen die Universität, 5 die Bergakademie. - Zu Meißen: Von den Nichtstudierenden wollte der eine Ökonom und der andere Militär werden.)

In Hessen-Darmstadt wurden 1839 die folgenden Durchschnittszahlen veröffentlicht [8]:

\begin{tabular}{|l|c|c|c|l|}
\hline Gymnasium & $\begin{array}{c}\text { Abgänge } \\
\text { pro Jahr }\end{array}$ & $\begin{array}{l}\text { Übergang zu aka- } \\
\text { demischen Studien }\end{array}$ & $\begin{array}{l}\text { Eintritt in bürger- } \\
\text { liche Geschäfte }\end{array}$ & $\begin{array}{l}\text { Wechsel zu andern } \\
\text { Gymnasien }\end{array}$ \\
\hline Darmstadt & 68 & 25 & 43 & \\
Gießen & 36 & 19 & 17 & \\
Worms & 24 & 4 & 20 & 3 \\
Büdingen & 19 & 8 & 8 & \\
Bensheim & 10 & 4 & 6 & \\
\hline
\end{tabular}

(Zu Büdingen: Dic Väter der Schüler »sind meistens Staatsbeamte, wenige gehören andern Stän- 
den an«. - Zu Bensheim: »Die Schüler sind theils Söhne von Beamten, theils von Kaufleuten, Handwerkern und Bauern. "Die Studenten sind »mit seltenen Ausnahmen lauter katholische Theologen «.)

\subsubsection{Beispiele für die Verbindung von Gymnasium und Realschule}

(a) Einzelne Länder. In Hessen-Nassau dienten die Pädagogien oder Untergymnasien (Dillenburg, Hadamar, Wiesbaden; Idstein bis 1822) nach dem Edikt vom 24. März 1817 bis zur Reorganisation des Gelehrtenschulwesens 1844 als »allgemeine höhere Bildungsanstalten « für alle, »welche dem eigentlich gelehrten Staatsdienst sich nicht widmen wollten «, und zugleich als »besondere Vorbereitungsanstalten « für Studierende. [9] Sie gaben, mit einer Menge berufsbezogener Lehrstoffe, »eine möglichst abgeschlossene, zum Eintritt in das praktische Berufsleben befähigende Bildung«. [10] - Als im Königreich Hannover 1846 der Realunterricht eingeführt wurde, war die Trennung der Bürgerschule vom Gymnasium nur in der Hauptstadt voll durchzuführen, während die beiden Bildungswege sonst bis zur Quarta vereinigt blieben.[11] Noch 1855 war die Schulorganisation sehr unterschiedlich: »Völlig getrennt von Quarta an sind die Realklassen von den humanistischen jetzt in vier größeren Gymnasien; größtentheils getrennt und nur in Fächern, welche mehr der allgemeinen Bildung angehören, vereinigt, sind sie in sechs Gymnasien; zur Hälfte etwa getrennt und zur Hälfte vereinigt, was wegen der geringen Schülerzahl möglich und unnachtheilig, und wegen der beschränkten Lehrerzahl notwendig war, bei drei Gymnasien «. [12] Zwei Gymnasien unterrichteten Real- und Gymnasialschüler auch in Quarta noch zusammen; in Aurich dauerte die Gemeinsamkeit bis zur Sekunda, neben welcher eine obere Realklasse besondere Stunden erhielt.

(b) Einzelne Anstalten: In Braunschweig wurde 1828 das höhere Schulwesen in einem »Gesammtgymnasium « zusammengefaßt. Es setzte sich aus einem »Obergymnasium «, eine »reine « Gelehrtenschule für den Úbergang auf die Universität, einem parallelen »Realgymnasium«, das »zu den höheren Stufen des bürgerlichen Geschäftslebens, namentlich des kaufmännischen und ökonomischen« vorbereitete, und einem »Progymnasium « als gemeinsamer Unterstufe zusammen. [13] Die humanistischen und realistischen Ansprüche werden im Progymnasium durch einen etwa gleich intensiven Unterricht in den alten (Latein; Griechisch nur für Studierende) und neuen Sprachen (Deutsch, Französisch) ausgeglichen. Doch bildet das Progymnasium nur mit dem Obergymnasium »ein genau zusammenhängendes Ganze « [14]: Ins Obergymnasium wird man nur aus der letzten Klasse des Progymnasiums aufgenommen, fürs Realgymnasium benötigt man nicht alle Klassen und kann auch direkt aus der Waisenhaus- und Bürgerschule kommen. - Die höhere Schule in Detmold bestand 1819 aus einer »Bürgerschule «, auf die das »Gymnasium« folgte. »Da es sich nun aber oft zuträgt, daß Aeltern wünschen, ihr 12 bis 14jähriger Knabe möge, während er die Bürgerschule besucht, auch Etwas Latein lernen, und da der künftige Gymnasiast in der genannten Abtheilung sich ebenfalls schon mit den Elementen dieser Sprache bekannt machen muß: so hat man es zweckmäßig gefunden, die unterste Classe des Gymnasiums zu einer Art von Uebergangs- oder Verbindungsclasse zu 
bestimmen «. Außer dieser »Elementarclasse « hatte das Gymnasium noch drei Klassen für die Studierenden, »welche der künftige Kaufmann, Forstmann, Oekonom etc. so lange benutzen mag, als es ihm die Umstände erlauben «. [15] - Das Katharineum in Lübeck war 1819 »Bürger- u[nd] Gelehrten-Schule « (»Vorschule für jedes edlere Gewerbe u[nd] für das Studium jeglicher Wissenschaft «). Die Nichtstudierenden besaßen in der zweiten Klasse »einen besonderen Kursus«, ohne Griechisch, ohne lateinischen Stil, mit nur zwei statt drei lateinischen Autoren, wo sie »Handlungskenntnisse u[nd] kaufmännischen Briefstil«, »Handelsgeographie, Waarenkunde, Fabrik- u[nd] Manufakturwesen « sowie »Rechnungsstunden « hatten. [16]

Zwei Anstalten aus Preußen sollen die aus verschiedenen Staaten und in ihrer Bevölkerungs- und Wirtschaftsstruktur ganz unterschiedlichen Städten gewählten Beispiele vervollständigen. In Minden war 1825 »von der Tertia an Alles vorzüglich auf die classische Bildung " bezogen. "Allein die unteren Classen sind vielmehr auf die Allgemein [!] menschliche und bürgerliche, als auf die gelehrte Bildung berechnet. So sind in der Sexta, von 31 Stunden nur 6, in der Quinta, von 34 nur 7, in der Quarta, von 37 nur 10 Stunden den alten Sprachen gewidmet, während die übrigen alle nur solche Kenntnisse umfassen, die jedem Menschen, in jedem Berufe nothwendig sind «. [17] - Das Gymnasium in Prenzlau war nach der Neuorganisation von 1816 »nicht bloss gelehrte Anstalt «, wenn auch Latein in allen Klassen obligatorisch war. "Die allgemeine Bildung ist der Hauptzweck; auf die Vorbereitung für das bürgerliche Leben kann nur nebenher Rücksicht genommen werden. Doch bilden je zwei Klassen eine Stufe, so daß die beiden untern, Sexta u[nd] Quinta, dem Handwerker, die beiden mittleren, Quarta u[nd] Tertia, den mittleren Ständen, z. B. dem Kaufmann u[nd] mechanischen Künstler, die beiden obern, Sekunda u[nd] Prima, dem Gelehrten u[nd] Künstler zur Vorbereitung dienen. Die Lateinische Sprache aber bezeichnet die gelehrte Anstalt, $u[n d]$ ist gleichsam das Kennzeichen der höheren Bildung «. [18] Somit setzte dieses Gymnasium Vorschläge zu einem Stufenaufbau (s. Kap. 1.3.2.3) in die Praxis um.

\subsubsection{Schulorganisatorische Vorstellungen}

\subsubsection{Trennung der Schularten}

Konservative begründen eine vertikale Trennung der Schularten vor allem sozialpolitisch: mit der vorgegebenen, göttlich und geschichtlich legitimierten Ständeordnung, die Kinder in verschiedenen Lebenssphären aufwachsen läßt und damit in ihrer Begabungsrichtung prägt. [19] »Verschiedenheit des Standes verlangt Verschiedenheit der Unterrichtsmittel und der Schulen «, lautet die Úberschrift des maßgebenden Kapitels bei Ohlert. Er unterscheidet drei Stände mit zugeordneten Schultypen [20]:

- Die »Gelehrten« (Geistliche, Rechtsgelehrte, »Staatsgelehrte «, Ärzte) bilden die regierende »Seele des Staates«. Der Schwerpunkt ihrer Bildung liegt in der »Bekanntschaft mit der Vergangenheit «, die das Gymnasium vermittelt. 
- Es folgt der »Stand der Bürger«: »die Offizianten, welche nicht studiert haben dürfen [d. h. müssen], die Künstler, Kaufleute, Fabrikherren und größere Landleute - Gutsbesitzer und Amtleute « wie Offiziere. Die »Bürgerschule « befriedigt ihr Interesse für »die Gegenwart und deren Verhältnisse «.

- Den dritten Stand stellen die »Handarbeiter « - »alle Handwerker, Bauern, und die ganze dienende Klasse« -, für die »Elementarschulen« sorgen.

Im Standardwerk zum Gymnasialunterricht von $\rightarrow$ Deinhardt [21] wird die Gliederung des Schulwesens ebenso »ausschließlich durch den Unterschied der Stände bestimmt, in die der Staat zerfällt «. Der Verfasser geht von zwei parallelen weiterführenden »Standesschulen « aus: Das Gymnasium ist »die allgemeine Vorbereitungsschule für die theoretischen Stände «, d. h. für » Ärzte, Juristen, Geistliche, Lehrer der höheren Schulen und Universitäten «; die Realschule gibt »die allgemeine Vorbildung aller practischen Stände«, d. h. für »Bauern und Bürger, Polizei und Militär«. Ein solches Nebeneinander von Schultypen soll zur Reproduktion der bestehenden gesellschaftlichen Schichtung beitragen: »Die Erziehung eines Volkes hat den Zweck, die Jugend zu dem zu machen, was das Volk schon ist«. [22]

\subsubsection{Gemeinsame Unterstufe für Gymnasien und Realschulen}

Bei den Reformern ist die Forderung nach einer gemeinsamen Unterstufe für alle Arten höherer Schulen am verbreitetsten. Auch hierin drückt sich in erster Linie eine sozialpolitische Zielsetzung aus. Da man befürchtet, daß die Trennung von Gymnasium und Realschule "zwei von einander ihrer Natur und ihrem innnersten Wesen nach ganz verschiedene Arten von höheren Volksbildungen «, nämlich »eine antike und eine moderne «, ins Leben ruft, malt man »das Wehe eines solchen Schisma's in der allgemeinen höheren Volksbildung und in Folge dessen die Zerrissenheit des ganzen höheren socialen Volkslebens « [23] in grellen Farben. Die Kluft zwischen der beamteten staatlichen und der gewerblichen, kaufmännischen und technischen Intelligenz, der steigende Bedeutung zukommt, soll durch gemeinsamen Schulbesuch gemildert werden. $\rightarrow$ Klumpp, ein maßgeblicher württembergischer Schulpolitiker, begründet sein Votum »für Gemeinschaftlichkeit des früheren Unterrichts « und »der früheren Bildung" und "gegen die Errichtung besonderer Realschulen « mit dem Einfluß auf die socialen Verhältnisse «: »Die Schüler der Realanstalten werden als Männer eine wichtige Classe der Gesellschaft, sie werden, gemeinschaftlich mit den Staatsdienern, den sogenannten gebildeten Theil des Volkes ausmachen, und die Intelligenz desselben repräsentiren, sie werden die Gemeindeämter einnehmen und dadurch, sowie durch das Uebergewicht ihrer materiellen Mittel und den dadurch ihnen zu Gebot stehenden Einfluß auf die unteren Volksclassen der öffentlichen Stimmung einen sehr bedeutenden Theil ihrer Richtung geben «. [24] Schleiermacher macht ganz ähnlich die Bildung »der mittleren Klasse« von ihrer gesellschaftlichen Funktion und »von politischen Verhältnissen « [25] abhängig. Bei sozialem Aufstieg und politischer Mitsprache sollte sie »in den Besiz [!] aller leitenden Prinzipien « gesetzt werden. »Je mehr für nothwendig und unerläßlich im Staate gehalten wird[,] 
daß alle[,] welche an dem Regieren Theil nehmen wollen, wenigstens der Form nach die wissenschaftliche Laufbahn durchmachen: um so nothwendiger wäre es, in so fern auch die Gewerbetreibenden an der Leitung Antheil haben können, auch diesen die wissenschaftlichen Principien mitzutheilen, damit sie ohne Schwierigkeit in die leitende Klasse übergehen können «. [26]

Die drei unteren Klassen der Gymnasien nicht nur für Studierende, sondern auch für künftige Handwerker, Kaufleute und Techniker einzurichten, zählte aus den angegebenen Gründen zu den obligaten Diskussionspunkten der Lehrerversammlungen und Schulkonferenzen um 1848. Die »Versammlung der Schulmänner der Preussischen Provinz Sachsen « hielt es »in nationaler und politischer Hinsicht « für wünschenswert, daß alle Schüler bis zum 14. Lebensjahr, d. h. bis zum Zeitpunkt der Konfirmation und des Úbertritts in die berufliche Lehre, »ein und denselben Unterricht « erhalten. [27] Die Mehrheit der Deputierten (32 gegen 17 Stimmen) auf der »Schul-Conferenz« des Königreichs Hannover sprach sich grundsätzlich für »eine völlige Scheidung« von Gymnasium und Realschule aus. [28] Doch erzwang die Úberzahl der Nichtstudierenden auf Gymnasien - insgesamt $74 \%$, davon in den drei unteren Klassen $87 \%$ [29] - Reformen zu ihren Gunsten. Während es über eine teilweise »Verschmelzung « eines humanistischen und realistischen Unterrichtszweiges zu keiner Einigung kam, wurde eine Umwandlung der Progymnasien in Realschulen, die gleichzeitig auf das Gymnasium vorbereiten, mit nur zwei Gegenstimmen gutgeheißen. [30] Die Kommission, welche die »Verhandlungen über die Reorganisation der höheren Schulen « in Berlin vorbereitete, votierte mit 9 gegen 3 Stimmen für eine möglichst weitgehende Verschmelzung der gymnasialen und realen Lehrpläne in den drei Unterklassen. Nach den Beschlüssen der Versammlung umfassen diese Klassen »für diejenigen Zöglinge, welche aus dieser Abtheilung ins bürgerliche Leben übergehen, einen für sich bestehenden Cursus«. [31] Der von der nachmärzlichen Reaktion unterdrückte Entwurf zu dem allgemeinen Schulgesetz für das Königreich Sachsen, dem zwei Gymnasiallehrerversammlungen vorausgingen, sah ein gemeinsames Progymnasium (»vom vollendeten neunten Jahre an «, mit drei Klassen) für die parallelen >Human-८ und >Realgymnasien sung Gesetz werden, die Dietsch auf der Leipziger Konferenz vertrat: »daß die unteren Klassen der Gymnasien wieder werden müssten, was sie früher gewesen, Vorbereitungsanstalten für Alle, welche eine höhere Bildung suchten, in denen der künftige Kaufmann neben dem künftigen Techniker und Gelehrten seinen Platz fänden «. [33]

\subsubsection{Der Stufenaufbau der höheren Schule}

Eine Minderheit der Reformer wollte das Gymnasium den verschieden hohen Bildungsansprüchen der einzelnen Berufszweige und den vielfältigen ökonomischen, sozialen und individuellen Bildungsmöglichkeiten und -ansprüchen noch stärker anpassen. Die Lösung suchte man zum Teil in einem gestuften Aufbau einer einheitlichen höheren Schule, zum Teil im Fachklassensystem, das den Schülern die Wahl der Fächer gestattet. 
$\rightarrow$ Bernhardi, der Direktor des Friedrich-Wilhelm-Gymnasiums in Berlin, empfahl »drei Bildungsstufen « mit je zwei Klassen, »in welchen die vorbereitenden Kenntnisse jeder Classe der Stände niedergelegt sind, so daß also die zwei untersten Classen die Bürgerschule, die zwei mittlern die Künstlerschule [für »die expedirenden Secretaire, die Kaufleute im Ganzen, die bildenden Künstler«.], oder meinetwegen das Realgymnasium, die beiden obern die gelehrte Schule ausmachen. Diese drei verschiedenen Schulen sollen getrennt, aber dennoch zu einer Organisation vereinigt sein«. [34] Das Gymnasium in Prenzlau war nach diesen Prinzipien eingerichtet (s. Kap. 1.3.1.2b). Der Historiker Onno Klopp ging noch weiter, indem er den Plan eines »Mustergymnasii (Sexta: Englisch, Quinta: Französisch, Quarta: Latein, Tertia: Griechisch) entwarf, wo jede Klasse »für sich einen Abschluß« gewährt. [35]

\subsubsection{Das Fachklassensystem}

Das Fachklassensystem, das sich im späten 18. Jahrhundert besonders an Stadtschulen durchgesetzt hatte (s. Kap. 1.2.2), war nach 1815 Schritt für Schritt abgeschafft worden (z. B. in Preussen durch die Verfügung vom 9. Juni 1821), spielte in der Reformdebatte aber weiterhin eine Rolle. Der Aufklärer Stephani, der eine "Staatsschulorganisationskunde « begründete [36], stellte 1828 folgende Vorteile der »sächlichen Klassen-Eintheilung« (»Spezialklassen-Eintheilung« oder Fachsystem) vor der "persönlichen Klassen-Eintheilung « (»Generalklassen-Eintheilung oder Jahrgangsklassen) zusammen [37]:

- Die Gymnasien werden »wahre höhere Bildungsschulen für alle Jünglinge der Nation von der verschiedensten künftigen professionellen Bestimmung «, weil die Schüler diejenigen Fächer wählen können, worin sie »eine höhere Befähigung « wünschen.

- Über Aufnahme und Versetzung entscheidet nicht mehr einseitig das Latein. »In welchem Lehrfache ein Jüngling sich für höhern Unterricht befähiget hat, in dem steigt er, unrücksichtlich auf sein Zurückbleiben in andern Fächern, immer vorwärts«.

- Die Organisation fordert Fachlehrer (statt Klassenlehrer), die dem wissenschaftlichen Fortschritt folgen können. Die »Geisteskraft « des Schülers wird »von Seiten mehrerer und verschiedenartiger Lehrer « angeregt und vielseitiger entwickelt.

- Kostenersparnis (keine anderen höheren Schulen, weniger Lehrer).

Die Gymnasien sollten durch das Fachklassensystem »die allgemeinste Bestimmung « erhalten und nicht nur »für die höhere Staats- und Kirchendienerschaft « vorhanden sein. [38] Die Einführung der Jahrgangsklassen (mit Altphilologen als Klassenlehrern) hat den Gymnasien - wie es für Preußen kritisch heißt - »den Charakter von Hauptgrundschulen der Nation genommen und ihnen den mangelhaften von Beamten- oder Fachschulen aufgeprägt«. [39] 


\subsubsection{Bildungskonzepte}

Im folgenden stelle ich die wichtigsten bildungstheoretischen Begründungen des Sprach- und Literaturunterrichts in ihren Grundzügen dar und untersuche, welche Folgen für die Lehrplangestaltung und Organisation der höheren Schulen sich aus ihnen ergeben. Dabei gehe ich nicht der Geschichte der Ideen nach, sondern erfasse sie in der Gestalt, in der sie in der Restaurationszeit virulent werden.

\subsubsection{Sprachlich formale Bildung}

Die Anhänger des formalen, besonders des grammatisierenden Sprachunterrichts variieren, seit Wilhelm von Humboldt sie in seinen sprachtheoretischen Schriften kanonisiert hat, zwei aufeinander bezogene Argumente:

(a) Sprache wird mit Denken, Sprach- und Ausdrucksfähigkeit mit Intelligenz in eins gesetzt. Für Humboldt denkt der Mensch »nur in und durch Sprache«; sie ist »das bildende Organ des Gedankens«. [40] Die Gleichsetzung von Sprache und Denken wird in der idealistischen Spekulation, die den Geist zu einem eigenhandelnden Wesen hypostasiert, metaphysisch verankert.

In der Studie, die Bäumlein im Auftrag der Basler Philologenversammlung von 1847 als »Grundlage für ein gemeinsames Votum des philologischen Schulstandes« erarbeitete, heißt es [41]:

Die formal bildende Kraft des Sprachunterrichts beruht auf der ganz einzigen Verbindung, in welcher die Sprache zum menschlichen Geist steht. Die Sprache ist nichts Anderes, als der Geist selbst in seiner konkreten Erscheinung. Sie ist nicht seine Erfindung, seine Schöpfung; sie ist er selbst, aus formloser Anlage und abstrakter Allgemeinheit hervortretend in bestimmter Form und Begränzung.

Die Wesensbestimmung der Sprache als konkrete Erscheinungsweise des Geistes erklärt ihre Bedeutung »als intellectuell-formales Bildungsmittel «. [42] Während der Schüler im Sprechen und Schreiben die Gesetze des Denkens einübt, lernt er in der Grammatik die logischen Kategorien in einer ihm faßbaren anschaulichen Gestalt kennen. Die Grammatik ist somit - nach einem Wort Hegels - »die elementarische Philosophie « [43]; ihr Studium ist, »ohne daß der Schüler es denkt und weiß, ein Ueben in den Kategorien der Logik und Metaphysik «. [44] Im praktischen Teil ist der Sprachunterricht »die Schule der geistigen Operationen « [45], im theoretischen Teil ist das Ziel die »Erkenntnis der Sprachgesetze und der in ihnen ausgeprägten Denkgesetze «. [46] Die Grammatik gilt als »die Logik des Gymnasiums « (mit der Mathematik)[47] und als »der eigentliche Nerv der Gymnastik des Geistes« auf Schulen. [48]

Zwei bedeutsame Folgerungen für die Stellung der alten Sprachen und der Grammatik im Lehrplan knüpfen sich an dieses Argument: Erstens bevorzugt die Pädagogik eine in ihrer Grammatik möglichst entwickelte Sprache, da sich bereits an den Formen, ganz abgesehen von den Inhalten, die logische Durchbildung ermessen läßt. »Eine solche Sprache bildet durch sich selbst das sprechende Denken «. [49] Die »hohe Formausbildung « [50] läßt die antiken Flexionssprachen, mit ihren ausgeprägten Modi, Kasus und Zeiten, für die Entwicklung der Sprach- und Denkfähigkeiten 
am geeignetsten erscheinen. »Ist die Sprache der körperliche Organismus, in welchem der Geist, und vornehmlich die Intelligenz zur Wirklichkeit gelangt, sind die Formen der Sprache gleichsam die Glieder und Organe, vermittelst deren der Geist sich regt, so ist es klar, daß die Regsamkeit und freie Bewegung des Geistes in dem Maaße erhöht werden muß, als er über einen größeren Reichthum von sprachlichen, also auch von Denkformen zu gebieten vermag«. [51] Dabei behauptet sich die lateinische Sprache als »Mittelglied «[52] zwischen Altertum und Neuzeit wie als »grammatischer Kanon « [53] gegenüber dem freieren Griechischen.

Durch das Vorherrschen der Grammatik auf der Unterstufe - und das ist die zweite Folge - besteht das Gymnasium aus »zwei scharf geschiedene[n] Stufen «. [54] Im Sprachunterricht der ersten Klassen überwiegen die »Gedächtnißübungen«, die »ihren Endzweck in sich selber « haben [55]; die Lektüre wird hier »vorzugsweise zur Befestigung in der Grammatik « [56] benutzt. So macht der »empirische Sprachunterricht«, wie ihn $\rightarrow$ Deinhardt - der Direktor des Bromberger Gymnasiums - entwirft [57], den Schüler zunächst in den Formen und Regeln der alten Grammatik sattelfest und stattet ihn mit einem Vorrat von Worten aus. Erst in der Oberstufe beginnt der »rationale Unterricht «, der die Klassiker inhaltlich aufschließt und die Sprache in ihren Gesetzen zu begreifen sucht. Als durchaus typisches Beispiel können die Anstalten in Baden gelten. Um die Mitte des Jahrhunderts werden von 78 lateinischen Wochenstunden aller Klassen 41 auf Grammatik (mit lateinischen Stilübungen) verwendet. »Die unteren Classen sind von diesen grammatischen Uebungen ganz beherrscht, nach oben gewinnt allmälig die Lectüre das Uebergewicht. Die Progression ist etwa folgende: I 10:0, II 8:2, III 5:5, IV 4:4, V 3:5, VI 2:6«. [58] Zu der Notwendigkeit, für die alten Sprachen eine solide grammatische Grundlage zu schaffen, tritt ein entwicklungspsychologisches Argument, wonach es »eine Stufe des Gedächtnisses « [59] im Knabenalter gibt. Das Gedächtnis ist danach »die auffassende Kraft« [60], »die eigentliche Blüthe des jugendlichen Geistes« [61], die durch Auswendiglernen fruchtbar gemacht wird.

(b) Das Wesen der Nation stellt sich in der Sprache dar. Sprache ist bei Humboldt »der Grund von Individualität und Nation«, die Nation selbst »eine durch eine bestimmte Sprache charakterisirte geistige Form der Menschheit «. [62] In der Nachfolge von Herder, Humboldt und der Romantiker werden ähnliche Formulierungen stetig wiederholt. »In der Sprache offenbart sich die Individualität eines Volkes « [63]; sie ist »ein unmittelbares Erzeugniß der Gesammtbildung einer selbständigen Nation « [64], »ein sprechendes Gemälde von den Einsichten und den Sitten eines Volkes« [65] und somit dessen »vollkommenste Selbstbiographie«. [66] Da die Sprache »das Festgewordene in der Bildung der Völker « [67] enthält, dringt man mit ihrer Erlernung in den Charakter einer Kultur ein und macht sich ihre Vorzüge zu eigen. Die Sprache selbst wird dadurch zum »Hauptklassiker« einer Nation, zu dem die literarischen Werke »gleichsam nur die Commentare und Excurse « liefern. [68]

Das Argumentationsmodell kann den altklassischen Unterricht rechtfertigen, aber auch die nationalen Forderungen nach Vermehrung des Deutschen (s. u.) begründen. Wer mit mehreren Sprachen lebt, durchbricht in seiner Bildung die Schranken der Nation. 
Denn die Literatur jedes Volks ist ein Ausdruck des Volksgeistes und wenn ich daher von dem vaterländischen Geiste und Bewußtseyn aus die Literatur eines fremden Volkes mit Fleiß studire, so kommen zwei Volksgeister mit einander in Berührung, die nur in dem über allen Volksgeistern liegenden gemeinschaftlichen Menschengeiste ihre Vermittlung, ihre Verständigung und ihre Vereinigung finden. [69]

Mehrere Argumente, die sich an den Nachweis der formalen Vorzüge der alten Sprache anschließen (das »Schöne« des Griechischen und Lateinischen; die »Classicität « der Werke des Altertums; die alten Schriftsteller als »Quelle der Wissenschaften « im Abendland; der »Schatz sittlicher Grundsätze und Beispiele« bei den Alten) [70], unterstreichen die eminente Bedeutung des Lateinischen und Griechischen für einen Sprachunterricht, der von praktischen Bedürfnissen weitgehend absieht.

\subsubsection{Die Auswirkungen des formalen Bildungskonzepts auf den Lehrplan und die} Organisation der Gymnasien

(a) Durch die Grammatisierung des Lateinunterrichts verliert die gymnasiale Unterstufe ihre Eigenständigkeit. Da die Fertigkeiten in der Grammatik und die Verfügung über einen Vorrat von Worten sich erst bei der zusammenhängenden Lektüre der oberen Klassen auszahlen, erhalten die Schüler, die nicht das Abitur und das Studium anstreben, keinen sinnvollen Abschluß ihrer Bildung.

Wie die Art des Sprachbetriebs mit sozialpolitischen Entscheidungen verknüpft wird, kann die Gegenüberstellung von zwei Lehrplänen verdeutlichen: dem zur Revolutionszeit ausgearbeiteten österreichischen Schulorganisationsentwurf von 1849 und der, 1854 nur unwesentlich revidierten, bayerischen Studienordnung von 1830 (dazu Kap. 2.2.3, mit Stundenzahlen). Die bayerische `Lateinische Schule $<$, die die vier unteren Klassen des Gymnasiums vom 8. bis zum 14. Lebensjahr umfaßt, hat »den Hauptzweck, für das Gymnasium vorzubereiten; nach diesem Hauptzwecke richtet sich Stoff, Umfang und Art des Unterrichtes, an welchem auch solche Knaben Antheil nehmen können, die ihre künftige Bestimmung nicht in das Gymnasium führen wird «. [71] Die »doppelte Bestimmung « der Lateinischen Schule geht auf den von $\rightarrow$ Thiersch entworfenen Plan von 1829 zurück: »sie soll auf das Gymnasium und soll zugleich auf das bürgerliche Leben vorbereiten«. [72] Der »Bürgerstand « sollte an der formalen Bildung durch das Studium des Lateins teilhaben, ja Thiersch hoffte sogar, daß die höheren Bürgerschulen »überflüssig " würden und »der Aufwand für sie in der Zukunft füglicher den lateinischen Stadtschulen « bestimmt werden könnte. [73] Der Widerspruch, eine für alle höheren Schichten konzipierte Schule mit einem ganz auf das folgende humanistische (Ober)Gymnasium ausgerichteten Lehrplan auszustatten, führte zu einem Schulkampf in Bayern. Die Opposition ging von dem »doppelten Zweck « der Lateinischen Schule [74] aus:

Diese doppelte Bestimmung für eine gleichmäßige annehmend haben viele und nicht nur Einzelne, sondern auch Corporationen, dort Bürgermeister und Magistrat, hier Landrath und Regierung Verwahrung dagegen eingelegt. Sie haben in ihr [der Lateinischen Schule] über dem künftigen Gelehrten den künftigen Bürger zu spärlich bedacht gefunden, und für diesen mehr 
Geographie und Geschichte, dazu Naturgeschichte, Physik, Technologie, praktische Geometrie, Zeichnen und neuere Sprachen begehrt. [75]

Thiersch drohte daraufhin, »die lateinische Schule dem künftigen Bürger zu schliessen und ihn in die deutsche wieder hinüberzuweisen «, wenn er »die für das Gymnasium nöthige Vorbereitung « der Studierenden »durch seine ihm fremden Ansprüche zu stören oder zu schwächen « fortfahre. [76] Ein formaler Latein- und Griechischunterricht, mit über der Hälfte aller Stunden, beherrschte das Gymnasium ganz und gar: Einprägung von Worten in das Gedächtnis, Grammatik mit ihren Anomalien, lateinische Prosodie und Metrik, lateinische Sprechübungen und Aufsätze, nach denen die »Schul-Plätze « [77] bestimmt wurden - d. h. die Rangfolge der Schüler, nach der sich die Sitzordnung der Klasse richtete.

Anders in Österreich. Das »Untergymnasium «, das die gleichen vier Klassen zusammenfaßt, gewährt hier, »indem es jeden seiner Lehrgegenstände zu einem relativen Abschlusse führt, und mehrere davon in vorherrschend populärer Weise und praktischer Richtung behandelt, ein in sich abgeschlossenes Ganzes von allgemeiner Bildung ", das »zum Eintritte in manche Berufe des praktischen Lebens" befähigt. [78] Der Lehrplan berücksichtigt die Realien und hat seinen "Schwerpunkt « »nicht in der klassischen Literatur « - die mit dem Deutschen »ungefähr die Hälfte der gesammten Unterrichtszeit « erhält - »sondern in der wechselseitigen Beziehung aller Unterrichtsgegenstände aufeinander «. [79] Der »Lesung der klassischen Schriftsteller «, die als »Hauptzweck der Erlernung der alten Sprachen « gilt, wird »die durch grammatische Studien zu erwerbende formelle Bildung " [80] nachgeordnet.

(b) Das bildungstheoretische Primat der klassische Sprachen erschwerte es, die modernen Fremdsprachen, vor allem das Französische und Englische angemessen auf Schulen zu treiben. Wissenschaftliche Behandlung und pädagogischen Wert reklamierten die alten Sprachen für sich, während praktische Einübung für die Bedürfnisse des Lebens bei den modernen Sprachen zu genügen schien. Dem Verhältnis der klassischen zu den neueren Fremdsprachen kommt bei den Reformdiskussionen der Jahrhundertmitte eine grundsätzliche Bedeutung zu. Bei der Umgestaltung der Unterstufe des Gymnasiums zu einer Einheitsschule aller höheren Schichten wird neben der Stärkung der Realien - die Sprachenfolge zum wichtigsten Programmpunkt: Aus Rücksicht auf Schüler, die nicht »für die sogenannten theoretischen Stände und Berufsarten " gebildet werden [81], soll der Unterricht in einer oder zwei modernen Fremdsprachen vor oder gleichzeitig mit dem Lateinischen und Griechischen beginnen. Die Lehrerkonferenzen haben »Gesammtgymnasien« vor allem mit folgenden sprachlichen Stufengängen vorgeschlagen [82]:

Englisch - Französisch - Latein - Griechisch (in Hannover, Sachsen und SchleswigHolstein);

Französisch - Englisch - Latein - Griechisch (vom >Dresdner Gymnasialverein` mit $\rightarrow$ Köchly);

Französisch - Lateinisch - Griechisch - Englisch (vom Braunschweiger Konsistorium und der Wolfenbütteler Lehrerversammlung 1849); Lateinisch - Französisch - Englisch - Griechisch (in Schleswig-Holstein). 
Diese Pläne sind pädagogisch am Anspruch der Altphilologen auf eine grammatische Grundlegung in den unteren Klassen und politisch mit der Revolution von 1848 gescheitert.

\subsubsection{Universell-historische Bildung}

Bei den Reformpädagogen, die auf eine Umgestaltung des altsprachlichen und eine Erweiterung des deutschen Unterrichts drängten, überwog ein historisches Bildungskonzept. Das sich bildende Individuum vollzieht nach dieser Auffassung die menschheitliche und nationale kulturelle Entwicklung für sich nach. Es eignet sich die Bildungsgrundlagen, auf der die Gegenwart beruht, an und begreift seine Zeit als Resultat der Geschichte. Der junge Mensch durchmißt - wie man es sich vorstellt »den Weg, auf dem die. Weltgeschichte im Großen und Ganzen (in ihrem Makrokosmus) sich entwickelt hat, in seinem individuellen Geiste (dem Mikrokosmus)«. [83] Das Gymnasium bringt die Schüler - so schreibt Mützell in einem programmatischen Aufsatz des ersten Bandes der von ihm mitbegründeten Zeitschrift für das Gymnasialwesen - zur »Erkenntniss des Zusammenhangs zwischen Vergangenheit und Gegenwart «; »sie werden unterwiesen, wie sie die nationale Gegenwart als ein Moment in dem historischen Entwicklungsgange ihres Volks, in dem aller Bildung zu begreifen haben «. [84] Das historische Prinzip hat Folgen für den Fächerkanon und den Sprachund Literaturunterricht, wie ich im folgenden zeige.

\subsection{Der universalistische Bildungskanon}

Das historische Konzept fordert die Berücksichtigung aller die Gegenwart prägenden geschichtlichen Kräfte. „Als Princip alles Unterrichts muß man daher den Satz aufstellen: Er muß die gesammte Cultur der Welt in sich fassen «. [85] Der Naturwissenschaftler Oken, von dem diese Bestimmung stammt, definiert Unterricht als »die geistige Abbildung der Welt, oder die Einkehr der Welt in den Menschen «. [86] Neben der Antike machen die christliche Welt des Mittelalters, die modernen Nationalkulturen und die Naturwissenschaften Anspruch, im Lehrstoff der Schule angemessen vertreten zu sein. $\rightarrow$ Hiecke, der führende Didaktiker des Deutschen, war auf der Leipziger Schulkonferenz von 1848 der Meinung, »dass dieselben Bildungselemente, welche auf die deutsche Nation eingewirkt haben, auch die Grundlage der Schule sein müssten, also Christenthum, klassisches Alterthum, Literatur der Deutschen und der wichtigsten neueren Völker, Naturwissenschaften «. [87] $\rightarrow$ Köchly verlangte gleichzeitig »nach einem modern universellen Principe «, wonach das Gymnasium »alle Bildungsmittel « benutzt, »damit es Vorschule für die Naturwissenschaften, wie für die historisch-ethischen Wissenschaften sein könne«. [88] Der Wunsch nach mehr Erziehung, besonders nach christlicher, nationaler und ethisch-ästhetischer Erziehung - der vor allem dem deutschen Unterricht zugute kommt (vgl. u.) verbindet sich in der Regel mit diesen Forderungen; er kann sich im christlichkonservativen Lager aber auch gegen die angeblich materialistischen Naturwissenschaften richten. Auf alle Fälle hat das Gymnasium die »intellectuelle «, »religiösmoralische« und »ästhetische Cultur« [89] zu einer Einheit zu verschmelzen. 
Fast alle hier ausgewerteten Reformer, die für eine gemeinsame Unterstufe eintraten, sprachen sich für einen revidierten Fächerkanon aus. Schleiermacher machte für die Bevorzugung der klassischen Sprachen zum einen die Tradition des gelehrten Schulwesens seit der Reformation, zum anderen »eine große Sorglosigkeit in Beziehung auf die materielle Entwikklung [!] des Volkes hinsichtlich der Gewerbe « [90] verantwortlich. „Der Zustand ist also ein unvollkommener; die alten Sprachen allein und für alle gleichmäßig zum Grunde der allgemeinen und gesellschaftlichen Bildung zu legen, ist ein dem Leben nicht angemessener Bildungstypus « [91] - wie es in einem gesperrten Leitsatz seiner Pädagogikvorlesungen heißt. Schleiermacher läßt sich von der Idee leiten, »daß die Universalbildung eine größere Ausdehnung gewinnen müsse «, und kritisiert, daß »das große Uebergewicht der klassischen Philologie den Gymnasien das Ansehen von Specialschulen für das gelehrte Schulwesen « gebe. [92]

$\rightarrow$ Klumpps Hauptwerk Die gelehrten Schulen nach den Grundsätzen des wahren Humanismus und den Anforderungen der Zeit hat eine zeitgemäße Erweiterung des Humanismus zum Ziel. Da sich die »Einseitigkeit in zweifacher Beziehung ausspricht, »einmal in Hinsicht der Richtung, durch Vernachläßigung des christlichen und nationalen Princips«, sodann »in Hinsicht des Inhalts« durch Ausschließung oder wenigstens Hintansetzung aller Gegenstände des Wissens außer dem Studium der alten Sprachen, so lautet die Forderung: »daß die Schule das humanistische Princip theils durch Verfolgung jener doppelten Richtung, theils durch Beiziehung weiterer. Unterrichts-Gegenstände ergänzen und vervollständigen müsse«. [93] Neben Mathematik und Naturwissenschaften dienen zur Ergänzung: die »nationale Richtung «, die den »Geist der Vaterlands-Liebe und des vaterländischen Selbstgefühls « [94], und die »christliche Richtung «, welche die im Lateinbetrieb vernachlässigte Pflege des Herzens und der Gesinnung ins Gymnasium einführen soll.

$\rightarrow$ Dilthey, der Direktor des Darmstädter Gymnasiums, macht vergleichbare Vorschläge und arbeitet dabei die gesellschaftspolitischen Motive bei der Reform der Gymnasien stärker heraus. Er befürwortet einen universalen Fächerkanon und regt eine »Milderung des philologischen Zwangssystems « an, wonach jedem Schüler »innerhalb gewisser Schranken eine seiner Fähigkeit und Bestimmung angemessene Auswahl der Lehrgegenstände " gestattet wird. [95] Das Gymnasium sollte sich seiner Meinung nach allseitig erweitern, indem es »mit dem Antiken das Moderne, mit dem Classischen das Nationale, mit dem Gelehrten das Volksthümliche, mit dem Sprachlichen das Sachliche, mit der Theorie die Praxis « [96] verbindet. Die Argumente Diltheys konzentrieren sich auf die folgenden Punkte:

- Die Reform soll die Úberproduktion an Akademikern verhindern, die aufgrund ihrer einseitigen Ausbildung auf Staatsstellen angewiesen sind. Die »überhandnehmende Studiersucht « [97] wird seit dem Ende der zwanziger Jahre, als die Meldungen über den »Ueberfluß an studierenden Individuen «[98] einsetzen, mit dem humanistischen Gymnasium in Verbindung gebracht. Die Begründung lautet: Das Fehlen geeigneter Mittelschulen treibt die eine höhere Bildung suchende Jugend auf die Gymnasien, wo ein auf die alten Sprachen konzentrierter und theoretisierender Unterricht keine Fähigkeiten für praktische Tätigkeiten entwickelt. ja einen vornehmen Dünkel ihnen gegenüber erzeugt. "Schon in den Schulen, welche auf 
die Universität vorbereiten, wird daher den jungen Leuten recht steif und fest der Gedanke eingeprägt: Du mußt angestellt werden. Sein ganzes Dichten und Trachten geht daher schnurstracks auf Anstellung und Besoldung aus Staatsmitteln «. [99] Dagegen wird »die Heranbildung von Naturforschern « [100] vernachlässigt, die der Gesellschaft produktiv nützlich werden. Das Überangebot an Akademikern bereitet auch Sorge, weil es ein revolutionäres Potential schafft. "Von 30 Competenten, die sich um eine Stelle bewerben, werden durch ihre Besetzung immer 29 Feinde des Staates und der Staatsregierung, falls sich ihnen keine andere Aussicht mit Hoffnung baldigen Erfolgs eröffnet «. [101]

- Das Gymnasium muß seinen Fächerkanon erweitern, damit es »über der Vorbildung künftiger Geistlichen und Justizbeamten nicht die Vorbildung der zu andern akademischen Studien, zum Militär und in die Berufsarten des praktischen Bürgerthums übergehenden, der Zahl nach weit überwiegenden Schüler verabsäumt «. [102] Dilthey führt eine Reihe von Berufen auf, die das Gymnasium zu verlieren drohte: »Forstmänner, Finanzbeamte, Berg- und Hüttenbeamte, Militärs, Ingenieurs, Baumeister, Cameralisten, Pharmaceuten, Tierärzte, Chirurgen «. [103] Die Darmstädter Anstalt suchte die widersprüchlichen Anforderungen durch Dispensationen zu befriedigen und stellte ein Entlassungszeugnis aus, das nur »für ein bestimmtes Berufsstudium gültig « war. [104]

- In der Revolutionszeit teilte Dilthey die Hoffnung, daß »die früheren Unterschiede zwischen Wissenden und Unwissenden, Gelehrten und Ungelehrten, Beamten und Volk «[105] verschwinden. Die »gelehrte Bildung" sollte keine »specifisch verschiedene « mehr sein, sondern »nur eine erhöhte, erweiterte und mittelst der alten Sprachen nach Möglichkeit auf ihre Quellen zurückgeführte Volksbildung «. [106] »Es muß darum dem Gymnasium der Charakter einer höheren Volksschule (Secundärschule, Mittelschule) zu Theil werden, wenn es nicht außer und über dem Volke in der Luft schweben soll, und es darf seinem Kreise nichts entzogen werden, was in der Volks- und Bürgerschule als für allgemeine Bildung erforderlich betrieben wird «. [107]

\subsection{Die historische Interpretationsweise}

Die Reformer unter den Altphilologen machen einen Unterschied zwischen »lateinischer Sprachbildung " und »alt-classischer Bildung» [108], zwischen "philologischer « und »humanistischer Bildung « [109], der auch in Lehrpläne eingegangen ist. Die »Philologen der stricten Observanz« wollen »die antiken Sprachen«, »die Philologen der laxen Observanz die antiken Kunstschöpfungen in der Sprache zum Bildungsmittel der Jugend an Gymnasien gemacht wissen «. [110] Die historische Richtung der Altphilologen betrachtet die antiken Klassiker als Grundschriften der europäischen und deutschen Kultur, die es in inhaltlicher Interpretation aufzuschließen gilt, und wirft dem Schulbetrieb vor, daß die "grammat[isch] - lexic[alische] Bewältigung der Sprache « »das wesentliche, einzig bedeutende Resultat « des Unterrichts bleibt. [111] Am präzisesten, doch mit Úbergehung vielfacher Vermittlungsversuche hat $\rightarrow$ Köchly, der an der Spitze der Neuerer stand, die Fronten umrissen: »Unser ganzer 
altklassischer Unterricht läuft fast nur auf die Sprache hinaus. Die Schriftsteller werden bis in die obern Klassen nur als ein Mittel betrachtet, alle mögliche Einzelheiten der Grammatik im weitesten Sinne des Wortes [. . .] einzuüben und einzuprägen; nur zu häufig werden die Schüler sogar mit Varianten und Wortkritik gequält «. »Wir dagegen verlangen: die Sprache soll nur als das Mittel, die Schriftsteller kennen zu lernen, betrachtet, und die Schriftsteller selbst sollen historisch aufgefasst werden; d. h. mittelst ihrer Schriften sollen wir sie selbst in ihrer ganzen Totalität, und daraus zugleich ihre Zeit, deren Spiegel sie alle, deren Bildner sie zum Theil gewesen sind, kennen lernen«. [112]

Das historische Prinzip beeinflußt den Literaturunterricht, sobald sich die Schüler auf den unteren Klassen die elementaren grammatischen Regeln und einen genügenden Wortvorrat angeeignet haben. Der Lehrer bringt neben dem »formalen Zweck « (»Erkenntnis der Sprachgesetze überhaupt und der in ihnen ausgeprägten Denkgesetze $)$ den »materialen Zweck« des klassischen Unterrichts, der in einer »klaren Gesammtanschauung des Alterthums als der Vorstufe unserer gesammten geistigen Entwickelung« besteht, verstärkt zur Geltung. [113] Die Latein- und Griechischstunden sollen den Heranwachsenden in seiner Entwicklung allseitig fördern: Einmal durch die Fülle der antiken Welt (Philosophie, Kunst, Verfassung, Geschichte), die ihm erschlossen wird, dann aber auch durch das Erlebnis der Texte, die ihm nicht durch grammatische und lexikalische Erörterungen vergällt werden. $\mathrm{Zu}$ diesem Zweck geht der Lektüre, die sich möglichst auf vollständige Werke beschränkt, eine »historische Einleitung « voran, welche die Individualität des Autors und die Rolle bespricht, die er in seiner Epoche gespielt hat [114]:

Eine kurze Einleitung über den Schriftsteller, seine Werke, sein Verhältnis zu seiner Zeit und zu andern Werken und in der höhern Stufe auch über seine wichtigsten Erklärer und Herausgeber ist vorauszuschicken, doch so, daß nicht Notizen gehäuft, sondern die Schüler auf den gehörigen Standpunct gestellt werden, um die Schrift, so viel als möglich, im Geiste ihres Urhebers aufzufassen.

Mit der Einführung verbindet der Lehrer eine »Uebersicht des Inhalts«, worauf »ein möglichst schnelles Lesen « folgt, so daß das Werk »als ein Ganzes, als ein Kunstwerk « rezipiert werden kann. »Durch diese ganze Methode muss der Schüler immer mehr sich gewöhnen, den fremden Schriftsteller wie ein deutsches Buch zu lesen «. [115] Den Rahmen für das Verständnis der Texte stecken die alte Geschichte und die Altertumskunde ab. »Der Geschichtsunterricht, in welchem der Verfassungs-, Cultur- und Litteraturgeschichte die gebührende Rücksicht zu widmen ist, bildet das gemeinsame Band; an ihn haben sich Einleitung, Lectüre und Sacherklärung anzuschliessen«. [116]

\subsection{Der Deutschunterricht als Mittelpunkt christlich-nationaler Bildung}

Mehrere Entwicklungen machen den Deutschunterricht zum Mittelpunkt der Bildung: a) Im realistischen Schulwesen kann Deutsch an die Stelle der alten Sprachen treten. b) Im Gymnasium fällt dem Deutschen eine einheitsstiftende Rolle im Lehrplan zu, wo der Universalismus ein Konglomerat von Fächern zu schaffen droht. 
c) Schließlich erweitert sich Deutsch (mit vaterländischer Geschichte, Gesetzeskunde und Volkskunde) zur Nationalbildung über die Grenzen der einzelnen Schularten hinweg.

\section{(a) Die Aufwertung des Faches Deutsch auf Realschulen}

Die Unterrichtsgegenstände der Realschulen richteten sich bei ihrer Gründung nach den naturwissenschaftlichen, technischen und zum Teil auch kaufmännischen örtlichen Bedürfnissen. Bei der Begründung der Eigenständigkeit der Realschule spielte der formale oder historische Sprachunterricht kaum eine Rolle, wie aus den zur Abgrenzung vom Gymnasium verwandten Gegensatzpaaren (naturwissenschaftliche und mathematische versus sprachliche und historische Bildung) hervorgeht.

Einige Bestimmungen maßgeblicher Pädagogen sollen das Gesagte verdeutlichen. Für Spilleke - der als Direktor des Berliner Friedrich-Wilhelms-Gymnasiums und der damit verbundenen Realschule das »Wesen « der Gelehrten- und Bürgerschule vergleichend darstellte - ist Naturkunde der »Mittelpunkt « der Realschule; Mathematik, "der zweite Hauptgegenstand «, tritt in die Rolle, die »für die Gelehrtenschule die alten Sprachen« spielen. [117] Als »Hauptmittel« der Realschule betrachtet $\rightarrow$ Klumpp »das unmittelbare Schöpfen aus der physischen Natur und ihrer Gesetzmäßigkeit vermittelst der Naturkenntnisse und der mathematisch-technischen Wissenschaften «. Dagegen sucht das Gymnasium seine Ziele »durch Sprachbildung und, in höherer Stufe, durch Studium und Aneignung der geistigen Schätze der alten Welt « zu erreichen. [118] $\rightarrow$ Köchly macht den >Realgymnasien` »die Vorbereitung zum selbständigen Erfassen der Naturwissenschaften«, den `Humangymnasien« »die Vorbereitung zum selbständigen Erfassen der historischen Wissenschaften « [119] zur Aufgabe. An die Stelle des historischen Verständnisses tritt in der Realschule die praktische Orientierung an der Gegenwart.

Welche Argumente machten die Sprachen (Deutsch, zum Teil mit Lateinisch) bis zur Mitte des 19. Jahrhunderts zu einem Zentrum der Realbildung? In dem Maße, wie sich die Auffassung von der Konstituierung der Nation durch Sprache und Literatur verbreitete, forderten nationale Gesichtspunkte Beachtung; da die Philologen den allgemeinbildenden Wert von Sprache und Literatur zur Norm erhoben, gerieten die naturwissenschaftlichen Fächer, aber auch die Mathematik bildungstheoretisch in die Defensive; Konservative und orthodoxe Protestanten diffamierten die Realschulen politisch und moralisch und propagierten einen gesinnungsbildenden Deutschunterricht als Heilmittel. Während das Latein durch die an ihn gebundenen Ansprüche auf Allgemeinbildung, die das Berechtigungswesen gesellschaftlich durchsetzte, im Fächerkanon der höheren Realschulen (später Realgymnasien) eine feste Stelle erhielt, wirkten sich die nationalen und zeitkritischen sittlichen Forderungen zugunsten des Deutschen aus.

Ich ziehe zwei exemplarische Fälle zur Illustration heran, da das durch soziale und politische Interessen gelenkte Zusammenspiel der Argumente noch nicht erforscht ist. Günther - ein Lehrer am Pädagogium in Halle, der in seiner Schrift Über den deutschen Unterricht auf Gymnasien »den didaktischen Standpunkt der neuen Frömmigkeitsbewegung « der Restaurationszeit [120] vertrat - befehdete die Realschulen 
als »Töchter des Rationalismus«, erwachsen »auf den Trümmern der Revolution «. [121] Seine Ansichten lauteten:

- Die Realschulen müssen »christliche Schulen « [122] werden (geistliche Aufsicht, geistliche Lehrer, 8 Wochenstunden Religionsunterricht mit Gottesdienst).

- Den Realschulen fehlt »das nationale Fundament«. Gänzliche Streichung der modernen Fremdsprachen: »Die französischen Giftlolche und die englischen Geldphantasten können Niemanden retten vor'm geistigen Hungertode «. »Aber deutsche Sprache, deutsche Litteratur, deutsche Geschichte: das seyen die Faden, welche den Jüngling an sein Vaterland knüpfen!« Besonders in den Poesien des Mittelalters könne der Lehrer »ein Gegengewicht gegen das moderne Heidenthum « finden. [123] - »Man treibe Lateinisch«. [124]

Das national-christliche Bildungskonzept, das die Realanstalten zu höheren sdeutschen< Schulen machte, trat auch ohne reaktionäre Folgerungen auf. [125]

$\rightarrow$ Götzinger - Lehrer am Gymnasium in Schaffhausen und Autor weitverbreiteter Lehrmittel - sieht im Fach Deutsch auf Realschulen einen Ersatz für die alten Sprachen. Es richtet sich, als formales Bildungsmittel, gegen das Nützlichkeitsdenken und neutralisiert, als nationales Bildungsmittel, die angeblich entsittlichenden Wirkungen des Französischen. Überdies stellt das Deutsche ein Gegengewicht zur Abstraktheit der Naturwissenschaften (»Abwehr gegen den Einfluß der mathematischen und physikalischen Wissenschaften «) [126] dar.

Dem schädlichen Einflusse des einseitigen Haschens nach bloß praktischen Fertigkeiten, nach Kenntnissen, die sich sogleich in baare Münze umsetzen lassen, trete nun der strenge Unterricht in der deutschen Sprache hemmend entgegen; er bilde ein geistiges Gegengewicht gegen das Zudringen der nakten [!] Nützlichkeit; er sey nicht bloß Knecht und Handlanger zu praktischen Bedürfnissen, etwa zum Briefschreiben, sondern behaupte seinen selbstständigen [!] Platz; er ersetze jenen Anstalten das, was den Gelehrtenschulen das Studium des Alterthums ist; er lenke den Blick ab von der bloßen Materie und von ihrer Form zu der Idee und ihrer Form. [127]

Die Aufwertung des Faches geht, wie das Zitat zeigt (»nicht bloß Knecht und Handlanger zu praktischen Bedürfnissen«), mit einer Änderung der Inhalte und Methoden einher. Solange das Deutsche Nebenfach war, beschränkte es sich auf Grammatik und Geschäftsstil, wozu zuweilen Vortrags- und Redeübungen traten, alles mit wenig Theorie und in praktischer Absicht. [128] Im ersten Viertel des 19. Jahrhunderts - im Zeitalter Napoleons, der Befreiungskriege und der Reformen wurde deutsche Literatur zum ersten Mal auf einzelnen Bürgerschulen in aller Breite getrieben (Beispiel Nürnberg, Real-Studien-Anstalt 1809-10, s. Kap. 2.2.2). In Schleiermachers Votum zu Süverns Gesamtinstruktion für Preußen heißt es 1814: "Auf der Stadt- und höheren Bürgerschule muß gründliche Interpretation deutscher Schriften in desto reicherem Maße getrieben werden, als die alten Sprachen nicht zum allgemeinen Unterrichtssystem gehören sollen «. [129] Aber erst nach 1830 übernahm der Deutschunterricht an höheren Bürgerschulen, soweit man bei der lokalen Vielgestaltigkeit sehen kann, in erheblichem Umfang allgemeinbildende formale sowie national- und gesinnungsbildende Funktionen. [130] Die Klassikerlektüre und die Aufsatzschulung traten in den Vordergrund, so daß kein prinzipieller Unterschied 
zum Gymnasialunterricht mehr bestand und das Fach Deutsch als Klammer zwischen dem realistischen und humanistischen Bildungsweg dienen konnte.

\section{(b) Deutsch als Mittelpunktsfach auf Gymnasien}

Wie kann das Deutsche zum »Anfangs-, Mittel- und Ausgangspunct des gesammten Unterrichts « auf Gymnasien [131] werden, mit dem alle anderen Lehrgegenstände »in die innigste Wechselbeziehung « [132] treten müssen? Das Fach begründet seine zentrale Rolle nicht so sehr durch die sprachliche und literarische Schulung, die es leistet, als durch National- und Charakterbildung. „Schwerpunkt, Endziel aller Klassen, aller Fächer muß das Deutsche, die Bildung zum deutschen Menschen sein «. [133] Im folgenden wird die Entwicklung des Deutschunterrichts dargestellt, die solche Argumente ermöglicht hat.

Lektüre mit Literaturgeschichte erfüllen die nationalbildende Aufgabe des deutschen Unterrichts. Das setzt voraus, daß die Definition des Klassikerbegriffs, nach der die Auswahl der zu behandelnden Werke erfolgt, und die Konstruktion der Literaturgeschichte im nationalen Sinne vorgenommen werden. Nach $\rightarrow$ Koberstein - der auf amtliche Anregung hin die für Preußen maßgebliche Schulliteraturgeschichte (1. Aufl. 1827) verfaßte - beinhaltet die deutsche »National-Litteratur « diejenigen Werke, »welche auf künstlerischem Wege hervorgebracht, sowohl ihrer Form, wie ihrem innern Wesen nach ein eigenthümlich deutsches Gepräge an sich tragen, wodurch sie sich von den litterarischen Erzeugnissen anderer Nationen unterscheiden«. [134] Diese Bestimmung, welche das Deutsche an der Form(!) und dem Gehalt zum Wertkriterium macht, wurde in der Folge häufig wiederholt.[135] Da die Literatur den Nationalcharakter ausdrückt, nimmt der Jugendliche beim Lesen die vaterländische Bildungswelt in sich auf. »Wie die Sprache und die classische Literatur die würdigste Erscheinung von dem Wesen des Nationalgeistes ausmachen, so gibt es auch kein geeigneteres Mittel, in die Tiefe des Volksgeistes und Volkscharakters einzudringen, als ein gründliches Studium der Muttersprache und ihrer Literatur«. [136] Die Schüler leben sich, wie $\rightarrow$ Hiecke es formuliert, »durch die Bekanntschaft mit der vaterländischen Literatur, welche als der klar herausgearbeitete Ausdruck des nationalen Geistes die wahre ideale Heimath ihres Gemüthes ist, in ein bewußteres geistiges Verhältniß zu ihrer Nation « hinein. [137] Lektüre und Interpretation der Nationalklassiker (evtl. im Kontext der Kulturgeschichte) schließen den deutschen Unterricht ab. Die »Vollendung der Identifikation unsers individuellen Geistes und Organismus mit dem Organismus des zur Volkssprache gewordenen Volksgeistes « geschieht, nachdem »historische Sprachstudien « sie vorbereitet haben, durch »Aneignung « der Literaturgeschichte. [138]

Die Nationalbildung erfordert eine angemessene Weise der Lektüre und Interpretation. Die Literatur soll weniger den Intellekt entwickeln als die Phantasie anregen, den Charakter formen und dem Willen eine feste Richtung geben. Bei der »Erziehung zur Nationalität « wird besonders auf »die Bildung der Phantasie « geachtet, »indem man ihr nur das vorführen soll, was das Bild des Vaterlandes rein, treu und kräftig ausspricht «. [139] Zum Bildungsziel der deutschen Lektüre wird »die Cultivirung der Gesinnung « [140] gemacht; »deutsche Bildung« hat nur der, der nicht bloß 
um seine nationalen Eigenschaften weiß, sondern auch »deutsch gesinnt « ist: »er muß als ein Deutscher wollen, handeln und fühlen «. [141] $\rightarrow$ Deinhardt nennt die »Volksbildung «, die im Deutsch- und Geschichtsunterricht erworben wird, »ein lebendiges Wissen, welches das ganze Individuum durchdrungen hat « und »zu einer practischen Kraft geworden ist, die Herz und Gemüth bewegt « und »als Gesinnung und Handlungsweise « hervortritt. [142] Die Beschäftigung mit der deutschen Literatur soll die am Altertum gewonnene Bildung ergänzen und üble Wirkungen der heidnischen und oft materialistischen und sinnlichen antiken Autoren verhindern. Sie vertritt »das moderne Element gegen das antike «[143] und setzt die »heidnisch-egoistische Lebensauffassung «, die der Knabe aus dem Umgang mit den Griechen und Römern schöpft, "mit der christlich-humanen Denkungsart in das gehörige Gleichgewicht «. [144] Die Autoren wissen einen ganzen Katalog von »Tugenden der christlich-germanischen Welt « aufzuzählen, welche die charakterbildende Lektüre anerziehen soll, z. B. »die Gefühle der Frömmigkeit, der Liebe, der Zärtlichkeit, der Treue, der Geduld, der Demuth, der Bescheidenheit, der Zufriedenheit, der Ehre«. [145] Nach christlich-nationalen Grundsätzen wird die Literatur bewertet (Hauptbeispiel: August Friedrich Christian Vilmar, Geschichte der deutschen National-Literatur 1845 u. ö.) und für die Schule ausgewählt.

Mit der National- und Charakterbildung hängen zwei Tendenzen im deutschen Unterricht zusammen, die um die Mitte des Jahrhunderts einen Höhepunkt erreichen: Es sollen sich alle Aufgaben um die Lektüre gruppieren und theoretische Unterweisungen nicht mehr systematisch erfolgen; entweder knüptt man die Theorie ebenfalls an die Lesestücke an oder verwirft sie ganz, weil sie die Unmittelbarkeit des Erlebnisses zerstört. Die Kampagne gegen die Überschätzung des theoretischen (rhetorischen, ästhetischen, metrischen etc.) Wissens wird mit der organischen Individualität jedes Kunstwerks begründet, doch stecken die Schriften gleichzeitig voll Invektiven gegen die `Kritisiersucht< und den >Verstandesdünkek der Jugend. »Was soll das razionalistische [!] Generalisieren, das Spekulieren und Abstrahieren in unsern Schulen? Dadurch wird der unmittelbare Eindruck, den Inhalt und Darstellung machen, von vorn herein getrübt und abgeschwächt «. [146] Zum »Ausgangspunkt des gesammten deutschen Unterrichts « wird die »bildende Lektüre « erklärt: "An die Lektüre schließt sich alles, was die Wissenschaft Logik, Ästhetik, Psychologie, Stilistik, Rhetorik und Mythologie nennt, aber nicht als Selbstzweck, sondern als Mittel, das Gelesene zu erläutern und zu ergänzen «. [147] Kellner und Otto haben für die Volksschule gezeigt, wie man das Lesebuch zum »Grund und Mittelpunkt « macht und »Denken und Sprechen, Reden und Schreiben, Lesen und Vortragen, Rechtschreibung und Satzzeichnung, Grammatik und Stilistik « mit den Lesestücken in Verbindung setzt. [148] Dasselbe hat $\rightarrow$ Hiecke für die höhere Schule geleistet: »Man lasse das Wissen um die Sprache und Literatur, um ihre Gesetze und Geschichte hervorgehen aus der Lectüre«. [149]

Wie verträgt sich »die Unbefangenheit der Hingabe, die Frische des Genusses « [150] mit der für den grammatischen, stilistischen, ästhetischen und literaturgeschichtlichen Unterricht notwendigen verstandesmäßigen Durcharbeitung literarischer Werke? Nach der Methode von Hiecke und Otto, die sich weitgehend durch- 
setzte, gibt der Lehrer zuerst einen »Totaleindruck «, indem er den Text selbst vorträgt oder durch Schüler vortragen läßt, und geht dann den »Weg der Zergliederung und des Wiederaufbaues«[151] (z. B. bei der Interpretation eines Dramas: Inhaltsangabe, Exposition und Handlungsführung, Charaktere und Konflikte; zuletzt wird »der geistige Gehalt und Sinn des Ganzen« bestimmt und »eine Reconstruction des Stückes von innen heraus « vorgenommen). [152]

Ein fertiger Gedanken- und Sprachbau liegt in dem Lesestücke vor. Der Unterricht soll in sein Verständniß einführen. Zu diesem Ende wird das Ganze zergliedert, und die Glieder werden nach Inhalt und Form betrachtet und begriffen; es wird, so viel möglich, das Feste wieder flüssig gemacht, das Fertige auf seinen Entstehungspunkt zurückgeführt, und dann durch eine sachliche und sprachliche Reconstruction das Ganze wieder hergestellt. Der Schüler hat das vom gereiften Geiste Gebildete nachzubilden, nachzuconstruiren und am Unerstiegenen das Steigen zu lernen. [153]

Die extremen Vertreter einer literarischen Gesinnungsbildung gehen weiter und fordern einen Unterrichtsstil, der dem Schüler den Gehalt des Werkes emotional nahebringt. Der Lehrer muß selbst »Gemüthstiefe und Innigkeit « besitzen, um »der reichen Innerlichkeit in der Literatur seines Volks « gerecht zu werden, »damit so der deutsche Geist im deutschen Geiste dargelegt werde«.[154] Die Jugend soll in »Nationalwerke « »so lebendig « eingeführt werden, »daß sie den in diesen Worten enthaltenen Sinn und Geist nicht blos erkennen, sondern im Innersten fühlen, sich dafür begeistern und ihr Leben danach einrichten lernt «. [155]

Während man von der Literatur und Literaturgeschichte vor allem nationale Bildung erwartete, werden die Aufsätze zum hauptsächlichen Mittel der individuellen Charakterbildung. Da sie ein »Sich-Aussprechen « von Empfindungen und Urteilen ermöglichen, geben sie dem Lehrer den »Schlüssel zu den jugendlichen Herzen « in die Hände. [156] Der Aufsatz verarbeitet alle Schulstoffe - aus der Literatur, Moral, Geschichte und Natur - und bietet damit eine Kontrolle, wieweit der Schüler sich den Unterrichtsstoff angeeignet hat und selbständig mit ihm umzugehen vermag. Schon vor $\rightarrow$ Deinhardt, der oft zitierte mustergültige Formulierungen fand, galten die deutschen Arbeiten als »die Blüthe der ganzen Bildung « [157] oder als »die Blüthe aller Leistungen eines Schülers « [158]:

Alles, was der Schüler in einer gewissen Classe geworden ist, in Wissenschaft, Sittlichkeit und Religion, sein Verhältniß zu Gott, zu den Menschen und zur Natur, kurz Alles, was in ihm eine geistige Existenz gewonnen hat, das soll sich in seiner Gesammtheit, in seiner lebendigen Einheit und individuellen Zusammenfassung durch die deutschen Aufsätze offenbaren. Sie sind die Blüthen der Schülerbildung. In ihnen treten die verschiedenen Seiten der Gymnasialbildung in einer individuellen Spitze zusammen. [159]

Die »Gesammtbildung « wurde in Preußen seit den zwanziger Jahren am deutschen Aufsatz gemessen (vgl. den Antrag der Direktoren der Berliner Gymnasien 1828, dem stattgegeben wurde [160], und das Gesetz über die Abiturientenprüfung von 1834 [161]).

Gleichzeitig war die Aufsatzerziehung, allerdings weit weniger stark als die Lektüre und Interpretation, am Abbau des Rhetorik-, Poetik- und Ästhetikunterrichts beteiligt. So konzipiert $\rightarrow$ Bernhardi die Schulaufsätze als logische (»praktische Logik«) 
und ästhetische Úbungen ("praktische Aesthetik «), die geeignet sind, »die Aesthetik, die Poetik und die Rhetorik zu verdrängen «. [162] Die traditionellen rhetorischen Aufgaben, die Einkleidungsformen und Stilmittel selbständig variieren, gerieten mit den Forderungen nach >Wahrheit<, >Natürlichkeit und >Originalität ‘ des Ausdrucks in Konflikt. „Die Aufsätze, welche von den Schülern ausgearbeitet werden, sollen nicht Beispiele sein für einzelne Abschnitte aus einer Theorie der Dicht- oder Redekunst «, vielmehr müssen die Gegenstände »durch ihre eigene Natur die Form der Behandlung « bestimmen. [163] Die Attacken gegen den bayerischen Lehrplan von 1854, der an Rhetorik und Poetik festhielt, zeigen, wie fragwürdig formale Stilübungen um die Mitte des Jahrhunderts geworden waren.

\section{(c) Die fach- und schulartenübergreifende Nationalbildung}

Unter dem Oberbegriff der »Nationalitätsbildung " schließen sich Deutsch und Geschichte, erweitert um landes- und volkskundliche Unterrichtsstoffe, zusammen. Das Programm der Nationalitätsbildung wurde vor allem auf den sächsischen Lehrerkonferenzen erörtert, aber auch von württembergischen [164] sowie bayerischen und österreichischen Pädagogen [165] vertreten. Die einzige mir bekannte amtliche Formulierung stellen die Sätze $\rightarrow$ Köchlys in dem Schulgesetzentwurf des Königreichs Sachsen dar [166]:

Den einigenden Mittelpunkt für beide Arten von Gymnasien [d. h. `Human-८ und `Realgymnasien«] bildet die möglichst hohe Entwickelung der volksthümlich-deutschen Bildung.

Dazu gehört:

a) möglichst freie und selbständige Beherrschung der Muttersprache in Wort und Schrift;

b) gründliche, theilweise wenigstens auf einigen Hauptquellen beruhende Kenntniß der Entwikkelung des deutschen Volkes, namentlich in Staat und Verfassung einerseits, in Poesie und Nationalliteratur andererseits, wobei einige Bekanntschaft mit dem Mittelhochdeutschen zu erreichen ist;

c) lebendige Bekanntschaft mit dem deutschen Lande nach seinen natürlichen und politischen Verhältnissen.

Die hier aufgezählten Fächer (Deutsch, Geschichte, Landes- und Gesetzeskunde, Geographie) wurden von Fall zu Fall um deutsche Mythologie, Altertumskunde, Kunstgeschichte sowie um Turnen erweitert. Mit der Nationalbildung hoffte man, wie das Zitat zeigt, den gemeinsamen »Mittelpunkt « für die humanistischen und realistischen Anstalten zu finden. Die Nationalerziehung, die in den gleichen Jahren von den Volksschullehrern (z. B. auf der Versammlung des >Allgemeinen Deutschen Lehrervereins in Nürnberg 1849) und besonders von Diesterweg propagiert wurde [167], verband auch die höheren mit den elementaren Schulen.

Die nationale Bildung und der gemeinsame Schulbesuch der Humanisten und Realisten bilden bei den fortschrittlichen Vormärzpädagogen noch ein zusammenhängendes Programm. Die Gefahr, daß die National- und Charakterbildung, obwohl noch lange nach 1848 im Widerstreit mit formalen Lernzielen, das Deutsche zu dem Fach macht, das den Schüler in eine gegebene Tradition und ein bestehendes System von Werten und Ordnungen einbindet, deutet sich aber an. Während die schulische Integration der höheren Schichten nach 1848 scheiterte, sollte auf diesem Wege ihre ideologische weitgehend gelingen. 


\section{Staatliche Differenzierungen}

In den Epochenkapiteln wurden die Begründung, der Widerstreit und Wechsel der Prinzipien des Sprach- und Literaturunterrichts im Zusammenhang der Diskussion um die Organisationsweisen höherer Schulen thematisiert. Die einzelstaatlichen Entwicklungen, die den historischen Ablauf sachlich und zeitlich differenzieren, werden im folgenden dargestellt. Die drei herangezogenen Staaten konturieren die starken regionalen Unterschiede im deutschen Kulturbereich. Für das Gebiet des kleindeutschen Kaiserreichs von 1871 wurde neben Preußen, das durch Größe und Macht die Entwicklung im Schulwesen spätestens ab der zweiten Hälfte des 19. Jahrhunderts beherrscht, Bayern als wichtigstes süddeutsches Land ausgewählt. Österreich, die mit Preußen um die Vorherrschaft in Deutschland rivalisierende Großmacht, erlebt unter Maria Theresia und besonders unter Joseph II. eine Aufklärungsphase, die mindestens programmatisch auswärtigen Vorbildern in nichts nachsteht, schert aber in der Restaurationszeit aus der allgemeinen Entwicklung aus, indem es ein Gymnasial- und Universitätssystem aus der Zeit vor den Humboldtschen Reformen bewahrt.

Der Aufbau dieser Arbeit und die unterschiedlichen historischen Gegebenheiten erfordern eine wechselnde Akzentuierung der Darstellung. Da Preußen die jeweiligen historischen Standards ausprägt, besteht die Gefahr, das in anderen Teilen der Arbeit Gesagte zu wiederholen. Deshalb liegt das Augenmerk hier auf der konkreten Ausgestaltung des Unterrichts, wozu die Quellenpublikation von Schwartz für die Zeit des Oberschulkollegiums (1787-1806) mit den Visitationsberichten, den (von jeder Schule gesondert gestellten) Themen der Abituraufsätze und den Fragen der mündlichen Prüfung, teilweise sogar mit Ausschnitten aus den Prüfungsarbeiten selbst, bislang kaum ausgewertetes Material bietet. Weil die preußische Situation weitgehend die Entwicklung im späteren Reichsgebiet repräsentiert oder vorwegnimmt, werden an dieser Stelle auch die Probleme der Lehrplangestaltung diskutiert. In Bayern können sich alle für die Geschichte des Sprach- und Literaturunterrichts relevanten Positionen - Aufklärung, Neuhumanismus und Realismus, altphilologische Reaktion und rhetorische Restauration - fast bilderbuchartig nach- und nebeneinander verwirklichen. Die dadurch bedingte disruptive und uneinheitliche Entwicklung hat eine lebhafte Kontroversliteratur begünstigt, in der sich Motivationen und Begründungen zu formulieren gezwungen waren. Das Österreich der ersten Hälfte des 19. Jahrhunderts kann als Gegenmodell dienen, an dem der Funktionszusammenhang des Sprach- und Literaturunterrichts mit Bildungskonzepten überprüfbar wird. Da das österreichische höhere Schulwesen in zunehmender Isolation bis 1848 gleichsam `ein geschlossenes System bildet, läßt sich das Zusammenspiel verschiedener Faktoren, von sozial- und schulorganisatorischen Voraussetzungen bis zur literari- 
schen Kanonbildung, besonders gut beobachten. Hierdurch hat das Kapitel darstellungsmäßig einen fast monographischen Charakter erhalten.

Der Wechsel von Programmen zu konkreten Entwicklungen verändert auch die Auswahl des Quellenmaterials. Während sich die Epochenkapitel über weite Strekken auf intentionale Aussagen von Lehrern stützten - wie sie sich ihren Unterricht vorstellen, welche Ziele und Zwecke sie damit verfolgen und wie sie diese begründen -, erlauben die jetzt verstärkt herangezogenen Lehrpläne und die Jahresberichte der einzelnen Anstalten, in denen sie Rechenschaft ablegen und sich zugleich dem örtlichen Schulpublikum empfehlen, der Unterrichtspraxis ein Stück näher zu kommen.

\subsection{Preußen}

\subsubsection{Die Spätaufklärung}

Das Profil der Schule der Spätaufklärung bietet Preußen musterhaft dar. Das Niveau ist allerdings äußerst unterschiedlich, ist noch lokal an die Anstalten und personal an die Lehrer gebunden. Die Möglichkeiten, die diese Schule bietet, fallen aber klar ins Auge, auch wenn sie hier akzentuiert werden. Die deutschen Stunden in den Oberklassen werden als »Oratorie «, »Poetik «, »Stilübungen«, »Epistolographie « o. ä. bezeichnet. In den unteren Klassen findet stets eine Unterweisung in Grammatik und Orthographie statt, während in den mittleren Klassen der deutsche Unterricht noch fehlen kann. [1] Der Grammatikunterricht auf der unteren, der Rhetorik- und Poetikunterricht auf der oberen Stufe sind die Grundpfeiler, auf denen der Deutschunterricht sich historisch gründet, ohne vorerst eine zusammenhängende Konzeption zu besitzen.

Die Rhetorik steht unter den Unterrichtsgegenständen, die sich zum Deutschen zusammenfinden, obenan. Der Briefstil [2] pflegt im allgemeinen zur systematischen Behandlung des Lehrgebäudes überzuleiten. Damit nimmt die Epistolographie im Studienaufbau noch gegen Ende des 18. Jahrhunderts eine Stelle ein, die fortan der Stilistik zukommt. Úber die behandelten Gegenstände der Rhetorik geben die mündlichen und schriftlichen Abituraufgaben Auskunft. Zum Kernbestand gehört die Stilistik, mit den immer wiederkehrenden Fragen nach dem »deutschen Stil und dessen Haupteigenschaften « (Königsberg/Neumark 1792) und »den Fehlern der Schreibart « (Aschersleben 1791). [3] Das Protokoll der mündlichen Prüfung in Stargard (1804) zeigt, wie die Bestimmungen, die Adelung für einen guten Stil gibt, getreu durchgenommen werden: »das Hochdeutsche, Sprachrichtigkeit, Sprachreinigkeit, Deutlichkeit und Klarheit, Schicklichkeit, Natürlichkeit, Bestimmtheit, Praecision, Würde und Wohlklang«. [4] Ganz die sprachlich korrekte, gesellschaftsund sachbezogene Form, die im Dienste der Mitteilung steht. Die zahlreichen Stilarten lernt der Schüler noch scharf zu trennen. Man prüft die Unterschiede des historischen, rednerischen und poetischen Stils (Aschersleben 1795) und frägt nach 
den Charakteristika »des vertraulichen, historischen, blühenden und erhabenen Stils « (Hamm 1802). [5] Beim prosaischen Stil will man die »Hauptgattungen in Absicht seiner Würde« (Prenzlau 1791)[6], also seine Abstufungen nach Gegenstand und Absicht wissen, wie sie die Lehre von den sgenera dicendi< vornimmt. Die Geschichtsschreibung, von der viele Texte im Unterricht gelesen werden (vgl. Kap. 3.1), ist im Rahmen der Rhetorik auch theoretisch präsent. "Sind die Reden der Alten in ihren historischen Schriften auch von den Neuern nachzuahmen? (Züllichau 1805); »wievielerlei ist der historische Stil, welchen Stoff bearbeitet jede Art, und was ist bei einer jeden zu beobachten? « (Königsberg/Neumark 1802) [7] Mehr ins Detail gehen die beliebten Fragen nach Figuren und Tropen, den Perioden und ihrer Einrichtung, nach dem Unterschied der logischen und rhetorischen Schlüsse (Hamm 1795, 1800), den Metaphern und ihren Fehlern (Hamm 1800), den stehenden Beiwörtern Homers oder dem tertium comparationis seiner Gleichnisse (Züllichau 1802, 1803). [8] „Über die von Homer gebrauchten Bilder und Vergleichungen, wobei zugleich untersucht wird, woher sie genommen und warum sie für Leser unsers Zeitalters anstößig sind.« (Herford 1793) [9]

Solche Fragen waren kein Schulballast, sondern der kaum vergangenen oder gegenwärtigen Diskussion - um die Grenze von Logik und Dichtung, um das dichterische Bild und die Sprache Homers - entnommen. Die letztgenannte Frage lautet beispielsweise übersetzt: Inwiefern sind die bäuerlichen Gegenstandsbereiche der Bildlichkeit Homers, die einer frühen Kulturstufe entsprechen, im gesellschaftlich differenzierten und zivilisierten 18. Jahrhundert für Gebildete anstößig? Damit bringt der Unterricht kultursoziologische Determinanten des Stils zur Sprache. Die Spätaufklärung führt gesellschaftliche und ökonomische Gründe an, um die Höhe der Sprach- und Kunstbildung einer Region, wie Leipzigs und Sachsens, zu erklären. „Warum blühen Künste und Wissenschaften im Westfälischen Kreise nicht so als im Obersächsischen? « (Halle, Reformierte Schule 1805) [10] Dem politischen Gesichtspunkt, der Verknüpfung von Beredsamkeit und Republikanismus seit Cicero und Tacitus (vgl. zum Zusammenhang von Rhetorik und Liberalismus Kap. 3.3), kommt sogar eine bevorzugte Stellung an manchen Anstalten zu. In Stettin (Ratsschule) wird der deutsche Aufsatz 1795 über die Frage »Woher es gekommen, daß Griechen und Römer in der Beredsamkeit so vollkommen geworden, da sie in der Theorie unter den neuen Nationen zurückstehen " geschrieben. [11] Stargard 1800: „Warum ist in unsern Zeiten die Beredsamkeit nicht so blühend als ehemals? « [12] Warum? »Man kann sich nur dann die Ursachen davon erklären, wenn man in ihre Staatsverfaßung einen genauen Blick geworfen hat. Griechenlands und Roms goldene Freyheit war der Boden, auf welchem jene herrlichen Früchte zur Reife gediehen. «[13] Warum, »als wegen der dämokratischen[!] Regierungsform «, wogegen jetzt »die meisten Reiche unter Monarchen ständen, wo das Volk nur Gesetze annehmen und befolgen kann, aber nie selbst eigne Vorschriften machen darf «. [14] Das sind Auszüge aus den Antworten der Schüler! Man sieht: Die Rhetorik ist kein toter Gedächtniskram, sie liefert der künstlerischen wie der gesellschaftlichen und politischen Diskussion der Zeit ihre Argumente und begleitet sie.

Die Gattungstheorie [15] und die Geschmackslehre, Lieblingskinder des 18. Jahr- 
hunderts, nehmen im Unterricht gleichfalls einen breiten Raum ein. Poetik ist im wesentlichen Gattungspoetik. Mit welcher Ausführlichkeit das Gattungssystem der Lehrbücher abgefragt wird, führt das Stargarder Protokoll der mündlichen Prüfung (März 1806) vor Augen: Der Lehrer spricht »von den verschiedenen Arten der Poesie; der lyrischen, wohin die Ode, das Lied, die Elegie, die Kantate und Dithyrambe gehöret; ferner der historischen, wohin die Fabel, die Epopee, die poetische Erzählung und Beschreibung und das Drama zu rechnen ist; weiter der didaktischen, zu welcher das Lehrgedicht und die Satire gehöret; endlich den gemischten Gedichten, wohin das Epigramm und Sinngedicht zu zählen ist. «[16] Eine Zusammenstellung zeigt, wie auch die schriftlichen Arbeiten kaum eine traditionelle Gattung auslassen, wie die Fragen aber auch ins Einzelne gehen können [17]:

Was ist lyrische Poesie überhaupt und wie viele Hauptgattungen begreift sie? (Prenzlau 1790) Wie unterscheidet sich das lyrische Gedicht von dem dramatischen? (Stargard 1797) - Worauf sieht die Kritik besonders bei der Beurteilung des Trauerspiels? (Küstrin 1805) - Wie unterscheidet sich lyrische und didaktische Poesie, und welches sind die berühmtesten alten und neuern Dichter in beiden Arten? (Berlin, Friedrichswerdersches Gymnasium 1790) - Wie pflegt man den Stoff, die nähere Einteilung und die Haupteigenschaften des Lehrgedichts zu bestimmen, und welches sind die Meister unter den Griechen und Römern, besonders unter den Deutschen? (Prenzlau 1794) - Worin besteht das Wesen der Satire? welches sind die vorzüglichsten Regeln für den satirischen Dichter und welches seine vorzüglichsten Muster? (Berlin, Friedrichswerdersches Gymnasium 1791) - De origine, indole, et virtute fabulae Aesopianae. (Züllichau 1804) - Was sind Maschinen in der Epopöe? Zu welchem Endzweck gebraucht sie der epische Dichter? (Minden 1792) - Was ist eine Heroide? (Ziillichau 1795)

Aus der Beispielreihe geht hervor, wie die Schule das Bewußtsein einer legitimen Gattungsvielfalt aufrechterhält und bereits umstrittene Gattungen wie das Epos, das Lehrgedicht und die Heroide [18] noch in ihren Kreis zieht. An die Unterscheidung der Gattungen, der mehrere Aufgaben gelten, konnten klassizistische Strömungen, wenn sie die Gattungsreinheit als Wertkriterium behaupteten, anschließen. Dabei werden die Gattungen durchaus rational und handwerklich als Macharten verstanden, die nach Gegenstand und Zweck verschiedenen Regeln gehorchen. Die Autorennennungen, die Zusammenstellung der >Meister`, ersetzen keine Literaturgeschichte, bieten jedoch einen Kanon, der nationalitäts- wie epochenmäßig verschiedenartigen Werken Raum gibt. Dem entspricht der voridealistische Horizont der Ästhetik, ein Raum ohne nationalstaatliche Grenzen, dem auch die vergangenen Autoritäten gegenwärtig waren. Bei der Frage, was die Alten und Neuen für die Theorie der schönen Wissenschaften und der Poesie insbesondere getan haben (Aschersleben 1793), reihen die Abiturienten den Autoritäten der Antike französische, englische und deutsche Namen, von Boileau bis Marmontel, von Vida bis Home, von Gottsched und Breitinger bis $\rightarrow$ Sulzer an. [19] Diese Namen konnten die Schüler ihren Lehrbüchern entnehmen, die kompendienhaft die wichtigsten Lehrmeinungen zusammenstellten.

Die Streitpunkte der Spätaufklärung werden neben diesen, oft akademischen Themen nicht ausgespart. Der als jugend- und volksverderblich eingeschätzte Einfluß von Theater und Roman hat die Kulturkritiker, Pädagogen und Geistliche, am damaligen literarischen Leben wohl am meisten bewegt. „Über den sittlichen Wert 
des Schauspiels auf den Jüngling« (Züllichau 1806), »Warum ist es nicht ratsam, viele Romane zu lesen? « (Aschersleben 1794) [20] Darüber äußert ein Schüler in seinem Abituraufsatz: „Die Sucht zu lesen ist so eingerißen, daß Menschen von der niedrigsten Caste sogar bey ihren Verrichtungen lesen und dadurch oft dieselben verabsäumen; ohne zu gedenken daß einige ganz unglücklich dadurch werden, indem sie die Wahl der Bücher, welche sie lesen, nicht verstehen, und es überdies auch an schicklichen Büchern für diese Classe von Menschen fehlet.«[21] Der künftige Gelehrte beklagt somit nicht nur standesgemäß die Ausweitung des Lesens (um 1800 bereits altbewährte Topoi), ihm ist auch die Notwendigkeit neuer Volksbücher deutlich. Der Wind des Tages weht gleicherweise in den spekulativen Themen. So will man wissen, ob die Ästhetik eine Wissenschaft sei (Züllichau 1805), wie sich »die Wahrheit des Philosophen von der des Dichters unterscheide und ob »etwas in der Moral Schändliches oder in der Natur Häßliches ästhetisch schön « sein könne (Aschersleben 1802). [22] Ohne Bedenken wird von Schülern eine Stellungnahme zu schwierigen ästhetischen Fragen erwartet.

\subsubsection{Die Restaurationszeit}

Preußen zeigt in der Restaurationszeit ein zwiespältiges Antlitz. Rhetorik und Poetik können im Extrem systematisch vorgetragen oder völlig negiert werden. Den beiden Fächern wird in den westlichen und katholischen Landesteilen zwar größeres Gewicht gegeben, doch zeichnen sich die grundsätzlichen Möglichkeiten jenseits regionaler und konfessioneller Unterschiede ab. In Magdeburg, im Pädagogium zum Kloster Unser Lieben Frauen, wird 1847 in der Sekunda die Rhetorik »beendet «, die Prima nennt gesondert »Meditation « (inventio) und Disposition, während das Kölner Friedrich-Wilhelms-Gymnasium 1848 und 1849 Rhetorik und Poetik nicht kennt. In der Provinz Westfalen weisen 1847 zwei von fünf evangelischen Programmen Rhetorik, eines zusätzlich Poetik aus, von vier katholischen drei Poetik, eines Rhetorik. [23] Zwei führende Anstalten Berlins können den Horizont der Hauptstadt abstecken. Das Friedrichswerdersche Gymnasium gibt 1839 der Prima »Anleitung zur Bearbeitung von Abhandlungen und Reden «, wozu der Lehrer »die Literatur der Beredsamkeit « vorträgt, das Joachimsthalsche Gymnasium vermeidet 1839, 1840 und 1846 also wohl durchgehend - jede Andeutung des Faches, auch der Poetik. Wenngleich das Lehrgebäude noch zuweilen vermittelt wird, ist die Rhetorik doch auf ganzer Linie im Abbau begriffen. Ein Indiz ist das geringe Gewicht, das die Lehrerschaft auf sie legt. In Preußen handeln von 1825 bis 1850 nur drei Schulprogramme über Rhetorik, in Bayern zur gleichen Zeit dagegen neun, in dem kleinen Baden allein vier. [24]

Preußen ist es auch, das die für das 19. Jahrhundert repräsentativen Schwundstufen der Rhetorik auf der Schule ausbildet. Es ist einmal die Reduktion auf die Stilistik (z. B. Minden 1825, Merseburg 1836, Naumburger Domgymnasium 1842), die Lehre »von der Darstellung des Stoffes, oder vom Stil im Allgemeinen, dessen grammatischen, logischen, ästhetischen Eigenschaften« (Paderborn 1830), wie sie seit Adelung 
(s. Bibliographie Bd. 2, Kap. 1.3.2) vorliegt, zum anderen die Beschränkung auf die Aufsatzlehre: "Rhetorik, als Anleitung zur Ausarbeitung schriftlicher Aufsätze« (Posen 1837, Sekunda). Bildet bei der Stilistik den Kern der Reduktion die relocutio des Lehrgebäudes, so bei der Aufsatzlehre die sdispositio<, daneben die sinventio<. [25] Von einer Aufsatzlehre ist also überall dort zu sprechen, wo »zur Erleichterung der Erfindung und Behandlung des Stoffes zuvor die nöthigen Winke« (Stendal 1829, Obertertia) erfolgen. Wenn sich die Aufsatzlehre und die Stilistik verbinden, dann scheint noch etwas vom rhetorischen System (mit >inventio<, >dispositio<, >elocutio<) durch. So folgen im Katholischen Gymnasium Kölns (1843) der »Anleitung zu freien schriftlichen Aufsätzen« die »Hauptregeln der Stilistik «. Die Stilistik hat neben den Tropen und Figuren ihr zweites Schwergewicht in der Unterscheidung der verschiedenen Stilarten. Die letztmögliche Verengung liegt deshalb erst dort vor, wo nurmehr Tropen und Figuren auf dem Plan stehen (Rosleben 1842, Sekunda; Stendal 1842, Tertia; Berlin, Friedrichswerdersches Gymnasium 1842, Prima).

Ein Mittelpunkt des literarischen Unterrichts wird in Preussen seit 1812, wo die Prüfungsordnung Kenntnis der deutschen Literatur vorschreibt, die Literaturgeschichte. Sie findet sich "fast überall in den Plänen als besonderer Lehrgegenstand «. [26] Erfaßt sie zunächst noch als »Literärgeschichte der deutschen Sprachund Redekunst « (Trier 1830) die Gesamtheit der redenden Künste ohne nationalen Gedanken, so herrscht seit den 30er Jahren die Literaturgeschichte vor, wie sie sich mit der Romantik entwickelt. [27] Die historische Ausrichtung verdrängt die Systeme der Rhetorik und Poetik, die ahistorisch konzipiert sind. Damit nimmt in Preußen die Literarhistorie den Platz ein, den zu dieser Zeit in Baden, Bayern oder Österreich noch die Rhetorik und Poetik beanspruchen. Diese Länder haben die Literaturgeschichte ja charakteristischerweise spät (Bayern 1834/35, Baden 1837, Österreich erst nach 1848) eingeführt. Die preußischen Gymnasien legen demgegenüber mit der Kombination von Literaturgeschichte und Lektüre das Fundament für die künftigen Jahrzehnte. Eine Anzahl von Schulen von Berlin (Joachimsthalsches Gymnasium 1839, 1840, 1846) und Potsdam (1831) bis Halberstadt (1842) und Köln (FriedrichWilhelms-Gymnasium 1848, 1849) kennen in den obersten Klassen, außer schriftlichen und mündlichen Ưbungen, nichts als Literaturgeschichte, die oft mit »biographischen Notizen « (Heiligenstadt 1842, Sekunda) beginnt und sich über mehrere Klassen hinzieht, sowie Lektüre. Die wegweisende erste Ostpreußische Direktorenkonferenz (1831) stellte sich einen zusammenhängenden Vortrag über die verschiedenen Perioden und Persönlichkeiten vor, der durch »Musterstellen aus dem Gebiete der Prosa und Poesie « illustriert wird. [28] Die Programme sprechen davon, daß die Historie »in Verbindung mit Erklärung einzelner Stücke aus den Werken jener Zeit « (Stendal 1829) unterrichtet wird; sie wird »verbunden mit Erklärung klassischer Dichtungen « (Rosleben 1842). Auf diese Weise wird »mehr Literaturgeschichte als Literatur « [29] getrieben. Die Mediatisierung der Lektüre ist in der Restaurationszeit die Regel, geschehe sie durch Literaturgeschichte (Preußen) oder durch Rhetorik und Poetik (Baden, Bayern, Österreich).

Diese Entwicklungstendenzen können an zwei Querschnitten überprüft werden, die einmal eine Provinz, vorzüglich mit ihren kleineren Anstalten, das andere Mal 
Tabelle 1: Deutschlehrpläne schlesischer Gymnasien 1830/36 (ohne philosophische Propädeutik)

\begin{tabular}{|c|c|c|c|c|}
\hline Anstalt und Jahr & Prima & Sekunda & Tertia & Quarta \\
\hline $\begin{array}{l}\text { Glatz } \\
\text { kath. Gymnasium } \\
1831\end{array}$ & $\begin{array}{l}\text { das schöne Schriftthum der } \\
\text { Teutschen, vorzüglich } \\
\text { von den schlesischen } \\
\text { Dichterschulen an; alle } \\
4 \text { Wochen eine schriftl. } \\
\text { Ausarbeitung; freier, } \\
\text { mündl. Vortrag, abwech- } \\
\text { selnd mit eignen dichte- } \\
\text { rischen Versuchen (3 St.) }\end{array}$ & $\begin{array}{l}\text { Die Lehre von den Dicht- } \\
\text { arten; alle } 14 \text { Tage eine } \\
\text { schriftl. Arbeit; freier } \\
\text { Vortrag (3 St.) }\end{array}$ & $\begin{array}{l}\text { die Eigenschaften des Styls, } \\
\text { die besondern Schreibarten } \\
\text { u. Anordnung des Stoffes } \\
\text { in den teutschen Ausarbei- } \\
\text { tungen; Aufsätze alle } 8 \text {, } \\
\text { sodann alle } 14 \text { Tage; } \\
\text { mündl. Vortrag (3 St.) }\end{array}$ & $\begin{array}{l}\text { von den Perioden; vom } \\
\text { Aufsaze überhaupt; } \\
\text { wöchentlich eine auch zwei } \\
\text { schriftl. Uebungen; mündl. } \\
\text { Vortrag (4 St.) }\end{array}$ \\
\hline $\begin{array}{l}\text { Gleiwitz } \\
\quad \text { kath. Gymnasium } \\
1830\end{array}$ & $\begin{array}{l}\text { Theorie des Styls u. } \\
\text { Grammatik ( } 1 \text { St.); } \\
\text { Aufsätze (1 St.); Vorlesung } \\
\text { deutscher Musterschriften } \\
\text { u. Uebung im freien mündl. } \\
\text { Vortrage ( } 1 \text { St.); Ge- } \\
\text { schichte der deutschen } \\
\text { Literatur, Vorlesung u. } \\
\text { Erklärung vorzügl. Stücke } \\
\text { (1 St.) }\end{array}$ & $\begin{array}{l}\text { Theorie des Styls; Aufsätze; } \\
\text { Vorlesung deutscher } \\
\text { Musterschriften; Uebung } \\
\text { im Vortrage (3 St.) }\end{array}$ & $\begin{array}{l}\text { das Wesentliche vom Briefe } \\
\text { u. dem deutschen Style im } \\
\text { Allgemeinen: Erklärung } \\
\text { einiger Musterstücke; Auf- } \\
\text { sätze alle } 14 \text { Tage; mündl. } \\
\text { Vortrag (3 St.) }\end{array}$ & $\begin{array}{l}\text { die Lehre von der Satzver- } \\
\text { bindung; schriftl. Arbeiten; } \\
\text { mündl. Vortrag ( } 3 \text { St.) }\end{array}$ \\
\hline $\begin{array}{l}\text { Glogau } \\
\text { evang. Gymnasium } \\
1836\end{array}$ & $\begin{array}{l}\text { Literaturgeschichte von } \\
\text { Anfang bis um das Jahr } \\
\text { 1780; alle } 14 \text { Tage ein Auf- } \\
\text { satz (2 St.) }\end{array}$ & $\begin{array}{l}\text { Theoric der Dichtungs- } \\
\text { arten; alle } 14 \text { Tage ein Auf- } \\
\text { satz, Beurteilung der Dis- } \\
\text { position (ohne St.-Angabe) }\end{array}$ & $\begin{array}{l}\text { alle } 14 \text { Tage cin Aufsatz } \\
\text { (1 St.); mündl. Vortrag, } \\
\text { Berichte über die gelesenen } \\
\text { Bücher (1 St.); Sprach- } \\
\text { lehre (1 St.) }\end{array}$ & $\begin{array}{l}\text { Syntax; alle } 14 \text { Tage ein } \\
\text { Aufsatz; Declamiren } \\
\text { (3 St.) }\end{array}$ \\
\hline
\end{tabular}




\begin{tabular}{|c|c|c|c|c|}
\hline Anstalt und Jahr & Prima & Sekunda & Tertia & Quarta \\
\hline $\begin{array}{l}\text { Glogau } \\
\text { kath. Gymnasium } \\
18.32\end{array}$ & $\begin{array}{l}\text { Aufsätze (1 St.); Erklä- } \\
\text { rung deutscher Muster. } \\
\text { namentlich Gedichte von } \\
\text { Klopstock, Schiller, Göthe, } \\
\text { Uhland, so wie Grillparzer's } \\
\text { goldenes Vließ (1 St.); } \\
\text { mündl. Vortrag (1 St.) }\end{array}$ & $\begin{array}{l}\text { Theorie des deutschen Stils } \\
\text { ( } 2 \mathrm{St} .) ; \text { wöchentl. eine } \\
\text { schriftl. Arbeit; mündl. } \\
\text { Vortrag mit Prima }\end{array}$ & $\begin{array}{l}\text { Anleitung zu schriftl. Auf- } \\
\text { sätzen (2 St.); alle } 14 \text { Tage } \\
\text { ein Aufsatz ( } 1 \text { St.); } \\
\text { Declamation mit Quarta }\end{array}$ & $\begin{array}{l}\text { Syntax (2 St.); schriftl. } \\
\text { Arbeiten (1 St.); Decla- } \\
\text { mation (1 St.) }\end{array}$ \\
\hline $\begin{array}{r}\text { Lauban } \\
1836\end{array}$ & $\begin{array}{l}\text { Rhetorik in Verbindung } \\
\text { mit Correktur schriftl. } \\
\text { Ausarbeitungen ( } 1 \text { St.); } \\
\text { Lectüre von Klopstock u. } \\
\text { Schiller, schriftl. ausge- } \\
\text { arbeitete Commentare der } \\
\text { Schüler (2 St.); mündl. } \\
\text { Vortrag. Versuche in der } \\
\text { extemporanen Beredsam- } \\
\text { keit (1 St.) }\end{array}$ & $\begin{array}{l}\text { ausführl. Anleitung zum } \\
\text { Disponiren nebst Erläute- } \\
\text { rung über das Wesen u. den } \\
\text { Gebrauch der Tropen u. } \\
\text { Figuren, Abriß der Litera- } \\
\text { turgeschichte von Klop- } \\
\text { stock bis auf die neueste } \\
\text { Zeit (1 St.); Aufsätze } \\
\text { (1 St.); Lectüre von Klop- } \\
\text { stocks Oden. schriftl. aus- } \\
\text { gearbeitete Commentare } \\
\text { der Schüler (1 St.); mündl. } \\
\text { Vortrag (1 St.) }\end{array}$ & $\begin{array}{l}\text { Anleitung zu schriftl. Auf- } \\
\text { sätzen (1 St.); Aufsätze } \\
\text { (1 St.); Lectüre (1 St.); } \\
\text { mündl. Vortrag (1 St.) }\end{array}$ & $\begin{array}{l}\text { Grammat. Erläuterungen } \\
\text { (3 St.); Erklärung von } \\
\text { Fabeln u. Erzählungen } \\
\text { (1 St.); Declamation } \\
\text { (1 St.) }\end{array}$ \\
\hline $\begin{array}{l}\text { Lcobschütz } \\
1830\end{array}$ & $\begin{array}{l}\text { Stilübungen. Erklärung von } \\
\text { Musterstücken, Vortrag } \\
\text { von Reden ( } 2 \text { St.); Lite- } \\
\text { raturgeschichte (1 St.) }\end{array}$ & $\begin{array}{l}\text { Stilübungen u. Vortrag } \\
\text { von Musterstellen ( } 2 \mathrm{St} \text { ); } \\
\text { nach Ostern zusätzlich: } \\
\text { die ältere deutsche Lite- } \\
\text { ratur ( } 1 \text { St.) }\end{array}$ & $\begin{array}{l}\text { praktische Anleitung zu } \\
\text { deutschen Aufsätzen; } \\
\text { Orthographie; mündl. } \\
\text { Vortrag ( } 2 \mathrm{St} \text {.) }\end{array}$ & $\begin{array}{l}\text { Sprachlehre; Geschäfts- } \\
\text { Aufsätze ( } 2 \text { St.) }\end{array}$ \\
\hline
\end{tabular}


Fortsetzung Tabelle I

\begin{tabular}{|c|c|c|c|c|}
\hline Anstalt und Jahr & Prima & Sekunda & Tertia & Quarta \\
\hline $\begin{array}{l}\text { Neisse } \\
1836\end{array}$ & $\begin{array}{l}\text { theoretische u. practische } \\
\text { Anleitung zum Stil, Auf- } \\
\text { sätze, freier Vortrag, Dis- } \\
\text { putiren, Interpretiren } \\
\text { einzelner Stücke aus deut- } \\
\text { schen Klassikern; National- } \\
\text { Literaturgeschichte von } \\
\text { dem 2. Viertel des } 18 . J h . s \\
\text { bis auf die neueste Zeit } \\
\text { (4 St.) }\end{array}$ & $\begin{array}{l}\text { theoretische u. practische } \\
\text { Anleitung zum Stil. Auf- } \\
\text { sätze, Vorlesen u. freier } \\
\text { Vortrag, Interpretation } \\
\text { einzelner Gedichte aus } \\
\text { deutschen Klassikern; } \\
\text { Geschichte der National- } \\
\text { Literatur von der ältesten } \\
\text { Zeit bis gegen die Mitte } \\
\text { des 18. Jh.s (4 St.) }\end{array}$ & $\begin{array}{l}\text { Satz- u. Verslehre; } \\
\text { wöchentl. Aufsätze; mündl. } \\
\text { Vortrag (3 St.) }\end{array}$ & $\begin{array}{l}\text { Lehre von dem Bindeworte, } \\
\text { Anfang der Satzlehre; } \\
\text { Aufsätze; Briefe u. andere } \\
\text { Aufsätze des tägl. } \\
\text { Verkehrs; mündl. Vortrag } \\
\text { (3 St.) }\end{array}$ \\
\hline $\begin{array}{l}\text { Oppeln } \\
\text { kath. Gymnasium } \\
1836\end{array}$ & $\begin{array}{l}\text { National-Literatur- } \\
\text { geschichte (1 St.); Stil- } \\
\text { übungen in Aufsätzen, } \\
\text { Elemente der allg. Sprach- } \\
\text { lehre (1 St.): Lektüre: } \\
\text { Zriny von Körner u. Bal- } \\
\text { laden von Schiller, mit } \\
\text { besonderer Berücksich- } \\
\text { tigung des mündl. Vortrags } \\
\text { (1 St.) }\end{array}$ & $\begin{array}{l}\text { Lesung u. Erklärung epi- } \\
\text { scher Gedichte u. nach- } \\
\text { folgende Darstellung der } \\
\text { Theorie von der epischen } \\
\text { Dichtgattung ( } 1 \text { St.); } \\
\text { National-Literatur- } \\
\text { geschichte ( } 1 \mathrm{St} \text {.); Stil- } \\
\text { übungen, nach mitgetheil- } \\
\text { ten Dispositionen (1 St.) }\end{array}$ & $\begin{array}{l}\text { Syntax des einfachen } \\
\text { Satzes (1 St.); Lesung, } \\
\text { Erklärung u. Vortrag } \\
\text { erzählender Gedichte u. } \\
\text { prosaischer Aufsätze } \\
\text { (1 St.); Stilübungen (1 St.) }\end{array}$ & $\begin{array}{l}\text { Grammatik: Etymologie, } \\
\text { Syntax (2 St.); schriftl. } \\
\text { Ubungen (1 St.); mündl. } \\
\text { Vortrag u. Lektüre deut- } \\
\text { scher Prosaiker (1 St.) }\end{array}$ \\
\hline
\end{tabular}

Nach den Programmen. Die Zahl der Wochenstunden ist nach Möglichkeit nach den Unterrichtsgegenständen differenziert angegeben. Hinweise auf Lehrbücher sind nicht aufgenommen. 
Orte aus dem Westen (Rhein, Ruhr) wie dem Osten (Memelland) umfassen, um den Spielraum der Entwicklung abzustecken. In den Lehrplänen der schlesischen Gymnasien der dreißiger Jahre (s. Tabelle 1) prägt sich sowohl der Abbau von Rhetorik und Poetik wie ihre Konkurrenz zur Literaturgeschichte deutlich aus. Die Rhetorik, die in keiner Anstalt mehr voll gelehrt wird, ist zur »Theorie des Styls (Gleiwitz: Prima u. Sekunda; vgl. Glatz: Tertia, Glogau, kath. Gymn.: Sekunda) und »Anleitung zum Disponiren« (Lauban: Sekunda) geschrumpft. Die Bezeichnungen »Rhetorik in Verbindung mit Correktur schriftl. Ausarbeitungen « (Lauban: Prima) und »theoretische u. practische Anleitung zum Stil« zeigen, wie man rhetorische Lehren vor allem als »Anleitung zu schriftlichen Aufsätzen« gebraucht. Die Poetik taucht in den meisten Gymnasien gar nicht mehr, und wenn, dann nur als Gattungslehre (Glatz: Sekunda; Glogau, evangel. Gymn.: Sekunda) auf. Die Periodenlehre und Stilistik, Metrik und Gattungslehre - die sich hier noch finden - bereiteten früher auf einen zusammenfassenden Rhetorik- und Poetikunterricht vor; jetzt, wo dieser Abschluß fehlt, verlieren die Restbestände von Rhetorik und Poetik ihre Einbettung in einen zusammenhängenden Lehrgang. Die Unterschiede in den Lehrplänen resultieren in erster Linie aus dem ungeklärten Verhältnis des Rhetorik- und Poetikunterrichts zur Literaturgeschichte. Meist wird die sTheorie des Stils und die sLehre von den Dichtarten geschichte (Glatz; Glogau, evangel. Gymn.). Wo man die Rhetorik oder Stilistik noch in Prima fortsetzt (Gleiwitz; Neisse) oder die Literaturgeschichte schon in Sekunda beginnt (Oppeln), kommt es zu einer Aufsplitterung des Unterrichts. Die zeitliche Nacheinanderordnung - exemplarisch in Glatz, wo Stilistik (Tertia), Gattungspoetik (Sekunda) und Literaturgeschichte (Prima) auf drei Klassen verteilt werden - gefährdet jedoch andererseits den Zusammenhang des Lehrgangs. In der Konkurrenz von Poetik und Literaturgeschichte liegt ein anderer Faktor, der den hier versuchten Ausgleich untergräbt. Während sich die Rhetorik zur Aufsatzlehre transformiert, erhält sich die Poetik nur so lange am Leben, wie sie das Verständnis der gelesenen Texte zu bestimmen vermag. Die folgenden Angaben aus Programmen der vierziger Jahre konzentrieren sich auf das Verhältnis von Literaturgeschichte, Poetik und Lektüre in den beiden obersten Klassen und illustrieren zugleich die Weiterentwicklung der Lehrpläne.

Elberfeld 1843. Prima: „Deutsche Literaturgeschichte«, »Lectüre größerer Stücke von Schiller und Göthe und daran geknüpfte Sprechübungen « (gemeinsam mit Sekunda); Sekunda: »Literaturgeschichte; mündliche Referate über die deutsche Lectüre, besonders Schillers«. - Halberstadt, Domgymnasium 1842. Prima: "Geschichte der deutschen Literatur bis auf Göthe. Erklärung einzelner Dichtungen von Göthe, Schiller, Uhland«; Sekunda: »Freie Aufsätze und freie Vorträge, theils in Verbindung gesetzt [. . .] mit Erklärungen deutscher Klassiker, die in historischer Reihenfolge [...] gelesen und mit einer gedrängten Uebersicht der Literaturgeschichte seit der Mitte des 18ten Jahrhunderts begleitet wurden «. - Köln, Kath. Gymnasium 1843. Oberprima: Erklärung von Gedichten »von Opitz, Flemming, Klopstock und Goethe. Geschichte der deutschen Literatur bis auf die Zeit von Opitz«; Unterprima: Erklärung Schillerscher Gedichte, »die auch memorirt wurden. Hauptregeln der Stilistik «; Obersekunda: "Literaturgeschichte des siebzehnten und zum Theil achtzehnten Jahrhunderts, Lesung und Erklärung vieler Gedichte aus diesem Zeitraume «, »Erklärung einiger Dichtungsarten, Declamation erklärter und memorirter Gedichte«; Untersekunda: »Erklärung prosaischer und poeti- 
scher Muster «, wobei im Sommer »vorzüglich auf Schiller Rücksicht genommen « wurde. Magdeburg, Pädagogium zum Closter Unser Lieben Frauen 1847. Prima: »In der ältern Literaturgeschichte wurde die Periode der Meistersänger fortgesetzt und vollendet. In der neuern wurde über Göthe gesprochen und die Reihe der lyrischen Dichter seit 1770 weiter behandelt und beendigt «, im Hinblick auf schriftliche Arbeiten »die Hauptsachen aus der Lehre von der Meditation. Angefangen wurde die Lehre von der Disposition «; Sekunda: "Die Rhetorik ward beendet. Aus der Litteraturgeschichte: Rolandslied, K. Rother, Alexander, Nibelungen $\ll$. - Tilsit 1844-46 ( $\mathrm{a}=$ Winter 1844/45, $\mathrm{b}=$ Sommer 1845, $\mathrm{c}=$ Winter 1845/46). Prima: »a. Geschichte der deutschen Lit. und Mittheilung von Proben. Lectüre: Göthe's Egmont und Schiller's Abhandlung über Egmont und über naive und sentimentale Dichtung «, »b. und c. Geschichte der deutschen Lit. vom 15. bis zur Mitte des 18. Jhd. nebst vielen Proben. Lectüre: Schiller's Don Carlos, seine Briefe über Don Carlos, Gedanken über den Gebrauch des Gemeinen und Niedrigen in der Kunst und seine Recensionen von Bürger's und Matthisson's Gedichten «; Sekunda: »a. Aus der Rhetorik die beiden Abschnitte von der Erfindung und Anordnung, verbunden mit Uebungen im Disponiren. Lectüre von Schillers akademischer Antrittsrede und anderer auserwählter Reden von Herder und Jacobs nebst einer kurzen Theorie der verschiedenen Stylarten «, »b. und c. Die Lehre von den Tropen und Figuren. Die ältere deutsche Literaturgeschichte mit besonderer Hervorhebung des Nibelungenliedes, dessen Lectüre im Original begonnen wurde. Außerdem wurden mehrere Abhandlungen Schillers gelesen und größere Abschnitte aus Mansos, Müllers und v. Raumers historischen Werken mitgetheilt und besprochen «. [30]

Literaturgeschichte wird jetzt durchgehend auf beiden oberen Klassen gelehrt. Die Lesestoffe werden zum Teil parallel »in historischer Reihenfolge " (Halberstadt) durchgenommen oder als »Proben « (Tilsit) behandelt, so daß die Literaturgeschichte Auswahl und Anordnung der Lektüre wesentlich mitbestimmt. Daß die Gattungspoetik noch einen größeren Einfluß auf die Behandlung von Dichtungen hat - wie in Köln, wo altväterlich von »Mustern « die Rede ist -, scheint bereits eine Ausnahme zu sein. Die Rhetorik bestimmt weiterhin die Aufsatzlehre mit der »Meditation « und »Disposition « (Magdeburg), d. h. der »Erfindung « und »Anordnung « (Tilsit), sowie der »Stilistik ", während sie interpretatorisch allenfalls für Reden herangezogen wird (Tilsit). Entschieden zugenommen hat die Bedeutung der Lektüre. Schiller und Goethe - in dieser Reihenfolge - und die klassische Ästhetik, aber vielfach auch ältere Literatur wird intensiv studiert. Damit hat das preußische Gymnasium die Wende vom rhetorischen zum historischen und ästhetischen Verständnis von Literatur spätestens in den vierziger Jahren allgemein vollzogen.

\subsection{Bayern}

Bayern beansprucht Interesse durch das Nacheinander unterschiedlicher Lehrpläne, durch die frühe Betonung der Lektüre, dann aber durch eine Restauration der Rhetorik. In der Bildungspolitik fanden aufklärerische Tendenzen unter Braun und Wismayr ebenso klaren Ausdruck wie neuhumanistische und altphilologische Vorstellungen unter Niethammer und Thiersch, wenngleich sich die Verwaltung gegenüber der vom Klerus geprägten Schulpraxis nie in allen Anstalten voll durchzusetzen vermochte. Eine der gymnasialen parallele höhere realistische Bildung mit Deutsch als Mittelpunkt nahm zudem früh, freilich nur für wenige Jahre, in dem von Nietham- 
mer ins Leben gerufenen Nürnberger Realinstitut Gestalt an. Begründung, Durchsetzung und Zurückdrängung des deutschen Unterrichts stehen mit im Mittelpunkt der publizistischen, die Lehrplanentwicklung begleitenden Diskussionen.

\subsubsection{Die Zeit der Aufklärung von Braun bis Wismayr (1804)}

Die die Aufklärer in Bayern leitenden Vorstellungen vom Sprach- und Literaturunterricht drücken sich auf geradezu emphatische Weise in der von $\rightarrow$ Braun entworfenen »Einrichtung « des mit der Landesuniversität verbundenen Ingolstädter Gymnasiums von 1777 [1] und in gleichzeitigen Schriften von Lorenz Westenrieder aus. Wie das in der späteren Aufklärung allgemein zu beobachten ist (vgl. Kap. 1.2.3), werden der sachliche Inhalt eines Werkes und die geschmackliche Bildung des Schülers betont; sie gehen der Erlernung der Sprache und des (grammatischen, rhetorischen, poetischen) Regelwerks auch im Unterricht voraus. "Wir sollen gleich Anfangs unsere Hauptabsicht auf den Inhalt des Buches richten, sollen, ohne die bloße Sprache der Jugend eben ausdrücklich zur Hauptsache zu machen, und gleichsam, ohne sie es wissen zu lassen, daß sie selbe dennoch erlernen, den Inhalt des Buches, das man vorlegt, hervornehmen, und, indem wir ihnen zur Aufsuchung der Dinge eine Begierde erwecken, selben zugleich das Verlangen einflößen, bald durchzudringen, und sich unaufgehalten desselben Vorzug zuzulegen «. [2] Die Geschmackserziehung beruht auf einer nacherlebenden Einfühlung in den Text; eine emotionale und situative Literaturdidaktik ruft den Lehrer dazu auf, »die Poesie aus dem Herzen des Menschen « und seinen »Erfahrungen « hervorzuholen. »Wer während, daß er etwas las, nicht außerordentlich bewegt, hingerissen worden, las entweder kein Meisterstück, oder las nicht, wie er gesollt hätte, oder ist unfähig, etwas zu lesen «. [3] Statt Regeln der Rhetorik zu pauken, wird zuerst gelesen und dann der empfangene Eindruck in einer Unterhaltung zwischen Lehrer und Schülern reflektiert und dabei auf den Inhalt und die Machart des Textes bezogen. Diese Unterredung soll mehr »einer angenehmen Unterhaltung als einer schulmäßigen Lection « ähneln [4], d. h. ein Literaturgespräch unter Gebildeten einüben. Der Ingolstädter Lehrplan hebt die zentrale Stellung der Lektüre in einem solchen Unterricht hervor [5]:

Damit der Schüler frühezeitig an die Lecture gewöhnt, und mit dem Geiste der claßischen Schriftsteller desto eher bekannt werde (und was will man itzt mehr als Lecture - Lecture - -) so ist an ordentlichen Schultagen als Montage, Mittwoche und Freytag 1) wenigst eine kurze Zeit z. B. eine Stunde der Vorlesung der besten Muster im Deutschen und Latein zu wiedmen, und 2) über deren Innhalt, Plan, und Ausführung nach Batteux und Ramler ein verträuliches Gespräch zu führen.

Die näheren Anweisungen verdeutlichen, wie die Unterweisung in >Realien Rhetorik- und Poetikunterricht mit der Lektüre verbunden werden sollen. Braun nennt als Ziel: »die Kunst bey Lesung classischer Schriftsteller mit zu philosophiren«. [6] Bei der Erklärung der Schriftsteller geht es darum, dem Text möglichst nahe zu bleiben; darum geht man zum einen von den auftauchenden Sachfragen (Unterricht in >Realien in Fortführung einer sachlichen Interpretation) und zum anderen von der Komposition und Wirkungsabsicht des Werkes aus (Rhetorik, Stilistik und 
Poetik in Fortführung einer sprachlichen Interpretation). In diesem Sinne legt die Interpretation Regeln zugrunde, »die sich 1) auf die Natur der Sache beziehen, wovon der Auctor redet; 2) auf die Ordnung der Gedanken und Sätze, wie einer aus dem andern fließt, 3) auf die Mittel, wie er zu seinem Ziele kömmt, und 4) auf die Wegräumung oder Vermeidung der Hindernisse, die ihm hätten seine Absicht vereiteln, ihn aufhalten, oder vom Ziele entfernen können «. [7] In einlässigen Analysen untersucht man im einzelnen bei einem Redner »die Erfindung, die Kunstgriffe zu überreden, zu rühren, u.s.f.«, bei einem Dichter »die poetische Malerey, Wendung, Harmonie u.s.f. «, bei einem Philosophen »die Schlüsse, die Denkensart, die Folge der Gedanken nach den damaligen Meynungen u.s.f.«. [8] Dazu treten schriftliche rhetorische Arbeiten, wobei der Schüler auch hier nicht ein Regelwerk einübt, sondern von fertigen Mustern ausgeht, deren Techniken er sich durch Úbersetzungen und Nachahmungen (Variationen des Musters nach Inhalt und Form) zu eigen macht. Erst dann versucht er die geforderten Textsorten selbst zu produzieren: „Briefe, Bittschriften, Dialogen, Erzählungen[,] Schilderungen, Berichte, und endlich [...] Complimentreden in deutscher sowohl als lateinischer, mehr aber in deutscher Sprache; weil man dieser bey künftigen Berufsgeschäften am nöthigsten hat «. [9] Die beiden Zielsetzungen des höheren Sprach- und Literaturunterrichts in diesem Lehrplan, Geschmackserziehung durch Lektüre und rhetorische Schulung für das praktische Leben, spiegeln genau die Spannung der spätaufklärerischen Pädagogik zwischen zwei Blickrichtungen wieder: dem Individualismus mit Rücksicht auf die Entwicklung des Einzelnen und dem Utilitarismus im Hinblick auf Staat und Gesellschaft. Wie die Akzente dabei durchaus verschieden gesetzt werden können, zeigt die Stellung der »Dichtkunst «. In Ingolstadt wird vor allem das Lesen eingeübt und die kritische Urteilsfähigkeit geschärft, produktiv wird die Dichtkunst nur »als ein[e] Hilfswissenschaft zur gemeinnützlichen Redekunst « [10] verwertet. »Der Schüler muß eben kein Dichter werden; er muß aber doch 1) Dichter lesen, 2) beurtheilen, und 3) sich selbe zu Nutzen machen können«. [11] Anders in München, wo als »Jugendfrüchte « [12] Ausarbeitungen »von Knaben, deren die meisten das fünfzehnte Jahr noch nicht erreicht haben «, als Schaustück des »churfürstlichen Schulhauses « und zu weiterem Ansporn der Schüler publiziert werden.

Wie der Rhetorik- und Poetikunterricht an einer mittleren Anstalt zu dieser Zeit, im Schnittpunkt der Entwicklungen, aussah und wie sich der Deutsch- und Geschmacksunterricht ihm einfügte, können die beiden letzten Klassen des Gymnasiums in Münnerstadt (würzburgisch, ab 1803/14 bayerisch, Reg.bezirk Unterfranken) verdeutlichen (Tabelle 2, aus den Schulprogrammen). Traditionellerweise bilden in den Oberklassen Rhetorik und Poetik - hier unter den Namen »Rede-» und »Dichtkunst « - eigene Fächer neben den Sprachen (Latein, Griechisch). Ein Überblick über das vollständige Lehrgebäude kann in $\mathrm{V}$ den rhetorischen Kursus krönen (Erfindung = inventio, Anordnung/Abteilung = dispositio, Ausarbeitung = elocutio, 1775 auch Vortrag = actio/declamatio), weil in IV die Kerngebiete bereits durchgenommen wurden: die >Erfindung beitung als die stilistische Gestaltung eines Textes. In der Stilistik werden die Schmuck- und Ausdrucksmittel der Tropen und Figuren und die Schreibarten (genera 
Tabelle 2: Unterricht in Münnerstadt 1775-77

\begin{tabular}{|c|c|c|c|c|}
\hline Jahr & Klasse & $\begin{array}{l}\text { Titel der } \\
\text { Fächer }\end{array}$ & Rhetorik & Poetik \\
\hline \multirow[t]{2}{*}{1775} & V & \multirow[t]{2}{*}{$\begin{array}{l}\text { a) Deutsche } \\
\text { Sprache; } \\
\text { b) Rede- } \\
\text { kunst; } \\
\text { c) Dicht- } \\
\text { kunst }\end{array}$} & $\begin{array}{l}\text { Allg., Erfindung, Anord- } \\
\text { nung, Ausarbeitung, } \\
\text { Vortrag. - Getrennt: } \\
\text { "geistliche Redekunst « } \\
\text { Dt. Sprache: Reden }\end{array}$ & $\begin{array}{l}\text { Lyrische, satirische } \\
\text { Dichtkunst }\end{array}$ \\
\hline & IV & & $\begin{array}{l}\text { Allg., Erfindung, Aus- } \\
\text { druck. - Úbungen: } \\
\text { Erzählungen, Reden } \\
\text { Dt. Sprache: Schreibart, Verse }\end{array}$ & $\begin{array}{l}\text { Allg., epische, didaktische } \\
\text { Gattung, je mit Unterarten }\end{array}$ \\
\hline \multirow[t]{2}{*}{1776} & V & \multirow[t]{2}{*}{$\begin{array}{l}\text { a) Deutsche } \\
\text { Sprache; } \\
\text { b) Rede- } \\
\text { kunst; } \\
\text { c) Dicht- } \\
\text { kunst; } \\
\text { d) Aesthetik }\end{array}$} & $\begin{array}{l}\text { Allg., Historisches, Erfin- } \\
\text { dung, Anordnung, Aus- } \\
\text { arbeitung. - Ubungen: } \\
\text { Reden zergliedern, ver- } \\
\text { fertigen }\end{array}$ & $\begin{array}{l}\text { Satire, lyrische, dramatische } \\
\text { Dichtkunst, je mit Unter- } \\
\text { arten } \\
\text { Aesthetik: Schöne Künste } \\
\text { und Wissenschaften, } \\
\text { Geschmack } \\
\text { rößere Reden }\end{array}$ \\
\hline & IV & & $\begin{array}{l}\text { Allg., Erfindung, Tropen } \\
\text { und Figuren, Erzählung } \\
\text { Dt. Sprache: } \text { Schreibart. Verse }\end{array}$ & $\begin{array}{l}\text { Allg., epische, didaktische } \\
\text { Gattung, je mit Unter- } \\
\text { arten } \\
\text { kleine Reden }\end{array}$ \\
\hline \multirow[t]{2}{*}{1777} & V & \multirow[t]{2}{*}{$\begin{array}{l}\text { a) Deutsche } \\
\text { Sprache; } \\
\text { b) Rede- } \\
\text { kunst; } \\
\text { c) Dicht- } \\
\text { kunst; } \\
\text { d) Aesthetik }\end{array}$} & $\begin{array}{l}\text { Allg., Historisches, Erfin- } \\
\text { dung, Abteilung, Aus- } \\
\text { arbeitung. - Getrennt: } \\
\text { "geistliche Redekunst « } \\
\text { Dt. Sprache: Lyrische Verse, g }\end{array}$ & $\begin{array}{l}\text { Aesthetik: Schöne Künste } \\
\text { und Wissenschaften, } \\
\text { Geschmack } \\
\text { rößere Reden }\end{array}$ \\
\hline & IV & & $\begin{array}{l}\text { Allg., Erfindung. Aus- } \\
\text { arbeitung (Tropen, } \\
\text { Figuren), Erzählung, } \\
\text { Schreibart } \\
\text { Dt. Sprache: } \text { Schreibart. Verso }\end{array}$ & $\begin{array}{l}\text { Allg., erzählende, unter- } \\
\text { richtende, lyrische, vorstel- } \\
\text { lende Gattung, je mit } \\
\text { Unterarten } \\
\text { und Reden }\end{array}$ \\
\hline
\end{tabular}

dicendi) als wichtigste Teile genannt; von den rhetorischen Gattungen wird zunächst die einfache >Erzählung〈 (narratio) gelehrt. 1775 und 1777 taucht gesondert »geistliche Redekunst « auf, womit den Berufserfordernissen der künftigen Theologen unter den Schülern Rechnung getragen wird. Die parallele »Dichtkunst « konzentriert sich auf eine noch nicht triadisch begrenzte Gattungslehre.

Der deutsche und ästhetische Unterricht droht diesen herkömmlichen Rahmen nun 
zu sprengen (hierzu allgemein Kap. 1.2.3). Rhetorik und Poetik überschnitten sich schon immer mit dem sprachlichen, vor allem dem lateinischen Unterricht, dem sie die meisten Beispiele entnahmen. Doch behielt der Lateinlehrer, auch wo die aktive Sprachbeherrschung nicht mehr im Vordergrund stand, eine selbständige Aufgabe: einen Kanon klassischer Texte, den er sprachlich zu erarbeiten und zu interpretieren hatte, so daß es zu keiner Konkurrenzsituation kam. Beim deutschen Unterricht liegt der Fall auf mehrfache Weise anders: Als Muttersprache muß Deutsch nicht erst auf literarischem Weg eingeübt werden; ein Textkanon bildet sich erst mit der Entwicklung des Faches selbst heraus; und - was durch die aufklärerische Pädagogik am wichtigsten wird-deutsche Muster spielen in Rhetorik undPoetik eine umso größere Rolle, je mehr auf den praktischen Gebrauch und die gegenwärtigen Interessen gesehen wird. Das Fach »Deutsche Sprache« im Münnerstädtischen Lehrplan umgreift Rhetorik und Poetik und stellt sich - sieht man von der stilistischen Unterweisung in IV ab - als deren Anwendung im Deutschen dar (Verfertigung von Reden und Versen). Auf Grund der Konkurrenz der Fächer zeichnet sich die Möglichkeit der Umkehrung des Verhältnisses hier schon ab; bis ca. 1850 wird in Bayern der Deutschunterricht Rhetorik und Poetik in sich aufgenommen haben. Eine andere für den deutschen Unterricht relevante Entwicklungslinie wird mit dem Fach »Aesthetik « sichtbar. Dabei geht es um eine (popular)philosophische Einführung in Kunst und Literatur, weniger praxisbezogen als in der poetischen Unterweisung, mit einer Geschmackslehre im Zentrum. Wie aus dem herangezogenen Lehrplan abzulesen ist, steht »Aesthetik « in Konkurrenz zu »Dichtkunst « und vermag diese zeitweilig zu ersetzen (in Klasse V: 1775 nur Poetik, 1776 Poetik und Ästhetik, 1777 nur Ästhetik). Im späteren 18. Jahrhundert wird die Gattungspoetik erstmals - wie wir am Ingolstädter Beispiel sehen - zugunsten einer Geschmacksbildung durch Lektüre zurückgedrängt; ein Vorgang, der sich in den 30er und 40er Jahren des 19. Jahrhunderts wiederholt (s. Kap. 2.1.2), jedoch in Bayern gegen die inzwischen siegreiche Restauration von Rhetorik und Poetik (s. Kap. 2.2.2) nicht durchdringen kann.

Aufklärerische Grundsätze werden mit der Schulordnung von 1782 und dem $\rightarrow$ Wismayr'schen Lehrplan von 1804 (s. Kap. 2.2.1) für ganz Bayern fixiert. [13] Sachliche Information, verstandesmäßige Schulung und ästhetische Bildung gehen im Sprachunterricht Hand in Hand (s. Kap. 1.2.3). "Sprach Studium (sowohl deutsches, als lateinisches und griechisches) soll und darf durchaus nicht als inhaltsleeres Gedächtnis Werk betrieben; sondern muß möglichst mit dem Sach Unterrichte verwebt [...] werden«. [14] »Die Poesie studiert man nicht, um blos Poet zu werden « [15], sondern um im Umgang mit Literatur sprachliche Fähigkeiten zu entwikkeln und ästhetische Maßstäbe auszubilden. Durch poetische Ǔbungen erhält man »eine praktische Kenntniss, dass wir Dichter harmonisch, mit Nutzen und Vergnügen lesen können, ja man wird selbst in der Sprache, in der Stärke des Ausdruckes, und in den Gedanken fester, und geübter, und erlangt kritische Kenntniss über ihre Schönheit «. [16] In der Poetik und Rhetorik bleiben der deutsche und lateinische Unterricht verbunden, doch wird in der »Redekunst «, mit Rücksicht auf die spätere Verwertbarkeit, »sonderbar die deutsche in Vorlesungen, und Aufgaben betrieben «. [17] 1803 fordert die Regierung die Schüler zudem auf, »zur Uebung in ihrer teutschen 
Vaterlands- und künftigen Geschäftssprache « mit ihren Lehrern »Zirkel « zu bilden, wo größere Aufsätze »mit anpassender Deklamation « vorgelesen und beurteilt werden. [18]

Lehrplangeschichtlich stellt die Schulordnung von 1804 einen Wendepunkt in der Entwicklung des Faches Deutsch in Bayern dar. Was sich bei der Analyse Münnerstadts abzeichnete, ist jetzt eingetreten: Rhetorik und Poetik erscheinen unter dem Obertitel »Deutsche Sprache«. Das Fach kann somit erstmals gesondert auftreten und stundenmäßig gewichtet werden. Tabelle 3 zeigt, was in den drei mittleren Klassen, »den eigentlichen gymnastischen «, gelehrt wird. Die zwei Schienen - nach dem Wegfall der Grammatik sichtbar im 2. und 3. Jahr -, in denen der deutsche Unterricht folgerichtig verläuft, verweisen auf seine Entstehung aus Rhetorik und Poetik. Von der Grammatik wird (über die sSyntaxis ornata) zur Stilistik übergeleitet, die in einzelnen Aufgaben bearbeitet und sodann in systematischer Zusammenfassung durchgenommen wird. Die Stilistik legt für die Rhetorik, deren wichtigster Teil sie ist, den Grund. In der >Poesie wird zunächst an Ausschnitten das Lesen und Verstehen von Texten geübt, um dann über die Metrik zur Gattungslehre zu kommen. Pölitz, Adelung/Heinsius, Eschenburg und $\rightarrow$ Sulzer, nach denen dieser Unterricht erteilt werden soll, zählen zu den besten, im Falle von Adelung/Heinsius und Pölitz zudem zu den neuesten Lehrbüchern nach der Gottschedzeit. Im Sinne dieser Autoren sieht der Lehrplan auf Lektüre und Interpretation, doch bleibt diese auf die »Dicht-« und »Redekunst « bezogen, die den Unterrichtsgang abschließen. Nach dem Vorgang von Pölitz wird dabei das Attribut »kiassisch « den deutschen Dichtern des 18. Jahrhunderts zuerkannt, um sie als mustergültig den antiken Autoren an die Seite zu stellen. Mit dieser Schulordnung hat die Aufklärungszeit in Bayern ihren Höhepunkt und Abschluß erreicht.

\section{Tabelle 3: »Deutsche Sprache« im Zweyten Triennal-Kurs 1804 [19]}

\section{Erstes Jahr (3 Wochenstunden)}

- »allgemeine Grund Sätze zum Behufe des Richtigschreibens (Stylisierens) überhaupt. nach Wismayr's Grund-Sätzen der hochdeutschen Sprache (2te Aufl. 1803) [. . .]«;

- »Eigenheiten der deutschen Sprache, nach Pölitz Analisis stylisierter Aufgaben «;

- »Anleitung zur Kenntniß des Geistes der deutschen Sprache, nach Pölitz Vorlesungen über Fragmente aus deutschen Schriftstellern etc. «.

Zweites Jahr (3 Wochenstunden)

- »vollständige Theorie des deutschen Styles, nach Adelung im Auszuge von Heinsius. Berlin $1800 \ll$;

- »Anleitung zur Fertigung verschieden-stylisierter Aufsätze, als Briefe, Erzählungen, Fabeln, Gespräche u. dgl.«;

- »Einleitung zum Studium der deutschen Dichter; Prosodie, Mechanik und Erleichterungs Mittel des deutschen Verse Baues. Als Muster dienen die leichteren klassischen Dichter «.

Drittes Jahr (3 Wochenstunden)

- »Allgemeine Theorie der Dichtkunst, und besonders der lyrischen und anderer Dichtungs Arten, nach Eschenburgs Theorie der schönen Wissenschaften, oder nach Loreyes Dichtisunst, mit latein. und deutschen Beyspielen beleuchtet «;

- »Anleitung zur Redekunst, nach Eschenburg, Sulzer u. A. Posselts Reden in dessen kleineren Schriften (Nürnberg 1795) dienen als Muster«. 


\subsubsection{Neuhumanismus und rhetorische Restauration, die Zeit von 1808} (Niethammersches Normativ) bis 1829 (Thierschs Schulplanentwurf)

Für die Stärkung des Deutschunterrichts verbinden sich in den ersten Dezennien des 19. Jahrhunderts, trotz unterschiedlicher Bildungsauffassungen, Spätaufklärung (Wismayrscher Lehrplan 1804) und Neuhumanismus (Niethammersches Normativ 1808). Wohl nie wieder wurde bayrischen Gymnasiasten die Literatur der Aufklärung, der Weimarer Klassik und der Gegenwart so intensiv vermittelt. $\rightarrow$ Niethammers Auswahl (s. Tabelle 4) traf mit sicherem Griff meisterhafte, aber auch sehr anspruchsvolle Werke. Nicht alles fand gleicherweise Eingang in die Schule; so tauchen Haller und Jacobi in den Programmen nur kurzzeitig, Lessing - außer mit Fabeln - selten auf, und Schiller überwiegt Goethe ganz, von dem nur Hermann und Dorothea zur Standardlektüre wird. Ebenso gängig werden von Klopstock die Oden und der Messias, und diese Texte halten sich sogar als fast einzige deutsche Gymnasiallektüre unter Thiersch (s. Kap. 2.2.3). Der von Niethammer auf die Klassik und ihre Vorstufen gesetzte Akzent wird vor allem durch die Ausrichtung des Schulbetriebs an der Spätaufklärung und der Rhetorik verändert. So behaupten die Popularautoren des späten 18. Jahrhunderts - obwohl im `Normativ< nicht erwähnt - einen bevorzugten Platz. Bevor ich auf diese beiden herrschenden Tendenzen eingehe, soll an einem Beispiel deutlich werden, wie sich ein avancierter Deutschunterricht gestalten konnte.

Tabelle 4: Der deutsche Lektürekanon nach dem Niethammerschen Normativ von $1808[20]$

\begin{tabular}{|l|l|l|}
\hline Gymnasialklasse & Poesie & Prosa \\
\hline Unter-Cl. & $\begin{array}{l}\text { Lyrik: Auswahl aus } \\
\text { Göthe's, Schillers und } \\
\text { Herders Liedern. }\end{array}$ & Auswahl aus Herders und Göthes Werken. \\
\hline $\begin{array}{l}\text { Untere } \\
\text { Mittel-Cl. }\end{array}$ & $\begin{array}{l}\text { Lyrik: Auswahl aus Utz [!], } \\
\text { Haller, Voß, Klopstock } \\
\text { vorzüglich Ubung an den } \\
\text { schwereren Oden der } \\
\text { beiden Letztern. }\end{array}$ & $\begin{array}{l}\text { Auswahl aus [Fr. H.] Jacobis und Leßings } \\
\text { Schriften. Zu den letztern kann dic } \\
\text { Leßingsche Chrestomathic von Fr. Schlegel } \\
\text { benutzt werden. »Leßings Gedanken und } \\
\text { Meinungen aus deßen Schriften zusam- } \\
\text { mengestellt und erläutert von Friedrich } \\
\text { Schlegel Leipzig 1804.« }\end{array}$ \\
\hline $\begin{array}{l}\text { Obere } \\
\text { Mittel-Cl. }\end{array}$ & $\begin{array}{l}\text { Epik: Hermann und } \\
\text { Dorothea von Göthe. } \\
\text { Louise von Voß. } \\
\text { Stücke aus Klopstocks } \\
\text { Meßias. }\end{array}$ & $\begin{array}{l}\text { Leßings Schriften, Schillers Geschichte der } \\
\text { Niederlande und des dreißigjährigen } \\
\text { Krieges, neben Johannes von Müllers } \\
\text { Schweizergeschichte. }\end{array}$ \\
\hline Ober-Cl. & $\begin{array}{l}\text { Dramatik: Leßings, } \\
\text { Göthe's, Schillers Werke. }\end{array}$ & \begin{tabular}{l} 
Winkelmanns Werke. \\
\hline
\end{tabular} \\
\hline
\end{tabular}


Die Nürnberger Real-Studien-Anstalt von 1808 bis 1816 - die Vorstufe des Polytechnikums und der Technischen Hochschule - mit Schülern von 10 bis 17/18 Jahren war den Gymnasien »parallel gestellt«. Wie diese, sollte sie »einer höheren wißenschaftlichen Bildung « dienen, nur daß an die Stelle der alten Sprachen »ein unmittelbares Studium der Natur und der gegenwärtigen Welt « trat. [21] Sie war somit von gymnasialen Traditionen frei; im Sprachunterricht suchte man nicht Regeln einzuüben und Muster zu adaptieren, sondern ging den entgegengesetzten Weg »der eignen lebendigen Anschauung, der Ausbildung des eignen warmen Gefühls«. »Bildung der Sprache mit und aus unmittelbarer Anschauung und Weltbetrachtung « [22], hieß hier die Losung. Der Vorstand der Anstalt, der romantische Naturphilosoph Schubert, gestaltete den deutschen Unterricht - um Úbersetzungen erweitert als »Studium der deutschen Sprache und allgemeinen klassischen Litteratur « - so aus, daß er Latein als sprachliches Mittelpunktsfach ersetzen konnte. Im Zentrum stand die Lektüre, wobei neben der Klassik und der Aufklärung auch die altdeutsche Literatur und in Übersetzungen nicht nur die antiken Klassiker (mit Schwerpunkt bei den Griechen), sondern die Weltliteratur überhaupt (Dante, Calderon, Shakespeare, Milton, wohl auch Cervantes und Boccaccio) präsent sind. Ein Geschmack auf der Höhe der Zeitbildung und größte Offenheit kennzeichnen Schuberts Auswahl: Germanisches (Edda) und Mittelhochdeutsches (Nibelungen, Wolframs Parzival) wie betont Christliches (Dante, Calderon) tritt zu den Alten, auch moralisch (Wielands Oberon, 1810 Ariosts Rasender Roland), politisch (Forster) oder gegenüber dem ästhetisch immer noch verdächtigen Roman werden keine Scheuklappen sichtbar. Bei den Lesestoffen, hier nach dem Programm von 1809 wiedergegeben, wird nach Unterrichtsstufen gereiht: zunächst »die Werke der episch-erzählenden Art, deren Stoff aus der Welt des Sinnlichen und der Anschauung (Homer, Vergil; Edda, Nibelungen, Parzival; Wielands Oberon, Herders Cid, Goethes Hermann und Dorothea), dann jene »der episch-darstellenden Art, deren Stoff schon mehr aus der Welt der Ideen und des Gefühls genommen ist « (Dante, Milton, Klopstock), schließlich Werke »von dramatischer Natur« (Griechen, Shakespeare, Calderon, Schiller, Goethe).

1. Unterrichtsstufe: »das eigentliche klassische Studium«: »Es möge dieses von der poetischen Seite mit dem Homer, besonders mit der Odyßee, beginnen, der Innhalt des Virgil wird darauf meist mündlich von dem Lehrer, mit Hervorhebung einiger vorzüglichen Stellen gegeben, von Ossian werden nur erst einige leichtere Stücke hier ihre Stelle finden können«.

Altdeutsches Studium: »Man wird hier den Fabelkreis des Heldenbuches herausheben, als denjenigen, welcher dem deutschen Geist in Hinsicht des Stoffs und der Form, der eigenthümlichste ist. [. . . ] Zu diesem Zweck wird man einige hieher gehörige Fabeln aus der Edda (z. B. den Tod des von keinem Geschoß zu verletztenden Balders u.s.w.) auch schon um ihrer selbst willen auswählen, um dann auf den eigentlichen Kreis des Heldenbuches und der Nibelungen überzugehen «. »Parzival«.

»Herders Romanzen vom Cid und Legenden, Göthes Hermann und Dorothea und Wielands Oberon «.

»eine Auswahl guter prosaischer Stücke«: Schiller, Georg Forster, Herder, $\rightarrow$ Engel.

2. Unterrichtsstufe: „Stellen aus Dantes, Miltons, hierauf ein großer Theil von Klopstock's religiöser Epopee (Herder's Geist der ebräischen Poesie u. f.)«, damit abwechselnd »lyrische Gedichte aus Klopstocks, Hallers, Herders, Schillers, Göthes u. a. Werken«. 
Das »Studium der Prosaiker « wird »außer dem Roman, (besonders nach den besten aus dem Spanischen und Italiänischen übersezten und nach den besten deutschen Mustern) und ausser dem fortgesetzten Studio der Meisterwerke eines Göthe, Schiller, Herder, [Joh. v.] Müller; auch Muster einer klaren, reinen und gedrängten Darstellung wissenschaftlicher und praktischer Gegenstände wählen «.

3. Unterrichtsstufe: »Unter den Dichtern [...] nennen wir nur den Shakspear, Calderone, Schiller, Göthe u.f.[,] zugleich aber wird auch hierbey einige Anleitung zur Kenntniß der griechischen Dramatiker, in einer guten deutschen Uebersetzung gegeben. Wir denken uns [...] diesen Unterricht größtentheils auf günstigere Gelegenheit des Privatstudiums, dessen Leitung sich der Lehrer vorbehält. beschränkt. Zugleich wird hiermit die Anleitung zu dem (größtentheils Privat-) Studio der Werke eines Winkelmann, Herder, [F. H.] Jacobi, Lessing u.a.m. verbunden seyn «.

1810 werden einige Texte vertauscht. In der Unterstufe finden sich unter den Gedichten jetzt Bürger und Hölty, bei den Epen Tassos Befreites Jerusalem in der Griesschen Übertragung; in der Oberstufe wird »eine Auswahl aus Ariosts Roland (nach Heinse und Gries) und Cervantes (nach Tie[c]k)«, Lessings Nathan und Goethes Wilhelm Meisters Lehrjahre neu aufgeführt. Da die Fülle des Lesestoffes wie schon im vorigen Jahr nicht in der Unterrichtszeit zu bewältigen war, benutzten die Lehrer »einzelne freye Nachmittage«, um Lesezirkel mit ihren Schülern zu bilden. Neu sind in der Oberklasse »Disputirübungen «, die in einem eigenen Traditionsbuch (»Erinnerungszeichen«) festgehalten werden, mit gewählten Schülern als »Censoren«, die auch bei der Organisierung der Privatlektüre tätig werden. Ein derartiger Deutschunterricht, der den Niethammerschen Kanon im romantischen weltliterarischen Sinne ausweitet und so eindeutig auf das Lesen und die Kenntnis der Texte selbst abhebt, findet sich sonst nirgends in Bayern.

Im Durchschnitt des gymnasialen Unterrichts bleibt die Lektüre fest in den Rahmen der Poetik und Rhetorik eingespannt. Die Schulnachrichten drücken es deutlich aus. Die Stilistik bildet in den mittleren Klassen den Richtpunkt. Man macht die Stileigenschaften »in Beyspielen aus teutschen Klassikern anschaulich « (Salzburg, Untergymnasialklasse 1813 - Salzburg und Innsbruck gehörten 1809 bis 1814 zu Bayern). Exemplarisch Passau 1818: »Nach Adelungs deutschem Stil im Auszuge von Heinsius die allgemeinen Eigenschaften eines richtigen, klaren und schönen Stils, besonders Tropologie, nachgewiesen an den Elegien des Ovid u. an Goethe, Schiller, Matthisson, Nicolay, Zachariae, Wilh. Schlegel, Collin, Tiedge, Körner u. a.« [23] Die Dichter der Gegenwart und jüngsten Vergangenheit werden von der Stilistik und Gattungstheorie der Aufklärung und der Metrik aus erschlossen. In Innsbruck (Untergymnasialklasse 1813) wird die Theorie der Dichtungsarten »mit vielen passenden Muster-Stellen der besten deutschen Dichter « belegt. Kempten (3. und 2. Gymnasialklasse 1818) behandelt nach dem Unterricht über lyrische Dichtung »viele Gedichte mit Rücksicht auf Versbau und Silbenmass, auf Figuren und Tropen «. [24] Die beiden obersten Gymnasialklassen schliessen die Lektüre an die Poetik und Rhetorik an. Sie lesen (Salzburg, Mittelgymnasialklasse 1813) »Von der teutschen Literatur mehrere klassische Muster des prosaischen und poetischen Styls aus Göthe, Schiller, Herder und Pfeffel in Verbindung mit der Theorie der äsopischen Fabel, der poetischen Erzählung und Beschreibung, der Idylle, Satyre, Ode, des Lieds und Epigramms nach Eschenburg «[25] oder erklären die Theorie »mit stetem Hinblick 
auf die Klassiker deutscher Nation « (Speyer, Mittelgymnasialklasse 1821). In Speyer (Obergymnasialklasse 1820) werden die Regeln des Epos »in den vorzüglichsten Mustern nachgewiesen « und »zu festerer Begründung der rhetorischen Regeln, gewählte Stellen aus Herders, Joh. v. Müllers und Schillers Schriften gelesen «.

Für versepische Produkte zeigen die bayerischen Gymnasien eine Vorliebe, die für die einsetzende Restaurationszeit nicht untypisch [26], aber doch geschmacklich konservativ ist (s. Tabelle 5). Der im >Normative vorgeschriebene Kreis von Werken

\section{Tabelle 5: Epische, idyllische und beschreibende Poesie} als Schullektüre [27]

\begin{tabular}{|c|c|c|c|}
\hline Ort & Jahr & Gymnasialklasse & Autoren und Werke (mit Kurztitel) \\
\hline Amberg & 1812 & Oberklasse & Goethe: Hermann und Dorothea \\
\hline Ans & 1818 & Obermittelklasse & ckk « \\
\hline- & 1819 & Obermittelklasse & »vorn. Heinrich der Löwe, von Kunze« \\
\hline- & 1821 & Obermittelklasse & »die größern Gedichte, Adelaide von \\
\hline & & & $\begin{array}{l}\text { Lindenhan, die Herbstfeier und der Tag auf } \\
\text { dem Lande von Neuffer» }\end{array}$ \\
\hline - & - & Untermittelklasse & Voß: Luise \\
\hline- & 1822 & Obe & $\begin{array}{l}\text { »die größern Gedichte, der Herbst und Winter } \\
\text { aus Thomsons Jahreszeiten, übers. von Harries; } \\
\text { Hermann der Cherusker von Braune» }\end{array}$ \\
\hline Bamberg & 1813 & Mittelklasse & $\begin{array}{l}\text { » Beschreibende Gedichte von Opitz, Haller, } \\
\text { [E. v.] Kleist « }\end{array}$ \\
\hline Innsbruck & 1813 & Oberklas & Klopstock: Messias, Tiedge: Urania \\
\hline Kem & 1810 & Mitt & Goethe: Her \\
\hline München & 1809 & Oberklasse & $\begin{array}{l}\text { Klopstock: Messias, I. und II. Gesang in } \\
\text { Auszügen }\end{array}$ \\
\hline - & - & Unterklasse & $\begin{array}{l}\text { Kleist: Frühling; Tiedge: Urania, } \\
\text { IV. und V. Gesang }\end{array}$ \\
\hline - & 1810 & Obermittelklasse & Goethe: Hermann und Dorothea, Voß: Luise \\
\hline Nürnberg & 1813 & Ober & Klopstock: Messias, Ausschnitte \\
\hline Passau & 1812 & Oberklasse & $\begin{array}{l}\text { »Hermann und Dorothea von Goethe, } \\
\text { Luise von Voss; mehrere Gesänge aus } \\
\text { Klopstocks Messias« }\end{array}$ \\
\hline Regensburg & 1813 & Obermittelklasse & Goethe: Hermann und Dorothea, Voß: Luise \\
\hline & 1818 & Oberklasse & Goethe: Hermann und Dorothea \\
\hline Speyer & 1823 & Unterklasse & „Paraphrase von Vossens Luise u. A.» \\
\hline
\end{tabular}

Außer den bekannten Dichtungen von Goethe, E.v. Kleist, Klopstock, Tiedge und Voß handelt es sich um folgende Werke und UUbersetzungen (nach Kayser): Geo. Chr. Braun: Herrmann der Cherusker. Ein Heldengedicht in 12 Gesängen, Mainz 1819, 2. Aufl. 1821 ; (Hnr.) Stephan Kunze: Heinrich der Löwe. In ein und zwanzig Gesängen. Mit historischen und topographischen Anmerkungen. 3 Bde. Quedlinburg 1817. N.Aufl. 1822; Andr. Cph. Lindenhan: Adelaide. Ein Gedicht in sieben Gesängen, Gotha 1815; Chr. Ldw. Neuffer: Dic Herbstfeier, ein Sittengemälde in 9 Gesängen. Ein Taschenbuch auf das Jahr 1802. Stuttgart 1802; Drsl.: Der Tag auf dem Lande. Idylle in 10 Gesängen. N.umgearb. Aufl. (Die erste Aufl. in Leipzig erschien ohne des Verfassers Namen und ein Nachdruck mit dem Beisatz auf dem Titel: v. Jh. H. Voß. Leipzig 1802) Reutlingen 1805; Jak. Thomson: 4 Jahreszeiten, in deutschen Jamben, mit e. Lebensbeschreibung des Dichters und erklärenden Anmerkungen von H. Harries, Altona 1796. 
(Klopstocks Messias, Voß' Luise, Goethes Hermann und Dorothea) wird von Fall zu Fall durch formbildende Muster des 18. Jahrhunderts (Thomsons Jahreszeiten, E. v. Kleists Frühling), durch beliebte und literaturkritisch bereits anerkannte Texte jüngerer Zeit (Tiedges Urania, Neuffer) wie auch durch Neuerscheinungen ergänzt, die nur vorübergehende Beachtung fanden (Braun, Kunze, Lindenhan). Dabei erscheint die Versdichtung in verschiedenen Spielarten - als shohes« christliches (Messias) oder heroisches historisches Epos (Hermann der Cherusker, Heinrich der Löwe; Pyrker, s. u.), als idyllisches Epos (Luise, Hermann und Dorothea, Der Tag auf dem Lande), lyrisch-episches Mischprodukt (Amaranth, s. u.), Lehrgedicht (Urania) oder beschreibendes Gedicht (Jahreszeiten, Frühling); es fehlt vor allem das komische und satirische Epos, das als moralisch und politisch anstößig galt (Wieland, Heine), wie überhaupt der niedere Stil in dieser Gattung. Auch nach 1830 findet die versepische Tradition in Bayern eine wichtige Stütze. Pyrkers Hexameterepen mit Stoffen aus der Geschichte Habsburgs und dem Alten Testament machten nun Klopstock Konkurrenz, für einige Jahre auch Redwitz' Amaranth (1849). Das Gymnasium war so zweimal am Versuch beteiligt, konservative katholische Ependichter (im Falle von Pyrker einen ungarischen Kardinal) [28] zu modernen Klassikern zu erheben.

In Eichstätt und Münnerstadt wurden ganze Bücherlager von Klopstocks und Pyrkers Werken als Schulpreise verschenkt. Die Werke Pyrkers kamen in Eichstätt, einem klerikalen Zentrum, von $1839 / 40$ bis $1851 / 5213$ mal zur Verteilung, dazu noch zweimal die Perlen der heiligen Vorzeit, je einmal das Epos »Tunisias« und der Kommentar zu Johann Ladislaw Pyrker's Werken in Form einer Blumenlese von Söller (1840). Daneben gingen fünf Ausgaben des Messias und vier der Amaranth in die Hände der Schüler über. In Münnerstadt werden von 1846/47 bis 1861/62 Pyrkers Werke 22mal als Schulpreise genannt, dazu zweimal die Bilder aus dem heiligen neuen Bunde und Legenden. Klopstocks sämtliche Werke vergab man hier achtmal, den Messias und die Amaranth je einmal. Da sich mehrere Preisträger in die umfangreichen Ausgaben teilen mußten, erfuhren die Versprodukte eine breitere Streuung, als es die obigen Zahlen ausdrücken.

Die Behandlung prosaischer Muster erhält einen gleich großen Raum, weil die Rhetorik mit nicht geringerer Intensität als die Poetik getrieben wurde. Das $>$ Normativ< von 1808 nennt an. Prosaschriftstellern (s. Tabelle 4): Herder und Goethe für die Unterklasse, Lessing und F. H. Jacobi für die Untermittelklasse, Lessing, Schiller (Geschichte des Abfalls der vereinigten Niederlande, Geschichte des Dreißigjährigen Kriegs) und Johannes von Müller für die Obermittelklasse, Winckelmann für die Oberklasse des Gymnasiums. Schon der Lehrplan läßt erkennen, welchen Raum die didaktische und historische Prosa einnehmen. Schiller ist nicht nur als Dramatiker und lyrisch-didaktischer Dichter, sondern auch als Prosaschriftsteller sklassisch Jahresprogramme (s. Tabelle 6) führen am häufigsten Herder, Schiller und Johannes von Müller, oft in Verbindung mit der Rhetorik, auf. So heißt es in Passau (Obergymnasialklasse 1812): „Rhetorik: Muster aus mehreren klass. Prosaikern, bes. aus Schillers, Engels, Joh. von Müllers und Winckelmanns Werken«. Außer den im `Normativ genannten Schriftstellern findet die populäre Sachprosa der Spätaufklärung - über philosophische und theologische, historische, philologische oder medizinische Fragen - stärkste Beachtung: $\rightarrow$ Engel, Funke, Garve, Heydenreich, Heyne, Hufeland, Jacobs, Jerusalem, Posselt, Sturz. Der Rhetorikunterricht bringt es mit 
Tabelle 6: Didaktische, historische und oratorische Prosa als Schullektüre [30]

\begin{tabular}{|c|c|c|c|}
\hline Ort & $\mathrm{Jahr}$ & Gymnasialklasse & Autoren und Werke (mit Kurztitel) \\
\hline Amberg & 1812 & Obermittelklasse & J. v. Müller, Posselt, Reinhard \\
\hline Ansbach & 1820 & Oberklasse & Engel, Heydenreich, Zollikofer, Sturz \\
\hline- & 1823 & Untermittelklasse & $\begin{array}{l}\text { Hufeland: Makrobiotik, Funke: Geschichte des } \\
\text { Menschen }\end{array}$ \\
\hline $\begin{array}{l}\text { Aschaffen- } \\
\text { burg }\end{array}$ & 1821 & Oberklasse & $\begin{array}{l}\text { »Schulreden von Herder, Mörlin, Matthiä, } \\
\text { Kanzelreden von Sailer, Zollikofer, Reinhard « }\end{array}$ \\
\hline Innsbruck & 1811 & Mittelklasse & Winckelmann, Engel \\
\hline Kempten & 1810 & Mittelklasse & $\begin{array}{l}\text { Schiller: Universal-Geschichte, Stücke aus } \\
\text { prosaischen Schriften }\end{array}$ \\
\hline- & 1810 & Unterklasse & Herder, Stücke prosaischer Aufsätze \\
\hline- & 1818 & Oberklasse & $\begin{array}{l}\text { „Die meisten Abhandlungen in Herders } \\
\text { XII. Bande über schöne Literatur und Kunst; } \\
\text { einige Stücke in Schillers prosaisch. Schriften." }\end{array}$ \\
\hline- & 1818 & 3. und 2. Klasse & $\begin{array}{l}\text { „Die Griechenland und Rom betreffenden } \\
\text { Abschnitte aus Herders Ideen zur Philosophie } \\
\text { der Geschichte der Menschheit. « Engels Lob- } \\
\text { rede auf Friedrich d. Großen }\end{array}$ \\
\hline München & 1809 & Oberklasse & $\begin{array}{l}\text { Schiller: Universal-Geschichte. Melles Rede } \\
\text { über den Satz: Nichts macht den Weisen ruhm- } \\
\text { würdiger als der Großmut }\end{array}$ \\
\hline- & 1818 & Oberklasse & $\begin{array}{l}\text { J. v. Müller, Herder (theoretische Abhand- } \\
\text { lungen) }\end{array}$ \\
\hline Passau & 1812 & Oberklasse & $\begin{array}{l}\text { "Muster aus mehreren klassischen Prosaikern, } \\
\text { besonders aus Schillers, Engels, Joh. von } \\
\text { Müllers und Winckelmanns Werken « }\end{array}$ \\
\hline Regensburg & 1813 & Obcrmittelklasse & Jerusalem, Heyne, Melle, Engel \\
\hline- & 1818 & Oberklasse & $\begin{array}{l}\text { Garve, Zollikofer, Reinhard, Jakobs, Morgen- } \\
\text { stern, Heydenreich, Glatz }\end{array}$ \\
\hline Speyer & 1818 & Mittelklasse & $\begin{array}{l}\text { Schiller: Universal-Geschichte, Geschichte des } \\
\text { 30jährigen Krieges }\end{array}$ \\
\hline- & 1820 & Oberklasse & J.v. Müller, Herder, Schiller \\
\hline
\end{tabular}

Zu den Rednern s. Joseph Kehrein: Die weltliche Beredsamkeit der Deutschen. Mainz. 1846. S. 321 über Fr. Aug. Christ. Mörlin (1775-1806), Prof. am Gymnasium zu Altenburg, S. 288/89 über J. Engel. Dersl.: Geschichte der katholischen Kanzelberedsamkeit der Deutschen. Bd. 1: Regensburg 1843, S. 159-63 über J. M.v. Sailer, Bischof von Regensburg. Ein Porträt von Franz Volkmar Reinhard (1753-1812), zuletzt Oberhofprediger in Dresden, bei August Nebe: Zur Geschichte der Predigt. Bd. 2. Wiesbaden 1879, S. 181-234. - In der ADB Artikel über die Genannten wie auch zu: Jakob Glatz (1776-1831), pädagogischer, homiletischer und asketischer Schriftsteller; Karl Heinrich Heydenreich (1764-1801), Prof. der Philosophie in Leipzig; Friedrich Jacobs (1764-1847), Gymnasiallehrer, Oberbibliothekar und Direktor des Münzkabinetts in Gotha, Mitglied der Akademic der Wissenschaften in München, wo er 1807-10 am Lyzeum lehrte; August Matthiae (1769-1835), Prof. am Gymnasium zu Altenburg; Karl Simon Morgenstern (1770-1852). Prof. d. klass. Philologie und Ästhetik an der Univ. Dorpat; Georg Joachim Zollikofer (1730-88), gefeierter Prediger in Leipzig. Ausführlicher. mit Schriftenverzeichnis zu Glatz: Constant v. Wurzbach: Biographisches Lexikon des Kaiserthums Oesterreich ctc. Tl. 5. Wien 1859, S. 207-12; zu Heydenreich: K[arl] H[einrich] Jördens: Lexikon deutscher Dichter und Prosaisten mit Supplement. Bd. 6. Leipzig 1811, S.819-45; zu Morgenstern: Johann Fried- 
sich, daß oratorische Prosa gleichfalls herangezogen wird. Auch als Redner (Was heißt und zu welchem Ende studiert man Universalgeschichte?) ist Schiller am beliebtesten. Man läßt »Schulreden von Herder, Mörlin, Matthiae «, »Kanzelreden von Sailer, Zollikofer, Reinhard « (Aschaffenburg, Obergymnasialklasse 1821), daneben Lobreden (Engels Lobrede auf Friedrich II.) lesen, also Redegattungen, in denen das absolutistische Deutschland Muster bot.

Der übernationale Standpunkt von Rhetorik und Poetik hat es erlaubt, die Stil- und Versübungen in verschiedenen Sprachen zusammenzulegen und insbesondere die antiken Redner und Dichter in den Deutschunterricht der oberen Klassen zu ziehen. Österreich, das bis 1848 deutsche Literatur nur im Rahmen der Rhetorik und Poetik zu Wort kommen läßt (s. Kap. 2.3), mag manche Anstalten Bayerns beeinflußt haben. Die beiden Disziplinen bildeten gleichsam ein Rangierglied zwischen den sprachlichen Fächern, das den Schulen intern Gewichtsverlagerungen gestattete - und das hieß bei der Präponderanz der Altphilologen im Gymnasialbetrieb in der Regel: auf Kosten des Deutschen. Der Lateinunterricht in Innsbruck (Obergymnasialklasse 1813) beispielsweise ergänzte die Behandlung von Vergils Aeneis »mit Bemerkungen über die Oekonomie eines Helden-Gedichtes überhaupt nach Eschenburg und anderen, wie auch Vergleichung mit andern Gedichten dieser Art der alten sowohl als neuern Zeiten und Nationen «. Die Grundsätze der epischen, lyrischen und dramatischen Poesie werden in München (Obergymnasialklasse 1814) »aus griechischen und deutschen Klassikern entwickelt «, die Theorie der Beredsamkeit und des Dramas (Obergymnasialklasse 1816) wird »durch griechische, lateinische und deutsche Muster erklärt «. [31] Die altphilologische Reaktion der zwanziger und dreißiger Jahre hat dann die Bindung der Theorie an Latein und Griechisch ausdrücklich gefördert; der Erlaß vom 3.2. 1834 will sie »unter steter Hinweisung auf die schon erklärten oder gleichzeitig zu erklärenden Muster aus der griechischen, römischen und deutschen Literatur « [32] gelehrt wissen. Insgesamt gab so der nachaufklärerische Deutschunterricht in Bayern, anders als in Preußen, einer rhetorischen und poetischen Schulung herkömmlicher Art den Rückhalt.

\subsubsection{Die altphilologische Reaktion: Der Streit um Thierschs Lehrplanent- wurf von 1829 und die Schulordnung 1830}

Der Plan der künftigen Einrichtung der lateinischen Schulen in Bayern, von $\rightarrow$ Thiersch mit Hilfe Schellings und der Rückendeckung des Königs 1829 durchgesetzt (s. Kap. 1.3.3.2) [33], hat das altphilologische Prinzip der Konzentration alles höheren Unterrichts auf die alten Sprachen wie in keinem anderen deutschen Staat

rich v. Recke u. Karl Eduard Napiersky: Allg. Schriftsteller- und Gelehrten-Lexikon der Provinzen Livland, Esthland und Kurland. Bd. 3. Mitau 1831, S. 247-65, u. Nachträge und Fortsetzungen. Bd. 2. 1861. S. 50-54. - Über die Schriften von Johann Jakob Melle (geb. 1752) s. Kayser. 
verwirklicht. Dabei schwebten Thiersch lateinische Kaderschmieden vor: die württembergischen niederen Seminare, die das `Landexamen` (zentrale Stipendienprüfung für angehende Theologen) zur Einübung der alten Sprachen zwang und die sich aufklärerischen Reformen entzogen hatten [34], die sächsischen Fürstenschulen und ausländische Anstalten wie Eton, »eine Schulpforte auf englische Art«.[35] Er konnte von dem Lateinschüler in Württemberg schwärmen, der »in der Regel « mit zwölf Jahren »in der lateinischen Grammatik fest ist, mit vierzehn auch in der griechischen und selbst in der hebräischen «, und bildete danach seine Ansichten von der Gymnasialreife. [36] In der von ihm eingerichteten Lateinschule, einer sechsklassigen Vorbereitungsanstalt für das Gymnasium für Schüler von 8 bis 14 Jahren, geht »die Hauptkraft des formellen Unterrichts « demnach »auf eine genaue, beharrliche und umfassende Erlernung der lateinischen Sprache«, damit »die Bildung guter Lateiner « vorbereitet und überhaupt der Erziehung »ihr alter und fester Grund " wieder gewonnen werde. [37] Die Zahl der Wochenstunden betrug in jeder Klasse 26; dem Latein gehörten in den drei ersten Jahren $16(61,5 \%)$, in den drei letzten 12, weil das Griechische mit 6 Stunden eintritt (zusammen $69 \%$ ). Von den ebenfalls je 26 Wochenstunden der vier Gymnasialklassen waren dem Latein 33, dem Griechischen 27 (den alten Sprachen zusammen also 60 Stunden oder 57,7 \%), der Mathematik jedoch nur 15, Geographie und Geschichte 9 Stunden zugedacht. Thierschs Plan sah keine eigenen Deutschstunden und keine neueren Fremdsprachen vor. Die revidierte Schulordnung von 1830, die Friedrich von Roth redigierte [38], hat die krassesten Auswüchse beseitigt (Verminderung des Lateins, das mit dem Griechischen zusammen aber immer noch 57 bzw. $55 \%$ der Unterrichtszeit beansprucht; eigene Deutschstunden), ohne die Grundgedanken zu ändern. Nach diesem Lehrplan (s. Tabelle 7) wurde in Bayern bis zur »revidirten Ordnung " von 1854 [39] unterrichtet, die sich mit Verbesserungen am alten Bau begnügte (die alten Sprachen mit 52 bzw. $50 \%$ aller Stunden wurden nur leicht reduziert) und so die prägende Kraft der Thierschen Reform bestätigt.

Die Eliminierung eigener Deutschstunden rechtfertigt Thiersch mit einem satirischen Bild von den scheinbaren Ausartungen unter $\rightarrow$ Braun und $\rightarrow$ Niethammer. »Heute wird aus Hölti oder Bürger deklamirt, morgen werden Fabeln oder Nathan der Weise vorgelesen. Es war ein fortgehender Fest- und Feyertag den leichtlebenden Menschen durch die ganze Woche hin ausgebreitet «, mit dem die Schule »den Hang zur heillosen deutschen Leserey « befördert und die Jugend »in den Leihbibliotheken unter Romanen und Schauspielen einheimisch « gemacht habe. [40] Thiersch sah das Heilmittel darin, »das Studium des Deutschen mit dem Lateinischen und Griechischen auf das engste zu verknüpfen, und es durch den classischen Unterricht in Bewegung und Thätigkeit zu setzen«. [41]

Wie realisiert sich dieses Prinzip in den Lehrplanvorschlägen? Im Sprachunterricht wird »in den nöthigen Fällen « auf eine deutsche Grammatik in der Hand des Schülers verwiesen, doch »ohne daß es gestattet ist, ihren Inhalt zum Gegenstand zusammenhängender Lehrvorträge zu machen «. [42] Die schriftlichen Stilübungen bestehen in der Lateinschule in Übersetzungen, für die ein antikes Muster »zur Nachbildung « gegeben wird (so wie sich der Kunstschüler in der Akademie »nach vorgelegten 
Tabelle 7: Wochenstundenzahl nach der bayerischen Schulordnung 1830

\begin{tabular}{|c|c|c|c|c|c|c|}
\hline \multirow[t]{2}{*}{$\begin{array}{l}\text { Lateinschule } \\
\text { Fach }\end{array}$} & \multicolumn{4}{|c|}{ Klasse } & \multirow[t]{2}{*}{ Summe } & \multirow[t]{2}{*}{ Prozent } \\
\hline & I & II & III & IV & & \\
\hline Latein & 12 & 12 & 10 & 12 & 44 & 45 \\
\hline Griechisch & - & - & 6 & 6 & 12 & 12 \\
\hline Deutsch & 2 & 4 & 2 & 2 & 10 & 10 \\
\hline Religion & 2 & 2 & 2 & 2 & 8 & 8 \\
\hline Arithmetik & 2 & 2 & 3 & 3 & 10 & 10 \\
\hline $\begin{array}{l}\text { Geographie (mit Geschichte } \\
\text { in Kl. III, IV) }\end{array}$ & 2 & 2 & 2 & 2 & 8 & 8 \\
\hline Kalligraphie & 2 & 2 & 1 & 1 & 6 & 6 \\
\hline Summe & 22 & 24 & 26 & 26 & 98 & 99 \\
\hline
\end{tabular}

\begin{tabular}{|c|c|c|c|c|c|c|}
\hline \multirow[t]{2}{*}{$\begin{array}{l}\text { Gymnasium } \\
\text { Fach }\end{array}$} & \multicolumn{4}{|c|}{ Klasse } & \multirow[t]{2}{*}{ Summe } & \multirow[t]{2}{*}{ Prozent } \\
\hline & I & II & III & IV & & \\
\hline Latein & 8 & 8 & 7 & 6 & 29 & 30 \\
\hline Griechisch & 6 & 6 & 6 & 6 & 24 & 25 \\
\hline Deutscher Styl & 2 & - & - & - & 27 & \\
\hline Theorie der redenden & & & & & & 8 \\
\hline Künste & - & 2 & 2 & 2 & 6 & \\
\hline Religionslehre & 2 & 2 & 2 & 2 & 8 & 8 \\
\hline $\begin{array}{l}\text { Geschichte nebst Geographie } \\
\text { Mathematik (nebst mathe- } \\
\text { matisch-physikalischer }\end{array}$ & 3 & 3 & 3 & 4 & 13 & 14 \\
\hline Geographie in Kl. IV) & 3 & 3 & 4 & 4 & 14 & 15 \\
\hline Summe & 24 & 24 & 24 & 24 & 96 & 100 \\
\hline
\end{tabular}

Mustern « und nicht nach der Natur in der Zeichenkunst übt). [43] Auch im Gymnasium bleibt die Jugend »vor der fruchtlosen Plage der sogenannten freien oder eigenen deutschen Aufsätze « bewahrt, indem sich die Úbungen fast ganz an den klassischen Unterricht anlehnen: »schriftliche Uebersetzungen vorzüglicher Stellen der Alten, Auszüge aus denselben, zergliedernde Uebersichten oder gedrängte Darstellungen des Hauptinhalts«, die zu Kompositionsanalysen verwendet werden. [44] Deutsche Dichtungen werden den unteren Klassen nur zur Erquickung, »als Erheiterung und Erfrischung « der klassischen Studien [45] geboten; in den oberen Klassen läuft der Kursus deutscher Dichtung dem Lateinischen und Griechischen parallel. Die zuhause gelesenen Werke finden in den Schulstunden nur im Vergleich mit antiken Autoren, "mit Bezeichnung des Aehnlichen oder Abweichenden « [46], Beachtung. Beispielsweise werden die Voßsche Luise und Goethes Hermann und Dorothea zur Odyssee gestellt oder Dramen von Lessing, Goethe und Schiller »zur 
Erläuterung des Verhältnisses der griechischen und deutschen Tragödie « beigezogen. [47] Im Unterricht selbst dürfen höchstens mittelhochdeutsche Epen (»die Nibelungen, der Titurell, Parceval «) oder Klopstocksche Oden durchgenommen werden. [48] Diese Ausnahmen erlaubt das Kriterium der philologischen Arbeit am Text: Da sich solche Werke auf Grund ihrer Úberlieferungsprobleme, ihrer Varianten und sprachlichen Schwierigkeiten grammatisch und kritisch behandeln lassen, fügen sie sich dem formalen altphilologischen Literaturunterricht ein. Diesen Vorschlägen liegen klassizistische Wertmaßstäbe zugrunde, wie sie unter Ludwig I. in Bayern herrschend wurden. Da Thiersch »für keine Gattung einen rein ausgebildeten, in sich abgeschlossenen deutschen Styl « kennt [49], auch nicht bei Werken der Weimarer Klassik, spricht er der deutschen Literatur stilbildende Fähigkeiten ab. Große Literatur könne nur auf dem Nährboden der Antike gedeihen, und selbst »die besten deutschen Schriftsteller « bedürften in Hinblick auf Stil und Gehalt »noch der Berichtigung « durch die Alten. [50]

In der Schulordnung 1830 ist trotz des selbständigen Deutschunterrichts - mit den für weite Strecken des 19. Jahrhunderts obligaten minimalen zwei Stunden (mit einer Ausnahme auch für die Unterklassen, s. Tabelle 7) - der lehrplangeschichtliche Rückschritt schon an den Fachbezeichnungen ablesbar. Das Fach hat sich so halb wieder in seine Bestandteile Grammatik, Stilistik, Poetik und Rhetorik aufgelöst, aus denen es entstanden war (s. Kap. 2.2.1). In der Lateinschule heißt es »Deutsch «: »ein fortschreitender grammatikalischer Unterricht « in den beiden ersten Klassen, dazu Lesen, Vortragen, Nacherzählen und erste Aufsatzübungen (»Uebersichten und Auszüge des Gelesenen «). [51] In Gymnasien wird das Fach zutreffend »Deutscher Styl « (für die unterste Klasse) und »Theorie der redenden Künste " genannt. Denn zum einen zeichnet sich der alte Weg von der Stilistik zur Rhetorik und Poetik ab und zum anderen gilt der Unterricht keineswegs dem Deutschen allein. In der zweiten Klasse beginnt »eine zunächst auf die altklassischen Muster zu begründende und hauptsächlich aus ihnen herzuleitende "Poetik; in der dritten und vierten Klasse sind in der Rhetorik »neben den altklassischen Mustern « zwar »besonders deutsche « beizuziehen, »jedoch auch die der neu europäischen Literatur, so wie die vorzüglichsten lateinischen Dichter und Redner der drey letzten Jahrhunderte nicht zu übergehen «. [52] Der Lehrplan fixiert somit die rhetorische Restauration (s. Kap. 2.2.2), behält von Thiersch jedoch die Ausrichtung auf das klassische Altertum bei. Die Vorschriften zur »Bildung des deutschen Ausdruckes « weiten die von ihm empfohlenen Úbungen (Ưbersetzungen, Auszüge, Übersichten, Zusammenfassungen, "zuweilen auch metrische Uebersetzungen und Nachbildungen altklassischer Muster «) lediglich auf »deutsche Klassiker " aus. [53] Der Hinweis auf die neulateinische Literatur kommt wohl klerikalen Kritikern entgegen, die die Tradition der Klosterund Ordensschulen verteidigten und den Plan von 1829 mit zu Fall gebracht hatten. Dieser Lehrplan gilt - modifiziert durch Einführung der Literaturgeschichte mit Erlaß vom 3. 2. 1834 - bis 1854. Erst jetzt findet sich das Fach Deutsch wiederhergestellt, und wird »ein sorgfältiges Studium der deutschen Literatur « [54] angeordnet. Doch bleiben die Entscheidungen von 1829/30 greifbar - in der Stilbildung an lateinischen Mustern, in der Einrichtung der Aufsätze und der Auswahl der Lektüre nach den 
Erfordernissen der »Theorie der Dicht- und Redekunst «, also im »Götzendienst des Formalismus « [55], wie ein Vertreter nationaler Bildung kritisiert.

\section{3. Österreich*}

Obwohl zu den Eigenheiten der kulturellen und geistigen Entwicklung, mit denen sich Österreich von Deutschland abhebt, eine Reihe von Arbeiten und Thesen vorliegen [1], ist der Sprach- und Literaturunterricht unter dieser Fragestellung noch nicht systematisch untersucht worden. Diese Darstellung versucht in ersten Grundlinien deutlich zu machen, wie das Gymnasium das literarische Leben beeinflußt hat. Um geschichtliche Phasenverschiebungen, konfessionelle und regionale Besonderheiten zu erkennen, werden die österreichischen Gymnasialstudien mit den oben skizzierten Verhältnissen in Deutschland, besonders in seinen zwei Exponenten Preußen und Bayern, verglichen. Die bildungsgeschichtlichen Einschnitte von 1773 (Aufhebung des Jesuitenordens) und 1848 (Reorganisation der Gymnasien und philosophischen Fakultäten) stecken dabei den Untersuchungszeitraum ab.

\subsubsection{Schulorganisatorische und sozialhistorische Voraussetzungen}

Was in Österreich vor 1848 Gymnasium heißt, umfaßt nur einen Teil der Anstalt, die in Deutschland und auch in Österreich nach 1848 unter diesem Namen verstanden wird. Bis zu diesem Zeitpunkt bestanden die drei-, nach 1824 zweijährigen philosophischen Obligatkurse, die ein Schüler nach den fünf bzw. sechs Gymnasialklassen (drei bzw. vier Grammatikal- und zwei Humanitätsklassen) besuchte. Sie waren seit Joseph II. schulmäßig eingerichtet und bildeten einen Ưbergang zu den höheren Fakultätsstudien. Erst nachdem die zwei philosophischen Abteilungen dem Gymnasium eingegliedert worden waren, hatte auch das österreichische Gymnasium die üblichen acht Klassen. „Die bisherigen `Hörerく und `Herrenく der philosophischen Jahrgänge wurden dadurch zu Gymnasialschülern herabgedrückt, in Wien 5-600, in Prag 6-700 Jünglinge von der Universität an das Gymnasium zurückgewiesen. « [2] Bis dahin hat man es auf dem Gymnasium nur mit ca. 10- bis 16jährigen Schülern zu tun. $\mathrm{Da}$ in der Philosophie neben diesem Fach vor allem Mathematik und Physik gehört wurden, aber weniger Philologie, bleiben diese Studien außer Betracht.

\footnotetext{
* Dieses Kapitel ist zuerst erschienen in: Die österreichische Literatur. Ihr Profil an der Wende vom 18. zum 19. Jahrhundert (1750-1830) (Die österreichische Literatur. Eine Dokumentation ihrer literarhistorischen Entwicklung) Hg. v. Herbert Zeman. Tl. 1. Graz 1979, S. 85-118. Durch die Beiträge dieses Bandes werden die von mir angesprochenen Probleme in einen größeren epochalen Rahmen gestellt. Das von Prof. Zeman geleitete Eisenstädter Symposion über »Die österreichische Literatur von der Zeit Maria Theresias bis zur Restauration unter Franz I.« (Sept. 1977) erlaubte mir die Diskussion und fruchtbare Weiterentwicklung meiner Thesen.
} 
Mehrere sozialhistorische Bedingungen, die sich unmittelbar auf den Sprach- und Literaturunterricht auswirken, helfen die charakteristisch österreichischen Entwicklungen verstehen:

- In Österreich konnte sich vor 1848 kein selbständiger säkularer Gymnasiallehrerstand bilden. Die Ansätze zur Lehrerbildung, die nach 1773 gemacht wurden [3] als der Jesuitenorden nicht mehr für Nachwuchs sorgte -, blieben erfolglos. Unter Franz II. (I.) wurden die Gymnasien wieder möglichst den geistlichen Korporationen übergeben. Mehrere Orden besaßen oder versorgten schon zur Zeit der Jesuiten zahlreiche Schulen, vor allem die Piaristen (1779 24 Gymnasien) und Benediktiner (Stift Kremsmünster, Melk). Jetzt kam das Akademische Gymnasium zu Wien an den Piaristenorden (1802, obschon es ein Staatsgymnasium blieb und vom Studienfonds erhalten wurde), »und das ehemals am Hof, später bei St. Anna bestandene Gymnasium wurde in das Schottenstift (1807), das St. Pöltner in das Stift Melk (1804), das Leobner in das Stift Admont verlegt, das Gymnasium zu Linz (1807) den vier oberösterreichischen Stiften (ohne Kremsmünster, welches seine eigene Lehranstalt behielt), jenes zu Gratz [!] dem Stifte Admont anvertraut (1804), das Klagenfurter gieng an das Stift St. Paul (1809), das Pilsener an das Stift Tepl (1806), das Komotauer an das Stift Ossek über«. [4] Von den 22 Gymnasien, die nach der vorübergehenden Verringerung der Zahl der Anstalten im Anschluß an die Aufhebung des Jesuitenordens bis 1810 wieder eröffnet oder neu eingerichtet wurden, gehörten 7 den Piaristen, 3 den Benediktinern, 2 den Prämonstratensern und je 1 den Regulierten Chorherrn, den Cisterziensern, den Augustinern und den Basilianern; nur 6 standen allen Bewerbern auf Lehrämter offen. »In Oesterreich unter und ob der Ens sowie in Kärnten befanden sich seither alle Gymnasien in geistlichen Händen. « [5] Gleichzeitig wurden die meisten (gegenüber den philosophischen Kursen weniger ausgebauten und minder berechtigten) Lycealkurse an 'philosophischen Lehranstalten< (von 13, die es 1818 gab, betreuten die Piaristen 5, die Benediktiner, Prämonstratenser und die Stifter Mährens je 1) sowie die philosophischen Kurse in Linz und Klagenfurt den Orden anvertraut. Die einzelnen Klöster und Stifte, denen die Schulen jeweils zugeteilt waren, stellten die Lehrer und bildeten sie aus.

- Die Ausbildung der Gymnasiallehrer kam nicht - wie in den Staaten des späteren deutschen Reiches von 1871, auch in süddeutschen Ländern wie Bayern - in die Hände der Altphilologen und ihrer Seminare. Da die Klöster und Stifte die Lehrer stellten, folgt dies scheinbar von selbst; es hängt jedoch ebensosehr mit der Zwitterstellung der philosophischen Fakultät (s.o.) zusammen. Den deutschen vergleichbare, mit der Lehrerbildung betraute altphilologische und germanistische Universitätsseminare wurden erst nach 1848 eingerichtet. Das philologische Seminar der Universität Wien wurde beispielsweise 1850 gegründet (Lehrer bis 1867 der aus Preußen berufene, bei G. Hermann philologisch geschulte $\rightarrow$ Bonitz). [6] Während man in Preußen bereits in der ersten Hälfte des 19. Jahrhunderts von einer >Philologisierung` des Gymnasiums durch an Universitäten ausgebildete Lehrer sprechen kann, hielt der lateinische und griechische Unterricht in Österreich mit den Fortschritten in den jeweiligen Fachdisziplinen nicht Schritt. Auch die ältere 
deutsche Philologie gewann im Unterschied zu Preußen keinen Einfluß auf die Schule.

- Österreich behielt den Klassenlehrer, der (außer Religion) alle Fächer zu behandeln hatte. [7] Die seit 1774 kontroverse Frage, ob Klassen- oder Fachlehrer vorzuziehen seien, wurde 1804 vorläufig zugunsten, 1818 jedoch endgültig gegen den Fachlehrer entschieden. Da der Lehrer wieder alle Stoffe vorzutragen hatte, griff der Lehr- und Schulmechanismus erneut um sich. Konsequenterweise ging mit dem Rückgriff auf den Klassenlehrer eine Konzentration auf das Lateinische im Unterricht Hand in Hand.

Diese Zusammenhänge beeinflussen die Gewichtung der Fächer und die Methode des Unterrichts allgemein. Für die (Nicht-)Entwicklung des Deutschunterrichts wurde eine weitere sozialhistorische Voraussetzung wichtig: In Österreich kommt es bis nach der Mitte des 19. Jahrhunderts zu keiner mit dem Gymnasium konkurrierenden allgemeinbildenden Realschule. In Deutschland wirkten vor 1848 führende Deutschdidaktiker (Mager, $\rightarrow$ Viehoff, $\rightarrow$ Ph. Wackernagel) an oder für Realanstalten, wie nach 1848 auch in Österreich (Vernaleken). Da an Realschulen die deutsche Sprache und Literatur die antike Kultur als Bildungsmittel ersetzen mußten, machte man sich hier über das Fach, die Lehrpläne und Lehrmittel die meisten Gedanken.

\subsubsection{Der altsprachliche Unterricht}

Das österreichische Gymnasium konzentrierte sich bis 1848 auf die praktische Aneignung des Lateins in Schrift und Rede. Dabei wurde »wenig Bedacht « auf die Lektüre der Klassiker genommen, »indem man hauptsächlich nur auf die lateinische Sprache sah «. [8] Die - nach der Zurückziehung der Schulordnung von Hess (s. u.) von $\rightarrow$ Gratian Marx eingeführten Realfächer wurden nach dem Tode Josephs II. wieder zurückgedrängt. Die Vorschriften von 1818/19 fixieren die bis 1848 nicht mehr revidierten Stundenzahlen (Tabelle 8). Der Lateinunterricht wurde (von 1805 54 bis 56 auf 63 Wochenstunden aller Klassen) ausgedehnt und Griechisch gegenüber der bisherigen Regelung um eine Klasse früher (statt in der vierten jetzt in der dritten Klasse) begonnen. Dagegen wurde die Anzahl der geographisch-historischen Lehrstunden (von 180516 bis 18 auf 13) vermindert. In der Mathematik wurden die Anforderungen herabgeschraubt: Algebra blieb nun auf die Humanitätsklassen beschränkt. Der Unterricht in Geometrie sowie in Naturgeschichte und Naturlehre fiel ganz weg.

Um die Eigenart des Lehrplans kennzeichnen zu können, wird er im folgenden mit einem preußischen und einem bayerischen Muster verglichen. Aus Preußen, das ja bis 1837 keinen allgemein verbindlichen Lehrplan für die höheren Schulen besaß, wird der Stundenplan Schulpfortas (Tabelle 9) herangezogen. Die alte sächsische Musteranstalt war 1815 von Preußen in Besitz genommen und 1819 von Johannes Schulze, dem Leiter des Gymnasialwesens, mit der Absicht reformiert worden, »daß sie auch ferner, wie vormals, die vorzüglichste Schule Deutschlands genannt zu werden verdiene«. [9] In Bayern wurde 1830 [12], nach mehrfachem Wechsel der Lehrpläne, 
Tabelle 8: Österreichischer Lehrplan nach den Veränderungen 1818/19 [10]

\begin{tabular}{|c|c|c|c|c|c|c|c|c|}
\hline \multirow[t]{2}{*}{ Fach } & \multicolumn{4}{|c|}{ Grammatikalklassen } & \multicolumn{2}{|c|}{ Humanitätsklassen } & \multirow[t]{2}{*}{ Summe } & \multirow[t]{2}{*}{ Prozente } \\
\hline & I & II & III & IV & I & II & & \\
\hline Latein & 11 & 11 & 9 & 9 & 10 & 10 & 60 & 55,56 \\
\hline Griechisch & - & - & 2 & 2 & 2 & 2 & 8 & 7,41 \\
\hline Mathematik & 2 & 2 & 2 & 2 & 2 & 2 & 12 & 11.11 \\
\hline Geographie & & & & & & & & \\
\hline m. Geschichte & 3 & 3 & 3 & 3 & 2 & 2 & 16 & 14,81 \\
\hline Religion & 2 & 2 & 2 & 2 & 2 & 2 & 12 & 11.11 \\
\hline Summe & 18 & 18 & 18 & 18 & 18 & 18 & 108 & 100,00 \\
\hline
\end{tabular}

Tabelle 9: Lehrplan von Schulpforta nach dem Protokoll 1819 [11]

\begin{tabular}{|l|rrrrr|r|r|}
\hline Fach & \multicolumn{5}{|c|}{ Klasse } & Summe & Prozente \\
& Tertia inf. & sup. & Secunda inf. & sup. & Prima & & \\
\hline Latein & 15 & 15 & 13 & 11 & 9 & 63 & 42,86 \\
Griechisch & 5 & 5 & 5 & 6 & 6 & 27 & 18,37 \\
Deutsch & 2 & 2 & 2 & 2 & 2 & 10 & 6,80 \\
Französisch & - & - & 2 & 2 & 2 & 6 & 4,08 \\
Mathematik & 4 & 4 & 4 & 4 & 4 & 20 & 13,60 \\
Geographie & 2 & 2 & -- & - & - & 4 & 2,72 \\
Geschichte & - & - & 2 & 2 & 2 & 6 & 4,08 \\
Physik & - & - & - & - & 1 & 1 & 0,68 \\
Religion & 2 & 2 & 2 & 2 & 2 & 10 & 6,80 \\
\hline Summe & 30 & 30 & 30 & 29 & 28 & 147 & 99,99 \\
\hline
\end{tabular}

Zur Erläuterung: »Das Studium der alten Sprachen soll, der Stiftung gemäß, der Mittelpunkt sein, worauf sich die ganze Tendenz der Anstalt bezieht. Zur Aufnahme ist das Alter von 13 Jahren und sind die Kenntnisse erforderlich, welche auf der untersten Bildungsstufe eines vollständigen Gymnasii verlangt werden.« (Kirchner, S. 104)

ein fester Zustand erreicht (s. Kap. 2.2.2, mit Tabelle 7). Die Zahl der Wochenstunden, die österreichische Gymnasiasten in der Schule verbrachten, war vergleichsweise gering, so daß Hauslehrer, Repetitoren und Privatlehrer ihre Tätigkeit (z. B. hinsichtlich moderner Fremdsprachen) ungehindert entfalten konnten. Eine Debatte um die Úberbürdung der Jugend durch die Menge der Stunden und die fachlichen Anforderungen, wie sie der Mediziner Lorinser 1826 in Preußen auslöste, hat es in Österreich nicht gegeben. Mit mehr als der Hälfte aller Stunden nimmt Latein eine beherrschende Stellung ein; prozentual sogar einen größeren Raum als in Pforta, das für seinen ausgedehnten und strengen Lateinunterricht berühmt war. Auch im bayerischen Lehrplan hat Latein kein solches Ubergewicht, obwohl das Prinzip der Konzentration auf die alten Sprachen (im Gegensatz zu dem zwischen Sprachen und Realien ausgleichenden `Universalismus 
denzahlen bestimmte. Vergleicht man die sechs Klassen des österreichischen Gymnasiums mit den vier Klassen der Lateinschule und den zwei ersten Klassen des Gymnasiums in Bayern, die jeweils Schüler von ca. 10 bis 16 Jahren umfaßten, so beträgt die absolute Zahl der Lateinstunden in beiden Fällen 60. Wie wenig das Griechische in Österreich zählte, fällt bei der Gegenüberstellung mit neuhumanistischen Schulen besonders $\mathrm{kraß}$ auf ( 7 gegenüber $18 \%$ oder 2 gegenüber 5 bis 6 Wochenstunden). Eigene Deutschstunden fehlen nur in Österreich. Der Lateinunterricht der Humanitätsklassen besteht zum guten Teil aus Rhetorik und Poetik, wo auch auf deutsche Muster eingegangen und deutsche Stilübungen geschrieben werden (s. Kap. 2.3.3); aber die lehrplanmäßige Verselbständigung des Faches Deutsch - die in Bayern im Gang und in Preußen abgeschlossen war - hat hier noch nicht eingesetzt. Mathematik, der zweite Schwerpunkt humanistischer Gymnasien, ist in Österreich geringer vertreten. Französisch ist in Preußen fest eingeführt; Österreich und Bayern, wo es keine moderne Fremdsprache gibt, stellen - im Vergleich zu den Lehrplänen der anderen deutschen Staaten - Ausnahmen dar.

Drei Merkmale des altsprachlichen Gymnasialunterrichts in Österreich vor 1848, mit denen er sich von der neuhumanistischen Entwicklung unterscheidet, sollen näher gekennzeichnet werden: die Erlernung und Benutzung des Lateins zu praktischen Zwecken; die Verbindung des Lateins mit dem Realunterricht; die Ausrichtung des Griechischunterrichts auf die für die höheren Fakultätsstudien notwendigen grammatischen und lexikalischen Kenntnisse. Andere Eigenarten - der Formalismus des Elementarunterrichts (im Unterschied zu der von $\rightarrow$ Gesner begründeten >Göttingischen Lehrart oder zu der von $\rightarrow$ Gedike und Fr. Jacobs propagierten \Lesebuchmethode $<$ ) [13] und die Beschränkung auf Auszüge - hängen damit zusammen. (Für aus privater Initiative mögliche Ausnahmen vgl. Podlaha, S. 93-95).

Als Ausgangspunkt dient in allen drei Fällen der von dem »Lehrer der Universalund Litterärgeschichte auf der Universität zu Wien« $\rightarrow$ v.Heß erarbeitete und von Martini 1774 der Studien-Hofkommission vorgelegte Schulplan, der über Österreich hinaus einen Höhepunkt der Aufklärung in der Bildungsgeschichte darstellt. Seine Durchführung war bereits bekannt gegeben worden, als Maria Theresia ihn zurückzog und den Piaristen $\rightarrow$ Gratian Marx mit der Reform der Gymnasien betraute. Die Verhandlungen der Studien-Revisions-Hofkommission (1795 bis 1802) führten schließlich zu dem bis 1848 nicht außer Kraft gesetzten Gymnasialkodex (1808).

a) Latein »als die allgemeine Sprache der gelehrten Welt « [14] wird von Hess unter die "Instrumentalkenntnisse" - nicht unter die »wesentlichen Kenntnisse " (Religion, Sittenlehre, »Kenntniß der Natur «), die man um ihrer selbst wegen lernt - gerechnet, jedoch gleichzeitig als Völker, Zeiten und Räume verbindendes Verständigungsmittel hoch gepriesen: »sie [die lateinische Sprache], die uns den Mangel einer allgemeinen von Leibniz gedachten Sprache erträglich macht, die den äußersten Norden mit Süden zusammenhängt, die Arbeiten der Russischen Akademie den tiefsinnigen Spanier, die antiquarischen Entdeckungen des Welschen den grübelnden Britten geniessen läßt; die den Holländer in Batavia, und den Britten in Canada durch den Schüler van Swietens [also durch Ärzte] erhält; die den Sternseher in Kamschatka 
und Otaheite durch Hells Ephemeriden leitet etc.; die nun schon seit mehr als zwey vollen Jahrtausenden, als die Sprache der Gelehrten, sich erhalten, durch alle Finsternisse des Mittelalters durchgebrochen, und wenn wir es nur nicht verhindern, immer blühen wird: ein Schicksal, welches Pope und Premontval ihren Muttersprachen nicht weissagen«. [15] Ausschließlich als »Instrument «, das »keinen andern Zweck « hat, als »die Philosophie, die Medicin, das Jus, die Theologie zu erlernen, und also seinen Beruf zu erfüllen «, wird das Latein von Gratian Marx angesehen, der dabei deutlich auf die kirchlichen und staatlichen amtlichen Anforderungen hinweist: »Die lateinische Sprache kann meines Erachtens in unserer Verfassung nicht als eine todte Sprache, weder auch als eine gelehrte Sprache angesehen werden, sondern sie ist wirklich die Sprache aller Religions- und vieler Staats-[,] manchesmal sogar bürgerlicher Geschäfte. «[16] Auch unter Joseph II. blieb es »ein Hauptaugenmerk « der Gymnasiallehrer, »daß sich ihr ganzer Unterricht auf das Praktische der lateinischen Sprache beziehe, weil sonst der ganze Zweck der öffentlichen Anstalt verfehlt sein würde « - wie es der Schulplan von 1781 ausdrückt. [17] In der Studien-RevisionsHofkommission verwiesen der Praeses Rottenhan und Birkenstock »auf das Bedürfnis der Provinzialämter, da dort Latein Geschäfts- und teilweise auch Umgangssprache sei«. [18] Da Latein »gleichsam die Amts- und klassische Sprache« der katholischen Kirche sei, sollte nach einstimmigem Beschluß die Religion in den Humanitätsklassen »in lateinischer Sprache « erteilt werden. [19]

Da dem lateinischen Schreiben und Sprechen noch berufspraktische Bedeutung zukam, blieb Latein selbst als Unterrichtssprache (in der auch mehrere Lehrbücher abgefaßt waren) erhalten. Gemäß den Anordnungen von Gratian Marx durfte niemand in die Humanitätsklassen aufsteigen, der nicht korrekt und geläufig Latein sprach. Von der dritten (der letzten Grammatikal-)Klasse an - so wurde 1781 verfügt sei »über die Schulsachen kein anderer als ein lateinischer reiner und fertiger Vortrag gestattet«. [20] An den Universitäten führte Joseph II. 1784 die deutsche Sprache »an der Theologie für den Lehrvortrag über Pastoral, im Jus bei allen Fächern, das canonische Recht ausgenommen, an der Philosophie für sämmtliche Disciplinen, an der Medicin für den practischen Unterricht «[21] ein, so daß nun die modernen deutschen Lehrbücher (z. B. von dem Mathematiker A. G. Kästner oder dem Philosophen J. G. Feder) verwendet werden konnten. Nach der Ordnung der philosophischen Studien vom 12. Juli 1805 mußte der Unterricht in der Philosophie, Mathematik und Physik indessen wieder lateinisch erteilt werden. Sogar die Algebra auf Gymnasien mußte nach dem Hofdekret vom 28. September 1819 in Latein gelehrt werden (so blieb auch das Lehrbuch Elementa arithmetica et universalis bis 1848 im Gebrauch). »Als man sich an vielen Anstalten, auch am [Wiener] Schottengymnasium, daran nicht hielt, wurde dies strenge gerügt (St.-H.-K. 4. Aug. 1836).«[22]

b) »Verbindung der Realkenntnisse mit dem lateinischen Sprachunterrichte«. [23] Schon im Elementarunterricht der ersten Klasse möchte Hess den Schülern »lauter verständliche, angenehme und nützliche Sachen « [24] zu lernen geben. Der Lehrer soll Sätze und Sprüche aus Schriftstellern verwenden, »welche Sachen aus dem. 
gemeinen Leben behandeln, als Cicero und Plinius in der Moral, Varro und Columella in der Landwirthschaft, Plinius in der Naturhistorie, Celsus in der Diätetik, Mela in der Erdkunde etc. « (S. 68/69). Bei der Durchnahme solcher Stücke läßt sich »ein großer Vorrath von muntern und nützlichen Betrachtungen « (S. 71) anbringen. In der zweiten Klasse lesen die Schüler bereits (»munter und forteilend «) leichte Schriftsteller, »erst den P. Mela, der eine Geographie, oder den Justinus, der eine kleine Universalhistorie enthält, dann den C. Nepos zur Hülfe der griechischen Geschichte «. Stets ist hier »der Innhalt die Hauptsache, womit immer auf Erdbeschreibung, Geschichte, oder Sittenlehre hingewiesen wird «. [25] Erst in der dritten Klasse wird in erster Linie auf »die Schreibart (S. 107) gesehen und damit »die vollständige Lehre der schönen Wissenschaften«(S. 123), d. h. der Rhetorik und Poetik, in der vierten und fünften Klasse vorbereitet. Die Beschäftigung mit den Stoffen und Gedanken der Texte hört deshalb nicht auf. Es ändern sich nur die Anknüpfungspunkte: Die Naturwissenschaften, die Geographie und die Geschichte als bloße Kenntnis der Aufeinanderfolge von Ereignissen - treten in den Hintergrund; dafür lebt sich der Schüler in die Kultur und den Geist der Antike ein und beginnt aus der Geschichte zu lernen. Die bei der Lektüre erworbenen »Realkenntnisse « der oberen Klassen sind: „Sittenlehre, Erfahrung, Weltkenntniß aus dem Umgang mit so großen erfahrnen Männern; genaue Kenntniß des römischen Savoir-vivre, der Geschäfte, der herrschenden Philosophie, politischen Maximen, Verwüstungen des Luxus, der bürgerlichen Tugend etc. «(S. 157). Damit leitet der Lateinunterricht, der zunächst nur Fakten mitteilen hilft, zur (Moral-, Geschichts- und Staats-) Philosophie über.

Die Herausstellung der Sachwissenschaften und der Geschichte war ein Grund, der den Entwurf von Hess scheitern ließ. Gratian Marx warf dem Plan vor, die lateinische Sprache »als eine gleichgiltige Nebensache « anzusehen; "und wenn man die Sache genau betrachtet, scheint er fast aus den lateinischen Gymnasiis Realschulen umstalten [!] zu wollen «. [26] Mit der lateinischen Chrestomathie von Chompré führte Marx jedoch gleichzeitig ein Werk in die Schule ein, das antike Sachautoren auszog. Eine Verordnung von 1778 wies die Lehrer an, bei der Durchnahme der Sammlung beständig »auf Sachenkenntniß « zu sehen. »Aus diesem Grunde wünscht man, daß die Lehrer die auserlesenen Stellen aus den Philosophischen Schriften des Cicero [...]: item aus dem Valerio Maximo [. . . n nicht ausser Acht lassen; ferners [...] die Jugend etwas mit dem Vegetio de re militari, mit des Frontini Strategematis, mit dem Columella de re rustica [...], endlich mit des Plinii historia naturali und mit dem Celso de re medica bekannt, und vergnügt zumachen sich angelegen seyn lassen. « [27] In den Verhandlungen der Studien-Revisions-Hofkommission hatte Rottenhan diese Praxis vor Augen und wollte deshalb - mit Zustimmung Birkenstocks - die Naturgeschichte nicht als selbständigen Unterrichtsgegenstand gelten lassen. »Man habe sich doch über die Maxime geeinigt, das Sprachstudium soviel als möglich als Mittel für Erwerbung der Realkenntnisse zu gebrauchen. Deshalb solle die Naturgeschichte nur in Verbindung mit dem Latein behandelt werden. « [28] Hess und Rottenhan, die als Exponenten der Aufklärung und der Reaktion im österreichischen Bildungswesen gelten, wollten beide Realien im Sprachunterricht abhandeln lassen. Die spätantiken 
Sachautoren, die im neuhumanistischen Bildungsgang keine Rolle mehr spielen, sind also um 1800 durchaus noch gegenwärtig.

c) Die Erlernung der griechischen Sprache war vor dem Entwurf von Hess bereits mehrfach angeordnet worden (vor allem in den Studienordnungen Karls VI. von 1735 und Maria Theresias von 1752). [29] Aber erst Hess setzte sich entschieden für sie ein. Er wies ihr von der zweiten Klasse an »ein paar Stunden in der Woche« zu; vor allem damit die Schüler »mit den vorzüglichsten klassischen Schriftstellern in ihrer originellen Würde umgehen « können, aber auch damit sie die Sprache »als hermeneutisches Hülfsmittel in Verständniß des neuen Testaments und in den Terminologien aller Wissenschaften « kennenlernen. [30] Aus dem Umgang mit den Griechen erhoffte er sich bereits - lange vor Humboldt und den Klassikern - eine ästhetische Kultivierung der deutschen Sitten und der Sprache. Vom Griechischunterricht in den oberen Klassen heißt es [31]:

Hauptsächlich aber wird der eigene Charakter der griechischen so sehr kultivirten Nation, der sich in ihrer Sprache so sichtbar zeigt, ihre so einfachen, und doch so feinen Sitten, ihre Kunst, mit Mässigung zu genießen fühlbar gemacht, um dadurch auch auf unsere Kultur und Sitten, auf unser geselliges Leben, die Attische Grazie, die Jonische Simplicität zu verbreiten, und mit dem deutschen Ernste, gewiß nicht zum Nachtheil des feinen Tons in Leben, Denken und Schreiben, zu versetzen.

Mit dem »feinen Ton « spielt Hess auf die Verachtung des Griechischen beim romanisch gebildeten »Weltmann« an, dessen »harte[n] Klagen« er mit einem $\rightarrow$ Sulzer entnommenen »Beweis von der Würde der alten Sprachen« zu begegnen sucht. [32] Zeitgenossen bestätigen, daß die Erlernung des Griechischen in der österreichischen feinen Gesellschaft »für Pedanterey« galt: »Unglücklicher Weise aber herrschet dieses Vorurtheil nicht etwa nur über Leute, die mit den Perückenmachern in einerley Classe sind - oft auch über solche übt es seinen Despotismus aus, von denen die Perückenmacher leben müssen. « [33]

In den auf Hess folgenden Lehrplänen findet sich die gleiche Hochschätzung des Griechischen nicht wieder, obwohl seine Stellung durchaus schwankt. Gratian Marx bestimmt die griechische Sprache »nur den fähigen[,] hoffnungsreichen und lustbezeugenden Jünglingen«. [34] Die gleiche Wendung liest man in der Josephinischen Schulordnung von 1781; es werden zwei selbständige Abteilungen für Griechisch gebildet, wobei in die höhere nur aufgenommen wird, wer die Anfängerlektion »gehörig durchgearbeitet « hat. [35] Nach Verordnungen von 1782 bis 1785 schloß der Nichtbesuch des Griechischen von den Ehrenplätzen und den besten Noten aus. Denn es wurde bestimmt, »daß kein Schüler weder ein Stipendium, noch ein Prämium erhalten, noch auch unter die Accedentes ad praemiferos [d. h. unter die Schüler, die zwar keine Prämien bekommen, aber wegen ihrer Leistungen öffentlich genannt werden] gesetzt werden kann, wenn er nicht in der griechischen Sprache die erste Classe [d. h. die beste Note] erhalten hat, sowie auch keiner aus Latein die erste Classe bekommen darf, der nicht eine (wenn auch nicht gute) Classe aus dem Griechischen erhielt«. [36] Die in den neunziger Jahren herrschenden Ansichten lassen sich an dem von den Wiener Gymnasiallehrern erarbeiteten Lehrplan und der Stellungnahme zeigen, den die n. ö. Landesregierung dazu abgab [37]: 
Wiener Gymnasiallehrplan

»Das Griechische ist als obligater Lehrgegenstand nur im zweiten und dritten Schuljahr zu lehren und auf den sogenannten Graecismus communis zu beschränken, der den Lateinunterricht erleichtern soll«. Für »die außerordentlichen Griechen « der folgenden Klassen wird eine »Nebenschule des Graecismus singularis« errichtet. n. ö. Landesregierung

Die »griechische Grammatik « sollte »für alle obligatorisch " sein. "Aber auch dem weiteren griechischen Unterrichte, der ohnedies nicht zu hoch gespannt sein darf, sollen alle Schüler anwohnen, aber nur die fähigeren einer Prüfung unterzogen werden «.

Die Wiener Lehrer wollen sich mit Grammatik für die künftigen Theologen und mit Wortkenntnissen zum Verständnis der Fachtermini für die Mediziner begnügen. Aber auch die Regierung Niederösterreichs, die noch ganz von aufklärerischen Grundsätzen ausgeht, wagt höhere Anforderungen nicht mit Prüfungen verbindlich zu machen. Trotz der unter Joseph II. ergriffenen Maßregeln - die in erster Linie Schüler trafen, die auf Stipendien angewiesen waren und um Schulgeldbefreiung nachsuchten - ließ der Besuch des Griechischen »viel zu wünschen « [38] übrig. Die Lehrpläne von 1805 und 1819 sahen Dispensationen für Privatisten vor. Um 1828 erreichte »die gänzliche Nachsicht « für Privatisten »einen früher nie gekannten Umfang «, wobei »namentlich die Söhne der höheren Stände « fernblieben. [39] Aber auch wer an den wenigen Stunden (2 Stunden in 4 Klassen) teilnahm, kam kaum zu dem Wichtigsten: der bildenden Lektüre der Werke. »Ja, da hauptsächlich nur Grammatik betrieben wird, und das wenige Uebersetzen nur um der Grammatik willen, dieser für die Jugend so trockenen Wissenschaft, die doch nicht der letzte Zweck des Sprachlernens sein kann: so wird auf diese Weise das Griechische, diese edelste und herrlichste der Sprachen und Literaturen, der Jugend vielmehr verleidet«, wie Arneth 1838 im Sinne des Neuhumanismus klagt. [40] Als Folge des beschränkten Unterrichts - so heißt es noch nach 1848 - treffe man in Österreich »unter wissenschaftlich gebildeten Leuten die größte Unkunde in griechischer Sprache und Literatur« an. [41]

\subsubsection{Der Formalismus des Rhetorikunterrichts}

Für das Verhältnis des Gymnasiums zur Literatur ist der Rhetorikunterricht, der in den Humanitätsklassen viel Zeit beansprucht, von besonderer Bedeutung: In ihm konzentriert sich alle literarische Bildung, und deutsche Autoren kommen ausschließlich hier zu Wort. Unter dem Oberbegriff Rhetorik (oratoria, eloquentia) werden die allgemeine Stilistik und die Lehre von den prosaischen (Rhetorik im engeren Sinne) und poetischen Formen (Poetik) gemeinsam abgehandelt. $\rightarrow$ Gratian Marx verteilte Rhetorik (als Lehre von der Prosa) und Poetik auf zwei, den beiden letzten Klassen zugeordnete Bände (zu den Institutiones ad Eloquantiam s. S. 87ff.). Die poetische Sprache als »die feinste, vollkommenste und schwerste « wird von ihm »an das Ende « verschoben. [42] In der Institutio ad Eloquentiam (s. S. 91f.) wird die Lehre von der Rede- und Dichtkunst »wieder vereinheitlicht, wodurch die Hälfte der Zeit und des Umfangs der Bücher erspart werden kann « - wie es die Wiener Gymnasiallehrer bereits 1793 forderten. [43] In welcher Vermischung und Verschränkung Rhetorik 
und Poetik bis 1848 vorgetragen wurden, geht aus den Gliederungen der Institutio und der dazugehörigen Sammlung deutscher Beyspiele (s. S. 92f.) hervor. Gleichzeitig wird der Gang des Unterrichts deutlich, da die Lehrer streng nach den Lehrbüchern vorzugehen hatten. [44] Der Lehrgang beginnt mit allgemeinen Stilanforderungen (Institutio, pars I), wobei grammatische Richtigkeit und reines Deutsch auf den früheren Unterricht verweisen. Die Abschnitte über die Tropen und Figuren, den Periodenbau und den Numerus sowie die verschiedenen Stilarten behandeln alle Elemente, die man zur Charakteristik und zur Zergliederung der im zweiten Teil der Institutio durchgesprochenen Gattungen kennen muß. Die prosaischen und poetischen Formen folgen nach pädagogischen Gesichtspunkten aufeinander: nämlich nach dem Grad ihrer dispositionellen Komplexität und ihrer stilistischen Schwierigkeiten für den Schüler. Reden, Dramen und Epen bilden deshalb den Schluß. Das formale Unterscheidungskriterium von Vers und Prosa bestimmt die Unterteilung mehrerer Kapitel (narratio/Erzählungen; epistolae/Briefe; in der Sammlung auch »Beschreibungen und Charaktere «); die Erzählprosa kommt so neben die Geschichtsschreibung zu stehen. Die poetischen Formen sind zu keiner bestimmten Anzahl von Gattungen (etwa drei oder vier) zusammengefaßt, was den lehrhaften und gemischten Arten (Fabel, Satire, Epigramm und Sinngedicht, Idylle) zugute kommt. (Zum Lyrikbegriff s. S. 93; zur Ausgrenzung rhetorischer Einheiten aus dem Werkganzen s. S. 84).

\section{I. »Institutio ad Eloquentiam《}

Pars I.

Caput I. De stylo in genere

$\S 1$. De styli perspicuitate

$\S 2$. De styli suavitate

$\S 3$. De styli gravitate

Caput II. De Tropis

Caput III. De Periodis

Caput IV. De numero oratorio

Caput V. De Figuris

Caput VI. De stylo poetico eiusque differentia a prosaico Anhang. Von der Metrik der Deutschen

Caput VII. De aliis styli divisionibus

Caput VIII. De styli praesidiis

Pars II. De Scriptorum generibus

Caput 1. De Narratione
A. Narratio historica
B. Narratio poetica

Caput II. De Fabula Aesopica

Caput III. De Epistolis

A. De epistola prosaica

B. Epistola poetica
Caput IV. De carmine didactico

Caput V. De Satyra

Caput VI. De Epigrammate

Caput VII. De Idylliis

Caput VIII. De Elegia

Caput IX. De carmine lyrico Schemata metrorum lyricorum

Caput X. De Oratione

A. De Progymnasmatis

B. De Oratione

De Exordio

De Propositione

De Confirmatione

De Epilogo

De Pronuntiatione

Caput XI. De Dramate

De Tragoedia

De Comoedia

De Dramate musico, vulgo, Opera

Caput XII. De Epopoeia

Appendix. De Mythologia, seu Fabulosa

Deorum Gentilium Historia 


\section{II. »Sammlung deutscher Beyspiele zur Bildung des Styls«}

TI. I

I. Gleichnisse und Vergleichungen

II. Erzählungen
A. Prosaische
B. Poetische

III. Beschreibungen und Charaktere
A. Prosaische
B. Poetische

IV. Fabeln
A. Äsopische
B. Allegorische Dichtungen

V. Briefe
A. Prosaische
B. Poetische

VI. Lehrgedicht
A. Physikalisches
B. Beschreibendes

VII. Satyren

VIII. Epigramme und Sinngedichte

IX. Idyllen
Tl. II

I. Elegien

II. Lyrische Gedichte
a. Hymnen
b. Heroische Ode
c. Philosophische Ode
d. Dithyramben
e. Lieder

III. Reden

Beyspiel einer akademischen Rede Zwei Beyspiele einer geistlichen Rede Beyspiel einer Rede panegyrischen Inhalts Beyspiel einer Trauerrede

IV. Dramatische Gedichte
A. Trauerspiel
B. Lustspiel
(C. Schauspiel, s. S. 92)
A. Heroisches
B. Bürgerliches

V. Epische Gedichte

Die Schulrhetorik ist sowohl eine Anweisung zur Produktion wie zur Analyse von Texten. Verfertigung und Verständnis folgen denselben Regeln, wobei die Analyse den Weg nur umgekehrt nimmt: Sie zerlegt das Werk in alle seine Teile, aus denen es der Autor verfertigt hat, und führt es auf die Regeln zurück, nach denen es gebaut wurde (Interpretation als Umkehrung der Produktion). Von der rhetorischen Interpretation sind die stilistischen Ubungen in der Schule nicht zu trennen. Die folgenden Thesen zu Eigenart und Bedeutung des Rhetorikunterrichts, speziell für Österreich, beziehen sich deshalb nicht nur auf die Art, wie Texte verstanden, sondern auch wie sie (zumindest in der Schule) geschrieben wurden.

a) Das Regelwerk und das Gattungssystem der Rhetorik und Poetik sind ahistorisch. Da man das rhetorische System auf scheinbar allgemeingültige logische Kategorien (vor allem bei den Schlüssen und Beweisen) [45] und auf anthropologische Konstanten (besonders in der Affektenlehre) stützt, schreibt man ihm Geltung für unterschiedliche Epochen und für verschiedensprachige nationale Kulturen zu. »Die Regeln der Beredsamkeit sind in allen Sprachen die nämlichen «. [46] Der Schüler braucht die Regeln also nur an einer Sprache zu lernen, um sie dann übertragen zu können, oder er übt sie von vornherein parallel in mehreren Sprachen. Die Prinzipien der Ubertragung und der Parallelität verbinden in Österreich den deutschen mit dem lateinischen Unterricht, so daß es bis 1848 zu keinen eigenen Deutschstunden auf dem Gymnasium kommt. Bereits der Studienplan der österreichischen Piaristenprovinz von 1763, auf dem $\rightarrow$ Gratian Marx bei der Neugestaltung des Lehrplans nach der Aufhebung des Jesuitenordens aufbaute, sieht die Behandlung deutscher Werke 
und schriftliche Arbeiten in der Muttersprache regelmäßig vor. [47] In den Erinnerungen an die lateinischen Schullehrer auf das Schuljahr 1777 rät Marx den Lehrern der Rhetorikklasse, die Redekunst im Deutschen »in gleicher Stärke« wie im Lateinischen zu treiben, doch den Schülern die »Abwechslung " »als eine Gefälligkeit « erscheinen zu lassen: "Zwei so sehr verschiedene Sprachen brauchen jede eine besondere Verwendung und haben eigene Schönheiten. Da jedoch die Redekunst in allen Sprachen auf den nämlichen Gründen und Hauptlehrsätzen beruht, so mögen jezuweilen vom Lehrer Beispiele aus der deutschen Sprache eingestreut, die Jugend selbst manchesmal zu deutschen Aufsätzen angewiesen, endlich auch eine gute deutsche Rede vorgelegt, zergliedert und vorgelesen werden «. [48] Der Lehrplan Josephs II. von 1781 führt die Praxis paralleler Ubungen fort. [49] Der Gymnasialkodex von 1808 schließt das Deutsche gleichfalls in den lateinischen Unterricht ein [50]:

- Bei der Periodenlehre, die von der Syntax zur Rhetorik überleitet, zeigt der Lehrer den Schülern »das Abweichende der deutschen Periode ".

- Die Besprechung der Schemata lyrischer Versarten, die das Lehrbuch Institutio ad Eloquentiam enthält, führt auf »die Abweichungen «, »welche den deutschen Dichtern ihre Sprache auferlegte .

- Im Anschluß an die Theorie des Epos gibt der Lehrer »von den berühmtesten Epopöen der Iliade, Äneide und dem `Messias« von Klopstock eine etwas genauere Skizze«.

- »Da aber in unsern Gymnasien die deutsche wie die lateinische Sprache mit gleichem Eifer cultiviret werden soll; so muß der Lehrer auch mit den schriftlichen Aufsätzen in beyden Sprachen verhältnißmäßig abwechseln: auf zwey lateinische Aufsätze lasse er daher immer einen deutschen folgen. «

Noch die provisorischen Anordnungen für 1849, die der Einführung des »Organisationsentwurfs « vorangehen, belassen es bei einem, nun allerdings in deutscher Sprache vorzutragenden fächerübergreifenden Rhetorikunterricht. [51]

Wie Rhetorik und Poetik die Bezugspunkte für den in verschieden betitelten Stunden in Latein und Deutsch abgehandelten Lehrstoff der oberen Klassen setzen, kann der von den Wiener Gymnasiallehrern 1792/93 gemeinsam erarbeitete Schulplan verdeutlichen (Tabelle 10). Er bringt nicht nur zum Ausdruck, wie die Lehrer sich den Unterricht dachten, sondern wohl auch, wie sie ihn praktizierten. Was im Rhetorik- und Poetiklehrbuch durchgenommen wird, dazu liest man die kanonischen Quellenschriften in Latein (Cicero und Quintilian im V. Schuljahr, z. B. Ciceros Topica als Lehre von den "Erfindungsquellen «; Horaz Ars poetica im VI. Schuljahr) und zieht teils in den lateinischen, teils in den deutschen Stunden Beispiele heran (so werden die rednerischen "Erfindungsquellen « und »Beweisarten « an einem deutschen Muster von Sonnenfels aufgezeigt, die »Zergliederung « aber an Ciceros Rede "pro lege Manilia" geübt; bei der Komödie werden Plautus und Terenz, bei der Tragödie Lessing eingeführt). Wo lateinische und deutsche Beispiele nebeneinander erscheinen, beziehen sie sich auf die gleiche theoretische Unterweisung in der Gattungslehre (es stehen zusammen bei den Briefen: Cicero, Plinius, Muretus mit Gellert, Rabener, Riedel; bei den Fabeln: Phädrus mit Gellert, Lessing; beim Sinngedicht: Martial mit Lessing; bei der Satire: Horaz mit Michaelis; beim Schäfergedicht: Vergil mit Geßner; bei der Ode: Horaz mit Denis; beim Epos: Vergil mit 
Tabelle 10: Lehrplan der Wiener Gymnasiallehrerversammlung 1792 [52]

Deutsche und lateinische Aufsatzkunst (Rhetorik und Poetik). S. 238-39

(Beginnt erst im 4. Schuljahr. 2. Semester)

IV. Schuljahr. 2. Semester

a) Anleitung zum freundschaftlichen Briefstil nach Gellert;

b) Übung in deutschen und lateinischen freundschaftlichen Briefen.

V. Schuljahr, 1. Semester

a) Von den Perioden. Wort- und Gedankenfiguren; von der Nachahmung. Erzählung. Beschreibung. Beyspiele oder Muster.

b) schriftliche Übung in diesen Gegenständen, wie auch in zierlichern Briefen;

c) von dem Gedächtnisse und dem rednerischen Vortrage;

d) von den verschiedenen Versarten; von dem Wohlklange; der Leichtigkeit, den Freyheiten und der Zierlichkeit der Verse; von der Fabel.

V. Schuljahr, 2. Semester

a) Von den Erfindungsquellen, von dem Reichthum der Rede und den rednerischen Erweiterungen, von der dreyfachen Schreibart;

b) schriftliche Übung in diesen Gegenständen, wie auch in Trost-, Empfehlungs- und Bittschreiben in Erzählungen: Dahin gehören auch Anbringen und Berichterstattungen.

c) Unterschied der poetischen Erfindung und Schreibart von der rednerischen; von Epigrammen; vom Schäfergedichte; von der Elegie.

Deutsche Sprachlehre und Autoren, S. $234-35$

Muster freundschaftlicher Briefe aus dem Gellert, Rabencr, Riedel.

a) Einige zierlichere Briefe aus Stockhausens Sammlung;

b) von der Tonmessung und den Füßen;

c) Muster von Fabeln aus dem Gellert und Lessing.

(Es folgt im 2. Semester:) Von den verschiedenen Arten deutscher Verse und ihren Freyheiten.

Muster von Sinngedichten aus dem Lessing; von Schäfergedichten aus dem Gessner.
Lateinische Sprachlehre und Autoren, S. $235-38$

eine Sammlung kürzerer Briefe aus dem Cicero;

Briefe aus dem Plinius und Muretus

Ciceros zierlichere Wohlstandsbriefe, ein Auszug aus dessen Gesprächen vom Redner; Ovids Trauerbriefe.

Stücke aus dem Quintilian, Erzählungen und Beschreibungen aus dem Livius, Sallustius, Tacitus von den Sitten der Deutschen; Fabeln des Phädrus.

Ciceros Topica; Ovids Verwandlungen. Kurze Reden aus dem Sallustius,

Livius, Tacitus, Curtius; Stücke aus Vergils Schäfergedichten, aus dem Martial, Tibull, Properz. 
Deutsche und lateinische Aufsatzkunst (Rhetorik und Poetik)

VI. Schuljahr, 1. Semester

a) Von den Beweisarten; von den Sitten und Charakteren; von den Affecten;

b) schriftliche Úbung in diesen Stücken, in Gesprächen und kurzen Reden;

c) Unterschied der poetischen Sitten, Charakteren und Affecten von den rednerischen; von der Satyr;

d) poetische Versuche in der Muttersprache.

VI. Schuljahr, 2. Semester

a) Von der Anordnung und den Theilen einer Rede; von den verschiedenen Gattungen der Reden; von dem Gedächtnisse und dem rednerischen Vortrage;

b) schriftliche Úbung in einzelnen Theilen einer Rede; in der Ausführung und Verbindung der Beweise;

c) von dem Reime und den Gattungen deutscher Verse in verschiedenen Gedichten;

d) von der Ode, vom Heldengedichte, vom Schauspiele;

e) poetische Versuche in der Muttersprache.
Deutsche Sprachlehre und Autoren

Lateinische Sprachlehre und Autoren

a) Bemerkungen der Erfindungsquellen: der Beweisarten und ihrer Ausführung in der [Rede] von Sonnenfels auf Marien Theresien;

b) Muster von Satyren aus dem Michaelis.

Muster aus Denis' Liedern, aus Klopstocks Messias, Emilie Galotti

\section{Zergliederung der Rede pro lege}

Einige Reden des Cicero; Horaz von der Dichtkunst.

Ciceros Reden an den Brutus;

Satyren des Horaz.

Manilia; Vergils Aeneis; Reden des

Cicero, des Muretus.

Oden aus dem Horaz; Stücke aus dem

Plautus und Terentius. 
Klopstock). Rhetorik und Poetik sind im Unterricht miteinander verzahnt, wobei Vergleiche (in »Erfindung und Schreibart «, "Sitten, Charakteren und Affecten «) die Unterschiede verdeutlichen. Als schwerste Gattungen, mit denen der Lehrgang abschließt, gelten die eigentliche Rede in der Rhetorik, das Epos und das Drama in der Dichtkunst.

Die Lehrbücher der Rhetorik und Poetik gelten von der Aufklärung bis zum Vormärz für beide Sprachen, und nur ein »Anhang « (oder »Appendix «) macht auf die Besonderheiten im Deutschen aufmerksam. So heißt es in den Institutiones ad Eloquentiam im »Anhang von der teutschen Dichtkunst« [53]:

Das innere Wesen der Dichtkunst ist in allen Sprachen gleich; es ist daher alles, was wir immer von der inneren Einrichtung der lateinischen Dichtkunst gelehret haben, auf die teutsche anzuwenden, um zu einem teutschen Dichter gebildet zu werden.

Die Ausführungen beschränken sich auf Abschnitte über die `Tonmessung〈, die Versfüße und den Reim, da sich die deutsche Dichtung nur durch prosodische und metrische Eigenheiten (»in dem äußerlichen Kleide und Zierathen «, S. 571) unterscheiden soll. Das folgende Lehrbuch Institutio ad Eloquentiam arbeitet Beispiele aus deutschen Autoren in den Text selbst ein (s. S. 91f.). Trotzdem bleibt es bei einem »Anhang. Von der Metrik der Deutschen«, wo »nur jene Puncte « berührt werden, »in welchem die deutsche Metrik von der lateinischen abweicht «. [54]

b) Im Rhetorikunterricht lernt der Schüler eine Reihe von Wahrnehmungs- und Verarbeitungsmustern von Texten kennen, nach denen er sich bei der Analyse zu richten hat. Gegenüber dem Gedanken der Autonomie, der ein Werk als in sich abgeschlossenes Verweisungsgefüge zu interpretieren nahelegt, beharrt die Rhetorik auf einer kommunikationsorientierten wirkungsintentionalen Sicht. Sie ordnet Texte, indem sie sie nach dem Unterschied von Vers und Prosa, von Gattungen und Schreibarten klassifiziert. Bei der Analyse wird das Werk in zunehmend kleinere Teile zerlegt - von den dispositionellen Abschnitten bis zu den Wortfiguren - und mit der Frage ,Warum hat es der Autor an den Stellen X, Y, Z so gemacht? auf Produktionsregeln zurückgeführt. Das im Gymnasialkodex angeordnete Interpretationsverfahren soll als Beispiel dienen [55]:

Der Lehrer gibt »nach einer kurzen Notiz vom Verfasser

1) den Hauptinhalt des Stückes an, bisweilen auch die Veranlassung dazu.

2) Er zeige den Zweck, den der Verfasser bey der Bearbeitung dieses Stoffes etwa hatte,

3) wie er ferners diesem Zwecke gemäß den Stoff entwickle, anordne und zu einem Ganzen verbinde.

4) Bey Reden ins besondere gehe er die Haupttheile genauer durch, und zeige, wo der Verfasser den Eingang hernehme, mit welchen Gründen er seinen Satz unterstütze, woher er diese schöpfe, welche Beweiskraft sie haben, wie er die Beweise führe, in welcher Ordnung er sie aufstelle, und warum gerade in dieser «.

5) »In Rücksicht des Ausdruckes

a) erkläre er jedes Wort, welches ihnen [den Schülern] dunkel seyn könnte, jede Anspielung auf alte Geschichte, Geographie, Mythologie etc.

b) Er mache sie auf die eigentlichen und uneigentlichen Ausdrücke, auf das Periodische und Numeröse, auf die Ordnung und Stellung der Wörter aufmerksam, und warum der Verfasser gerade diesen Ausdruck und diese Stellung der Wörter gewählet habe. 
c) Er zeige, wie die einzelnen Sätze und Perioden, dann die größeren Theile des Aufsatzes mit einander verbunden sind «.

d) Bei poetischen Stücken erklärt er die Versart, zeigt »das Eigenthümliche des poetischen Ausdruckes « und macht den Schülern »den Unterschied desselben von dem prosaischen dadurch recht fühlbar, daß er ihn seines Schmuckes entkleidet in nackter Prose darstellt «.

Indem nach der >Veranlassung (es Textes und dem `Zweck ' gefragt wird, den der Autor mit ihm verfolgte, wird das Werk von einer historischen Kommunikationssitua-

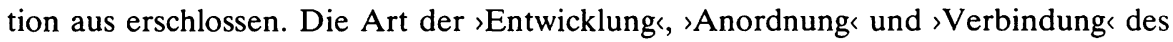
Stoffes - d. h. die im Rahmen der sinventio< und `dispositio festgestellten Merkmale werden aus den mit dem Text verfolgten Absichten erklärt. Nachdem der Lehrer »ein ganzes Skelet« (S. 96) der Schrift vorgelegt hat, wendet er sich den Stilmerkmalen, also der selocutio zu. Die besondere Aufmerksamkeit gilt den Kennzeichen, mit denen sich Poesie und Prosa und die Schreibarten (genera dicendi) unterscheiden: der Art und Häufigkeit der Tropen und Figuren, dem Periodenbau und dem Numerus sowie der Wortstellung. Das Interpretationsverfahren trennt erst auf der elokutionellen Ebene Poesie von Prosa. Das Verfahren der >Entkleidung zeigt, daß Poesie als gereimte und höher stilisierte (mit sSchmuck « verzierte) Prosa verstanden wird.

Die Vorwürfe, die der rhetorischen Analyse - auch in Österreich schon vor, besonders aber nach 1848 - gemacht werden, beruhen auf dem von der Klassik und Romantik vertretenen organischen Dichtungsbegriff. Da die Rhetorik jeden Text so ansieht, als sei er nach allgemeinen Regeln generiert worden, mißbraucht sie scheinbar die Werke als Demonstrationsobjekte ihres Systems. Wenn der Lehrer nach den Vorschriften des Gymnasialkodex vorgeht [56], legt er tatsächlich nur das Paragraphenwerk seines Lehrbuchs an den Text:

1) Er [der Lehrer] hält sich genau an die Ordnung der Kapitel des Buches [= Institutio ad Eloquentiam.].

2) Er suche den Schülern jede Bemerkung oder Regel durch angemessene Beyspiele einleuchtend zu machen.

3) Er zeige ihnen bey den Beyspielen [...], worin eigentlich, d. h. in welchen Worten etc. der Beweis der Regel enthalten ist.

In jeder Stunde wird das Pensum der vorhergehenden »durchgeprüft «. »Die Hauptsache war", heißt es von diesem Lehrbetrieb polemisch, »der Jugend das hohle Regelwerk der Rhetorik und Poetik einzutreiben, und zu dessen Exemplificirung diente die Lektüre «. [57] Die Rhetorik findet in allen Werken dieselben Elemente und Verfahrensweisen wieder; nur deren besonderes Verhältnis macht die Individualität des Textes aus. Das Verfahren der Segmentierung von Werken, d.h. der Ausgrenzung von Teilen ganz verschiedener Länge (von Gemälden oder Charakteristiken bis zu Figuren), das sich retrospektiv als Zerpflückung der Texte darstellt, ist dem Unterricht bis 1848 geläufig. So entnimmt noch die Sammlung deutscher Beyspiele zur Bildung des Styls Muster für »Gleichnisse und Vergleichungen«, »Beschreibungen und Charaktere « ohne Angaben dem Zusammenhang größerer Werke (z. B. die prosaische Beschreibung »Wahl eines Wohnortes für einen menschenfreundlichen Weltbürger « aus Wielands Geschichte des weisen Danischmende, 
die poetische Charakteristik »Die Vertriebenen « aus Goethes Hermann und Dorothea, mehrere Stellen aus Klopstocks Messias).

c) Die Schulrhetorik sucht sich die Texte danach aus, wie sie die Gattungsregeln erfüllen und wie vollendet sie formal und sprachlich sind. Da es in Österreich bis 1848 keinen literarhistorischen Unterricht und auch keine in Schulen eingeführte Literaturgeschichte gibt, spielen literarhistorische Gesichtspunkte bei der Auswahl, Anordnung und Wertung keine Rolle. Texte werden hier kaum - wie in gleichzeitigen außerösterreichischen Schulsammlungen - als Zeugnisse einer Epoche oder als sprachgeschichtliche Dokumente angesehen. Mit den deutschen Autoren des Mittelalters, des 16. und 17. Jahrhunderts (sieht man von einigen Epigrammen ab) wird der Schüler nicht bekannt. Erst mit den Reformen nach der Märzrevolution wird die »Geschichte der vaterländischen Literatur « [58] in den Lehrplan aufgenommen. Der Schüler erhält nun eine Zusammenstellung von »Sprachproben aus dem Gothischen und Althochdeutschen « mit weiteren »die aufeinanderfolgenden Stufen der Sprachentwickelung " charakterisierenden »Paradigmen « sowie eine mittelhochdeutsche Chrestomathie. [59] Mit Gervinus, Vilmar, Schäfer und $\rightarrow$ Koberstein werden den Lehrern die in Deutschland am weitesten verbreiteten Literaturgeschichten empfohlen. [60] Gleichzeitig erscheinen die ersten österreichischen Lesebücher, die ein »Kulturbild « geben, so daß der deutsche Unterricht »mit der Geschichte von Periode zu Periode Hand in Hand « [61] gehen kann.

\subsubsection{Die Kanonbildung im Deutschen}

Die Kanonbildung wird hauptsächlich in den allgemein eingeführten und vorgeschriebenen Lehr- und Lesebüchern der Humanitätsklassen verfolgt. Dabei wird zunächst gezeigt, wie bei $\rightarrow$ Gratian Marx in den letzten Jahren der Regierung Maria Theresias die engen poetischen Normen Gottscheds (und der ihm folgenden Grammatiker bis Adelung) aufgegeben werden. Die reimlose sprachschöpferische Dichtung von Klopstock an (mit Denis) wird jetzt voll vom Gymnasium rezipiert. Die Institutiones ad Eloquentiam (2 Bde, 1777/78 u. ö.) vereinen rhetorische und poetische Lehrtexte mit Beispielsammlungen. Mit der Institutio ad Eloquentiam und der Sammlung deutscher Beyspiele zur Bildung des Styls werden das Lehrbuch und die Anthologie zu eigenen, aber (z. B. in der Gattungseinteilung) eng aufeinander bezogenen Werken. Die drei Unterrichtswerke werden analysiert, mit ihren Vorgängern bzw. Nachfolgern sowie mit nord- wie süddeutschen (bayerischen) Beispielen verglichen. Die Untersuchung führt zu folgenden Hauptergebnissen:

- »Treue gegenüber den Autoren des 18. Jahrhunderts « [62], d. h. gegenüber vorklassischen Dichtern wie Gellert, Lessing oder Klopstock. Von den österreichischen Autoren der Aufklärungszeit erhält das Gymnasium $\rightarrow$ Denis und Sonnenfels, aber auch Alxinger, Blumauer und Mastalier gegenwärtig.

- Die Frühromantiker (A. W. und Fr. Schlegel, Novalis, Tieck) treten so gut wie nicht in Erscheinung; gleiches gilt von Hölderlin. Wenn sich »um 1808« - im Gefolge der Vorlesungen A. W. Schlegels - durch »das Eindringen der deutschen Literatur der 
Goethezeit « »ein Umschwung im literarischen Leben Österreichs « [63] vollzieht, so hat er sich kaum auf das Gymnasium ausgewirkt. Der Zuzug der deutschen Romantiker und die Tätigkeit Hofbauers bleiben hier (sieht man von Körner ab) ohne Folgen. Goethe und Schiller [64] werden nur selektiv (z. B. ohne die Frühwerke des Sturm und Drang, ohne die Balladen) und unter moralischen, weltanschaulichen wie politischen Widerständen rezipiert.

- Die Textsammlungen bleiben nach dem Gattungssystem gegliedert, wie es sich im 18. Jahrhundert gestaltet hat. Zu einer Dreiteilung in Lyrik, Epik und Dramatik wie in der Klassik und Romantik kommt es in den Schulbüchern nicht. (Die drei Dichtungsarten »als Haupt- oder Naturformen « [65] begegnen in der österreichischen Poetik fast ausschließlich bei dem Goetheaner Zauper 1821 und 1840.) Bei zahlreichen Formen, die im 18. Jahrhundert den Höhepunkt ihrer Entwicklung durchlaufen (wie Lehrgedicht, komisches Heldengedicht, Verssatire, Äsopische Fabel, poetische Erzählung, poetischer Brief), kommen später kaum neue Autoritäten hinzu, so daß sich das Gewicht der Aufklärungsliteratur schon dadurch verstärkt. Die von den Romantikern propagierten romanischen (Sonett, Terzine, Kanzone) und orientalischen Formen (Ghasel) bleiben ausgespart. Mit den Balladen fällt geradezu eine Modegattung weg.

- Mit Briefen und Reden wird die Prosa der Aufklärung ins Lesebuch aufgenommen. Sonnenfels' Lobrede auf Maria Theresia (1762) - in der sie als ideale aufgeklärte, um das Wohl ihres Landes bemühte Herrscherin erscheint - erlangt geradezu kanonische Geltung. [66] Dagegen kommt die (kunst- und literatur-)kritische, historische, philosophische und wissenschaftliche Prosa der Klassik, Romantik und des 19. Jahrhunderts (sieht man von der Wertung Schillers als Historiker ab) [67] kaum in den Blick. Die Mustersammlungen sind nach Gattungen unhistorisch angelegt. [68] Prosaanthologien, die einerseits Materialien für Erörterungen und Aufsätze liefern, andererseits die Geschichte der deutschen Sprache und der prosaischen Formen belegen [69], fehlen in Österreich, da der Unterricht hier formal bleibt (s. Kap. 2.3.3).

In den Jahrzehnten vor der Märzrevolution gelten die offiziellen Lehrbücher allgemein als veraltet. Ein Werk, das hier Abhilfe zu schaffen versucht: das Lesebuch von Podlaha (1842), wird deshalb zum Vergleich herangezogen. Es dient zur Gegenprobe; denn die Eigenarten, die es von deutschen Vorbildern unterscheidet (Ablehnung der Frühromantik und Hölderlins, formale Ordnung nach Gattungen, Ineinander poetischer und rhetorischer Formen), lassen sich weniger leicht aus einem amtlich verordneten Traditionalismus erklären. Podlaha macht deutlich, worin ein liberaler und der modernen Dichtung gegenüber sehr aufgeschlossener Schulmann - der als Direktor des Wiener Akademischen Gymnasiums (1848 bis 1853) an den Reformen nach 1848 mitwirkte - österreichischen Traditionen verpflichtet blieb. 


\section{Institutiones ad Eloquentiam}

a. »Anhang von der teutschen Dichtkunst «: Von Gottsched zu Klopstock

Die von $\rightarrow$ Marx verfaßten Institutiones ad Eloquentiam enthalten im zweiten Teil (»Pars Posterior Institutiones Poeticas complectens ad usum Scholarum Austriacarum «, hier nach der Ausgabe Wien bei Trattner 1778, S. 571-613) einen » Anhang von der teutschen Dichtkunst«. Er stellt eine Umarbeitung der »Einleitung zur deutschen Dichtkunst « des vorhergehenden Lehrbuchs dar: Oratoriae ac Poeticae Institutionis Pars Prior (hier nach der Ausgabe Freiburg i. Br. bei Anton Wagner 1774, S. 269-303). Dieses Werk von Joh. Bapt. Noghera ist erstmals in Wien 1753 erschienen; die Prager Ausgabe von 1765 enthält einen letzten Teil »De poesi Germanica«, der nach Wotke »sicherlich von $\rightarrow$ Denis verfaßt « ist. [70] Das am Stiftsgymnasium in Braunau verwendete Exemplar - das Maiwald [71] zwar beschreibt, aber bibliographisch nicht näher bezeichnet - hatte beigebunden eine »Einleitung zur deutschen Dichtkunst « von 40 gesondert gezählten Seiten. Es handelt sich also um einen späteren Zusatz, der in der von mir benutzten Freiburger Auflage (offensichtlich textgleich mit dem Braunauer Exemplar) bereits als fester Bestandteil auftritt. Nach der folgenden Analyse scheidet Denis als Autor der »Einleitung « aus.

Ein Vergleich zwischen dem »Anhang« und der »Einleitung « macht deutlich, wie sich die literarischen Normen und Wertungen wie die Auswahl der Autoren am Gymnasium ändern. $\rightarrow$ Marx mildert die Angriffe gegen »unsere neuen lateinischdeutschen Dichter (1774, S. 296), d. h. gegen Klopstock, Ramler, Zachariae und $\rightarrow$ Denis, die das Lehrbuch von 1774 (S. 301) als reimlose, in lateinischen Metren schreibende Dichter aufzählt. Als die »alten Versarten « den »Lateinischen und griechischen «, »die man seit einiger Zeit in die deutsche Dichtkunst eingeführt hat « (1774, S. 287), gegenübergestellt werden, heißt es

1774

Jedes [der Versarten] hat seine Vortheile, seine Schönheit; aber jedes hat auch seine Unbequemlichkeiten, und Fehler: besonders wenn man die Sprache verhunzet, griechische, lateinische und englische Wortfügungen als Blümchen ins Deutsche überträgt, und den Schwulst fürs Erhabene ansieht, wie es bisher von den meisten hexametrischen Dichtern geschehen. (S. 287)
1778

Jedes hat seine Vortheile und Schönheiten, jedes hat aber auch seine Unbequemlichkeiten und Fehler, besonders wenn man mit den Inversionen der Sprache gar zu kühn verfährt, fremde Wörter ohne Noth ins Teutsche mengt, und Schwulst fürs Erhabne ansieht, wie es von einigen reimlosen Dichtern bisher geschehen ist. (S. 593)

Ein Absatz (1774, S. 296), der »all jene häufigen Versetzungen « beklagt, »welche unsere neuen lateinischdeutschen Dichter mit einer ungezäumten Freyheit so sehr gebraucht [haben]«, daß sie das Verständnis erschweren, fällt weg. Bei den Zitaten werden drei fehlerhafte Beispiele aus Klopstock (1774, S. 281) gestrichen oder ersetzt; neu hinzu treten zwei Musterstellen von Ramler (1778, S. 591) und je eine von Denis (S. 592) und aus Ossian (S. 590). Kennzeichnend sind die Änderungen in den Gattungskapiteln (1774, S. 301-03; 1778, S. 610-13), wo auf kanonische Dichter und Dichtungen verwiesen wird. 


\begin{tabular}{|c|c|c|}
\hline Gattungskapitel & Hinzufügung 1778 & Streichung 1778 \\
\hline Heldengedicht & $\begin{array}{l}\text { Denis' Ubertragung Ossians; } \\
\text { Zachariae, »Cortes« }\end{array}$ & \\
\hline kom. Heldengedicht & Zachariae, »Murner in der Hölle « & \\
\hline Trauerspiel & Klopstock, »Salomo« und »David « & \\
\hline Ode & $\begin{array}{l}\text { (als Verfasser gereimter Oden und } \\
\text { Lieder:) Ramler, Blum, Jacobi, } \\
\text { Mastalier }\end{array}$ & $\begin{array}{l}\text { Günther, Canitz, E. v. Kleist, } \\
\text { Cronegk, Cramers Über- } \\
\text { setzung der Psalmen }\end{array}$ \\
\hline Elegie & Klopstock & Gottsched \\
\hline Lehrgedicht & $\begin{array}{l}\text { Wieland, »Die Natur der Dinge oder } \\
\text { die vollkommenste Welt « }\end{array}$ & \\
\hline Satire & Michaelis & \\
\hline Sinngedicht & Logau, Wernicke, Hagedorn & (ohne Namen) \\
\hline
\end{tabular}

Bei den Oden in »lateinischen Versarten « wird die Umschreibung »Klopstock und die Liebhaber seiner Muse « durch eine Reihe von Namen ersetzt: »Klopstock, Ramler, Zachariä, Sined [d. i. Denis]«. Der Abschnitt »Lobgedicht « - mit Opitz, Günther, Pietsch, Neukirch und Gottsched - fällt ganz weg. Neu ist die Rubrik »Bardenpoesie «, wobei Klopstock (Oden, Hermanns Schlacht), Denis (Ossian und Lieder Sineds des Barden), Kretschmann (Gesang Ringulphs des Barden) und Gerstenberg (Gedicht eines Skalden) genannt werden.

Der Text von 1774 folgt in der Wertung und Auswahl noch den Gottschedianern. Starke Abweichungen von der grammatischen Wortfolge, Wortneubildungen nach dem Englischen und Griechischen sowie die kühnere Bildlichkeit in reimlosen Versen - wie sie die Schweizer (Bodmer erscheint 1774, S. 280-82, mit fünf Beispielen für Fehler im Hexameter; übernommen 1778, S. 586-87) und Klopstock einführten werden als "Schwulst « bekämpft. Wie bei Schönaich (Neologisches Wörterbuch oder die ganze Ästhetik in einer $N u \beta, 1754$ ) werden Bodmer und Klopstock in die Nähe Lohensteins gerückt (1774, S. 294-97 mit drei abschreckenden Zitaten aus Lohenstein). Das Lehrbuch von Marx dagegen kanonisiert Klopstock und seine Nachfolger, während Gottsched und die Frühaufklärer (zusammen mit ihrer Autorität Opitz und dem von ihnen anerkannten Günther) teils wegfallen (so Gottsched an drei Stellen), teils zurücktreten. Die aufklärerische Forderung, die dichterische Sprache möglichst nahe an der grammatischen Norm zu halten, und das Streben nach >Klarheit >Deutlichkeit< der Rede bestehen dabei weiter. Es bleibt bei dem Grundsatz »Im Verse muß man eben die Wortfügung halten, die man in der ungebundenen Rede hält « (1778, S. 601; ähnlich 1774, S. 293), bei den Warnungen »vor dem gar zu vielen Gebrauche der Mittelwörter«, d. h. der Partizipien (1778, S. 601; 1774, S. 293 deutlicher gegen die Hexameterdichter), vor Zeilen- und Strophensprüngen, zu langen und verwickelten Perioden in Versen u. ä. Eine in dieser Weise moderierte aufklärerische Haltung, die Klopstock neben Gellert, Ramler neben Hagedorn gelten läßt, herrscht im österreichischen Gymnasium bis 1848 vor.

Die Abwendung von den Gottschedianern hat $\rightarrow$ Denis mit seinen Anthologien und seiner Unterrichtspraxis am Theresianum vorbereitet. Der zweite Band, der seiner Sammlung kürzerer Gedichte nachfolgte (s. Anm. 75), druckt drei Abhandlungen 
(Abhandlung von der heiligen Poesie, Nachahmung des griechischen Sylbenmaßes im Deutschen, Abhandlung vom deutschen Hexameter) und ein Trauerspiel (Der Tod Adams) von Klopstock ab. Die Jugendfrüchte des k.k. Theresianum (3 Bde, Wien bei Joseph Kurzböck 1772-74), in der Denis die Schulprodukte »adeliche[r] Jünglinge zwischen 14 und 17 Jahren « (Bd. 1, S. $2^{* \mathrm{v}}$ ) publiziert hat, bringen von Anton Graf von Magnis ein »Lob der deutschen reimlosen Dichter" (Bd. 2, S. 97-102), wobei namentlich Klopstock, Wieland (Cyrus) und Zachariae (Murner in der Hölle, Phaeton) gefeiert werden. Das Gedicht macht zu einer kühnen Schreibart Mut (»Reißet die Fesseln des Reimes entzwey, und lasset doch einmal / Den sich gleich Strömen hinwälzenden starken Gedanken / Freyeren Lauf «, S. 101/02) und verspottet die Bedenken des oben charakterisierten Lehrbuchs (»Dort jammert ein ängstiger Schulmann / Ueber die neue Versetzung, die freye Verbindung der Worte, / Ueber den dunkeln Verstand «, S. 101). Ludewig Graf von Bathyan macht sich über Schönaichs Heldengedicht Hermann oder das befreite Deutschland lustig, das den Schülern empfohlen wurde (1774, S. 301; übernommen 1778, S. 610). [72] So hat Denis die Parteigänger Gottscheds disqualifiziert und mit Erfolg Klopstock propagiert.

b) Die Beispielsammlung, im Vergleich mit den Anthologien von Denis, Weitenauer und Mertens

Die folgende Tabelle gibt an, welche Autoren mit mindestens drei Beispielen in den Institutiones ad Eloquentiam enthalten sind. Zum Vergleich werden die Schriftsteller mitgeteilt, die in drei vorausgehenden süddeutschen Sammlungen am zahlreichsten vertreten sind: bei dem Jesuiten $\rightarrow$ Denis (1766), seinem Ingolstädter Ordensbruder $\rightarrow$ Weitenauer (1768) und bei $\rightarrow$ Mertens (1772), dem protestantischen Rektor des St. Anna Gymnasiums in Augsburg.

Die Beispielsammlung von $1777 / 78$ ist deutlich moderner als ihre Vorgänger. Während Gellert [73] bei Denis und Weitenauer der am zweithäufigsten, bei Mertens gar der am meisten vertretene Autor ist, findet man hier im ersten Teil noch 6 Texte, im zweiten nichts mehr voll abgedruckt; Lessing hat Gellert bei den Fabeln verdrängt. Hagedorn, der bei Denis und Weitenauer an der Spitze steht, taucht nur noch mit Zitaten auf. Klopstock und Ewald von Kleist rücken dafür in den Vordergrund. Damit sind die Weichen bis 1848 gestellt: Lessing wird, was die Zahl der Texte betrifft, mit seinen Fabeln die Schulbücher beherrschen; Klopstock wird in höheren Gattungen (Epos, Ode, Hymne) den Ton angeben.

Die Anthologie von Denis wirkte in den sechziger Jahren als Schrittmacher, wie ein Vergleich mit Weitenauer ergibt. Texte von Hagedorn und Gellert finden sich bei beiden am häufigsten. Dann folgen bei Weitenauer Barockautoren mit Epigrammen (Opitz, Logau) und Schriftsteller der frühen Aufklärung und der Zeit Gottscheds (Brockes, König, Stoppe, Triller, Ludwig, Schrenkendorf; auch Canitz mit 3, Gottsched mit 1 Text), die alle bei Denis fehlen, der sich ausschließlich auf »die Neuern« beschränkt. [78] Bei Weitenauer taucht andererseits E. v. Kleist nur dreimal, Zachariae zweimal auf. Lessing wird von Denis mit 9, von Weitenauer mit 3 Beispielen vorgestellt. Österreich hatte also schon mit Denis und dann mit dem Lehrbuch von 1777/78 Mustersammlungen modernen Zuschnitts. 
Tabelle 11: Institutiones ad Eloquentiam [74]

\begin{tabular}{|c|c|c|c|c|}
\hline Autor & Summe & $\begin{array}{l}\text { Dt. Anhang, } \\
\text { Tl. } 1, \text { S. } 444-54\end{array}$ & $\begin{array}{l}\text { Beispielsammlung, } \\
\text { Tl. 2, S. 614-61 }\end{array}$ & $\begin{array}{l}\text { Zitate in der »Einleitung «, } \\
\text { Tl. 2, S. 571-613 }\end{array}$ \\
\hline Lessing & 20 & 3 & 17 (Fabeln) & $\begin{array}{l}1 \\
1\end{array}$ \\
\hline Klopstock & 13 & - & 6 & 7 \\
\hline E. v. Kleist & 12 & - & 7 & 5 \\
\hline Gellert & 8 & 6 & - & 2 \\
\hline Hagedorn & 6 & - & - & 6 \\
\hline Bodmer & 5 & - & - & 5 \\
\hline Denis & 4 & - & 3 & 1 \\
\hline Dusch & 4 & - & 4 & - \\
\hline $\mathrm{Uz}$ & 4 & - & 1 & 3 \\
\hline Wieland & 4 & - & - & 4 \\
\hline Haller & 3 & - & 2 & 1 \\
\hline Lichtwer & 3 & - & - & 3 \\
\hline Opitz & 3 & - & - & 3 \\
\hline Ramler & 3 & - & 1 & 2 \\
\hline
\end{tabular}

Tabelle 12: Denis, Sammlung kürzerer Gedichte [75]

\begin{tabular}{l|c} 
Autor & Anzahl der Texte \\
\hline Hagedorn & 38 \\
Gellert & 29 \\
Zachariae & 18 \\
E. v. Kleist & 16 \\
Uz & 13 \\
Lessing & 9 \\
Lichtwer & 9
\end{tabular}

Tabelle 13: Weitenauer, Sammlung kürzerer Gedichte [76]

\begin{tabular}{|c|c|c|}
\hline Autor & Anzahl der Texte & davon Sinngedichte, Epigramme, Rätsel \\
\hline Hagedorn & 43 & 25 \\
\hline Gellert & 33 & 1 \\
\hline Triller & 27 & 11 \\
\hline Opitz & 24 & 20 \\
\hline Stoppe & 23 & - \\
\hline Brockes & 20 & 17 \\
\hline Ludwig & 17 & 17 \\
\hline Logau & 16 & 16 \\
\hline König & 16 & 15 \\
\hline Lichtwer & 12 & - \\
\hline
\end{tabular}


Tabelle 14: Mertens, »Auserlesene kleinere Gedichte« [77]

\begin{tabular}{|c|c|c|c|}
\hline Autor & Anzahl der Texte & 1 & davon Sinngedichte \\
\hline Gellert & 53 & 1 & - \\
\hline Chr. F. Weiße & 39 & 1 & - \\
\hline Cramer (Úbersetzung der Psalmen) & 10 & 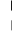 & - \\
\hline $\mathrm{Uz}$ & 8 & & - \\
\hline Geßner & 7 & & - \\
\hline Kästner & 6 & & 6 \\
\hline E. v. Kleist & 5 & & 4 \\
\hline
\end{tabular}

\section{Institutio ad Eloquentiam [79]}

Die Zusammenstellung der Musterautoren zu einzelnen Gattungen, die das Lehrbuch (hier nach der Ausgabe 1833) vornimmt, berücksichtigt vornehmlich das 18. Jahrhundert. Doch werden die Klassiker ergänzend aufgenommen. Bei der Komödie werden Goethe, Iffland und Kotzebue genannt, Goethe und Schiller werden bei der Tragödie und dem lyrischen Gedicht, Goethe allein beim bürgerlichen Epos (sepopoeia civica<) und Schiller bei der Elegie aufgezählt. Versdichter des frühen 19. Jahrhunderts (Tiedge für das Lehrgedicht, Kosegarten für die Idylle), darunter die Österreicher Karoline Pichler und Pyrker finden Eingang. Sie sind aber ebensowenig wie die Klassiker in den Text des Werkes eingearbeitet worden.

\section{Verzeichnis deutscher Musterautoren (ohne Oper)}

\begin{tabular}{l} 
Kapitel \\
\hline De Tragoedia \\
De Comoedia \\
De Epopoeia \\
De Epopoeia civica \\
De Epopoeia comica \\
De Epopoeia romanense \\
De Idylliis
\end{tabular}

Autoren

De Elegia

De Carmine lyrico

Lessing, Goethe, Schiller, Collin, Weisse, Leisewitz, Gerstenberg Lessing, Weisse, Brandes, Engel, Goethe, Schroeder, Stephanie, Iffland, Kotzebue

Klopstock, Bodmer, Wieland, Sonnenberg, Pyrker

Goethe (»Hermann und Dorothea «), Voß (»Luise«),

Pichler ( Ruth «)

Zachariae, Uz, Thümmel

Wieland, Ludwig Heinr. v. Nikolai, Alxinger

Geßner, Voß, E. v. Kleist, Bronner, Kosegarten, Krauseneck,

Pichler

Klopstock, Denis, Matthisson, Salis, Weisse, Gotter, Hölty, Ludwig Heinr. v. Nikolai, Voß, Schiller

Klopstock, Denis, Ramler, Mastalier, Uz, Matthisson, Salis,

Goethe, Schiller

De Carmine didactico

Haller, E. v. Kleist, Uz, Wieland, Cronegk, Lessing, Lichtwer, Hagedorn, Zachariae, Neubeck (»Gesundbrunnen «), Tiedge

De Satyra

De Epigrammate Haller, Rabener, Canitz, Hagedorn, Michaelis, Falk, Stolberg Logau, Wernicke, Kästner, Lessing, Pfeffel, E. v. Kleist,

Goeckingk, Ewald, Haug 
Die 60 Zitate aus deutschen Dichtern stammen fast alle von vorklassischen Autoren. Es führen Klopstock (»Klopstockius Germanorum Homerus est «, steht S. 20 zur Erläuterung der Stilfigur sindividuum pro specie`) mit 16 und Voß mit 5 Belegen; Goethe taucht dreimal (so oft wie Cramer, Haller oder E. v. Kleist), Schiller nur zweimal (so oft wie Geßner, Matthisson oder Wieland) auf. Romantiker sind nicht vertreten.

\section{Sammlung deutscher Beyspiele zur Bildung des Styls [80]}

Diese Sammlung blieb bis 1848 das einzige an österreichischen Gymnasien eingeführte Lesebuch. In der Ausgabe von 1812 sind folgende Autoren mit mindestens 5 Texten vertreten:

\begin{tabular}{l|c} 
Autor & Anzahl der Texte \\
\hline Lessing & 52 \\
Pfeffel & 23 \\
Gellert & 16 \\
Klopstock & 16 \\
Schiller & 13 \\
Haug & 12 \\
Matthisson & 8 \\
Ratschky & 8 \\
Garve & 7
\end{tabular}

\begin{tabular}{l|c} 
Autor & Anzahl der Texte \\
\hline L. H. v. Nikolai & 7 \\
Salis & 7 \\
Denis & 6 \\
Fr. L. v. Stolberg & 6 \\
Göckingk & 5 \\
Götz & 5 \\
Pezzl & 5 \\
Rabener & 5
\end{tabular}

Von Dichtern des Göttinger Hain, des Sturm und Drang und der Klassik sind noch Bürger mit 4, Claudius und Hölty (»Deutschlands Tibull«, Bd. 2, S. 234) mit 3, Herder und Voß mit 2, Goethe mit 1 (!) Text zu finden. Wieland fällt mit 4 Prosastücken auf - was seiner Wertschätzung in Österreich entspricht. [81] Salis wird an Sprachkraft neben Haller und Winckelmann gestellt. [82] Von den österreichischen Autoren wird $\rightarrow$ Denis als »der Vater und die Zierde der Dichter am Ister « (Bd. 1, S. 252; Bd. 2, S. 233) hervorgehoben. Das Werk bietet außer den oben Genannten: Von Alxinger 4, von H. J. v. Collin, Karoline Pichler und Sonnenfels je 2, von Blumauer und Mastalier je 1 Beispiel.

Bis auf einige ausgetauschte Texte enthalten die Bände von 1834/41, die verglichen wurden, fast die gleichen Muster. Neu sind aufgenommen Körner (Elegie $A u f$ dem Schlachtfelde von Aspern, Bd.2, Kap. I, Nr. 9; Hymne Gebet während der Schlacht, Bd.2, Kap. IIa, Nr.6), Grillparzer (Elegie Abschied von Gastein, Bd. 2, Kap. I, Nr. 16), Krummacher (zwei Fabeln) und Baggesen (ein Epigramm). Ins Gewicht fällt, daß nun als Muster des Schauspiels Goethes Iphigenie auf Tauris abgedruckt wird (Bd. 2, Kap. IV C, als neue Rubrik). Da in dem Stück »sehr viel von Ehebruch, Gatten- und Muttermord gesprochen werde«, hatte die n. ö. Regierung Bedenken angemeldet; die Studienhofkommission erstattete in ihrer Sitzung vom 28. September 1822 aber ein positives Gutachten (»ein Meisterwerk der dramatischen Kunst «). [83] 
Wie starr man bis zum Ende der Restaurationszeit am Kanon des 18. Jahrhunderts festhielt, wird an diesem Lesebuch eindrücklich sichtbar. Das aufklärerische Gattungssystem (s.S. \$6) wird nur in einem Fall-durch die Aufnahme des >Schauspiels ergänzt. Mit den Balladen und Romanzen bleibt eine der fruchtbarsten Formen außer acht, die mit ihren zum guten Teil (national-, wie lokal-) geschichtlichen Themen den Formalismus des Unterrichts gesprengt hätte. [84] Lyrik ist noch nicht auf das Liedhafte hin ausgerichtet, sondern konzentriert sich auf hochstilisierte Formen mit bedeutendem Gehalt (heroische und philosophische Oden, Hymnen, Dithyramben). [85] Das Sonett und andere von den Romantikern eingeführte romanische und orientalische Formen (Kanzone, Terzine, Ghasel) kommen nicht vor. Von den Klassikern ist nur Schiller (aber nicht mit Balladen) einigermaßen präsent. Die Romantiker bleiben gänzlich ausgeschlossen; von den Dichtern der Befreiungskriege macht nur Körner eine Ausnahme, der sich 1811 erfolgreich in Wien niederließ. Sein Gedicht Auf dem Schlachtfelde von Aspern bezieht sich auf den Sieg der Österreicher unter Erzherzog Karl über die Franzosen am 21./22. Mai 1809. Von keinem Autor der Biedermeierzeit gewinnt man ein Bild; gar nichts wird aus der damals (außerhalb Österreichs auch auf der Schule) beliebten Schwäbischen Romantik, etwa von Uhland, aufgenommen.

4. Podlahas Muster deutscher Redekünste (1842) [86], im Vergleich mit deutschen Lesebüchern

Podlahas Muster deutscher Redekünste stellen wohl das einzige vor 1848 in Österreich erschienene moderne Lesebuch dar, das Anschluß an die deutsche Entwicklung gewann. Dieses Werk, »ein Culturmoment in der österreichischen Erziehungsgeschichte « [87], wurde von der Jugend » jubelnd « [88] begrüßt. Ungerügt entfernte sich Podlaha von den oben beschriebenen amtlichen Lehrbüchern. »Er warf die berüchtigte sinstitutio ad eloquentiam` mit dem ganzen Plunder zusammengestoppelter `Chrestomathien` und `Sammlungen deutscher Beispiele` bei Seite, führte seine Schüler frischweg direct in das classische Alterthum und in die moderne Literatur ein«. [89] Wie die folgende Auszählung zeigt, rückt in der Sammlung die Literatur von der Klassik bis zur Gegenwart in den Mittelpunkt:

\begin{tabular}{l|c} 
Autor & Anzahl der Texte \\
\hline Rückert & 21 \\
Goethe & 17 \\
A. Grün & 9 \\
Chamisso & 8 \\
Herder & 7 \\
Jean Paul & 7 \\
Platen & 7 \\
J. G. Seidl & 7 \\
Freiligrath & 6
\end{tabular}

\begin{tabular}{l|c} 
Autor & Anzahl der Texte \\
\hline Lenau & 6 \\
Neuffer & 6 \\
Schiller & 6 \\
Uhland & 6 \\
J. N. Vogl & 6 \\
Hebel & 5 \\
Kerner & 4 \\
Pyrker & 4
\end{tabular}


Von weiteren Autoren, die in Österreich geboren wurden oder hier wirkten, finden sich 3 Texte von Gentz und Zedlitz, 2 von H. J. v. Collin, je 1 von Franz Exner, Enk, Grillparzer, Saphir und Fr. Schlegel.

Tabelle 15 a [93]

\begin{tabular}{r|lr|lr|lr} 
& Follen, 1828/29 & & Schwab, 1835 & & Uschold, 1835 & \\
\hline 1 & Goethe & 58 & Goethe & 27 & Goethe & 20 \\
2 & Herder & 56 & Rückert & 22 & Platen & 15 \\
3 & Uhland & 54 & Uhland & 17 & Fr. L. Stolberg & 14 \\
4 & Fr. Schlegel & 45 & Hölderlin & 12 & Voß & 10 \\
5 & A. W. Schlegel & 44 & Kerner & 10 & A. W. Schlegel & 9 \\
6 & Schiller & 39 & Schiller & 10 & Herder & 8 \\
7 & Schenkendorf & 38 & A. W. Schlegel & 10 & Tieck & 8 \\
8 & Tieck & 34 & Eichendorff & 9 & Klopstock & 7 \\
9 & Kerner & 25 & Heine & 9 & Rückert & 7 \\
10 & A. E. Fröhlich & 24 & Fr. Schlegel & 9 & E. v. Schenk & 7
\end{tabular}

\begin{tabular}{r|lr|lc} 
& Brederlow, 1839 & & Mustersammlung, 1845-47 \\
\hline 1 & Schiller & 26 & Schiller & 33 \\
2 & Herder & 21 & Goethe & 29 \\
3 & Rückert & 15 & Hebel & 24 \\
4 & Klopstock & 10 & Uhland & 20 \\
5 & Krummacher & 10 & Claudius & 15 \\
6 & Goethe & 7 & Gebr. Grimm & 15 \\
7 & Uhland & 6 & Rückert & 11 \\
8 & Lessing & 5 & Herder & 10 \\
9 & Platen & 5 & König Ludwig I. & 10 \\
10 & J. G. Jacobi & 4 & W. Müller & 10
\end{tabular}

Tabelle $15 b$

\begin{tabular}{l|rrrrr} 
Autor & Follen & Schwab & Uschold & Brederlow & Mustersammlung \\
\hline Rückert & 5 & 22 & 7 & 15 & 11 \\
Goethe & 58 & 27 & 20 & 7 & 29 \\
A. Grün & - & 2 & 3 & - & 2 \\
Chamisso & 1 & 7 & 4 & 2 & 4 \\
Herder & 56 & 7 & 8 & 21 & 10 \\
Jean Paul & - & - & 1 & 2 & 6 \\
Platen & 2 & 8 & 15 & 5 & 4 \\
J. G. Seidl & - & 2 & - & 1 & 1 \\
Freiligrath & - & - & - & 1 & 3 \\
Lenau & - & 5 & 3 & 1 & 2 \\
Neuffer & - & 1 & - & - & - \\
Schiller & 39 & 10 & 5 & 26 & 33 \\
Uhland & 54 & 17 & 6 & 6 & 1 \\
J. N. Vogl & - & - & - & - & 24 \\
Hebel & 15 & 1 & 1 & - & 6 \\
Kerner & 25 & 10 & 4 & 1 & - \\
Pyrker & - & - & 1 & - &
\end{tabular}


Historische Aussagen über die Leistung und Eigenart der Auswahl werden erst durch Vergleiche mit deutschen Lesebüchern möglich. Hierzu dienen fünf Werke: Zwei davon (Uschold, 1835; Brederlow, 1839) [90] - durchschnittliche Sammlungen waren im Besitz des Akademischen Gymnasiums und Podlaha also bekannt. $\rightarrow$ Follen $(1828 / 29)$ und $\rightarrow$ Schwab (1835) [91] zählen zu den modernsten Lesebüchern, die der Markt bot. Die wenige Jahre nach Podlaha publizierte offizielle bayerische Sammlung (1845-47) [92] führt die Kanonbildung im größten süddeutschen Land vor Augen. Tabelle 15a enthält die zehn am häufigsten vertretenen Dichter jeder Anthologie, Tabelle $15 \mathrm{~b}$ gibt an, wieviel Texte (einschließlich Epigramme) von den bei Podlaha genannten Autoren in ihnen vorkommen.

Bei einer Reihe von Gegenwartsautoren (Chamisso, Platen, Uhland, Kerner) schließt Podlaha nur an den außerösterreichischen Gebrauch an, wo sie an den Gymnasien bereits fest eingeführt waren. Rückert rangiert allerdings nur bei ihm vor Goethe und Schiller. Daß österreichische Autoren seiner Zeit (A. Grün, Lenau, Pyrker, J. G. Seidl) verstärkt zur Geltung kommen, ist selbstverständlich. Das Verhältnis von Goethe und Schiller stellt sich so unterschiedlich dar, daß die Minderwertung Schillers bei Podlaha nicht aus dem Rahmen fällt. Auffällig ist aber die geringe Anzahl romantischer Texte. A. W. und Fr. Schlegel sowie Tieck finden sich nur mit je einem Beispiel. Novalis fällt bei Podlaha ganz aus (bei Follen mit 21, Schwab mit 7, Uschold mit 3, in der Mustersammlung mit 2 Texten und nur bei Brederlow nicht vertreten). Ebenso ergeht es Hölderlin (bei Follen 2, Schwab 12, Uschold 5, in der Mustersammlung 1 Beispiel und wieder nur bei Brederlow nicht vorhanden). [94]

Unter >Redekünste $<$ begreift Podlaha traditionsgemäß die poetischen wie die prosaischen Gattungen. Er folgt damit der Sammlung deutscher Beyspiele zur Bildung des Styls, während alle verglichenen Anthologien die Mischung von poetischen mit rhetorischen Texten aufgegeben haben. Die rhetorische Prosakultur erstreckt sich auf alle Bereiche: Reden, belehrende, historische und briefliche Prosa, Geschäftsstil. Bei der »historischen Prosa « trifft man auf Lichtenberg (Garrik als Schauspieler), Goethe (Die letzten Tage des Karnevals zu Rom aus der Italienischen Reise), Heine (Henry Brougham, als Redner aus den Englischen Fragmenten der Reisebilder) und Fr. v. Raumer (aus seiner Geschichte der Hohenstaufen und ihrer Zeit), bei den »Erzählungen und Novellen « zweimal auf Jean Paul und auf H. v. Kleist (Das Bettelweib von Locarno). Gentz tritt dreimal als Stilist in Erscheinung. Von zeitgenössischen Parlamentsreden - die sich außerhalb Österreichs in vielen Sammlungen zum Rhetorikunterricht finden [95] - war wohl ein Abdruck schwerlich möglich. Podlaha hat über die Parlamentsberedsamkeit mit seinen Schülern mündlich gehandelt. [96] 


\section{Die literarische Kultur der höheren Schule}

Zuletzt soll die literarische Kultur der höheren Schule skizziert werden. Dies kann nur in Umrissen geschehen, denn hierzu wären vorerst eine Geschichte und Typologie der Lehrbücher - wie sie nur für die Lesebücher teilweise schon geleistet sind - und Spezialuntersuchungen (Rezeption wichtiger Autoren in der Schule, auf dem Hintergrund ihrer Wirkungsgeschichte; Schülerdichtungen und ihr Zusammenhang mit späterer literarischer Produktion; die Vorprägung geselliger und beruflicher schriftlicher Verkehrsformen durch den Unterricht u. a.) notwendig. Dennoch wird bereits deutlich, wie die höhere Schule die literarische Kultur von der Aufklärung bis in die Restaurationszeit mitbestimmte:

- Die Schule kanonisiert und konserviert die vorklassischen Autoren des 18. Jahrhunderts. Ihr Rhetorikunterricht ermöglicht eine intensive Prosakultur, die noch die Geschichts- und Reisebeschreibung wie große Teile der Sachprosa (besonders in Philosophie, Theologie, Kunstgeschichte und Pädagogik) mit dichterischen Formen (Roman, Prosaidylle, Naturschilderung) zusammenstellt. Auch die >Klassiker der Sachprosa gehören zum Großteil dem 18. Jahrhundert an.

- Der Rhetorikunterricht umfaßt wesentliche Teile der schriftlichen Kommunikation im privaten, gesellschaftlichen und beruflichen Leben und formt somit selbst alltägliche sprachliche Verhaltensweisen. Damit ist die Rhetorik noch ein kulturprägender Faktor weit über die engeren literarischen Gebiete hinaus.

- Die Redekultur, die durch die liberalen Prinzipien der Öffentlichkeit und Mündlichkeit in der politischen Bewegung nach den Befreiungskriegen einen Aufschwung erlebt, bindet Teile der politischen Diskussion und populären Bildung an die Rhetorik. Dies verschafft der Redekunst gerade bei fortschrittlichen Kräften ein neues Ansehen.

- Eine metrische Formkultur und ein literarischer Eklektizismus, der traditionell hochgewertete Gattungen und sgroße Inhalte pflegt, finden im höheren Schulunterricht eine wesentliche Stütze. Die Produktion wichtiger Autoren dieser Richtung wird schon in den Gymnasialjahren angeregt.

Diese Gesichtspunkte bestimmen die folgende Darstellung. Darüber hinaus werden die Konsequenzen der Wandlung von einem formalen zu einem historischen Bildungskonzept für die literarische Kanonbildung der Schule aufgewiesen. Ab etwa 1830 wird aus der rhetorischen Chrestomathie das nationalliterarische Lesebuch, in dem erstmals Goethe (statt Schiller) sowie Autoren der Romantik und der Befreiungskriege eine beherrschende Rolle spielen. 


\subsection{Die Prosakultur}

Die Rhetorik trägt von der Aufklärung bis zur Restaurationszeit in den Schulen eine Prosakultur, wie sie danach kaum noch denkbar ist. Sie hat nicht nur die antiken Muster, wie eh und je, sondern die besten deutschen Schriftsteller der unmittelbaren Vergangenheit, ja der Gegenwart in den Unterricht aufgenommen. Diese Entwicklung kulminiert in der Spätaufklärung, während in der Restaurationszeit die Verskultur mindestens gleichermaßen gepflegt wird. Die Spätaufklärung hat die Lehrbücher der Rhetorik und Stilistik bestimmt, solange noch ein eigener Unterricht in diesen Fächern erteilt wurde, und sie hat die zeitgenössische Prosa in den Mittelpunkt gestellt.

Das Lesebuch des Berliner Gymnasialdirektors $\rightarrow$ Meierotto (1794) [1], der sich als Organisator (Mitglied des Oberschulkollegiums) und Pädagoge einen Namen gemacht hat, bietet ein exemplarisches Beispiel. Die Zwecksetzung der Auswahl ist für den sozialen Grundansatz des Sprachunterrichts typisch. Die Beispiele sollen das Gespräch und die Rede einer gebildeten Gesellschaft lehren. Das Werk vermeidet demnach »die eigentliche Beredsamkeit «, also die förmliche öffentliche Rede, denn wo böte der Absolutismus die Gelegenheit dazu? Stilistisch gilt »das Einfache « »für das Höchste, für den letzten Zweck der Wohlredenheit «.[2] Es ist das Natürlichkeitsprinzip, wie es die späte Aufklärung gegen den Sturm und Drang radikalisierte. Meierotto hat aus didaktischen Gründen, um dem pathetischen und poetischen Stil beim Schüler keine Chance zu geben, keinerlei Verse aufgenommen. Beim Ausschluß der Poesie kann sich der zeitgenössische Horizont musterhafter Prosa voll entfalten. Breitesten Raum nimmt die engere Aufklärung und Spätaufklärung ein. Lessing ist von allen Autoren am stärksten, mit über 200 Auszügen vertreten, ganz vorwiegend aus der theoretischen Prosa, nur zum geringsten Teil aus den Prosadramen. Zwei reine Sachautoren, der Theologe Spalding und der Popularphilosoph Garve, nehmen den vierten und fünften Platz ein. Der Spätaufklärung gehören weiterhin der Philanthrop Campe, die Popularphilosophen und Ästhetiker $\rightarrow$ Engel und Eberhard an. Knigges Umgang mit Menschen ist $24 \mathrm{mal}$, ja noch $\rightarrow$ Sulzers Theorie der schönen Künste ist $10 \mathrm{mal}$ zu finden. Die Prosa bis hin zum Lehrbuch gilt noch als Kunst, steht noch nicht allein unter den Gesichtspunkten wissenschaftlicher Objektivität und Sachlichkeit. Meierotto hat Beispiele für »die gesellschaftliche Sprache « [3] ferner im Roman und Schauspiel gesucht. Shakespeare, ausschließlich in Prosaübersetzung, ist am zweithäufigsten, Wieland mit seinen Romanen am dritthäufigsten exzerpiert worden. Der Gesichtspunkt der gesellschaftsbezogenen Prosa bringt die verachtete Gattung des Romans zu Ehren. Man findet Sterne, Rousseau, Smollets Humphrey Clinker, Nicolais Sebaldus Nothanker, Hallers Staatsroman Usong, Goethes Werther, F. H. Jacobis Allwill u. a. Der Geschichte gesellen sich die Kunst- (Winckelmann) und Naturgeschichte (Buffon, Linné) bei. Die Reisebeschreibungen der Zeit sind noch zahlreicher und bilden einen Grundstock des Werkes. Die Vorzüge des Schulbuchs wie seine Schattenseiten, unhaltbare Umwertungen, beruhen auf dem Primat der Prosa, womöglich der Sachprosa. So bietet das Werk Texte aus den Grammatischen Gesprächen und der Gelehrtenrepublik, aber keine Verszeile Klopstocks. 
Dagegen fällt schon Gentz, der zukunftsträchtige Stilist, mit der Übersetzung von Burkes Betrachtungen über die französische Revolution (1793) und eigenen Zusätzen durch häufige Zitate auf.

In den folgenden Anthologien behalten die Prosaiker des 18. Jahrhunderts ihre Stelle, werden aber durch Schriftsteller der Klassik, der Romantik und der Restaurationszeit fortschreitend ergänzt. So nimmt Fülleborn in die »Prosaische Chrestomathie « seiner Rhetorik (1805) [4] K. Ph. Moritz und Georg Forster als Reiseschriftsteller, Johannes von Müllers noch nicht vollendete Geschichten Schweizerischer Eidgenossenschaft (1780-1808), in der Lehrprosa Kant mit den Beobachtungen über das Gefühl des Schönen und Erhabenen und der Kritik der praktischen Vernunft, im Roman Goethes Wilhelm Meister und Jean Pauls Siebenkäs auf. Die Auswahl in den Textsammlungen der Restaurationszeit (s. Tabelle 16) gruppiert sich um vier Schwerpunkte: (a) die Geschichtsschreibung, an die sich (Auto)Biographisches anschließt, (b) Reisebeschreibungen mit Naturschilderungen, (c) Philosophisches und Theologisches in populärer, oft erbaulicher Auswahl, (d) kunstästhetische, -historische und -kritische Prosa mit altertumswissenschaftlichen Beiträgen, (e) dichterische Prosa, mit ins Gebiet der Popularphilosophie hinüberweisenden Beispielerzählungen und Lehrgesprächen (z. B. Engel). Dabei nimmt das ästhetische Schrifttum in dem Maße zu, wie sich die Sammlungen an der >Kunstperiode Schwab, 1843; Kletke, 1844). Im einzelnen zählen folgende Autoren, deren am häufigsten abgedruckte Textstellen von mir markiert werden, zu den sSchulklassikern<:

(a) Geschichte. In reichem Maße ist die Historiographie der Aufklärung mit Johann von Archenholz (1743-1812), Isaak Iselin (1728-82), Ernst Ludwig Posselt (1763-1804), August Ludwig von Schlözer (1735-1809), Johann Matthias Schröckh (1733-1808), Ludwig Timotheus Freiherr von Spittler (1752-1810) und Helfrich Peter Sturz (1736-79) vertreten. Aus Archenholz' Geschichte des Siebenjährigen Krieges stammen die Beschreibungen der Schlachten, bei denen Friedrich d. Gr. siegreich blieb (Leuthen, Zorndorf, Liegnitz). Schröckh - »im Gebiete der Kirchengeschichte der erste Meister seiner Zeit « (G. Schwab) - liefert Bilder aus dem Glaubensleben, wie beispielsweise von Bonifatius. Von Sturz erscheinen regelmäßig Teile der Erinnerungen aus dem Leben des Grafen Johann Hartwig Ernst von Bernstorf, des dänischen Aufklärungsministers, dessen Privatsekretär der Autor war. Geschichtsphilosophische Reflexionen und kulturgeschichtliche Schilderungen werden Iselins Philosophische[n] Mutmaßungen über die Geschichte der Menschheit, Herders Ideen zur Philosophie der Geschichte der Menschheit und zur Geschichte der Menschheit, seiner Abhandlung über die Ursachen des gesunkenen Geschmacks bei den verschiedenen Völkern, da er geblühet sowie den Ideen über die Politik, den Verkehr und den Handel der vornehmsten Völker der alten Welt von Arnold Hermann Ludwig Heeren (1760-1842) entnommen. Von Mösers Patriotischen Phantasien (1774-78) finden sich im allgemeinen einige wenige Stücke (»Wie man zu einem guten Vortrage seiner Empfindungen gelange «, daneben auch: »Schreiben einer Hofdame an ihre Freundin auf dem Lande«, »Schreiben der Herrn von H . ..«, »Die Häuser des Landmanns im 
Tabelle 16: Deutsche Prosa ab 1750 in Textsammlungen für Gymnasien während der Restaurationszeit (ohne Briefe, Fabeln und Reden: Auswahl)

\begin{tabular}{|c|c|c|c|c|c|c|}
\hline $\begin{array}{l}\text { Sammlung } \\
\text { (mit Kurztitel) }\end{array}$ & $\begin{array}{l}\text { Dichterische } \\
\text { Prosa }\end{array}$ & $\begin{array}{l}\text { Geschichte, } \\
\text { Politik }\end{array}$ & $\begin{array}{l}\text { Biographie, } \\
\text { Autobiographie }\end{array}$ & $\begin{array}{l}\text { Orts- u. Reise- } \\
\text { beschreibung, } \\
\text { Naturschilderung, } \\
\text {-geschichte }\end{array}$ & $\begin{array}{l}\text { Philosophie, } \\
\text { Theologie, Päd- } \\
\text { agogik. Moral u. } \\
\text { Erbauung }\end{array}$ & $\begin{array}{l}\text { Ästhetik, Kritik, } \\
\text { Kunst-, Literatur- } \\
\text { u. Sprachge- } \\
\text { schichte, Alter- } \\
\text { tumswissenschaft }\end{array}$ \\
\hline $\begin{array}{l}\text { 1. Seber: Samm- } \\
\text { lung von Mustern } \\
\text { deutscher Pro- } \\
\text { saiker. } 2 \text { Abtt. } \\
1819 \text {. }\end{array}$ & $\begin{array}{l}\text { Engel (Lorenz } \\
\text { Stark). } \\
\text { Wieland }\end{array}$ & $\begin{array}{l}\text { Archenholz, } \\
\text { Heeren, Herder, } \\
\text { Luden, J. v. Mül- } \\
\text { ler, Schiller, } \\
\text { Woltmann }\end{array}$ & $\begin{array}{l}\text { Heeren (Heyne), } \\
\text { Herder (Winckel- } \\
\text { mann), Hottinger } \\
\text { (Geßner), Posselt, } \\
\text { Schiller, Spalding } \\
\text { (A), Sturz, Voß } \\
\text { (Hölty), Wolt- } \\
\text { mann (J. v. Mül- } \\
\text { ler) }\end{array}$ & $\begin{array}{l}\text { Engel, Forster, } \\
\text { Heinse, Hirsch- } \\
\text { feld, A. v. Hum- } \\
\text { boldt, Zimmer- } \\
\text { mann }\end{array}$ & $\begin{array}{l}\text { Fichte (Bestim- } \\
\text { mung des Men- } \\
\text { schen), Gellert, } \\
\text { Heydenreich, } \\
\text { Jerusalem, Men- } \\
\text { delssohn, Platner, } \\
\text { Schiller, Spalding, } \\
\text { Wieland }\end{array}$ & $\begin{array}{l}\text { Eberhard, Eich- } \\
\text { horn, Engel, } \\
\text { Garve, Goethe, } \\
\text { Heinse, Heyden- } \\
\text { reich, Lessing, } \\
\text { Manso, Schiller, } \\
\text { A. W. Schlegel, } \\
\text { F. Schlegel, } \\
\text { Winckelmann }\end{array}$ \\
\hline $\begin{array}{l}\text { 2. Erhard: Hand- } \\
\text { buch der teut- } \\
\text { schen Sprache. } \\
\text { 2. Cursus } \\
2 \text { Abtt. } 1822 .\end{array}$ & $\begin{array}{l}\text { Engel (Lorenz } \\
\text { Stark, Tobias } \\
\text { Witt), Fouqué } \\
\text { (Zauberring), } \\
\text { Geßner, Haller } \\
\text { (Usong), Herder, } \\
\text { Houwald, } \\
\text { F. H. Jacobi } \\
\text { (Woldemar), } \\
\text { Jean Paul (Titan), } \\
\text { Jung-Stilling } \\
\text { (Florentin von } \\
\text { Fahlendorn, } \\
\text { Heimweh), }\end{array}$ & $\begin{array}{l}\text { Archenholz, } \\
\text { Herder, Iselin, } \\
\text { J. v. Müller, } \\
\text { Rotteck, Schiller, } \\
\text { Spittler }\end{array}$ & $\begin{array}{l}\text { Goethe (A), } \\
\text { Jung-Stilling (A), } \\
\text { Schröckh, Sturz }\end{array}$ & $\begin{array}{l}\text { Forster, Goethe, } \\
\text { Herder, Hirsch- } \\
\text { feld, Hirzel, } \\
\text { A. v. Humboldt, } \\
\text { Matthisson, } \\
\text { Möser, Moritz, } \\
\text { Niebuhr, Schlö- } \\
\text { zer, Friedrich } \\
\text { L. v. Stolberg, } \\
\text { Tiedge, Zimmer- } \\
\text { mann }\end{array}$ & $\begin{array}{l}\text { Garve, Gellert, } \\
\text { F. H. Jacobi, } \\
\text { Jerusalem, Kant } \\
\text { (Kritik der prak- } \\
\text { tischen Ver- } \\
\text { nunft), Lessing, } \\
\text { Spalding, Weis- } \\
\text { haupt }\end{array}$ & $\begin{array}{l}\text { Bouterwek, } \\
\text { Engel, Heeren, } \\
\text { Lessing, } \\
\text { Winckelmann }\end{array}$ \\
\hline
\end{tabular}




\begin{tabular}{|c|c|c|c|c|c|c|}
\hline $\begin{array}{l}\text { Sammlung } \\
\text { (mit Kurztitel) }\end{array}$ & $\begin{array}{l}\text { Dichterische } \\
\text { Prosa }\end{array}$ & $\begin{array}{l}\text { Geschichte. } \\
\text { Politik }\end{array}$ & $\begin{array}{l}\text { Biographie, } \\
\text { Autobiographie }\end{array}$ & $\begin{array}{l}\text { Orts- u. Reise- } \\
\text { beschreibung, } \\
\text { Naturschilderung, } \\
\text {-geschichte }\end{array}$ & $\begin{array}{l}\text { Philosophie, } \\
\text { Theologie, Päd- } \\
\text { agogik, Moral u. } \\
\text { Erbauung }\end{array}$ & $\begin{array}{l}\text { Ästhetik, Kritik, } \\
\text { Kunst-, Literatur- } \\
\text { u. Sprachge- } \\
\text { schichte, Alter- } \\
\text { tumswissenschaft }\end{array}$ \\
\hline & $\begin{array}{l}\text { Krummacher, } \\
\text { Meißner (Alki- } \\
\text { biades). Moritz. } \\
\text { Rochlitz. Salz- } \\
\text { mann. E. Wagner. } \\
\text { Wieland } \\
\text { (Don Sylvio) }\end{array}$ & & & & & \\
\hline $\begin{array}{l}\text { 3. Reinbeck: } \\
\text { Handbuch der } \\
\text { Sprachwissen- } \\
\text { schaft. Bd. } 3 \text {. } \\
\text { Abt. 2. Bd. } 4 \\
1824-28 .\end{array}$ & $\begin{array}{l}\text { Engel (Lorenz } \\
\text { Stark). Fouqué } \\
\text { (Undine), } \\
\text { Geßner. Herder. } \\
\text { Jean Paul } \\
\text { (Leben Fibels). } \\
\text { Schiller (Geister- } \\
\text { seher). Thümmel }\end{array}$ & $\begin{array}{l}\text { Herder, Luden, } \\
\text { J.v. Müller. } \\
\text { Possclt, F.v. Rau- } \\
\text { mer. Schiller }\end{array}$ & $\begin{array}{l}\text { Goethe (A), } \\
\text { Heyne (A), } \\
\text { J. v. Müller, } \\
\text { Schiller }\end{array}$ & $\begin{array}{l}\text { Forster, Heinse, } \\
\text { A. v. Humboldt. } \\
\text { Kant, Meiners. } \\
\text { Johanna } \\
\text { Schopenhauer }\end{array}$ & $\begin{array}{l}\text { Engel (Mimik), } \\
\text { Eschenmayer, } \\
\text { Fichte (Bestim- } \\
\text { mung des Men- } \\
\text { schen), Garve, } \\
\text { Heydenreich, } \\
\text { Kant (Anthro- } \\
\text { pologie, Kritik der } \\
\text { Urteilskraft), } \\
\text { Knigge (Umgang } \\
\text { mit Menschen), } \\
\text { Krug }\end{array}$ & $\begin{array}{l}\text { Fernow, Goethe. } \\
\text { Heeren, Herder, } \\
\text { Jean Paul, Ch. G. } \\
\text { Körner, Lessing } \\
\text { (Laokoon, dazu } \\
\text { Herder), Quandt, } \\
\text { A. W. Schlegel, } \\
\text { F. Schlegel, Solger } \\
\text { (Erwin), } \\
\text { Winckelmann }\end{array}$ \\
\hline $\begin{array}{l}\text { 4. Hiecke: } \\
\text { Handbuch Deut- } \\
\text { scher Prosa. } \\
183.5 \text {. }\end{array}$ & & $\begin{array}{l}\text { Herder, Leo, } \\
\text { J. v. Müller, } \\
\text { Schiller. } \\
\text { A. W. Schlegel }\end{array}$ & Goethe (A) & $\begin{array}{l}\text { A. v. Humboldt, } \\
\text { Ritter, Steffens }\end{array}$ & $\begin{array}{l}\text { Fichte, Hegel } \\
\text { (Geschichte der } \\
\text { Philosophie), } \\
\text { Marhcinecke, } \\
\text { Schleiermacher }\end{array}$ & $\begin{array}{l}\text { Bopp. Creuzer, } \\
\text { Garve, Goethe, } \\
\text { J. Grimm, Hee- } \\
\text { ren, Hegel. } \\
\text { W. v. Humboldt, } \\
\text { F. Jacobs, Lessing, }\end{array}$ \\
\hline
\end{tabular}


Fortsetzung Tabelle 16

\begin{tabular}{|c|c|c|c|c|c|c|}
\hline $\begin{array}{l}\text { Sammlung } \\
\text { (mit Kurztitcl) }\end{array}$ & $\begin{array}{l}\text { Dichterische } \\
\text { Prosa }\end{array}$ & $\begin{array}{l}\text { Geschichte, } \\
\text { Politik }\end{array}$ & $\begin{array}{l}\text { Biographie. } \\
\text { Autobiographie }\end{array}$ & $\begin{array}{l}\text { Orts-u. Reise- } \\
\text { beschrcibung. } \\
\text { Naturschilderung. } \\
\text {-geschichte }\end{array}$ & $\begin{array}{l}\text { Philosophie, } \\
\text { Theologie, Päd- } \\
\text { agogik, Moral u. } \\
\text { Erbauung }\end{array}$ & $\begin{array}{l}\text { Ästhetik, Kritik, } \\
\text { Kunst-, Literatur- } \\
\text { u. Sprachge- } \\
\text { schichte, Alter- } \\
\text { tumswissenschaft }\end{array}$ \\
\hline & & & & & & $\begin{array}{l}\text { Manso, Möser, } \\
\text { W. Müller, Nie- } \\
\text { buhr, Rosenkranz, } \\
\text { Schiller, A. W. } \\
\text { Schlegel, F. Schle- } \\
\text { gel, Solger, Varn- } \\
\text { hagen von Ense, } \\
\text { Ch. H. Weiße, } \\
\text { Wieland }\end{array}$ \\
\hline $\begin{array}{l}\text { 5. Schwab: Die } \\
\text { deutsche Prosa. } \\
2 \text { Tle. } 1843 \text {. }\end{array}$ & $\begin{array}{l}\text { Börne, Chamisso } \\
\text { (Peter Schlemihl), } \\
\text { Claudius, Engel } \\
\text { (Lorenz Stark). } \\
\text { Fouqué. Goethe } \\
\text { (Wahlverwandt- } \\
\text { schaften), Brüder } \\
\text { Grimm, Gutz- } \\
\text { kow, Hauff, J. P. } \\
\text { Hebel. Heine. } \\
\text { Hölderlin (Hype- } \\
\text { rion). E. T. A. } \\
\text { Hoffmann (Ritter } \\
\text { Gluck), Immer- } \\
\text { mann. Jean Paul } \\
\text { (Siebenkäs. Titan), }\end{array}$ & $\begin{array}{l}\text { Archenholz, } \\
\text { Gentz, Görres, } \\
\text { Hammer-Purg- } \\
\text { stall, Kaiser Jo- } \\
\text { seph II.. Karl } \\
\text { Fricdrich von } \\
\text { Baden, Leo, } \\
\text { Menzel, F. K. } \\
\text { v. Moser,J.v. Mül- } \\
\text { ler, Niebuhr, } \\
\text { Posselt, Ranke, } \\
\text { F. v. Raumcr, } \\
\text { Rotteck, Schiller, } \\
\text { v. Schlabrendorf, } \\
\text { Schlosser, } \\
\text { Spittler, }\end{array}$ & $\begin{array}{l}\text { Arndt (Frhr. vom } \\
\text { Stein), Goethe } \\
\text { (A), Hamann (A), } \\
\text { Jung-Stilling (A), } \\
\text { Lavater (Tage- } \\
\text { buch). Schiller, } \\
\text { Schubart (A), } \\
\text { Voß (A) }\end{array}$ & $\begin{array}{l}\text { Alexis, Chamisso, } \\
\text { Heinse, Herder, } \\
\text { A. v. Humboldt, } \\
\text { Pückler-Muskau, } \\
\text { C. Ritter, L. Sche- } \\
\text { fer, Schubert, } \\
\text { Seume, Steffens, } \\
\text { F. L. v. Stolberg }\end{array}$ & $\begin{array}{l}\text { Abbt, Creuzer, } \\
\text { Fichte, Garve, } \\
\text { Gellert, Herder, } \\
\text { Hippel, Jahn, } \\
\text { Kant, Knigge, } \\
\text { Lavater, Men- } \\
\text { delssohn, } \\
\text { Neander, Pesta- } \\
\text { lozzi, Reimarus, } \\
\text { Sailer, Schelling, } \\
\text { F. Schlegel, } \\
\text { Schleiermacher, } \\
\text { Schubert, } \\
\text { Tholuck, } \\
\text { Zimmermann }\end{array}$ & $\begin{array}{l}\text { v. Arnim, Bois- } \\
\text { serée, Eberhard, } \\
\text { Fernow, Forster, } \\
\text { Garve, Gervinus, } \\
\text { Geßner (Land- } \\
\text { schaftsmalerei), } \\
\text { Goethe, Jacob } \\
\text { Grimm, Wilhelm } \\
\text { Grimm, Heeren, } \\
\text { Hegel, W.v. Hum- } \\
\text { boldt, F. Jacobs, } \\
\text { Klopstock, } \\
\text { Knebel, Lessing, } \\
\text { W. Müller, } \\
\text { Mundt, Passa- } \\
\text { vant, P. A. Pfizer, }\end{array}$ \\
\hline
\end{tabular}


Fortsetzung Tabelle 16

\begin{tabular}{|c|c|c|c|c|c|c|}
\hline $\begin{array}{l}\text { Sammlung } \\
\text { (mit Kurztitel) }\end{array}$ & $\begin{array}{l}\text { Dichterische } \\
\text { Prosa }\end{array}$ & $\begin{array}{l}\text { Geschichte, } \\
\text { Politik }\end{array}$ & $\begin{array}{l}\text { Biographie, } \\
\text { Autobiographie }\end{array}$ & $\begin{array}{l}\text { Orts- u. Reise- } \\
\text { beschreibung, } \\
\text { Naturschilderung, } \\
\text {-geschichte }\end{array}$ & $\begin{array}{l}\text { Philosophie, } \\
\text { Theologie, Päd- } \\
\text { agogik, Moral u. } \\
\text { Erbauung }\end{array}$ & $\begin{array}{l}\text { Ästhetik, Kritik, } \\
\text { Kunst-, Literatur- } \\
\text { u. Sprachge- } \\
\text { schichte, Alter- } \\
\text { tumswissenschaft }\end{array}$ \\
\hline & $\begin{array}{l}\text { H. v. Kleist } \\
\text { (Michael Kohl- } \\
\text { haas), Klinger, } \\
\text { Krummacher, } \\
\text { Maler Müller, } \\
\text { Musäus, Novalis, } \\
\text { Thümmel, Tieck, } \\
\text { E. Wagner, } \\
\text { Wieland }\end{array}$ & $\begin{array}{l}\text { Frhr. vom Stein, } \\
\text { Sturz, } \\
\text { Woltmann }\end{array}$ & & & & $\begin{array}{l}\text { Rosenkranz, } \\
\text { Schelling, } \\
\text { Schiller, A. W. } \\
\text { Schlegel, F. Schle- } \\
\text { gel, Solger, } \\
\text { Uhland, Waagen, } \\
\text { Wackenroder, } \\
\text { Winckelmann, } \\
\text { F. A. Wolf }\end{array}$ \\
\hline $\begin{array}{l}\text { 6. Kletke: } \\
\text { Deutsche Auf- } \\
\text { sätze. } 1844 \\
\text { (mit Auszügen } \\
\text { in Anmerkun- } \\
\text { gen) }\end{array}$ & & $\begin{array}{l}\text { Ancillon, } \\
\text { Heeren, Herder, } \\
\text { W. v. Humboldt, } \\
\text { Jahn, J.v. Müller, } \\
\text { Ranke, Schiller, } \\
\text { L. Wachler }\end{array}$ & & & $\begin{array}{l}\text { Abbt, Ancillon, } \\
\text { Fichte (Reden an } \\
\text { die deutsche } \\
\text { Nation), Garve, } \\
\text { Herder, Schleier- } \\
\text { macher }\end{array}$ & $\begin{array}{l}\text { Ancillon, Ger- } \\
\text { vinus, J. Grimm, } \\
\text { W. Grimm, } \\
\text { Goethe, O. F. } \\
\text { Gruppe, Heeren, } \\
\text { W. v. Humboldt, } \\
\text { F. Jacobs, Jean } \\
\text { Paul, Knebel, } \\
\text { Lessing, } \\
\text { Manso, Rosen- } \\
\text { kranz, Schiller, } \\
\text { A. W. Schlegel, } \\
\text { F. Schlegel, } \\
\text { W. Süvern, } \\
\text { W. Wackernagel, } \\
\text { F. A. Wolf, } \\
\text { K. Zell }\end{array}$ \\
\hline
\end{tabular}


Nach den Autorennamen sind auswahlhaft Werktitel verzeichnet, aus denen Auszüge stammen. In der Sparte >Biographie, Autobiographie wird die gewürdigte Persönlichkeit annotiert; $\mathrm{A}=$ autobiographische Äußerungen. - Vollständige Titel der Sammlungen: (1) F[ranz] J[oseph] Seber: Sammlung von Mustern deutscher Prosaiker für die mittlern und höhern Klassen der Gymnasien. 2 Abtt. Köln: Du Mont-Schauberg 1819 ; (2) Heinrich August Erhard: Handbuch der teutschen Sprache in ausgewählten Stücken teutscher Prosaiker und Dichter aus allen Jahrhunderten. 2. Cursus. Prosaischer Theil. A.u.d.T.: Schauplatz teutscher Prosa in ausgewählten Stücken mustergiltiger Schriftsteller neuerer Zeit. 2 Abtt. Erfurt: Maring 1822; (3) Georg Reinbeck: Handbuch der Sprachwissenschaft mit besonderer Hinsicht auf die deutsche Sprache. Zum Gebrauche für die obern Klassen der Gymnasien und
Lyceen. Bd. 3, Abt. 2. A.u.d. T.: Poetische Beispielsammlung zu Vorlesungen über Poetik und zur Declamation. Essen: Bädeker 1824 (Roman, Novelle, Prosaidylle, Märchen, Paramythie); Dass. Bd. 4. A.u.d.T.: Prosaische Beispielsammlung etc. Ebd. 1828; (4) Robert Heinrich Hiecke: Handbuch Deutscher Prosa für obere Gymnasialclassen; enthaltend eine auf Erweiterung des Gedankenkreises und Bildung der Darstellung berechnete Sammlung auserlesener Prosastücke. Zeitz: Webel, Leipzig: Eisenach 1835; (5) Gustav Schwab: Die deutsche Prosa von Mosheim bis auf unsere Tage. Eine Mustersammlung mit Rücksicht auf höhere Lehr-Anstalten. 2 Tle. Stuttgart: Liesching 1843; (6) H[einrich] Kletke: Deutsche Aufsätze [...]; nebst Anmerkungen und Aufgaben. Für die oberen Classen höherer Bildungsanstalten wie auch zum Selbststudium. Berlin: Amelang 1844. 
Osnabrückischen sind in ihrem Plan die besten «); Eisenschmids Polymnia 1827 (s. Bibliographie Bd 2, Kap. 1.3.3) gibt allerdings mit 10 Beiträgen eine breite Auswahl.

Eine beherrschende Stellung nehmen Schiller und Johannes von Müller (1752-1809) ein. Einige Abschnitte aus der Geschichte des Abfalls der vereinigten Niederlande von der spanischen Regierung (insbesondere die Charakteristik »Wilhelm von Oranien und Graf von Egmont « aus dem I. Buch, Albas Alpenüberquerung und Egmonts Gefangennahme aus dem IV. Buch sowie die zweite Beilage »Belagerung von Antwerpen durch den Prinzen von Parma in den Jahren 1584 und 1585 «) und der Geschichte des Dreißigjährigen Kriegs (z. B. Schlacht bei Lützen mit Gustav Adolphs Tod, Eroberung Magdeburgs) sowie die kleinere Schrift Über Völkerwanderung, Kreuzzüge und Mittelalter - ein Teil der unvollendeten Universalhistorischen Ubersicht - sind in fast jeder Sammlung vertreten. Ebenso die einleitende Beschreibung »Des Landes Urgestalt « und Schlachtenschilderungen (Morgarten, Laupen und vor allem Sempach) aus J. v. Müllers Geschichten Schweizerischer Eidgenossenschaft, die als »ein consommé von Geist, in der prägnantesten Form, nach Tacitus' Weise « [5] überaus hoch eingeschätzt werden. Ähnlich beliebt ist die farbige Schilderung der Kaiserkrönung Josephs II., wie sie Goethe selbst erlebte (Dichtung und Wahrheit, Tl. I, Buch 5). Mehrmals wird von Schiller die Jenaer Antrittsvorlesung Was heißt und $z u$ welchem Ende studiert man Universalgeschichte? und von J. v. Müller die Berliner Akademierede Uber die Geschichte Friedrichs des Zweiten (1805) nachgedruckt. Von den wichtigen historischen Werken der ersten Hälfte des 19. Jahrhunderts erhalten Niebuhrs Römische Geschichte (1811/12--32, meist die Einleitung), Friedrich von Raumers Geschichte der Hohenstaufen und ihrer Zeit (1823-25) sowie Rankes Römische Päpste (1834-36) und Deutsche Geschichte im Zeitalter der Reformation (1839-47) schon wenige Jahre nach ihrem Erscheinen einen Platz im Unterricht.

Nachweise (mit weiteren, verstreut gedruckten Autoren; ohne Goethe und Herder. Titel in Kurzform, vollständige bibliographische Angaben s. Bibliographie Bd. 2, Kap. 1.3.3 in alphabetischer Ordnung). Pischon, Handbuch, 1818: Archenholz, Bünau, Iselin, Meusel, Möser (»Osnabrückische Geschichte « u. a.), J. v. Müller, Schiller, Schlözer, Schröckh, F. L. v. Stolberg (»Leben Alfreds des Großen «), Sturz. - Seber, Sammlung, 1819: Archenholz, Heeren, Luden, J. v. Müller, Posselt, Schiller, Sturz, Woltmann. - Erhard, Handbuch, 2. Cursus, 1822: Archenholz, Bünau, Heeren, Iselin, Menzel (»Geschichte der Deutschen«), Möser (»Osnabrückische Geschichte«), J. v. Müller, Rotteck, Schiller, Schlözer, Schröckh, Spittler, Sturz. - Reinbeck, Handbuch, Bd. 3-4, 1824-28: Heeren, Luden, J. v. Müller (»24 Bücher Allgemeiner Geschichte etc. «), Posselt, F. v. Raumer, Schiller. - Eisenschmid, Polymnia, Abt. I, 1827: Möser, J. v. Müller, F. v. Raumer, Rotteck, Schiller (»Herzog von Alba bei einem Frühstück auf dem Schlosse zu Rudolstadt im Jahr 1547« u. a.), F. L. v. Stolberg. - Reinbeck, Vorhalle, 1827: Möser, J. v. Müller, Posselt, F. v. Raumer, F. L. v. Stolberg, Sturz, Woltmann. - Hiecke, Handbuch, 1835: Heeren, Leo (»Geschichte von Italien«), Möser, J. v. Müller, Niebuhr, Schiller. - Schwab, Deutsche Prosa, 1843: Archenholz, Hammer-Purgstall (»Geschichte des Osmanischen Reiches «), Heeren, Leo, Menzel, Möser, J. v. Müller, Niebuhr, Posselt, Ranke, F. v. Raumer, Rotteck, Schiller, Schlosser, Spittler, Woltmann. - W. Wackernagel, Lesebuch, Tl. 3, Bd. 2, 1843: Iselin, Möser, J. v. Müller, Niebuhr, Ranke, F. v. Raumer, Schiller. - Kletke, Deutsche Aufsätze, 1844: Heeren ("Geschichte der classischen Litteratur im Mittelalter", "Handbuch der Geschichte des europäischen Staatensystems und seiner Colonien etc. ", »Versuch einer Entwickelung der Folgen der Kreuzzüge für Europa « u. a.), W. v. Humboldt (»Ueber die Aufgabe des Geschichtsschreibers«), Möser, J. v. Müller, Ranke, Schiller, L. Wachler. - 
Pischon, Denkmäler, Tl. 4-6, 1845-51: Archenholz, Möser (»Osnabrückische Geschichte«, »Úber die deutsche Sprache und Litteratur« u. a.), J. v. Müller (»Ueber den Untergang der Freiheit alter Völker« u. a.), Niebuhr, Planck, Ranke, F. v. Raumer, Schiller, Schlözer, Schröckh, Sturz, Woltmann. - Mustersammlung (Bayern), Tl. 2, Abt. 1, 1847: Hammer-Purgstall, Möser (»Osnabrückische Geschichte « u. a.), J. v. Müller, Niebuhr, Ranke, Schiller. Schillers Rede »Was heißt und zu welchem Ende studiert man Universalgeschichte? «: Erhard, Handbuch, 2. Cursus, 1822; Rupp, Mustersammlung, 1842; Kannegießer, Redner, 1845; Wolff, Handbuch deutscher Beredsamkeit, 1846.

(b) Naturschilderung und Reisebeschreibung. Die Naturschilderungen sind teils Stimmungsbilder (Hirschfeld, Thümmel, Jean Paul), teils entspringen sie objektiver Beobachtung (Forster, A. v. Humboldt, Chamisso) und gehören so den noch übergänglichen Bereichen von Dichtung und Wissenschaft gleichermaßen an. Der eine Teil der Texte stammt demgemäß aus Dichtungen und Reisebeschreibungen von Dichtern wie Heinse, Goethe, F. L. v. Stolberg, Seume (Spaziergang nach Syrakus) oder Matthisson, die vor allem ein literarisches Interesse beanspruchen. In anderen Texten kommen die großen wissenschaftlichen Reisenden zu Wort, so Forster, A. v. Humboldt oder Chamisso. Eine Auswahl aus beiden Bereichen bildet den Grundbestand. Zu ihr gehören: die von Engel in didaktischer Absicht erzählte Reise auf den Ätna aus dem Philosoph für die Welt, die Beschreibung des Rheinfalls bei Schaffhausen (an F. H. Jacobi, 15. 8. 1780) und von Tivoli (an Gleim, vor dem Peterstage 1782) in Briefen Heinses, die Reise über Neapel nach der Insel Ischia aus Jean Pauls Titan (28. Jubelperiode), Forsters Schilderung der Insel Tahiti (Reise um die Welt, Tl. I, 8. Hauptstück) und Auszüge aus A. v. Humboldts Werken. Neben Texten, die die Grenze zur Naturphilosophie überschreiten (z. B. Forsters Blick in das Ganze der Natur, 1794), wird mit Karl Ritter (1779-1859) die wissenschaftliche Entwicklung der Geographie dokumentiert. Das Mit- oder Gegeneinander von Humanismus und Realismus bestimmt den Umfang der Thematik in den Anthologien; bei ganz auf sprachliche, ästhetische und philosophische Themen konzentrierten Sammlungen tritt die Beschäftigung mit der Natur in den Hintergrund (Hiecke, Handbuch Deutscher Prosa, 1835; W. Wackernagel, Deutsches Lesebuch, Tl. 3, Bd. 2, 1843; Kletke, Deutsche Aufsätze, 1844).

Nachweise. Seber, Sammlung, 1819: Engel, Forster (»Der Brodtbaum«, 1784; »Ein Blick in das Ganze der Natur « u. a.), Heinse, Hirschfeld, A. v. Humboldt, Zimmermann (»Taschenbuch der Reisen «). - Erhard, Handbuch, 2. Cursus, 1822: Forster, Goethe, Hirschfeld, Hirzel (»Eugenias Briefe«), A. v. Humboldt, Jean Paul, Matthisson ("Der große Bernhardsberg" und "Die Felsenkuppe zu Mayenne « aus den »Erinnerungen«), Moritz (»Die Höhle bei Castleton « aus »Reisen eines Deutschen in England im Jahr 1782«), F. L. v. Stolberg, Zimmermann. Reinbeck, Handbuch, Bd. 3-4, 1824-28: Heinse, A. v. Humboldt, Kant (»Das Erdbeben « aus „Physische Geographie «), A. W. Kephalides, Ch. Meiners, Johanna Schopenhauer. - Eisenschmid, Polymnia, Abt. I, 1827: Bonstetten, Engel, Forster (»Ein Blick in das Ganze der Natur « u. a.), Goethe, Heinse, Hirschfeld, A. v. Humboldt, Jean Paul, Matthisson, Meiners ("Briefe über die Schweiz«, 9 Auszüge), Moritz, Thümmel (»Reisen in die mittäglichen Provinzen von Frankreich «), J. Schopenhauer, F. L. v. Stolberg, Zimmermann. - Reinbeck, Vorhalle, 1827: Bonstetten, F. Brun, Buffon, Engel, Forster, Goethe, Heinse, A. v. Humboldt, Kephalides, Reimarus (»Allgemeine Betrachtungen ueber die Triebe der Thiere «), J. Schopenhauer, Seume, Zimmermann. - Schwab, Deutsche Prosa, 1843: Chamisso (»Reise um die Welt«), Heinse, A. v. Humboldt, Jean Paul, K. Ph. Fr. v. Martius, Pückler-Muskau, Ritter, L. Schefer, G. H. v. 
Schubert, Seume, Steffens, F. L. v. Stolberg. - Pischon, Denkmäler, Tl. 4-6, 1845-51: Forster (»Der Brodtbaum « u. a.), Heinse, A. v. Humboldt, Jean Paul, Moritz, Pückler-Muskau, Seume, Thümmel. - Mustersammlung (Bayern), 1845-47: Forster, Goethe, Heinse, A. v. Humboldt, Jean Paul, Martius, Matthisson, Pückler-Muskau, K. v. Raumer, Schubert.

(c) Philosophisches und Theologisches. Die populäre Philosophie und Theologie der Aufklärung nimmt in diesem Bereich den beherrschenden Raum ein, bevor sie in den $30 \mathrm{er}$ und 40er Jahren vom Idealismus teilweise verdrängt wird. Zu den Theologen Johann Friedrich Wilhelm Jerusalem (Betrachtungen über die vornehmsten Wahrheiten der Religion, 1768-69 u. ö.) und Johann Joachim Spalding (Die Bestimmung des Menschen, 1748 u. ö.) treten die berühmten geistlichen Redner: Johann Lorenz von Mosheim (1694-1755), der »Vater der modernen Kanzelberedsamkeit«(G. Schwab), Georg Joachim Zollikofer (1730-88) und Franz Volkmar Reinhard (1753-1812). Die Sammlungen der Popularphilosophen $\rightarrow$ Engel (Der Philosoph für die Welt, 1775-1800) und Garve (Versuche über verschiedene Gegenstände aus der Moral, der Literatur und dem gesellschaftlichen Leben, 1792-1802), die Schriften von Abbt (Vom Verdienste, 1765) und Knigge (Úber den Umgang mit Menschen, 1788) werden geradezu geplündert. Unübertroffen in ihrer Breitenwirkung sind die Lehrgespräche und Beispielerzählungen im Philosoph für die Welt, die den von der Schule propagierten Geist gemäßigter Aufklärung verdeutlichen können: Unerschrockenes tugendhaftes Streben, bei Ergebung in das Schicksal, hat absoluten Wert (Der Ätna, Das Irrenhaus), auch vor dem Glück wissenschaftlicher Erkenntnis (Traum des Galilei). Gott als Schöpfer der Welt und Garant ihrer Ordnung wird im Sinn von Leibniz gegen den französischen Materialismus verteidigt (Die Höhle auf Antiparos, wo d'Holbachs Système de la nature ins Feuer geworfen wird; Der Bienenkorb, Die Spinne); menschlichen Irrtum wendet die Vorsehung zum Guten (Entzückung des Las Casas). Bürgerliche Solidität im Geschäftlichen verbindet sich mit sgesundem Menschenverstand in geistigen Fragen. So enterbt Joseph Timm in dem gleichnamigen Stück sowohl den kaufmännisch wie den philosophisch in der Weise Fichtes spekulierenden Sohn. Im Ästhetischen wird der Kult des Genies zurückgewiesen, ohne daß die Kunst durch Regeln gegängelt oder auf die Moral verpflichtet wird (Zwei Gespräche, Von dem moralischen Nutzen der Dichtkunst). In ihrer ausgleichenden lebenspraktischen Tendenz und ihrer didaktischen Anlage boten sich diese in einem musterhaft klaren Stil erzählten Stücke für den Unterricht an.

Vom Idealismus erscheinen Schleiermachers Monologe (1800) und Fichtes Reden an die deutsche Nation (1808), zwei in weite Kreise wirkende Dokumente der geistigen Erneuerung, am häufigsten. Mehrmals begegnet von Fichte auch Die Bestimmung des Menschen (1800) und der Aufsatz Úber Belebung und Erhöhung des reinen Interesse für Wahrheit aus den Horen von 1795. Von Kant gibt es Auszüge aus der Allgemeinen Naturgeschichte und Theorie des Himmels (1755), den Beobachtungen über das Gefühl des Schönen und Erhabenen (1764), aus der Kritik der praktischen Vernunft (1788) und der Urteilskraft (1790), ohne daß sich eine bestimmte Auswahl durchsetzt. Die um einen theistischen Gottesglauben bemühten Schriften von F. H. Jacobi (Von den göttlichen Dingen und ihrer Offenbarung, 1811) und 
Schelling (Philosophische Untersuchungen über das Wesen der menschlichen Freiheit etc., 1809) dringen bis in die Gymnasien; Hegels Philosophie entfernt sich zu weit von der Alltagssprache und gilt wohl auch als zu gefährlich. Größte Resonanz findet Schleiermacher, der Begründer der liberalen protestantischen Theologie des 19. Jahrhunderts. Vor allem als Redner ist er in den verschiedensten Zusammenhängen gegenwärtig: Von den Reden Über die Religion. An die Gebildeten unter ihren Verächtern (1799), die den christlichen Glauben wieder gesellschaftsfähig zu machen halfen, den Predigten über den christlichen Hausstand (1818), einer Sittenlehre des Alltagslebens, bis zur Berliner Akademierede zum Geburtstag Friedrichs d. Gr. (24. Januar 1817) oder den Worten, die er am Grab seines einzigen Sohnes, des kleinen Nathanael, sprach (21. November 1829).

Nachweise. Seber, Sammlung, 1819: Engel (»Versuch einer Methode die Vernunftlehre aus Platonischen Dialogen zu entwickeln« u. a.), Fichte, Garve, Gellert (»Moralische Vorlesungen«), Heydenreich, Jerusalem, Mendelssohn, Platner, Reinhard, Spalding, Wieland (»Platonische Betrachtungen über den Menschen«, 1755), Zollikofer. - Erhard, Handbuch, 2. Cursus, 1822: Engel, Garve, Gellert, Herder, F. H. Jacobi, Jerusalem, Kant (»Kritik der praktischen Vernunft «), Mosheim, Reinhard, Spalding, Sturz, Zollikofer. - Eisenschmid, Polymnia, Abt. I, 1827: Engel, Herder, Jerusalem, Mendelssohn, Reinhard, Schleiermacher, F. L. v. Stolberg (»Uber die Fülle des Herzens «), Wieland, Zollikofer. - Reinbeck, Handbuch, Bd. 4, 1828: Engel ("Ideen zu einer Mimik « u. a.), Eschenmayer, Fichte ("Uber das Wesen des Gelehrten etc. « u. a.), Garve, Heydenreich, Kant (»Anthropologie in pragmatischer Hinsicht«, »Kritik der Urteilskraft «), Knigge, W. T. Krug, Schleiermacher. - Rupp, Mustersammlung, 1842: Fichte, Herder, Lessing (»Anti-Goeze«), Schleiermacher (»Rede an Nathanaels Grabe« u. a.), de Wette. - Schwab, Deutsche Prosa, 1843: Abbt, Creuzer (»Symbolik und Mythologie der alten Völker«), Fechner (Ps. Mises), Fichte, Garve, Hegel, Herder, Hippel (»Úber die Ehe«), Kant (»Kritik der Urteilskraft «), Knigge, Mendelssohn, Mosheim, Neander, Reimarus, Reinhard, Schelling, F. Schlegel (»Über die Sprache und Weisheit der Indier « u. a.), Schleiermacher, G. H. v. Schubert (»Die Geschichte der Seele «), Tholuck, Wieland. - W. Wackernagel, Lesebuch, Tl. 3, Bd. 2, 1843: Abbt, Engel, Fichte (»Anweisung zum seligen Leben etc. «u. a.), Hegel ("Wissenschaft der Logik«), Herder, F. H. Jacobi, Kant (»Kritik der praktischen Vernunft «), Lessing, Reinhard, Schelling (»Vorlesungen über die Methode des akademischen Studiums u. a.), Schleiermacher. - Kletke, Deutsche Aufsätze, 1844: Abbt, Ancillon (»Zur Vermittlung der Extreme in den Meinungen «, 4 Auszüge), Fichte, Garve, Herder, Schleiermacher, Zollikofer. Pischon, Denkmäler, Tl. 4-6, 1845-51: Engel, Fichte, Garve, Hegel, Herbart, Hippel, F. H. Jacobi (»Ueber die Lehre des Spinoza etc. «u. a.), Jerusalem, Kant, Krause, Mendelssohn ("Phädon, oder über die Unsterblichkeit der Seele «, "Jerusalem, oder Über religiöse Macht und Judenthum« u. a.), Reinhard, Schelling (»Bruno oder über das göttliche und natürliche Princip der Dinge « u. a.), Schleiermacher, Solger, Theremin, Zollikofer. - Mustersammlung (Bayern), Tl. 2, Abt. 1, 1847: Engel, Fichte, Hippel, F. H. Jacobi, Kant, Knigge, J. M. Sailer, Schleiermacher, Sturz.

(d) Asthetik, Kunst-, Literatur- und Sprachgeschichte. Wie sehr die höhere Schule das Interesse an Literatur und Kunst gepflegt und in welchem Maße sie mit dem historischen Wissen und den herrschenden Geschmacksrichtungen der Zeit von Winckelmann, Lessing und Herder an bekannt gemacht hat, zeigt die Überfülle der diesbezüglichen Beiträge. Von Lessing, Herder, Goethe - einschließlich der Erörterungen über Shakespeares Hamlet und das Verhältnis von Roman und Drama aus dem 5. Buch von Wilhelm Meisters Lehrjahre[n] und den Charakteristiken aus Dichtung und Wahrheit - und Schiller (mit dem Briefwechseln Goethe/Schiller und 
Schiller/Humboldt) sind alle wesentlichen Schriften in Auszügen zu finden. Von W. v. Humboldt werden die durch Goethes Hermann und Dorothea, einer obligaten Schullektüre, angeregten Ästhetische[n] Versuche (z. B. Kletke, Deutsche Aufsätze, 1844: »Das Wesen der epischen Dichtung «, »Unterschied zwischen der Epopöe und der Tragödie ", "Unterschied zwischen der Epopöe und der Idylle «) und teilweise auch seine sprachphilosophischen Werke (Über das Entstehen der grammatischen Formen und ihren Einflu $\beta$ auf die Ideenentwicklung, etwa bei Hiecke, Handbuch, 1835; Ueber die Verschiedenheit des menschlichen Sprachbaus und ihren Einflu $\beta$ auf die geistige Entwicklung des Menschengeschlechts, die Einleitung "Über die Kawisprache auf der Insel Java «, etwa bei Kletke) gelesen. Hie und da erscheinen von Jean Paul die Vorschule der Ästhetik (Kletke, über Herder) und die Kleine Bücherschau (z. B. Reinbeck, Handbuch, Bd. 4, 1828: »Ueber das Lächerliche«, der Kleine[n] Nachschule VI. Programm).

Zum Kernbestand des romantischen Schrifttums zählen A. W. Schlegels Wiener Vorlesungen über dramatische Kunst und Literatur, in den hier herangezogenen Sammlungen schon von Seber (1819) an, beispielsweise mit Auszügen »Ueber den Ursprung und Geist des Romantischen « und »Ueber das Wesen der drei Hauptgattungen der Poesie « (Mustersammlung [Bayern], Tl. 2, Abt. 1, 1847, aus der ersten und dritten Vorlesung). Dazu tritt ergänzend die Besprechung des Werkes durch Solger in den Wiener Jahrbüchern (Hiecke). Gelegentlich trifft man auf die damals nur bruchstückhaft publizierten Berliner Vorlesungen von 1802 (Schwab, Deutsche Prosa, 1843, s. Tabelle 17), die Würdigung von Hermann und Dorothea (Hiecke) u. a. Von F. Schlegel werden am meisten die Wiener Vorlesungen über Die Geschichte der alten und neuen Literatur berücksichtigt, daneben Uber die Sprache und Weisheit der Indier (Schwab; W. Wackernagel, Lesebuch, Tl. 3, Bd. 2, 1843) sowie Jugendschriften wie Uber Lessing (Kletke), Die Griechen und Römer und Geschichte der Poesie der Griechen und Römer (beide Seber). Mehrfach werden Fragmente von Novalis aus den von F. Schlegel und Tieck herausgegebenen Schriften übernommen (Schwab; Pischon, Denkmäler, Tl. 5, 1847), und sogar Auszüge aus Solgers Erwin (Reinbeck, Schwab) finden sich. Von den großen Sammlungen drucken die Schulanthologien die Einleitungen ab (A. v. Arnim zu Des Knaben Wunderhorn, die Brüder Grimm zu den Sagen und Märchen), von Jakob Grimm auch die für die romantische Sprachauffassung kennzeichnende Vorrede zur Deutsche[n] Grammatik (W. Wackernagel; Mustersammlung: »Der Nachtheil des grammatischen Unterrichts in der deutschen Sprache in Schulen «).

Wie die Klassik und Romantik ihre ästhetischen Ansichten ebenso an der bildenden Kunst wie der Literatur entwickelt haben, so werden beide Gebiete auch im Schulunterricht eng aufeinander bezogen. Die Auswahl aus Winckelmann ist bis heute gültig geblieben: Aus der Geschichte der Kunst des Altertums die Abschnitte »Von den Gründen und Ursachen des Aufnehmens und des Vorzugs der griechischen Kunst vor andern Völkern " (Buch 4, Kap. 1) und »Von dem Wesentlichen der Kunst « (Buch 4, Kap. 2), die ausgefeilten kleineren Vorarbeiten zu diesem Hauptwerk: Beschreibung des Apollo im Belvedere, Beschreibung des Torso im Belvedere zu Rom, Von der Grazie in den Werken der Kunst sowie die Gedanken über die 
Nachahmung der griechischen Werke in der Malerei und Bildhauerkunst mit den Ausführungen zum Laokoon. Neben der Lessingschen Schrift werden auch die Stellungnahmen Herders und Goethes zur Laokoonfrage abgedruckt. Die Gattung der Kunstbeschreibung, die einen hohen literarischen Rang und vor der Verbreitung der Druckgraphik im 19. Jahrhundert auch informativen Wert besaß, ist mit den besten Zeugnissen [6] vertreten: Nach Winckelmann die im Teutschen Merkur veröffentlichten Düsseldorfer Gemäldebriefe Heinses, die eine neue Würdigung von Rubens einleiteten (»Die Flucht der Amazonen ", "Rubens mit seiner ersten Frau, in Lebensgröße, in einem Garten «, an Gleim, Mai-Juli 1777), und Forsters Ansichten vom Niederrhein. Dabei enthalten die Sammlungen mehrfach parallele Stücke, die sich zum Vergleich eignen, so den »Johannes der Täufer in der Düsseldorfer Gallerie « in der Auffassung von Heinse (an Gleim, August 1776) und Forster oder den Kölner Dom in der Sicht von Forster und Görres (Rheinischer Merkur, 20. 11. 1814; bei Seber und Schwab). Aus den die Romantik einleitenden Herzensergießungen eines kunstliebenden Klosterbruders und den Phantasien über die Kunst (Schwab, Pischon) sowie den Kunstbeschreibungen von A. W. Schlegel (Schwab und Pischon aus dem Athenäumsgespräch »Die Gemälde «) und F. Schlegel (Eisenschmid, Polymnia, Abt. I, Bd. 2, 1827) gibt es Auszüge. Mehrmals finden sich die Reden Sailers Von dem Bunde der Religion mit der Kunst (Seber, Eisenschmid) und von Schelling Ueber das Verhältniß der bildenden Künste zu der Natur (Schwab, Pischon, Mustersammlung).

Eine Auswahl aus dem 18. Jahrhundert, die um die Weimarer Klassik erweitert wird, zu der aber nur in geringem $\mathrm{Maß}$ romantische Texte treten, bildet den Grundbestand der Sammlungen bis etwa 1830; danach kommt es zu romantisch akzentuierten und aktuelleren Zusammenstellungen. Romantische Publizisten und Sachschriftsteller aus allen Wissensgebieten sind gemeinsam mit Dichtern der Romantik und der Befreiungskriege in Schwabs Deutsche[r]Prosa (1843), in W. Wackernagels Lesebuch (1843) und der bayerischen Mustersammlung (1845-47) so stark vertreten, daß diese Werke geeignet sind, ein christlich-romantisches Weltverständnis zu verbreiten. In $\rightarrow$ Schwabs Anthologie (s. dazu Tabelle 17) fehlt kaum eines der romantischen Lieblingsthemen: Mythologie und germanisches Altertum, Verklärung des Mittelalters, Kölner Dombau, das Interesse an Raffael und den Präraffaeliten (mit Passavants Raffaelbuch von 1839), der Lobpreis der Volksdichtung und das patriotische Turnen. Durch zahlreiche der unmittelbaren Gegenwart entstammende Beiträge fällt $\rightarrow$ Hieckes Handbuch deutscher Prosa (1835) auf. Hiecke hat allein sieben Texte aus den Jahrbücher[n] für wissenschaftliche Kritik von 1827 bis 1834, dem anspruchsvollsten Rezensionsorgan seiner Zeit, aufgenommen. Darunter Franz Bopps Kritik der Grimmschen Grammatik, Äußerungen Wilhelm Müllers zur Lyrik, Varnhagen von Enses Betrachtungen über den Briefwechsel zwischen Goethe und Schiller und Christian Hermann Weiße Über den sittlichen Werth von Goethe's Kunst- und Literaturbetrachtungen.

Nachweise. Seber, Sammlung, 1819: J. A. Eberhard, Engel, Forster, Goethe, Heinse, Herder, Heydenreich, Hottinger (über Geßner), F. Jacobs, Lessing, Manso, F. Roth, J. M. Sailer, Schiller, A. W. Schlegel (»Briefe über Poesie, Silbenmaß und Sprache« u. a.), F. Schlegel, Voß 
(über Hölty), Winckelmann. - Erhard, Handbuch, 2. Cursus, 1822: Bouterwek, Engel, Heeren (»Ideen über die Politik, den Verkehr und den Handel der vornehmsten Völker der alten Welt «: »Homer«), Lessing, Winckelmann (»Geschichte der Kunst des Altertums«, 3. Buch: »Von der Kunst unter den Hetruriern«). - Eisenschmid, Polymnia, Abt. I, 1827: Forster, Goethe, Herder, F. Jacobs, Lessing, Manso, F. Roth, Sailer, Schiller, F. Schlegel, Winckelmann. - Reinbeck, Handbuch, Bd. 4, 1828: Fernow (»Römische Studien«: »Ueber die Begeisterung«), Forster, Goethe, Herder, Jean Paul, Ch. G. Körner (»Aesthetische Ansichten «), Lessing/Mendelssohn Nicolai (Briefwechsel), Quandt (»Entwurf zu einer Geschichte der Kupferstecherkunst etc. «: "Heinrich Golzius und sein Zeitalter «), A. W. Schlegel, F. Schlegel, Solger, Winckelmann. Hiecke, Handbuch, 1835: Bopp, Creuzer (»Die historische Kunst der Griechen etc. «, 1803; »Das academische Studium des Alterthums «, 1807), Goethe, J. Grimm, Heeren (»Ideen etc. : »Demosthenes«), W. v. Humboldt, F. Jacobs, Lessing, Manso, W. Müller, F. v. Raumer, Rosenkranz, F. Roth, Schiller, A. W. Schlegel, F. Schlegel, Solger (Rez. von A. W. Schlegels »Vorlesungen über dramatische Kunst und Literatur «), Varnhagen von Ense (Besprechung des Goethe/Schiller-Briefwechsels), Ch. H. Weiße, Wieland (»Uebersetzung von Horazens Briefen", Einleitung). - Schwab, Deutsche Prosa, 1843: A. v. Arnim ("Des Knaben Wunderhorn «, Vorrede), S. Boisserée, J. A. Eberhard, Fernow, Forster, Garve (aus der UUbersetzung von Ciceros Offizien), Gervinus ("Geschichte der poetischen National-Literatur der Deutschen «), Geßner (»Briefe über die Landschaftsmalerei«), Görres (»Die teutschen Volksbücher «: »Das Mittelalter «), Goethe, J. Grimm, W. Grimm, Heeren, Hegel, U. Hegner, W. v. Humboldt, F. Jacobs, Knebel, Lessing, Mundt (»Kunst der deutschen Prosa «), Novalis (Fragmente), Oken, J. D. Passavant (»Rafael von Urbino und sein Vater Giovanni Santi«), P. A. Pfizer (»Briefwechsel zweier Deutschen«: »Wesen und Würde der deutschen Poesie «), Reinbeck (»Theorie der Novelle « aus »Situationen«, 1841), Rosenkranz (»Geschichte der deutschen Poesie im Mittelalter «: »Das Epos des Volkes«), Schelling, Schiller, A. W. Schlegel, F. Schlegel, Solger (»Erwin«: "Der Humor«), Theremin, Uhland (»Sagenforschung «), Varnhagen von Ense, Waagen (»Niederländische Briefe«), Wackenroder/Tieck, Wessenberg (»Über den sittlichen Einfluß der Schaubühne«), Winckelmann, F. A. Wolf (»Darstellung der Altertumswissenschaft «). - W. Wackernagel, Lesebuch, Tl. 3, Bd. 2, 1843: Breitinger (»Critische Dichtkunst «), Engel, Gellert (»Abhandlung von dem guten Geschmacke in Briefen«), Görres, Goethe, J. Grimm, Hamann (»Aesthetica in nuce «), Herder, Lessing, Rumohr (»Italienische Forschungen «), Schiller, A. W. Schlegel, F. Schlegel, Winckelmann. - Kletke, Deutsche Aufsätze, 1844: Ancillon (»Zur Vermittlung der Extreme in den Meinungen «, Tl. 2: »Ueber die classische und romantische Poesie oder über die Leistungen der Poesie in den letzten Decennien «), F. Delbrück, Gervinus, J. Grimm, W. v. Humboldt, F. Jacobs, Jean Paul, Knebel, Lessing, Reinbeck, Rosenkranz (»Handbuch einer allgemeinen Geschichte der Poesie«, Tl. 3: »Über Klopstock «, »Natur und Kunstpoesie "), Schiller, A. W. Schlegel, F. Schlegel, W. Süvern (»Ueber Schiller's Wallenstein in Hinsicht auf griechische Tragödie «, 1800; "Uber den historischen Charakter des Drama«, 1825), W. Wackernagel (»Ưber die dramatische Poesie«, 1838). - Pischon, Denkmäler, Tl. 4-6, 1845-51: Bodmer (»Character der teutschen Gedichte«, »Discourse der Mahlern«), Breitinger (»Critische Dichtkunst «), Garve (über Goethes »Werther«), Goethe, Hamann, Hegel, Heinse, Herder, W. v. Humboldt, Lessing, Klopstock (»Gelehrtenrepublik«), Novalis (Fragmente), Rahel Varnhagen, Schelling, A. W. Schlegel (das Gedicht »Der Bund der Kirche mit den

Titel der Sammlung: Gustav Schwab: Die deutsche Prosa von Mosheim bis auf unsere Tage. Eine Mustersammlung mit Rücksicht auf höhere Lehr-Anstalten. 2 Tle. Stuttgart: Liesching 1843. Zu einzelnen Beiträgen: Görres Einleitung zum »Rheinischen Merkur « ist irrtümlich auf den 1.1.1814 datiert. - A. W. Schlegels Ausführungen über die Aufklärung stammen aus den Berliner Vorlesungen. Ders.: Ueber Litteratur. Kunst und Geist des Zeitalters. Einige Vorlesungen in Berlin. zu Ende des J. 1802, gehalten. In: Europa. Eine Zeitschrift. Hg. v. Friedrich Schlegel. Bd. 2. Frankfurt/M. 1803, S. 3-95. Hier S. 60-73 (Dritte Vorlesung). - Novalis' »Aphorismen über Poesie « sind zusammenhängend entnommen aus: Novalis Schriften. Hg. v. Friedrich Schlegel u. Ludwig Tieck. Tl. 2. Berlin 1802. Fragmente vermischten Inhalts, Abt. VI, hier S. 501-11. 
Künsten « u. a.), F. Schlegel, Solger (»Über die Wahlverwandtschaften«, »Über den Ernst in der Absicht und dem Studium der Kunst «), Sulzer (»Theorie der schönen Künste «), Theremin, Wackenroder, Winckelmann. - Mustersammlung (Bayern), Tl. 2, Abt. 1, 1847: Ancillon, Forster, Görres, Goethe, Brüder Grimm, Herder, F. Jacobs, Knebel, Lessing, Schelling, A. W. Schlegel, Winckelmann.

(e) Erzählprosa (für die Romantik vgl. Kap. 3.2). Eine so große Ausbeute an Romanen in einer Schulanthologie wie bei $\rightarrow$ Meierotto und eine ähnlich hohe Einschätzung des bildenden Wertes der Romanlektüre wie bei Trapp sind in der Restaurationszeit undenkbar. Die Polemik gegen die >Lesesucht< und >Lesewut<, die von konservativen wie aufklärerischen Pädagogen (Hauptbeispiel Campe) geführt wurde [7], bestimmt nun das Verhältnis der Schule zum Roman. Eine literarische Erziehung, wie sie etwa $\rightarrow$ Hiecke entwirft, soll der »Leserei«, die man »durch gehäufte Schularbeiten, durch Verbote der Leihbibliotheken « und ähnliche Maßnahmen erfolglos bekämpft, »durch positiv wirkende Mittel« vorbauen. [8] Mit der Kanonisierung der deutschen Klassiker will man eine sichere Geschmacksgrundlage schaffen, um die Jugend »von der erbärmlichen Lectüre geist- und hirnloser Romane und Liebesgeschichten « abzuziehen, »wie sie jetzt massenweise in den Leihbibliotheken aufgeschichtet sind«. [9] Die Romanabteilungen in den Anthologien werden »enger beschränkt «, »weil der jugendliche Geist, besonders in unsern Zeiten « - d. h. während der Blütezeit belletristischer Schriftstellerei und ihrer Vermittlungsinstitutionen, der kommerziellen Leihbibliotheken -, »nicht zu tief in das Gebiet des Romans und der Phantasie hineingeführt werden darf. « [10] Mit Geschichtswerken, Reisebeschreibungen und (Auto-)Biographien wird den Schülern eine Alternative zur Romanliteratur geboten, und auch deshalb nehmen diese Gattungen in den Sammlungen einen so breiten Raum ein.

Obwohl somit die Schulen der zeitgenössischen Romankultur entgegenarbeiteten, konnten sich einige Werke, die in Auszügen im Unterricht brauchbar waren, durchsetzen: Wielands in der Antike spielende Romane (vor allem Agathon und die Geschichte der Abderiten), $\rightarrow$ Engels »Charaktergemälde «Lorenz Stark, Thümmels Reisen in die mittäglichen Provinzen von Frankreich, Jean Paul und Goethes Wilhelm Meisters Lehrjahre. Ihnen werden meist Naturschilderungen und Ortsbeschreibungen (Thümmel, Jean Paul), Reflexionspartien (so die Interpretation von Shakespeares Hamlet und die Erörterungen über das Verhältnis von Roman und Drama aus dem 5. Buch von Wilhelm Meisters Lehrjahre[n]), Abschnitte mit viel Bildungsstoff (Wieland) und Charakterschilderungen entnommen, während Liebesszenen ausgespart bleiben. Von Jean Paul finden zwei, sonst wenig beachtete didaktische Erzählungen weiteste Verbreitung: Die Neujahrsnacht eines Unglücklichen, der Schreckenstraum von einem durch Ausschweifungen zugrundegerichteten Leben, und Der doppelte Schwur der Besserung, wo der Scheintod des Vaters den Jüngling zur Tugend zurückführt. Weitere Texte, oft mit didaktischer oder religiöser Tendenz (wie Pestalozzis Lienhard und Gertrud, Hallers Staatsroman Usong, Jung-Stilling, Ernst Wagner) sind nur sporadisch vertreten. 
Tabelle 17: Die Romantik in Schwabs Prosaanthologie (1843) (Auswahl)

\begin{tabular}{|c|c|c|}
\hline Autor & Werk/Quelle (mit Kurztitel) & Titel des Auszugs \\
\hline \multicolumn{3}{|l|}{ I. Sachprosa } \\
\hline Arnim, A. v. & Des Knaben Wunderhorn, 1806 (Vorrede) & Von Volksliedern \\
\hline Boisserée, S. & $\begin{array}{l}\text { Geschichte und Beschreibung des Doms von Köln, } \\
\text { 2. umgearb. Ausg. } 1842\end{array}$ & Der Dombau zu Cöln \\
\hline Creuzer & $\begin{array}{l}\text { Symbolik und Mythologie der alten Völker, TI. 4, 2. völlig } \\
\text { umgearb. Ausg. 1821. Kap. } 8, \S 22-25\end{array}$ & Geist der alten Religionen \\
\hline Gentz & $\begin{array}{l}\text { Fragmente aus der neusten Geschichte des Politischen } \\
\text { Gleichgewichts in Europa, } 1806 \text { (Vorrede) }\end{array}$ & Trostworte an die wahren Deutschen \\
\hline \multirow[t]{2}{*}{ Görres } & Die teutschen Volksbücher, 1807 & Das Mittelalter \\
\hline & Rheinischer Merkur, 1814-16 & $\begin{array}{l}\text { Vergangenheit und Zukunft nach den Freiheitskriegen } \\
\text { (Programm, 23.1.1814); Deutschlands Heil (geschrieben } \\
\text { den 18. August 1814, während des Wiener Congresses); } \\
\text { Der Dom zu Köln }(20.11 .1814)\end{array}$ \\
\hline \multirow[t]{4}{*}{ Grimm, J. } & Zeitung für Einsiedler, 1810 & Die Sagen \\
\hline & Altdeutsche Wälder, Bd. 1,1813 & Gesellenleben \\
\hline & Deutsche Grammatik, Tl. 1, 2. Aufl. 1822 & Die deutschen Mundarten \\
\hline & Dcutsche Rechtsalterthümer, 1828 & Deutsches und fremdes Recht \\
\hline \multirow[t]{2}{*}{ Grimm, W. } & Altdänische Heldenlieder, 1811 (Vorrede) & Die Poesie des Nordens \\
\hline & Die deutsche Heldensage, 1829 & Nibelunge Noth \\
\hline \multirow[t]{2}{*}{ Jahn } & Deutsches Volksthum, 1810 & Über das Bücherlesen; Mägdchenschulen \\
\hline & Deutsche Turnkunst, 1816 & Turnanstalten \\
\hline Müller, A. & $\begin{array}{l}\text { Vorlesungen über die deutsche Wissenschaft und } \\
\text { Literatur, } 1806\end{array}$ & Buchstabe und Tradition \\
\hline Novalis & Fragmente & Aphorismen über Poesie \\
\hline Oken & Lehrbuch der Naturphilosophie, Tl. 3, 1811. \$ 3515-48 & Kunst. In naturphilosophischen Grundlinien \\
\hline \multirow[t]{2}{*}{ Schclling } & $\begin{array}{l}\text { Ueber das Verhältnis der bildenden Künste zu der Natur. } \\
1807\end{array}$ & \\
\hline & $\begin{array}{l}\text { Philosophische Untersuchungen über das Wesen der } \\
\text { menschlichen Freiheit, } 1809\end{array}$ & Gott und das Böse \\
\hline
\end{tabular}




\begin{tabular}{|c|c|c|}
\hline Autor & Werk/Quelle (mit Kurztitel) & Titel des Auszugs \\
\hline \multirow[t]{3}{*}{ Schlegel. A. W. } & Die Gemälde. Gespräch. 1798 & Raphael's Madonna del Sisto \\
\hline & Über Literatur, Kunst und Geist des Zeitalters, 1803 & Die Aufklärung \\
\hline & Vorlesungen über dramatische Kunst und Literatur, 1809 & Ueber tragisches und komisches Drama \\
\hline \multirow[t]{3}{*}{ Schlegel. F. } & Dritter Nachtrag alter Gemälde, 1805 & Die Aufgabe der christlichen Kunst \\
\hline & Über die Sprache und Weisheit der Indier, 1808 & Verhältniß der orientalischen Religionen zur heil. Schrift \\
\hline & Geschichte der alten und neuen Literatur, 1812 & Sokrates unter den Philosophen seiner Zeit; Spinoza \\
\hline \multirow{2}{*}{ Schubert, G. H. v. } & Allgemeine Naturgeschichte, 1826 & Die Sonne \\
\hline & Die Geschichte der Seele, 1830 & Die Frage nach der Seele und ihrem Seyn \\
\hline Solger & Erwin. 1815 & Der Humor \\
\hline \multirow[t]{2}{*}{ Steffens } & Anthropologie. 1822 & Natur und Mensch in geheimer Verbindung \\
\hline & Wie ich wieder Lutheraner wurde, 1831 & Die Wunder der heiligen Geschichte \\
\hline Uhland & Sagenforschung, Bd. 1,1836 & Die nordischen Mythen \\
\hline \multicolumn{3}{|l|}{ II. Dichterische Prosa } \\
\hline Brentano & Gockcl. Hinkel, Gackeleja, 1838 & Gockels Leichenrede auf Alektryo \\
\hline Chamisso & Peter Schlemihl, 1814 & Peter Schlemihl, der Schattenlose \\
\hline \multirow{2}{*}{ Grimm, Brüder } & Deutsche Sagen, 1816-18 & Mummel-See; Brot und Salz segnet Gott \\
\hline & Kinder- und Haus-Märchen, $1812 \mathrm{ff}$. & $\begin{array}{l}\text { Der Arme und der Reiche; Der Sperling und seine vier } \\
\text { Kinder; Die zwölf Apostel }\end{array}$ \\
\hline Hoffmann. E. T. A. & Ritter Gluck, 1809 & Ritter Gluck \\
\hline Kerner & Reiseschatten, 1811 & Die Universität Mittelsalz \\
\hline \multirow[t]{2}{*}{ Novalis } & Die Lehrlinge zu Sais, 1798/99 & Die Natur \\
\hline & Heinrich von Ofterdingen, 1802 & Stilleben aus dem Mittelalter (TI. 1, Kap. 2) \\
\hline \multirow[t]{4}{*}{ Tieck } & Phantasus, 1812-16 & Die Kunst zu speisen; Elfenwunder (Die Elfen) \\
\hline & Der Aufruhr in den Cevennen, 1826 & Des Priesters Lebenslauf \\
\hline & Dichterleben. 1826 & Die drei Dichter und der Magier \\
\hline & Der Mondsüchtige, 1832 & Dichter, etymologisch betrachtet \\
\hline Wackenroder/Tieck & Phantasien über die Kunst. 1799 & $\begin{array}{l}\text { Die Peterskirche; Das Verführerische in der Kunst } \\
\text { (Ein Brief Joseph Berglingers) }\end{array}$ \\
\hline
\end{tabular}




\subsection{Der Wandel des Literaturkanons während der Restaurationszeit: Von der rhetorischen Chrestomathie zum nationalliterarischen Lesebuch}

Die Kanonbildung in den Textsammlungen für den höheren Unterricht ist in den ersten Jahrzehnten des 19. Jahrhunderts noch weitgehend vom 18. Jahrhundert bestimmt. Bei den Epen ragen Klopstock (Messias), Wieland (Oberon) und Voß (Luise, Der siebzigste Geburtstag) - also die Exponenten der religiösen, sromantischen und bürgerlichen Ependichtung - heraus, bei den vorromantischen ১Liedern und Elegien Claudius, Gleim, Hölty, Matthisson und Salis-Seewis. In der Idyllendichtung nimmt Geßner eine Monopolstellung ein, ähnlich wie Herder bei den Verslegenden, Parabeln und Paramythien (lehrhaften Erfindungen in der Art alter Mythologien), bevor Krummacher ihm zur Seite tritt. Gellert und Lessing bestreiten immer noch einen großen Teil des Bedarfs an Fabeln, obgleich ihnen jetzt häufig Pfeffel moderner als Gellert, politisch zahmer und in der moralischen Nutzanwendung eingänglicher als Lessing - vorgezogen wird. Tabelle 18 verdeutlicht, welche beherrschende Rolle diese Autoren bis in die zwanziger Jahre spielen. Von den Klassikern wird Schiller mit den Balladen, der Gedankenlyrik und Dramen von der Schule sofort eifrig rezipiert (z. B. Welcker, Lyrische Anthologie, 1809: Der Graf von Habsburg, Ritter Toggenburg, Der Taucher, Das Mädchen aus der Fremde, Die Theilung der Erde, Die Worte des Glaubens und des Wahns, Die vier Weltalter, Die Sänger der Vorwelt und Dramenauszüge, insgesamt 21 Stücke), während Goethe nur ausnahmsweise ähnlich stark vertreten ist (bei Welcker 25 Stücke; vgl. Reinbeck, 1824, in der Tabelle). Unterschiede ergeben sich aus den verschiedenen Zielrichtungen der Sammlungen. Wenn sie auch für die unteren Klassen konzipiert sind, treten vermehrt einfache didaktische Gattungen (Fabel, Legende, Parabel, Paramythie) auf (Förster, 1824; Trierer Lesebuch, 1825-27; Tetzner, 1827), während Kerndörffers Teone (1823) »für einen höhern Cursus « in Deklamation (Vorerinnerung, S.V) stilistisch anspruchsvolle Dichtungen (Oden Klopstocks, philosophische Gedichte Schillers und Goethes, Goethes Hymne Prometheus, Klopstocks Messias u. a.) bereitstellt. $\rightarrow$ Wilmsens Schönheit der Natur (1818) ist ein hervorragendes Beispiel für das Hinüberwirken der Empfindsamkeit in die Restaurationszeit. Die Anthologie sammelt elegische, erbauliche und idyllische Naturdichtungen, bis hin zu jüngsten Erscheinungen dieser Richtung (Louise Brachmann; Christian Friedrich Falkmanns Poetische Versuche von 1816). Tiedge, Matthisson - dessen Elegie, in den Ruinen eines alten Bergschlosses geschrieben zu den obligaten Schulgedichten zählt - und Salis-Seewis, die hier an der Spitze stehen, repräsentieren eine weit verbreitete, in der Forschung jedoch wenig beachtete sentimentale Unterströmung um 1800 .

Seit etwa 1830 spalten sich die Schulanthologien in eine klassische und romantische Richtung, wie sich an ihren Beständen und am Verhältnis von Schiller und Goethe [11] ablesen läßt (s. Tabelle 19). Als Indikatoren sind die Verteilung von Schillers Gedankenlyrik, zentralen Zeugnissen des Weimarer Klassizismus, einerseits (Tabelle 20) und von Texten Hölderlins, Autoren der Romantik und der Befreiungskriege andererseits (Tabelle 21) brauchbar. Wo sich die großen ästhetischen und 
geschichtsphilosophischen Programmdichtungen Schillers häufen (Die Götter Griechenlands, Die Künstler, Das Ideal und das Leben, Der Spaziergang), da sind die Romantiker meist kaum vertreten (Kerndörffer, 1823; Götzinger, 1840). Umgekehrt treten diese Dichtungen zurück, wo die Romantiker und die Lyriker der Befreiungskriege stark herangezogen werden (Curtman, 1829; Schwab, 1835; Mustersammlung, 1845-47). Am krassesten $\rightarrow$ Ph. Wackernagel: In dieser entschieden christlich-nationalen Sammlung kommt der Klassizismus gar nicht zu Wort. Bei Reinbeck und W. Wackernagel deutet sich ein Ausgleich an; beide verzichten auf die umstrittensten Gedichte, Die Götter Griechenlands und Das Ideal und das Leben: Das eine war wegen seiner wertenden Gegenüberstellung von Christentum und Antike der christlichen Partei zuwider, das andere den Nationalen, weil der Künstler sich vor den Aufgaben der Gegenwart in das Reich der Phantasie zu flüchten schien. Im übrigen konzentrieren sich die Anthologien, wo sie den großen Gedankendichtungen aus dem Wege gehen, auf die einfacheren, erzählenden oder moralisch leicht auslegbaren Texte; vor allem die Klage der Ceres, Das Eleusische Fest (Bürgerlied), Die Macht des Gesanges, Die Worte des Glaubens, Hoffnung und die Sprüche des Konfuzius gehören zum festen Schulbestand klassischer Lyrik.

Mit dem Bildersaal (1828-29) von $\rightarrow$ August Adolf Ludwig Follen, einem in die Schweiz emigrierten sfreiwilligen Jäger` und Burschenschaftler, entsteht, soweit ich sehe, die erste Schulanthologie, die einseitig vom Geist der Romantik und der Befreiungskriege geprägt wird. Sie enthält von F. Schlegel 45, von A. W. Schlegel 44, von Schenkendorf 38, von Tieck 34, von E. M. Arndt 22 und von Th. Körner 10 Texte (meist Gedichte). Gleichzeitig baut die Schwäbische Romantik ihre starke Stellung in der Schullyrik aus (Uhland 54, J. Kerner 25 Gedichte; vgl. Eisenschmid, Polymnia, Abt. II, 1829: 14 und Götzinger, Deutsche Dichter, Tl. 1, 1831: 10 Texte von Uhland). Noch programmatischer ist die Auswahl in $\rightarrow \mathrm{Ph}$. Wackernagels einflußreicher Gedichtsammlung von 1832 - dem »Archetypus eines Stemmas von Chrestomathien und Anthologien « [12] - akzentuiert. Hölderlin, die Romantiker, Autoren der Befreiungskriege und der Restaurationszeit (vor allem Rückert und Platen) stellen über $70 \%$ der Bestände (ca. 250 von 354 Texten). Darunter von A. W. Schlegel 36, Uhland 27, Hölderlin 17, Tieck 14, Chamisso 13, J. Kerner 10 und Arnim 8 Texte, denen von Goethe nur 8 und von Schiller 7 (ebensoviel wie aus Heines Buch der Lieder) gegenüberstehen. Im Lesestoff der unteren Klassen werden die Fabeln des 18. Jahrhunderts jetzt durch J. P. Hebel (bei Follen 15 Texte) sowie Grimmsche Märchen und Sagen abgelöst. Thematisch schließen sich die Texte in einigen romantisch orientierten Sammlungen zu weltanschaulichen Programmen zusammen, wie an Schwabs Prosaanthologie von 1843 gezeigt wurde (s. Kap. $3.1 \mathrm{zu}$ Tabelle 17). An Dichtungen bringt $\rightarrow$ Schwab Auszüge aus Novalis' Lehrlinge[n] $z u$ Sais und Heinrich von Ofterdingen, E. T. A. Hoffmanns Ritter Gluck, Stücke aus Tiecks Phantasus, Chamissos Peter Schlemihl und Gockels Leichenrede auf Alektryo aus Brentanos Gockel, Hinkel und Gackeleja in der Ausgabe von 1838. Die offiziöse bayerische Mustersammlung (1845-47), die Sachprosa (Fichtes Schlußrede »an die deutsche Nation «; Varnhagen von Enses Fürst Blücher von Wahlstadt; Gneisenaus Armeebericht über die Schlachten bei Ligny und Belle Alliance; Arndts Porträt des 


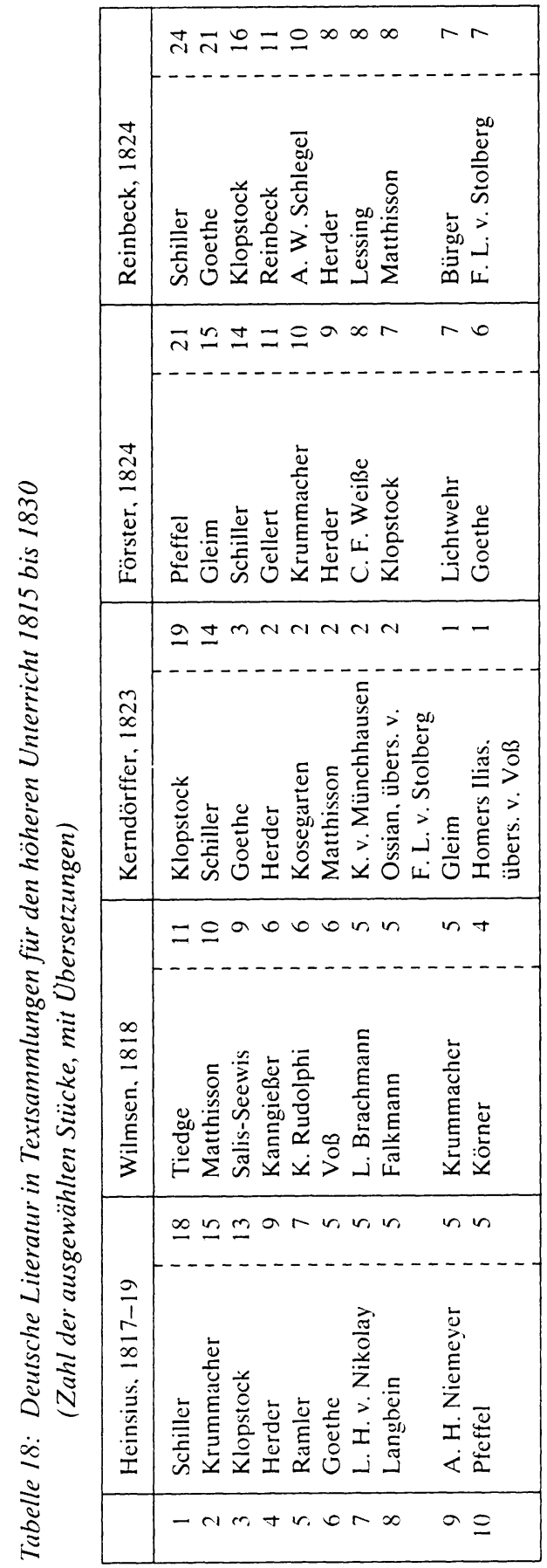

\begin{tabular}{|c|c|}
\hline 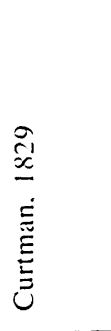 & 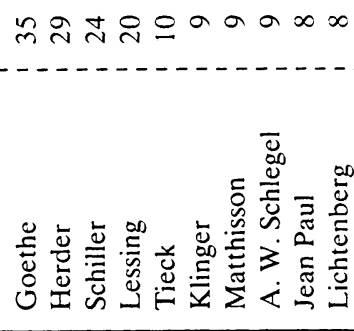 \\
\hline 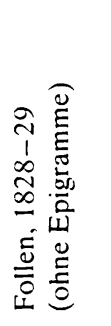 & 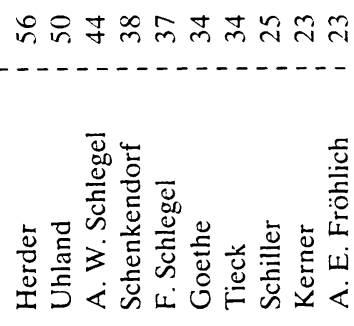 \\
\hline 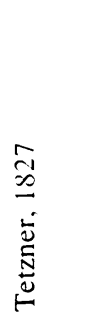 & 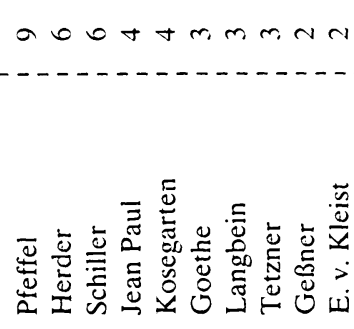 \\
\hline 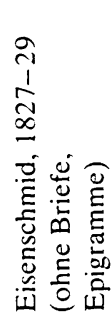 & 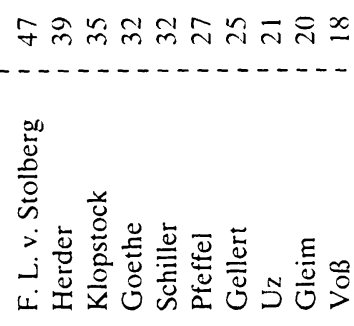 \\
\hline \multirow[t]{2}{*}{ 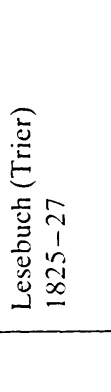 } & 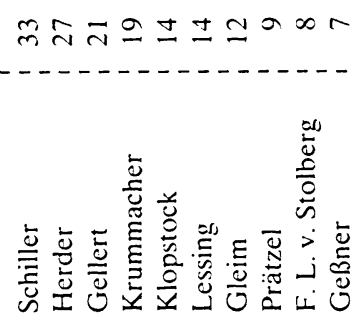 \\
\hline & - \\
\hline
\end{tabular}


Titel der Sammlungen: Theodor Heinsius: Der Bardenhain für Deutschlands edlc Söhne und Töchter. Ein Schul- und Familienbuch. 1. u. 2. Tl. 3. verb. u. verm. Ausg. Berlin: Dieterici 1819, 3. Tl. 2. verb. u. verm. Aufl. Ebd. 1817 (1. Aufl. 1808-10); F[riedrich] P[hilipp] Wilmsen: Die Schönheit der Natur geschildert von deutschen Musterdichtern. Eine Blumenlese für die Jugend zur Belebung des religiösen Gefühls und zur Uebung im Lesen mit Empfindung, auch als Gesellschafter auf einsamen Spaziergängen. Berlin: Amelang 1818; Heinrich August Kerndörffer: Teone oder Beispielsammlung für eine höhere Bildung des declamatorischen Vortrags, im öffentlichen und Privat-Unterrichte. Leipzig: Hinrichs 1823; Karl A [ugust] Förster: Sammlung auserlesener Gedichte für Gedächtniß- und Redeübungen; nach einer fünffachen Abstufung vom Leichten zum Schweren geordnet. 2. verb. Aufl. Dresden: Arnold 1824 (1. Aufl. 1819); Georg Reinbeck: Handbuch der Sprachwissenschaft mit besonderer Hinsicht auf die deutsche Sprache. Zum Gebrauche für die obern Klassen der Gymnasien und Lyceen. Bd. 3, Abt. 2. A.u.d.T.: Poetische Beispielsammlung zu Vorlesungen über Poetik und zur Declamation. Essen: Bädeker 1824; Deutsches Lesebuch für untere Gymnasialklassen. Hg. von den Lehrern des Gymnasium's zu Trier. Trier: Lintz 1825; Dass. für höhere Gymnasialklassen. Ebd. 1827: L[eonhard] M[artin] Eisenschmid: Polymnia, oder theoretisch-praktische Sammlung über das Gesammt-Gebiet teutscher Prosa und Dichtkunst in systematischer Ordnung. I. Abt.: Das Gebiet der Prosa. 4 Bdc. II. Abt.: Das Gebiet der Dichtkunst. 5 Bde. Bamberg u. Aschaffenburg: Dresch 1827-29; Theodor Tetzner: Lesebuch für Mittel- und Oberclassen höherer Bürgerschulen und Gymnasien. A.u.d.T.: Ausgewählte prosaische und poetische Lesestücke, in zweckmäßige Stufenfolge geordnet. Langensalza: Knoll. Nord- hausen: Landgraf in Comm. 1827; August Adolf Ludw[ig] Follen: Bildersaal deutscher Dichtung. Zunächst für Uebung in mündlichem und schriftlichem Erzählen, im Deklamiren und in ästhetischer Kritik. Geordnete Stoffsammlung zum Behuf einer allgemeinen, poetischen und ästhetischen Schulbildung. Nebst einer Uebersicht der deutschen Sprach- und Literatur-Geschichte. 2 Tle. Winterthur: Steiner 1828-29; W[ilhelm] J[akob] G[eorg] Curtman: Stylistische Perikopen, für den wissenschaftlichen Unterricht in der deutschen Sprache. 1. Dichter; für obere Klassen [mehr nicht erschienen] Gießen: Heyer 1829. - An Epigrammen kommen hinzu: Bei Eisenschmid: Goethe 20, Herder 23, Schiller 23; bei Follen: Goethe 24, Schiller 14. - Zu einzelnen Autoren: Louise Brachmann (1777-1822), Lyrikerin, dann Unterhaltungsschriftstellerin; Christian Friedrich Falkmann (1782-1844), Lehrer, "Poetische Versuche " 1816; Abraham Emanuel Fröhlich (1796-1865), kämpferischer konservativer Protestant und Lehrer in Aargau/Schweiz, Dichter von Fabeln und historischen Epen; Peter Friedrich Kanngießer (1774-1833), Lehrer, Historiker an der Univ. Greifswald, epischer und lyrischer Dichter; August Friedrich Ernst Langbein (1757-1835). fruchtbarer Berliner Schriftsteller, in die Schule dringen von ihm Fabeln und Schwänke; Karl Frhr. v. Münchhausen (1759-1836). Militär- und Staatsdienst in Hessen. Freund Seumes; August Hermann Niemeyer (1754-1828), Prof. an der Univ. Halle und Leiter der Franckeschen Stiftungen, einflußreicher Pädagoge, Erbauungsschriftsteller und religiöser Dichter; Ludwig Heinrich v. Nikolay (1737-1820). Karriere am Zarenhof, gewandter Aufklärungsdichter; Karl Gottlieb Prätzel (1785-1861), Verfasser beliebter heiterer und geselliger Dichtungen; Karoline Rudolphi (1754-1811), Erzieherin, pädagogische Schriftstellerin und Lyrikerin. 


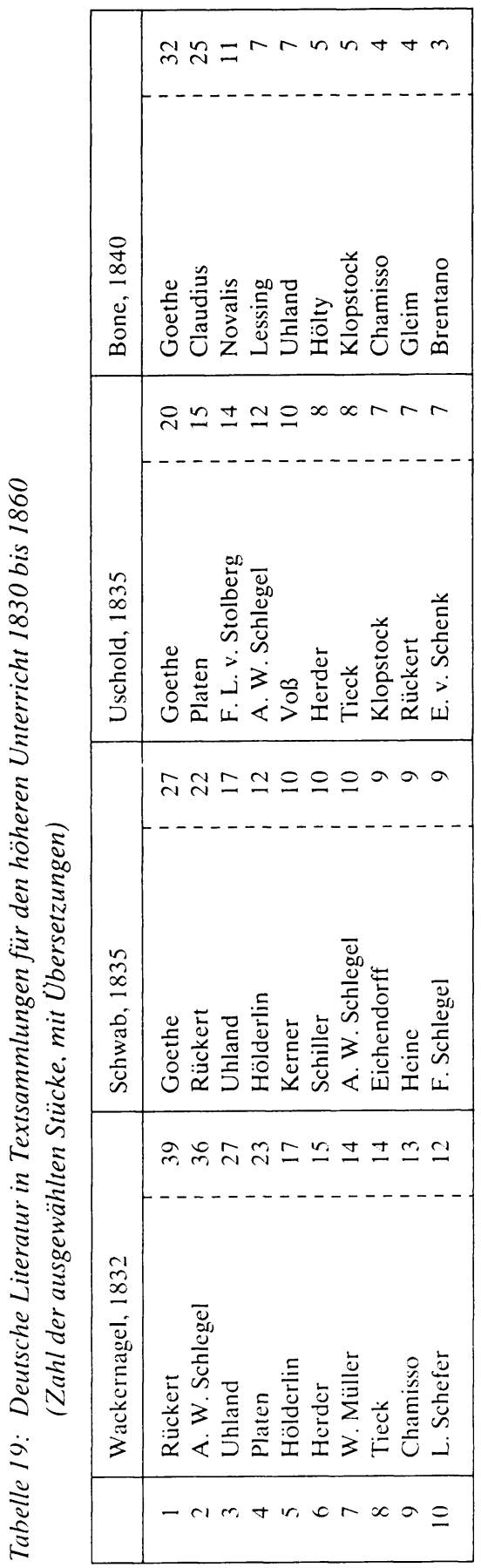

\begin{tabular}{|c|c|}
\hline 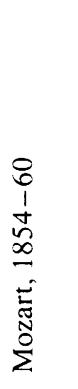 & 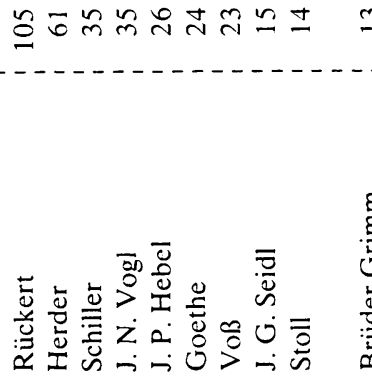 \\
\hline 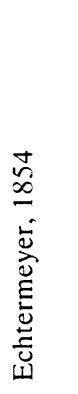 & 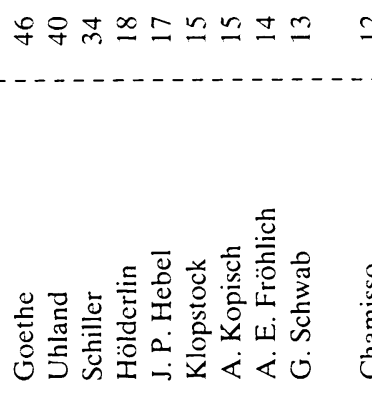 \\
\hline 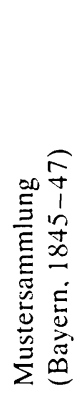 & 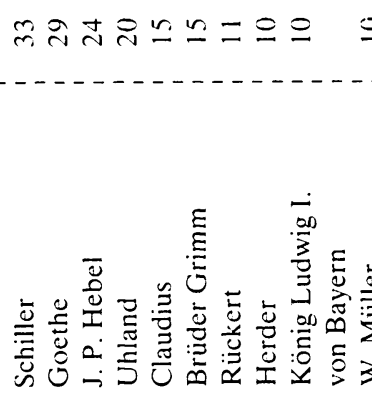 \\
\hline 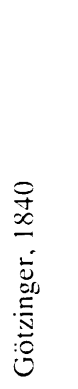 & 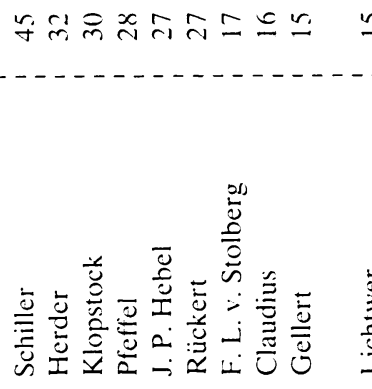 \\
\hline & $-r r_{1}+r_{0} \circ r_{0}$ \\
\hline
\end{tabular}


Titel der Sammlungen: K[arl] E[duard] P[hilipp] Wackernagel: Auswah] deutscher Gedichte für höhere Schulen. Berlin: Duncker u. Humblot 18.32: Gustav Schwab: Fünf Bücher deutscher Lieder und Gedichte. Von A. v. Haller bis auf die neueste Zeit. Eine Mustersammlung mit Rücksicht auf den Gebrauch in Schulen. Leipzig: Weidmann 1835 (Epigramme und kleine Stücke nur als eine Nummer gezählt); Joh[ann] Nep[omuk] Uschold: Lehrbuch der Poctik. Für Gymnasien bearbeitet. Tl. 2. A.u.d.T.: Systematisch geordnete Mustersammlung aus dem gesammten Gebiete der deutschen Dichtkunst. München: Lindauer 18.35: Heinrich Bone: Deutsches Lesebuch für höhere Lehranstalten, zunächst für die unteren und mittleren Klassen der Gymnasien, mit Rücksicht auf schriftliche Arbeiten der Schüler. Köln: Dietz 1840; Max[imilian] Wilhelm Götzinger: Dichtersaal. Auserlesene deutsche Gedichte zum Lesen. Erklären und Vortragen in höhern Schulanstalten. Nach den Dichtern geordnet. 2. verm. Aufl. Leipzig: Hartknoch 1840
(1. Aufl. 1832); Deutsche Mustersammlung für die lateinischen Schulen und Gymnasien im Königreiche Bayern. 2 Tle. München: CentralSchulbücher-Vlg. 1845-47; Theodor Echtermeyer: Auswahl deutscher Gedichte für gelehrte Schulen. 8. verb. u. verm. Aufl. Hg. v. Robert Heinrich Hiecke. Halle: Waisenhaus 1854; J[oseph] Mozart: Deutsches Lesebuch für die unteren Classen der Gymnasien. Wien: Gerold. Bd. 1-2 1854-55, Bd. 3 5. verb. Aufl. 1860, Bd. 4 2. verb. Auf1. 1855. - Zu einzelnen Autoren: Fröhlich, s. Legende zu Tabelle 18 August Kopisch (1799-1853), Malerpoet, nach Italienaufenthalt ab 1833 in Berlin. Lyriker in der Art der Volksdichter, unter Einfluß Platens auch Nachahmer der Alten; Eduard von Schenk (1788-1841), Minister und gefeierter Dichter unter König Ludwig I. von Bayern; Johann Ludwig Stoll (1778-1815), Dichter und Theaterregisseur in Wien. 


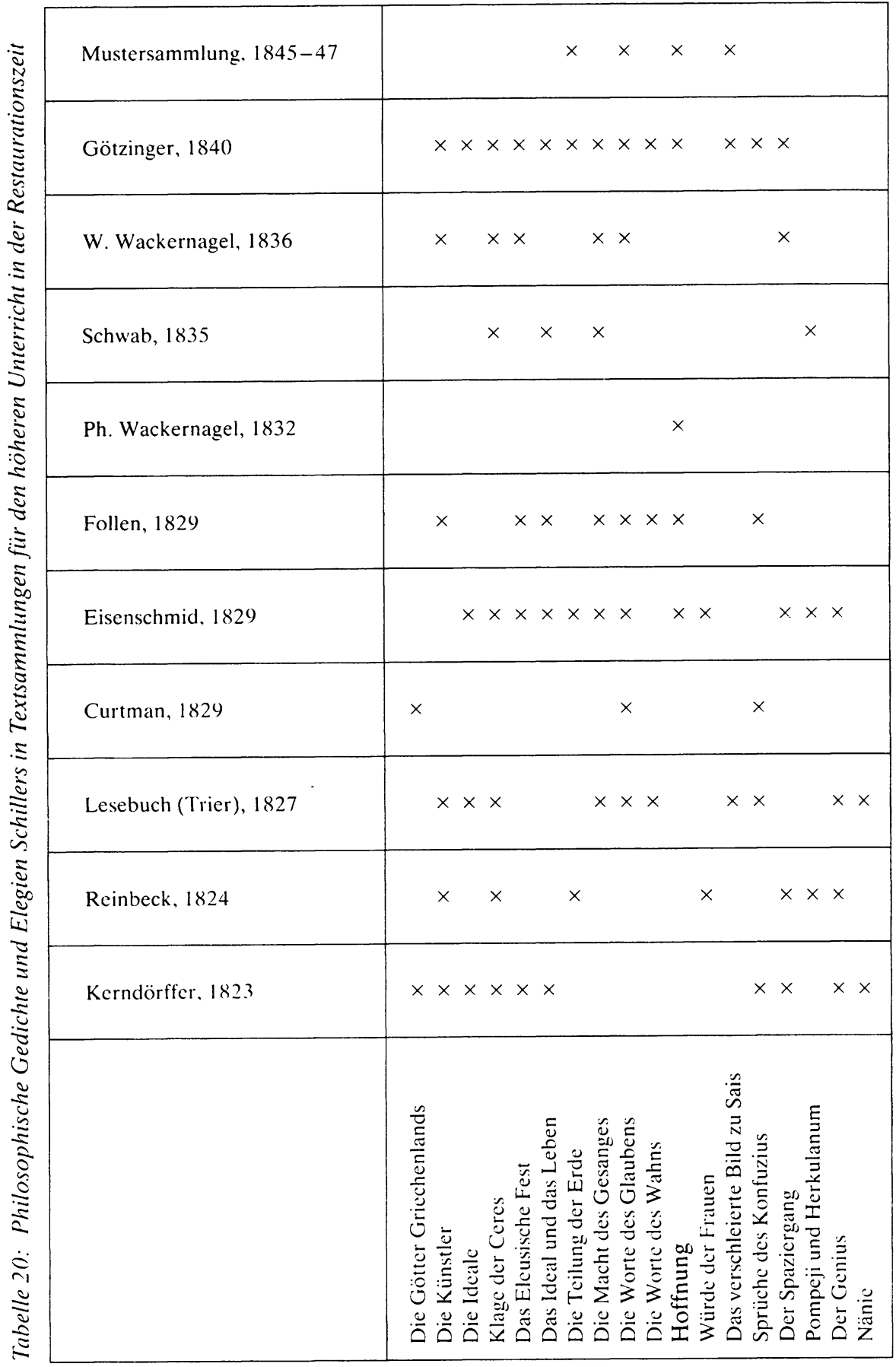


Titel der Sammlungen; mit Hinweisen auf Abdrucke weiterer verwandter Gedichte: Kerndörffer: Teone (s. Legende zu Tabelle 18), »Das Glück «; Reinbeck: Handbuch der Sprachwissenschaft. Bd. 3, Abt. 2 (s. ebd.); Deutsches Lesebuch für höhere Gymnasialklassen (s. ebd.); Curtman: Stylistische Perikopen (s. ebd.); Eisenschmid: Polymnia. II. Abt. (s. ebd.), »Der Tanz«; Follen: Bildersaal deutscher Dichtung. Tl. 2 (s. ebd.), »Die deutsche Muse«, »Die Antiken zu Paris«, »Die Sänger der Vorwelt «; Ph. Wackernagel: Auswahl deutscher Gedichte (s. Legende zu Tabelle 19), »Die Sänger der Vorwelt «; Schwab: Fünf Bücher deutscher Lieder und Gedichte (s. ebd.); Wilhelm Wackernagel: Deutsches Lesebuch. Tl. 2. A.u.d.T.: Proben der deutschen Poesie seit dem Jahre MD. Basel: Schweighauser 1836; Götzinger: Dichtersaal (s. Legende zu Tabelle 19), »Pegasus im Joche», »Die deutsche Muse «, "Licht und Wärme ", »Breite und Tiefe «, »Der Tanz «; Deutsche Mustersammlung für die lateinischen Schulen und Gymnasien im Königreiche Bayern (s. ebd.). 


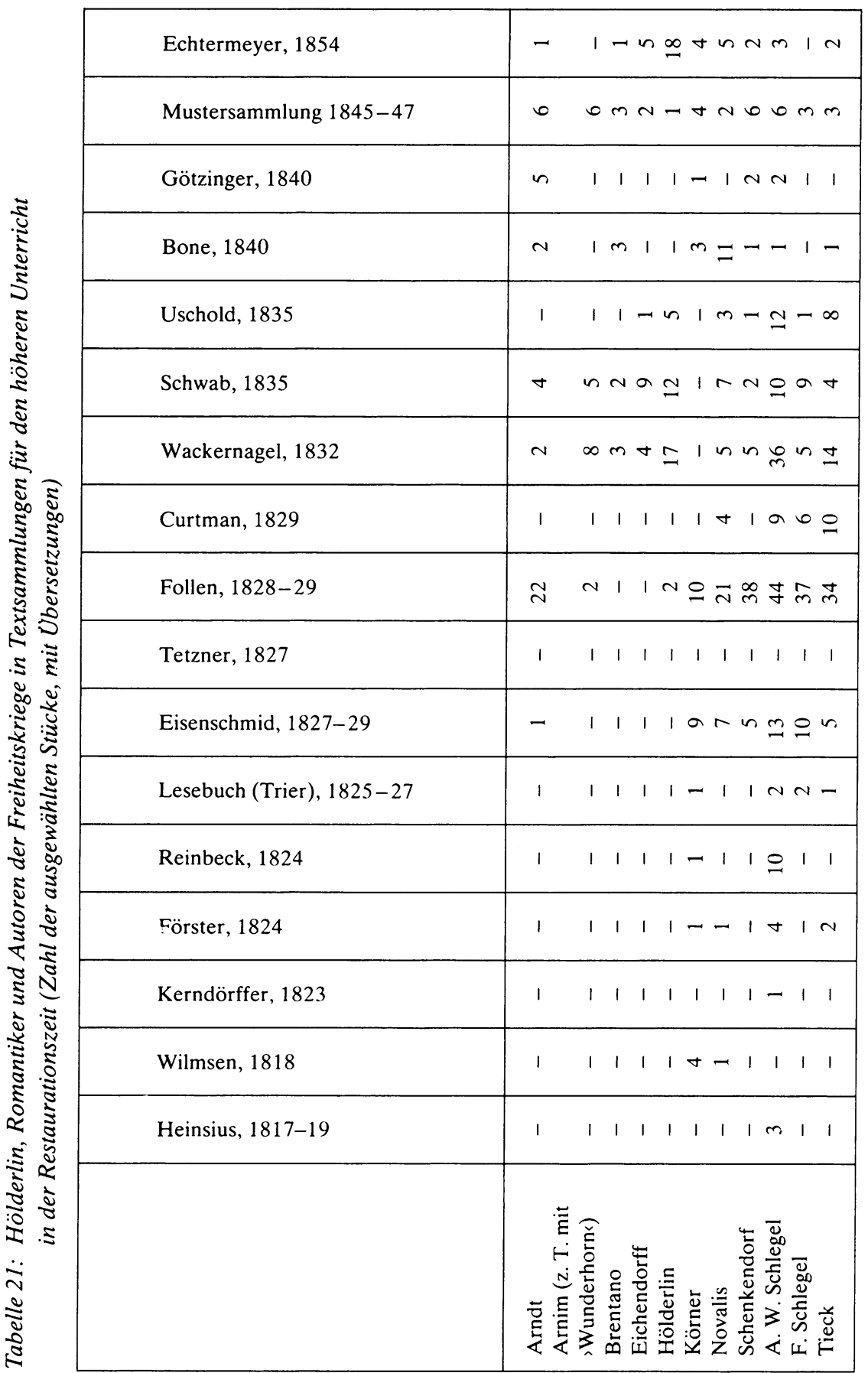


Freiherrn vom Stein; Görres über den Kölner Dom; Auszüge aus A. W. Schlegels Wiener Vorlesungen über dramatische Kunst und Literatur; J. Grimms Vorrede zur Deutsche[n] Grammatik) und Dichtung zu gleichen Teilen aufnimmt, verwirklicht für die Schule das an die Befreiungskriege anknüpfende nationale Kulturprogramm von König Ludwig I.: Sie bringt von E. M. Arndt 6 (Deutscher Trost, Wer ist ein Mann?, Das Lied vom Schill, Des deutschen Knaben Robert Schwur u. a.), von Schenkendorf gleichfalls 6 (Soldatenmorgen 1813, Das Lied von den deutschen Strömen, Die deutschen Städte, Andreas Hofer, Frühlingsgruß an das Vaterland. 1814, Freiheit) und von Körner 4 (Aufruf. 1813, Die Eichen. 1811 u. a.), zumeist betont patriotische Gedichte. Von der engeren Romantik wird eine Probe aus Novalis' Heinrich von Ofterdingen (Der Bergmann, Tl. 1, Kap. 5), Tiecks Getreuer Eckart aus dem Phantasus sowie von Brentano Gockels Leichenrede auf Alektryo und die Beschreibung einer Zigeunerherberge aus den Mehrere[n] Wehmüller[n] (Baciochis Erzählung vom wilden Jäger) abgedruckt. Zehn Texte steuert der regierende König Ludwig I., der mit seinen formstrengen Gedichten auch sonst eine Schulkarriere macht (z. B. Budde, Chrestomathie, Tl. 2, 1829: 15; Pischon, Denkmäler, Tl. 6, Abt. 1, 1850: 10 Gedichte), selbst bei.

Die Rezeption zentraler Dichtungen Hölderlins und der Romantik kann spätestens ab etwa 1830 in den Schulanthologien fortlaufend verfolgt werden. Hölderlin, der sich zuerst mit zwei Gedichten in $\rightarrow$ Follens Bildersaal, Tl. 2, 1829 (Dem Genius der Kühnheit, Das Schicksal) findet, erfährt seit $\rightarrow \mathrm{Ph}$. Wackernagels Auswahl deutscher Gedichte (1832, mit 17 Texten) eine »erstaunlich frühe Aufnahme und Verbreitung « [13] in der Schule. Die Dichtungen von Novalis, die schon ab 1809 (Welcker, Lyrische Anthologie, 1809: 6; Eisenschmid, Polymnia, Abt. 2, 1829: 7 Texte) nachgedruckt werden, sind in Follens Bildersaal, Tl. 2, 1829 (21 Gedichte, mit fast der ganzen geistlichen Lyrik) und Bones Lesebuch von 1840 (11 Texte) am stärksten vertreten (für weitere Beispiele s. Tabelle 21). Dabei favorisieren die Schulanthologien die geistlichen Gedichte, die Lieder aus dem Heinrich von Ofterdingen (das Sängerlied, den Kreuzgesang, die Bergmannslieder und das Weinlied) sowie Sehnsucht nach dem Tode, die letzte der Hymnen an die Nacht. Von Tiecks Erzählprosa taucht gelegentlich eine Probe aus Franz Sternbalds Wanderungen (Eisenschmid, Polymnia, Abt. I, 1827: „Franz Sternbalds Wiederkehr in's Vaterhaus «) auf, häufiger finden sich Auszüge aus dem Aufruhr in den Cevennen (Curtman, Perikopen, 1829; Schwab, Deutsche Prosa, 1843; W. Wackernagel, Lesebuch, Tl. 3, Bd. 2, 1843) und "Eulenböcks Rede über das Trinken « aus den Gemälde[n] (Philippi, Katechismus der Rhetorik, 1826; Kannegießer, Redner, 1845; Wolff, Handbuch deutscher Beredsamkeit, Tl. 2, 1846). Gedichte Brentanos und Eichendorffs (Schwab, Fünf Bücher, 1835: 9; Pischon, Denkmäler, Tl. 6, Abt. 1, 1850: 14 Texte; vgl. im übrigen Tabelle 21) begegnen nur in geringer Zahl und nicht regelmäßig. Ganz am Rande des Horizonts der Schule steht schließlich Heinrich von Kleist, von dem nur die kurze Schauererzählung Das Bettelweib von Locarno öfters mitgeteilt wird (Brederlow, Dichtungsarten, 1839; W. Wackernagel, Lesebuch, Tl. 3, Bd. 2, 1843). 
Zusätzliche Nachweise zur Romantik und zur Literatur der Restaurationszeit (zu Hölderlin vgl. Anm. 12, zu Novalis Anm. 4 und 22; im übrigen s. obigen Text und Tabelle 21. Titel in Kurzform, vollständige bibliographische Angaben s. Bibliographie Bd. 2, Kap. 1.3.3 in alphabetischer Ordnung). Heinsius, Bardenhain, Bd. 2, 1819: Zacharias Werner (»Martin Luther «). Reinbeck, Handbuch, Bd. 3, Abt. 2, 1824: Fouqué ("Undine «). - Budde, Chrestomathie, Tl. 2, 1829: Novalis (2 Gedichte), Platen (»Die verhängnisvolle Gabel«). - Curtman, Perikopen, 1829: Tieck (»William Lovell«). - Ph. Wackernagel, Auswahl deutscher Gedichte, 1832: Brentano, Heine ( 7 Gedichte aus dem »Buch der Lieder «). - Schwab, Fünf Bücher, 1835: Brentano, Heine (9 Gedichte), H. v. Kleist (4 Gedichte). - W. Wackernagel, Lesebuch, Tl. 2, 1836 u. Tl. 3, Bd. 2, 1843: Arnim (»Gräfin Dolores«, Abt. II, Kap. 19: »Der Dichter Waller und seine Frau, Traugott und Alonso«), Brentano, Chamisso (»Peter Schlemihl«, 12 Gedichte), Eichendorff (»Taugenichts «, 4 Gedichte), Heine (8 Gedichte), Novalis (6 Texte, davon 5 geistliche Lieder), Platen (Parabasen aus der "Verhängnisvollen Gabel « und dem "Romantischen Oedipus", Gedichte), Tieck (»Fortunatus«, »Prinz Zerbino«). - Rupp, Mustersammlung, 1842: Börne (»Denkrede auf Jean Paul «). - Schwab, Deutsche Prosa, Tl. 2, 1843: Börne (»Ưber den Umgang mit Menschen«), Heine (»Harzreise «), Immermann (»Journale, Reisen«), H. v. Kleist (»Michael Kohlhaas«). - Mustersammlung (Bayern), 1845-47: Gedichte von Brentano und Heine. - Pischon, Denkmäler, Tl. 5, 1847 u. Tl. 6, Abt. 1 u. 2, 1850-51: Arnim, Brentano, Eichendorff (»Taugenichts«, 14 Gedichte), Grabbe (»Herzog Theodor von Gotland «, »Marius und Sulla»), Grillparzer (»Die Ahnfrau«), Heine (21 Texte), E. T. A. Hoffmann (»Meister Martin der Küfner und seine Gesellen «), Immermann ( 7 Texte, darunter »Münchhausen «: »Der Oberhof«), H. v. Kleist (»Familie Schroffenstein«, »Penthesilea «), Körner (11 Texte), Lenau (»Faust «, »Savonarola«, »Die Albigenser«, Gedichte), Müllner (»Die Schuld»), Novalis (8 Texte), Platen (»Die verhängnisvolle Gabel«, »Der romantische Ódipus«, Gedichte), Schenkendorf (15 Texte), A. W. Schlegel (18 Texte), F. Schlegel (11 Texte), Tieck (»Kaiser Octavianus«, »Genoveva", Gedichte), Zacharias Werner (»Söhne des Thales«, »Martin Luther«, »24. Februar«).

Der Wandel im Lektürekanon hängt mit Veränderungen der Gebrauchsfunktion von Anthologien im Schulunterricht zusammen. Der Aufbau der Sammlungen und die Gebrauchshinweise, die sich in den Einleitungen finden, legen es nahe, die Änderungen in der Zusammensetzung des Lesestoffs mit dem Übergang von einem formalen zu einem historischen Bildungskonzept (s. Kap. 1.3.3) zusammenzusehen. Während im 18. Jahrhundert die poetischen Anthologien nach Gattungen geordnet sind, kommen in der Restaurationszeit mehrere Gesichtspunkte zur Geltung. Die Chrestomathien sollen [14]:

- »muster über die verschiedenen dichtungs- und versarten « darbieten,

- »belegstellen für die geschichte der deutschen poesie « an die Hand geben,

- als »handbuch für den sprachlichen unterricht «, insbesondere für »die historische grammatik « verwendbar sein und schließlich

- als »handbuch zur erklärung der schwersten gedichte « für Einzelinterpretationen die Textgrundlage, evtl. schon mit sprachlichen und sachlichen Erläuterungen bereitstellen.

Somit müssen die Verfasser von Anthologien - sieht man von Spezialsammlungen zur Deklamation etc. ab - zwischen einem (gattungspoetologischen, metrischen) systematischen, (literatur- und sprach-)historischen und interpretatorischen Ansatz entscheiden oder zwischen ihnen vermitteln. Mindestens bis 1830 und darüber hinaus, wo ein systematischer Rhetorikunterricht weiterbesteht (vgl. etwa zu Österreich Kap. 2.3.3), dominiert eine gattungspoetologische Systematik. So bietet etwa 
Reinbecks Poetische Beispielsammlung (1824) »Belege« »bei dem Vortrage der Rhetorik «bzw. Poetik und hat eine dem Lehrbuch folgende »streng systematische Eintheilung «. [15] Welche literarischen Präferenzen der Rhetorikunterricht entwikkelte, zeigen am deutlichsten die Sammlungen von Tropen und Figuren. Die Lehre von den 'Schmuckmitteln drittletzten Klasse) dem System der Rhetorik vorausging oder, wo das ganze Lehrgebäude nicht mehr vermittelt wurde, die Schwundstufe des rhetorischen Unterrichts darstellte. Tabelle 22 wertet sieben Beispielsammlungen aus, welche die Literatur von der Aufklärung bis zur Restaurationszeit nach Redeblumen zerpflücken und sie einem fein rubrizierten System einordnen. Von den aufgeführten Belegen stammen weitaus am meisten von Schiller (362, ca. $43 \%)$, gefolgt von Goethe (192, ca. $23 \%$ ) und Klopstock (98, ca. $12 \%)$. Das Rhetorische des Stils Schillers und Klopstocks war der Zeit überdeutlich bewußt und fand Nachahmung. Wenn aber aus vier Dramen Goethes - Faust, Egmont und den klassischen Dichtungen Iphigenie und Tasso - 70 Figuren, auf ein System von 40 Paragraphen verteilt (Kehrein, 1839), dem Schüler geboten werden, sieht man, wie wenig die organische Einheit des Werkes im rhetorischen Blickfeld stand. In einer Art >rhetorischer Rückübersetzung`werden hier klassische Texte, die doch weitgehend auf einer Ästhetik beruhen, die mit Fundamenten der Rhetorik, wie der Handwerklichkeit, dem Schmuckbegriff und dem Wirkungsprinzip gebrochen hat, vom traditionellen Schulbetrieb adaptiert. Der Unterricht stärkte eine Kleinteiligkeit des Hörens und Lesens, die partikulare Stilmittel noch als solche ausgrenzte. Auf dieser Grundlage werden »die dekorativ-rhetorische Sprache « und die »Ornamentalpoesie« (F. Sengle) der Restaurationszeit besser verständlich. Es ist kein Zufall, daß in zwei der herangezogenen Werke (Wilhelmi, 1839/41; Braun, 1847) Rückert, der beliebteste lyrische Rhetor der Zeit, den ersten und dritten Platz einnimmt. Kein Zufall auch, daß die umfangreichste Sammlung, mit etwa 400 Exempeln (Kehrein, 1839), sich auf das Drama konzentriert, wo die Sprache der Hoftheater wieder barocke Dekoration geworden war, voll »Papierblumenwerk « und »Blumenkränzen «, wie Heine spottet. [16]

Die romantisch gesinnten Anthologisten machen in der Regel die Geschichte - nach der Abfolge literarischer Richtungen oder einfach den Geburtstagen der Autoren (wie zum Beispiel Schwab, Deutsche Prosa, 1843) - zum obersten Ordnungsprinzip. Im einfachsten Fall illustriert eine solche Sammlung »in characteristischen Proben « »den Gang[,] den unsre Poesie in den letzten Jahrhunderten genommen hat « [17], oft in Anlehnung an eine Literaturgeschichte des gleichen Autors (wie bei Pischon). Einige Verfasser haben einen »Plan von vielfach sich durchkreuzenden und berührenden Wegen « [18] vor Augen gehabt, wobei sie die Texte »bald nach Dichtungsarten, bald nach äußerer Form, bald nach dem Inhalt, bald in chronologischer Folge « [19] reihten, und ihre Anthologien so kunstvoll »wie etwa ein Gothisches Bauwerk « [20] aufgeführt. Mit solchen Sammlungen soll nicht nur ein historisches Verständnis erreicht, sondern die »Phantasie « als »die Grundkraft des Menschengeistes « geweckt [21] und auf das »Gemüth « so eingewirkt werden, daß sich eine »Gesinnung « bildet. [22] $\rightarrow$ Schwab hat seine Prosaanthologie von 1843 in diesem Sinn ein »weltliches Erbauungsbuch«[23] genannt. Inhaltlich stehen diese Lesebücher im 
Tabelle 22: Auszüge und Belegstellen aus der deutschen Literatur in Rhetorik- und Poetiklehrbüchern der Restaurationszeit (mit Übersetzungen)

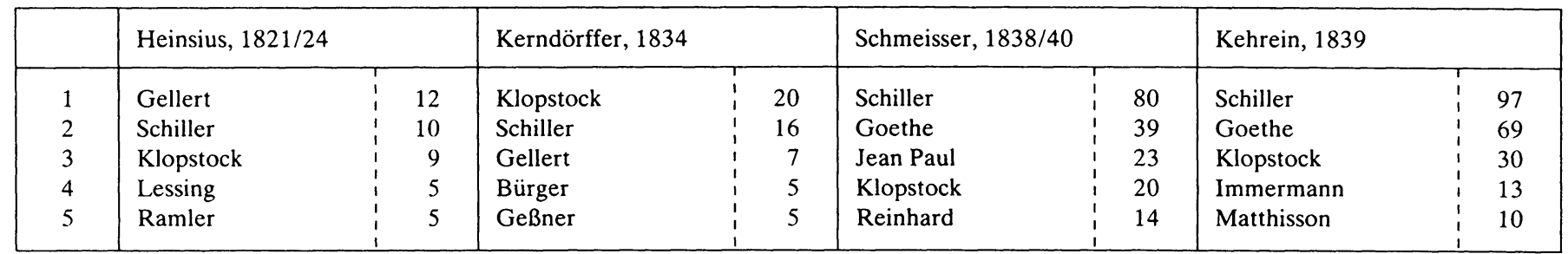

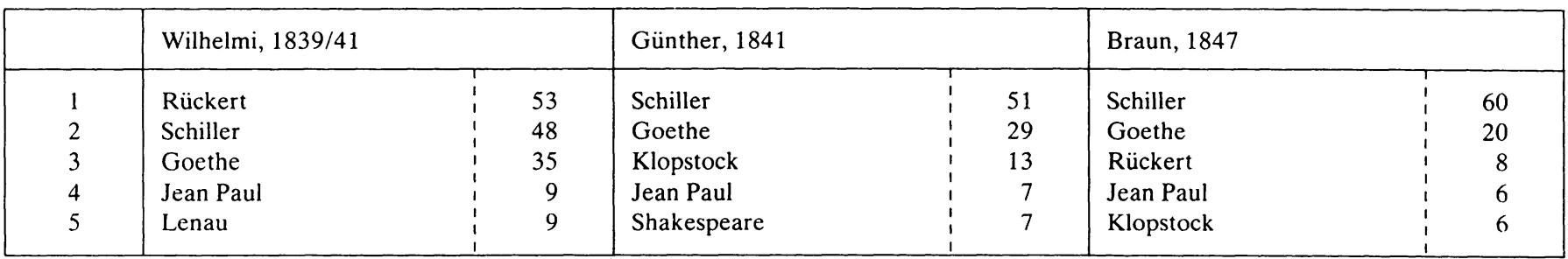

Titel der Lehrbücher: Theodor Heinsius: Teut, oder theoretisch-praktisches Lehrbuch der gesammten Deutschen Sprachwissenschaft, Tl. 2 (A. u. d. T.: Vorschule der Sprach- und Redekunst etc.) u. 3 (A.u.d. T.: Der Redner und Dichter etc.). 3. verb. u. verm. Ausg. Berlin: Duncker u. Humblot 1821-24 (Tl. 2 Beispiele nur in Abt. 2: Stylistische Vorübungen, S. 227 ff.); Heinr[ich] Aug[ust] Kerndörffer: Praktische Rhetorik. Ein Handbuch für Schulen, Gymnasien und zum gründlichen Selbstunterricht. Leipzig: Lauffer 1834; Joseph Nikolaus Schmeisser: Theoretisch-praktisches Lehrbuch der Rhetorik. 2 Tle. Karlsruhe: Groos 1838-40; Joseph Kehrein: Beispielsammlung zu der Lehre von den Figuren und Tropen in Theodor Heinsius Teut. Berlin: Duncker u.
Humblot 1839; H[einrich] F[riedrich] Wilhelmi: Von den Tropen. Ein Beitrag zu der Lehre von dem Figürlichen in der Rede. Pr. Lyceum Heidelberg 1839, Beil.; Ders.: Von den Figuren der Wortwiederholung. Ein zweiter Beitrag zu der Lehre von dem Figürlichen in der Rede. Ebd. 1841, Beil.; F[riedrich] J[oachim] Günther: Von den Tropen und Figuren. Für Schüler. Beilage zu F. J. Günther, über den deutschen Unterricht auf Gymnasien. Essen: Bädeker 1841 (Bezugstitel s. Bibliographie Bd. 2, Kap. 1.3.1.1); Alois Braun: Versuch über die Tropen mit Beispiel-Sammlung für Gymnasial-Schüler. Pr. Münnerstadt 1847. - Úber Reinhard s. Legende zu Tabelle S. 64. 
Dienst einer christlich-nationalen Bildung (s. Kap. 1.3.3.3.3), didaktisch erstreben sie eine erlebnismäßige Nachgestaltung des Textes durch den Schüler. Alles rhetorische »Zergliedern « hat zu unterbleiben, selbst auf die Gefahr hin, daß »in dem Gedächtniß der Schüler etwas Unverstandenes « zurückbleibt. [24] Wie sehr die Änderung des Literaturkanons und die Umorientierung in der Literaturdidaktik einander bedingten, zeigt eindringlich ein bislang nicht beachtetes Zusammentreffen: Die erste Sammlung, die dezidiert auf Texte der Romantik und der Befreiungskriege zurückgreift, $\rightarrow$ Follens Bildersaal (1828/29), enthält zugleich den wegweisenden Entwurf einer Literaturdidaktik, die von der Frage ausgeht: »Wie ist [die] Bildung der Phantasie pädagogisch zu realisiren?« [25]

\section{Anhang zu Kap. 3.1 und 3.2: Prosa und Poesie vom Mittelalter bis zum Barock}

Zeitlich reichen die Schulanthologien, die von der Aufklärung geprägt sind, in der Prosa kaum über das 18 . Jahrhundert und im poetischen Teil - mit Überspringung des verachteten Hochbarock (insbesondere der sog. ’Zweiten Schlesischen Schule〉) - bis auf Opitz zurück, der »bey den Deutschen die Bahn eines guten Geschmacks gebrochen « [26] habe. Seit der nationalen Rückbesinnung in der Napoleonischen Ära werden in die Anthologien Proben des Nibelungenliedes und der Minnelieder (z. B. Heinsius, Bardenhain, Tl. 3, 1817) wie auch der Barocklyrik (etwa Welcker, Lyrische Anthologie, 1809: Balde in der Übersetzung von Herder, Dach, Flemming, Opitz, Rist) aufgenommen, doch setzt die Prosa weiterhin erst mit Gellert, Lessing, Mosheim (im Rednerischen) und Winckelmann ein. Mittelhochdeutsche Dichtungen spielen - abweichend von den programmatischen Forderungen der für die alte deutsche Literatur begeisterten Germanisten, die von der Forschung [27] hervorgehoben werden - nur eine geringe Rolle. Für die Mehrzahl der altphilologisch geschulten und meist klassisch gesinnten Gymnasiallehrer hält das Nibelungenlied »keinen Vergleich " [28] mit Homer aus; das »meistens leere, matte, unpoetische Lied der Nibelungen « [29] liege "außerhalb unserer jetzigen nationalen Ideen « [30] und sei »nur durch den Zufall einer literärischen Entdeckung aus seinem halbtausendjährigen Pergamentgrabe entstanden «. [31] Da nur wenige Schullesebücher, die von einer romantisch orientierten nationalen Literaturdidaktik (s. Kap. 3.2) geprägt werden, dem älteren deutschen Schrifttum ganze Abteilungen zur Verfügung stellen (so Budde, Chrestomathie, Tl. 1: Von Ulphilas bis Haller, 1829; W. Wackernagel, Deutsches Lesebuch, 3 Tle, 1835-43), entstehen ergänzend Spezialsammlungen (beispielsweise Lachmann,Auswahl aus den Hochdeutschen Dichtern des dreizehnten Jahrhunderts, 1820; Lisch, Auswahl aus den Mittelhochdeutschen Dichtern, 1829; Ziemann, Altdeutsches Elementarbuch, 1833; Kehrein, Proben der deutschen Poesie und Prosa vom vierten Jahrhundert bis in die erste Hälfte des achtzehnten Jahrhunderts, 2 Tle, 1849-50). In einigen dieser Chrestomathien - insbesondere bei W. Wackernagel, der einen ganzen Band (Tl. 3, Bd. 1) der deutschen Prosa von 1500 bis 1740 widmet, und bei Kehrein - erscheint die ältere Prosa in reicher, nicht auf enge literarische Formen beschränkter Auswahl: Briefe, Chroniken, Predigten, Reisebeschreibungen, Úbersetzungen, Urkunden, Volksbücher usw. Eine große Bedeutung speziell für die Prosa 
Tabelle 23: Pischons »Denkmäler der deutschen Sprache«-Auswahl für den Zeitraum 1500 bis 1720

\begin{tabular}{|c|c|}
\hline Gliederung & Autoren und Texte (in der Schreibweise der Sammlung) \\
\hline \multicolumn{2}{|l|}{ IV. Zeitraum $1500-1620$} \\
\hline \multicolumn{2}{|l|}{ Poesie } \\
\hline A. Epische Poesie & Fischart (Glückhaftes Schiff von Zürich) \\
\hline B. Lyrische Poesie & $\begin{array}{l}\text { Hans Sachs (Die Wittenbergisch Nachtigall; Sanct Peter mit der Gaiß. Schwank; Geistl. Lied: Warumb } \\
\text { betrübstu dich mein hertz; Comedia: Die vngeleichen Kinder; Faßnacht Spiel: Das Narrenschneyden; } \\
\text { Ein Comödi von dem Reichen sterbenden Menschen der Hekastus genannt) - Das Volkslied (15 Beispiele, } \\
\text { u. a. von Fischart, Paul Melissus, Adam Puschmann) - Das Kirchenlied (Luther, } 10 \text { Beispiele; Paul Speratus } \\
\text { von Spretten; Nikolaus Decius; Joh. Poliander; Paul Eber; Nikolaus Hermann; Nikolaus Selneccer; Martin } \\
\text { Schalling; Philipp Nikolai; Churfürst Johann Friedrich von Sachsen; Albrecht von Brandenburg; Maria, } \\
\text { Königinn von Ungarn und Böhmen) }\end{array}$ \\
\hline \multicolumn{2}{|l|}{ C. Didaktische Poesie } \\
\hline 1. Das eigentliche Lehrgedicht & Bartholomäus Ringwaldt (Die lauter Warheit; Christliche Warnung des Trewen Eckarts; Geistl. Lieder) \\
\hline $\begin{array}{l}\text { 2. Allegorisch-satirisches } \\
\text { Lehrgedicht }\end{array}$ & Rollenhagen (Froschmeuseler) \\
\hline 3. Eigentliche Satire & $\begin{array}{l}\text { Murner (Narrenbeschwörung; Schelmenzunft; Geistliche Badefart; Geuchmat; Der lutherischen } \\
\text { evangelischen Kirchendieb und Ketzer Calender) }\end{array}$ \\
\hline 4. Fabeldichter & Burkhard Waldis (3 Beispiele) \\
\hline D. Dramatische Poesie & $\begin{array}{l}\text { Jakob Ayrer (Commedia Julius Redivivus; Tragedia Von dem Griechischen Keyser zu Constantinopel, } \\
\text { vnd seiner Tochter Pelimperia; Ein schöns neus singents Spil, von dem Eulenspigel) }\end{array}$ \\
\hline \multicolumn{2}{|l|}{ Prosa } \\
\hline \multicolumn{2}{|l|}{ A. Geschichtliche Prosa } \\
\hline 1. Volksromane & $\begin{array}{l}\text { Buch der Liebe, } 1587 \text { (Vom Keyser Octauiano; Historivom Edlen Ritter Galmy; Histori von Herrn Tristrant)- } \\
\text { Fortunatus mit seinem Seckel und Wunschhütlein, Ausg. } 1551 \text { - Wickram (Goldfaden)-Tyll Eulenspiegel, } \\
\text { Ausg. } 1538 \text { - Die Sage vom Erz-Schwarzkünstler Doctor Faust. Niederdt. Ausg. } 1588 \text { u. Bearbeitung von } \\
\text { Pfitzer } 1671 \text { - Die Sage vom ewigen Juden, Ausg. } 1634\end{array}$ \\
\hline
\end{tabular}




\begin{tabular}{|c|c|}
\hline Gliederung & Autoren und Texte (in der Schreibweise der Sammlung) \\
\hline 2. Satyrischer Roman & Fischart (Gargantoa vnd Pantagruel; Aller Practik Großmutter; Philosophisches Ehezuchtbüchlein) \\
\hline 3. Rein historische Werke & $\begin{array}{l}\text { Aventinus, Sebastian Frank, Aegidius Tschudi; andre Chronisten; Stilisten im geschichtlichen und beschrei- } \\
\text { benden Stil, u.a. Sebastian Münster, Götz von Berlichingen }\end{array}$ \\
\hline \multicolumn{2}{|l|}{ B. Didaktische Prosa } \\
\hline $\begin{array}{l}\text { 1. Eigentlich belehrende } \\
\text { Schreibart }\end{array}$ & Dürer (Vier Bücher menschlicher Proportion)-Luther-Zwingli \\
\hline $\begin{array}{l}\text { 2. Ausleger deutscher Sprüch- } \\
\text { wörter }\end{array}$ & Johann Agricola (Siebenhundert vnd funfftzig Deutscher Sprüchwörter) \\
\hline 3. Hauptasket & Johann Arndt (Vier Bücher vom wahren Christenthum; Paradiesgärtlein) \\
\hline 4. Satiriker & $\begin{array}{l}\text { Hutten (Gespräch Büchlin; Die verteutscht clag [...] an Hertzog Fridrichē zů Sachsen)-Erasmus Alberus } \\
\text { (Der Barfüßer Münche Eulenspiegel vnd Alcoran; Das Buch von der Tugent vnd Weißheit) }\end{array}$ \\
\hline C. Rhetorische Prosa & Johann Matthesius \\
\hline $\begin{array}{l}\text { [Anhang:] Behandlung der } \\
\text { Sprache }\end{array}$ & Valentin Ickelsamer \\
\hline \multicolumn{2}{|l|}{ V. Zeitraum $1620-1720$} \\
\hline \multicolumn{2}{|l|}{ A. Poesie } \\
\hline $\begin{array}{l}\text { 1. Den Úbergang bezeichnende } \\
\text { Dichter }\end{array}$ & Spee (Trutz Nachtigal; Goldnes Tugendbuch)-Weckherlin (12 Beispiele) \\
\hline $\begin{array}{l}\text { 2. Erste schlesische Schule oder } \\
\text { Opitz-Flemmingsche } \\
\text { Gruppe }\end{array}$ & $\begin{array}{l}\text { Opitz (Trostgedicht in Widerwärtigkeiten des Kriegs;Zlatna Oder Gedichte Von Ruhe des Gemüths; Vielguet; } \\
\text { Vesuvius; Schäfferey, Von der Nimfen Hercinie; Poetische Wälder, } 10 \text { Beispiele; Geistliche Gedichte, } 5 \text { Bei- } \\
\text { spiele)-Flemming (17 Beispiele)-Gryphius (Leo Armenius; Catharina von Georgien; Cardenio und } \\
\text { Celinde; Carolus Stuardus; Papinianus; Peter Squentz; Horribilicribrifax; Poetische Wälder, } 16 \text { Beispiele)- } \\
\text { Logau (100 Sinngedichte)-Tscherning(Deutscher Getichte Früling, } 7 \text { Beispiele; Vortrab des Sommers } \\
\text { Deutscher Gedichte;Sprüchwörter Ali's) }\end{array}$ \\
\hline
\end{tabular}




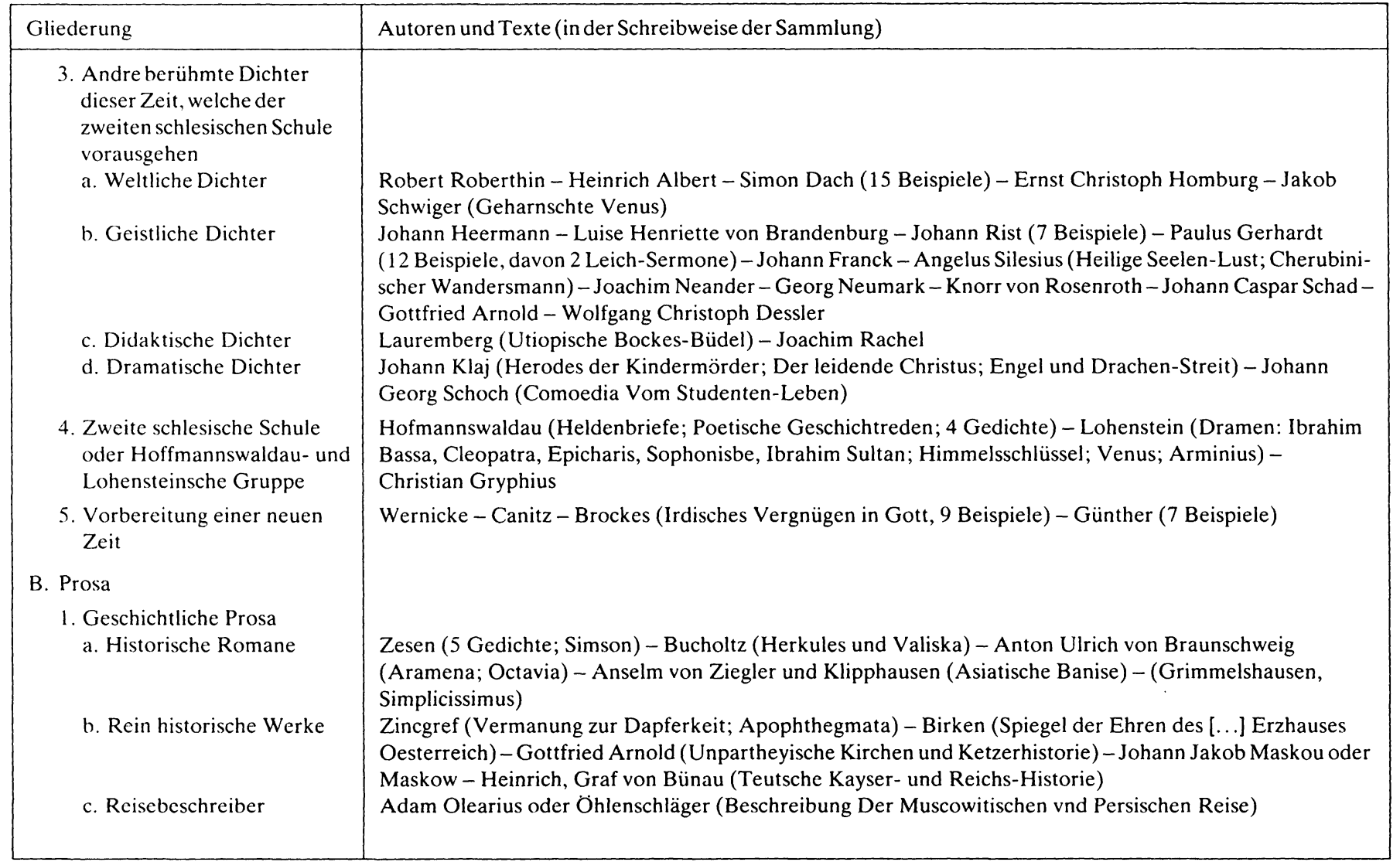




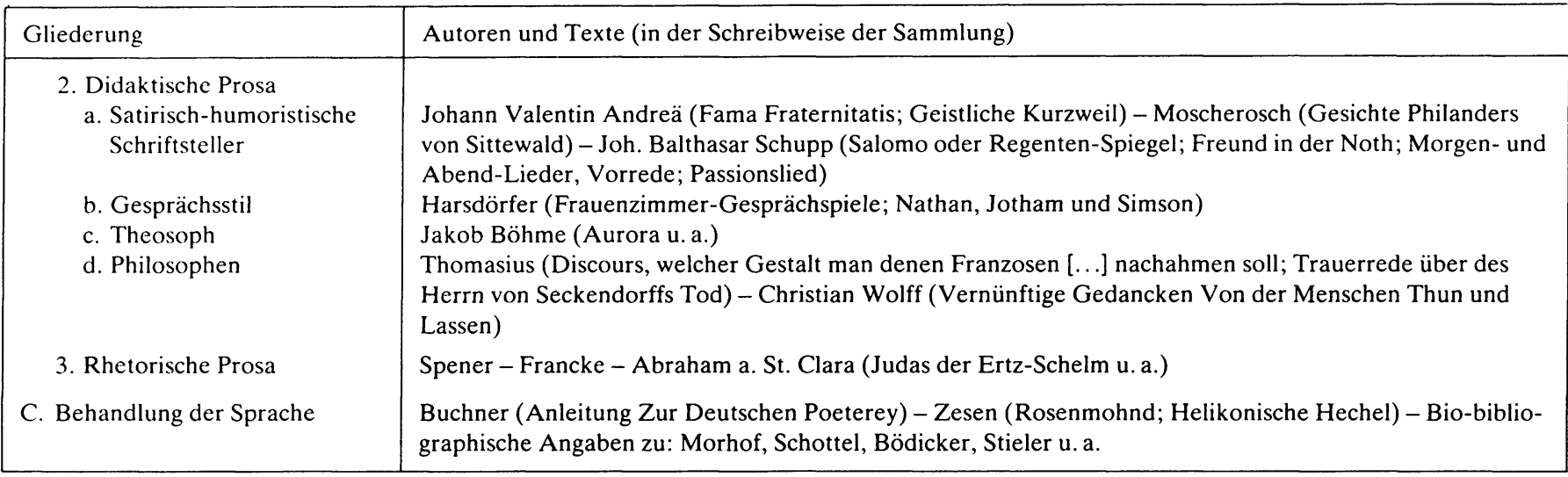

Titel der Sammlung: F[riedrich] A[ugust] Pischon: Denkmäler der deutschen Sprache von den frühesten Zeiten bis jetzt. Eine vollständige Beispielsammlung zu seinem Leitfaden der Geschichte der deutschen Literatur. 2. Tl., welcher die Zeit bis zum Jahre 1620 enthält; 3. Tl., welcher die Zeit vom Jahre 1620 bis 1720 umfasst. Berlin: Duncker u. Humblot 1840-43. XX, 604; XVI, 599 S. - Zu einzelnen Beiträgen:
Grimmelshausen erscheint noch (nach Ermittlung des wahren Namens 1837) anagrammatisch als Samuel Greifensohn von Hirschfeld (Tl. 3, S. 475-81). - Da P. »die Octavia selbst nicht erlangen « konnte, werden H. Künzels Auszüge (Drei Bücher deutscher Prosa. Tl. 1. Frankfurt/M. 1838, S. 284-87) übernommen (TI. 3, S. 463 Anm. 2). 
haben die umfangreichen Sammlungen von Erhard (Handbuch der teutschen Sprache, 3. Cursus, 1824) und Pischon (Handbuch der deutschen Prosa, Tl. 1, 1818; Denkmäler der deutschen Sprache, Tl. 2 u. 3, 1840-43, mit zusammen ca. 1240 Seiten - s. dazu Tabelle 23), an denen auch der Fortschritt der Quellenerschließung erkennbar wird. Erhard übernimmt die Texte zum Teil noch aus Schilters Thesaurus antiquitatum Teutonicarum (1728) und Menckes Scriptores rerum germanicarum (1728-30), den bahnbrechenden vorromantischen Quellensammlungen, zum Teil geht er auf Originale des von ihm geleiteten Archivs in Erfurt zurück. In dem Bestreben, über die Ausgaben der Autoren des 16. und 17. Jahrhunderts zu unterrichten und die eingesehenen Titel diplomatisch getreu wiederzugeben, gehört Pischons Werk in die Vorgeschichte des Goedeke. Seine Auswahl hat die geistliche Lyrik und den Königsberger Dichterkreis erstmals wieder in größerem Maße zugänglich gemacht. Die genannten Sammlungen sind für die Rezeptionsgeschichte gerade der mittleren deutschen Literatur von erheblicher Bedeutung, doch bleiben sie für den Schulunterricht, der sich nach wie vor auf die Literatur von der Aufklärung an konzentrierte, peripher.

\subsection{Redekultur und Liberalismus}

Reden werden in nicht geringer Anzahl regelmäßig in den Schulanthologien abgedruckt (s. Kap. 3.1). In erster Linie handelt es sich dabei um die Gattung der Kanzelrede, für die es eigene 'Klassiker` (Mosheim, Zollikofer, Reinhard, Schleiermacher) gibt. Die rhetorische Analyse der Lobrede auf Friedrich d. Gr. von $\rightarrow$ Engel (als Nachruf am 24. Januar 1781 gehalten) und in Österreichischen Schulen von Sonnenfels' Rede auf Maria Theresia (s. S. 86) gehören zum festen Unterrichtspensum. Muster für Schulreden liefert vor allem Herder, von Goethe finden sich die Gelegenheitsrede bei der Eröffnung des neuen Bergbaus zu Ilmenau (1784; Kannegießer, Der deutsche Redner, 1845 u. Wolff, Handbuch deutscher Beredsamkeit, 1846), die Worte »Zum brüderlichen Andenken Wielands« (1813; Kannegießer; Rupp, Mustersammlung, 1842; Wolff) und zur Trauer um Herzogin Anna Amalia (1807; Rupp). Da akademische Reden (etwa Schillers Antrittsrede, Schellings Vorlesungen über die Methode des akademischen Studiums oder seine Akademierede Ueber das Verhältniß der bildenden Künste zu der Natur) sowie öffentliche Reden (Fichtes Reden an die deutsche Nation) und Vorlesungen vor gemischtem, d. h. auch weiblichem Publikum (A. W. Schlegel, F. Schlegel) ein wichtiges zeitgenössisches Medium geistiger Äußerungen waren, nehmen die Sammlungen auch diese Formen auf.

Ein wichtiger Anstoß für die Pflege der Rede ging vom Liberalismus in seiner weitesten Bedeutung aus. Das Argumentationsschema, das die Beredsamkeit in der Öffentlichkeit der Republik ansiedelt, blieb seit Cicero und Tacitus ein fester, auch während des Absolutismus unvergessener Bildungsbestandteil. [32] Seit der Französischen Revolution, die als »die Erzeugerin der modernen Beredsamkeit «[33] gilt, haben das Prinzip der Öffentlichkeit, die Parlamente, die Geschworenengerichte, die Volksfeste und Vereine der Kunst der Rede eine neue Realität gegeben. Den Enthusiasmus der Zeit soll eine kennzeichnende Äußerung verdeutlichen [34]: 
Und wie mächtig regt sich der Geist der Zeit, das allgemeine, unaufhaltsame Verlangen nach Oeffentlichkeit und Mündlichkeit im wissenschaftlichen, bürgerlichen und socialen Leben! Historiker, Aerzte, Naturforscher, Land- und Forstwirthe, Gewerbsleute, Philologen, Juristen und Theologen versammeln sich aus allen Landen zu mündlichem Ideenaustausche, Vereine für kirchliche und weltliche Zwecke bilden sich in Menge und werden sammt ihren segensreichen Wirkungen zumeist durch die Macht der Rede getragen und gefördert, überall Sehnsucht nach öffentlicher, mündlicher Rechtspflege, überall ein lebhaftes Ergreifen jeglicher Gelegenheit zu vaterländischen Festen, welchen die Rede den wahren Gehalt verleihen muß, überall unzählige Veranlassungen, bei welchen es für jeden Gebildeten als unumgängliches Erforderniß erscheint, sich mit Würde öffentlich vernehmen lassen zu können. Grund genug also, dem oratorischen Elemente eine größere Fürsorge im Unterrichtswesen zu widmen, als demselben bis jetzt leider zu Theil ward.

Der Glaube an die Macht der Rede gehört zum akademischen Charakter des Vormärzliberalismus, der unter Professoren, Lehrern und Studenten viele seiner Sprecher fand. Lehrer nannten die Redekunst mit dem Verfassungsstaat in einem Atem und schätzten ihre Rolle viel zu hoch ein. In der deutschen Philologenversammlung von 1840 hält Günther eine begeisterte Rede darüber, »was die Gymnasien zur Wiederherstellung der öffentlichen Beredtsamkeit beitragen können«. »Ein Volk, das nicht reden kann, kann auch nicht handeln. Rede ist Handlung, ist die Mutter derselben bei Anderen. Zum Reden muß man erzogen werden. «[35] In einem »Repräsentativ-Staat « sei die Beredsamkeit »die Tugend der Tugend. Für jedes öffentliche Amt wird der Bürger nur mündig durch den Mund «. [36] Manche Pädagogen erwarteten vom Rhetorikunterricht, den sie »als Vorbereitung für den spätern staatsbürgerlichen Wirkungskreis der Zöglinge « [37] verstanden, revolutionäre Veränderungen. „Wer unsere nachwachsende Beamtenjugend reden lehrte, der würde auch der Freiheit eine Gasse brechen «, heißt es zum Beispiel 1847. [38] Die politische Rhetorik erfaßte die frühkonstitutionellen Staaten Süd- und Mitteldeutschlands wie die Schweiz am stärksten und scheint ein Hauptgrund, weshalb die Rhetorik gerade in diesen Staaten ein langes Ansehen genoß. [39]

Kein Wunder, daß die Schulbuchautoren Anthologien parlamentarischer Reden bereitstellten. Die Schweizer Mustersammlung der Beredsamkeit (1838) [40] enthält ausschließlich »Staatsreden « - eine Tat in der Restaurationszeit. Die noch heute zentralen Gestalten in der Kunst der politischen Rede Englands (William Pitt der Ältere, Horace Walpole, Edmund Burke, Charles James Fox, George Canning, Daniel O'Connell, Thomas Macaulay, Robert Peel u. a.) und Frankreichs (Mirabeau, Constant, Lamartine u. a.) dienen dem Schüler zum Muster, darunter die von Adam Müller gepriesene Streitrede von Burke gegen Fox über die Französische Revolution. Je länger sich die Parlamente in Deutschland bewährten, je mehr traten deutsche Beispiele in den Vordergrund. Kannegießers Deutscher Redner (1845) [41], dem »die edelste Freisinnigkeit « [42] bescheinigt wird, bringt von badischen Abgeordneten Reden Ueber Bedingung und Form des Untersuchungsarrestes (von K. Th. Welcker), über Judenemanzipation und Preßfreiheit. O. L. B. Wolffs Handbuch deutscher Beredsamkeit (1846) [43] druckt fünf Reden aus den badischen, je zwei aus den sächsischen und bayerischen Kammern ab. Die Mehrzahl behandelt Programmpunkte des Vormärzliberalismus - wie Preßfreiheit, Gerichtsöffentichkeit, die Landwehrverfassung -, womit auch diese Sammlung die Verbreitung freiheitlicher Prinzi- 
pien unterstützt. Vor diesem Hintergrund ist es verständlich, wie die Märzrevolution und das Frankfurter Parlament »die Krönung der deutschen Rhetoriktradition « (F. Sengle) [44] werden konnten, und nicht einmal deren Scheitern vermochte die Illusionen von der Wirksamkeit der Rede überall zu erschüttern.

\subsection{Schriftliche Übungen}

\subsubsection{Stilübungen}

Die Stil- und Versübungen höherer Schulen zeigen, wie die Kommunikation der sgebildeten Ständes, sowohl im Berufsleben wie in der Freizeit, bis in die erste Hälfte des 19. Jahrhunderts hinein von der Rhetorik voll durchdrungen wurde. Ich gehe dabei von der Analyse des Lehrgangs in zwei repräsentativen Unterrichtswerken aus:

(a) Johann Daniel Schulze: Ideenmagazin für Lehrer in obern Klassen der Gymnasien und Lyceen zu zweckmäßigen schriftlichen Arbeiten für ihre Schüler. Weißenfels u. Leipzig: Böse 1804.

\section{Gliederung der Ubbungen}

1. Skizzen

Geordnete Wiedergabe des Handlungsganges und der Argumentation gelesener Texte (z. B. von Cicero, Juvenal, Sophokles).

2. Anthropologische Fragmente [= Reflexionen]

Isolierung und Bearbeitung von Reflexionen aus Texten verschiedener Thematik (z. B. von Livius, Tacitus, Plautus).

2.1. Aufsuchen und Exzerpieren von Reflexionen nach vorgegebenem Muster

2.2 Systematisches Ordnen von Exzerpten

2.3. Prüfung der »Materie« der Reflexion, hinsichtlich der Art ihrer Erfassung und Thematisierung

2.4. Prüfung der »Form « der Reflexion

2.5. „Charakteristik des Schriftstellers (S. 37) aus seinen Maximen und Reflexionen

2.6. Erweiterung von Reflexionen zu allgemeinen Ansichten und Standpunkten, mit Hinzuziehung von Sprichwörtern

3. Kombinationen

Entwicklung der »Grundsätze eines Schriftstellers über gewisse Gegenstände « (S. 42) aus den hierzu gesammelten Zitaten (z. B. »über des Livius Denkart in Hinsicht auf Religion «, ebd.)

4. Fabeln

4.1. Die Fabel dient (nach Lessings Vorschlag [45]) »als Stoff«, an dem die Schüler »ihre Erfindungskraft äussern und üben« (S. 54):

4.1.1. Veränderungen der Fabel

4.1.2. Vergleich der Geschichte mit der »Moral«

4.2. Vergleichung ähnlicher Fabeln von Aesop und Phädrus (unter Hinzunahme von La Fontaine, Hagedorn u. a.)

4.2.1. Parallelisierung "in materieller Hinsicht «

4.2.2. Parallelisierung »in formeller Hinsicht « 
4.3. Ưbungen an Lessings Fabeln

Man untersucht, »welche Partie der Aesop. Fabel Lessing auffaßte « und »in welcher Hinsicht « er die Vorlage nutzte, ob sich aus der Lessingschen Fabel allein »oder in Verbindung mit der Aesopisch-Phädrischen « eine neue Fabel gewinnen lasse (S. 55).

4.4. Sammlung von »Stoff zu neuen Fabeln « sowohl »aus eigenen Beobachtungen « wie »aus verschiedenen Schriften über die Triebe und Kunstfertigkeiten der Thiere (S. 55/56; z. B. von Reimarus und Engel, s. Kap. 3.1.c).

5. Horazische Parallelen

Thematische Parallelen aus Horazischen Oden und Episteln (z. B. Bezeichnung der Jahreszeiten; Flüchtigkeit der Zeit und Kürze des Lebens; Unsterblichkeit; Gymnastik der römischen Jünglinge; Macht der Dichtkunst; Cäsar, der Sieger; frohes Mahl) werden zu folgenden Ưbungen gebraucht:

5.1. Inhaltliches und formales Verständnis der Zitate, z. B. Zusammenhang im Werk, Erhellung durch wechselseitigen Vergleich, Erläuterungen aus der antiken Kultur, Unterscheidung von »bildlichen « und »eigentlichen Darstellungen«, Merkmale des »poetischen Ausdrucks «.

5.2. Weitergehende inhaltliche und formale Zusammenhänge, z. B. »Verschiedenheiten des lyrischen Gedichts und der Epistel «, Betrachtung von vielfach modifizierten »Begriffen und Ideen« (z. B. über Macht und Herrschaft, Glück und Glückseligkeit, Gunst und Wohlwollen), Ausführungen aus der Altertumswissenschaft, Verarbeitung von Zitaten zu neuen Texten (Sentenzen, Beschreibungen, Schilderungen).

6. Ovidische Parallelen

Die Ovidischen Parallelen geben über die Horazischen hinaus zu neuen Úbungen Anlaß: Zunächst können Horaz und Ovid als Dichter und in der Sache verglichen werden. Die Ovidstellen erlauben zudem mehr »psychologische«, "physikalische und naturhistorische Bemerkungen« (S. 194).

7. Virgilisch-Homerische Parallelen

8. Virgilisch-Ovidische Parallelen

9. Untersuchung von Varianten in Klopstocks »Messias « auf ihren Zweck hin:

9.1. Belebung der Darstellung (z. B. „Vertauschung der Adjektiven mit aktiven Participien, der Abstrakten mit den Konkreten«; »Auflösung der Participien«; »Gebrauch des Präsens statt des Perfektums «)

9.2. Beförderung der Deutlichkeit (z. B. natürlichere Formung der Konstruktion; zweckmäßigere Interpunktion; Einschluß in Parenthesen, was vom Ganzen einer Periode zu trennen ist)

9.3. Erhöhung von Harmonie und Wohllaut (z. B. vokalreichere und längere Formen; Vermeidung von Zusammenziehungen in Partikeln; Komparative)

9.4. Schärfere Grenzziehung zwischen Prosa und Poesie (z. B. »Vertauschung der gemeinern Worte und Wortformen mit seltnern, edlern «; "Prolepsis des Genitivs «; "poetische Genetivendung «; "Auflösung zusammengesetzter Hauptwörter «, aber auch neue Zusammensetzungen; Stellung des Subjekts ans Ende der Periode)

10. Ubersetzungen aus dem Deutschen ins Lateinische (mit 7 Stellen aus dem »Messias«).

Bei der Verarbeitung von Texten spielen mehrere Gesichtspunkte nebeneinander eine Rolle: Die Ưbungen dienen (a) »in materieller (objektiver) Hinsicht « dazu, »die Gedanken, Meinungen etc., die in einer Schrift enthalten sind, kennen zu lernen « (S. 283), (b) »in formeller (subjektiver) Hinsicht «, um »die Eigenthümlichkeit des Schriftstellers « (S. 283) in Stil und Gattung zu erkennen, (c) »in historischer Rücksicht«, um die Geschichte des Textes und seiner Wirkung (»formell-historische 
Rücksicht«, S. 285) sowie seine kulturellen Entstehungsbedingungen und seine Bedeutung in der Geschichte der Literatur klarzumachen (»materiell-historische Rücksicht «, S. 286).

Im Vordergrund steht zunächst die Frage nach dem Ideengehalt der Texte. Schon die ersten Úbungen (»Skizzen«) lehren die Schüler, bei der Wiedergabe des Handlungsganges und der Argumentation der gelesenen Texte "Sache und Darstellung « (S. 26) zu trennen; sie erhalten Anleitung, die »Mannigfaltigkeit der Ideenverbindung « in ihrem »Zusammenhang ( (S. 26) zu erkennen und sodann den Stoff versuchsweise anders zu gruppieren. Darauf bauen die im Zentrum des Lehrbuchs stehenden Reflexionsübungen auf. Reflexionen verschiedener allgemeinmenschlicher Thematik - deshalb die Bezeichnung des Kapitels als »anthropologische Fragmente « werden isoliert, exzerpiert und geordnet. Die »Stellen« werden sodann hinsichtlich der »Materie«, d. h. des Verhältnisses von »Faktum« und Reflexion, im Einzelfall geprüft: Wird der Gegenstand »getreu « dargestellt, werden alle »Umstände « beachtet, ergeben sich die Bemerkungen »ohne Zwang « und läßt sich das in Rede stehende Phänomen »aus ihnen und durch sie befriedigend erklären « (S. 37)? Der Gehalt an Reflexionen kann schließlich - unter Hinzuziehung von Sprichwörtern - zu allgemeinen Ansichten und Standpunkten erweitert werden. Vorwiegend der gedanklichen Verarbeitung von isolierten Textaussagen dienen auch die Parallelen (»Horazische Parallelen «, »Ovidische Parallelen«, »Virgilisch-Homerische Parallelen « und »Virgilisch-Ovidische Parallelen «), die im Lehrbuch den breitesten Raum einnehmen (von S. 78 bis S. 239 bei insgesamt 312 Seiten). Wie schon bei den Reflexionen, werden hier themengleiche Textpartien zusammengestellt. Sie geben Anlaß zu sachlichen Belehrungen: »zu geographischen Erörterungen« (S. 135), zu »psychologischen«, »physikalischen und naturhistorischen Bemerkungen« (S. 194), »zur Erläuterung gewisser Punkte der Römischen und Griechischen Mythologie, Kultur und Literatur « (S. 135). Die Exzerpte aus Ovid, »welche auf literarische Bildung und Beschäftigung Bezug haben «, bieten Gelegenheit, auf mehrere »Erleichterungsmittel des Studiums « (S. 194) zu sprechen zu kommen. Auf diese Weise wird das künstlerische Werk stets partikularisiert und transzendiert: Ein thematisches Gespräch knüpft sich an einzelne Textstellen (Reflexionen), stiftet Beziehungen zwischen Partien aus Werken eines oder mehreren Autoren (Parallelen) und organisiert die Bruchstücke schließlich zu neuen Ganzen (Formung von Sentenzen, Beschreibungen und Schilderungen aus dem Fundus gesammelter Stellen).

Der formelle Gesichtspunkt, d. h. das Eindringen in künstlerische Techniken, steht zwar hinter der gedanklichen Verarbeitung zurück, doch wird er stets mit ihr verknüpft. So entwickelt das Lehrbuch vor allem eine Ästhetik der Reflexion. [46] Das künstlerische Gefühl wird durch Aufmerksamkeit auf die »Verschiedenheiten der Form « geschärft, indem Reflexionen »entweder als Bemerkungen des Schriftstellers selbst, oder der von ihm aufgestellten Personen von diesem oder jenem bestimmten Charakter erscheinen; entweder in das Ganze der Erzählung mehr oder weniger natürlich eingeflochten sind, oder isolirt dastehen; entweder als aus der Erzählung von selbst sich ergebende Resultate, oder als Prinzipe der Beurtheilung derselben aus höheren Gesichtspunkten, mitgetheilt sind und dgl. m.« (S. 37). In ähnlicher Weise 
wird bei den Fabelübungen die Geschichte mit der »Moral« verglichen: Ob die Moral sich »wirklich « und »in wie fern sie sich « aus der Fabel ergibt, ob »ungezwungen« und »bestimmt genug «, oder »ob nicht vielleicht aus der F[abel]), wie sie ist, sich noch eine andere Moral entwickele«(S. 55)? Bei den Parallelen wird auf den Textzusammenhang reflektiert, und was er zum Verständnis der Zitate beiträgt. Ebenso auf die poetische Ausdrucksweise im Unterschied zur Prosa, auf die Verschiedenheit der Gattungen usw. Das Kapitel »Varianten im Messias von Klopstock « (S. 240-61) [47] benutzt die zahlreichen stilistischen Änderungen in der Textgeschichte des Werkes, um in die stilistische Feinarbeit einzuführen. Dem gleichen Zweck dienen anschlieBend lateinische Übersetzungen aus dem »Messias « (S. 262 bis 276). Solche Úbersetzungen wie das Um- und Neudichten von Fabeln, das durch den Vergleich von thematisch ähnlichen Texten (Fabelreihen Aesop, Phädrus, Lessing, mit gelegentlicher Beiziehung von La Fontaine oder Hagedorn) angeregt wird, macht die produktive Haltung der Schule gegenüber der literarischen Tradition deutlich.

(b) C[hristian] F[erdinand] Falkmann: Methodik der deutschen Stylübungen. 2. gänzlich umgearb. u. bedeutend verm. Aufl. Hannover: Hahn 1823 [1. Aufl. 1818].

\section{Gliederung der Übungen}

Das Werk baut sich aus drei Lehrgängen für »Anfänger «, »Weitergekommene " und „Geübtere « auf. Die Übungen wiederholen sich, nach Schwierigkeitsgraden modifiziert, auf allen Stufen. Die »Nebenübungen « sind »nicht für Alle gleich anwendbar und zweckmäßig « und verlangen »besondere Erläuterung und mehr Zeit als gewöhnlich « (S. 498-99). Als Beispiel folgt der $» 3$. Cursus «:

\subsection{Vorübungen}

3.1.1. Periodirung

3.1.2. Disposition

3.1.3. Variation

3.1.4. Amplification

3.1.5. Concentration (»Zurückführen« eines Textes »auf die Hauptgedanken «)

3.1.6. Analyse (Zerlegung der Form »in ihre logischen, grammatischen und stylistischen Bestandtheile «)

3.1.7. Ubergangskunst (Verbindung von Sätzen, Abschnitten und Teilen eines Textes)

3.1.8. Figuren

3.1.9. Metrik

3.1.10. Einzelne Stylarten

3.1.11. Einzelne Tonarten (Unterarten des Stils)

3.2. Hauptübungen

3.2.1. Beschreibungen

(Lehr-, Geschäfts-, Schönbeschreibungen)

3.2.2. Erzählungen

(Lehr-, Geschäfts-, Schönerzählungen)

3.2.3. Abhandlungen

(entwickelnde, anwendende, vergleichende, beurtheilende, beweisende, untersuchende, betrachtende, umfassende Abhandlungen)

3.2.4. Briefe

(Geschäfts-, Sitte-, Freundschafts-, belehrende Briefe)

3.2.5. Geschäftsaufsätze

(z. B. Dienstgesuch, Zeitungsanzeige, öffentliche Danksagung, Anmeldung zum Examen, Instruction, Protestation) 


\subsubsection{Reden}

(Anreden, Geschäfts-, Actus-, Feier-, historische Reden)

3.2.7. Lecturberichte

(mit Zusammenstellung von Zeitungsnachrichten)

3.2.8. Úbersetzungen

3.3. Nebenübungen

3.3.1. Disputationen

3.3.2. Charakterschilderungen

3.3.3. Biographien

3.3.4. Poetische Beschreibungen

3.3.5. Poetische Erzählungen

3.3.6. Mährchen

3.3.7. Novellen

3.3.8. Balladen
3.3.9. Idyllen

3.3.10. Allegorien

3.3.11. Monologen

3.3.12. Heroiden

3.3.13. Poetische Episteln

3.3.14. Dialogen

3.3.15. Dramatische Versuche

3.3.16. Lyrische Versuche

Ein Unterricht, der sich an diesem Lehrbuch ausrichtet, führt den Schüler nicht nur umfassend in die literarische Formenwelt der Zeit ein, sondern gibt ihm auch Gelegenheit, sich in allen privaten, geselligen, beruflichen und öffentlichen schriftlichen (wie der schriftlich fixierten und dann mündlich vorgetragenen) Verkehrsformen seiner Zeit auszubilden. Somit erhält der Schüler eine im Hinblick auf seine späteren Verhältnisse funktionale Schulung seiner Ausdrucks- und Darstellungsfähigkeiten. Direkte praktische Bezüge haben viele Übungsaufgaben: Private Veranlassungen zu schriftlichen Äußerungen werden bei den »Freundschaftsbriefen (Briefe an Verwandte und Freunde) und den »Geschäftsaufsätzen « berücksichtigt, wo der Schüler Rechnung ablegen, Empfangsscheine und Vollmachten ausstellen, Aufstellungen (darunter einen Bücherkatalog) anlegen, Bittschriften und Anzeigen (bei Behörden, in Zeitungen) verfassen, einen Mietkontrakt aufsetzen oder einem Bediensteten ein Zeugnis ausstellen lernt. Schwergewichtig macht der Unterricht der Abschlußklassen mit den zur Aufnahme und Durchführung eines Studiums nötigen formalen sprachlichen Techniken bekannt; die Übungen befähigen gerade den armen Schüler, ein Stipendium zu erlangen und sich nach dem Studium in Hoffnung auf eine Pfarrer- oder Lehrerstelle als Hauslehrer [48] durchzuschlagen: »Bittschreiben um ein Stipendium « (S. 544), »Danksagungsschreiben an einen Consistorial-Präsidenten für ein ertheiltes Stipendium《 (S. 545), »Erkundigung bei einem Gönner nach zu ertheilenden Befehlen. (Vor der Abreise nach des letzteren Geburtsorte)« (S. 597), »Bittschrift um Befreiung von der Militärpflichtigkeit (S. 547), »Klage über eine erlittene Beleidigung bei der Polizei. (Der Studirende ist etwa von einem Bürger insultirt worden etc.)《(S. 547), Verfassung eines Lebenslaufes zu Prüfungszwecken (S. 535), »Bitte um ein Zeugniß« beim ehemaligen Lehrer (S. 545) und einen Taufschein beim Geistlichen (ebd.), "Dienstgesuch eines Hauslehrers. In einem öffentlichen Blatte. (Hier ist vorzüglich das Weitschweifige, Pathetische, Gesuchte - auch das Unwahre - zu vermeiden.) (S. 599), »An den Grafen von Ebersdorf. Annahme einer Hauslehrerstelle bei demselben. (Enthält die verlangten Bedingungen)« (S.596), »Beantwortung eines Gratulations-Schreibens. (Zu einer angetretenen Hauslehrerstelle, von einem Oheim, der den Schreibenden beim Studiren unterstützte.)《 (S. 597). Aus diesen Themen, in der von mir geordneten Form, läßt sich ein Stück Lebenslauf eines armen Studierenden rekonstruieren. 
Wie die Aufteilung der Beschreibungen und Erzählungen in lehrende, geschäftliche und ästhetische andeutet, richtet sich ein Gutteil der Ubungen nach den Erfordernissen des künftigen Berufs des Schülers: als Verwaltungsbeamter, Techniker/Ingenieur, Ökonom, Lehrer (an Schulen wie Universität), Pfarrer usw. Die Abteilungen »Geschäftsbeschreibungen «, »Geschäftserzählungen « und »Geschäftsreden « stellen den Beamten in folgenden realistischen Situationen vor, die er sprachlich bewältigen muß:

"Besichtigungsbericht über einen, in der Feldmark durch einen Fluß angerichteten Schaden « (Geschäftsbeschreibung, S. 530). - »Kurzer Bericht über den Zustand, worin der Unterzeichnete das Gut Lindenthal gefunden. (Nebst Hinweisung auf Beilagen, worin das Einzelne befindlich.)《 (Geschäftsbeschreibung, S. 586). - »Bericht eines Beamten über einen vorgefallenen Feuerschaden. (Geschäftserzählung, S. 535). - »Bericht eines Beamten in einem Grenzdorfe über eine statt gehabte Durchreise des benachbarten Fürsten.« (Geschäftserzählung, S. 589). - »Ein Beamter fordert die Landleute auf, zum Bau einer neuen Kirche beizutragen." (Geschäftsrede, S. 600)

Bei den »Abhandlungen « herrschen moralisierende, betrachtende bis philosophische, geschichtliche und ästhetische Themen vor. Diese allgemeine humanistische Thematik wird durch »Lehrbeschreibungen « und »Lehrerzählungen « ergänzt, die sehr oft tiefere naturkundliche oder technische Kenntnisse und Interessen voraussetzen und sich speziell an die im Entstehen begriffene Berufsgruppe der Techniker, Ingenieure und Naturwissenschaftler wenden:

»Die Papierfabrik, oder: die Entstehung unsers Schreibmaterials. «(Lehrbeschreibung, S. 529). »Die Baumwollspinnerei. (Hauptpunkt: das Zusammengesetzte der Maschine.) (Lehrbeschreibung, S. 585). - »Der Bergbau. (Oder: die Hauptmomente der Metallgewinnung an den verschiedenen Orten auf der Erde.) « (Lehrbeschreibung, S. 586). - »Wie die Dampfmaschinen erfunden worden sind. (Etwa nach Poppen's technologischem Wörterbuche [49], oder nach einer andern, ausführlichen Erzählung.) (Lehrerzählung, S. 533). - »Die Familie der Liliaceen. Eine botanische Monographie.« (Lehrbeschreibung, S. 585). - „Die Nagethiere oder Glires. Eine zoologische Darstellung. (Bei Blumenbach. [50])« (Lehrbeschreibung, S. 586)

Neben Studium und Beruf zeichnet sich in den Ưbungen das gesellschaftliche und gesellige Leben ab, an dem der Schüler schon teilhat oder in das er hineinwächst: »Sittebriefe« (d. h. private, aber konventionelle Schreiben an Vorgesetzte, Wohltäter, Bekannte), »Anreden « (d. h. personengerichtete Fest-, Lob- und Glückwunschreden bei öffentlichen und geselligen Zusammenkünften; vom Lobpreis des die Schule besuchenden Landesfürsten bis zum Glückwunsch für ein Jubiläum im Familienkreise), »Feierreden « (bei aktuellen offiziellen Anlässen und Gedächtnistagen). Selbst die informellen Vorformen der Erwachsenenbildung werden rhetorisch durchformt. In Lehrbriefen, in Vorlesungen mit sgemischtem Publikum ker sein Wissen den von den höheren Schulen ausgeschlossenen Frauen weiter, z. B. »Die altnordische Mythologie. Eine Reihe von Briefen an eine Schwester. (Sie ist durch die neuern Beziehungen darauf in den schöngeistigen Schriften begierig geworden, etwas Näheres darüber zu erfahren.) «(S. 598) Die halb belehrenden, halb witzigen Vorträge in kleinem Kreise (z. B. über Tassos Befreites Jerusalem; den Tee; »die Gaserleuchtung in ihren Hauptmomenten«, ausgeführt »mit Feinheit, Witz, Redeschmuck etc.« - S. 577, 595) waren in der geselligen Kultur der Zeit beliebt. 
Zum Dichten wird das Gros der Schüler nicht angehalten; eine Reihe von Aufgaben macht sie allerdings mit literarischen Techniken bekannt. Dabei ist die Zielsetzung eine doppelte: Der Schüler wird mit der Machart literarischer Produkte vertraut, und diese Schulung fördert die Ausbildung der eigenen sprachlichen Fähigkeiten. Vor allem metrische Übungen und Versübertragungen (z. B. Übertragung einer Stelle aus Vergils Aeneis »in der Art, wie es Schiller mit dem vierten Gesange gethan «, S. 580) gelten als »unumgänglich nöthig " »nicht allein zur Bildung der eignen Sprache, sondern auch zur Beurtheilung jedes Werks der schönen Redekunst « (S. 525). Zuweilen wird »aus dem Stegreife« versifiziert, z. B. »Beschreibung eines schönen Sommermorgens im elegischen Versmaße. (Muß ex tempore in der Lehrstunde niedergeschrieben werden.)«(S. 580) Die Figurenlehre wird so gründlich getrieben, daß der Schüler »beim Lesen der Dichter und Redner und beim eignen Schreiben leicht davon Anwendung machen « (S. 524) kann. Auf diese Weise verbinden mehrere Stilübungen Textanalyse mit praktischen Versuchen: »Periodirung (mit Bezug auf die Periodologie der antiken Rhetorik und in Verbindung mit der noch nicht mechanisch geregelten Interpunktion) [51], »Ưbergangskunst « (d. h. Verbindung von Sätzen, Abschnitten, Teilen eines Textes »sowohl hinsichtlich der Gedanken als der Einkleidung«; S. 522), »Disposition« (»Aufsuchen des Plans « in Musterwerken wie eigene Entwürfe zu prosaischen und dichterischen Arbeiten; S. 515). Breiten Raum nehmen die »Lecturberichte « ein, die im Dienste einer Leseerziehung die häusliche Lektüre leiten und kontrollieren. Der Schüler muß die abgesprochenen Texte (etwa Klopstocks Messias, Herders Legenden, Engels Lobrede auf Friedrich d. Gr., Schillers Antrittsrede) so konzentriert lesen, daß er den »Inhalt « und »Gedankengang " wiederholen sowie seinen kritischen »Eindruck « begründen kann (z. B. »Welchen Eindruck Tiedge's Urania auf den Schreibenden gemacht habe. [Keineswegs kritisch; aber ins Einzelne gehend, motivirend, mit Stellen belegend.]« - S. 554). Wer mit solchen Úbungen die Schule absolviert, der hat das literarische Metier auf eine Art kennengelernt, daß er dichterische Produkte formal genießen kann und ein Gespräch über ihre Techniken nicht scheuen wird.

Alle bisher genannten Arbeiten gehören zu den für alle Schüler verbindlichen »Vor-« und »Hauptübungen«. Die »Nebenübungen« erlauben, lokalen Möglichkeiten der Schule und individuellen Fähigkeiten und Neigungen der Schüler entgegenzukommen. Von der Einrichtung der Anstalt (Schüler- und Klassenzahl; Internat) hängt es beispielsweise $a b$, wieweit sich die Schüler selbst gegenseitig unterrichten können (»Vorschriften zu Aufsätzen «, wobei ein Schüler dem anderen eine Aufgabe stellt; »Kritiken«, wo ein Schüler die Arbeit eines anderen beurteilt). Erst die »Nebenübungen « erschließen voll und ganz das Feld der Dichtung; hier treten die pädagogischen Bedenken gegen obligates und übermäßiges Dichten auf Schulen zurück. Jeder Schüler muß in der "Schönbeschreibunģ" und "Schönerzählung " zweckfreie ästhetische Prosa liefern; jetzt darf er auch »poetische «, d. h. versifizierte Beschreibungen und Erzählungen (als Teile von Heldengedichten, Lehrgedichten, Schauspielen oder Idyllen) verfertigen. Überhaupt stehen ihm jetzt alle Gattungen offen: Monologe, Dialoge, Charaktergemälde, Allegorien (mit Rätseln), Fabeln, 
lyrische Versuche, Balladen, Heroiden, poetische Episteln, komische Erzählungen, Novellen, Märchen, dramatische Versuche. Beispiele:

„Der Abschied aus dem elterlichen Hause. (In dem Geiste und der Manier des Voß'schen 70sten Geburtstages.) ( (Poetische Beschreibung, S. 608). - »Kriegsgetöse. Bruchstück aus einem Heldengedichte. ([. . . In Hexametern.) (Poetische Beschreibung, S. 608). - »Schilderung eines wohlthätigen Fürsten. (Bruchstück aus einem Lehrgedichte: die Kunst zu herrschen. Alexandrinen.) « (Poetische Beschreibung, S. 608/09). - »Der menschenfreundliche Teufel. Komische Erzählung. (Einem von Räubern angefallenen Dorfbewohner bringt ein Neger, von Beiden für den Teufel gehalten, das, Jenem abgenommene, Geraubte zurück, und der Bauer wundert sich, daß der böse Geist, der sonst nur hole, dießmahl [!] gebracht habe. (Poetische Erzählung, S. 609/10) - „Cäsar's Tod. (Bruchstück aus einem Trauerspiele: die Schlacht bei Philippi. Fünffüßige Jamben.)《 (Poetische Erzählung, S. 610). - »Björn, oder: der Alte vom Berge. (Aus der nordischen Vorzeit; als Gebrauch der altnordischen Götterlehre.) (Märchen, S. 610/11). »Der Nußbaum. Ein ländliches Gedicht. (Nach einer Erzählung in Wyß's schweizerischen Idyllen, Legenden und Volkssagen. [52]" (Idylle, S. 613). - »Monolog eines Geizigen. Bruchstück aus einem Lustspiele." (Monolog, S. 615). - "Sadi. Eine morgenländische Novelle. (Erfindung ziemlich gleichgültig; nur Beobachtung des Landes- und Sitten-Costümes.)« (Novelle, S. 612). - »Blumen und Schmetterlinge. Ein Wechsellied. (Blumen, sagt Jean Paul, sind festsitzende Schmetterlinge, so wie diese fliegende Blumen.) (Lyrischer Versuch, S. 620). »Die Weisheit. (Gegenstück zu Hallers Ode: die Tugend.) (Lyrischer Versuch, S. 620)

Auch zum literarischen Kritiker kann sich nach eigens dafür eingerichteten Aufgaben ausbilden, wer mag.

\subsubsection{Versübungen}

Metrische Úbungen gehörten bis mindestens zur Mitte des 19. Jahrhunderts zu den Pflichtaufgaben eines Gymnasiasten. Die Versbearbeitungen dienten dabei zum einen der Sprachbildung. Das Metrum zwinge den Schüler »über die Wahl des Ausdrucks, über die Ordnung und Stellung der Wörter nachzudenken, gewöhnt sein Ohr an Wohlklang und Numerus, und erwirbt ihm eine genauere Kenntniß der Sprache«. [53] Das Verständnis der Dichtung galt neben der »Herrschaft über die Sprache « [54] als zweites Unterrichtsziel. Es komme darauf an, die Mehrzahl der jungen Leute dahin zu bringen, »dass sie Dichterwerke gehörig verstehe, empfinde und vortrage«. [55] Die metrischen Arbeiten blieben in der Regel an gegebene stoffliche Muster gebunden, da freie poetische Versuche aus didaktischen Gründen abgelehnt wurden. Die Praxis hat díesen Grundsatz freilich oft negiert (vgl. Kap. 3.4.3). Die gleitenden Úbergänge von der selbstverständlichen Beherrschung literarischer Techniken über dilettantische Versuche zur anspruchsvollen Dichtung, die besonders für die Biedermeierzeit so typisch sind, finden in dieser Art der Stilübungen auf Schulen eine Erklärung. Insbesondere die klassizistische Verskultur wäre ohne diesen Unterricht, der die stilkonservativen Gattungen gegenwärtig hielt, nicht möglich gewesen. Da der Unterricht wohl jedem Gebildeten eine gewisse literarische Kompetenz verlieh, wird auch verständlicher, wieso das Gespräch über literarische und künstlerische Fragen in der Gesellscahft der Zeit einen so breiten Raum einnehmen konnte. 
Zwei Beispiele, die unmittelbar aus der Praxis stammen, sollen den metrischen Lehrgang vergegenwärtigen. Gotthold, dessen metrisches Lehrbuch (Hephästion 1820, 2. Aufl. 1824) weite Verbreitung fand, war Direktor des Friedrichs-Kollegiums in Königsberg, der angesehensten Anstalt Ostpreußens. $\rightarrow$ Viehoff, der als Kommentator der Klassiker bekannt wurde, hat die erste Fachzeitschrift für den deutschen Unterricht (Archiv für den Unterricht im Deutschen, 1843-44) begründet, aus der die folgenden Zitate stammen. Auch Viehoff hat seine Beispiele der eigenen Lehrtätigkeit entnommen.

Gotthold [56] beginnt in Quarta mit der »metrische[n] oder rhythmische[n] Bestimmung gegebener Wörter und Worte, und Aufsuchung passender Wörter und Worte zu gegebenen Füssen «. Dabei lernt der Schüler, durch welches Wortmaterial die einzelnen Füße gebildet werden. "So sind Stammsilben mit angehängter Ableitungssilbe Trochäen (Steine), Stammsilben mit vorgesetzter kurzer Vorsilbe Jamben (Gestein). Amphibrachen ( $v^{-} \cup$ ) entstehen aus Stammsilben, die vorn und hinten von Kürzen eingeschlossen werden (versteinen). « Spondeen finden sich nur in zusammengesetzten Worten (Rennbahn), Anapäste meist in Fremdworten (Elephant, Melodie, Amethyst usw.). Nach diesen Ubungen ahmt der Anfänger die Silbenanordnungen, die zur Herstellung der verschiedenen Versfüße notwendig sind, »oft und sorgfältig « nach. Trimeter und Hexameter folgen auf Tertia, wobei man den Schüler »auf den Unterschied der Lateinischen und Deutschen Prosodie und die daraus fliessenden Verschiedenheiten des alten Hexameters und des unsrigen « aufmerksam macht. Prosaische Fabeln, Erzählungen und Idyllen werden zur praktischen UUbung in Verse gebracht. "Auf Secunda und Prima kommt nun der daktylische Pentameter, und aus dem alten Drama der trochäische und der jambische Tetrameter, der anapästische Dimeter und Tetrameter nebst den Sapphischen, Alcäischen und andern Strophen hinzu. «

Die eigene Praxis am Friedrichs-Kollegium weicht vom Lehrbuch insofern ab, als der metrische Kursus erst in Tertia beginnt. Der Metrik wird in Tertia und Sekunda wöchentlich eine halbe Stunde, in Prima »im ganzen Monate kaum mehr als Eine Stunde " gewidmet. Monatliche schriftliche Arbeiten treten hinzu: Man verlangt vom Tertianer »etwa zwölf bis vier und zwanzig Deutsche Verse «, vom Sekundaner »eben so viel, und noch zehn Griechische wiederhergestellte«, vom Primaner »die gleiche Anzahl Deutscher, und nach Kräften, entweder fünf bis sieben wiederhergestellte Griechische Trimeter und eben so viel Hexameter, oder eine Äsopische in fünf bis sieben Trimeter gebrachte Fabel. « [57] Gotthold übt die deutsche und die antike Metrik in parallelen Arbeiten. Es kommt in den zwanziger und dreißiger Jahren aber noch vor, $\mathrm{da} ß$ die metrischen Versuche überwiegend den alten Sprachen gelten. [58]

Viehoff [59] beginnt mit (1) Wiederherstellung ungereimter jambischer und trochäischer Verse - den Stoff bietet Goethes Elpenor-Bruchstück in wechselnden VersmaBen-, worauf »die Uebersetzung eines Bruchstückes aus einem englischen oder französischen versificirten Drama in deutsche reimlose fünffüßige Jamben « (z. B. Racines Athalie) folgt. Darauf werden (2) „Versuche im heroischen und elegischen Versmaße « vorgenommen, wobei zuerst »einige in poetischer Prosa abgefaßte Stellen zur Bearbeitung in heroischem oder elegischem Versmaß« (Geßners Idyllen, Hirschfelds Landschaftsgemälde, Andersens Bilderbuch des Mondes) aufgegeben werden. Als schwerere Úbungen in Hexametern und Distichen gelten metrische Bearbeitungen der philosophischen Abhandlungen Schillers - als Beispiel wird die Úbertragung eines Bruchstücks aus dem neunten Brief Uber die ästhetische Erziehung des Menschen in Distichen mitgeteilt - und Übersetzungen der alten Klassiker. (3) Die gereimten jambischen und trochäischen Maße werden durch Wiederherstellung der Reime, durch Ergänzung der fehlenden Reimreihe in Gedichten, worin gereimte und 
reimlose Verse abwechseln, durch die Reimbearbeitung reimloser Stücke und schließlich durch Übersetzungen französischer und englischer Gedichte eingeübt. Der Kursus geht sodann (4) zur metrisch treuen Nachbildung lateinischer Gedichte in komplizierten antiken Versmaßen über und nähert sich zuletzt den freien Arbeiten. Hier (5) werden den Schülern Stellen aus prosaischen Schriften angedeutet, »die sich zu poetischen Beschreibungen, Genre-Bildchen, didaktischen Poesien, Balladen und dgl. umgestalten lassen « (z. B. eine metrische Bearbeitung von Jean Pauls Neujahrsnacht eines Unglücklichen).

Die »Uebungen, die zwischen den metrischen Uebersetzungen und freien metrischen Versuchen in der Mitte stehen «, hat Viehoff später [60] durch weitere Beispiele aus den eigenen Klassen vermehrt: Modernisierung älterer Epigramme (z. B. von Logau); Verarbeitung von Sentenzen, die der Schüler aus seiner Prosalektüre gezogen hat, zu Epigrammen in Alexandrinern oder Distichen; »ein Urtheil in compacter gnomischer oder epigrammatischer Form « »über bedeutende literarhistorische und welthistorische Männer, Ereignisse, Epochen «; metrische Bearbeitungen von Rätseln und Charaden; Nachbildungen, wobei verwandte Stoffe in die metrische Form anerkannter Muster gegossen werden - z. B. »ein Herbstlied in Ton und Versmaß des Winterliedes« von Salis-Seewis; Versübertragungen von Prosastücken z. B. eine Balladenbearbeitung von Schillers Chronikauszug Herzog von Alba bei einem Frühstück auf dem Schlosse zu Rudolstadt im Jahr 1547 oder eine Versfassung Grimmscher Sagen, wie sie auch Simrock geliefert hat; endlich metrische Übersetzungen von mittelhochdeutschen (Walther von der Vogelweide) oder mundartlichen Dichtern (Hebel, Usteri). Freie metrische Arbeiten schließt der Verfasser auch hier von der Schule aus.

Viehoff stellt den gesamten Umfang der metrischen Übungen exemplarisch vor. Die einzelnen Anstalten beschränkten sich meist auf einige Beispiele. Leichtere Umbildungen von Prosa in Poesie, vor allem Versbearbeitungen Geßnerscher Idyllen (wofür Ramler ein Muster abgab), und Úbersetzungen aus den alten Klassikern finden sich am häufigsten. Im übrigen bestimmte der Geschmack des Lehrers die Aufgaben. Beispielsweise hat $\rightarrow$ Koberstein, der den Deutschunterricht in Schulpforta leitete, gern vaterländische Sagen (oft nach Grimm) versifizieren lassen. [61]

\subsubsection{Schul- und Jugenddichtungen}

Dichterische Versuche, wie sie Falkmann nur als »Nebenübungen» anbietet (Kap. 3.4.1), waren in mehreren Gymnasien obligater Unterrichtsstoff. Neben Gelegenheitsdichtungen, zu denen Festlichkeiten des Herrscherhauses, der Besuch hoher Gäste und Schulfeste (Gründung, Patronat, Stiftungen u. a.) Anlaß boten, wurden vor allem klassische und romantische lyrische und kleinere versepische Produkte gefordert. Zusammen könnten die genannten Arbeiten gut einen Musenalmanach füllen.

Im Programm des Naumburger Domgymnasiums (1841/42) heißt es für Deutsch in Sekunda: "Zu poetischen Versuchen nach selbstgewählten und nach aufgegebenen Stoffen boten die Prüfungen und Schulfeste die Veranlassung, und bei diesen Gelegenheiten musste jeder 
Secundaner etwas Poetisches liefern. «Für Latein in Prima: »Zu poetischen Versuchen, die alle Primaner machen mussten, wurde der Stoff in deutscher oder lateinischer Prosa dictirt. Ausserdem lieferten die Geübteren bei Gelegenheit des Geburtstags Sr. Majestät des Königs, des Bücherfestes u.s.w. selbständig gearbeitete Gedichte. «[62] Wie sahen solche Schülerprodukte aus? In Ansbach wurden von 1815 bis 1823 folgende Eigenprodukte an den Schulfesten vorgetragen: »Elegische Gedanken am Fusse einer Felsburg « - wohl nach Matthissons »Elegie, in den Ruinen eines alten Bergschlosses geschrieben " - und "Horazius Kokles " (1815), »Orpheus « und » Kato « (1819), »Auf Leipzigs Schlachtgefild « - wohl nach Körners Muster »Auf dem Schlachtfelde von Aspern « - und »Arnulf« (1820), "Die Glocke« (1822), »Der Glaube" und »Der Roßtrapp« (1823). Lahr (Baden) [63] nennt 1841/42 an metrischen Versuchen der obersten Klasse: "Ode an den Schutterlindenberg, in asklepiadeischen Versen «, variiert nach Tages- und Jahreszeiten (»Am Abend", »Am Morgen«, »Im Herbst «, »Im Frühling «), ein Triolett »Die Hyacinthen im Winter «, ein Rondeau »Die verstummte Nachtigall«, ein Sonett "Die Nachtigall auf dem Kirchhof «, eine Romanze und eine Ballade »Dido«. Und 1843/44: Drei Sonette ("Sehnsucht im Winter nach dem Frühling«, »Des Frühlings Lust ", »An das Veilchen «), zwei Gedichte in Stanzen (»Der Frühlingsmorgen «, "An den Mond «), »Vergänglichkeit. Sestinen«, »Sparta. Elegie«, »Der Sternenhimmel. Ode«, »Abend. Madrigal ", "Abendstille. Triolett «, "An die Ruine Sponeck. Lied" und eine zweisilbige Charade. Die Schüler mußten sich also in Lahr die vorrealistische lyrische Formenvielfalt voll aneignen. In Innsbruck wurden nachstehende Themen noch 1855 am Obergymnasium bearbeitet. Im fünften Kurs: »Kanut der Große beschämt seine Schmeichler. Poetische Erzählung «; »Die Rast auf der Flucht nach Egypten; metrische Legende " sowie "Naemi und Ruth, in Idyllenform erzählt «, nach dem Vorbild der biblischen Versdichtungen von Pyrker. Im sechsten Kurs wurden eine Erzählung Gellerts und ein Gedicht Weißes in Hexameter, ein Gedicht Höltys und Goethes in Distichen übertragen. Der siebte Kurs hat epische und lyrische mittelhochdeutsche Dichtungen metrisch übersetzt (z. B. das Nibelungenlied in Hexameter).

Der stete Rückbezug auf vorliegende Muster, verbunden mit der Pflege der Versgattungen, überhaupt der shohen< Gattungen mit entsprechend sgroßen< (historischen, biblischen, gedanklichen) Stoffen, sowie die Vertrautheit mit den zu ihrer Produktion nötigen stilistischen und metrischen Techniken gaben einem eklektizistischen literarischen Konservativismus im Gymnasium der Restaurationszeit einen starken Rückhalt. Die Jambendramatiker und Versepiker gediehen in der Atmosphäre der Schule. [64] Zwei Autoren können mit ihren großenteils dem Schulbetrieb verpflichteten Jugenddichtungen den Zusammenhang illustrieren: Rudolf Gottschall, ein Hauptvertreter der klassizistischen Poetik und Kritik nach 1848, aber auch Dramatiker und Epiker, und Robert Hamerling, als >Makart der Poesie` ein Gründerzeitautor par excellence.

Gottschall [65] hat während seiner Gymnasialzeit in Koblenz, Mainz und Rastenburg in den dreißiger Jahren folgende dichterische Versuche unternommen: das Drama »Wilhelm von Oranien «; eine Ode auf »Gott « in reimlosen Versen nach Klopstock; »Cajus Gracchus «, ein dreiaktiges Trauerspiel in fünffüßigen Jamben; die Tragödie »Catilina«; »Hippodamia «, eine Jambentragödie mit freirhythmischen Einlagen im klassischen Stil von Goethes »Iphigenie «; das historische Drama »Ladislaus Hunyades" aus der mittelalterlichen Geschichte Ungarns; das Stanzenepos »Ferdinand Cortez « mit 24 Gesängen von je 80 bis 90 Strophen; eine Úbersetzung der ersten Metamorphosen Ovids in deutsche Verse; zwei Dramen freier Erfindung, die - nach dem Vorbild von Grabbes »Herzog Theodor von Gothland — im sagenhaften Nordland spielen: "Die Doppelgänger «, »voll kühner Bildlichkeit und gewagter Hyperbeln « im Stil Grabbes, und »Cerigo«, eine Oedipusträgödie mit einem Prachtstück von Monolog; eine Úbersetzung der »Antigone « »in deutsche Verse und zwar die Chöre in gereimte Verse «; »Heinrich Monte, der Preußische Heerfürst «, ein schwülstiges Trauerspiel. 
Die Schul- und Studentenzeit Hamerlings [66] im Ósterreich der vierziger Jahre brachte an größeren poetischen Versuchen: „Columbus«, ein zweiaktiges Drama; »Die Märtyrer«, ein fünfaktiges Drama; die Canzone »Eutychia oder die Wege zur Glückseligkeit « in drei Gesängen; die »Elegie auf dem Schlachtfelde von Aspern «, eine Schulaufgabe; »Die Bethuliade «, eine epische Dichtung; das Prosawerk »Die beste Welt«; eine Erörterung in Briefen »Ueber die Glückseligkeit «; ein Hermann-Drama und ein didaktisches Märchen »Atlantis «, halb in Versen, halb in Prosa, worin die Ideen der Schönheit und der Liebe verkündet werden; ein märchenhaftes philosophisches Drama "Aurora«, aus dem der "Ahasverus « entstand, ein Gedankendrama, das »die Entwicklungsweise der Menschheit an einem Individuum « darstellen soll, wobei Luzifer, Orpheus, Helena und Christus symbolisch auftauchen.

In Gottschalls Gymnasialzeit entstanden sechs historische Tragödien, ein Stanzenepos, eine Ovid- und Sophoklesübersetzung und eine freirhythmische Ode. Er bevorzugte also hohe Formen, besonders geschichtliche Dramen und Epen, und eignete sich metrische Fertigkeiten in einem Maße an, das ihn. fließend zu produzieren erlaubte. Die Bindung an die Schule ist dabei eng: Die Ovidübersetzung wurde in der Klasse vorgelesen; das Stanzenepos wurde vom Klassenlehrer in Mainz, Joseph Kehrein - einem in dieser Arbeit mehrfach herangezogenen Lehrbuchautor -, pedantisch glossiert; die Sophoklesübersetzung, die im Anschluß an die griechische Klassenlektüre entstand, wurde dem Rastenburger Direktor übergeben, »der sich anerkennend darüber aussprach «. [67] Bei Hamerling trat zur Pflege konservativer Gattungen und zur metrischen Kultur der Anspruch auf den großen philosophischen und weltanschaulichen Gehalt - wobei er sich an Goethes Faust, an Novalis, Leopold Schefer u. a. orientierte. Die Beispiele zeigen die schulische Verwurzelung des literarischen Konservativismus, sei es daß er (im Sinne des Klassizismus) mehr auf die korrekte Form oder (eher im Sinne der Romantik) auf den gedanklichen Gehalt sah. Das Gymnasium hat über 1848 hinaus, im Zeitalter des Realismus, die Versgattungen und hohen Stillagen konserviert und damit ihre Wiederbelebung in der Gründerzeit mit ermöglicht. 


\section{Offene Fragen und Probleme}

Vorliegende Untersuchung der Entstehung und des Wandels des deutschen Unterrichts blieb mit Absicht beim Aufweis von Funktionszusammenhängen höherer Schulen (Lehrpläne und Methoden, Schulorganisationsmodelle, Verhältnis humanistischer und realistischer Bildungswege) stehen. Die Beziehung von Schul- und Sozialsystem wurde wesentlich nach den zeitgenössischen Argumenten und Angaben der Bildungspolitiker und Pädagogen skizziert. Damit sollten einerseits Globalurteile über die funktionale Abhängigkeit der Schulentwicklung von komplexen sozialen und politischen Faktoren (gesellschaftliche Mobilität und Schichtenbildung, Beschäftigungssystem und Laufbahnstrukturen, Schulverwaltung und Schulpolitik etc.) vermieden werden. Für die Gestaltung des literarischen Unterrichts wäre vor allem die Untersuchung der Auswirkungen der Professionalisierung der Altphilologen durch die Universitätsausbildung an den neugegründeten Philologischen Seminaren (s. unter Gesner, F. A. Wolf, Thiersch in den Kurzbiographien) und der davon beeinflußten allmählichen Etablierung der Altgermanistik als Universitätsfach von Interesse. Andererseits sollte die gängige ideengeschichtliche durch eine institutionengeschichtliche Darstellung der Geschichte des Deutschunterrichts ergänzt werden. Die in den vergangenen Jahren unter Pädagogen und Germanisten virulente Ideologiekritik lief nur zu häufig auf eine Neukonstruktion und Umwertung geistesgeschichtlicher Zusammenhänge hinaus, deren Fundierung in realgeschichtlichen Prozessen nicht empirisch kontrollierbar aufgewiesen wurde. Von den Ergebnissen dieser Arbeit aus sind hoffentlich neue fundiertere ideologiekritische Analysen der literaturdidaktischen Intentionen, der Kanonbildung und Interpretation möglich. Die Untersuchungen zu einzelnen Autoren und Werken müßten dabei auf dem Hintergrund der Textgeschichte (mit Aufweis der aus moralischen, ästhetischen oder pragmatischen Gründen vorgenommenen Texteingriffe in Schulanthologien) und der außerschulischen Rezeption erfolgen. Innerhalb dieser Arbeit bedarf besonders der Wandel des Literaturkanons während der Restaurationszeit (Kap. 3.2) einer weitergehenden ideologiegeschichtlichen Deutung, wobei auch nach fachlichen Funktionsdifferenzierungen - Charakter- und Gemeinschaftsbildung in Deutsch/verwissenschaftlichte Arbeitsstruktur in Latein - zu fragen wäre.

Das für die Literaturwissenschaft zentrale Problem der geschichtlich wechselnden literarischen Qualität des Deutschunterrichts an höheren Schulen ist für den hier behandelten Zeitraum kaum diskutiert und nicht beantwortet worden. Nach meinen Beobachtungen lassen sich mehrere Indikatoren für die Feststellung und Wertung der Bedeutung der höheren Schule, speziell des Gymnasiums, für die literarische Kultur heranziehen; sie betreffen den relativen Rang der Gymnasien gegenüber niedereren wie höheren Bildungsinstitutionen, die Konkurrenz mit anderen kulturellen Institutionen und den Medien, die Aktivitäten der Lehrer im literarischen Leben und ihre 
Publikationen. Sowohl institutionell (akademische Gymnasien; Lyzeen in Bayern; »philosophische Obligatkurse « in Österreich) wie personell ist noch bis zur Mitte des 19. Jahrhunderts die Grenze zwischen Gymnasium und Universität fließend. Ein Wechsel von der Gymnasial- zur Hochschullehrerlaufbahn war üblich, sogar umgekehrt (s. Bonitz, Gesner, Köchly, Thiersch, F. A. Wolf in den Kurzbiographien); die Gymnasialdirektoren wurden - häufig von auswärts - >berufen her großer haupt- und residenzstädtischer Anstalten besser bezahlt und höher angesehen als Inhaber mittlerer Professorenstellen an Universitäten. Wie Biographien und Publikationslisten zeigen, waren die Lehrer an höheren Schulen durchaus in der Lage und bereit, erhebliche publizistische, kritische und wissenschaftliche Aktivitäten zu entfalten. Einige der in den Kurzbiographien aufgeführten Pädagogen leben als Ästhetiker und Dichter (Denis, Engel, Schwab, Sulzer), als Kritiker und durch ihre Beziehungen zu Dichterkreisen und namhaften Autoren (Resewitz' Kontakte zum nordischen Dichterkreis und Mitarbeit an den Litteraturbriefen und der Allgemeinen Deutschen Bibliothek; Gedike als Mitherausgeber der Berliner Monatsschrift; Niethammers und F. A. Wolfs Verbindung mit Goethe und Schiller; Bernhardis Beziehung zum frühromantischen Kreis) im Gedächtnis der Literaturgeschichte fort. Von anderen gingen bei der Verbreitung und Interpretation der Weimarer Klassiker (Hiecke, Viehoff), in der Literaturgeschichtsschreibung (Koberstein) und der engeren Fachgermanistik (Götzinger als Mundartforscher, Ph. Wackernagel als Hymnologe) bemerkenswerte Leistungen aus. In einem so zentral auf Erziehung und Bildung gerichteten Zeitalter ergeben sich natürlich ideen- wie realgeschichtlich enge Bezüge zwischen dem literarischen und pädagogischen Bereich; in welchem Maße außerschulische Aktivitäten mit der pädagogischen Tätigkeit zusammenhängen und auf sie zurückwirken, wurde in dieser Arbeit von Fall zu Fall vermerkt, wäre aber in biographischen Untersuchungen im einzelnen zu klären.

Von der großen Bedeutung der damaligen höheren Schule, die erst ansatzweise mit Massenmedien zu konkurrieren hat, für die literarische Rezeption und Geschmacksbildung ist ihr weit problematischeres Verhältnis zur literarischen Produktion zu trennen. Hier ist eine grundlegende Unterscheidung nach Ebenen und Bereichen nötig. Im Bereich der >Hochliteratur hung zum Lesen und Verständnis kanonisierter Literatur) beschränkt, je stärker auf Grund des Selbstverständnisses des freien Schriftstellers, wie es sich in der Genielehre ausdrückt, das literarische Schaffen seine handwerkliche rhetorische Grundlage verliert. Daß diese Entwicklung sich bis zur Mitte des 19. Jahrhunderts verstärkte, aber noch nicht allgemein durchsetzte, ist ein die Epochendarstellung Sengles generell bestätigendes Ergebnis dieser Untersuchung. Es ist im Hinblick auf Versund Prosagattungen weiter zu differenzieren. Während die höhere Schule Versmaße und Strophenformen aller Art einübt und eine zuletzt epigonale Verskultur am Leben erhält (Kap. 3.4.2-3), opponiert sie seit dem ausgehenden 18. Jahrhundert gegen die aufsteigende Erzählprosa, wie die von Zensurmaßnahmen begleitete pädagogische Polemik gegen gewerbliche Leihbibliotheken und die von ihnen geförderte >Lesesucht< belegt (s. S. 111 mit Anm. 7-9). Wirksam erweist sich die höhere Schule demgegenüber bei der Ausbildung schriftlicher Verkehrs- und literarischer Zweck- 
formen. Die aufklärerischen Reformen des Sprach- und Literaturunterrichts haben wie hier gezeigt wurde - nicht zuletzt die Erfordernisse des bürokratischen, geschäftlichen und privaten Verkehrs im Auge gehabt. Um die schulische Ausbildung an der Praxis zu kontrollieren, fehlt es jedoch weitgehend an Untersuchungen zur Entwicklung schriftlicher Kommunikationsformen in diesen Bereichen (für die Verwaltungsreform in Österreich s. S. 11f. mit Anm. 17-20). Ein eindrückliches Beispiel für die Relevanz des Rhetorikunterrichts bildet die Redekultur. Zu den im absolutistischen Staat traditionellen Redeanlässen (kirchlicher und akademischer Bereich) treten im 19. Jahrhundert das im Dienst der Erwachsenen- und Volksbildung sich schnell verbreitende Vortragswesen und vor allem die vom akademischen Liberalismus getragene politische Rede, die der Rhetorik einen fortschrittlichen Anwendungsbereich und neue Geltung (Kap. 3.3) brachte.

Wieweit diese Probleme künftig erörtert und geklärt werden können, hängt entscheidend davon $\mathrm{ab}$, ob in den angesprochenen philologischen und historischen Disziplinen dafür Verständnis und Interesse zu finden sein wird. Während in den Philologien weiterhin Bedenken gegen die Einbeziehung institutioneller Bedingungen literarischer Kultur in ihr Forschungsspektrum auszuräumen sind, hat die sich entwickelnde sozialgeschichtlich orientierte Bildungsgeschichte die Untersuchung der Bildungsinhalte bisher weitgehend außer acht gelassen. Das Ziel dieser Arbeit wäre erreicht, wenn es ihr gelungen ist, zwischen der literarischen Entwicklung und der Schule als einer für sie wichtigen Institution gangbare Brücken zu schlagen. 


\section{Kurzbiographien}

Verzeichnet sind die im Zusammenhang der Arbeit wichtigsten Bildungspolitiker und Pädagogen, abgesehen von den bekanntesten Namen (W. v. Humboldt, Schleiermacher). Verweis im Text durch $\rightarrow$.

Bernhardi, August Ferdinand. Berlin 1769-1820 Berlin. Philologiestudium bei $\rightarrow$ F. A. Wolf in Halle. Lehrer, 1806 Direktor des Werderschen, 1820 Direktor des Friedrich-Wilhelm-Gymnasiums in Berlin. Privatdozent, 1816 Konsistorialrat. Durch seinen Schwager Tieck Beziehungen zum frühromantischen Kreis. Sprachphilosoph.

Bonitz, Hermann. Langensalza 1814-1888 Berlin. Zögling Schulpfortas, Philologiestudium bei G. Hermann in Leipzig und bei Boeckh in Berlin. Gymnasiallehrer, 1849 als Prof. der klass. Philologie an der Univ. und ministerieller Mitarbeiter nach Wien, 1867 als Direktor des Gymnasiums zum Grauen Kloster Rückkehr nach Berlin, seit 1875 Vortragender Rat im Preuß. Unterrichtsministerium. Mit Exner grundlegende Reorganisation der höheren Schulen Österreichs (Schaffung des modernen Gymnasiums), Neueinrichtung der philologischen Studien (Philolog. Seminar in Wien).

Braun, Heinrich. Trostberg a. d. Alz (Oberbayern) 1732-1792 München. Benediktiner, 1767 Kanonikus am Münchener Liebfrauenstift, 1768 Mitglied des Geistlichen Rates, 1770 Landeskommissar für das Volksschulwesen, 1777 Direktor sämtlicher Lyzeen und Gymnasien, Stadtund Landschulen. "Geistiger Vater der öffentlichen Volksschule in Bayern ", seine Reform der Mittelschulen vereinigt »das klassisch-humanistische und das weltbürgerliche Bildungsideal « (NDB). Verf. zahlreicher Lehrbücher, die einen »Markstein in der Entwicklung der deutschen Schriftsprache in Bayern « (NDB) bilden.

Deinhardt, Johann Heinrich. Nieder-Zimmern bei Weimar 1805-1867 Bromberg. Im Hinblick auf den Lehrberuf Studium an der Univ. Berlin (Mathematik, Naturwissenschaften, Philologie bei Boeckh und Bopp, Philosophie bei Hegel). Ab 1844 Direktor des erfolgreich neuorganisierten Gymnasiums in Bromberg. 1848 entschiedener Liberaler.

Denis, Michael. Schärding (Oberösterr.) 1729-1800 Wien. Nach Studium am Passauer Jesuitengymnasium Eintritt in den Orden. Lehrer der schönen Wissenschaften und der Rhetorik an der Theresianischen Adelsakademie in Wien von 1760 bis zur Aufhebung des Ordens 1773, danach Leiter der Garellischen Bibliothek und Kustos der Hofbibliothek. Bahnbrechend für den deutschen Rhetorik- und Poetikunterricht in Österreich. Neulateinischer und deutscher Dichter (Ossian-Nachdichtung, Bardenpoesie unter dem Ps. Sined der Barde), Bibliograph.

Dilthey, Julius Friedrich Karl. Nordhausen 1797-1857 Darmstadt. Studium in Göttingen. 1823 Prof., ab 1826 Direktor des Gymnasiums in Gießen, Mitglied der Oberstudiendirektion. Als Schulpolitiker setzte sich D. für die Vereinigung von Realismus und Humanismus ein.

Engel, Johann Jakob. Parchim 1741-1802 Parchim. Ab 1776 Prof. der Moralphilosophie und der schönen Wissenschaften am Joachimsthalschen Gymnasium in Berlin; Lehrer der Brüder A. und W. v. Humboldt; Prinzenerzieher (Friedrich Wilhelm III). »Repräsentativer Vertreter der Berliner Aufklärung (NDB). Theaterdichter und -leiter (Berliner Nationaltheater), vielgelesener Popularphilosoph, Essayist.

Follen, August Adolf Ludwig. Gießen 1794-1855 Bern; Bruder von Karl, dem Anführer der 
Gießener »Schwarzen «. Freiwilliger Jäger in den Befreiungskriegen, Studium in Heidelberg, als Redakteur der Elberfelder "Allgemeinen Zeitung « in burschenschaftliche )Umtriebe « verwickelt und 1819-21 in Haft. Auswanderung in die Schweiz, Prof. der deutschen Sprache und Literatur an der Kantonsschule Aarau. Dichter.

Gedike, Friedrich. Boberow bei Lenzen (Prignitz) 1754-1803 Berlin. Subrektor, 1779 Direktor des erfolgreich neuorganisierten Friedrich-Werderschen Gymnasiums, 1793 Direktor des Vereinigten Berlinisch-Köllnischen Gymnasiums in Berlin. 1784 Oberkonsistorialrat, Mitglied des Oberschulkollegiums (Abiturientenexamen), Initiator der Gymnasiallehrerbildung (philologisch-pädagogisches Seminar seit 1787). Ging vom Philanthropismus aus, um sich später stärker dem Neuhumanismus zuzuwenden. "Führender Vertreter der friderizianischen Aufklärung in den Berliner Gesellschaften « (NDB), Mitherausgeber der »Berliner Monatsschrift « 1783-91.

Gesner, Johann Matthias. Roth bei Nürnberg 1691-1761 Göttingen. 1715 Konrektor in Weimar, 1730 Rektor der Thomasschule in Leipzig, ab 1734 Prof. der Poesie und Beredsamkeit an der neugegründeten Univ. Göttingen. Neben Haller und Mosheim »der stärkste Anziehungspunkt « der Univ. (NDB). Wegbereiter des Neuhumanismus, wirkte erfolgreich für die Reform der gelehrten Schulen (Schulordnung für die Braunschweig-Lüneburgischen Lande; Einrichtung des ersten Philolog. Seminars).

Götzinger, Maximilian Wilhelm. Neustadt bei Pirna 1799-1856 Bad Oeynhausen. Lehrtätigkeit am Blochmannschen Institut in Dresden und bei Fellenberg in Hofwil; 1827-50 auf der neuerrichteten Lehrstelle für deutsche Sprache und Literatur am Gymnasium Schaffhausen. Verf. weitverbreiteter Lehrmittel, Germanist (Mundartforschung).

Hess, Ignaz Matthias v. Würzburg 1746 - Wien 1776. Studium der Rechtswissenschaft. Auf Empfehlung des Ministers Graf v. Stadion Hofrat und Archivar am Haus-, Hof- und Staatsarchiv und 1774 Prof. der Universal- und Literaturgeschichte an der Univ. Wien. Früh verstorbener, zu Unrecht vergessener Hauptvertreter der Aufklärungspädagogik in Österreich.

Heyne, Christian Gottlob. Chemnitz 1729-1812 Göttingen. 1763 als Nachfolger von $\rightarrow$ Gesner Prof. der Poesie und Beredsamkeit an der Univ. Göttingen. Sekretär und Reorganisator der Akademie (Redaktor der »Gelehrten Anzeigen«), Bibliothekar. Prägender Einfluß auf das Gelehrtenschulwesen Norddeutschlands durch Schulreformen (Ilfeld/Harz 1770, Göttingen 1789, Hannover 1802) und Lehrerausbildung. »Allseitige Erweiterung des philologischen Gesichtskreises« (NDB), mit Wirkung über die Fachwissenschaft hinaus.

Hiecke, Robert Heinrich. Penig (Sachsen) 1805-1861 Greifswald. Studium in Halle und Berlin (Hegel). Mit Unterbrechungen Lehrer am Merseburger, 1850 Direktor des Greifswalder Gymnasiums. Wegweisender Fachdidaktiker des Deutschen; schulpolitisch gemäßigter Liberaler (Berliner Lehrerkonferenz 1849). Literargeschichtliche, -ästhetische und -kritische Studien.

Klumpp, Friedrich Wilhelm. Klosterreichenbach (Murgtal) 1790-1868 Stuttgart. Tübinger Stift; pädagogische (Pestalozzi, Salzmann, Gutsmuths) und realistische Studien im Zusammenhang mit Auswanderungsplänen. Seit 1821 am Gymnasium in Stuttgart, 1848 provisorisch, 1850 definitiv Rat und Referent für die realistischen Lehranstalten im Studienrat. Trat als Schulpolitiker für Gleichberechtigung von Deutsch, Realien und neueren Sprachen im Gymnasium ein (Reformanstalt Stetten).

Koberstein, August. Rügenwald 1797-1870 Kösen. Studium in Berlin (Philologie: $\rightarrow$ Wolf, Boeckh; Philosophie: Solger, Hegel). Seit 1820 Lehrer in Schulpforta, zunächst für Mathematik und Geschichte, seit 1824 Prof. des Deutschen und Französischen. Erkämpfte »dem deutschen Unterricht die Gleichberechtigung neben den classischen Sprachen « (ADB). Auf amtliche Anregung hin entstand die einflußreiche Literaturgeschichte (zuerst 1827); Germanist.

Köchly, Hermann. Leipzig 1815-1876 Triest. Fürstenschule Grimma, Philologiestudium bei G. 
Hermann in Leipzig. 1840 Lehrer an der Kreuzschule in Dresden, führender sächsischer Schulreformer (Dresdener Gymnasialverein, Entwurf eines Unterrichtsgesetzes). Nach Niederlage der Revolution Flucht in die Schweiz. 1850 Prof. der klassischen Philologie an der Univ. Zürich, beteiligt an der dortigen Gymnasialreform. 1864 Berufung nach Heidelberg. Rege wissenschaftliche Tätigkeit.

Marx, Gratian. 1720-1810 Leoben. Piarist. Vorstand der Savoyischen Ritterakademie in Wien; 1775 Assessor bei der Studienhofkommission, Referent in Gymnasialsachen und Studiendirektor. Seit 1786 Domprobst in Leoben. Planung und Durchführung der Gymnasialreformen nach Aufhebung des Jesuitenordens lagen in seiner Hand. Lehrbuchautor.

Meierotto, Johann Heinrich Ludwig. Stargard 1742-1800 Berlin. Theologiestudium, Hauslehrer beim Berliner Bankier Schickler. 1771 Prof. der Beredsamkeit, seit 1775 Direktor des vorbildlich neuorganisierten Joachimsthalschen Gymnasiums in Berlin. 1768 Kirchenrat, Mitglied des Oberschulkollegiums. Neben $\rightarrow$ Gedike bedeutendster Berliner Aufklärungspädagoge.

Niethammer, Friedrich Immanuel. Beilstein bei Heilbronn 1766-1848 München. Tübinger Stift, Studium der Philosophie und Theologie. 1793 a. o. Prof. der Philosophie (Anschluß an Fichte), 1795 Extraordinarius der Theologie in Jena; Verbindung mit Schiller und Goethe. Prof. der Theologie in Würzburg, Landesdirektionsrat für Schul- und Kirchenwesen in Bamberg, 1808 von Montgelas als Centralschulrat und Oberkirchenrat nach München berufen. Neuhumanistische Gymnasialreform mit einem erstmals an der Weimarer Klassik ausgerichteten Deutschunterricht.

Resewitz, Friedrich Gabriel. Berlin 1729-1806 Magdeburg. Theologiestudium in Halle. 1767 Predigerstelle in Kopenhagen, wo sich R. dem nordischen Literaturkreis um Klopstock anschloß. 1775 aufgrund seiner pädagogischen Reformversuche zum Abt des säkularisierten preußischen Klosters Berge und Leiter des dortigen Pädagogiums berufen. Pädagogischer Schriftsteller und Publizist. Zusammenarbeit mit den Berliner Aufklärern (Mitarbeit an den »Litteraturbriefen« und der »Allgemeinen Deutschen Bibliothek «).

Schwab, Gustav. Stuttgart 1792-1850 Stuttgart. Theologiestudium, am Tübinger Stift Freundschaft mit Uhland. 1817 Prof. am obern Gymnasium, 1841 Stadtpfarrer und Amtsdekan (Superintendent für den Landbezirk) in Stuttgart, 1845 Oberkonsistorialrat, Mitglied des Studienrats. Pädagogische, historische und publizistische Tätigkeit für die deutsche Literatur. Dichter und Übersetzer.

Seibt, Karl Heinrich, Ritter v. Mariental (Oberlausitz) 1735-1806 Prag. Philosophische und juristische Studien in Prag und Leipzig (Gellert). 1763 a. o. Prof. der schönen Wissenschaften in Prag, nach Aufhebung des Jesuitenordens 1775 Direktor der Philosoph. Fakultät und der Prager Gymnasien. Österr. Aufklärer, der im Sinne Gellerts für Erziehung und deutsche Literatur wirkte; irenisches Christentum.

Steigentesch, Johann Joseph Friedrich. Geburtsjahr, Herkunft (Österreich?), Todesjahr unbekannt. Herausgeber der Mainzer Wochenschrift »Der Bürger " (1765-69; vielleicht Beziehungen zum Kreis um Wieland, La Roche, Dalberg). Unter Kurfürst Emmerich Joseph (1763-74) und seinem Kanzler Bentzel-Sternau maßgeblicher Ratgeber der weithin beachteten Mainzer Schulreformen; Hofgerichtsrat, Direktor und Prof. der »Schullehrer-Akademie«. Beim Tod des Kurfürsten Flucht vor ihm in Effigie lynchenden Volk. Biographie des radikalen, aber unsteten Aufklärers bleibt »ein Desiderat« (H.-M. Elzer).

Sulzer, Johann Georg. Winterthur 1720-1779 Berlin. Theologiestudium in Zürich, wo er von Bodmer und Breitinger in die Literatur und Ästhetik eingeführt wurde. 1743 nach Magdeburg (Hauslehrer), 1747-63 Prof. der Mathematik am Joachimsthalschen Gymnasium, 1765 Prof. an der neuerrichteten Ritterakademie in Berlin. Tätiges Mitglied der Akademie (seit 1775 Direktor der philosophischen Klasse). Mehrfach mit Neuordnung von Schulen beauftragt; Entwurf 
des Gymnasiums in Mitau. Hervorragende Persönlichkeit des literarischen Berlin Friedrichs II., Enzyklopädist der Aufklärungsästhetik.

Thiersch, Friedrich. Kirchscheidungen bei Freiburg a. d. Unstrut 1784-1860 München. Schulpforta, theologisches und philologisches Studium (u. a. bei G. Hermann), 1808 Habilitation in Göttingen. Ab 1809 als Prof. am Gymnasium, dann am Lyzeum und der Univ. in München. Umfängliche schul- und hochschulpolitische Aktivitäten: Gründung des Philolog. Seminars, Neuorganisation der Gymnasien (Ausrichtung an den alten Sprachen) und der Universität, Sekretär der philolog.-histor. Klasse der Akademie. Lehrer im Königshaus (Töchter Max Josephs, Kronprinz Maximilian). »Praeceptor Bavariae « unter Ludwig I., Exponent altphilologischer Bildung. Reiche wissenschaftliche Tätigkeit.

Viehoff, Heinrich. Büttgen bei Neuß 1804-1886 Trier. Studium der Philologie (A. W. Schlegel) und Naturwissenschaften in Bonn. 1833 Lehrer am Gymnasium in Emmerich, 1838 an der Realschule in Düsseldorf, seit 1850 Direktor der höheren Bürgerschule und der damit vereinigten Provinzialgewerbeschule (später Realschule I. Ordnung) in Trier. Reiche literarische Tätigkeit zur Verbreitung und zum Verständnis der Weimarer Klassiker. Begründer der ersten Fachzeitschrift für deutschen Unterricht (»Archiv für den Unterricht im Deutschen«, 1843-44 $\rightarrow »$ Archiv für das Studium der neueren Sprachen und Litteraturen«).

Wackernagel, (Karl Eduard) Philipp. Berlin 1800-1877 Dresden. Als Schüler des Grauen Klosters in Berlin Liebling Jahns; im Hause und unter der Leitung Karl v. Raumers Studium der deutschen Grammatik und Literatur sowie der Naturwissenschaften (Mineralogie). 1828 Lehrer an der Berliner Gewerbeschule, 1839 am Privatgymnasium (Reformanstalt) Stetten bei Stuttgart, 1845 Prof. am Realgymnasium in Wiesbaden, 1849-61 Direktor der Real- und Gewerbeschule in Elberfeld. Konzeption eines christlich-nationalen Deutschunterrichts, Germanist (Kirchenlied).

Weitenauer, Ignaz. Ingolstadt 1709-1783 Salomonsweiler. Jesuit, 1753 Magister der Philosophie und Prof. der griechischen und hebräischen Sprache an der Univ. Innsbruck, nach Aufhebung des Ordens im Zisterzienserstift Salomonsweiler. Ein Beförderer des deutschen Unterrichts unter den Jesuiten $(\rightarrow$ Denis), fruchtbarer gelehrter Schriftsteller.

Wilmsen, Friedrich Philipp. Magdeburg 1770-1831 Berlin. Schulbildung in Berlin unter K. Ph. Moritz und $\rightarrow$ Engel, Theologiestudium. Lehrer (u. a. an der Luisenstiftung), Prediger und Verwaltungsbeamter in Berlin. Äußerst erfolgreiche Kinderbücher ("Deutscher Kinderfreund «), zahlreiche Erbauungsschriften und Lehrbücher.

Wismay(e)r, Joseph. Freising 1767-1858 München. Studium in Freising und Salzburg, Weltpriester. 1792 Präfekt des Lodronisch-Rupertinischen Erziehungsstiftes in Salzburg. 1803 Schuldirektionsrat (Mittelschulplan 1804, bekämpft von Schelling und Voß), 1808-11 Oberschulrat in München; nach Konflikt mit $\rightarrow$ Niethammer versetzt in die Ministerialsektion der kirchlichen Angelegenheiten (Oberkirchenrat), ab 1817 Tätigkeit in der Akademie (Kalenderwesen). Deutsche Sprachlehrbücher.

Wolf, Friedrich August. Hainrode bei Nordhausen 1759-1824 Marseille. Wunderkind, Studium in Göttingen. 1779 Kollaborator am Pädagogium in Ilfeld (Harz), 1782 Rektor der (gymnasialen) Stadtschule in Osterode (Harz), 1783 Prof. der Philologie und Beredsamkeit in Halle (Philolog. Seminar), 1810 in Berlin. Mitwirkung bei der Gründung der Berliner Universität und der Gestaltung der Gymnasien in Preußen. 1810 Direktor der wissenschaftlichen Deputation für die Sektion des öffentlichen Unterrichts. Epochemachender Altertumswissenschaftler; freundschaftliche Verbindung mit W. v. Humboldt und Goethe. 


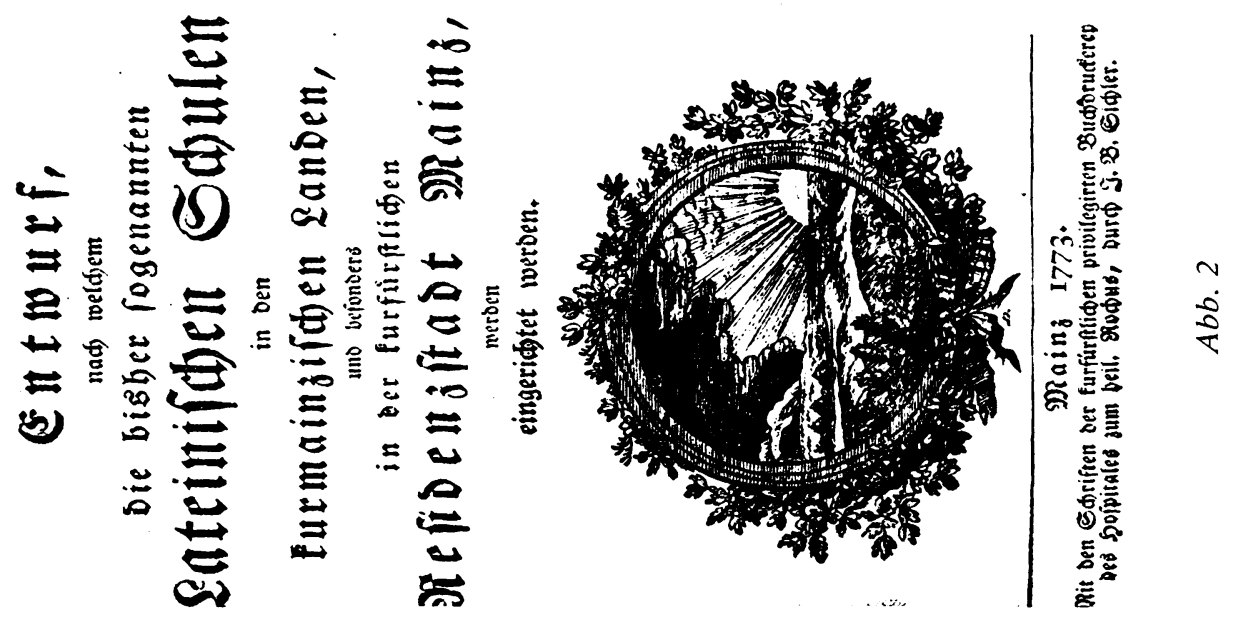

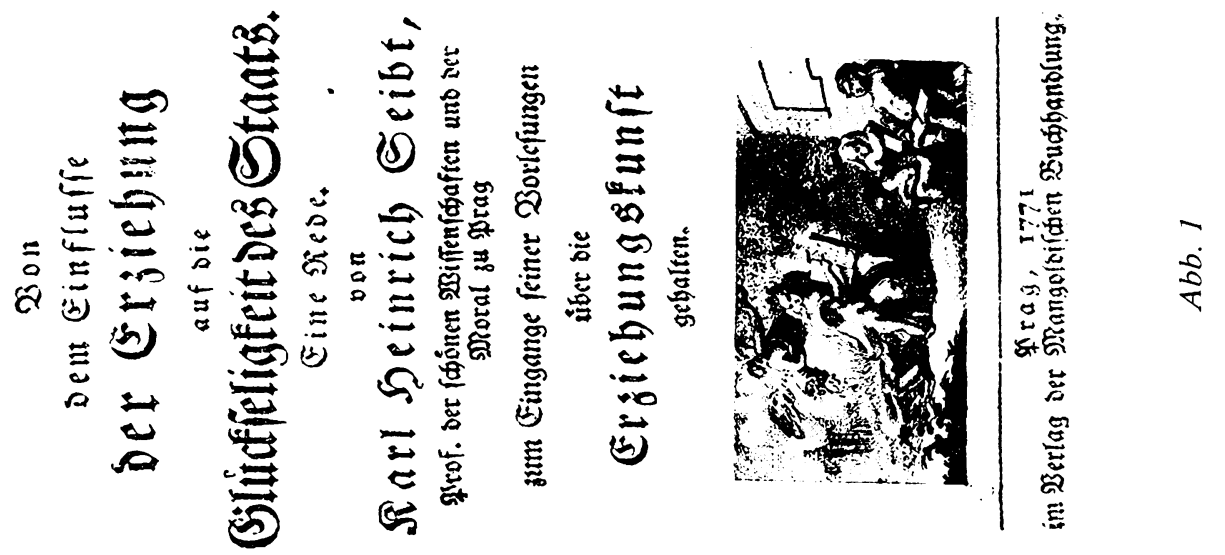



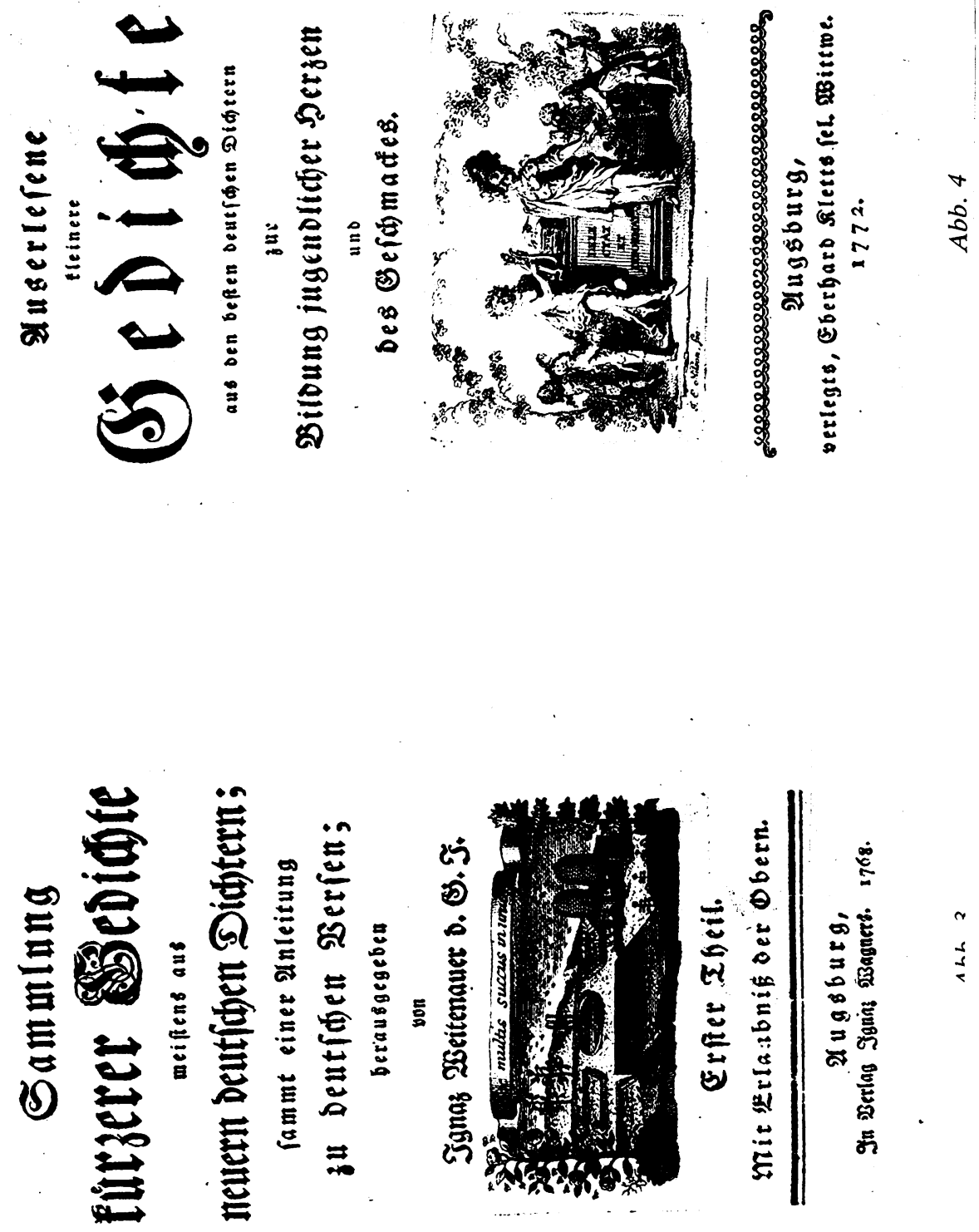

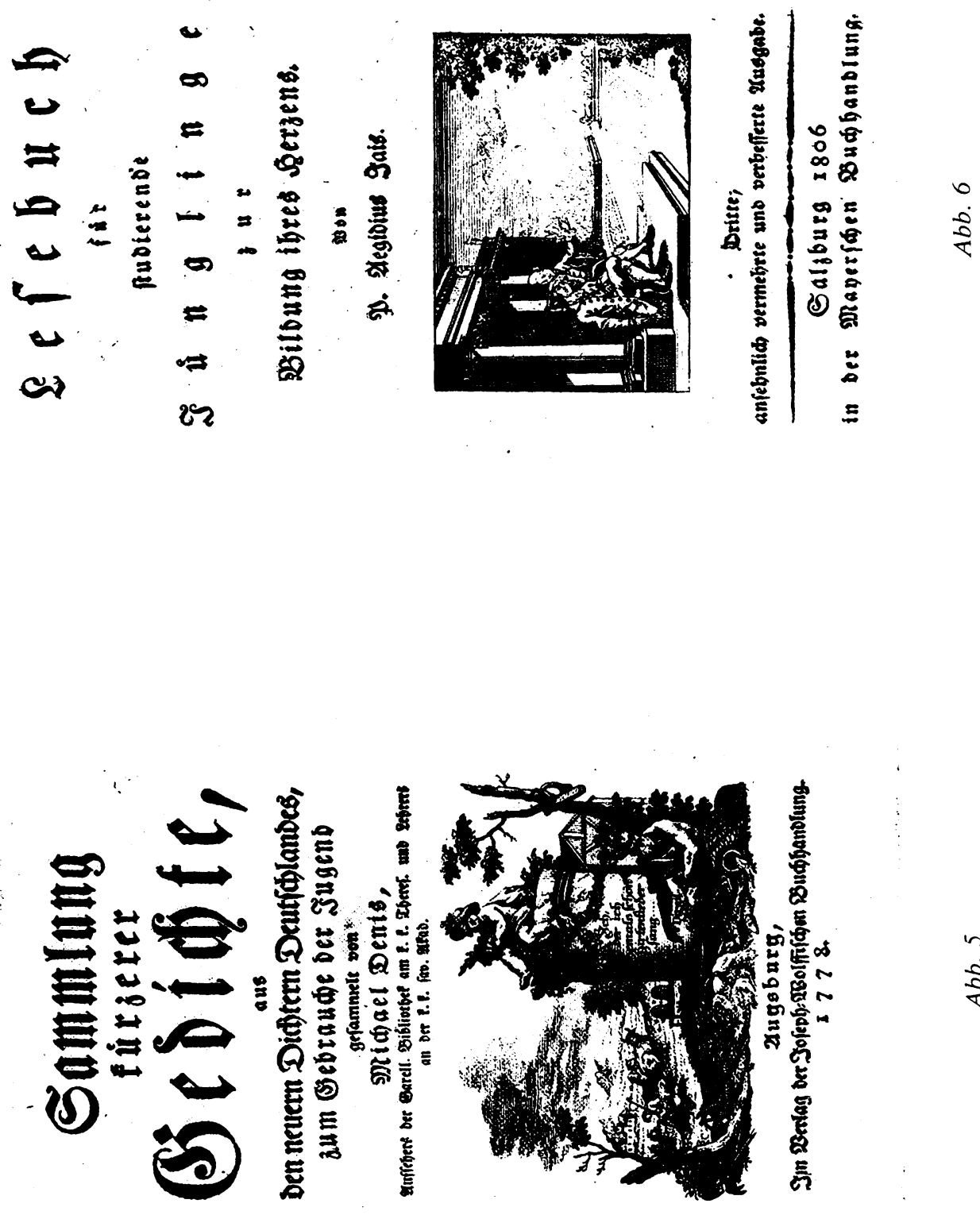

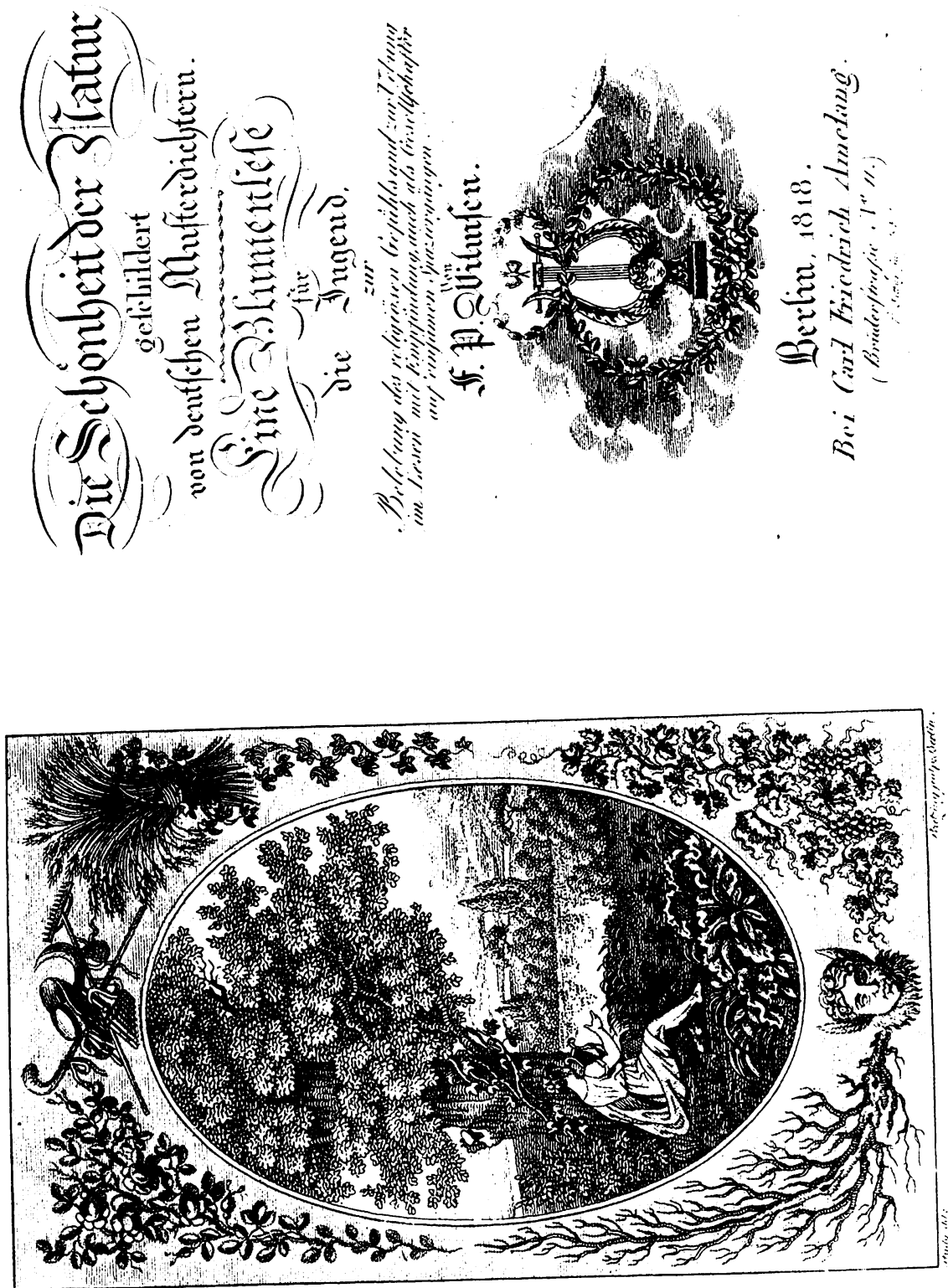


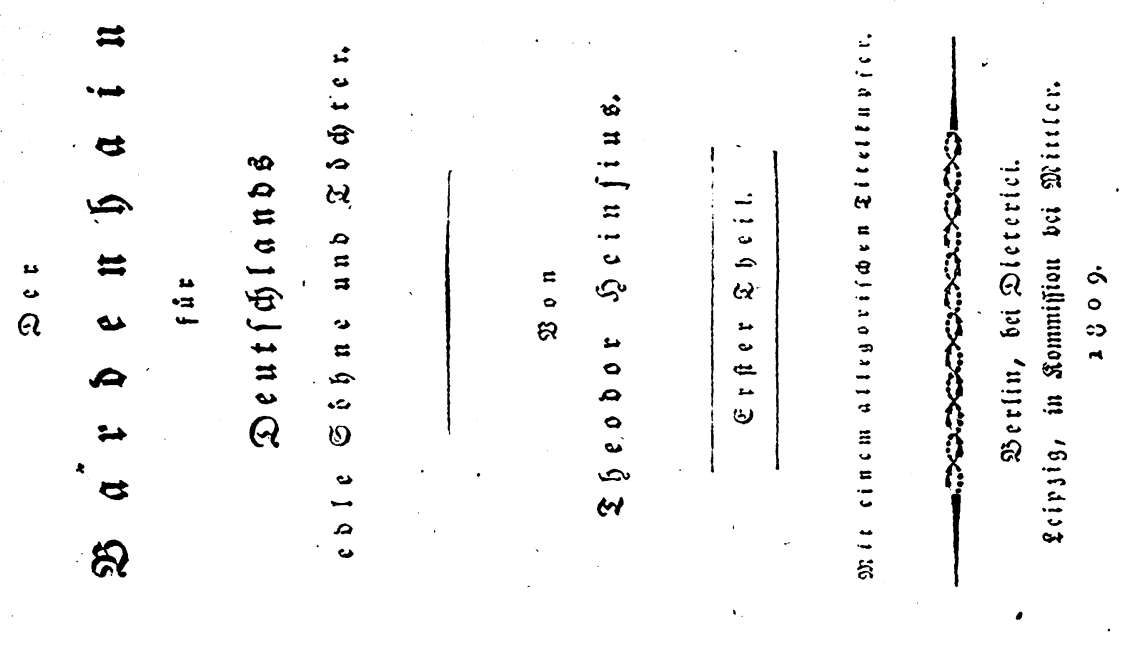

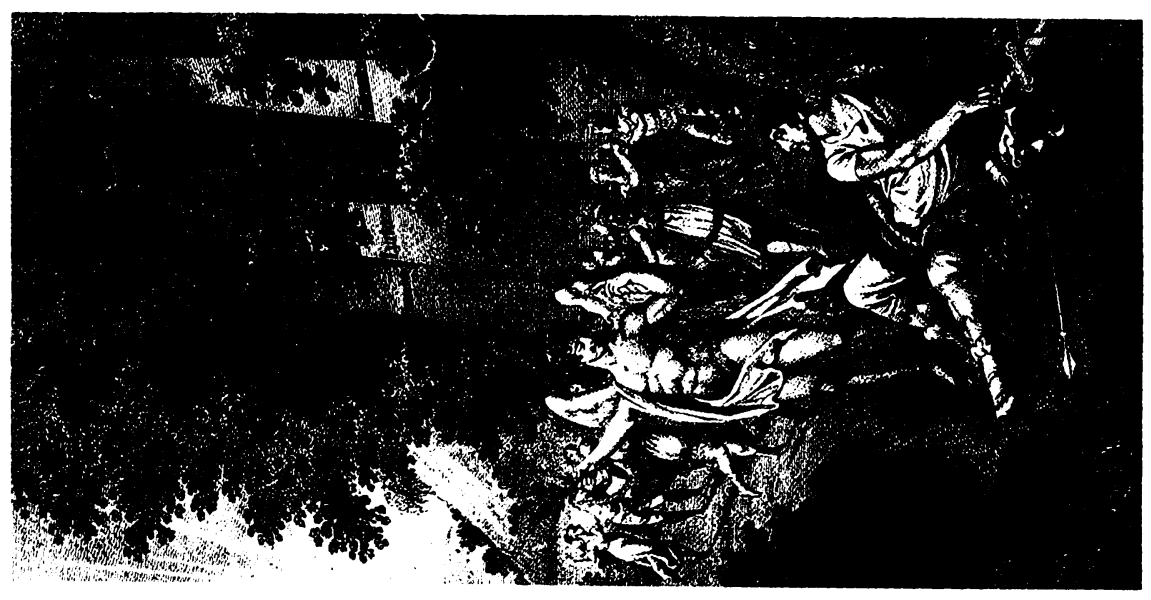




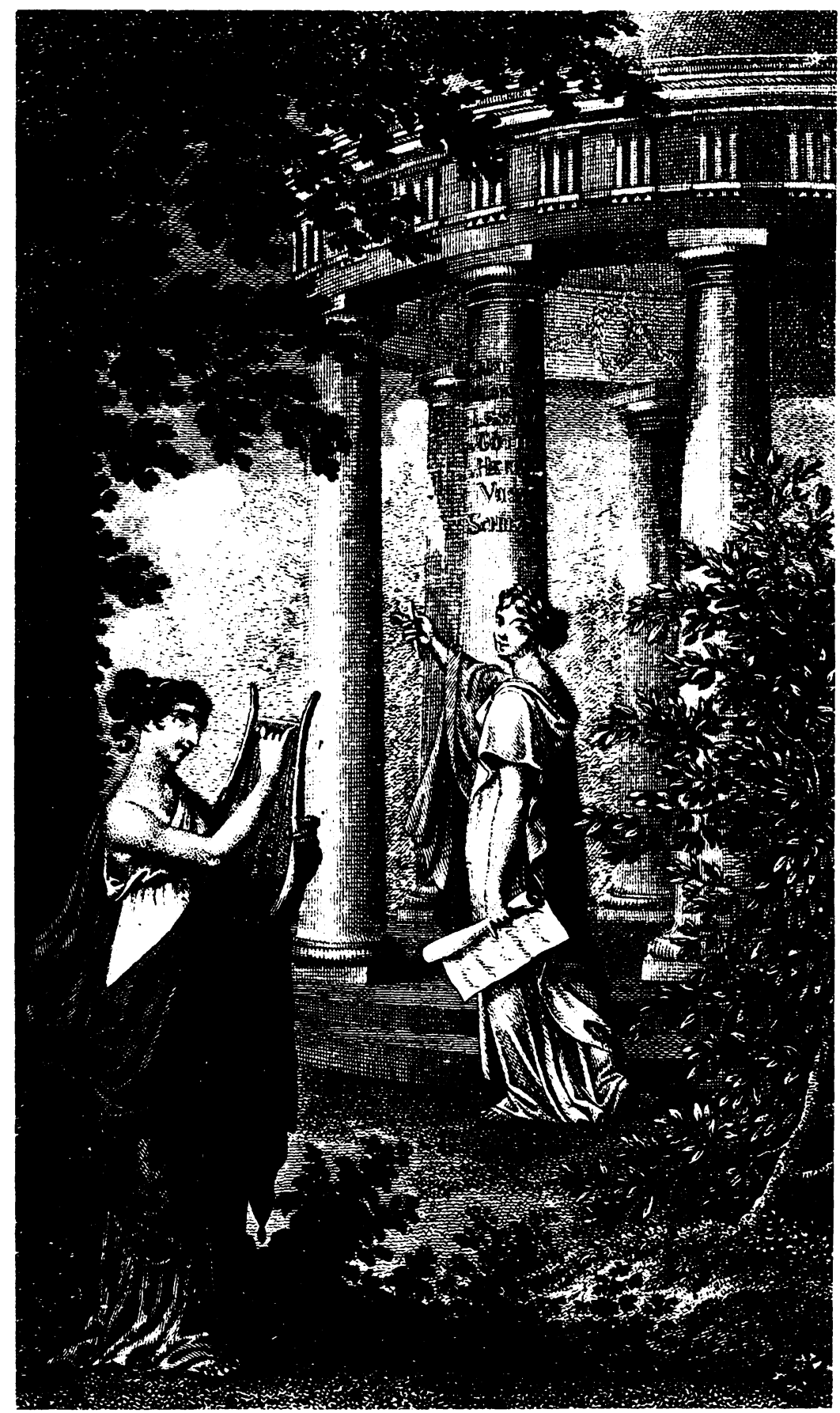




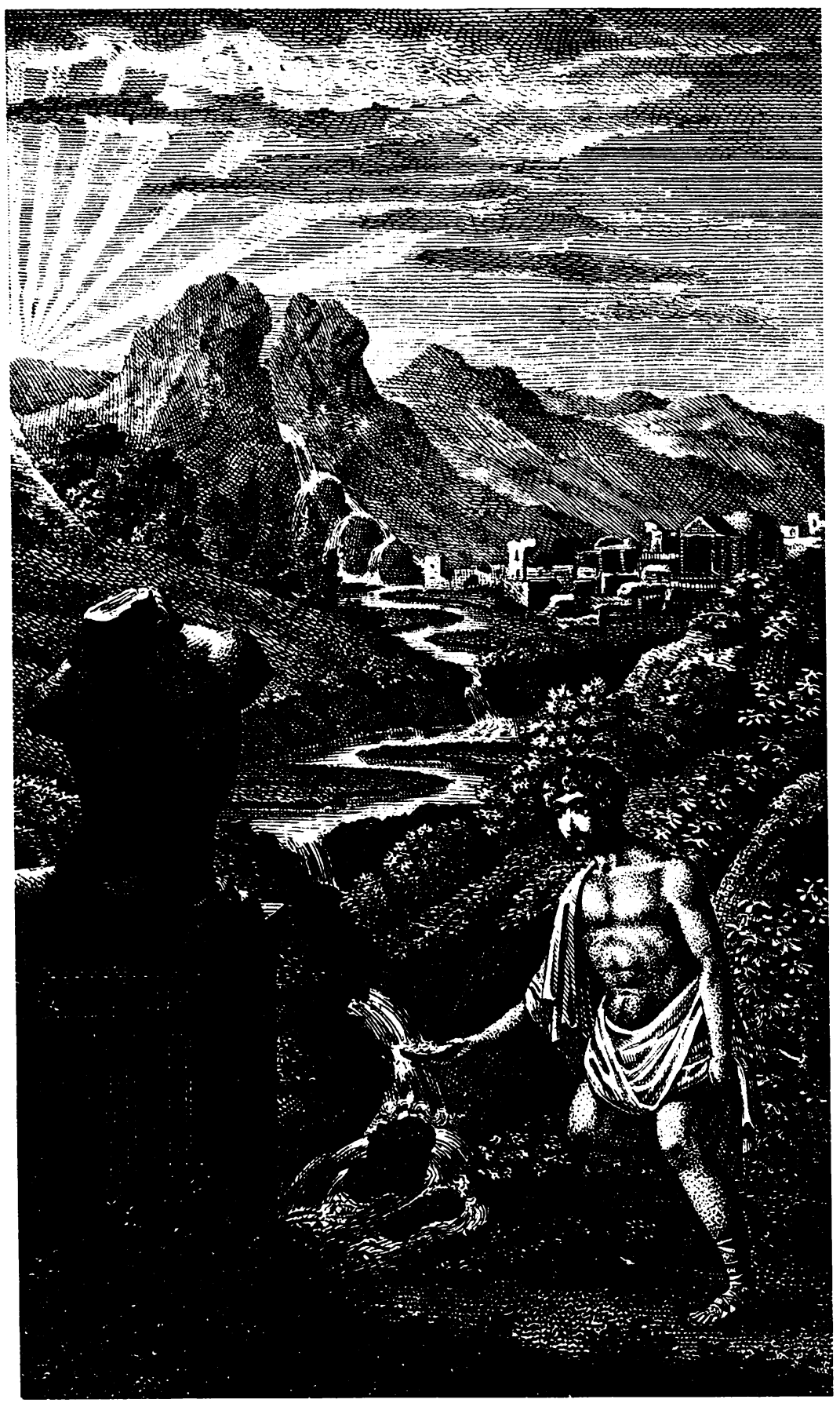

Abb. 10 


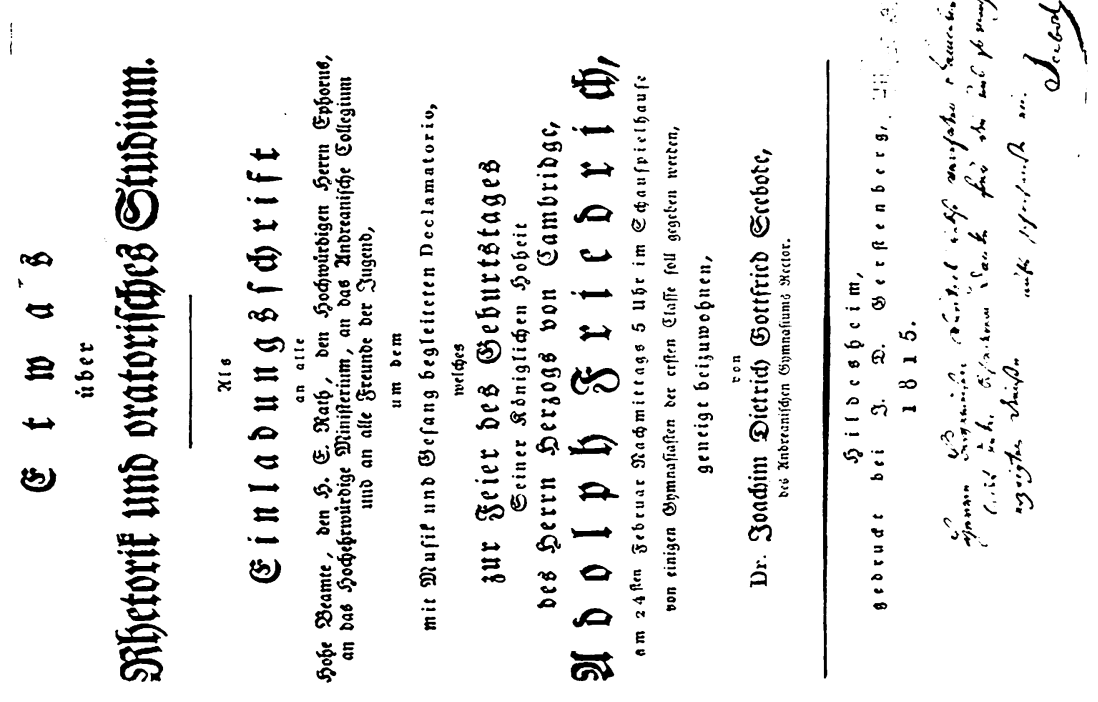

$\frac{1}{2}$

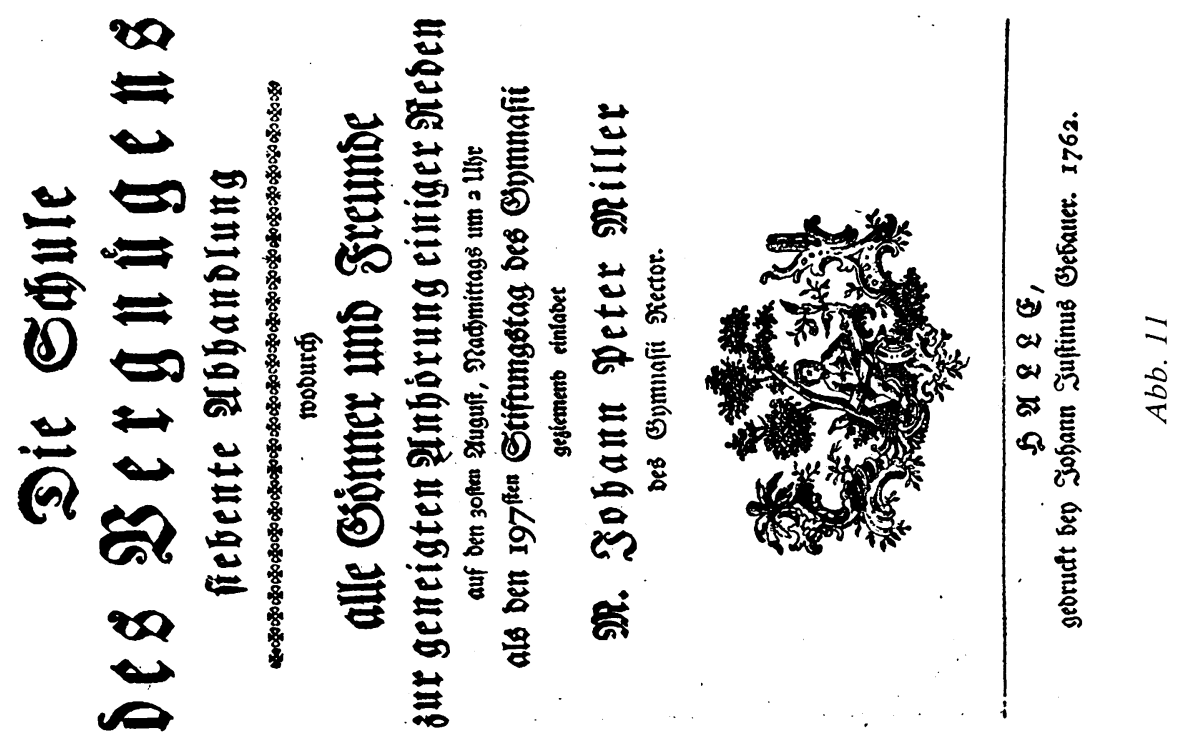




\title{
Erläuterungen zu den Abbildungen
}

\section{Aufklärerische Schulreform}

\author{
Abb. 1 \\ Seibt: Von dem Einflusse der Erziehung ... 1771 \\ (Ex. Stadtbibliothek Wien) \\ Vignette gestochen von Carl Salzer (1740-1812). Allegorie der Erziehungskunst: Eine Frau \\ unterweist Putten vor antikem Fragment; als Lehrbuch dient Seibts Erziehungskunst. Hinter ihr \\ Zeichen der Belohnung (Genius mit Füllhorn) und Bestrafung (Rute). Tempel der Weisheit im \\ Hintergrund.
}

Abb. 2

Entwurf, nach welchem die bisher sogenannten Lateinischen Schulen ... 1773.

(Ex. Bayer. Staatsbibliothek München)

Vignette: Landschaft, über der die Sonne (Aufklärung) aufgeht und die dunklen Nachtwolken vertreibt; gefaßt in einem Kranz von Eichenlaub und Rosen.

\section{Anthologien}

\section{Abb. 3}

Weitenauer: Sammlung kürzerer Gedichte ... Tl. 1. 1768.

(Ex. Bayer. Staatsbibliothek München)

Vignette, Allegorie der Anthologie: Aus unterschiedlichsten Gartenbeeten, die um eine Fontäne (Quelle der Weisheit) gruppiert sind, tragen Bienen die Tracht in ihre Körbe. Monogramm wahrscheinlich Buchdruckerzeichen.

Abb. 4.

Auserlesene kleinere Gedichte ... 1772.

Verf.: Hieronymus Andreas Mertens.

(Ex. Bayer. Staatsbibliothek München)

Vignette von Johannes Esaias Nilson (1721-1788). Links der von den Schülern bewunderte Apollo (delectat), rechts die Bücher (Wissen) austeilende Minerva (informat).

Abb. 5

Denis: Sammlung kürzerer Gedichte ... 1778.

(Ex. Bayer. Staatsbibliothek München)

Vignette wahrscheinlich aus der Klauberschen Offizin, vgl. Vignette der 2. Sammlung (ebd. 1772). Allegorie der ländlichen Poesie: Mit Verweis auf Vergil werden verschiedene Bereiche ländlicher Poesie (Ackerbau, Viehzucht, Bienenhaltung, Jägerei, Fischerei) dargestellt. Fortführung der antiken Poesie (Satyr mit Arm um den Namen Virgil) in der Aufklärung (Rokokoputto). 
Abb. 6

Jais: Lesebuch ... 1806.

(Ex. Stadtbibliothek Wien)

Vignette: Der Lehrer nimmt dem vor dem Tempel der Weisheit sitzenden Schüler den Schleier von den Augen und weist ihm die Sonne, die über dem von Sphinxen flankierten Tempeleingang aufgeht.

Abb. 7

Wilmsen: Die Schönheit der Natur ... 1818.

(Ex. UB Eichstätt)

Titelkupfer von Georg Bretzing (tätig in Berlin 1802-22) nach Heinrich Study; Typographie u. Vignettte von Ferdinand Jättnig. Im Medaillon lyraspielender Jüngling unter Eiche, mit Blick auf antiken Tempel. Sinnbild sehnsüchtiger Einheit von deutscher Natur und antiker Kunst. Umgeben von Pflanzenmotiven der vier Jahreszeiten; der Satyrkopf (unten), Erntegeräte und Wanderutensilien (oben) weisen auf verschiedene Formen der Naturerfahrung.

Abb. 8

Heinsius: Der Bardenhain ... Tl. 1. 1809.

(Ex. German. Nationalmuseum Nürnberg)

Titelkupfer von Wilhelm Juri (1763-1829). Angesichts der aufgehenden Sonne erweckt der Genius den deutschen Jüngling (Mohnkapseln als Sinnbild des Schlafes) zum Kampf, d. h. zum Befreiungskrieg gegen Napoleon I. Tanz der Jugend vor den von Eichen überwucherten Ruhmessäulen von Herrmann dem Cherusker, Luther und Friedrich II. von Preußen.

Abb. 9

Dass. Tl. 2. 1809.

(Ex. w. o.)

Titelkupfer von Juri, w. o. Erklärung: »Das, nach meiner Angabe von dem verehrten Juri gearbeitete und mit wahrem Künstlerfleiß ausgeführte Titelkupfer stellt einen Tempel des Ruhms dar, in dessen Pfosten mehrere berühmte Namen Deutscher Dichter eingegraben sind. Clio, die, als Muse der Geschichte, alles Schöne und Gute verewigt, steht mit aufgehobenem Griffel, hindeutend auf eine noch unbeschriebene Säule des Tempels, um noch anderen, auf ihrer Rolle verzeichneten Namen die verdiente Unsterblichkeit zu geben. Seitwärts lehnt sich an eine altehrwürdige Eiche die Muse, die ihre Harfe stimmt, um die großen Namen auch durch Musik und Gesang zu feiern. Sie ist nach einer schönen, antiken Gemme geformt, und bezeichnet hier die Muse überhaupt, in so fern die Tonkunst nach den Begriffen des frühsten Alterthums ihr Hauptgeschäft ist. Das Ganze versinnbildet eine belohnende und ermunternde Erhebung Deutscher Dichter, die, durch ihre Kunst in den Tempel der Unsterblichkeit eingeführt, sich des verdienten Nachruhms eines dankbaren Vaterlandes erfreuen."

Abb. 10

Dass. Tl. 3. 1810.

(Ex. w. o.)

Titelkupfer von Franz Joseph Leopold (1783-1832). Erklärung: »In dem Hintergrunde erblickt man den Parnaß mit seinen zwei Spitzen, unter welchem Delphi liegt. Zwischen den beiden Felsenspitzen quillt nach Pausanias (Lib. 10. c. 8.) dick sprudelnd der Kastalische Quell hervor, der den Musen geheiligt war. Herab in die Tiefe strömend, ergießt er sich in schlängelnden Windungen durch blumige Thale, wo im Vordergrund ein Jüngling die rieselnde Fluth mit einer Schaale auffängt, um sich an dem reinen Kristall zu laben. Seitwärts steht der berühmte Torso, mit dem an ihm befindlichen Namen des Künstlers Apollonius, - ein Kunstwerk, an welchem Michael Angelo sieben Jahre studierte. - Diese antiquarischen Vorstellungen zu einem Bilde vereint, sprechen die Idee aus: die neuere Welt (der Jüngling) verdankt ihre Kenntnis dem Alterthume, dessen klassische Werke sie (wie Michael Angelo den Torso) mit ausdauerndem Fleiße studirt. « 


\section{Einladungsschriften}

Abb. 11

Miller: Die Schule des Vergnügens siebente Abhandlung ... 1762.

(Ex. UB Erlangen)

Abb. 12

Seebode: Etwas über Rhetorik ... 1815.

(Ex. Stadtarchiv Hildesheim)

Auf dem Titelblatt handschriftl. Einladung Seebodes an den Bürgermeister.

(Den genannten Bibliotheken und Archiven wird für die Reproduktionsgenehmigung gedankt.) 


\section{Anmerkungen}

\section{Anmerkungen zu O. Einleitung}

1 Peter Bürger: Theorie der Avantgarde (Frankfurt/M. 1974), S. 17. Nach ihm wird »die Trennung der Kunst von der Lebenspraxis zum entscheidenden Merkmal der Autonomie der bürgerlichen Kunst « (S. 66). Eine historische Differenzierung der Entwicklungsschritte zur Moderne fehlt bei Bürger. Zur umfangreichen Diskussion vgl. >Theorie der Avantgarde`. Antworten auf Peter Bürgers Bestimmung von Kunst und bürgerlicher Gesellschaft. Hg. v. W. Martin Lüdke (edition suhrkamp 825) (Frankfurt/M. 1976).

2 Vgl. Renate Lachmann: Rhetorik und kultureller Kontext. In: Rhetorik. Kritische Positionen zum Stand der Forschung. Hg. v. Heinrich F. Plett (Kritische Information 50) München 1977, S. 167-86. In diesem für eine Sozialgeschichte der Literatur sehr brauchbaren Modell wird Rhetorik als Selbstbeschreibungssystem einer Kultur in Form von Metatexten verstanden. Ihre Funktion liegt dann in der Regulierung, Offizialisierung und Vereinheitlichung des Kommunikationssystems und der darin erfaßten Kommunikationssituationen.

3 Friedrich Sengle: Biedermeierzeit. Deutsche Literatur im Spannungsfeld zwischen Restauration und Revolution 1815-1848. Bd. 1-3. Stuttgart 1971-80. Hier vor allem Bd. 1, Kap. 2 u. 5. Aus den Arbeiten seiner Schule vgl. Helga Dierichs: Stilschichten bei Charles Sealsfield. Magisterarbeit München 1968; Herbert Neumaier: Der Konversationston in der frühen Biedermeierzeit 1815-1830. Phil. Diss. München 1972 (Druck Bergatreute 1974); Hans Helfrid Schmidt: Untersuchungen zum Stilideal des Lakonismus in der Biedermeierzeit 1830-1848. Thesis Mc Gill Univ. Montreal, P. Q. 1972. Im übrigen siehe das »Verzeichnis der im Zusammenhang mit dieser Epochendarstellung entstandenen Dissertationen «, in Bd. 3.

4 Gert Ueding: Einführung in die Rhetorik. Geschichte-Technik-Methode. (Stuttgart 1976.) Hier Tl. 1, Kap. IV »Literarische Wirkungsabsicht und rhetorische Tradition im 18. und 19. Jahrhundert « von Jürgen Fröchling u. Gert Ueding, S. 100-55. Zitat S. 120. Die Arbeiten von Breuer, Jäger, Linn, Schaub und Sengle fehlen im Literaturverzeichnis. Keine Auseinandersetzung mit Dockhorn, kein Bewußtsein vom Zusammenhang LiberalismusRhetorik, ohne Kenntnis der Schul- und Bildungsgeschichte! - Den besten Úberblick, mit breiter Quellenkenntnis, gibt Heinrich Bosse: Dichter kann man nicht bilden. Zur Veränderung der Schulrhetorik nach 1770. In: Jahrbuch für internationale Germanistik 10 (1978), S. 80-125. Doch werden die grundlegenden Wandlungen, die an ästhetischen und sprachphilosophischen Spitzenwerken (Herder, Kant, W. v. Humboldt, Grimm) zu beobachten sind, $\mathrm{m}$. E. zu schnell auf die Ebene des institutionalisierten Unterrichts übertragen. Auch scheint mit die »Wendung zum Schriftlichen « (S. 85) überbetont (vgl. Vortragskultur der Goethezeit mit der sie begleitenden Flut von Deklamationslehrbüchern; Erneuerung der öffentlichen Rede im Zeichen des Liberalismus etc.). Vgl. auch Dieter Breuer: Schulrhetorik im 19. Jahrhundert. In: Rhetorik. Beiträge zu ihrer Geschichte in Deutschland vom 16.-20. Jahrhundert. Hg. v. Helmut Schanze (Fischer Athenäum Taschenbücher 2095) (Frankfurt/M. 1974), S. 145-79. - Uber den Stand der Rhetorikforschung orientiert Walter Jens: Rhetorik. In: Reallexikon der deutschen Literaturgeschichte. 2. Aufl. Hg. v. Werner Kohlschmidt u. Wolfgang Mohr. Bd. 3, Lief. 5. Berlin 1971, S. 432-56. Mit reicher Literatur, auch zu Rhetorik/Kommunikation.

5 Gerhard Schaub: Georg Büchner und die Schulrhetorik. Untersuchungen und Quellen zu seinen Schülerarbeiten (Regensburger Beiträge zur deutschen Sprach- u. Literaturwissenschaft 3) Bern u. Frankfurt/M. 1975; Ders.: Georg Büchner u. Friedrich Ludwig Weidig: 
Der Hessische Landbote. Texte, Materialien, Kommentar (Reihe Hanser. Literatur-Kommentare 1) (München u. Wien 1976), bes. „Versuch einer rhetorischen Analyse ", S. 153-61. Wie zeitgenössische poetische Auffassungen für die Interpretation fruchtbar gemacht werden können, zeigt Renate von Heydebrand: Eduard Mörikes Gedichtwerk. Beschreibung und Deutung der Formenvielfalt und ihrer Entwicklung. Stuttgart 1972, bes. die Kap. »Dichtungsgattungen oder -arten « und »)Töne und `Tonarten« «, S. 191-281.

6 Vgl. Peter Lundgreen: Historische Bildungsforschung. In: Historische Sozialwissenschaft. Beiträge zur Einführung in die Forschungspraxis. Hg. v. Reinhard Rürup (Kleine Vandenhoeck-R. 1431) Göttingen (1977), S. 96-125. Bibliographie S. 117-25; Historische Pädagogik. Hg. v. Ulrich Herrmann (Zeitschrift für Pädagogik, 14. Beih.) Weinheim u. Basel 1977; Historische Pädagogik. Methodologische Probleme der Erziehungsgeschichte. Hg. v. Volker Lenhart (Erziehungswissenschaftl. R. 17) Wiesbaden 1977.

7 Der Literaturunterricht. Bearb. v. Dietrich Boueke (Quellen zur Unterrichtslehre 14) Weinheim u. a. 1971. Einleitung, S. 1. - Die einzige neuere zusammenfassende Darstellung, Horst Joachim Franks »Geschichte des deutschen Unterrichts. Von den Anfängen bis 1945 « (München 1973), eine einsame monumentale Leistung, hält sich wesentlich an die zum Teil ideologiekritisch interpretierten Theoretiker und Programmatiker. Die ältere Monographie von Adolf Matthias (Geschichte des deutschen Unterrichts. München $1907=$ Handbuch des deutschen Unterrichts an höheren Schulen, Bd. 1, Tl. 1) hat demgegenüber die schulische Institutionalisierung und Praxis des Deutschunterrichts stärker miteinbezogen.

8 Aus der umfänglichen Literatur vgl. die Sammelbände: Die Diskussion um das deutsche Lesebuch. Hg. v. Hermann Helmers (Wege der Forschung CCLI) Darmstadt 1969; Lesebuchdiskussion 1970-1975. Hg. v. Heinz Geiger (UTB 641) München (1977). - Zu den historischen Arbeiten von Roeder (1961), Herrlitz (1964) und Helmers (1970) vgl. Bibliographie Kap. 6.3.

9 Dietrich Steinbach: Der literarische Wertbegriff und das Lesebuch (1966). In: Die Diskussion um das deutsche Lesebuch, S. 219-31. Hier S. 222.

10 Friedrich-Ernst Missfeldt: Uber den Aufbau von Lesebüchern (1966). In: Ebd., S. 232-47. Hier S. 239, 244. Zum literarischen Arbeitsbuch s. Hermann Helmers: Geschichte des deutschen Lesebuchs in Grundzügen. Stuttgart (1970), S. 229-85.

11 Die Gelehrtenschulen Preußens unter dem Oberschulkollegium (1787-1806) und das Abiturientenexamen. Hg. v. Paul Schwartz. Bd. 1 (Monumenta Germaniae Paedagogica 46) Berlin 1910, S. 26. Dazu Georg Jäger: Der Deutschunterricht auf Gymnasien 1780 bis 1850. In: DVjs 47 (1973), S. 120-47. Das quantitative Gewicht, S. 122-26.

12 Alfred Kelletat: Die frühe Rezeption Hölderlins in Schule und Lesebuch (1830-1850). In: Abhandlungen aus der Pädagogischen Hochschule Berlin. Bd. 3: Fachdidaktik und fächerübergreifender Unterricht. Red. Reinhard Dithmar u. Jörg Willer. Berlin (1976), S. 87-115. Hier S. 107 Anm. 38. - Vgl. Dieter Breuer u. Günther Kopsch: Rhetoriklehrbücher des 16. bis 20. Jahrhunderts. Eine Bibliographie. In: Rhetorik. Hg. v. H. Schanze, S. 217-355. Für die Titel ab 1750 bedienen sich die Verff. »einer abkürzenden Schreibweise " (S. 218); die Angaben beruhen nicht auf Autopsie und sind offenbar den Bücherverzeichnissen entnommen. Roeder (Geschichte und Kritik, S. 246-65) beläßt es bei der Zusammenstellung der von ihm eingesehenen Deutschlesebücher gleichfalls bei lückenhaften Angaben (Vornamen nur teilweise aufgelöst; keine Verlagsangaben) und gibt keine Standortnachweise.

\section{Anmerkungen zu 1.1. Grundzüge der Entwicklung}

1 Joseph Dolch: Lehrplan des Abendlandes. Ratingen (2. Aufl. 1965), S. 243. Zur Konkurrenz mit der Lateinschule vgl. S. 244-46.

2 Willy Scheel: Die deutschen Grammatiker des 16. Jahrhunderts und ihr Verhältnis zum 
deutschen Unterricht. In: Mitteilungen der Gesellschaft für deutsche Erziehungs- und Schulgeschichte 15 (1905), S. 87-99. Hier S. 89.

3 Dolch: Lehrplan, S. 197.

4 Wilfried Barner: Barockrhetorik. Untersuchungen zu ihren geschichtlichen Grundlagen. Tübingen 1970. »Rhetorik an den protestantischen Gelehrtenschulen«, S. 258-321, mit weiterführender Literatur. Hier S. 275; »das Deutsche erfüllt eine reine Dienstfunktion « (S. 276/77).

5 R. Hanns: Beiträge zur Geschichte des deutsch-sprachlichen Unterrichts im siebzehnten Jahrhundert. Phil. Diss. Leipzig 1881, S. 24. In dieser, wie überhaupt in den älteren, wegen der dort geleisteten Quellenaufarbeitung immer noch wichtigen Arbeiten stehen »die historische Perspektive und insbesondere die pädagogische Wertung der Phänomene « »im Zeichen der nationalen muttersprachlichen Pädagogik des 19. Jahrhunderts «. Wilfried Barner: Einführendes Referat zum Rahmenthema: Schule und Literatur im 17. Jahrhundert. In: Stadt-Schule-Universität-Buchwesen und die deutsche Literatur im 17. Jahrhundert. Hg. v. Albrecht Schöne. München (1976), S. 175-84. Hier S. 177. - Für das 16. Jahrhundert vgl. Johannes Müller: Quellenschriften und Geschichte des deutschsprachlichen Unterrichtes bis zur Mitte des 16. Jahrhunderts. Einführung von Monika RössingHager (Reprint der Ausg. 1882) Darmstadt 1969; Wild: Der Stand des deutschsprachlichen Unterrichts im sechszehnten Jahrhundert (Pädagogische Sammelmappe. Reihe 1, H. 4) Leipzig o. J.

6 Barner: Barockrhetorik. »Die rhetorischen Schulactus«, S. 291-302. Hier S. 296.

7 Ebd. S. 319. Úber das protestantische Schultheater »als Teil des >eloquentia<-Betriebs «S. 302-18. Uber die »Schuldramatiker` s. Marianne Kaiser: Mitternacht/Zeidler/Weise. Das protestantische Schultheater nach 1648 im Kampf gegen höfische Kultur und absolutistisches Regiment (Palaestra 259) Göttingen 1972; Konradin Zeller: Pädagogik und Drama. Untersuchungen zur Schulcomödie Christian Weises (Studien zur deutschen Lit. 61) Tübingen 1980.

8 Ebd. »Rhetorik an den Jesuitengymnasien«, S. 321-66. Hier S. 324.

9 Ebd. S. 347. Zum Schultheater jetzt umfassend Jean-Marie Valentin: Le théâtre des Jésuits dans les pays de langue allemande (1554-1680). Salut des âmes et ordre des cités. 3 Tle (Berner Beiträge zur Barockgermanistik 3) Bern, Frankfurt/M, Las Vegas (1978). Besonders Kap. »L'école et la rhétorique «, Tl. 1, S. 205-57.

10 Barbara Bauer: Theorie und Praxis der jesuitischen Rhetorik und Poetik. Ein Beitrag zur bayerischen Kulturgeschichte des 16. und 17. Jahrhunderts. Phil. Diss. München 1980. Zitiert nach dem Manuskript, S. 17.

11 Georg Mertz: Úber Stellung und Betrieb der Rhetorik in den Schulen der Jesuiten, mit besonderer Berücksichtigung der Abhängigkeit von 'Auctor ad Herennium‘. Heidelberg 1898, S. 102. Die Ergebnisse dieser Dissertation sind eingegangen in: G. M.: Die Pädagogik der Jesuiten nach den Quellen von der ältesten bis in die neueste Zeit. Heidelberg 1898.

12 Barner: Referat, S. 180.

13 Dolch: Lehrplan, S. 278. Grammatik, Poetik und Rhetorik galten Ratke nur als "Dienstlehre « für die Sachwissenschaften (S. 284). Exemplarisch für eine Schulreform: Ludwig Fertig: Obrigkeit und Schule. Die Schulreform unter Herzog Ernst dem Frommen (1601-1675) und die Erziehung zur Brauchbarkeit im Zeitalter des Absolutismus. Neuburgweier/Karlsruhe 1971 (Einrichtung von »deutschen Klassen« für Nichtstudierende S. 68-70, Entwicklung des pädagogischen Realismus S. 104-58). Auf die Anführung der Spezialliteratur zu den Reformern wird hier verzichtet.

14 Ebd. S. 292.

15 Volker Sinemus: Poetik und Rhetorik im frühmodernen deutschen Staat. Sozialgeschichtliche Bedingungen des Normenwandels im 17. Jahrhundert (Palaestra 269) Göttingen 1978. Uber Weise S. 108-44, hier S. 109. In der Literatur sind unter bildungsgeschichtlichen Gesichtspunkten wichtig: Hans Arno Horn: Christian Weise als Erneuerer des deutschen Gymnasiums im Zeitalter des Barock. Der »Politicus « als Bildungsideal (Marburger Pädagogische Studien 5) Weinheim/Bergstr. (1966); Max Carl Friedrich Wünschmann: 
Gottfried Hoffmanns Leben und Bedeutung für das Bildungswesen und die pädagogische Theorie seiner Zeit, mit eingehender Berücksichtigung seines Zittauer Vorgängers und Lehrers Christian Weise. Ein Beitrag zur Geschichte der Pädagogik und des Schul- und Bildungswesens im 17. und 18. Jahrhunderte. I. Tl., 1. Hälfte [mehr nicht erschienen]. Phil. Diss. Leipzig 1895.

16 Ebd. S. 116.

17 Ebd. S. 112. Zitat »Instrumental-Wesen« S. 143.

18 Hermann Peter: Die Pflege der deutschen Poesie auf den sächsischen Fürstenschulen im zweiten Viertel des vorigen Jahrhunderts. In: Mitteilungen des Vereins für Geschichte der Stadt Meissen. Bd. 1, H. 3 (1884), S. 23-69 mit Proben von Schulgedichten und Produktionen der »deutschen Gesellschaft «.

19 Dazu ergänzend zu der in der vorhergehenden Anmerkung genannten Untersuchung von Hermann Peter: G. E. Lessing und St. Afra. In: Deutsche Rundschau 26 (1881), S. 366-88; Das Urkundliche über G. E. Lessings Aufenthalt auf der Landesschule St. Afra 1741-1746. In: Archiv für Litteraturgeschichte 10 (1881), S. 285-308. Zu Klopstock s. Franz Muncker: Friedrich Gottlieb Klopstock. Geschichte seines Lebens und seiner Schriften. Stuttgart 1888, S. 29-42.

20 Dazu Fertig: Obrigkeit und Schule (vgl. Anm. 13), Horn: Weise. "Zahl und Herkunft der Schüler des Gymnasiums unter Weises Rektorat «, S. 162-68. Die von Barner (Referat, S. 177-81) entwickelten »Aufgaben der pädagogikhistorischen Forschung « für das 17. Jahrhundert sind weiterhin unerledigt.

\section{Anmerkungen zu 1.2. Aufklärung}

1 Ignaz Mathes v. Heß: Gedanken über die Einrichtung des Schulwesens. Halle: Gebauer 1778 , S. 52. Úber die Vorschläge von $\mathrm{He} ß$ zur Umgestaltung der österreichischen Gymnasien s. Kap. 2.3.2.

2 Weitere Beispiele bei Heinrich-Wilhelm Brandau: Die mittlere Bildung in Deutschland. Weinheim u. Berlin (1959).

3 Joh. Jos. Friedr. Steigentesch: Abhandlung von Verbesserung des Unterrichtes der Jugend in den Kurfürstlich Mainzischen Staaten 1771. Hg. v. August Messer. 3 Tle. Beilage zum Programm des Gymnasiums zu Giessen 1896/97, 1897/98, 1898/99. Hier Tl. 2, S. 9; ähnlich bei Braun. Revidierte und kommentierte Neuausgabe in: Zwei Schriften der Kurmainzischen Schulreform von 1770-1784. Eingel. u. hg. v. Hans-Michael Elzer (Frankfurter Beiträge zur Historischen Pädagogik) Frankfurt/M. (1967). Über die Aufnahme der Reformvorschläge in Bayern s. Anm. 36.

4 Johann Michael Afsprung: Patriotische Vorstellung an seine liebe Obrigkeit, die Nothwendigkeit einer Schulenverbesserung betreffend. Amsterdam [Frankfurt/M.]: o. Vlg. 1776. Für die Teilung eines Gymnasiums in »Gelehrten- und Bürgerschule « (letztere aus 4 Klassen) vgl. Friedrich Wilhelm Döring: Nachricht von der gegenwärtigen Verfassung des Herzogl. Gymnasiums zu Gotha. Gotha: Ettinger 1794. »Die Gelehrten-Schule, oder das eigentliche Gymnasium macht ein für sich bestehendes Ganze aus«. (S. 4)

5 Friedrich Gedike: Ueber den Begrif [!] einer Bürgerschule [Einladungsschrift]. Berlin: Unger 1799. Zu Gedikes schulpolitischem Wirken vgl. Karl-Ernst Jeismann: Das preußische Gymnasium in Staat und Gesellschaft. Die Entstehung des Gymnasiums als Schule des Staates und der Gebildeten, 1787-1817 (Industrielle Welt 15) Stuttgart (1974).

6 [Heinrich Braun]: Gedanken über die Erziehung und den öffentlichen Unterricht in Trivial-, Real- und lateinischen Schulen nach den katholischen Schulverfassungen Oberdeutschlandes. [Ulm: Wohler] 1774, S. 129, 131. Über diese Schrift, im Vergleich mit der gleichzeitigen programmatischen Rede Ickstatts (Johann Adam Freyherr von Ickstatt: Akademische Rede von der Stufenmässigen Einrichtung der niederen und höheren Landschulen in Rücksicht auf die churbaierischen Lande. Ingolstadt: Lutzenberger 1774), s. Ludwig Wolfram: Heinrich Braun. Ein Beitrag zur Geschichte der Aufklärungsepoche in 
Bayern (Histor. Abhandlungen aus dem Münchener Seminar 3) München, Bamberg, Leipzig 1892, S. 38-46; über die teilweise Verwirklichung der Vorschläge in der Schulordnung vom 8. Okt. 1774 S. 48-51. Zu Braun vgl. weiter unter Bayern Kap. 2.2.1.

7 Joh[ann] Heinr[ich] Phil[ipp] Seidenstücker: Programme, Schulreden und Briefe über die Deutsche Sprache. Soest: Nasse, Leipzig: Fleischer in Komm. 1836. Darin: [Lippstadter] Programm vom Jahr 1797, über Schulbibliotheken und Specialklassen, S. 1-11. Hier S. 5,9. Die Schule in Lippstadt, eine für einen Gewerbeort typische Mischanstalt, ist auch für den Handwerker bestimmt, dem das »Universalklassensystem « Nachteile brachte: Er »bedarf gewiß des Lateins nicht, allein er muß es mitlernen, weil er mit dem künftigen Gelehrten in einerKlasse sitzt; dagegen ist ihm Schreiben und Rechnen unentbehrlich, allein er wird in eine höhere Klasse versetzt, ehe er darin weit gekommen ist; seine anderweitigen Fortschritte qualificiren ihn dazu. Da nun nicht jeder Lehrer Schreibmeister sein[,] auch nicht jede Klasse Stunden dazu hergeben kann, so lernt er entweder nie recht schreiben und rechnen, oder er muß sich privatim unterrichten lassen «. (S. 9)

8 Ankündigung eines neuen Lehr-Planes für alle churpfalzbaierischen Mittel-Schulen, (die Realklassen, Gymnasien und Lyzeen) nebst einem wesentlichen Auszuge desselben. In: Churpfalzbaierisches Regierungs-Blatt 1804, Sp. 807-10. Hier Sp. 807/08. Abdruck des Schulplans: Mittelschulgeschichtliche Dokumente Altbayerns, einschließlich Regensburgs. Hg. v. Georg Lurz. Bd. 2: Seit der Neuorganisation des Schulwesens in der 2. Hälfte des 16. Jahrhunderts bis zur Säkularisation (Monumenta Germaniae Paedagogica 42) Berlin 1908, S. 522-56. Dazu Oskar Steinel: Der Wismayer'sche Lehrplan. Das Beispiel einer wirklich in's Leben getretenen Staatlichen allgemeinen Mittel-Schule an Stelle der jetzt existirenden drei Anstalten Humanistisches Gymnasium, Realgymnasium und Realschule. Würzburg 1888. - Das `General-Schul- und Studien-Direktorium< teilt die Statistik des "lateinischen Schulstandes « jährlich mit. Bei der sozialen Zusammensetzung der Lateinschüler fällt der hohe Prozentsatz der Bauernkinder auf. So befanden sich z. B. 1802 auf den zwei Lyzeen (München, Amberg) und den fünf Gymnasien (München, Amberg, Landshut, Neuburg a. d. Donau, Straubing) 1244 Schüler. »Unter diesen waren 244 Söhne siegelmäßiger Eltern, 665 bürgerliche und 335 aus dem Bauernstande «, wobei die letzteren zum großen Teil katholische Theologen werden wollten. 1803 waren es insgesamt 1170 Studierende, »nämlich 232 von gefreyten oder siegelmäßigen Eltern, 619 von bürgerlichen, und 319 aus dem Bauern- oder sogenannten gemeinern Stande «. Die Zahl der Schüler bäuerlicher Herkunft nahm dieses Jahr in den Gymnasien wegen der aufgehobenen Kloster-Seminarien, »wo [...] ehedem viele Dorfjungen ihren ersten lateinischen Unterricht erhielten «, um 70 ab (Churbaierisches Regierungs-Blatt 1803, Sp. 174-75; Churpfalzbaierisches Regierungs-Blatt 1804, Sp. 155-56). - Rainer A. Müller (Sozialstatus und Studienchance in Bayern im Zeitalter des Absolutismus. In: Historisches Jahrbuch 95/I, 1975 , S. 120-41) arbeitet eine restriktive Gymnasialpolitik heraus, ohne auf die hier diskutierte Schulorganisation einzugehen. Doch wird zugleich die hohe Zahl von Gymnasiasten aus nichtakademischen Berufen (zwischen 1780 und $1800 \mathrm{ca}$. Drei-Fünftel in den Oberklassen des Münchner Gymnasiums, S. 134/35) deutlich. Zur Klerikerlaufbahn S. 135.

9 Ankündigung eines neuen Lehr-Planes, Sp. 808. Besonders wichtig war die Bestimmung, $\mathrm{da} ß$ die Schüler, »welche sich zur gründlichern Erlernung einer Kunst, oder zum Umgange mit der feinern Welt blos in dazu erforderlichen Real-Gegenständen vollkommner auszubilden wünschen «, von den »gelehrten Sprachen « dispensiert werden. Latein und Griechisch war nur für künftige Rechtsgelehrte, Priester, Ärzte, Apotheker, Chirurgen und Buchdrukker obligatorisch. Gesetze und Vorschriften für die Schüler der churbaierischen Gymnasien, § 7. In: Churbaierisches Regierungs-Blatt 1803, Sp. 120.

10 Ernst Gottfried Fischer: Ueber die zweckmäßigste Einrichtung der Lehranstalten für die gebildetern Stände. Versuch einer neuen Ansicht dieses Gegenstandes mit besonderer Rücksicht auf Berlin. Berlin: Maurer 1806, S. 14, 38. F. gibt Frequenz- und Abgangsstatistiken für das Berlinisch-Cöllnische Gymnasium 1795 bis 1805. Zwei Drittel Nichtstudierende, die meist nach der Konfirmation/Kommunion in eine Lehre überwechseln, werden 
allgemein angenommen. Vgl. etwa Helfrich Bernhard Wenck: Ueber die Trennung des gelehrten Unterrichts auf Schulen von dem allgemeinnützigen. Zugleich eine Nachricht von einigen Verbesserungen in den Lehranstalten des Fürstl. Pädagogiums zu Darmstadt. Darmstadt: Heyer 1799. In Darmstadt können die verbleibenden Nichtstudierenden, die sich dem Militär oder der "Schreiberei « widmen, auf Dispensationen oder Erleichterungen rechnen (S. 10). - Detlef K. Müller: Sozialstruktur und Schulsystem. Aspekte zum Strukturwandel des Schulwesens im 19. Jahrhundert (Studien zum Wandel von Gesellschaft u. Bildung im 19. Jh., Bd. 7) Göttingen 1977 unterstreicht aufgrund einer Schulstatistik des Berliner Raumes die soziale Offenheit des älteren Gymnasiums. Zur Problematik der Deutung der Statistiken vgl. Peter Lundgreen: Die Bildungschancen beim Úbergang von der »Gesamtschule « zum Schulsystem der Klassengesellschaft im 19. Jahrhundert. Úberlegungen zur Reichweite und Interpretationsmöglichkeit schulgeschichtlicher Befunde anläßlich des Buches »Sozialstruktur und Schulsystem « von Detlef K. Müller. In: Zeitschrift für Pädagogik 24 (1978), S. 101-15.

11 Erneuerte Schulordnung für die Chur-Sächsischen drey Fürsten- und Landschulen Meißen, Grimma und Pforta 1773, bei der Begründung des deutschen Unterrichts. In: Evangelische Schulordnungen. Hg. v. Reinholdt Vormbaum. Bd. 3. Gütersloh 1864, S. 613-48. Hier S. 622.

12 Heinrich Braun: Akademische Rede von den Vortheilen des Staats aus der deutschen Sprachkunst, welche bey Eröffnung der öffentlichen Vorlesungen über die deutsche Sprach- und Redekunst gehalten worden. Den 2ten May, 1765. München: o. J. Unpag.

13 Helfrich Bernhard Wenck: Nachricht von der gegenwärtigen Einrichtung des Fürstlichen Pädagogs in Darmstadt. [Einladungsschrift]. Darmstadt: Will (1774). Die Lehrer suchen den Geist der Schüler »zu jener Philosophie des Lebens zu erheben, wovon sie im Buche Ciceros von den Pflichten, und in Xenophons Denkwürdigkeiten des Socrates Muster lesen«. (S. 7) »Noch fehlt uns eine gute Schulmoral. Ich lese davor, so oft es die Zeit erlaubt, ein Stück aus Gellerts Moral, oder der ganzen Pflicht des Menschen vor «. (Ebd.) Dazu [Ernst Christian] Trapp: Ueber das Studium der alten classischen Schriftsteller und ihre Sprachen, in pädagogischer Hinsicht. In: Allgemeine Revision des gesammten Schulund Erziehungswesens. Hg. v. Johann Heinrich Campe. Tl. 7. 1787, S. 309-553. Hier S. 315: "Sollte die Moralität unserer Jugend nicht wenigstens eben so sehr durch Gellerts Moral, als durch Cicero's Buch von den Pflichten gewinnen? Und wenn es denn durchaus Cicero seyn soll, ist für einen Deutschen nicht der von Garve verdeutschte und mit so treflichen Zusätzen vermehrte Cicero für Jung und Alt lehrreicher, als der lateinische? « Garves Ausgabe schreibt Wismayr vor, s. Anm. 14.

14 Ankündigung eines neuen Lehr-Planes, Sp. 809/10. Zur Erreichung dieser Zwecke wird den Sprachen »wenigstens die Hälfte der sämmtlichen Unterrichts Stunden « gewidmet. Der zweite Triennal-Kurs sieht Ciceros »de officiis " "mit Garve's Anmerkungen « vor. Mittelschulgeschichtliche Dokumente Altbayerns. Bd. 2, S. 541, 535. Zum Deutschunterricht dieses Lehrplans s. Kap. 2.2.1.

15 Karl Heinrich Seibt: Von dem Einflusse der Erziehung auf die Glückseligkeit des Staats. Eine Rede [...] zum Eingange seiner Vorlesungen über die Erziehungskunst gehalten. Prag: Mangold 1771, S. 45, 26/27. Durch sittliche Erziehung entsteht »der wahre Patriot « (S. 40), »ein stiller Beförderer des gemeinschaftlichen Wohls« (S. 41), der aus innerem Antrieb für das Ganze tätig wird. Ebenso fördert sie ökonomische Tugenden: "Arbeitsamkeit und Emsigkeit der Bürger « (S. 18), »Mässigkeit, Sparsamkeit, Häuslichkeit « (S. 22).

16 Karl Heinrich Seibt: Akademische Blumenlese. Prag, in der k.k. Normalschulbuchdruckerey durch Wenzel Piskaczek Faktorn, verlegt von den Elsenwangerischen Erben 1784, S. VII, YI. Beispiele für Themen aus dem Gebiet von »Gesinnungen und Sitten « S. YII-YIII.

17 Karl-Heinz Osterloh: Joseph von Sonnenfels und die österreichische Reformbewegung im Zeitalter des aufgeklärten Absolutismus (Historische Studien 409) Lübeck u. Hamburg 1970, S. 235. Zum französischen Vorbild vgl. etwa Henri-François d'Aguesseau: Unterricht von dem Studieren und den Uebungen, die zum Amte eines königlichen Sachwalters 
geschickt machen können (1719). In: d'Aguesseau: Reden und andere Werke. 2 Tle (durchgehende Zählung) Leipzig 1762, S. 211-46. A. drängt auf eine gründliche rhetorische Schulung, die er im einzelnen darstellt.

18 Johann Heinrich Gottlob von Justi: Anweisung zu einer guten Deutschen Schreibart und allen in den Geschäfften und Rechtssachen vorfallenden schriftlichen Ausarbeitungen, zu welchem Ende allenthalben wohlausgearbeitete Proben und Beyspiele beygefüget werden. 2. verb. Aufl. Leipzig: Breitkopf \& Sohn 1769, a2R/V. Neben allgemeinen rhetorischen Lehren enthält das Buch Regeln und Muster für private und dienstliche Schreiben, für »Hof- und Staatsreden « und für obrigkeitliche Verlautbarungen und Verordnungen. - Vgl. F. Frensdorff: Úber das Leben und die Schriften des Nationalökonomen J. H. G. von Justi (Neudruck d. Ausg. Göttingen 1903) Glashütten i. Taunus 1970, S. 21-37 über die österreichische Zeit von 1750-53.

19 Osterloh: Sonnenfels, S. 237. Doch war seine Wirkung begrenzt. Er selbst (Úber den Geschäftsstil. Die ersten Grundlinien für angehende österreichische Kanzleybeamten. 2. verm. Aufl. Wien: Kurzbek 1785, unpag. 1. Aufl. 1784, 4. Aufl. 1820) stellt fest, daß die von Joseph II. erlassenen Verordnungen »über die Abkürzung der Geschäftsaufsätze « vom 3.1. und 23.1. 1783 -, »weil die Routine noch aller Orten übermächtig herrscht, nirgend beobachtet werden «. Zu Leben und Werk s. Franz Kopetzky: Josef und Franz von Sonnenfels. Das Leben und Wirken eines edlen Brüderpaares. Wien 1882, besonders S. 283-93.

20 Anhang zu dem Werke über den Geschäftsstil des Hrn. Hofraths und Professors von Sonnenfels. Hg. v. einem seiner Zuhörer. Wien: Kurzbek 1787, S. 78; »das Volkswort, das Provinzialwort, etc. das in jedermanns Munde ist, muß hier der Sprache der Weilande [für: Wielande] und Lessinge vorgezogen werden « (ebd.). Dieser Grundsatz führte zu einer Auseinandersetzung mit der normativen Sprachauffassung Adelungs.

21 Über Niethammers Streitschrift sagt ganz richtig Franz Passow (Die griechische Sprache, nach ihrer Bedeutung in der Bildung deutscher Jugend. In: Archiv deutscher Nationalbildung. Hg. v. Reinhold Bernhard Jachmann u. F. P. Bd. 1, 1812, S. 99-140. Hier S. 139/40), daß sie »einem paar ganz wesenloser Gegensätze, die nur Hader stiften können, unverdiente Realität gegeben « habe. Über die radikalen Neuhumanisten Passow und Evers, der in seiner Polemik Niethammer noch übertraf, vgl. Klaus Sochatzky: Das Neuhumanistische Gymnasium und die rein-menschliche Bildung. Zwei Schulreformversuche in ihrer weiterreichenden Bedeutung (Studien zum Wandel von Gesellschaft u. Bildung im 19. Jh. 6) Göttingen 1973. Aufschlußreich Clemens Menze: Wilhelm von Humboldt und Christian Gottlob Heyne. Ratingen (1966), bes. über den »Wandel vom philologischen Humanismus zum Neuhumanismus « S. 23-42. Zur Lage der Forschung, mit Kritik an noch immer der alten Polemik verhafteten Wertungen s. Lenore O'Boyle: Education and Social Structure. The Humanist Tradition Reexamined. In: IASL 1 (1976), S. 246-57.

$22 \mathrm{Chr}[$ istian] G[ottlob] Heyne: Neue Schulverfassung und Schulordnung für die Stadtschule zu Göttingen. o. O. u. o. Vlg. Ausgang des Mays 1798, S. 7. Über die entsprechende, z. T. zum Vorbild genommene `Zentralschule` der Französischen Revolution vgl. Emile Durkheim: Die Entwicklung der Pädagogik. Zur Geschichte und Soziologie des gelehrten Unterrichts in Frankreich. Weinheim u. Basel 1977, S. 270-83.

23 Ebd. S. 9, 12. Dazu Friedr[ich] Aug[ust] Wolf: Ủber Erziehung, Schule, Universität. Hg. v. Wilhelm Körte. Quedlinburg u. Leipzig: Becker 1835, S. 157-65. Auszüge mit Kommentar, beim Fachklassensystem: »bene optime!«, S. 162. Dagegen Wenck: Ueber die Trennung des gelehrten Unterrichts auf Schulen von dem allgemeinnützigen.

24 Wolf: Erziehung, Schule, Universität, S. 80, 100.

25 Ebd. S. 99/100, 103, 105-08, 112/13 (griechische Sprachübungen), 128 (Französisch, privatim Englisch).

26 Karl Ludwig Roth: Gymnasial-Pädagogik. Stuttgart 1865, S. 39/40.

27 Wilhelm von Humboldt: Werke. Hg. v. Andreas Flimer u. Klaus Giel. Bd. 4 (2. Aufl.) Darmstadt (1964). »Ueber die mit dem Koenigsbergischen Schulwesen vorzunehmende Reformen « (1809), S. 168-87. Hier S. 174-75. Zu Humboldts Gymnasialreform s. Eduard 
Spranger: Wilhelm von Humboldt und die Reform des Bildungswesens. 3. unveränd. Aufl. Tübingen 1965, S. 165-99; Clemens Menze: Die Bildungsreform Wilhelm von Humboldts (Das Bildungsproblem in der Geschichte des europäischen Erziehungsdenkens, Bd. 13) Hannover u. a. (1975), S. 232-79; Jeismann: Das preußische Gymnasium in Staat und Gesellschaft. Eine konzise Interpretation des Humboldtschen Bildungsbegriffs und seiner gesellschaftspolitischen Folgen bei Hans-Georg Herrlitz: Studium als Standesprivileg (Frankfurt/M. 1973), S. 119-29.

28 »Das Princip, nach welchem im Besonderen die Bedeutung der Lehrgegenstände zu bemessen ist, kann demnach weder ein einseitig humanistisches noch einseitig realistisches sein«. Studienplan für die Gymnasien des Großherzogthums Hessen. o. O. u. o. Vlg. [1833], S. 3. - In Sachsen machte die Konferenz von 1835 Zugeständnisse an die realistischen Fächer und die neueren Sprachen. A[chmed] Scholtze: Humanismus und Realismus im höhern Schulwesen Sachsens während der Jahre 1831-1851. Wiss. Beilage zu dem Programm der städt. Realschule zu Plauen i. V. 1894. Hier S. 18. Zur Diskussion über Schulorganisation und Lehrpläne in der Restaurationszeit vgl. insgesamt Kap. 1.3.

29 Entwurf einer neuen Schulordnung für die gelehrten Anstalten Württembergs, (lateinische Schulen, Lyceen, Gymnasien) verfaßt und mit höherer Genehmigung dem Druck übergeben von der hierzu beauftragten Commission von Schulmännern. Stuttgart u. Tübingen: Cotta 1848, S. 27. 16 Wochenstunden für Latein und Griechisch.

30 Ludwig Renatus de Caradeuc de la Chalotais: Versuch über den Kinder-Unterricht aus dem Französischen übersetzt und mit Anmerkungen und einer Vorrede, die Unbrauchbarkeit und Schädlichkeit der Basedowschen Erziehungs-Projecte betreffend. Göttingen u. Gotha: Dieterich 1771, S. 54 mit Berufung auf Condillac.

31 [Johann Georg Sulzer]: Gedanken über die beste Art die claßischen Schriften der Alten mit der Jugend zu lesen. Berlin: Voß 1765. »Analytische« Methode im Unterschied zur »demonstrativen « S. 20. „Wir bekommen die nöthigen Begriffe selten durch abstrakte Erklärungen, sondern durch Beyspiele, durch Betrachtungen angenehmer Bilder, und die Schlüsse sind eine Art von natürlichen höchstwahrscheinlichen Folgerungen, die man Inductionen nennt « (ebd.). Ähnlich Braun: Gedanken über die Erziehung, S. 134 (»1) vom Sinnlichen zum Intellectuellen «, »2) vom Practischen erst zur Theorie «); [Ignaz Matthias Ritter v. Hess]: Entwurf zur Einrichtung der Gymnasien, in k.k. Erblanden. Wien: Kurzböck 1775, S. 11 (»vom sinnlichen zum abstracten, von Faktis zur Theorie «) u. 26 (Latein »nach der neuen analytischen Methode «).

32 Friedrich Gabriel Resewitz: Die Erziehung des Bürgers zum Gebrauch des gesunden Verstandes, und zur gemeinnützigen Geschäfftigkeit, 2. veränd. Aufl. Kopenhagen: Heineck u. Faber 1776, S. 20, 25, 31.

33 Ebd. S. 36, 34. »Was [. . ] Sinne und Erfahrung für das theoretische Urtheil der Menschen sind, das ist die innere Empfindung für seine practischen Urtheile und für seine EntschlieBungen«. (S. 33) »Und eine durch Empfindung angewöhnte Tugend ist eine sichere und wirksame Tugend «. (S. 37)

34 v. Heß: Gedanken über die Einrichtung des Schulwesens, passim. Henrich Martin Gottfried Köster: Gedanken von den Schulsachen. 2. umgearb. u. verm. Aufl. Frankfurt/M.: Varrentrapp 1776, S. 60. [Peter] Villaume: Methode junge Leute zu der Fertigkeit zu verhelfen, ihre Gedanken schriftlich auszudrücken. Dessau: Buchhandlg. der Gelehrten 1784, S. 36: "Sprache ist ein Mittel[,] wodurch man die Dinge sieht, und ein jedes Mittel hat etwas Unreines, Ungetreues, es giebt niemals das Bild[,] so wie es ist «. Sprache als »Zauberlaterne (ebd.); über sprachliche Verzerrungen der Realität S. 36-37.

35 [Johann Matthias Gesner]: Ob man aus der Grammatic die lateinische Sprache zu lernen anfangen müsse? In: Hannoverische Gelehrte Anzeigen 1751, St. 97, S. 899-904; St. 102, S. 831-37. Hier S. 903.

36 Steigentesch: Abhandlung von Verbesserung des Unterrichts. Tl. 3, S. 4; Hervorhebungen getilgt. Der »Grundsatz « wurde fast wörtlich in den amtlichen Reorganisationsplan übernommen: Entwurf, nach welchem die bisher sogenannten Lateinischen Schulen in den hurzmainzischen Landen, und besonders in der kurfürstl. Residenzstadt Mainz, werden 
eingerichtet werden. In: Sammlung aller Schriften der verbesserten öffentlichen Schulen in den Kurmainzischen Landen, und besonders in der Kurfürstlichen Residenzstadt Mainz. Stockholm: Löwhaupt 1776, St. 8, hier S. 198. Der »Entwurf « war schon vor Drucklegung, durch Vermittlung des bayerischen Gesandten am pfälzischen Hof, in München bekannt und wurde von Braun und Ickstatt genutzt; s. Wolfram: Braun, S. 38.

37 Gesner: Grammatic, S. 903. La Chalotais: Kinder-Unterricht, S. 108: "Der Gedanke ist sehr natürlich, daß man, um eine todte Sprache zu lernen, so viel möglich, die Manier nachahmen müsse, wie Kinder ihre Muttersprache, und wie wir Erwachsne fremde Sprachen lernen, nemlich durch Gesellschaft, Uebung und Fertigkeit «.

38 Martin Ehlers: Gedanken vom Vocabellernen beym Unterricht in Sprachen. Altona: Iversen 1770, S. 48. Mainz empfiehlt die Schrift als »treffliche Abhandlung« (Entwurf, S. 223/24) den Lehrern.

39 Gesner: Grammatic, S. 831-32. G. zählt zu den Bahnbrechern einer offen organisierten höheren Schule, wie sie Kap. 1.1 skizziert; dazu Herrlitz: Studium als Standesprivileg, S. $60-65$.

40 Allgemeine deutsche Bibliothek, Bd. 110, St. 1, Kiel 1792, S. 190 (Rez.: Freymüthige Beschreibung des neuesten krichlichen Zustandes im Herzogthum Wirtemberg. Frankfurt u. Leipzig 1791). Gegen die Herrschaft einer formalen Rhetorik und das Auswendiglernen von Regeln wandte sich die Regierung von Württemberg zu dieser Zeit mehrfach. Vgl. General-Rescript, mechanisches Auswendiglernen log. und rhetor. Definitionen betreffend, vom 16. Mai 1788: Es sollten »nicht nur die in den sogenannten phrasibus liegende Schönheiten bemerkt, sondern die Gemüther der Schüler auch auf die Behandlung und Darstellung der ganzen Sache [.. .] aufmerksam gemacht werden «; Verordnung wegen des lateinischen Schulwesens in dem Herzogthum Wirtemberg, vom 11. März 1793: Die Lehrer sehen "mehr auf maschinenmässiges Memoriren einer beträchtlichen Anzahl von Definitionen «, als darauf, »ob die Schüler mit dem Auswendig Gelernten einen Begriff verbinden? und ob dieser richtig sey? «Die Rhetorik sei »praktisch « zu behandeln. Carl Hirzel: Sammlung der württembergischen Schulgesetze. 2. Abt., enthaltend die Gesetze für die Mittel- und Fachschulen bis zum Jahr 1846 (A[ugust] L[udwig] Reyscher: Vollständige, historisch und kritisch bearbeitete Sammlung der württembergischen Gesetze, Bd. 11) Tübingen: Fues 1847, S. 268, 287.

41 [Franz Anton Pitzenberger]: Freundschaftliche Briefe an den Herrn von S-t, über den Entwurf zur Einrichtung der Gymnasien in den k.k. Erblanden. Nebst dem Entwurfe selbst. o. O. u. o. Vlg. 1776 , S. $25 / 26$.

42 Köster: Gedanken von den Schulsachen. Neue Methode zur Erleichterung des Lateins, S. 261-89. Hier S. 267. Ähnlich Fürstenberg in der Schulordnung des Hochstifts Münster 1776. Wilhelm Esser: Franz von Fürstenberg. Dessen Leben und Wirken nebst seinen Schriften über Erziehung und Unterricht. Münster: Deiters 1842. Abdruck Anhang, S. 73-106. Hier S. 87; Johann Lebrecht Tamm: Ueber die Verbindung des wissenschaftlichen Schulunterrichts mit der Lektüre der Alten; besonders über die Absichten, die man bey der letztern zu erreichen suchen muß. In: Gedanken Vorschläge und Wünsche zur Verbesserung der öffentlichen Erziehung. Hg. v. Friedrich Gabriel Resewitz. Bd. 5, St. 1. Berlin 1784, S. 1-67, hier S. 39/40. Beim »Lesen der Alten « werde »die Rhetorik weit practischer " gelehrt »als nach einem besondern Lehrbuche".

43 Steigentesch: Abhandlung von Verbesserung des Unterrichts. Tl. 3, S. 3.

44 Ebd. S. 18. Amtliche Fassung: Entwurf Lateinische Schulen, S. 209/10.

45 Ebd. Ähnlich Sulzer: Gedanken, S. 30/31.

46 Sulzer: Gedanken, S. 27. »Weil auch der Lehrer dabey Gelegenheit hat, sehr vielerley Fragen überall anzubringen; so wird durch eine solche Lehrart nicht blos das Gedächtnis, sondern hauptsächlich der Verstand, die Aufmerksamkeit und die Scharfsinnigkeit der Jugend geübet «. (Ebd.) J[ohann] J[akob] Engel: Versuch einer Methode die Vernunftlehre aus Platonischen Dialogen zu entwickeln. Berlin: Voß 1780, S. 155/56: »eben diese Methode ists, was ganze Stände gut; ihr herrschender Mangel, was ganze Stände schlecht macht«. Auch für Friedrich Gedike (Ueber die Verbindung des wissenschaftlichen und 
philologischen Schulunterrichts. In: Magazin für die Erziehung und Schulen besonders in den Preußischen Staaten. Bd. 1, St. 1. 1781, S. 71-90. Hier S. 84) war der platonische Sokrates »für den mündlichen Unterricht das vollkommenste Muster«. Vgl. [Hans Hinrichsen]: Versuch eines sokratischen Unterrichts in der deutschen Sprachlehre und im schriftlichen Gedankenausdrucke. Mit e. Vorrede v. Joh. Friedr. Christoph Gräffe. Tl. 1.2, 2 Abtt. Schleswig: RöhB 1800-02, Vorwort, wo allerdings »sokratisch « mit »katechetisch « gleichgesetzt wird.

47 Entwurf nach welchem die Trivial- und Realschulen in den Pfarreyen der kurfürstl. Residenzstadt Mainz werden eingerichtet werden. In: Sammlung aller Schriften, St. 6, hier S. 140.

48 Erneuerte Statuten des Fürstl. Pädagogs in Darmstadt 1778. Abdruck in: Die Schulordnungen des Großherzogtums Hessen. Hg. v. Wilhelm Diehl. Bd. I: Die höheren Schulen der Landgrafschaft Hessen-Darmstadt. Tl. 1 (Monumenta Germaniae Paedagogica 27) Leipzig 1903, S. 347-84. Hier S. 363. »Die Lehrer sollen jede Classe durch die Schüler die ihrem Alter angemeßne gute deutsche Schriftsteller kennen lernen, und die Eltern zur Anschaffung eines und des andern zu bewegen suchen «. (Ebd.)

49 Entwurf Lateinische Schulen, S. 206-07. Es werden u. a. als »klassische Schriften « gelesen: »die politischen Werke des Gellerts, die Briefe desselben; Duschs Briefe zur Bildung des Herzens; die Gedichte Gessners; die Briefe Rabeners «, »einige Auszüge der Denisischen Gedichte ", "Stockhausens Briefe « sowie kritische und ästhetische Werke (S. 222/23).

50 [Johann Georg Sulzer]: Entwurf der Einrichtung des von Sr. Hochfürstl. Durchl. dem Herzoge von Curland in Mitau neugestifteten Gymnasii Academici. Mitau: Hinz 1774, S. 61-62. Dazu Karl Dannenberg: Zur Geschichte und Statistik des Gymnasiums zu Mitau. Mitau 1875. - In Darmstadt liest der Lehrer öfters "Stellen aus guten deutschen Schriftstellern, zumahl erst neu heraus gekommnen, vor, und das im Ton, den mir mein Gefühl stimmt «. Wenck: Nachricht 1774, S. 9. Zur bahnbrechenden Rolle des `Carolinums für die Pflege zeitgenössischer deutscher Literatur auf Schulen s. Kap. 1.2.4.

51 Die Geschichte des Emotionalismus, leider noch nicht für das späte 18. Jahrhundert, wurde gründlich erarbeitet von Alberto Martino: Geschichte der dramatischen Theorien in Deutschland im 18. Jahrhundert. I: Die Dramaturgie der Aufklärung (1730-1780). Tübingen 1972; Ders.: Emotionalismus und Empathie. Zur Entstehung bürgerlicher Kunst im 18. Jahrhundert. In: Jahrbuch des Wiener Goethe-Vereins 81-83 (1977-79), S. 117-30.

52 Akademische Vorübungen aus den von Karl Heinr[ich] Seibt, Prof. der schönen Wissenschaften und der Moral zu Prag, gehaltenen Vorlesungen über die deutsche Schreibart. Altstadt Prag: Elsenwanger 1769, S. 17. Vgl. wie Villaume (Methode, S. 65) das »Gefühl « über die Regel setzt.

53 Trapp (Ueber das Studium der alten classischen Schriftsteller, S. 377, 379, 381) beispielsweise rechnet den »feinen Geschmack « »nicht zu den wahren gemeinnützigen Kenntnissen « und ist von seinem Einfluß »auf Vernunft, Tugend und Sitten nicht so überzeugt wie viele Andere «; ja er sieht in dem Bestreben nach allgemeiner Verbreitung von Geschmack in zivilisationskritischer Wendung - „sowohl ein vergebliches als ein schädliches Unternehmen «.

54 Pitzenberger: Freundschaftliche Briefe, S. 60. P. tritt dafür ein, »den Realinnhalt der physischen alten Schriftsteller eines Plinius, Celsus u.s.w. mit der beyläufigen Sprachübung zu verbinden « (S. 73).

55 Gedike: Verbindung des wissenschaftlichen und philologischen Schulunterrichts, S. 78; »laßt uns die Sprache durch die Wissenschaften und nebenher mit den Wissenschaften zugleich lehren $\ll(S .73)$.

56 Ebd. S. 83. Engel (Versuch einer Methode, S. 4) schlägt vor, »die Wissenschaften, so viel ihrer und in so weit sie auf Gymnasien sollen getrieben werden, in den Werken der alten selbst, oder wenigstens bey Gelegenheit dieser Werke « zu studieren. - In Württemberg wird verordnet, »die Lectüre der classischen Auctoren ausdrücklich als Anlaß zur Belehrung über Antiquitäten, Mythologie und alte Geographie, besonders auch für Rhetorik und Aesthetik « zu benutzen. »Der besondere, von der Behandlung der classischen Auctoren 
abgesonderte Vortrag aller dieser Gegenstände kann sodann füglich unterbleiben «. Vorschriften für die neue Einrichtung des combinirten Seminariums zu Maulbronn in Hinsicht auf Unterricht und Disciplin, vom 11. Febr. 1807. In: Hirzel: Sammlung der württembergischen Schulgesetze, Abt. 2, S. 345; weiter Einführung S. LXXXVII-VIII.

57 Anton Friedrich Büsching: Liber Latinus in Usum Puerorum Latinam Linguam Discentium. 2. Aufl. Berlin u. Stralsund: Lange 1769. Als pädagogischer Grundsatz gilt: »man müsse die Kinder zur Erlernung der lateinischen Sprache durch die Sachen reitzen, welche in derselben vorgetragen werden « (S. X).

58 v. Heß: Gedanken über die Einrichtung des Schulwesens, S. 95. Vgl. Tamm: Verbindung des wissenschaftlichen Schulunterrichts mit der Lectüre der Alten, S. 26: Die kursorische Lektüre ziele, »mit Uebergehung grammatischer Erörterungen, allererst und eigentlich auf Realien und Bildung des Geschmacks«. Ein Hauptzweck der Klassikerlektüre ist »die Erlernung der nützlichsten Kenntnisse aus vielen Wissenschaften. Geschichte, alte Geographie, Mythologie, Antiquitäten, Philosophie nach ihren Theilen und ihrer Geschichte, können daraus erlernt werden; besonders die im eigentlichen Verstande practische Philosophie, oder eine genaue Welt- und Menschenkenntniß« (S. 28).

59 Tamm: Verbindung, S. 12, 7/8, 6.

60 Villaume: Methode, S. 4. »Denn Autoren müssen wir nicht bilden wollen. Wir haben deren schon zum Ueberfluß, befugter und unbefugter. Also nur Geschäftsmänner, Geschäftsschreiberey « (Ebd.).

61 Entwurf Trivial- und Realschulen, S. 127, 131.

62 J(ohann) B(ernhard) Basedow: Elementarwerk. Hg. v. Theodor Fritzsch. Bd. 2. Leipzig 1909, S. 523. Dazu Karl Kehrbach: Deutsche Sprache und Litteratur am Philanthropin in Dessau (1775-1793). In: Mitteilungen der Gesellschaft für deutsche Erziehungs- und Schulgeschichte 7 (1897), S. 333-59.

63 Auszug aus dem Schreiben eines Privaterziehers, über die Bildung des Styls junger Leute. In: Gedanken Vorschläge und Wünsche zur Verbesserung der öffentlichen Erziehung. Hg. v. Friedrich Gabriel Resewitz. Bd. 3. St. 4. Berlin u. Stettin 1782, S. 3-23. Hier S. 22 Anm. v. Resewitz. »Ein Quintilian für dieses Fach, welche Wohlthat für die Jugend und für unsre ganze Nation würde er seyn!« (S. 23). Vgl. die Ausschreibung eines Aufsatzes »Methode den Styl junger Leute zu bilden«, ebd. Bd. 2, St. 3, 1779, S. 124-27; St. 4, 1780, S. 115, 116; Bd. 3, St. 3, 1781, S. 73-77. Darauf gehen zurück die Arbeiten von Tamm und Villaume (s. Bibliographie Bd. 2, Kap. 1.3.1.3).

64 [Johann Friedrich Wilhelm Jerusalem] : Vorläufige Nachricht von dem Collegio Carolino zu Braunschweig (1745). In: Braunschweigische Schulordnungen von den ältesten Zeiten bis zum Jahre 1828. Hg. v. Friedrich Koldewey. Bd. 1 (Monumenta Germaniae Paedagogica 1) Leipzig 1886, S. 203-17. Hier S. 204. Zur Entwicklung der Anstalt, mit Schülerlisten vgl. Johann Joachim Eschenburg: Entwurf einer Geschichte des Collegii Carolini in Braunschweig/1745-1808/1812. Nachdr. mit Registern, Ưbersetzungen u. Erläuterungen v. Ernst-Eberhard Wilberg. 2 Bde (Beiträge zur Geschichte der Carolo-Wilhelmina II) Braunschweig 1974.

65 Ebd. S. 214.

66 Vorlesungen und Úbungen in dem Collegio Carolino. Michaelis 1745 bis Ostern 1746. Ebd., S. 229-43. Hier S. 233-35.

67 Ebd., S. 407-10. Zu den Lehrbüchern vgl. die Bibliographie Bd. 2, Kap. 1.3.2. Dazu Fritz Meyen: J. J. Eschenburg. 1743-1820. Kurzer Abriß seines Lebens und Schaffens nebst Bibliographie (Braunschweiger Werkstücke 20) Braunschweig 1957.

68 [Leonhard Usteri:] Nachricht von den neuen Schul-Anstalten in Zürich. Zürich: Orell, Geßner, Füeßlin 1773, 6. St.: Das Mittel-Studium oder Collegium Humanitatis, S. 145-226. Zitate S. 149, 199, 201/02, 199. Die induktive Lehrmethode führt anhand von lateinischen und deutschen Mustern in die rhetorischen und stilistischen Techniken ein: »Zu dem Ende hin wird das, was die Sache selbst ausmacht, was zu einer Erläuterung, zum Beweis, zur Empfehlung dienet, von dem Vortrag unterschieden, und gezeiget, woher es genommen [inventio], wodurch es sinnlich gemachet, vergrössert werde, wie die Einklei- 
dung desselben beschaffen, die Art es zu sagen, der Ausdruk, die Wendungen der Rede beschaffen sey, wie das, was man zu sagen hat, durch den wohlgewählten, eigentlichen oder metaphorischen, Ausdruk, und durch alles, was die Annehmlichkeit des Vortrags ausmacht [elocutio], an Deutlichkeit, an Glaubwürdigkeit, an Nachdruk gewonnen; wie eben die Sachen, wenn sie nicht so gut, so bestimmt, so stark wären gesagt worden, vieles verloren, und viel weniger Eindruk gemacht hätten«. (199/200)

69 Einrichtung der niederen, mittleren und hohen Schulen zu Fuld[!]. Nebst einem Berichte von der Verfassung des bischöflichen Seminarium. Gedr. mit Stahelischen Schriften 1774. Zitate S. 19, 36-37.

70 Friedrich Gabriel Resewitz: Nachricht von der gegenwärtigen Einrichtung in Unterricht, Lehrart und Erziehung auf dem Paedagogio zu Kloster Bergen. Magdeburg: Faber 1776. Zitate S. 115-17.

71 Gothilf Sebastian Rötger: Ausführliche Nachricht von dem Pädagogium am Kloster Unser Lieben Frauen in Magdeburg. Magdeburg: Creutz 1783. Zitate S. 189-90, 192/93.

\section{Anmerkungen zu 1.2. Restauration/Vormärz}

1 Úber den Stand der Forschung und die methodischen Ansätze informiert Peter Lundgreen: Historische Bildungsforschung. In: Historische Sozialwissenschaft. Beiträge zur Einführung in die Forschungspraxis. Hg. v. Reinhard Rurüp (Kleine Vandenhoeck-Reihe 1431) Göttingen (1977), S. 96-125. Zusammenstellung des Zahlenmaterials bei Wolfgang Zorn: Hochschule und höhere Schule in der deutschen Sozialgeschichte der Neuzeit. In: Spiegel der Geschichte. Festgabe für Max Braubach. Hg. v. Konrad Repgen u. Stephan Skalweit. Münster 1964, S. 321-39. Aufgrund einer Schulstatistik des Berliner Raumes unterstreicht Detlef K. Müller (Sozialstruktur und Schulsystem. Aspekte zum Strukturwandel des Schulwesens im 19. Jahrhundert $=$ Studien zum Wandel von Gesellschaft $u$. Bildung im 19. Jahrhundert, Bd. 7. Göttingen 1977) die ursprünglich offene Form der höheren Schule. Zur Problematik der statistischen Interpretation vgl. Peter Lundgreen: Die Bildungschancen beim Úbergang von der »Gesamtschule « zum Schulsystem der Klassengesellschaft im 19. Jahrhundert. Úberlegungen zur Reichweite und Interpretationsmöglichkeit schulgeschichtlicher Befunde anläßlich des Buches »Sozialstruktur und Schulsystem « von Detlef K. Müller. In: Zeitschrift für Pädagogik 24 (1978), S. 101-15. Gemeinhin gilt das deutsche Gymnasium des 19. Jahrhunderts als schichtenspezifische elitäre Anstalt, was es erst später, vor allem im Kaiserreich, war. Für Fritz K. Ringer (Education and Society in Modern Europe. Bloomington, Indiana, u. London 1979) stellt das Bildungssystem im hochindustrialisierten Deutschland beispielsweise den klassischen Fall einer shorizontalen Segmentierung dar.

2 [Ludwig Dietrich] W[ilhelm] Landfermann: Zur Revision des Lehrplans höherer Schulen und der Abiturienten-Prüfungs-Reglements. Berlin: Enslin 1855, S. 1. »Auch bei denjenigen rheinischen Gymnasien, neben denen Realschulen an demselben Orte bestehen, z. B. in Cöln, Aachen, Düsseldorf, Elberfeld, stellte sich das Verhältnis wenig anders«. (Ebd.)

3 [Carl Friedrich] Merleker: Statistik der Gymnasien und Progymnasien der Provinz Preussen. In: Zeitschrift für das Gymnasialwesen 2 (1848), S. 245-55, 427-31. Hier S. 254. - Der Direktor des Königsberger Friedrichskollegiums, der angesehensten Anstalt Ostpreußens, schätzt, daß von seinen Schülern »wohl ein Drittel « studieren will. Friedrich August Gotthold: Beantwortung der Frage: Ist es rathsam die Real- oder Bürgerschulen mit den Gymnasien zu vereinen? Zur Berichtigung der neusten pädagogischen Verirrungen herausgegeben und den Magisträten und Schuldeputationen gewidmet. Königsberg: Bornträger 1825, S. 38.

4 Ebd. S. 253.

5 Ebd. S. 254/55, 253/54. Margret Kraul (Untersuchung zur sozialen Struktur der Schüler- 
schaft des preußischen Gymnasiums im Vormärz. In: Bildung und Erziehung 29, 1976, S. 509-19), welche die Zahlen für das Gymnasium in Minden von 1822 bis 1848 errechnet, bestätigt die Rolle des Gymnasiums als Mittelschule (die häufigsten Abgänge "zum einen aus Quarta und Tertia mit 43,4 \% und zum andern aus Prima mit 29,1\%«, S. 15) und weist nach, wie sich die soziale Herkunft der Schüler von den unteren (bis Quarta verstärkt Schüler »aus der unteren Mittelschicht «) zu den oberen Klassen (verstärkt Schüler »aus der oberen Mittelschicht «) ändert. Entsprechend ist die obere Mittelschicht »bei dem Eintritt in Sexta unterrepräsentiert, die untere überrepräsentiert « (ebd.). - Nach Abschluß des Manuskripts erschien von M. K.: Gymnasium und Gesellschaft. Neuhumanistische Einheitsschule, städtische Gesellschaft und soziale Herkunft der Schüler (Studien zum Wandel von Gesellschaft u. Bildung im 19. Jahrhundert 18) Göttingen 1980.

6 Ernst Adolf Eduard Calinich: Das gesammte Unterrichtswesen im Königreiche Sachsen. Leipzig: Tauchnitz 1843, S. 26/27.

7 Ebd. S. 27.

8 Justin Timoth[eus] Balth[asar] Linde: Uebersicht des gesammten Unterrichtswesens im Großherzogthum Hessen, besonders seit dem Jahre 1829, nebst gelegentlichen Bemerkungen über die neueste Beurtheilung desselben durch den Herrn Hofrath Thiersch in München. Amtlich dargestellt. Gießen: Ferber 1839, S. 274-82.

9 Bellinger: Zur Geschichte des realistischen Schulwesens in dem vormaligen Herzogthum Nassau, vom Jahre 1817 bis 1861 incl. Jahresbericht des Realgymnasiums in Wiesbaden 1869, S. 2.

10 Ebd. S. 2. Aus dem Lehrstoff der II. Kl.: »Belehrung über die verschiedenen Maasse, Gewichte und Geldsorten «; »Behandlung der Botanik mit Hinsicht auf Technologie, ferner Anthropologie mit Diätetik « (S. 4); I. (oberste) Kl.: »Wechselrechnung und die Geldsorten«; »Anleitung zu der einfachen Buchhaltung «; »die ersten Grundsätze der Mechanik «; »das Wichtigste aus der Zoologie und Mineralogie «, »mit Hinweisen auf Technologie» (S. 4). Dispensationen von Griechisch wurden von 1836 bis 1860 erteilt.

11 [Friedrich Kohlrausch]: Das höhere Schulwesen des Königreichs Hannover seit seiner Organisation im Jahre 1830. Hannover: Culemann 1855, S. 33-34. Vgl. O[nno] Klopp: Die Reform der Gymnasien in Betreff des Sprachunterrichts. Ein Entwurf. Leipzig: Reichenbach 1848, S. 13-15 über die Errichtung von Parallelklassen für Quarta und Tertia durch das Oberschulkollegium von Hannover. Der Schüler muß sich »mit dem vollendeten 12 ten Lebensjahre " (S. 15) für die humanistische oder realistische Abteilung entscheiden.

12 Ebd. S. 43.

13 Friedr[ich] Traug[ott] Friedemann: Allgemeine Umrisse der Verfassung des Gesammtgymnasiums zu Braunschweig nebst dem Lehrplane bis Ostern 1828. Braunschweig: Waisenhaus 1828, S. 1-4. Die Anstalt wird von Schülern »vom 8ten oder 9ten bis zum Anfange des 18ten oder 19ten Jahres« bzw., wenn sie nicht studieren, »bis zum Anfange des 16ten oder 17 ten Jahres« besucht (S. 4).

$14 \mathrm{G}$ [eorg] T[heodor] A[ugust] Krüger: Das Gesammtgymnasium zu Braunschweig. Nachrichten über den gegenwärtigen Zustand desselben. Pr. Gesammtgymnasium Braunschweig 1831, S. 4. Von 1828 bis 1831 wurden vom Progymnasium 61 Schüler ins Obergymnasium und 52 ins Realgymnasium versetzt, während 40 »auf andere Lehranstalten « und 83 direkt ins Berufsleben überwechselten (S. 35). - In Gera wurden 1835 von den 12 Klassen die 4 oberen als »Gymnasialklassen «, die fünfte als »Progymnasialklasse « bezeichnet und die 8 letzten als »Bürgerschule « davon geschieden. Das Progymnasium war hier »eine den 3 oberen Klassen der Bürgerschule parallel laufende Vorbereitungsklasse für das Gymnasium«. Doch blieb das Ganze bis 1864 »noch eine Schule, und der Lektionsplan führte die Aufschrift: Verzeichnis der Lektionen auf der Hochfüstlichen Landesschule zu Gera. A. Gelehrtenschule, B. Bürgerschule «. R[ichard] Büttner: Geschichte des Fürstlichen Gymnasiums Rutheneum zu Gera. Festschrift zur Feier des 300jährigen Bestehens des Gymnasiums. Gera 1908, S. 104-05.

15 C[hristian] F[riedrich] Falkmann: Nachricht von der gegenwärtigen Einrichtung des Gym- 
nasiums und der Bürgerschule zu Detmold, nebst einer neuen Schulordnung [Schulprogramm] Lemgo: Meyer 1819, S. 6.

$16 \mathrm{H}$ [einrich] Kunhardt: Genügen die gelehrten Schulen dem für den Kaufmanns-Stand zu bildenden Jünglinge? In: Kritische Bibliothek für das Schul- und Unterrichtswesen, 1. Jg., 1819 , Bd. 1 u. 2, S. 532-51. Hier S. 533, 548, 549.

17 Programm Minden, Gymnasium, 1824/25, S. 21.

$18 \mathrm{~K}$ [arl] [Friedrich] L[udwig] Kannegiesser: Gymnasium zu Prenzlau. In: Kritische Bibliothek für das Schul- und Unterrichtswesen, 3. Jg., 1821, Bd. 1, S. 267-71. Hier S. 267, 268. - In der Provinz Brandenburg bestanden besondere Realklassen »bei den Gymnasien zu Potsdam und Guben, theilweise auch bei den Gymnasien zu Luckau, Königsberg [Neumark] und Prenzlau « (Otto Schulz: Aus einem Gutachten über die höhern Bürgerschulen. In: Pädagogische Revue 20, 1848, S. 141-60. Hier S. 158). Schulz schlägt die Bildung »einer an die Quarta des Gymnasiums sich anschließenden Realclasse « vor, womit er »das Bedürfniß vieler Mittelstädte (S. 159) nach einer Schulbildung bis etwa zum 15. Lebensjahr zu befriedigen hofft.

19 Für den Umschwung von der Aufklärung zur Restauration vgl. C[arl] C[hristoph] Schmieder: Ueber die Einrichtung höherer Bürgerschulen, ein Versuch. Halle: Gebauer 1809. Sch. läßt »die Idee einer Universalschule für alle Menschenklassen: (S. 1; vgl. Kap. 1.2.1) fallen. Denn die drei »Hauptstände « sind »so auffallend verschieden«, daß man sie gleichsam »Abarten der Menschheit « (S. 3) nennen kann; zudem sind sie wegen den verschiedenen familiären und überhaupt sozialen wie ökonomischen Voraussetzungen der Sozialisation »erblich « (S. 4, 6, 7). Da die »Kultur jener drei Menschenklassen « »nicht dem Grade nach«, so daß sie sich auszugleichen vermöchte, sondern »specifisch verschieden « ist, sind drei »Hauptschulen« erforderlich (S. 9): Volksschulen, Bürgerschulen, Gymnasien. - Vgl. Gustav Thaulow: Die Schule der Zukunft mit besonderer Rücksicht auf die Herzogthümer Schleswig und Holstein. Ein Vortrag gehalten bei Eröffnung seines pädagogischen Seminars im Wintersemester 1845-46. Kiel: Schwers 1846: »die Eintheilung der Stände keine menschliche That «, sondern »eine göttliche«, »objektiv vernünftige«; »die Substanz der Familie ein wesentlicher Factor für die Begabung des in ihr gebornen Kindes « (S. 20).

20 Alb[ert] Leop[old] Jul[ius] Ohlert: Die Schule. Elementarschule, Bürgerschule und Gymnasium in ihrer höhern Einheit und nothwendigen Trennung. Königsberg: Bornträger 1826. Zitate S. 32, 41, 40. Uber »Unzweckmäßigkeit und Schädlichkeit des Gymnasialbesuchs für Nichtstudirende « S. 104-17; eine strenge Scheidung von Gymnasium und Bürgerschule S. 117-42.

21 Johann Heinrich Deinhardt: Der Gymnasialunterricht nach den wissenschaftlichen Anforderungen der jetzigen Zeit. Hamburg: Perthes 1837. Zitate S. 11, 23, 23, 17, 19, 17. „So viele wesentlich verschiedene Stände es gibt, so viel wesentlich verschiedene Schulen gibt es auch «. (S. 11)

22 Ebd. S. 3.

23 A. Steffenhagen: Zur Reform des deutschen Gymnasiums. Berlin: Vereins-Buchhandlg. 1848, S. 45-46. »Es giebt nur eine Bildungsanstalt, welche die allgemeine höhere Volksbildung bei der heranwachsenden Jugend zu vermitteln hat. Diese Anstalt ist das Gymnasium. Es giebt also keine dieser Anstalt ebenbürtige Realgymnasien oder Realschulen mehr, so wenig als sogenannte reine Gymnasien im Gegensatze gegen jene Realschulen «. (S. 88) Das »untere Gymnasium «, eine selbständige Anstalt, umfaßt drei Klassen vom 9. bis zum 13. oder 14. Lebensjahr.

24 F[riedrich] W[ilhelm] Klumpp: Ueber die Einrichtung von Realschulen. Ein Wort zur Verständigung über diese wichtige Frage. Stuttgart: Metzler 1836, S. 6 u. 9. Der Verf. will die Lateinische Schule »zu einer gemeinschaftlichen Vorschule (S. 18; Unterrichtsfächer: Deutsch, Latein, Französisch, Geschichte u. Geographie, Mathematik u. Geometrie, Naturgeschichte u. Naturlehre, Zeichnen; Beschränkung des Griechischen. Fortfall der lateinischen Versübungen) bis zum 14. Lebensjahr machen. - Dieselben Vorschläge in kürzerer Form bei Klumpp: Die gelehrten Schulen nach den Grundsätzen des wahren 
Humanismus und den Anforderungen der Zeit. 2 Bde. Stuttgart: Steinkopf 1829-30. Hier Bd. 1, S. 42-44.

25 Friedrich Schleiermacher: Erziehungslehre. Hg. v. C. Platz (Sämmtliche Werke, Abt. 3, Bd. 9; Literarischer Nachlaß, Bd. 7) Berlin 1849, S. 449. Úber den Gedanken der 'Einheitsschules in den Vorlesungen von 1826 vgl. Franz Kade: Schleiermachers Anteil an der Entwicklung des preußischen Bildungswesens von 1808-1818. Leipzig 1925, S. $151 \mathrm{ff}$.

26 Ebd. S. 449.

27 [Wilhelm] Weissenborn: Versammlung der Schulmänner der Preussischen Provinz Sachsen und der angrenzenden Länder in Halle, den 16. und 17. Juli 1848. In: Zeitschrift für das Gymnasialwesen 2 (1848), S. 821-31. Hier S. 822. Die folgende Frage wurde einstimmig bejaht: "Sollen die Schüler bis zum 14ten Jahre (in der Mittelschule, oder in den drei untersten Klassen [des Gymnasiums], ehe der Unterricht im Griechischen beginnt) ein und denselben Unterricht erhalten?«(S. 823). In der Diskussion machte es Hermann Sauppe, der Direktor des Weimarer Gymnasiums, »als Forderung der Zeit geltend, dass alle Bürger eines Staats bis auf einen für sie erreichbaren Grad gleiche Gefühle und Gesinnungen hegen und darum gleiche Bildung geniessen, wenn sie einmal in demselben Staate zusammen wirken sollen « (S. 822).

28 Protocolle über die vom 2. bis 7. October 1848 in Hannover abgehaltene allgemeine SchulConferenz der Vorsteher und Lehrer der höheren Unterrichts-Anstalten des Königreichs. Hannover: Göhmann 1848, S. 3, 7. Für die Minderheit vgl. Brandt, Direktor des Gymnasiums in Emden: "Eine Trennung in den Anstalten sei gefährlich; es würde dadurch eine Scheidung der Stände in der Bildung und Gesinnung hervorgerufen, es würde politische Scheidung dadurch geschaffen «. (S. 4) Friedrich Rothert (Das Latein im Deutschen Gymnasium, eine Lebensfrage des höheren Schulwesens. Braunschweig: Westermann 1850), als Direktor des Gymnasiums zu Aurich Teilnehmer der Konferenz, spricht von einem »Sondergymnasium für den Studirtenadel«, das er durch ein »Gesammtgymnasium « für den »höheren Bürgerstand « (S. 27) ersetzen will. Dadurch hofft er »den Gegensatz zwischen Studirten und Beamten einerseits, und Bürgern andererseits als einen unberechtigten und verderblichen « (S. 30) aufheben zu können. - Ausführlicher Bericht über die Konferenz bei G[eorg] T[heodor] A[ugust] Krüger: Die Bestimmung, Einrichtung und Lehrverfassung der höheren Schulanstalten, nach den Ergebnissen der auf den Lehrerconferenzen zu Leipzig und Meissen, Hannover, Berlin darüber gepflogenen Verhandlungen. In: Zeitschrift für das Gymnasialwesen 3 (1849), S. 765-807.

29 Dazu A. Tellkampf: Bericht der statistischen Commission an die Versammlung. Ebd., S. 23 (»unter je 500 Aufgenommenen 130 Studirende, also etwa 1/4 Studirende und 3/4 Nichtstudirende «); Auszug aus dem am 5. October 1848 in der allgemeinen SchulConferenz vom Director Rothert mündlich erstatteten Berichte über die statistischen Verhältnisse der Gymnasien und Progymnasien. Ebd., S. 24-25. Von den ca. 1500 Schülern der drei unteren Klassen der 15 Gymnasien des Landes studieren 1300 nicht; demgegenüber befinden sich unter den etwa 1100 Schülern der drei oberen Klassen 740 künftige Studenten $(67 \%)$.

30 Ebd., S. 12-15 u. Zusatz zum Protokoll der 3. Sitzung am 4. Okt. 1848, nach S. 47 unpag. Im Hannoverischen bestanden 11 Progymnasien.

31 Verhandlungen über die Reorganisation der höheren Schulen. Berlin, den 16. April 14. Mai 1849. Berlin: Decker (1849), S. 120, 134, 207. So schon die ministerielle Vorlage S. 4. Der Provinzialschulrat der Provinz Brandenburg Otto Schulz (Aus einem Gutachten über die höhern Bürgerschulen. In: Pädagogische Revue, Bd. 20, 1848, S. 141-60) denkt an eine »Mittelschule " (bisher »allgemeine Stadtschule« oder »niedere Bürgerschule «), die den »gewerbetreibenden Stand « und den »mechanischen Geschäftsdienst « mit der nötigen Bildung versorgt, zugleich aber einen gemeinsamen Unterbau für das Gymnasium (anstelle der Klassen Sexta, Quinta und Quarta) und die höhere Bürgerschule bildet.

$32 \mathrm{H}$ [ermann] Köchly: Der ursprüngliche Entwurf zu dem allgemeinen Schulgesetz für das Königreich Sachsen. Leipzig: Wigand 1850. „Das Progymnasium ist für beide Gymnasien gleich" (S. 28). Von den beiden unteren Klassen der Realschule unterscheidet sich das 
Progymnasium nur durch Latein. Im Exil schlug Köchly (Ueber die Reform des Zürcher Gymnasiums. Zürich: Höhr 1859, S. 32) für die Züricher Anstalt ein Progymnasium »für zukünftige Gymnasiasten und Industrieschüler gemeinschaftlich « mit zwei Jahreskursen vor. Dazu Ernst Böckel: Hermann Köchly. Heidelberg 1904, S. 107/08 über das Schulgesetz in Sachsen, S. 191-95 über die Schulreform in Zürich.

33 Bericht über die Versammlung sächsischer Gymnasiallehrer zu Leipzig am 17., 18. und 19. Juli 1848. Aus den Protokollen zusammengestellt von [Heinrich Rudolf] Dietsch. o. O. u. o. J., S. 15.

34 A[ugust]F[riedrich] Bernhardi: Ansichten über die Organisation der gelehrten Schulen. Jena: Frommann 1818, S. 25, 24. Dazu Wilhelm Horstmann: August Ferdinand Bernhardi (1769-1820) als Pädagoge (Forschungen zur Geschichte der Philosophie u. der Pädagogik I, 3) Leipzig 1926. »Die Schulorganisation«, S. 14-26.

35 Klopp: Reform der Gymnasien, S. 23.

36 Heinrich Stephani: Ueber Gymnasien, ihre eigentliche Bestimmung und zweckmäßigste Einrichtung. Erlangen: Palm 1828, S. 45. Dazu Stephani: Grundriß der Staatserziehungswissenschaft. Weißenfels u. Leipzig 1797. Eine Darstellung bei Helmut König: Zur Geschichte der Nationalerziehung in Deutschland im letzten Drittel des 18. Jahrhunderts (Monumenta Paedagogica 1) Berlin 1960, S. 417-30.

37 Ebd. S. 114-24.

38 Ebd. S. 41. Die Mangelhaftigkeit der bayerischen Gymnasien - auf die sich der Verf. hauptsächlich bezieht - besteht darin, $\mathrm{da} ß$ »zwei ganz verschiedene Zwecke, die allgemeine und die spezielle Bildung « für Staats- und Kirchenbeamte miteinander verbunden werden. "Letzterer Zweck macht unsere Gymnasien allen denjenigen Jünglingen unbrauchbar, welche zu ihrer speciellen Bestimmung der todten Sprachen nicht bedürfen «. (S. 45)

39 Ueber Preußisches Gymnasialwesen in den letzten dreißig Jahren. In: Janus (Berlin) 1 (1845), S. 633-72; 2 (1845), S. 603-34. Hier Bd. 1, S. 654; über Vor- und Nachteile des Klassensystems insgesamt S. 638-58. Die Realschulen sind seine nothwendige Folge des Klassensystems « gewesen (Bd. 1, S. 655). Die Konzeption des Gymnasiums als »Grundschule « aller höheren Bildung Bd. 2, S. $621 \mathrm{ff}$. "Wenn das Gymnasium richtig für die höchste Stufe der Bildung, für die Wissenschaften, wie sie auf der Universität gelehrt werden, vorbereitet, so muß es auch richtig für alle niedrigeren Stufen, für niedere Staatsämter, Künste und Handwerke in jeder seiner Klassen vorbereiten «. (Bd. 2, S. 623)

40 Clemens Menze: Wilhelm von Humboldts Lehre und Bild vom Menschen. Ratingen (1965). "Sprachanthropologie und das Problem der Bildung «, S. 203-64. Hier S. 233, 232. Dazu Ders.: Ưber den Zusammenhang von Sprache und Bildung in der Sprachphilosophie Wilhelm von Humboldts. In: Pädagogische Rundschau 18 (1964), S. 768-85.

41 [Friedrich] W[ilhelm] Bäumlein: Die Bedeutung der klassischen Studien für eine ideale Bildung. Heilbronn: Landherr 1849, S. 20.

42 Wilhelm Münscher: Ansichten über die Bestimmung und Einrichtung der Gymnasien. Nebst einer kurzen Darlegung des bisherigen Zustandes und der gegenwärtigen Bedürfnisse der Gymnasial-Anstalten in Kurhessen. Hanau: König 1833, S. 39; i. O. gesp. Gemeint sind besonders die alten Sprachen, vgl. Anm. 52.

43 Georg Wilhelm Friedrich Hegel: Sämtliche Werke. Jubiläumsausgabe. Hg. v. Hermann Glockner. Bd. 3. Stuttgart 1927. Gymnasialrede vom 29. Sept. 1809, S. 231-45. Hier S. 242. Die Grammatik macht »den Anfang der logischen Bildung " aus, weil sie »die Kategorien, die eigenthümlichen Erzeugnisse und Bestimmungen des Verstandes zu ihrem Inhalte " hat; »in ihr fängt also der Verstand selbst an, gelernt zu werden « (S. 241). Dazu Theodor Bodammer: Hegels Deutung der Sprache. Interpretationen zu Hegels Äußerungen über die Sprache. Hamburg (1969); „Sprache und Bildung", S. 168-81; Daniel J. Cook: Language in the Philosophy of Hegel (Janua Linguarum. Series Minor, 135).) The Hague u. Paris 1973; besonders "Language as the Medium of Culture and Morality ", S. 78-97.

44 Deinhardt: Gymnasialunterricht. »Von dem grammatischen Unterrichte«, S. 56-65. Zitat S. 58. »Die Kategorien für sich [»Mittel und Zweck, Inhalt und Form, Qualität und 
Quantität, Grund und Folge, Möglichkeit, Wirklichkeit, Nothwendigkeit« etc.] werden in der Logik entwickelt und in ihrem nothwendigen Zusammenhang erkannt. Aber zu dieser Erkenntniß soll der Gymnasiast erst erzogen werden. Auf dem Gymnasium faßt und übt der Gymnasiast die Kategorien an dem Stoffe der Sprache. An den Biegungen und Verbindungen der Worte werden die Kategorien wie im Spiegel gesehen «. (S. 57)

45 Gregor Wilhelm Nitzsch: Ueber Reform der Gymnasien als allgemeinerer Bildungsanstalten. Kiel: Schröder u. Co. 1849, S. 33.

46 Friedrich Palm: Ueber Zweck[.] Umfang und Methode des Unterrichts in den classischen Sprachen auf den Gymnasien. Bericht im Auftrage der ersten Versammlung sächsischer Gymnasiallehre und im Namen des von ihr erwählten Ausschusses für alte Sprachen. Leipzig: Vogel 1848, S. 2.

47 Deinhardt: Gymnasialunterricht, S. 64. „Die Mathematik enthält die systematische Form der Logik, die Grammatik ihren Inhalt «. (ebd.)

48 Gustav Thaulow: Die Gymnasial-Pädagogik im Grundrisse. Kiel: Akad. Buchhandlg. 1858 , S. 131. Somit ist die Grammatik »ein wesentlicher Theil der philosophischen Propädeutik « (S. 138).

49 Nitzsch: Reform der Gymnasien, S. 39.

50 Deinhardt: Gymnasialunterricht, S. 61. Die "geistigen Begriffsbeziehungen « gewinnen durch und durch »ihre Verleiblichung in den grammatischen Flexionen. Jedes innere Gedankenverhältniß tritt auch äusserlich durch eine bestimmte Flexion in die Erscheinung. Alle unsichtbaren Gedankenbeziehungen werden in den grammatischen Formen der antiken Sprachen sichtbar«. (S. 62)

51 Bäumlein: Bedeutung der klassischen Studien, S. 24.

52 Münscher: Ansichten, S. 44. Wenn man »die Sprachen an sich« vergleicht, so ragt die griechische »durch Mannigfaltigkeit, Reichthum, Anmuth, Wohllaut, Geschmeidigkeit und anschauliche Malerei der Gedanken « (S. 42) hervor. Doch stellen die römischen Schriftsteller »den Zusammenhang zwischen der neuern Zeit und der gricchischen Mutter aller höheren Bildung « (S. 44) her. Auch empfiehlt sich Latein »wegen der strengen RegelmäBigkeit« (S. 45).

53 Nitzsch: Reform der Gymnasien, S. 33.

54 Deinhardt: Gymnasialunterricht, S. 192.

55 Ebd. S. 198.

56 Palm: Zweck, Umfang und Methode, S. 13.

57 Deinhardt: Gymnasialunterricht. »Von dem empirischen Sprachunterrichte «, S. 195-206. »Auf der empirischen Stufe wird die Sprache gelernt, auf der rationalen wird sie begriffen. Auf der empirischen Stufe gilt es, die Erscheinungen der Sprache kennen zu lernen, auf der rationalen bezieht sich der Unterricht auf das Wesen der Spracherscheinungen « (S. 192).

$58 \mathrm{~K}[\mathrm{arl}] \mathrm{v}[\mathrm{on}]$ Langsdorff: Versuch einer grundsätzlichen Anordnung des deutschen Unterrichtes für die badischen Lyceen. Beilage zum Programm des Lyceums in Wertheim für 1855, S. 8.

59 Deinhardt: Gymnasialunterricht, S. 198.

60) Ebd.

61 Thaulow: Gymnasial-Pädagogik, S. 142. Vgl. Heinr[ich] Wilh[elm] Bensen: Die öffentliche Erziehung, aus dem Gesichtspunkte des Staats. In: Bayerisches Volksblatt (Würzburg), 2. Jg., 1830, Sp. 137-598 in Fortsetzungen (genauere Angabe s. Bibliographie Bd. 2, Kap. 1.1): "Legt man also den ersten Grund der Sprachkenntniß durch Auswendiglernen von Wörtern und Regeln, so entspricht dieses dem Seelenzustand des Kindes « (Sp. 343).

62 Menze: Humboldts Lehre und Bild vom Menschen, S. 227, 252. Über »Volk, Nation und Sprache« S. 251-57. Überblick über die romantischen Auffassungen bei Eva Fiesel: Dic Sprachphilosophie der deutschen Romantik. Tübingen 1927; Otto Friedrich Bollnow: Die Pädagogik der deutschen Romantik. Von Arndt bis Fröbel. Stuttgart u. a. (1952), speziell zu Jahn und Arndt S. 96-105.

63 Deinhardt: Gymnasialunterricht, S. 208. „Die Sprache selbst ist der individuelle Geist des Volks«. (Ebd.) 
64 Bensen: Öffentliche Erziehung, Sp. 322.

$65 \mathrm{C}$ [aspar] $\mathrm{Ch}$ [ristoph] Gottlieb Wiß: Melanchthon oder Encyclopädie und Methodologie der Gymnasialstudien mit der nöthigsten Literatur. Lemgo: Meyer 1830, S. 46.

66 Johann Christian Friedrich Schaub: Gesammelte Schriften. Hg. v. Friedrich August Eckstein. Halle: Waisenhaus 1858. Darin: Ueber höheres Sprachstudium, S. 65-78. Hier S. 67. Die Sprache ist »das sichtbar gewordene innere Leben, der Geist, der sich selbst offenbart « (ebd.).

67 Friedrich Wilhelm Tittmann: Ueber die Bestimmung des Gelehrten und seine Bildung durch Schule und Universität. Berlin: Reimer 1833. "Die Grammatik, der Sprache Logik, enthält in den Formen der Worte und ihrer Zusammensetzung die Formen des Denkens. Das genaue Studium der Wortbedeutungen aber schließt den Sinn der Welt und ihrer Erscheinungen auf. Die Sprachen enthalten das Festgewordene in der Bildung der Völker, die allgemeinen Begriffe und Ansichten, den Styl und die Manier der Erscheinungen des Geistes, was einen so großen Theil aller geistigen Leistungen ausmacht. In der Sprache fühlt man die innerste Eigenthümlichkeit des Einzelnen, wie der Nation«. (S. 162)

68 Schaub: Gesammelte Schriften, S. 67.

69 Johann Heinrich Deinhardt: Der Begriff der Bildung mit besonderer Rücksicht auf die höhere Schulbildung der Gegenwart. Bromberg: Mittler 1855, S. 21/22. Der Unterricht in fremdsprachigen Literaturen bringt »das gemeinsam Menschliche« (S. 22) zum Bewußtsein.

70 Wiß: Melanchthon, S. 30-33. Ein anderes Beispiel etwa die differenzierte Begründung des altsprachlichen Unterrichts bei Münscher: Bestimmung und Einrichtung, S. $46 \mathrm{ff}$.: (a) »Studium der Sprachgesetze und des Sprachvorraths«, (b) »Verhältniß der alt-classischen Studien zu den einzelnen Wissenschaften«, (c) »Einfluß auf die Moralität « mit Erziehung zum »Staatsbürgerthum».

71 Ordnung der lateinischen Schulen und der Gymnasien in dem Königreiche Bayern. München: Central-Schulbücher-Vlg. 1830, S. 5. Entsprechend: Revidirte Ordnung der lateinischen Schulen und der Gymnasien im Königreiche Bayern. München: CentralSchulbücher-Vlg. 1854, S. 7-8.

72 Fr[iedrich] Thiersch: Ueber die lateinischen Schulen nach dem neuen Schulplane. In: Das Inland (München) 1829, Nr. 316, 12. Nov., S. 1267-68. Hier S. 1267.

73 Friedrich Thiersch: Ueber gelehrte Schulen, mit besonderer Rücksicht auf Bayern. 3 Bde. Stuttgart u. Tübingen: Cotta 1826-29. „Von dem Verhältniß der lateinischen Schule zum Bürgerstande und zu den Gemeinden «, Bd. 3, S. 109-12. Hier S. 112. »Indem wir auch dem künftigen Bürger die lateinische Schule öffnen, ihm Gelegenheit geben, eine beträchtliche Reihe von Jahren an einem strengen und andauernden Unterricht im Latein Theil zu nehmen, glauben wir ihn am zweckmäßigsten für die Pflichten und Verhältnisse, die ihm bevorstehen, auszurüsten «(S. 110/11). Weiter: Ueber das Verhältniß der lateinischen Schule zum Bürgerstande, Bd. 3, Tl. 3, S. 402-11.

74 So der »Plan der künftigen Einrichtung der lateinischen Schulen in Bayern « von 1829 (Thiersch: Ueber gelehrte Schulen, Bd. 3, S. 9 ff.): »Die lateinische Schule [...] hat den doppelten Zweck: auf das Gymnasium vorzubereiten, und denjenigen, welche künftig im Gewerbstande und in öffentlichen Verrichtungen, an denen er Theil nimmt, einen mehr als gewöhnlichen Grad formeller Bildung nöthig haben, dieselbe vor dem Antritt ihres Berufes zu gewähren« (S. 10).

75 Thiersch: Ueber die lateinischen Schulen, S. 1267. »Ist aber Vorbereitung auf das Gymnasium zunächst ihre [der Lateinischen Schulen] Bestimmung, so folgt offenbar, daß in derselben der Maasstab [!] für ihre Forderungen und Anordnungen gegeben ist « (ebd.).

76 Ebd. S. 1268: „Die lateinische Schule steht der deutschen parallel, beyde entlassen den Knaben mit dem vierzehnten Jahre. Wenn nun der höhere Bürgerstand an dem Unterrichte, welcher den künftigen Gelehrten für das Gymnasium vorbereitet, nicht Theil nehmen oder den ihm gewährten Antheil nicht benützen wollte, und im Gegentheil darauf beharrte, die für das Gymnasium nöthige Vorbereitung der andern durch seine ihm fremden Ansprüche zu stören oder zu schwächen, so bliebe nichts übrig, als die lateinische 
Schule dem künftigen Bürger zu schließen und ihn in die deutsche wieder hinüberzuweisen «. Dagegen: Beleuchtung der vom Hrn. Hofrath Thiersch versuchten Vertheidigung des neuen Schulplanes. In: Bayer'sches Volksblatt (Würzburg), 1. Jg., 1829, 19. Dez., Sp. 791-94; Ueber den neuen, bayrischen Schulplan. In: Hesperus (Stuttgart u. Tübingen) 1830, Nr. 32-34, 6., 8., 9. Febr., S. 127-28, 131, 135-36: »[. . .] aber Gelehrte, welche vom Schweiße des Volkes leben, sollten bedenken, ob dieses Volk nicht etwa auch Anspruch auf einige Früchte ihrer Arbeiten habe; ob Erforschung der vaterländischen Charaktere, Sitten, Geschichte, Institute, Erwerbsquellen nicht eben so nützlich sey als Sylbenstechereien « (S. 136). - Dazu Fritz Bihrle: Der Kampf um Friedrich Thierschs Lehrplan vom 8. Febr. 1829. Phil. Diss. München 1920 [masch.].

77 Ordnung 1830, S. 8.

78 [Franz Exner u. Hermann Bonitz]: Entwurf der Organisation der Gymnasien und Realschulen in Österreich. Vom Ministerium des Cultus und Unterrichts. Wien: Hof- u. Staatsdruckerei 1849, S. 3 u. 15. Dazu Helmut Engelbrecht: Der Einheitsschulgedanke in Österreich im 19. Jahrhundert. In: Österreich in Geschichte und Literatur 15 (1971), S. 3-13. Hier S. 3-4. Úber das Zustandekommen der Schulreform s. S[alomon] Frankfurter: Graf Leo Thun-Hohenstein, Franz Exner und Hermann Bonitz. Wien 1893.

79 Ebd. S. 8.

80 Ebd. S. 5.

81 Nitzsch: Reform der Gymnasien, S. 11.

82 Julius Mützell: Pädagogische Skizzen, die Reform der deutschen höheren Schulen betreffend. Der elften Versammlung der deutschen Philologen, Schulmänner und Orientalisten im Auftrage des berlinischen Gymnasiallehrervereins überreicht. Berlin: Schade 1850, S. 2 ff. Vgl. die Lektionstabellen für die Sprachenfolgen Englisch - Französisch - Latein Griechisch, Latein-Französisch-Englisch-Griechisch, Latein-Griechisch-FranzösischEnglisch, in: Entwurf einer Gymnasialordnung für die Herzogthümer Schleswig-Holstein, vorgelegt von der [!] auf der Rendsburger Lehrerversammlung den 30. Septbr. 1848 erwählten Committee. Kiel: Schwers 1850, S. 30-32. Die Wahl sollte den Anstalten frei stehen.

83 Friedrich Lübker: Die Organisation der Gelehrtenschule, mit besonderer Rücksicht auf die Herzogthümer Schleswig und Holstein. Leipzig: Herrmann 1843, S. 11. Die Aufgabe der Gelehrtenschule besteht deshalb darin, "auf geschichtlichem Wege allmählich in das Bewußtsein der Gegenwart « einzuführen; »ihr Princip ist also im Wesentlichen ein historisches « (S. 9-10).

84 J[ulius] Mützell: Ueber die Behandlung der deutschen Literaturgeschichte, namentlich der älteren, auf Gymnasien. In: Zeitschrift für das Gymnasialwesen 1 (1847), H. 1, S. 34-71. Hier S. 45. Ebenso [Christian] Wurm: Promemoria. Die Grundursache der ungenügenden Leistungen der gelehrten Schulen. In Wurm: Die deutsche Sprache an der gelehrten Schule, mit besonderer Rücksicht auf die revidirte Studienordnung in Bayern. Freiburg i. Br.: Herder 1856, S. 76-89. Uber Gymnasialbildung »durch Reproduction des nationalen Culturganges«: Die »gelehrte Bildung « hat zum Ziel, »das junge Geschlecht durch eine belebende Nach- und Wiederholung des von unserer Gesammtgattung und insbesondere von dem eigenen Volke zurückgelegten Lebensganges in die Gegenwart einzuführen " (S. 79); Alexander Kapp: Zur Förderung des Deutschen Unterrichts auf der oberen Bildungsstufe der Gymnasien. Oder: Das Gymnasium nach seiner concentrirten Bedeutung im Deutschen Unterrichte. Pr. Gymnasium Soest 1852, S. 1-10: Erziehung als »Wiederholung " des Bildungsprozesses des Abendlandes »im Kleinen " hat die Schüler »in die historischen Bildungsphasen der Menschheit «(S. 6) einzuführen. Dabei macht das Deutsche die »Substanz des gesammten Unterrichtes« (S. 9) aus, weil Griechisches, Römisches und Christliches sich in der deutschen Kultur vereint. Erweiterter Abdruck unter dem gleichen Titel: Archiv für das Studium der neueren Sprachen und Literaturen 12 (1853), S. 1. 41.

85 [Lorenz] $O[k e n$ ]: Für die Aufnahme der Naturwissenschaften in den bayer'schen Schulplan. In: Das Ausland (München) 1829, S. 1329-33. Hier S. 1330. Dagegen Fr[iedrich] 
Thiersch: Warum die Naturwissenschaften in den Plan zur Einrichtung der lateinischen Schulen und Gymnasien nicht aufgenommen wurden. In: Das Inland (München) 1829, S. 1380-82, 1384-85. Weiter: Noten zum Text in causa Thiersch contra Oken. In: Bayer'sches Volksblatt (Würzburg), 1. Jg., 1829, 26. Dez., Sp. 811-14.

86 Ebd. S. 1332.

87 [R.[ Albani: Versammlung von Gymnasiallehrern des Königreichs Sachsen zu Leipzig am 17., 18., 19. Juli 1848. In: Zeitschrift für das Gymnasialwesen 2 (1848), S. 832-50. Hier S. 840. Es wurde folgender Antrag (mit 34 gegen 16 Stimmen) angenommen: »Das Gymnasium hat seine Institutionen nach den begründeten Forderungen der Zeit und der Wissenschaft zu gestalten, mit Festhaltung des historischen als seines Grundprincips, aber voller Anerkennung der Bildungselemente, welche in den exakten Wissenschaften liegen « (S. 842).

88 Ebd. S. 839.

89 Bernhard Hieronymus Böhme: Schule und Zeitgeist. Ein Beitrag zur Pädagogik für Gelehrtenschulen. Neustadt a. d. O.: Wagner 1824. Der Verf. teilt die Unterrichtsgegenstände der »Gelehrtenschule« danach ein, was sie zur »intellectuellen« (S. 243-309), »religiös-moralischen « (S. 332 ff.) und »ästhetischen Cultur« (S. 309-32) beitragen. Letztere ist »ein Haupttheil der Bildung zur christlichen Humanität « (S. 311).

90 Schleiermacher: Erziehungslehre, S. 451.

91 Ebd. S. 451/52.

92 Ebd. S. 523.

93 Klumpp: Gelehrte Schulen, Tl. 1, S. 12. Zum Meinungsstreit, den das Werk veranlaßte, vgl. die Besprechung in der »Allgemeinen Schulzeitung « (1829, Abt. II, Sp. 857-63; 1831, Abt. II, Sp. 353-68). Die »Tendenz der Schrift« soll sein, »dem Realismus und den lebenden Sprachen den entschiedenen Sieg zuzuwenden« und den Humanismus »zu untergraben « (1829, Sp. 857). Der Rezensent verfolgt die Absicht, »ohne Zeitverlust die Koryphäen in den betreffenden Lehrfächern auf die Gefahr aufmerksam zu machen, die diesen von der angezeigten Schrift droht, damit sie sich bei Zeiten aufmachen, um als Vorkämpfer in die Schranken zu treten « (Sp. 859). Gegen die Gefühlsbildung 1831, Sp. 358-59. »Der Jugendbildner ist kein Confitürenkünstler; und eine Welt voll zuckersüsser Püppchen, wie ich mir nur die von Hrn. K. hergestutzte denken kann, ist keine Männerwelt « (Sp. 358).

94 Ebd. Tl. 1, S. 22.

95 J[ulius]F[riedrich] K[arl] Dilthey: Über das Verhältniß der Real- und Gewerbschulen zu den Gymnasien, Universitäten und zum Staatsdienst und seine fernere Gestaltung in den teutschen Staaten. Darmstadt: Papst 1839, S. 32-33. Der Direktor versucht »den philologischen Unterricht des Gymnasiums auf der einen, den naturwissenschaftlichen und Zeichenunterricht auf der andern Seite in eine fortlaufende Parallele « (S. 43) zu bringen, so daß der Schüler sich entscheiden kann. Der »philologische Lehrcurs« ist »nur in der Lectüre der lateinischen Autoren für alle Schüler zugleich verpflichtend. Der grammatisch-stylistische Theil des lateinischen, so wie der gesammte griechische Sprachunterricht kann kunftigen Cameralisten, Forstmännern und Baumeistern ganz, den künftigen Medicinern wenigstens in den beiden obersten Classen erlassen werden « (S. 33). Frei bleibt »die Wahl zwischen dem Griechischen und Französischen, in der Maturitätsprüfung die Wahl zwischen dem lateinischen und französischen Aufsatz « (S. 38).

96 Dilthey: Zur Gymnasialreform. 3 Tle. Programm Darmstadt, Gymnasium, Herbst 1848, Ostern 1849 u. 1850 . Hier Tl. 2, S. 40.

97 W[ilhelm] B[ernhard] Mönnich: Einige Bemerkungen zur Erklärung der überhandnehmenden Studiersucht in Deutschland. In: Hesperus (Stuttgart u. Tübingen) 1828, S. 577-79, 582-83, 585-87, 589-90, 593-94; mit ergänzenden Zuschriften S. 813-14, 904. Mönnich führt mehrere Gründe für den Drang in die Beamtenlaufbahn (»Alles eilt, in die große Lotterie des Staatsdienstes zu setzen «, S. 583) an: a) Eine sichere Existenz (»ein sicheres, wenn auch nicht überall glänzendes Einkommen und persönliche Anerkennung und Ehre«, S. 583); b) das gesellschaftliche Ansehen: »die persönliche Ehre« (S. 585). 
»Wer aber hat sich diese Ehre jetzt [!] ausser Adlichen und Reichen in der That zu erfreuen als Staatsdiener, Gelehrte und Schriftsteller etwa? (S. 585); c) die »Beschaffenheit des Nationalunterrichtswesens « (S. 586). Über Studienbeschränkungen S. 578. - Über »das humanistische Gymnasium als politische und institutionelle Basis des Beamtenstaates « und über den Zusammenhang von »Bildung und Beamtentum «, »Bildung und Versorgung" handelt Ulrich K. Preuß: Bildung und Bürokratie. Sozialhistorische Bedingungen in der ersten Hälfte des 19. Jahrhunderts. In: Der Staat 14 (1975), S. 371-96. Die Klagen über das Übermaß an Studierenden vergleicht im internationalen Rahmen Lenore O'Boyle: The Problem of an Excess of Educated Men in Western Europe, 1800-1850. In: Journal of Modern History 42 (1970), S. 471-95.

98 (Augsburger) Allgemeine Zeitung 1827, Nr. 25, 25. Jan., S. 99-100, Nachricht aus Berlin: "Es gibt hier und anderswo so viele Referendarien, daß man alle Kollegien vierfach besezen [!] könnte; die Schulamtskandidaten sind in großer Zahl und mehren sich täglich. so daß die sonst surrogirenden Hauslehrerstellen nicht mehr ausreichen wollen; wöchentliche Promotionen häufen die Zahl der Aerzte ins Ungeheure, und auch Theologen gibt es weit über den Bedarf« (S. 99). Ebd. Nr. 96, 6. April, S. 383 über die Úberzahl der Studierenden in Bayern.

99 Hat die Beförderung der Naturwissenschaften Einfluß auf Vermehrung oder Verminderung des jetzt so großen Andranges zum Staatsdienste? In: Hesperus (Stuttgart u. Tübingen) 1830, S. 155-56. Hier S. 155. - Vgl. die Niederschrift von Hermann Saupe, dem Direktor des Weimarer Gymnasiums, vom 14. März 1846. Der »Zudrang zum Studium « sei »soviel als möglich zu verhüten, da in hiesiger Gegend wie in Deutschland überhaupt so gut als niemand studiert, um zu studieren, sondern zu einer Staatsstellung zu gelangen, und Lebensunterhalt zu erwerben das Ziel aller ist, die das Gymnasium besuchen «. Der Verf. empfiehlt die Gründung von Realschulen. „Dann werden alle die, welche nur Bildung, nicht wissenschaftliche Laufbahn im Auge haben, vom Gymnasium abgelenkt, während jetzt viele, die entweder nur ailgemeine Ausbildung oder Vorbildung für eine praktische Richtung suchen, in Ermangelung einer dafür geeigneten Anstalt das Gymnasium wählen und dann durch die Macht der Gewöhnung sich von einer Klasse zur andern hinauftragen lassen, bis sie am Ende auf die Universität kommen«. Otto Francke: Geschichte des Wilhelm-Ernst-Gymnasiums in Weimar. Weimar 1916, S. 316.

100 Ebd. S. 155. „Unser Unterricht auf den Mittelschulen entzieht der Gesellschaft stets eine gewisse Anzahl junger Leute, welche, mit Lust zum Naturstudium erfüllt, unter den Classikern erliegen « (S. 156).

101 Dilthey: Verhältniß der Real- und Gewerbschulen zu den Gymnasien, S. 57. „Es ist berechnet worden, daß wenn nicht politische Umwälzungen und neue Organisationen, Krieg, Cholera, Pest und Seuchen dazwischen treten, theilweise dreißig Jahre erforderlich sind, um nach dem ordnungsmäßigen Laufe der Dinge die jetzt vorhandenen Candidaten alle zu placiren « (S. 56).

102 Dilthey: Gymnasialreform, Tl. 2, S. 41.

103 Dilthey: Verhältniß der Real- und Gewerbschulen zu den Gymnasien, S. 5.

104 Dilthey: Gymnasialreform, TI. 1, S. 23-24.

105 Ebd., Tl. 1, S. 21.

106 Ebd., Tl. 2, S. 38.

107 Ebd., Tl. 1, S. 22. Der Verf. spricht »von dem ideellen Aufgehen der Volks- und Bürgerbildung in der Gelehrtenbildung « (Tl. 2, S. 39).

108 H[ermann] Köchly: Vermischte Blaetter zur Gymnasialreform. Eigenes und Fremdes. Dresden u. Leipzig: Arnold 1847, S. 21. „Es ist cin eben so grober als allverbreiteter lrrthum, diese altclassische Bildung mit Lateinsprechen und Lateinschreiben zu verwechseln, während Viele diese vollkommen handhaben, ohne von jener eine Spur zu besitzen, und so umgekehrt « (S. 22). Ähnlich Köchly: Reform des Zürcher Gymnasiums, S. 9. Das Ziel des modernen Gymnasiums ist »die sprachlich-historische Bildung, nicht mehr einscitig die lateinische Sprachbildung (S. 21). Bereits vor Köchly waren ähnliche Gegenüber- 
stellungen üblich, z. B. Stephani: Gymnasien, S. 52 (»Humanitätsbildung « versus "philologische Bildung «).

109 Regulativ für die Gelehrtenschulen im Königreiche Sachsen. Leipzig: Teubner 1847. Die Anforderungen in Latein und Griechisch werden quantitativ und qualitativ vermindert. „Qualitativ ist der Unterricht in den altclassischen Sprachen zu beschränken, weil die Gelehrtenschule nicht philologische, sondern humanistische Bildung zum Zwecke hat « (S. 6/7). Das Regulativ verlangt »eine lebendige Darstellung des Geistes des Atlerthums, mit Rücksicht auf Sitte, Geschichte und Culturzustände, da hierin für Geist und Gemüth der Schüler ein weit fruchtbareres humanistisches Bildungsmittel liegt, als in bloßer Sprachund Literaturkenntniß«(S. 7). Zur Entwicklung in Sachsen siehe A[chmed] Scholtze: Humanismus und Realismus im höhern Schulwesen Sachsens während der Jahre 1831-1851. Wiss. Beilage zu dem Programm der städtischen Realschule zu Plauen i. V. Ostern 1894.

110 Steffenhagen: Reform des deutschen Gymnasiums, S. 60. Der Verf. verknüpft die philologische Interpretation mit dem statarischen Lesen ("philologisch-statarische Methode «), die historische Auslegung mit der kursorischen Lektüre (»historisch-cursorische« Methode, S. 60).

111 Langsdorff: Versuch einer grundsätzlichen Anordnung, S. 7. Ein solcher Sprachunterricht geht »dem Wesen nach über Einzeloperationen des Verstandes, über das Reflektiren an den Dingen nicht hinaus (S. 6); er übt nur »Verstand und Gedächtniß« (S. 5).

112 Hermann Köchly: Ueber das Princip des Gymnasialunterrichtes der Gegenwart und dessen Anwendung auf die Behandlung der griechischen und römischen Schriftsteller. Eine Skizze. Dresden u. Leipzig: Arnold 1845, S. 6 u. 8. Zu den Aktivitäten und Kontroversen des Autors vgl. Böckel: Köchly. »Köchly und die Gymnasialreform«, S. 49-70.

113 Palm: Zweck, Umfang und Methode, S. 2.

114 Münscher: Ansichten, S. 62.

115 Köchly: Princip des Gymnasialunterrichtes, S. 25-27. Steffenhagen möchte bei der Lektüre der alten Klassiker allein das »ästhetisch-ethische « Prinzip festhalten (Steffenhagen: Reform des deutschen Gymnasiums, S. 69). Wenn die Jugend das Kunstwerk nacherlebt, hat sie a) "intellectuell gewonnen «, weil ohne ein genaues sprachliches und sachliches Verständnis ein solcher Erfolg nicht möglich ist, b) »ethisch gewonnen «, denn »nur das, was innerlich bewegt und erregt, läßt große und gute Vorsätze in unserem Gemüthe zurück «, und c) »ästhetisch gewonnen«, »denn jedes Kunstwerk, welches uns innerlich rührt und ergreift, ist eben dabei, unseren Geschmack zu bilden und zu verfeinern « (S. 67). Uber den Gegensatz von formaler und ästhetischer Bildung vgl. [Johann Andreas Gottfried] Steuber: Ueber den heutigen Standpunct der altclassischen Philologie in Beziehung auf den Unterricht darin in den Gelehrtenschulen. In: Allgemeine Schulzeitung 1830, Abt. II, Sp. 393-99. »Lassen wir unsern philologischen Unterricht vorzugsweise grammatischkritischer Natur sein, so verlieren wir die ästhetische Seite jenes philologischen Unterrichts. Ein bloss grammatisch-kritischer Unterricht vermag keine Geschmacksbildung hervorzubringen « (Sp. 396).

116 Palm: Zweck, Umfang und Methode, S. 15/16.

117 August Spilleke: Ueber das Wesen der Bürgerschule. Programm des Friedrich-WilhelmsGymnasium und der Realschule in Berlin 1822, S. 17, 47. Vgl. Ernst Gottfried Fischer: Ueber die zweckmäßigste Einrichtung der Lehranstalten für die gebildetern Stände. Versuch einer neuen Ansicht dieses Gegenstandes mit besonderer Rücksicht auf Berlin. Berlin: Maurer 1806, S. 58. Mathematik ist das, »was für das gelehrte Gymnasium die alte Literatur ist«. »Die Mathematik muß hauptsächlich die Klasse und den Rang der Schüler bestimmen «.

118 Klumpp: Einrichtung von Realschulen, S. 7.

119 Köchly: Princip des Gymnasialunterrichtes, S. 4.

120 Frieda Böhnke: Die deutsche Dichtung in der Schule. Geschichte und Probleme 1750-1860. Phil. Diss. Frankfurt/M. 1967, S. 143. Vgl. Kap. »Die deutsche Lektüre unter dem Einfluss von orthodoxer und nationaler Bewegung«, S. 143-54. 
121 Joachim Günther: Die Realschulen und der Materialismus. Halle: Anton 1839, S. 23, 25.

122 Ebd. S. 29.

123 Ebd. S. 32, 33.

124 Ebd. S. 43. Deutsch, Latein, Geschichte 12; Mathematik, Physik, Chemie 10 Wochenstunden.

$125 \mathrm{Vgl}$. Schulz: Gutachten über die höhern Bürgerschulen, S. 148: „Die höhere Bürgerschule soll uns eine durch deutsche Literatur vermittelte, volksthümliche, christlich-deutsche Bildung geben, und man möchte deßhalb der höheren Bürgerschule, statt dieser unpassenden Benennung, den Namen der deutschen beilegen «. Deutsche Sprache und Literatur bilden den »Mittelpunkt« (S. 148) des Unterrichts. Der Verf. will auch Latein, um die Bildungswege durchlässig zu halten.

126 M[aximilian] W[ilhelm] Götzinger: Deutsche Dichter. Erläutert. Für Freunde der Dichtkunst überhaupt und für Lehrer der deutschen Sprache insbesondere. 2 Tle. Leipzig: Hartknoch, Zürich: Ziegler u. Söhne 1831-32. Hier Tl. 2, S. 583. So schon Fischer: Einrichtung der Lehranstalten, S. 80/81: Die deutsche Literatur muß auf den Realgymnasien »für die ästhetische Bildung das ergänzen, was Mathematik und Naturlehre nicht vermögen «. F. sieht deshalb »die Lesung der besten deutschen Prosaiker und Dichter, so wie meisterhafte Uebersetzungen aus alten und neuen Sprachen als eine Sache von Nothwendigkeit « an.

127 Ebd., Tl. 2, S. 582. Ähnlich Moritz Axt: Das Gymnasium und die Realschule. Ein Gutachten, veranlasst durch den Dilthey-Schachtischen Streit. Darmstadt: Jonghaus 1840. Gewerbeschulen als "Kinder und Trägerinnen der sinnlichen Bestrebungen unserer Zeit « (S. 88): "Was die Motten fressen und wonach die Diebe graben, das erzielt die Gewerbschule" (S. 9).

$128 \mathrm{Vgl}$. für die ältere Auffassung Schmieder: Einrichtung höherer Bürgerschulen. Der deutsche Stil muß »in Bürgerschulen ganz anders geübt werden, als in Gelehrtenschulen. Nicht jener philosophische Styl, der den Schriftsteller ausmacht, sondern Geschäftsstyl gehört hierher « (S. 43). Der Lehrplan enthält für Prima (Schüler von 14 bis 16 Jahren): a) "Geschäftsstyl«: »Geschäftsbriefe, Kontrakte, Quittungen, Wechsel, Obligationen, Protokolle, Berichte, Specifikationen«; b) »Rhetorik, ganz ohne Lehrbuch, in beständiger praktischer Uebung « (S. 101).

129 Schleiermachers Votum vom 10. Juli 1814 zu Süverns Gesamtinstruktion vom 7. Februar 1813. Abdruck bei Kade: Schleiermachers Anteil, S. 184-200. Hier S. 192. „Ich würde also für alle Schulen, die nicht Gymnasien sind, die alten Sprachen aus dem Kreise der notwendigen Unterrichtsgegenstände ausschließen, und die dadurch gewonnene Zeit teils zur Erweiterung des Unterrichts in der Muttersprache anwenden, teils dazu, daß der Mathematik und Physik um so eher ihr volles Recht widerfahren könne (S. 185). Randbemerkung von Süvern: »accedo« (S. 201). Ausführliche Begründung, mit einer Darstellung des deutschen Unterrichts, bei Schleiermacher: Erziehungslehre, S. 454-77.

130 Beispielhaft formuliert der österreichische »Entwurf der Organisation der Gymnasien und Realschulen « von 1849: "Zur Grundlage für die allgemeine Bildung [auf Realschulen] ist zumeist die moderne Literatur genommen, denn es handelt sich in diesen Schulen wesentlich um den kürzesten Weg zum Ziele, und die moderne Literatur hat unbestreitbar einen Stand erreicht, auf welchem auch sie Trägerin echt humaner Bildung ist, und hinreichende Mittel bietet, sie zu erzeugen « (S. 222). Dazu Theodor Vernaleken: Die sallgemeinen Bildungsmittel der Realschule mit besonderer Rücksicht auf den deutschen Unterricht in den Oberklassen. Jahresbericht der Ober-Realschule in Wien 1852/53, S. 3: »Im Gymnasium schließt sich die sallgemeine Bildung gutentheils an das Lateinische, in der deutschen Realschule an das Deutsche; im Gymnasium an die alten Klassiker, in der Realschule an die deutschen Klassiker, die in ähnlicher sorgfältiger Auswahl zu lesen sind wie im Gymnasium die römischen und griechischen «. - Mit welchem Enthusiasmus ein junger Lehrer die Lektüre zum fast ausschließlichen Unterrichtsgegenstand machen konnte, zeigt $\mathrm{K}$ [arl] G[eorg] Högelsberger: Der Unterricht in der deutschen Sprache an der Landstraßer OberRealschule. Zweites Programm der Ober-Realschule in der Vorstadt Landstrasse in Wien 
1853. H. las im ersten Jahr, 1850/51, 18 Lesestücke, darunter Gedichte von Herder, Goethe, Schiller, Körner (»Auf dem Schlachtfelde von Aspern«), Rückert, Platen (»Das Grab im Busento «, »Der Pilgrim vor Sanct Just «), Lenau (»An mein Vaterland ), Anastasius Grün (»Die Martinswand «). Im zweiten Jahr, 1851/52, waren es 11 Lesestücke, darunter Stellen aus Epen (Homers »Ilias « in der Ubersetzung von Voß; "Edda «; »Nibelungenlied « und »Gudrun « in der Ubertragung von Simrock) und aus Uhlands Drama »Herzog Ernst «. Im dritten Jahr, 1852/53, folgten Gedichte und Balladen von Bürger, Schiller, Goethe und Uhland. Als »Musterstücke« wurden »Hyperions Schicksalslied " von Hölderlin, historische Prosa von Raumer, ein Schreiben Schillers u. a. diktiert. - Zur Realschulsituation in Wien vgl. Hubert Ch. Ehalt: Das Wiener Schulwesen in der liberalen Ära. In: Forschungen und Beiträge zur Wiener Stadtgeschichte 1 (1978), S. 120-47. Hier S. $129 \mathrm{ff}$.

131 Köchly: Blaetter zur Gymnasialreform, S. 19: Die »Muttersprache« bildet »den Anfangspunct, insofern der Elementarunterricht in ihr zugleich die Grundlage für die Erlernung der fremden Sprachen nach Methode und Lehrgang ist; den Mittelpunct, insofern aller eigentliche Unterricht in ihr ertheilt wird; den Ausgangspunct, insofern die Gewandtheit, Sicherheit und Selbstständigkeit [!] im mündlichen und schriftlichen Gedankenausdruck [...] die eigenthliche Blüthe und Spitze der ganzen Gymnasialbildung, sowie der Masstab [!] für den höheren oder geringeren Grad der geistigen Reife werden soll«. Köchly wendet sich hier gegen die Erlernung der Grammatik im Lateinunterricht (statt im Deutschunterricht) der Unterstufe und gegen das damals in Sachsen noch übliche lateinische Sprechen und Interpretieren in den obersten Klassen.

132 Gustav Schubert: Úber den Unterricht in der deutschen Sprache. In Köchly: Blaetter zur Gymnasialreform, S. 70-76. Hier S. 72. Der Deutschunterricht muß »zum Mittelpunct des gesammten Gymnasialunterrichts« (S. 71/72) werden und »den Maasstab für die höhere oder geringere Reife « (S. 72) abgeben.

133 Rothert: Latein im Deutschen Gymnasium, S. 9.

134 August Koberstein: Grundriß zur Geschichte der deutschen National-Litteratur. Zum Gebrauch auf gelehrten Schulen entworfen. Leipzig: Vogel 1827, S. 1. - Unter den zahlreichen, meist ideologiekritischen Arbeiten zur sprachlichen und literarischen Nationalerziehung vgl. vor allem Horst-Joachim Frank: Geschichte des Deutschunterrichts. Von den Anfängen bis 1945. (München 1973), Kap. "Nationalerziehung und Germanistik", S. 373-484; Germanistik und deutsche Nation 1806-1848. Zur Konstitution bürgerlichen Bewußtseins. Hg. v. Jörg Jochen Müller (Literaturwissenschaft und Sozialwissenschaften 2) Stuttgart (1974) - darin besonders Müller: Germanistik - eine Form bürgerlicher Opposition, S. 5-112; Klaus Garber: Martin Opitz - »der Vater der deutschen Dichtung «. Eine kritische Studie zur Wissenschaftsgeschichte der Germanistik. Stuttgart 1976, S. 84 ff. Die Literaturgeschichte übernimmt die Aufgabe, »die politisch noch ausstehende nationale Einheit im Medium der Geschichte der deutschen Sprache und Poesie zur Darstellung zu bringen und die geschichtliche Rekonstruktion der kulturellen Einheit der Nation als Bürgschaft ihrer politischen zu antizipieren « (S. 89).

135 Karl Herzog: Geschichte der deutschen National-Litteratur mit Proben der deutschen Dichtkunst und Beredsamkeit. Jena: Schmid 1831, S. V: „Die National-Litteratur eines Volkes umfaßt jene Schriftwerke, die erzeugt und hervorgegangen aus dem Geiste der Nation, dem innern Wesen, den Vorstellungen, Ansichten, Gefühlen und Bestrebungen, wie der Form, der Sprache und Darstellungsweise nach, nationell, und von den Geisteserzeugnissen anderer Völker wesentlich verschieden sind; in denen sich das eigenthümliche geistige Leben eines Volkes am treusten und klarsten ausspricht «. - Karl Matthisson: Bemerkungen über das Studium der deutschen Nationalliteratur-Geschichte auf gelehrten Schulen. 2 Tle. Programm Brieg, Gymnasium, 1831 u. 1836. Hier Tl. 1, S. 4: „der Inbegriff der auf künstlerischem Wege hervorgebrachten, sowohl der Form wie dem Wesen nach ein eigenthümlich deut[sches] Gepräge tragenden Schriften «.

136 Deinhardt: Begriff der Bildung, S. 13. Ähnlich schon Deinhardt: Ueber die Stellung und Bedeutung des deutschen Unterrichts auf Gymnasien. In: Zeitschrift für das Gymnasialwe- 
sen, Jg. 2, Bd. 2, 1848, S. 513-21. Hier S. 513/14: Das »Studium der classischen Nationallitteratur « bringt »den Zögling von selbst in unmittelbare Berührung mit dem Nationalgeiste selbst, der sich seine entwickeltste und idealste Gestalt in der classischen Nationallitteratur gegeben hat «.

137 Robert Heinrich Hiecke: Der deutsche Unterricht auf deutschen Gymnasien. Ein pädagogischer Versuch. Leipzig: Eisenach 1842, S. 65. Dazu Alexander Kolbe: Lebensbilder von Schulmännern der Neuzeit als Spiegel für die Gegenwart. H. 1: Robert Heinrich Hiecke. Breslau 1891.

138 August Adolf Ludw[ig] Follen: Bildersaal deutscher Dichtung. Zunächst für Uebung in mündlichem und schriftlichen Erzählen, im Deklamiren und in ästhetischer Kritik. Geordnete Stoffsammlung zum Behuf einer allgemeinen, poetischen und ästhetischen Schulbildung. Nebst einer Uebersicht der deutschen Sprach- und Literatur-Geschichte. 2 Tle. Winterthur: Steiner 1828-29. Tl. 1, S. YVI; hier nach der Zitatcollage der Einleitung: Ueber den Bildungsgang auf unsern gelehrten Schulen. In: Hesperus (Stuttgart u. Tübingen) 1828, S. 1223-1256 in Fortsetzungen (genauere Angabe s. Bibliographie Bd. 2, Kap. 1.3.3). Hier S. 1240, wobei Follen die Literatur- mit Kunstgeschichte verknüpft. Zu der Anthologie vgl. Böhnke: Die deutsche Dichtung in der Schule, S. 115-18.

139 Karl Besseldt: Ueber die Nothwendigkeit, altdeutsche Gedichte auf Schulen zu lesen. In: Archiv deutscher Nationalbildung. Hg. v. Reinhold Bernhard Jachmann u. Franz Passow. Bd. 1, 1812, S. 368-96. Hier S. 381-82. Úber die Phantasie wird das »Gemüth « ergriffen und der »Wille « bestimmt. Auf diese Weise arbeitete die Nationalbildung zur Zeit der Befreiungskriege an einer sittlichen und politischen Reform. Dazu Helmut König: Zur Geschichte der bürgerlichen Nationalerziehung in Deutschland zwischen 1807 und 1815. 2 Tle (Monumenta Paedagogica 12, 13) Berlin 1972-73. Úber Besseldt s. Register. - Der Burschenschaftler A. A. L. Follen (Bildersaal, Tl. 1, 1828, Vorrede; s. Bibliographie Bd. 2, Kap. 1.3.3) hat die Phantasiebildung zum Ziel seines Literaturunterrichts gemacht.

140 Wurm: Revidirte Studienordnung, S. 59.

141 Deinhardt: Begriff der Bildung, S. 12. "In's Besondere hat der Unterricht in der deutschen Geschichte und in noch ungleich höherem Grade in der Muttersprache und der classischen Literatur unseres Volks keinen höheren Zweck, als dem Knaben und Jüngling die Volksbildung anzueignen « (S. 13).

142 Ebd. S. 12.

143 Friedrich Cramer: Ueber das Wesen und die Bedeutung der deutschen Literaturgeschichte auf Gymnasien und über Schillers Maria Stuart ins Besondere. Stralsund: Löffler 1838, S. 2. Die »Gefühls- und Gemüthsbildung " schöpft »aus der heimischen Literatur die reichste Nahrung (S. 2). Die deutsche Literatur wird gekennzeichnet durch »Religiosität und Gemüthsinnigkeit«, die in der »Richtung nach der Tiefe und nach dem Innern « wurzelt, und durch »Vielseitigkeit und Reichhaltigkeit «, weil die Länder sich kulturell frei entwickeln konnten (S. 3 u. 4). Der Verf. hebt die Lyrik »als die besonders deutsche Gattung " (S. 4) hervor.

144 Wurm: Revidirte Studienordnung, S. 53.

145 Ebd. S. 54.

146 Vernaleken: Bildungsmittel der Realschule, S. $3 / 4$.

147 Ebd., S. 4.

148 Friedrich Otto: Das Lese-Buch als Grundlage und Mittelpunkt eines bildenden Unterrichts in der Muttersprache. 3. verb. Aufl. Erfurt u. Leipzig: Körner 1849, S. V. Erste Auflage 1844. Für die Durchsetzung der »analytischen Methode « im Deutschunterricht der Volksschule s. Th[eodor] Kriebitzsch: Das Sprachstück und dessen Behandlung. In: Geschichte des deutschen Unterrichts in der Volksschule (Geschichte der Methodik des deutschen Volksschulunterrichts. Hg. v. C[arl] Kehr. 2. Aufl. Bd. 1) Gotha 1889, S. 418-67. Hier S. 434-50, Verordnungen S. 465-66.

149 Hiecke: Deutscher Unterricht, S. 85. Die theoretische und geschichtliche Belehrung soll nicht bloß an die Lektüre »anschließen ", »sondern auch aus dieser hervorwachsen. Gewöhnlich giebt man die Theorie vorn weg, und läßt Lectüre nur zur Exemplification 
folgen « (S. 84). Gesetze sollten »nur als Summe von Beobachtungen, als Resultat der Betrachtung einer beschränkten Zahl von Werken « (S. 85) auftreten.

150 Ebd., S. 84.

151 Otto: Lese-Buch, S. 138.

152 Hiecke: Deutscher Unterricht, S. 172-75. Vgl. das Verfahren bei der Interpretation erzählender Gedichte in untern und mittlern Klassen (S. 150-56): »Totaleindruck « durch Vorlesen; Angabe von Inhalt und Gang der Handlung; Bestimmung des Metrums; Entwicklung der inhaltlichen Gliederung und Komposition; Bestimmung der Charaktere; »Ausdruck « und auffällige Stilmittel; Betrachtung der »Bedeutung des Ganzen «, indem man »eine sinnvolle Ueberschrift « oder »ein treffendes Motto sucht; Vergleiche mit anderen Gedichten nach Stoff, Personen, Stil.

153 Otto: Lese-Buch, S. 138. Anhand der Gellertschen Fabel »Der großmüthige Räuber « gibt Benjamin Aug[ust] Bernh[ard] Otto (Ausführlicher Plan zu einer verbesserten GelehrtenSchule. Leipzig: Kayser in Comm. u. bei dem Verf. 1831, S. 7-9) ein Beispiel für die Behandlung der deutschen Lektüre in Sexta. Die Erzählung soll sich »dem interessirten Verstande und Gemüthe in einem Totalausdrucke einprägen « (S. 8).

154 Cramer: Wesen und Bedeutung der deutschen Literaturgeschichte, S. 9. Charakteristisch für die emotionale Literaturdidaktik der Jahrhundertmitte Heinrich Bone: Ueber den lyrischen Standpunkt bei Auffassung und Erklärung lyrischer Gedichte. Aus dem Programm [der Rheinischen Ritter-Academie zu Bedburg] von 1851. Paderborn: Schöningh 1852. Der »lyrische Standpunkt erlaubt, das Gedicht aus dem eigenen Gefühl nachzuschaffen: „da steht er [der Leser oder Hörer] dem Liede nicht mehr gegenüber, sondern er lebt in ihm; da nur kann er empfinden jenes Unaussprechliche des Gemüthes, wovon die Worte nur Andeutungen, gleichsam nur die Ufer sind, zwischen denen es hinströmt « (S. 5). Dazu die zustimmende Besprechung von J[ohann] G[abriel] Seidl, in: Zeitschrift für die österreichischen Gymnasien 3 (1852), S. 397-402. - Zur Kritik an der »romantischen « Richtung des Deutschunterrichts (Ph. Wackernagel, R. v. Raumer, s. unter ihnen Bibliographie Bd. 2, Kap. 1.3.3 bzw. 1.3.1.1) vgl. Langsdorff: Versuch einer grundsätzlichen Anordnung, S. 20: »Da wird nicht nur das Uebermaß der Grammatik, der Poetik, der Rhetorik, der Regel über Bord geworfen, sondern aller Verstand, alle Norm, alle Uebung; nur anempfunden soll fortan werden. Der Lehrer lese vor, der Schüler höre; so empfinde er sich musikalisch in Sinn und Form der besten Muster ein und befruchte sich sympathisch; die besten Muster aber sind meist die gefühlichen, vor allem die religiösgefühlichen «.

155 Deinhardt: Begriff der Bildung, S. 16. Der Verf. zählt an dieser Stelle als "Nationalwerke« auf: »Nibelungen«, »Gudrun«, Lessing, Claudius, Goethes »Hermann und Dorothea « und »Iphigenie «, Schiller, Körners »Leyer und Schwert «. Uhlands Balladen.

$156 \mathrm{C}$ [hristian] F[erdinand] Falkmann: Methodik der deutschen Stylübungen. 2. gänzlich umgearb. u. bedeutend verm. Aufl. Hannover: Hahn 1823, S. 79. Der Lehrer kann des Schülers "geheimste, unwillkührlich hervorbrechende Gefühle belauschen; er kann sie anzünden die reine Flamme, die dem Wahren, dem Schönen, dem Guten, dem Großen im jugendlichfrischen Menschenherzen lodert « (ebd.).

157 [G. Alb. Ph.] Lorberg: Thiersch, über gelehrte Schulen. Einige Bemerkungen zu dessen Ansicht vom teutschen Sprachunterricht. In: Allgemeine Schulzeitung 1826, Abt. II, Sp. 777-84. Hier Sp. 783.

158 [Friedrich Gottfried Wilhelm] Hertel: Ansichten über den Unterricht in der deutschen Sprache und den Vortrag der deutschen Litteraturgeschichte auf Gymnasien. Programm des Zwickauer Gymnasiums Ostern 1834, S. 4. Der Schüler zeigt in den Aufsätzen, »mit welchem Nutzen er den gesammten Unterricht, vorzüglich auch in den alten Sprachen, benutzt, welche Fertigkeit er in einem richtigen Denken und einer angemessenen Darstellung erreicht habe, kurz, welches der Standpunkt seiner geistigen Ausbildung im Allgemeinen sei (ebd.).

159 Deinhardt: Gymnasialunterricht, S. 138. „Der deutsche Aufsatz ist die freie Darstellung der Gesammtbildung des Schülers« (S. 139). Ähnlich Thaulow: Schule der Zukunft, S. 43 
(»die Crystallisation der geistigen Verfassung«); Ders.: Gymnasial-Pädagogik, S. 169 in direktem Anschluß an Deinhardt; für die Realschule I[saak] M[arcus] Jost: Deutsche Stilübungen in den höhern Bürgerschulen. In: Pädagogische Revue, Bd. 19, 1848, S. 173-201. Hier S. 185: Die Schule macht die deutschen Arbeiten »zum Mittelpunct der Gesammtbildung«, da der Schüler in ihnen »seine ganze Entwickelungsstufe « zu erkennen gibt.

160 Ludwig Giesebrecht: Der deutsche Aufsatz in Prima. Eine geschichtliche Untersuchung. In: Zeitschrift für das Gymnasialwesen 10 (1856), S. 113-52. Hier S. 136.

161 Reglement für die Prüfung der zu den Universitäten übergehenden Schüler. Berlin: Duncker \& Humblot 1834. Zu den schriftlichen Prüfungsarbeiten zählt ein »in der Muttersprache abzufassender Aufsatz, welcher die Gesammtbildung des Examinanden, vorzüglich die Bildung des Verstandes und der Phantasie, wie auch den Grad der stilistischen Reife [...] beurkunden soll« (S. 7, § 16).

$162 \mathrm{~A}$ [ugust] F[erdinand] Bernhardi: Von der Bedeutung des Unterrichts in der Muttersprache in den höhern Classen der Bildungsanstalten. Programm des Friedrich-Wilhelms-Gymnasium und der Realschule in Berlin April 1820, S. 28. Deutsche Arbeiten gelten auch später als »die beste praktische Logik « (Lorberg: Thiersch, Sp. 783) und als »ein geistiges Turnen« (Jost: Deutsche Stilübungen, S. 185).

163 Ueber die revidirte Ordnung der lateinischen Schulen und der Gymnasien im Königreiche Bayern. Wien: Gerold 1854, S. 22. Die »Zusammensetzung kleiner Beschreibungen und Erzählungen, auch Briefe aus gegebenen Sätzen «, die der Lehrplan in der Lateinischen Schule, d. h. der Unterstufe, verlangt (Revidirte Ordnung der lateinischen Schulen und der Gymnasien im Königreiche Bayern. München: Central-Schulbücher-Vlg. 1854, S. 10), fordert nach Meinung des Kritikers eine »naturwidrige Operation «, die »ein mit Draht zusammengehaltenes Skelettt « produziere (S. 18). Das Streben nach »Gewandtheit in den verschiedenen Stylgattungen " auf der Oberstufe, dem Gymnasium (Revidirte Ordnung, S. 19), lasse sich »mit der Forderung innerer Wahrheit und Natürlichkeit « kaum vereinen; es werde in der Regel »in ein schauspielartiges, carikirtes Verkleiden in verschiedene Masken « ausarten (S. 20). Die Schrift richtet sich gleicherweise gegen die »Theorie der Dicht- und Redekunst « (»ein Aggregat leerer Begriffe«, S. 22) und tadelt die »theoretische >Verstiegenheit « bei der Literaturgeschichte (S. 23). Vgl. Kap. 2.2.3.

164 [Friedrich Wilhelm Klumpp:] Unser Unterrichtswesen im Verhältniß zur Nationalität. In: Deutsche VierteljahrsSchrift 1841, H. 1, S. 126-48. Zur "Nationalerziehung " wirken zusammen: »das Christenthum als Unterlage des Ganzen und als belebende Kraft «, »die Muttersprache mit ihrer Literatur «, »die deutsche Geschichte und Geographie" und endlich »das Turnen « (S. 147). Ein »nationaler Festkalender « (S. 145) soll in das Schulleben eingeführt werden.

165 C. Burkhard: Grundzüge einer Gymnasialreform in Bayern in Zusammenhang mit der allgemeinen deutschen Schulreform. München: Kaiser 1849, S. 27: »In Verbindung mit vaterländischer Geschichte und Landeskunde ist es [das Deutsche] das Hauptmittel zur Erreichung volksthümlicher Bildung - Nationalitätsbildung - zur Erweckung und Belebung eines ächt deutschen Sinnes, der Freude und Liebe zum eigenen Volk und zum Vaterlande«. - Für Österreich vgl. Theodor Vernaleken: Das deutsche Sprachfach in einem kurzen Úberblicke, mit Rücksicht auf den schulmässigen Unterricht. In: Zeitschrift für die österreichischen Gymnasien 6 (1855), S. 208-18. Hier S. 217.

166 Köchly: Entwurf zu dem allgemeinen Schulgesetz, S. 27. Vgl. die Vorlage des Ausschusses für »Nationalitätsbildung ", die auf der Konferenz in Meißen 1848 zur Diskussion stand: »Zur Nationalitätsbildung gehören: a) freie Beherrschung der Sprache in mündlichem und schriftlichem Gebrauche; b) Kenntniss des Vaterlandes; c) Kenntniss der Geschichte des Volks und seiner Literatur «. R. Albani: Zweite Versammlung von Gymnasiallehrern des Königreichs Sachsen, in Meissen, d. 28, 29., 30. December 1848. In: Zeitschrift für das Gymnasialwesen 3 (1849), S. 853-76. Hier S. 855.

167 F[riedrich] A[dolf] W[ilhelm] Diesterweg: Deutsche Nationalerziehung, ihre Bedeutung, ihre Zwecke, ihre Mittel. In: Germania (Leipzig), Bd. 1, 1851, S. 64-72. Zum gesamten 
Komplex vgl.: Programme zur bürgerlichen Nationalerziehung in der Revolution von 1848/ 49. Hg. v. Helmut König, Berlin 1971.

\section{Anmerkungen zu 2.1. Preußen}

1 Die Gelehrtenschulen Preußens unter dem Oberschulkollegium (1787-1806) und das Abiturientenexamen. Hg. v. Paul Schwartz. 3 Bde (Monumenta Germaniae Paedagogica 46, 48, 50) Leipzig 1910-12. Hier Bd. 1, S. 32/33, 31.

2 Dazu Reinhard M. G. Nickisch: Die Stilprinzipien in den deutschen Briefstellern des 17. und 18. Jahrhunderts. Mit einer Bibliographie zur Briefschreiblehre (1474-1800) (Palaestra 254) Göttingen 1969; Ders.: Gottsched und die deutsche Epistolographie des 18. Jahrhunderts. In: Euphorion 66 (1972), S. 365-82; Diethelm Brueggemann: Gellert, der gute Geschmack und die üblen Briefsteller. Zur Geschichte der Rhetorik in der Moderne. In: DVjs 45 (1971), S. 117-49. Theorie und Praxis der Brieflehre in Schulen wurden bis Anfang des 19. Jahrhunderts weitgehend von Gellert bestimmt; Neuausgabe: Die epistolographischen Schriften. Faksimiledruck nach den Ausgaben von 1742 und 1751. Nachwort v. Reinhard M. G. Nickisch (Deutsche Neudrucke. Reihe Texte des 18. Jh.s) Stuttgart (1971). Zur Wirkungsgeschichte der Gellertschen Brieflehre s. Nickisch: Stilprinzipien, S. 189-93 und Nachwort des Reprints, S. 12.

3 Schwartz: Gelehrtenschulen Preußens. Bd. 2, S. 284, 168; Bd. 3, S. 131.

4 Ebd. Bd. 2, S. 182. Die Prüfung folgt den Kapiteln im 1. Teil: »Allgemeine Eigenschaften des Styles« von Johann Christoph Adelung: Ueber den Deutschen Styl. Berlin: Voß u. Sohn 1785 (Reprint Hildesheim u. New York 1974 = Documenta Linguistica. Ergänzungsreihe): „Gebrauch der Hochdeutschen Schriftsprache «, "Sprachrichtigkeit « (grammatische Korrektheit), »Reinigkeit « (keine Archaismen, Provinzialismen, unnötigen Fremdworte), »Klarheit und Deutlichkeit «, »Angemessenheit «, »Präcision«, »Würde«, »Wohlklang«. Schon vor der von Heinsius 1800 herausgegebenen Kurzfassung (s. Bibliographie Bd. 2, Kap. 1.3.2) machten sich die Lehrer Auszüge dieses Werkes. So Jak. W. Bertuch, Prorektor der Gelehrtenschule in Küstrin (Bd. 2, S. 313). Für die Wertschätzung Adelungs vgl. den Abituraufsatz "Wodurch hat sich das 18. Jahrhundert in der Geschichte ausgezeichnet? « des Gymnasiums (Stadtschule) der Altstadt Magdeburg vom 1. Februar 1790 (Bd. 3, S. 60).

5 Ebd. Bd. 3, S. 136, 267. Für den Deutsch- und Rhetorikunterricht in Hamm s. Helmut vom Berg: Der Einfluß des Neuhumanismus auf die Entwicklung des höheren Schulwesens in Cleve-Mark (1770-1810). Auf Grund der Cleve-Märkischen Verordnung für die höheren Schulen vom Jahre 1782 und der in jener Zeit gebrauchten Schulbücher (Forschungen zur Geschichte der Philosophie u. der Pädagogik. Bd. II, H. 1) Leipzig 1927, S. 65-71, $100-02,144-46$.

6 Ebd. Bd. 2, S. 528. Die Dreistillehre (hoher, mittlerer, niederer Stil) gehört zum Grundbestand der Schulrhetorik.

7 Ebd. Bd. 2, S. 353/54, 289.

8 Ebd. Bd. 3, S. 258 u. 265 ; Bd. 2, S. 346 u. 348. Zum Verhältnis von rhetorischen und logischen Schlüssen s. Rainer Klassen: Logik und Rhetorik der frühen deutschen Aufklärung. Phil. Diss. München 1973 (Druck Augsburg 1974), Kap. 3: Schluß.

9 Ebd. Bd. 3, S. 344. Zur zeitgenössischen Homerauffassung s. Georg Finsler: Homer in der Neuzeit von Dante bis Goethe. Italien. Frankreich. England. Deutschland. Leipzig u. Berlin 1912; Kirsti Simonsuuri: The original genius of Homer. Eighteenth-century notions of the early Greek epic (1688-1798). Cambridge u. a. (1979), Part II: Primitivism and Realism. - Vgl. das Thema des Abituraufsatzes am Collegium Groeningianum in Stargard vom 8. Sept. 1804: „Warum sind die rohen Zeitalter gerade die Zeitalter für Poesie? « (Bd. 2, S. 182)

10 Ebd. Bd. 3, S. 26. Das Thema ist ein Nachklang der von Adelung ausgelösten Diskussion um die Rolle Obersachsens als »Deutschlands Athen und Toscana«, d. h. als die die 
sprachliche und kulturelle Entwicklung bestimmende Region. Gegen die Ansichten Adelungs (Magazin für die Deutsche Sprache. Leipzig 1782 bis 83 . Reprint Hildesheim u. New York 1969. Darin: Was ist Hochdeutsch? Bd. 1, St. 1, S. 1-31; Auch etwas von dem Zustande der Deutschen Litteratur, ebd. S. 84-100. Weiter: Bd. 1, St. 2, S. 104-08; St. 4, S. 79-111, S. 112-26 gegen den »Teutsche[n] Merkur «; ebd. S. 134-59 gegen die »Berlinische Monatsschrift«; Bd. 2, St. 1, S. 3-31; St. 4, S. 138-63. Zitat Bd. 1, St. 2, S. 105) wenden sich u. a. "Der Teutsche Merkur « (Ueber die Frage: Was ist Hochteutsch? und einige damit verwandte Gegenstände. 1782, 4. Vierteljahr, S. 145-70, 193-216. Unterz. Musophilus) und die »Berlinische Monatsschrift « (J[ohann] E[rich] Biester: Ist Kursachsen das Tribunal der Sprache und Litteratur für die übrigen Provinzen Deutschlands? Jg. 1783. Bd. 1, S. 189-99). Eine Skizze der Argumente Adelungs bei Dieter Nerius: Untersuchungen zur Herausbildung einer nationalen Norm der deutschen Literatursprache im 18. Jahrhundert. Halle/S. 1967, S. 63-66.

11 Ebd. Bd. 2, S. 108. Andere Prüfungsaufgaben zur Redekunst: „Der Nutzen der Beredsamkeit für den Theologen und den Juristen « (Neustadt Brandenburg 1789; Bd. 2, S. 440); »Sind die Eingänge ein so wesentlicher Teil einer Rede, daß sie nie fehlen dürfen, wie werden sie am besten gemacht, und welche Eigenschaften müssen sie haben? (Hamm 1801; Bd. 3, S. 267); „Ưber die Würde der Beredsamkeit, mit Rücksicht auf die verschiedenen Gattungen derselben, welche von ältern und neuern Völkern kultiviert worden sind « (Königsberg/Neumark 1805; Bd. 2, S. 290); »Was ist der Zweck der Rede überhaupt? Was der Zweck der schönen und der verschönerten Rede, und welche Gemütsvermögen werden dadurch besonders beschäftigt? « (Züllichau 1806; Bd. 2, S. 356)

12 Ebd. Bd. 2, S. 177/78.

13 Ebd. Bd. 2, S. 108.

14 Ebd. Bd. 2, S. 178. Demosthenes und Cicero konnten sich - so ein anderer Schüler - »nur allein in freien Staaten « solchen Ruhm erwerben. »Die ganze Beredsamkeit schränkt sich in Deutschlands Staaten bloß auf die Kanzel Beredsamkeit [!] ein, und blüht izt nur noch in England « (ebd.).

15 Zur Gattungspoetik vgl. Irene Behrens: Die Lehre von der Einteilung der Dichtkunst vornehmlich vom 16. bis 19. Jahrhundert. Studien zur Geschichte der poetischen Gattungen (Beihefte zur Zeitschrift für Romanische Philologie XCII) Halle/S. 1940; Klaus R. Scherpe: Gattungspoetik im 18. Jahrhundert. Historische Entwicklung von Gottsched bis Herder (Studien zur Allgemeinen u. Vergleichenden Literaturwissenschaft 2) Stuttgart (1968), hierzu meine Rezension in: GRM N.F. 19 (1969), S. 118-22; mit besonderer Berücksichtigung des Schulbereichs Georg Jäger: Das Gattungsproblem in der Ästhetik und Poetik von 1780 bis 1850. In: Zur Literatur der Restaurationsepoche 1815-1848. Hg. v. Jost Hermand u. Manfred Windfuhr. Stuttgart 1970, S. 371-404.

16 Schwartz: Gelehrtenschulen Preußens. Bd. 2, S. 185.

17 Ebd. Bd. 2, S. 527, 174, 325, 407, 529, 407, 353; Bd. 3, S. 371; Bd. 2, S. 337. Vgl. wciter folgende Themen: "Welches sind die hauptsächlichsten Eigenschaften des Dramas, wodurch unterscheidet es sich von der Erzählung, wie bestimmt man die vornehmsten Arten desselben, und welches sind die merkwürdigsten Dichter unter den ältern und neuern Nationen in jeder Art? « (Prenzlau 1791; Bd. 2, S. 527/28, es werden genannt für das Trauerspiel: Babo, Iffland, Lessing, Schiller, Wieland, für das Lustspiel: Brandes, Engel, Gellert, Goethe, Kotzebue, Lessing, Weiße, für die Oper: Wieland); »Was heißt ein Heldengedicht, und wo nimmt man den Stoff dazu her? Was ist der Endzweck eines Heldengedichts, und welches sind seine Bestandteile? Welches sind die vorzüglichsten Dichter in der epischen Dichtkunst unter den Griechen, Römern, Deutschen, Engländern, Franzosen und Italienern? «(Aschersleben 1792; Bd. 3, S. 133); »Ursprung der Tragödie. Was hat das Drama mit dem Epos gemein, und worin unterscheiden sie sich? Vorzügliche Dramatiker der Alten. Was sind lyrische Gedichte? wie lassen sie sich abteilen? Sind die 4 Bücher der Oden und die Epoden des Horaz alle Oden? « (Küstrin 1805; Bd. 2, S. 324); "[...] vom Charakter, der Hauptperson und den Episoden eines epischen Gedichts überhaupt und der Klopstockschen Messiade und Wiclands Oberon insonderheit; desgleichen 
von dem Unterschiede eines epischen und dramatischen Gedichts « (Stargard 1806; Bd. 2, S. 186).

18 Zum Versepos s. Friedrich Sengle: Biedermeierzeit. Deutsche Literatur im Spannungsfeld zwischen Restauration und Revolution 1815-1848. Bd. 2. Stuttgart 1972, S. 626-742. Eine spezielle Studie zur Theorie und Kritik des deutschen Versepos im 18. und 19. Jahrhundert fehlt. - Úber die Versdidaktik vgl. L[eif] L[udwig] Albertsen: Das Lehrgedicht. Eine Geschichte der antikisierenden Sachepik der neueren deutschen Literatur mit einem unbekannten Gedicht Albrecht von Hallers. Aarhus 1967, dazu kritisch und weiterführend Hans-Wolf Jäger: Zur Poetik der Lehrdichtung in Deutschland. In kritischen Zusätzen zu L. L. Albertsens Buch `Das Lehrgedichts. In: DVjs 44 (1970), S. 544-76; Christoph Siegrist: Das Lehrgedicht der Aufklärung (Germanistische Abhandlungen 43) Stuttgart 1974.

19 Schwartz: Gelehrtenschulen Preußens. Bd. 3, S. 134.

20 Ebd. Bd. 2, S. 354; Bd. 3, S. 135.

21 Ebd. Bd. 2, S. 181. Ähnlich äußert sich ein Abiturient in Hamm am 19. Sept. 1798: Die Romanlektüre nimmt uns »alle Lust zu ernsthaften Geschäften, die Stand und Beruf uns zur Pflicht machen. Wer also ein glücklicher Mensch, und ein nützlicher Staatsbürger werden will, der fliehe diese Art von Schriften, woran Deutschland seit einiger Zeit so fruchtbar ist " (Bd. 3, S. 262). Für die hier wiedergegebene Auffassung vgl. das Gutachten von Karl Friedrich Flögel, Lehrer an der Ritterakademie in Liegnitz, vom 13. Januar 1788: "Die unbändige Lesewuth, die sich aller Stände bemächtigt hat, erweckt ihnen [den Schülern] Ekel an gelehrten Sprachen und ernsthaften Wißenschaften. Da wir besonders mit einer unendlichen Menge Romanen und Komödien im Zorn heimgesucht werden, so finden sie allenthalben Stoff genug sich zu amüsiren, und machen ihre Hauptbeschäftigung daraus, da es blos Erholung seyn sollte. Dieses Unheil ist so allgemein, daß auch niedere Stände dadurch angestekt sind, und Handwerkspurschen, Bürgerstöchter und Mägde dadurch vom Arbeiten abgehalten werden, und romantische Begriffe in den Kopf saugen, die sie zum gemeinen Leben ganz untüchtig machen." (Bd. 1, S. 80/81) K. Gottlieb Weißer, Konrektor des Friedrichswerderschen Gymnasiums in Berlin, "suchte die hie und da sich zeigenden Folgen der Romanenlektüre, Empfindelei, Unzufriedenheit mit der Welt u.s.w. wegzuschaffen «, indem er körperliche Úbungen empfiehlt (Bd. 2, S. 395). Über die Polemik der Schule gegen die Belletristik s. Kap. 3.1.e, dort auch Literatur. - Zu den Volksbildungsbestrebungen vgl. Heinz Otto Lichtenberg: Unterhaltsame Bauernaufklärung. Ein Kapitel Volksbildungsgeschichte (Volksleben 26) Tübingen 1970 und Reinhart Siegert: Aufklärung und Volkslektüre. Exemplarisch dargestellt an Rudolph Zacharias Becker und seinem `Noth- und Hülfsbüchlein<. Mit einer Bibliographie zum Gesamtthema. In: Archiv für Geschichte des Buchwesens 19 (1978), Sp. 565-1348; bes. Sp. 1114-25: Das >Noth- und Hülfsbüchlein als Schulbuch. Das Werk spielte »eine der wichtigsten Rollen in der Schulreformbewegung des ausgehenden 18. Jahrhunderts « und war »eines der drei oder vier meistverbreiteten Schulbücher der Zeit « (Sp. 1124/25).

22 Ebd. Bd. 2, S. 353; Bd. 3, S. 140. In Thorn kündigt sich schon der Úbergang zur idealistischen Ästhetik an. Der Direktor Johann Wilhelm Süvern, seit 1809 Leiter der Unterrichtsabteilung in der Sektion für Kultus und Unterricht im preußischen Innenministerium, schließt »die sogenannten schönen Wissenschaften « aus der Zahl der Unterrichtsobjekte aus, "weil unserer Kunst- und Geschmackslehre eine viel zu große Revolution bevorsteht, als $\mathrm{da} ß$ man bei der üblichen Art, sie vorzutragen, und den gewöhnlichen Lehrbüchern beruhen könnte, die neuern Untersuchungen aber noch nicht so aufs Reine gebracht sind, $\mathrm{da} ß$ man junge Leute auf Gymnasien schon mit den Resultaten bekannt machen könnte « (Bd. 1, S. 301). Zu seinem im März 1801 dem Oberschulkollegium überreichten Plan »einer Grundverfassung des Thornschen Gymnasii «, aus dem das Zitat stammt, vgl. KarlErnst Jeismann: Das preußische Gymnasium in Staat und Gesellschaft. Die Entstehung des Gymnasiums als Schule des Staates und der Gebildeten, 1787-1817 (Industrielle Welt 15) Stuttgart (1974), S. 200-01. "An die Stelle der Regelübermittlung trat das sexemplum maiorum<, an Stelle der Abstraktion setzte er die Anschauung und das Nacherleben des Kunstwerks. «(S. 200) 
23 Zusammengestellt in der Zeitschrift für das Gymnasialwesen 2 (1848), S. 856-63.

24 (Franz Winiewski:) Systematisches Verzeichniß der in den Programmen der Preußischen Gymnasien und Progymnasien, welche in den Jahren 1825-1841 erschienen sind, enthaltenen Abhandlungen, Reden und Gedichte. Münster: Regensberg 1844; Gustav Hahn: Systematisch geordnetes Verzeichniß der Abhandlungen, Reden und Gedichte, die in den an den Preußischen Gymnasien und Progymnasien 1842-1850 erschienenen Programmen enthalten sind. Salzwedel: Schmidt in Comm. 1854; Joseph Gutenäcker: Verzeichniß aller Programme und Gelegenheitsschriften, welche an den K. Bayer. Lyzeen, Gymnasien und lateinischen Schulen vom Schuljahre 1823/24 bis zum Schlusse des Schuljahres 1859/60 erschienen sind. Bamberg: Buchner in Comm. 1862; Jakob Köhler: Die Programmbeilagen der badischen höheren Lehranstalten usw. Beil. zum Programm Rastatt 1888.

25 Die Verengung der Rhetorik zur Stilistik wird außerhalb der Schule nachgewiesen von Marie-Luise Linn: Studien zur deutschen Rhetorik und Stilistik im 19. Jahrhundert (Marburger Beiträge zur Germanistik 4) Marburg 1963. Den Zusammenhang von Rhetorik und Aufsatzlehre bei Hermann Bukowski: Der Schulaufsat7 und die rhetorische Sprachschulung. Rhetorische Methoden und Aufgaben in der Institutio orateria Quintilians und die Theorie des deutschen Schulaufsatzes. Phil. Diss. Kiel 1956 [masch].

26 Adolph Matthias: Geschichte des deutschen Unterrichts (Handbuch des deutschen Unterrichts an höheren Schulen. Bd. 1, Tl. 1) München 1907, S. 392.

27 Eva D[orothea] Becker: >Klassiker in der deutschen Literaturgeschichtsschreibung zwischen 1780 und 1860. In: Zur Literatur der Restaurationsepoche, S. 349-70. B. weist nach, $\mathrm{da} ß$ »die Literatur-Lehrbücher und Literaturgeschichten der Zeit von 1780 bis zum Ende der 1820 er Jahre nach den 30er Jahren - etwa 1835 - nicht mehr neuaufgelegt worden « sind (S. 358). Den gleichen Schnitt zeigen die Schulprogramme.

28 Zit. bei Philipp Wegener: Zur Geschichte des deutschen Unterrichts. Beil. zum Jahresbericht des Gymnasiums und der Realschule zu Greifswald 1906, S. 20/21.

29 Matthias: Geschichte des deutschen Unterrichts, S. 392.

30 Friedrich Jacobs (1764-1847), Schulmann, Altphilologe und Dichter; Johann Kaspar Friedrich Manso (1760-1826), Schulmann, Historiker, Übersetzer und Dichter. - Zu den Historikern Johannes von Müller und Friedrich von Raumer sowie zu Schillers Rede »Was heißt und zu welchem Ende studiert man Universalgeschichte« vgl. Kap. 3.1.a.

\section{Anmerkungen zu 2.2. Bayern}

$1 \mathrm{H}$ [einrich] $B$ [raun]: Entwurf der Einrichtung des churfürstlich akademischen Gymnasiums zu Ingolstadt. München: Crätz 1777. Abdruck in: Pragmatische Geschichte der Schulreformation in Baiern aus ächten Quellen. [Frankfurt M.]: o. Vlg. 1783, S. 154-95. Zu Leben und Werk vgl. die Würdigung von (Joseph Burgholzer): Heinrich Brauns Thatenleben und Schriften. Ein Beytrag zur baier'schen Schul- und Gelehrtengeschichte. Von einem dankbaren Zögling seines Zeitalters. München: Hübschmann 1793; Martinus Gückel: Heinrich Braun und die Bayerischen Schulen von 1770-1781. Phil. Diss. Erlangen. München 1891; Ludwig Wolfram: Heinrich Braun. Ein Beitrag zur Geschichte der Aufklärungsepoche in Bayern (Histor. Abhandlungen aus dem Münchener Seminar 3) München, Bamberg, Leipzig 1892 (detaillierte Darstellung des Wirkens für deutsche Sprache und Bildung). - Als Verf. der »Pragmatischen Geschichte « macht Georg Lurz (Wer schrieb die »Pragmatische Geschichte der Schulreformation in Baiern aus ächten Quellen «? In: Mitteilungen der Gesellschaft für deutsche Erziehungs- und Schulgeschichte 14, 1904, S. 306-17) Gerhoh Steigenberger, einen Anhänger der Aufklärer Ickstatt und Lori aus dem Orden der regulierten Chorherren in Polling, namhaft.

2 [Lorenz Westenrieder:] Erinnerungen über Ursachen des geringen Nutzens, den man in Schulen aus der Lecture der alten classischen Autoren erhält. Landsberg: Selbstvlg. 1774, S. 8/9. Neudruck: L. v. W.: Sämmtliche Werke. Bd. 15. Kempten: Kösel 1833, S. 181-215. Zitat hier stilistisch verbessert S. 186/87. 
3 Ebd. S. 27, 11 (recte 25). Beispiel der Lektüre der »Aeneis« S. 20-25. - Vgl. Fassung 1833, S. 202: „Wer einen Künstler oder Dichter beurtheilen will, muß ihn nach der wahren Empfindung und dem stillen Ausdrucke derselben beurtheilen. Beides hervorzufinden, und für den Schüler sinnlich zu machen, darin besteht die Pflicht des Lehrers:

4 Pragmatische Geschichte der Schulreformation in Baiern, S. 172. Gemeint ist ein "sokratisches Gespräch « »nach Sulzers Methode« (ebd.); zu dieser Schrift s. Bibliographie Bd. 2, Kap. 1.2.

5 Ebd. S. 170/71. Batteux/Ramler s. Bibliographie Bd. 2, Kap. 1.3.2.

6 Ebd. S. 173.

7 Ebd. S. 172/73.

8 Ebd. S. 174.

9 Ebd. S. 175. Vgl. dazu das Rhetoriklehrbuch von Braun, Bibliographie Bd. 2, Kap. 1.3.2.

10 Ebd. S. 176.

11 Ebd. S. 175. Hier wird Dubos (S. 176) genannt, von dem der Emotionalismus dieser Literaturdidaktik sich herleiten dürfte, vgl. Kap. 1.2.3c - Die schriftlichen Úbungen zur Dichtkunst gehen wiederum den induktiven Weg: „Der Lehrer legt z. B. dem Schüler 1) schlechte Gedichte vor, und läßt ihn die Fehler, und die Ursachen, warum sie Fehler sind, anzeigen. 2) Er legt ihm auch gute Gedichte vor, und läßt ihn sagen, was davon schöne sey, und warum es schöne sey. Das Schöne hat nun seine Grade «, deshalb legt man dem Schüler mehrere schöne Stücke vor und läßt ihn 3) »die Grade aus einander setzen, und niederschreiben « (S. 177). - Vgl. Brauns Poetik (Bibliographie Bd. 2, Kap. 1.3.2), vor allem jedoch seine achtbändige "Sammlung von guten Mustern in der deutschen Sprach- Dichtund Redekunst. Zur Beförderung des guten Geschmackes in Oberdeutschland (ebd. Kap. 1.3.3).

12 Jugendfrüchte von der zweyten Grammatik des churfürstlichen Schulhauses zu München. Bd. 1 [mehr nicht erschienen]. München: Crätz 1779. 94 S. (Bayer. SB München.) Es sind "Früchte « (S. 3) der neuen Schulpläne von 1774 und 1775, z. T. mit Verfassernamen der Schüler. Zur österreichischen Anthologie gleichen Titels s. Wolfgang Martens: Drei Sammlungen von Schülerdichtungen aus dem Wiener Theresianum. In: Die österreichische Literatur. Ihr Profil an der Wende vom 18. zum 19. Jahrhundert (1750-1830). Hg. v. Herbert Zeman. 1. Tl. Graz 1979, S. 1-22, sowie in vorliegender Arbeit Kap. 2.3.4/1a.

13 Mittelschulgeschichtliche Dokumente Altbayerns, einschließlich Regensburgs. Hg. v. Georg Lurz. Bd. 2: Seit der Neuorganisation des Schulwesens in der 2. Hälfte des 16. Jahrhunderts bis zur Säkularisation (Monumenta Germaniae Paedagogica 42) Berlin 1908. Schulordnung vom 30. Aug. 1782, S. 270-83; Lehr-Plan für alle kurpfalzbayerischen Mittel-Schulen, oder für die sogenannten Real-Klassen (Principien), Gymnasien, und Lyceen. 1804, S. 522-56. - Für die Lehrplanentwicklung im Deutschen und den klassischen Sprachen vgl. Johannes Griessbach: Die geschichtliche Entwicklung des altklassischen und deutschen Unterrichts an den Gymnasien im Königreich Bayern. Pr. Gymnasium Hof 1892 u. 1893 u. Max Hergt: Beiträge zur Geschichte des deutschen Unterrichts an den humanistischen Gymnasien des Königreichs Bayern. 2 Tle. Pr. Theresien-Gymnasium München 1900 u. 1901, Wiss. Beil. Einen Uberblick gibt Adolf Matthias: Geschichte des deutschen Unterrichts (Handbuch des deutschen Unterrichts an höheren Schulen Bd. 1, Tl. 1) München 1907, S. 243-45.

14 Lehrplan 1804. Ebd. S. 541.

15 Schulordnung 1782. Ebd. S. 275. Fortsetzung des Zitates: »[...], sondern um eine gute Kritik über die in die schönen Künsten und Wissenschaften einschlagenden Gegenstände zu erlernen «.

16 Ebd. S. 274. Als Lehrbuch wird Lindners »Kurzer Inbegriff der Ästhetik, Redekunst und Dichtkunst « (Königsberg u. Leipzig 1771/72, s. Bibliographie Bd. 2, Kap. 1.3.2) anempfohlen und besprochen. "Dieses Buch hat eigentlich das, was ein Vorlesbuch haben soll, es ist kurz, vollständig, hält Ordnung, und trägt zur litterarischen Kenntniss sehr viel bey« (S. 275).

17 Ebd. S. 277. 
18 Gesetze und Vorschriften zur äußern, intellektuälen und sittlichen Bildung der Studierenden in churbaierischen Lyzeen, § 16. In: Churbaierisches Regierungs-Blatt 1803, Sp. 279/ 80. Hier Sp. 280.

19 Mittelschulgeschichtliche Dokumente Altbayerns. Bd. 2, S. 534-35, Sperrungen aufgehoben. Zur Biographie Wismayers und den von ihm zuletzt verlorenen Schulkämpfen (gegen Schelling, Voß, Niethammer) s. Friedrich Schul: Joseph Wismayer, ein Freisinger Gelehrter. In: Achtes Sammelblatt des Historischen Vereins Freising (1906-1910). Freising 1910, S. 27-46. - Bei Pölitz »Analisis stylisierter Aufgaben « (recte: Versuch in der Analyse stylistischer Aufgaben) und "Vorlesungen über Fragmente aus deutschen Schriftstellern « (recte: Vorlesungen über Fragmente aus teutschen Autoren, als Versuche in der Interpretation) handelt es sich um sein Lehrbuch: Versuch eines Systems des teutschen Styls, Tl. 1 u. 2, Görlitz 1800 (s. Bibliographie Bd. 2, Kap. 1.3.2). Adelung/Heinsius (1. Aufl. 1800), Eschenburg (1. Aufl. 1783), Loreye (1. Aufl. 1802); s. gleichfalls Bibliographie Bd. 2, Kap. 1.3.2. Von Sulzer gab Kirchmayer in München 1786 eine Bearbeitung der rhetorischen Artikel für die Schule heraus (ebd.). - Einen Deutschlehrplan für Tertia bis Prima im Hinblick auf die Wismayr'sche Schulordnung entwirft folgender Artikel: Wie sollten die gelehrten Schulen auf den academischen Unterricht vorbereiten? In: Reichs-Anzeiger 1804, Nr. 60, Sp. 785-89. Bei insgesamt 3 Wochenstunden soll je eine der »statarische[n] und cursorische[n] Lectüre der deutschen Classiker « (Sp. 788) nach Pölitz gewidmet werden; vgl. dessen »Praktisches Handbuch zur statarischen und cursorischen Lektüre der teutschen Classiker «, 5 Bde, 1804-17 (Bibliographie Bd. 2, Kap. 1.3.2). Die Schulordnung von 1804 wird begeistert begrüßt: Mit ihr führe der Kurfürst von Bayern »den Morgen der Aufklärung am Horizonte seiner Nation herauf « (Sp. 785).

20 Ebd. S. 580-81, Sperrungen aufgehoben. Dazu Hans-Georg Herrlitz: Der Lektüre-Kanon des Deutschunterrichts im Gymnasium. Heidelberg 1964, S. 91-98.

21 Pr. Real-Studien-Anstalt Nürnberg 1809, S. 3. Úbergang von den mittleren Klassen »zum Militär-, zum Forst- und Bauwesen und zum Schullehrerstande «, nach dem abschließenden >Absolutorium ‘ zum Universitätsstudium, »besonders zur Kameralistik und zur Medizin «. Georg Wilhelm Hopf: Entwicklung des Realschulwesens in Nürnberg. Fürth: Schmid 1854, S. 28. Zum Deutschunterricht S. 24-26.

22 Pr. Real-Studien-Anstalt Nürnberg 1810, S. 20, 21. Zur Rolle des Deutschunterrichts im Bildungsprogramm der Anstalt vgl. Gotthilf Heinrich von Schubert: Der Erwerb aus einem vergangenen und die Erwartungen von einem zukünftigen Leben. Eine Selbstbiographie. 2. Bd., 2. Abt. Erlangen: Palm u. Enke 1855, S. 298, 311 (»Ersatz«»für die grammatischen Studien und die Befreundung mit den Werken der Sprachen des klassischen Alterthums «). 1809 leitete den Unterricht Schubert selbst; für die öffentliche Prüfung ließ er "ganz lange Parthieen « aus mittelalterlichen Epen auswendig lernen, »wie etwa Wolfram von Eschenbach's Parcival und Titurel, wie Chriemhilden's Rache, wie mehrere epische Gedichte in der Sammlung des Heldenbuches « (S. 326; mit der Rüge des Rationalisten Heinr. Eberhard Gottlob Paulus, damals Vorsteher des Kirchen- und Schulwesens in Nürnberg: »längst vergessene Kindereien einer Zeit «, »darin nur ein mönchisches Dunkel sein Wesen trieb «, S. 327). Sch. hat auch die Programme verfaßt, aus denen zitiert wird (S. 492/93). Das Fach Deutsch übernahm Simon Erhardt (über ihn S. 434/35). Als Lehrer der Archäologie, d. i. der Geschichte und Mythologie, war Johann Arnold Kanne tätig. Die in Nürnberg aufgewiesenen romantischen Tendenzen haben Parallelen in München um 1820: Hier wird die Geschichte der dramatischen Literatur nach A. W. Schlegel gelehrt $(1818,1820,1821)$, Symbolik und Mythologie nach Creuzer (1821) sowie die Geschichte des deutschen Epos vorgetragen und das Nibelungenlied behandelt (1819). Hergt: Geschichte des deutschen Unterrichts. Tl. 1, S. 27-35.

23 Hergt: Geschichte des deutschen Unterrichts. Tl. 1, Tabelle. Adelung/Heinsius s. Bibliographie Bd. 2, Kap. 1.3.2.

24 Ebd.

25 Eschenburg: Entwurf einer Theorie und Literatur der schönen Wissenschaften, s. Biblio- 
graphie Bd. 2, Kap. 1.3.2. Kurze Darstellung bei Hergt: Geschichte des deutschen Unterrichts. Tl. 1, S. 59/60.

26 Die reiche versepische Kultur des Zeitraums hat Friedrich Sengle (Biedermeierzeit. Bd. 2. Stuttgart 1972) erschlossen. Doch fehlt weiterhin eine Monographie des Gegenstandes.

27 Exemplarisch zusammengestellt aus Schulprogrammen und nach Hergt: Geschichte des deutschen Unterrichts.

28 Vgl. Sengle: Biedermeierzeit. Bd. 2, S. 649-53 über die Diskussion zu Pyrker, S. 662-67 über die Epen des Dichters. Redwitz wurde zwei Jahre nach der »Amaranth « Prof. für deutsche Literatur in Wien. Eine Darstellung der Entstehungs- und Wirkungsgeschichte des Werkes gibt Bernhard Lips: Oskar von Redwitz als Dichter der »Amaranth «. Phil. Diss. Münster 1908.

29 Die Angaben sind aus den Programmen der genannten Jahre gezogen. - Zu Eichstätt und Münnerstadt stellt sich Hadamar in Hessen, ebenfalls eine katholische Traditionsanstalt. Joseph Kehrein, ein bekannter Lehrbuchautor und Wörterbuchschreiber, hat Pyrkers kleine biblische Epen (aus den »Perlen der heiligen Vorzeit «) und Redwitz' »Amaranth « neben Klopstocks »Messias « um 1850 mit seinen Schülern durchgesprochen.

30 Exemplarisch zusammengestellt aus Schulprogrammen und nach Hergt: Geschichte des deutschen Unterrichts.

31 Hergt: Geschichte des deutschen Unterrichts. Tl. 1, S. 28. Wo keine Nachweise gegeben werden, sind die Angaben aus den Schulprogrammen übernommen. Zu Eschenburg s. Bibliographie Bd. 2, Kap. 1.3.2.

32 Ebd. S. 23. In diesem Sinne heißt es etwa in Straubing (3. Gymnasialklasse) von der Rhetorik 1837: »Alles in Beziehung auf die griechischen und lateinischen Klassiker und mit häufiger Vorlesung und Erklärung von deutschen Mustern «.

33 Friedrich Thiersch's Leben. Hg. v. Heinrich W. J. Thiersch. Bd. 1. Leipzig u. Heidelberg 1866, S. 300: »der Schulplan war ebenso Schellings wie Thiersch's Werk «. Über die Zusammensetzung und Majoritätsbildung in der Schulkommission vgl. den Brief an Jacobs vom 28. 2. 1829, S. 350. Zur Vorgeschichte s. Hans Loewe: Die Entwicklung des Schulkampfs in Bayern bis zum vollständigen Sieg des Neuhumanismus (Monumenta Germaniae Paedagogica, Beih. 2) Berlin 1917.

34 In den württembergischen Lateinschulen hatte die Lehrerschaft »das Prinzip des reinen Klassizismus « festgehalten und die Reformen der Regierung (vor allem unter Karl Eugen, 1737-93, und Wilhelm I., 1816-64) vereitelt, welche »die dem philologischen Unterricht bestimmten Stunden zugleich für die Mitteilung von Realkenntnissen « bestimmte. Otto Duerr: Die Einführung des Neuhumanismus in Württemberg. Stuttgart 1930, S. 190 u. 56 (Zitat aus der Zuschrift des Ministeriums an die Studienbehörde vom 2. 6. 1820). Die Wandlung der Schulpolitik kam den Anstalten, die Thiersch in Bayern "einheimisch" machen wollte, zugute (Thiersch: Ueber gelehrte Schulen, mit besonderer Rücksicht auf Bayern. [Bd. 1]-3. Stuttgart u. Tübingen: Cotta 1826-30. Hier Bd. 1, S. 233); »die württ. Schulpläne werden häufig von auswärtigen Behörden verlangt, um bei den neuen Schuleinrichtungen zum Muster zu dienen « (Gutachten des Lehrerkollegiums des Stuttgarter Gymnasiums vom 3. 9. 1819; Duerr, S. 189).

35 Thiersch war selbst ein Schüler Pfortas, dazu s. Thiersch s Leben. Bd. 1, S. 6-15 u. Hans Loewe: Friedrich Thiersch. Ein Humanistenleben im Rahmen der Geistesgeschichte seiner Zeit. Die Zeit des Reifens. München u. Berlin 1925, S. 20-30. König Ludwig I. soll auf Einwendungen gegen den Lehrplan von 1829 erklärt haben: »Nun ich will, daß meine Schulen werden sollen wie die in Sachsen und Würt[t]emberg « (Thiersch's Leben. Bd. 1, S. 351). - Das Zitat über Eton aus den Reiseeindrücken im Brief an Lange vom 21. 10. 1815 (ebd. Bd. 1, S. 130/31); Thierschs Urteil schränkt später Jacobs in seinem Schreiben vom 29. 6. 1831 ein (ebd. Bd. 2, S. 39).

36 Thiersch: Ueber gelehrte Schulen. Bd. 1, Abt. 3, S. 233. Ebd. S. 234: »Ein zwölfjähriger Knabe, der nicht seine kleine lateinische Grammatik genau und vollständig kennt, der in seinen Uebersetzungen in das Latein noch syntaktische Fehler macht, dem der Cornelius Nepos in den leichten Biographien oder der Inhalt einer nicht unbeträchtlichen prosaischen 
und poetischen Chrestomathie nicht geläufig ist, ist unreif für das Gymnasium «, d. h. den Ubertritt von den niederen Klassen der 'Lateinschule in die höheren des 'Gymnasiums`.

37 Ebd. Bd. 3, S. 17. Prägnante Formulierungen des Konzentrationsprinzips auch bei Sebastian Freudensprung: Historische und pädagogische Bemerkungen über Gymnasialunterricht mit besonderer Rücksicht auf Bayern. In: Jahres-Bericht des kgl. neuen Gymnasiums und des kgl. Erziehungs-Institutes für Studierende in München 1827/28, S. 3-28, etwa S. 19: Die lateinische Sprache »soll der Mittelpunct sein, um den sich der gesamte Gymnasialunterricht bewegt «. »Ihr muß alles untergeordnet werden, sie muß der Anfang und das Ende des Ganzen seyn. «

38 Ordnung der lateinischen Schulen und der Gymnasien in dem Königreiche Bayern. München: Central-Schulbücher-Vlg. 1830. Dazu Fritz Bihrle: Der Kampf um Friedrich Thierschs Lehrplan vom 8. Febr. 1829. Phil. Diss. München 1920 [masch.].

39 Revidirte Ordnung der lateinischen Schulen und der Gymnasien im Königreiche Bayern. München: Central-Schulbücher-Vlg. 1854. Christian Wurm (Die revidirte Studienordnung in Bayern und die deutsche Bildung. In: C. W.: Die deutsche Sprache an der gelehrten Schule mit besonderer Rücksicht auf die revidirte Studienordnung in Bayern. Freiburg i. Br.: Herder 1856, S. 1-75) beklagt »das exorbitante Gewicht «, das die Studienordnung »der lateinischen und griechischen Stylistik, dem formellen und technischen Theile des classischen Alterthums « (S. 45) beilegt. Ähnlich äußern sich Vertreter der österreichischen Unterrichtsreform nach 1848 (Ueber die revidirte Ordnung der lateinischen Schulen und der Gymnasien im Königreiche Bayern. Besonders abgedruckt aus der Zeitschrift für die österr. Gymnasien. 1854, Heft V. Wien: Gerold 1854, S. 35), die den einzelnen Fächern ihr Recht lassen und in ihrem Zusammenwirken eine allseitige Bildung nach Herbarts Grundsätzen erstreben: "Lateinisch und Griechisch die ausschliessliche Aufgabe", Geschichte und Mathematik »Minimum «, Naturgeschichte »nichts«.

40 Thiersch: Ueber gelehrte Schulen. Bd. 1, Abt. 4, S. 340, 341.

41 Ebd. S. 349.

42 Ebd. Bd. 3, S. 20. Ähnlich Bd. 1, Abt. 4, S. 350.

43 Ebd. Bd. 1, Abt. 4, S. 351.

44 Ebd. S. 362 u. Bd. 3, S. 50, Deutsche Aufsätze werden auch über Gegenstände des Gymnasialunterrichts, jedoch nicht über allgemeine oder freie Themen geschrieben und dienen der Exemplifizierung rhetorischer Lehren. In der obersten Klasse können philosophische Werke der Antike dazu herangezogen werden.

45 Ebd. Bd. 1, Abt. 4, S. 355. Die Privatlektüre soll durch eine Anthologie mit einer kurzen Ubersicht der Geschichte der deutschen Literatur und durch Schulbibliotheken gefördert und geleitet werden. Ebd. S. 352 u. Bd. 3, S. 50.

46 Ebd. Bd. 3, S. 50.

47 Ebd. Bd. 1, Abt. 4, S. 356 u. 358. "Mit dem Studium der alten Literatur ist das der deutschen auf das Genaueste zu verknüpfen. «(Bd. 3, S. 50)

48 Der »altepische Gesang der Deutschen « eignet sich für die Schule, »weil er wegen des Alterthümlichen der Sprache die gelehrte Sorgfalt des Unterrichts nöthig hat " (Bd. 1, Abt. 4, S. 355). Diese Ansicht unterstreicht Johann Andreas Schmeller (Ueber das Studium der deutschen Sprache auf Schulen. In: Thiersch: Ueber gelehrte Schulen. Bd. 1, S. 486-92). Nur die Behandlung der alten Sprach- und Literaturdenkmäler habe auf Gymnasien Platz, da ihr Studium »ein grammatisch exegetisches" (S. 488) sei. Im übrigen geschehe für das Deutsche fast alles »durch das Leben und die Lektüre « sowie auf der Schule »durch den beständigen Parallelismus oder Gegensatz der Muttersprache mit den classischen « (S. 487). - Von der deutschen Lyrik paßt »kein Werk « außer den Oden Klopstocks auf die Schule, wobei sich Thiersch auf die eigene Lehrpraxis beruft: „Die Behandlung war wie eines lateinischen oder griechischen Werks« (Bd. 1, Abt. 4, S. 356). Schwierige Stellen Klopstocks zu erklären u. Varianten beizubringen, war ein Hobby der Philologen; vgl. die Miszellen in der »Kritische[n] Bibliothek für das Schul- und Unterrichtswesen «, 2. Jg. 1820, Bd. 1, S. 241; 3. Jg. 1821, Bd. 1, S. 249; Bd. 2, S. 837-38, 1076-77 zum »Messias«, Gesang III, Vers 563-66. Hinweise bei Erhard Hirsch: Klopstock 
und die Pädagogen des XVIII. und XIX. Jahrhunderts. In: Friedrich Gottlieb Klopstock. Werk und Wirkung. Hg. v. Hans-Georg Werner. Berlin (Ost) 1978, S. 125-42. Für den Schulgebrauch erschienen erläuterte Odenausgaben von Vetterlein (3 Bde, 1827-28 u. 1833) und Gruber (2 Bde, 1831), s. Gerhard Burkhardt u. Heinz Nicolai: KlopstockBibliographie (Klopstock. Histor.-Krit. Ausg. Addenda I) Berlin, New York 1975, Nr. 69-70.

49 Ebd. Bd. 3, S. 392. Unsere Literatur ist »zu jung «, "zu frei, um sich einer bestimmten Norm zu bequemen ", und in Grammatik, Rhythmus und Numerus "nur zu oft ungleich " (S. 392/93). Diese "allgemeine stylistische Unvollkommenheit « habe »das geschmackloseste Bunterlei des Styls« (S. 393) zur Folge.

50 Ebd. S. 397. Das Münchner "Inland « (Ueber falsche Ansichten von der höhern Schulbildung. 1829, S. 83-84, 89-90, 100-01) übernimmt die Argumentation der Klassizisten, »welche entschieden uns eine National-Literatur wünschen, eine solche jedoch, im Sinne der Griechen, noch nicht bey uns finden ", und erklärt sich darum »für den classischen Unterricht « (S. 83). - Als metrischer Ratgeber Platens und Pyrkers hat Thiersch selbst an der formalen Vervollkommnung der deutschen Dichtersprache mitgewirkt.

51 Ordnung 1830, S. 9.

52 Ebd. S. 27.

53 Ebd. S. 27. Vgl. Thiersch: Ueber gelehrte Schulen. Bd. 1, Abt. 4, S. 364-65; Bd. 3, S. 50, 52.

54 Revidirte Ordnung 1854, S. 19.

55 Wurm: Revidirte Studienordnung, S. 46. Eine Abfuhr erhält der bayrische Rhetorik- und Poetikbetrieb durch die österreichischen Reformer: »Unbefangene, hingebende, eindringende Lectüre hat die Grundlage zu bilden«, aus welcher sich "Sinn und Tact « für poetische Fragen entwickeln; » Reflexion, oder wenn man es so nennen will Theorie, darf sich nur an die bestimmten Gegenstände der Lectüre anschliessen « (Ueber die revidirte Ordnung, S. 22). In der Aufsatzschulung richtet sich die »Forderung innerer Wahrheit und Natürlichkeit «, mit der der Schüler sich auszudrücken habe, gegen jede vorgefertigte "Schablone « (S. 21). - Nach den Bestimmungen des angegriffenen Lehrplans soll der deutsche Sprachunterricht an Gymnasien »an der Hand eines passenden theoretischen Leitfadens « erfolgen und »Gewandtheit in den verschiedenen Stylgattungen « erzielen (Revidirte Ordnung 1854, S. 19). In den beiden letzten Klassen werden sich "größere schriftliche Aufsätze an die Theorie der Dicht- und Redekunst und die zur Erläuterung hierüber gewählten deutschen Autoren « (S. 20) anschließen.

\section{Anmerkungen zu 2.3. Osterreich}

1 Einen zusammenfassenden Úberblick gibt Herbert Seidler: Die österreichische Literatur als Problem der Forschung. In: Ósterreich in Geschichte und Literatur 14 (1970), S. 354-68. Hinweise auf das Schulwesen bei Roger Bauer: Die Welt als Reich Gottes. Grundlagen und Wandlungen einer österreichischen Lebensform (Wien 1974). Hier besonders S. 69-71.

2 S[alomon] Frankfurter: Graf Leo Thun-Hohenstein, Franz Exner und Hermann Bonitz. Wien 1893, S. 106. Ausführliche Darstellung u. Dokumentation bei Richard Meister: Entwicklung und Reformen des österreichischen Studienwesens (Österr. Akademie der Wissenschaften. Philosoph.-histor. Kl. Sitzungsberichte, Bd. 239, Abh. 1) 2 Tle. Wien 1963.

3 Dazu Karl Wotke: Die im Jahre 1777 gemachten Vorschläge zur Heranbildung von Gymnasiallehrern. In: Beiträge zur Österr. Erziehungs- und Schulgeschichte. H. 6. Wien u. Leipzig 1905, S. 241-44. - Drsl.: Beiträge zur Gymnasiallehrerfrage in Österreich in den Jahren 1796-1800. In: Ebd. H. 12. 1910.

4 [Adolf] Ficker: Oesterreich. In: Encyklopädie des gesammten Erziehungs- und Unterrichtswesens. Hg. v. K. A. Schmid. Bd. 5. Gotha 1866, S. 242-566. Hier S. 391.

5 Ebd. Die folgende Angabe nach S. 392. 
6 Frankfurter: Thun-Hohenstein, Exner und Bonitz. Úber Bonitz' Werdegang S. 92-98, über seine Wiener Lehrtätigkeit S. $116 \mathrm{ff}$. Er fand, wie ihm sein Lehrer Hartenstein am 9. Aug. 1848 prophezeite, »in philologicis einen ganz rohen Acker « vor (zit. S. 99). Vgl. Anm. 42. Úber die Berufungspolitik siehe Hans Lentze: Die Universitätsreform des Ministers Graf Leo Thun-Hohenstein (Österr. Akademie der Wissenschaften. Philosoph.-histor. Kl. Sitzungsberichte, Bd. 239, Abh. 2) Wien 1962, S. $32 / 33$ über die Widerstände gegen den Protestanten Bonitz.

7 Heribert Timp: Die Problematik »Klassenlehrer oder Fachlehrer « in den Gymnasialreformen von 1792 bis 1849 (Annex zum Jahrbuch 1968 der Österr. Pädagogischen Gesellschaft) Wien 1968, mit einer Quellenpublikation aller wichtigen Akten.

8 [Michael Arneth:] Bemerkungen über die Mängel der österreichischen Gymnasial-Einrichtung und Vorschläge zur Verbesserung derselben 1838. Hg. v. Josef Cales. Arneth. Linz 1849 , S. 5.

9 C[arl] Kirchner: Die Landesschule Pforta in ihrer geschichtlichen Entwicklung seit dem Anfange des XIX. Jahrhunderts bis auf die Gegenwart. Einladungsschrift zur dritten Säcularfeier ihrer Stiftung. Naumburg (1843), S. 104.

10 Albert Hübl: Geschichte des Unterrichtes im Stifte Schotten in Wien. Wien 1907, S. 122. Ein »Vergleich des prozentualen Anteiles der einzelnen Unterrichtsgegenstände « in den Lehrplänen von Marx, Lang und nach der Reform 1818 bei Timp: "Klassenlehrer oder Fachlehrer «, S. 79.

11 Kirchner: Landesschule Pforta, S. 105.

12 Ordnung der lateinischen Schulen und der Gymnasien in dem Königreiche Bayern. München 1830.

13 Dazu Julius Lattmann: Geschichte der Methodik des lateinischen Elementarunterrichts seit der Reformation. Göttingen 1896. Auf L. stützt sich Andreas Fritsch: Sprache und Inhalt lateinischer Lehrbuchtexte. In: Abhandlungen aus der Pädagogischen Hochschule Berlin. Bi. 3. Redaktion Reinhard Dithrnar u. Jörg Willer. Berlin (1976), S. 116-69.

14 [Ignaz Mathes von Heß:] Entwurf zur Einrichtung der Gymnasien, in k.k. Erblanden. Wien: J. Kurzböck 1775, S. 14. Es handelt sich um eine knappere Fassung des Gymnasialplanes der >Gedanken (s. Anm. 15) ohne Anmerkungen. Der Text (ÖNB Wien: 47.K.54) ist nicht »verschollen " (Timp: "Klassenlehrer oder Fachlehrer«, S. 15 Anm. 1) und auch abgedruckt bei [Franz Anton Pitzenberger:] Freundschaftliche Briefe an den Herrn von S-t über den Entwurf zur Einrichtung der Gymnasien in den K.K. Erblanden. o. O. u. o. Vlg. 1776, S. 131-208.

15 Ignaz Mathes von $H e \beta$ : Gedanken über die Einrichtung des Schulwesens. Halle 1778, S. 145 ff. u. 153 ff., S. 66.

16 Karl Schrauf: Des P. Gratian Marx ursprünglicher Entwurf für die Reform der österreichischen Gymnasien vom 7. Juli 1775. In: Mitteilungen der Gesellschaft für deutsche Erziehungs- und Schulgeschichte 6 (1896), S. 122-50. Hier S. 137. Die Gymnasien hatten sich so auf Latein konzentriert, daß es ihnen schwerfiel, die von Marx geforderten Realien mitzuunterrichten. So erstreckte sich die Grazer Maturitätsprüfung, die zu Beginn des Schuljahres 1776/77 erstmals vorgenommen wurde, »blos auf die Erprobung der Kenntniß der lateinischen Sprache. Dies wurde zwar anfänglich in Wien nicht gutgeheißen, sda die lateinische Sprache nur ein Werkzeug und keine Grundlage zu den Wissenschaften ist «", schließlich aber doch der Umstände halber für 1777 und 1778 gestattet. Richard Peinlich: Geschichte des Gymnasiums in Graz, dritte Periode [1774-1849]. In: Festprogramm des k.k. ersten Staatsgymnasiums in Graz zur Jubelfeier seines dreihundertjährigen Bestandes. Hg. v. R. P. Graz 1874,S. 1-165. Hier S. 34.

17 Handbuch aller unter der Regierung des Kaisers Joseph des II. für die K. K. Erbländer ergangenen Verordnungen und Gesetze in einer sistematischen [!] Verbindung. Bd. 1. Wien 1875, S. 447.

18 Karl Wotke: Die von der Studien-Revisions-Hofkommission (1797-1799) vorgeschlagene Reform der österreichischen Gymnasien (Beiträge zur Österr. Erziehungs- und Schulgeschichte, H. 17) Wien u. Leipzig 1915, S. 12. Sitzung v. 27. Dez. 1797. 
19 Ebd. S. 117. Sitzung v. 16. u. 24. Okt. 1798.

20 Handbuch, Bd. 1, S. 450.

21 Peinlich: Geschichte des Gymnasiums in Graz, dritte Periode, S. 85. „Die Doctordissertationen und die öffentlichen Disputationen sollten ebenfalls in Zukunft deutsch und nur noch in der nächsten Zeit nach freier Wahl lateinisch gehalten werden « (ebd.). Der Erzbischof von Wien klagte (16. April 1790) »gegen die Einführung der deutschen Unterrichtssprache in den philosophischen Studien und gegen die dadurch geförderte Bekanntschaft der Schüler mit den Schriften deutscher Akatholiken «. Ficker: Oesterreich, S. 377.

$22 \mathrm{Hübl:}$ Geschichte des Unterrichtes im Stifte Schotten, S. 121.

$23 \mathrm{He \beta}$ : Gedanken über die Einrichtung des Schulwesens, S. 157. Die Seitenzahlen im Text beziehen sich auf diese Ausgabe.

24 Antonius Frider[icus] Büsching: Liber Latinus in Usum Puerorum Latinam Linguam Discentium Editus. Editio Secunda. Berlin u. Stralsund 1769, S. V. Aufbau des Werkes: 1) »Entwurf der Naturhistorie«, 2) »Lehre von dem Daseyn Gottes « und der »Regierung der Welt « mit Pflichtenlehre und Diätetik, 3) »Ackerbau « und »Oeconomie«. Heß (Gedanken, S. 69 Anm. e) bezieht sich beim folgenden Zitat auf dieses Lehrbuch: "Schier so, wie in Büschings \Liber latinus« «.

$25 \mathrm{He} \beta$ : Entwurf zur Einrichtung der Gymnasien, S. 36. Pitzenberger (Freundschaftliche Briefe, S. 60) bekräftigt den Grundsatz, »mit den Wörtern zugleich Sachen « zu geben. Man solle »den Realinnhalt der physischen [!] alten Schriftsteller eines Plinius, Celsus u.s.w. mit der beyläufigen Sprachübung (S. 73) verknüpfen.

26 Schrauf: Marx ursprünglicher Entwurf, S. 133.

27 Karl Wotke: Das Oesterreichische Gymnasium im Zeitalter Maria Theresias (Monumenta Germaniae Paedagogica, Bd. XXX) Bd. 1. Berlin 1905. Nothwendige Erinnerung an die Lehrer in Gymnasiis der Kaiserl. Königl. Staaten 1778, S. 336-42. Hier S. 341, 342. Über Chomprés SSelecta Latini Sermonis Exemplariar (Wien 1777/78) mit Inhaltsangabe S. 574-82.

28 Wotke: Studien-Revisions-Hofkommission, S. 11. Sitzung v. 27. Dez. 1797. Der Lateinlehrplan, der von Lang für die Kommission ausgearbeitet wurde, sah die »kursorische Lesung " von "Eutropius und Mela" im dritten Gymnasialjahr vor. C[hristian] U[lrich] $\mathrm{D}$ [etlev] von Eggers: Nachrichten von der beabsichtigten Verbesserung des öffentlichen Unterrichtswesens in den österreichischen Staaten. Tübingen 1808, S. 138.

29 Nach der Studienordnung Kaiser Karls VI. vom 16. Nov. 1735 soll die griechische Sprache »nebst [d. h. neben] der Lateinischen, eodem servato docendi ordine, per classes, die Woche zweymal wenigstens durch eine halbe Stunde tradiret « werden (Wotke: Das Oesterreichische Gymnasium, S. 6). Maria Theresia (Reformatio Studiorum, hier nach dem Einzeldruck Wien 1753, S. 7) befahl an, daß das Griechische »in Zukunft nicht mehr in denen untern Schulen [d. h. Gymnasien] abgetheilter [d. h. in besonderen Fachklassen] gelehrnet, sondern von dern ohnehin angestelten [!] Professore Linguae Hebraicae von nun an vollständig tractiret « werde.

30 Hess: Gedanken über die Einrichtung des Schulwesens, S. 75.

31 Hess: Entwurf zur Einrichtung der Gymnasien, S. 62.

32 Hess: Gedanken über die Einrichtung des Schulwesens, S. 72-75. Die Stelle stammt aus Sulzers 'Gedanken über die beste Art, die Klassiker mit der Jugend zu lesen< (Berlin 1765).

33 Erinnerung über einen wichtigen Gegenstand von einem Böhmen. Prag 1773. Vom Griechischen, S. 136-41. Hier S. 140.

34 Schrauf: Marx ursprünglicher Entwurf, S. 140.

35 Handbuch, Bd. 1, S. 444. Die zweite Abteilung ist "nur für fähigere und Lust bezeigende Jünglinge bestimmt « (ebd.). Die griechischen Sonderklassen wollte schon Maria Theresia aufheben, s. Anm. 29.

36 Peinlich: Geschichte des Gymnasiums in Graz, dritte Periode, S. 85.

37 Karl Wotke: Gymnasiallehrplan der Wiener Gymnasiallehrerversammlung vom Jahre 
1792. In: Beiträge zur Ósterr. Erziehungs- und Schulgeschichte. H. 15. Wien u. Leipzig 1914, S. 189-259. Hier S. 220, 227, 228, 252.

38 Albert Hübl: Das Gymnasium bei St. Anna in Wien (1775-1807). Wien 1909, S. 26 Anm. 1 mit Nachweisen für 1799 und 1801.

39 Ficker: Oesterreich, S. 399 Anm. 4. Am Wiener Schottengymnasium waren vielfach »über 50 Prozent « der Schüler befreit; Hübl: Geschichte des Unterrichtes im Stifte Schotten, S. 145.

40 Arneth: Bemerkungen, S. 7. Als Autorität nennt A. am häufigsten Thiersch. Vgl. dessen Klage, die griechische Literatur sei »eine provincia deserta in hiesigen Landen «. »In den niedern Schulen bis zur Philosophie [d.h. Universität] wird das Lateinische nach Chrestomathien getrieben, von dem Griechischen so gut wie nichts, und die Methode hat sich über ein geistloses Anfüllen des Gedächtnisses noch nicht erhoben «. Brief an Lange, Wien v. 20. Sept. 1814; Friedrich Thiersch's Leben. Hg. v. Heinrich W. J. Thiersch. Bd. 1. Leipzig u. Heidelberg 1866, S. 119, 120.

41 Beiträge zur Geschichte des österreichischen Unterrichtswesens. In: Deutsche Vierteljahrs Schrift 1855, H. 3, S. 63-108. Hier S. 104. Verf. (lt. Auskunft des Schiller-Nationalmuseums, Cotta-Archiv): Dr. Frederichs. Vgl. Hamerling, der bei Bonitz im philologischen Seminar studierte: „Der Unterricht, den ich auf dem Schotten Gymnasium im Griechischen erhalten, war so gut wie keiner, ich kam als Autodidakt ins Seminar «. Brief v. 8. Nov. 1866 an Bonitz; Abdruck bei Frankfurter: Thun-Hohenstein, Exner und Bonitz, S. 130-31. Hier S. 130.

42 Schrauf: Marx ursprünglicher Entwurf, S. 147.

43 Wotke: Gymnasiallehrplan, S. 220.

$44 \mathrm{Vgl}$. Sammlung der Verordnungen und Vorschriften über die Verfassung und Einrichtung der Gymnasien. 5. Aufl. Wien 1847, S. 33: „Die Lehrer sollen sich an die vorgeschriebenen Lehrbücher genau halten «. Sie müssen »die Abweichungen und Zusätze«, sofern sie »von Wichtigkeit « sind. »durch den Präfect an die Behörde» einsenden (Hofdekrete v. 4. Okt. 1790 u. 12. März 1806).

45 Rainer Klassen: Logik und Rhetorik der frühen deutschen Aufklärung. Phil. Diss. München 1974. Eine vergleichbare Studie über den Zusammenhang der rhetorischen Entwicklung mit der Affektenlehre fehlt.

46 Institutiones ad Eloquentiam. Pars Prior. Wien 1779, S. 443.

47 Versuch einer Studienreform der oesterreichischen Piaristenprovinz aus dem Jahre 1763. Von dem Provinzial Niceforus Deltl a. S. Stephano (Wotke: Das Oesterreichische Gymnasium, S. 72-86). Neben den lateinischen Werken werden gelegentlich deutsche besprochen. »Multum etiam proderit ad proprium poetarum stilum adcuratius dignoscendum, selecta poetarum germanicorum carmina nonnunquam praelegere « (S. 83). Mit den lateinischen schriftlichen Úbungen (Periodenbau, Ausschmückung durch Figuren, oratorische Amplifikationen und Beschreibungen, Chrien, Reden) wechseln deutsche ab. Als Lehrbücher werden Gottsched und Breitinger für die Dichtkunst und Gottsched für die Redekunst empfohlen.

48 Abdruck bei Peiniich: Geschichte des Gymnasiums in Graz, dritte Periode, S. 40-44. Hier S. 43.

49 Handbuch, Bd. 1, S. 432 ff. In der Grammatikalklasse: „Elaboratio dialogorum germanicorum \& latinorum «; in der Syntaxklasse: »Elaboratio epistolarum germ. \& lat. «; in der Rhetorik: »Orationis latinae \& tandem Germanicae elaboratio publica in scholastico «; im ersten Semester der Poesie: "Elaborationes oratoriae lingua vernacula \& latina alternatim«, »Animadversiones de Poesi germanica « [des Lehrbuchs >Institutiones ad Eloquentiam. Pars Posteriors]; im zweiten Semester: "Elaborationes alternae latinae \& germanicae«, »Elaborationes germanicae tantum « (S. 474-78). Die Ausarbeitungen folgen jeweils auf die Theorie.

50 Sammlung der Verordnungen und Vorschriften über die Verfassung und Einrichtung der Gymnasien. Wien 1808, S. 94, 94, 95, 99/100.

51 [Provisorische Anordnungen für das Schuljahr 1849], 6 Seiten ohne Titelei. »Die Theorie 
der Redekünste in den Humanitätsklassen ist in deutscher Sprache vorzutragen, in ihren Umfang aber nicht nur die deutsche, sondern auch die classische Literatur aufzunehmen « (S. 3). Die >Institutio ad Eloquentiamı kommt »außer Gebrauch « (S. 3).

52 Wotke: Gymnasiallehrplan. Die Versammlung bestand aus 11, mit Eintritt der Piaristen aus 17 Lehrern. Der Plan wurde von H. v. Brink, dem Präfekten von St. Anna, erarbeitet und von $\mathrm{H}$. Lessacher redigiert.

53 Institutiones ad Eloquentiam. Pars Posterior. Wien 1778, S. 571. Der Text ist aus dem vorhergehenden Lehrbuch übernommen und nur stilistisch neu gefaßt: Oratoriae ac Poeticae Institutionis Pars Prior. Freiburg i. Br. 1774, S. 269. Zum Verhältnis beider Werke vgl. S. 87.

54 Institutio ad Eloquentiam. Wien 1833, S. 51.

55 Sammlung der Verordnungen 1808, S. 96-97. Gute Angaben über »die Art zu interpretiren« (S. 137) finden sich bei Franz Innocenz Lang. Vgl. Eggers: Nachrichten, S. 135-39 über den »lateinischen Sprachunterricht « und S. 143-44 über »allgemeine Theorie des Stils im fünften und sechsten Gymnasialjahre «.

56 Sammlung der Verordnungen 1808, S. 92-93.

57 Beiträge zur Geschichte des österreichischen Unterrichtswesens, S. 103.

58 Entwurf der Grundzüge des öffentlichen Unterrichtswesens in Oesterreich [Wien, Sommer 1848], S. 9. Dazu: Entwurf der Organisation der Gymnasien und Realschulen in Oesterreich. Wien 1849. Geschichte der deutschen National-Literatur und der Entwicklung der Sprache, S. 140-45. In Ansätzen hatte sich bereits die Literaturgeschichte aus der traditionellen `Litterärgeschichte ‘ der Wissenschaften und Künste entwickelt; vgl. Kurt Adel: Die Anfänge der österreichischen Literaturgeschichtsschreibung. In: Österreich in Geschichte und Literatur 13 (1969), S. 352-64.

59 Entwurf der Organisation, S. 141. „Für die älteste Zeit nämlich ist die den Schülern zu gebende Literaturgeschichte überwiegend Geschichte der Sprachentwickelung«. (S. 142). Seit 1851 wird Karl Weinholds »Mittelhochdeutsches Lesebuch " (Wien 1850), das nach »Aufforderung des Ministeriums « entstanden war, "Norm für den mittelhochdeutschen Unterricht an österreichischen Gymnasien«. Bericht über österreichisches Unterrichtswesen. Aus Anlass der Weltausstellung 1873. Tl. 1. Geschichte, Organisation und Statistik des österreichischen Unterrichtswesens von Adolf Ficker. Wien 1873, S. 257.

60 Entwurf der Organisation, S. 143. Einen allerdings unkritischen Úberblick über die damaligen Literaturgeschichten gibt Gisela Knoop: Die Gesamtdarstellungen der deutschen Literatur bis zu Wilhelm Scherer. Phil. Diss. (masch.) Münster 1952.

61 Theodor Vernaleken: Litteraturbuch. Tl. 1-2. 3. gänzlich umgearb. Aufl. Wien 1854-55. Zitate Tl. 2, S. III; Tl. 1, S. IV.

62 Bauer: Die Welt als Reich Gottes, S. 61-63.

63 Herbert Seidler: August Wilhelm Schlegels Vorlesungen über dramatische Kunst und Literatur 1808. In: Jahrbuch des Wiener Goethe-Vereins 78 (1974), S. 54-75. Hier S. 74. Bauer (Die Welt als Reich Gottes. Der Widerhall der norddeutschen Geistesströmungen in Ósterreich, S. 86-117, besonders S. 100-01) schätzt die Wirkung der Romantiker sehr gering ein.

64 Zur Beurteilung Schillers, besonders bei Johann Schwaldopler (Ps. K. L. Schaller), vgl. Norbert Oellers: Schiller. Geschichte seiner Wirkung bis zu Goethes Tod 1805-1832 (Bonner Arbeiten zur deutschen Literatur 15) Bonn 1967. Bei der Wahl der Prämienbücher wurde von der politischen Landesbehörde Schillers »Wallenstein « als ungeeignet beanstandet (Ficker: Oesterreich, S. 386 Anm. 1). - Die Kontakte Goethes mit Österreich belegt August Sauer: Goethe und Österreich (Schriften der Goethe-Gesellschaft, Bd. 17-18) 2 Tle. Weimar 1902-04. Der »Werther" stand auf dem Index (Catalogus Librorum a Commissione Caes. Reg. Aulica Prohibitorum. Editio nova. Wien 1776, S. 173), ebenso mehrere Wertheriaden (ebd. S. 195; Supplement II, 1778, S. 14 u. 21; Supplement III, 1780, S. 11). Doch war das Werk »keineswegs von epochaler Bedeutung «, wenn es auch zu einer »Modesache " wurde (Das Wertherfieber in Oesterreich. Eine Sammlung von Neudrucken. Hg. v. Gustav Gugitz. Wien 1908, S. XXV/XXVI). Zur 
weltanschaulichen und politischen Opposition vgl. Konrad Kienesberger: Sebastian Brunners Stellung zu Lessing, Goethe und Schiller. In: Öffentl. Gymnasium der Benediktiner zu Kremsmünster. 108. Jahresbericht, Schuljahr 1965, S. 1-196. Zu den Schwierigkeiten, die »Iphigenie « ins Lesebuch aufzunehmen, s. S. 92 dieser Arbeit.

65 Joseph Stanislaus Zauper: Grundzüge zu einer deutschen theoretisch-praktischen Poetik aus Goethe's Werken entwickelt. Neue durchges. u. verm. Aufl. (Studien über Goethe, Bd. 1) Wien 1840, S. 3. »Die didaktische [Gattung], welche einige als Hauptform in Schutz nehmen, kann nur, wenn sie in der ersten Form [als Lyrik] erscheint, auf den Namen Poesie Anspruch machen « (S. 3/4). Franz Ficker (Aesthetik oder Lehre vom Schönen und von der Kunst in ihrem ganzen Umfange. 2. verm. u. verb. Aufl. Wien 1840, S. 425-26) deduziert vier Gattungen und schließt sich damit (wie Podlaha 1842) einem weitverbreiteten Kompromiß an. Dazu Georg Jäger: Das Gattungsproblem in der Ästhetik und Poetik von 1780 bis 1850. In: Zur Literatur der Restaurationsepoche 1815-1848. Hg. v. Jost Hermand u. Manfred Windfuhr. Stuttgart 1970, S. 371-404.

66 Institutiones ad Eloquentiam. Pars Prior. Wien 1779 (Erstauflage 1777), S. $471 \mathrm{ff}$. Von der »Rede auf Marien Theresien ", die Sonnenfels "an ihrem Geburtstage in einer feyerlichen Versammlung der deutschen Gesellschaft « am 13. Mai 1762 gehalten hat, wird zunächst eine »Zergliederung (S. 473-76) und dann der Text gegeben. Im zweiten Band der »Sammlung deutscher Beyspiele zur Bildung des Styls« erscheint das Werk als »Beyspiel einer Rede panegyrischen Inhalts «.

67 Sammlung deutscher Beyspiele zur Bildung des Styls. Bd. 1. Wien 1812. Von Schiller S. 258: "Seine Stärke war die Geschichte, wie der von ihm geschriebene sdreyßigjährige Krieg« beweiset «. Der Rhetorikunterricht hat Schiller stets auch als Historiker behandelt, vgl. Georg Jäger: Der Deutschunterricht auf Gymnasien 1780 bis 1850. In: DVjs 47 (1973), S. 120-47. Hier S. 128, 136-37.

$68 \mathrm{Vgl}$. Theorie der Beredsamkeit für alle Formen prosaischer Darstellung (Rhetorische Chrestomathie) (Bibliothek der Humanitäts-Wissenschaften zur Selbstbildurig für Jünglinge von reiferem Alter. Philosoph. Wissenschaften, Bd. 6) Wien 1825 mit folgenden Rubriken: Sprichwörter; Sentenzen, Aphorismen und Maximen; Briefe; Anekdoten; Charakteristiken; Beschreibungen und Gemälde; Erzählungen; Gespräche; Parallelen; oratorischer Styl; philosophischer und wissenschaftlicher Styl; historischer Styl.

69 Maßgebende deutsche Sammlungen: Heinrich August Erhard: Handbuch der teutschen Sprache etc. 2. Cursus. 2 Abtt. A. u. d. T.: Schauplatz teutscher Prosa in ausgewählten Stücken mustergiltiger [!] Schriftsteller neuerer Zeit. Erfurt 1822-23; Robert Heinrich Hiecke: Handbuch deutscher Prosa für obere Gymnasialclassen; enthaltend eine auf Erweiterung des Gedankenkreises und Bildung der Darstellung berechnete Sammlung auserlesener Prosastücke. Zeitz 1835; Wilhelm Wackernagel: Deutsches Lesebuch. Tl. 3: Proben der deutschen Prosa seit d. J. MD. 2 Bde. Basel 1841-43; Gustav Schwab: Die deutsche Prosa von Mosheim bis auf unsere Tage. Eine Mustersammlung mit Rücksicht auf höhere Lehranstalten. 2 Tle. Stuttgart 1843. Mit Ausnahme von Hiecke (der thematisch gliedert) sind alle genannten Werke chronologisch geordnet.

70 Wotke: Das Oesterreichische Gymnasium, S. XL.

71 V[incenz] Maiwald: Geschichte des öffentlichen Stiftsgymnasiums in Braunau. In: Beiträge zur Österr. Erziehungs- und Schulgeschichte. H. 13. Wien u. Leipzig 1912, S. 1-288. Hier S. 66-67.

72 »Auf die Hermannias«, Bd. 1, S. 178:

Drey Dinge sind nicht zu ertragen:

Ein Herz, das schwarze Sorgen plagen,

Von schwerem Blut' entstandne Träume,

Und Schönaichs Reime.

Úber die Kontrahenten und Argumente im Reimstreit unterrichtet Claus Schuppenhauer: Der Kampf um den Reim in der deutschen Literatur des 18. Jahrhunderts (Abhandlungen zur Kunst-, Musik- und Literaturwissenschaft 91) Bonn 1970. - Zu den »Jugendfrüchte[n] « s. Wolfgang Martens: Drei Sammlungen von Schülerdichtungen aus dem Wiener There- 
sianum. In: Die österreichische Literatur. Ihr Profil an der Wende vom 18. zum 19. Jahrhundert (1750-1830). Hg. v. Herbert Zeman. Tl. 1. Graz 1979, S. 1-22.

73 Dazu Carsten Schlingmann: Gellert. Eine literarhistorische Revision (Frankfurter Beiträge zur Germanistik 3) Bad Homburg v. d. H. u. a. 1967, Tl. 1 über die Wirkungsgeschichte. Vgl. Mertens: Kleinere Gedichte, S. 1: "Seine [Gellerts] Gedichte sind das Buch der Nation geworden, welches, nach dem Katechismus und den biblischen Sprüchen, zuerst den Kindern sollte in die Hände gegeben werden «.

74 Institutiones ad Eloquentiam. 2 Tle. Wien. 1. Tl. 1779, 2. Tl. 1778. - Für die oberste Grammatikalklasse geht voran: Institutionum Grammaticarum Latinae Linguae Pars Tertia. Wien, hier nach der Ausg. 1783. Das Lehrbuch beinhaltet den Briefstil und druckt je 6 Briefe von Gellert und Riedel (S. 491-503) als Muster ab.

75 Michael Denis: Sammlung kürzerer Gedichte, aus den neuern Dichtern Deutschlandes, zum Gebrauche der Jugend (Zweyte, Dritte Sammlung kürzerer Gedichte, meist aus Deutschlands Originaldichtern). 3 Bde. Augsburg: Joseph Wolff 1778. 72.76. Der Verleger hat dem Nachdruck des in Wien 1766 erschienenen Werkes (hier dem ersten Band) zwei weitere, nicht von Denis stammende Bände folgen lassen. P. v. Hofmann-Wellenhof (Michael Denis. Innsbruck 1881, S. 302/03 Anm.) erkennt nicht, daß mit dem in der Vorrede des zweiten Bandes angesprochenen "protestantischen Schulmann « Mertens gemeint ist. Úber sie Sammlung S. $302 \mathrm{ff}$.

76 Ignaz Weitenauer: Sammlung kürzerer Gedichte meistens aus neuern deutschen Dichtern; sammt einer Anleitung zu deutschen Versen. 2 Tle. Augsburg: Ignaz Wagner 1768. Gedruckt »mit Erlaubniß der Obern«. Die Vorrede (Tl. 1, S. a2 ${ }^{\mathrm{R}}$ ) weist auf »die wienerische Sammlung kürzerer Gedichte" als Vorbild: „Die gegenwärtige [Sammlung] folget ihr nach, und hat einerley Absichten mit ihr .

77 (Hieron. Andr. Mertens:) Auserlesene kleinere Gedichte aus den besten deutschen Dichtern zur Bildung jugendlicher Herzen und des Geschmackes. Augsburg: Eberhard Kletts sel. Wittwe 1772. Von der Denis'schen Sammlung grenzt sich der Verf. in der Vorrede ab. Úber M. informiert Karl Köberlin: Geschichte des Hum. Gymnasiums bei St. Anna in Augsburg von 1531 bis 1931. Augsburg 1931, S. 240-73.

78 Denis: Sammlung kürzerer Gedichte, Bd. 1, S.x3 ${ }^{\mathrm{R}}{ }^{\mathrm{V}}$ : Die Auswahl erfolgt »nur aus den Neuern; indessen bleiben doch die Aeltern, Opitz, Flemming, Dach, Kanitz, Besser, Pietsch, Amthor, Brockes, Triller, u. a. m. um die deutsche Dichtkunst unendlich verdient. Man wird sie bey reiferem Alter lesen, so wie auch die größern Gedichte der Neuern z. E. Klopstocks Messiade, Wielands Cyrus, Kleistens Frühling, die Gräber des von Kreuz, [J. E.] Schlegels und Gellerts theatralische Werke u.s.w.«. Bei Mertens (Kleinere Gedichte, S. 192 Anm.) wird Opitz »als der einzige Alte « aufgenommen: »Er hat wirklich bey den Deutschen die Bahn eines guten Geschmacks gebrochen; vor ihm war Dunkelheit in den Schriften, nach ihm Schwulst «.

79 Hier wurde folgende Ausgabe ausgewertet: Institutio ad Eloquentiam. Vindobonae 1833. Eine Charakteristik bei Enzinger: Stifters Studienjahre, S. 42-44, 228-29; Wolfgang Neuber: Zur Dichtungstheorie der österreichischen Restauration. Die »Institutio ad Eloquentiam «. In: Die österreichische Literatur (s. Anm. 72), Tl. 1, S. 23-53.

80 Sammlung deutscher Beyspiele zur Bildung des Styls. 2 Bde. Wien 1812.

81 Die Verehrung, die Wieland in Österreich erfuhr, belegt Friedrich Rosenthal: Wieland und Österreich. In: Jahrbuch der Grillparzer-Gesellschaft 24 (1913), S. 55-102.

82 Sammlung deutscher Beyspiele, Bd. 2, S. 236: "Salis hat mit der Deutschen Sprache gerungen, wie Winkelmann und Haller, und gleich ihnen dadurch an Kraftfülle des Ausdrucks gewonnen «.

83 Zit. n. Enzinger: Stifters Studienjahre, S. 42, 42/43.

84 Für die geschichtliche und nationale Inanspruchnahme der Ballade im 19. Jahrhundert vgl. Werner Welzig: Der Typus der deutschen Balladenanthologie (Ósterr. Akademie der Wissenschaften. Philosoph.-histor. Kl. Sitzungsberichte, Bd. 313) Wien 1977.

85 Einen Úberblick über die lyrische Formenwelt vor 1848, unter Hinweis auf die nach der Klassik und Romantik weiter oder erneut gepflegten älteren Arten gibt Friedrich Sengle: 
Biedermeierzeit. Bd. 2. Stuttgart 1972. Weiter Alfred Michail Söntgerath: Das Weiterleben des 18. Jahrhunderts in der Lyrik der Biedermeierzeit. Phil. Diss. (masch.) Tübingen 1953.

86 Wilhelm Podlaha: Muster deutscher Redekünste mit besonderer Rücksicht auf neuere Literatur zur Bildung des Geschmacks und des Stils. Wien 1842. Auszählungen nach dem Inhaltsverzeichnis, das kleinere Texte zuweilen zu Gruppen zusammenfaßt.

87 Constant von Wurzbach: Biographisches Lexikon des Kaiserthums Oesterreich. Tl. 23. Wien 1872, S. 2. Von den 13 unmittelbar nach 1848 den Lehrern empfohlenen Werken für die `Theorie der Redekünste`stammt nur Podlaha aus Österreich. Provisorische Anordnungen 1849, S. 3.

88 v. Hoffinger: Wilhelm Podlaha, ein deutscher Lehrer aus dem Böhmerlande. In: Oesterreichische Revue 1864, Bd. 3, S. 101-14. Hier S. 108.

89 Ebd. S. 107.

90 Joh[ann] Nep[omuk] Uschold: Lehrbuch der Poetik. Für Gymnasien bearbeitet. Tl. 2: Systematisch geordnete Mustersammlung aus dem gesammten Gebiete der deutschen Dichtkunst. München 1835. - C. G. F[riedrich] Brederlow: Die Dichtungsarten (Lesebuch zur Bildung des Geschmacks und zur Veredlung des Herzens. Hg. v. Joh. W. H. Ziegenbein. 4. völlig umgearb. Ausg. Bd. 1) Quedlinburg u. Leipzig 1839. - Die beiden aus dem Antiquariatshandel erworbenen Werke tragen den Besitzvermerk »K.k.akad. Gymn., Wien «.

91 August Adolf Ludw[ig] Follen: Bildersaal deutscher Dichtung. 2 Tle. Winterthur 1828-29.Gustav Schwab: Fünf Bücher deutscher Lieder und Gedichte. Von A. von Haller bis auf die neueste Zeit. Eine Mustersammlung mit Rücksicht auf den Gebrauch in Schulen. Leipzig 1835. - Hinweise auf die Entwicklung der Gedichtsammlungen für die Schule bei Roderich Wais: Lyrikanthologien für den Deutschunterricht an höheren Schulen im 19. Jahrhundert. In: Die deutsche Anthologie. Hg. v. Joachim Bark u. Dietger Pforte (Studien zur Philosophie u. Literatur des 19. Jh.s 2) Bd. 2. Frankfurt/M. (1969), S. 267-97.

92 Deutsche Mustersammlung für die lateinischen Schulen und Gymnasien im Königreiche Bayern. 2 Tle. München 1845-47.

$93 \mathrm{Zu}$ einigen Besonderheiten: Fröhlich ist bei Follen, einem emigrierten Burschenschaftler, so stark vertreten, weil das Werk für Schweizer Anstalten konzipiert wurde. Uschold, Professor am Gymnasium in Straubing, hat sein Lehrbuch dem bayerischen Minister und Dichter Eduard von Schenk gewidmet. Die offizielle bayerische Sammlung berücksichtigt naturgemäß die Gedichte des regierenden Königs (bei Uschold 3 Texte). - Da Epigramme mitgezählt werden, ergeben sich Unterschiede zu Tab. 18 u. 19.

94 Dazu Alfred Kelletat: Die frühe Rezeption Hölderlins in Schule und Lesebuch (1830-1850). In: Abhandlungen aus der Pädagogischen Hochschule Berlin. Bd. 3. Redaktion Reinhard Dithmar u. Jörg Willer. Berlin (1976), S. 87-115. K. läßt allerdings Follen, das früheste an der Romantik orientierte Lesebuch, außer acht.

95 Jäger: Deutschunterricht auf Gymnasien. Rhetorik und Liberalismus, S. 131-33.

96 v. Hoffinger: Podlaha, S. 106: „Die Berichte über große Parlamentsdebatten ging er mit seinen jungen Freunden eifrig durch, verglich sie mit andern neuen und classischen Mustern und gab so einen höchst anziehenden und praktischen Unterricht in der Redekunst «.

\section{Anmerkungen zu 3. Literarische Kultur}

1 Johann Heinrich Ludwig Meierotto: Abschnitte aus deutschen und verdeutschten Schriftstellern, zu einer Anleitung der Wohlredenheit, besonders im gemeinen Leben geordnet. Berlin: Preuss. Akad. Kunst- u. Buchhandlg. 1794. Úber seinen Rhetorikunterricht s. Friedrich Leopold Brun: Versuch einer Lebensbeschreibung J. H. L. Meierotto's. Berlin: Kgl. Preuß. akad. Kunst- u. Buchhandlg. 1802, S. 416-24. Seine Auswahl behandelt HansGeorg Herrlitz: Der Lektüre-Kanon des Deutschunterrichts im Gymnasium. Ein Beitrag zur Geschichte der muttersprachlichen Schulliteratur. Heidelberg 1964, S. 57-65. 
2 Ebd. S. XXVI, 670.

3 Ebd. S. XXVIII. "So sehr wir sonst über die Menge dieser Schriften [Schauspiele und Romane] klagen; so dürfte für unsre Absicht schwerlich genug, sicher nicht ein Buch der Art zu viel geschrieben seyn. " (S. XV) - Bei einem Vergleich der antiken und modernen Literatur preist Ernst Christian Trapp (Ueber das Studium der alten classischen Schriftsteller und ihre Sprachen, in pädagogischer Hinsicht. In: Allgemeine Revision des gesammten Schul- und Erziehungswesens. Hg. v. Johann Heinrich Campe. Tl. 7. 1787, S. 309-553) Romane und Schauspiele für Bildungszwecke an. Zum Studium des Menschen könne "nichts mehr « beitragen als die "Romane von Cervantes, Fielding, Richardson und andern Meistern « (S. 317). „Muß man sich nicht wundern, daß auf keiner einzigen Schule Grandison gelesen wird, der doch [...] dem Verstande und dem Herzen der Jugend sicherlich reineres und besseres Wasser giebt, als Homer, Virgil, Ovid, die auf allen Schulen gelesen werden « (S. 318)?

4 G[eorg] G[ustav] Fülleborn: Rhetorik. Ein Leitfaden beym Unterrichte in obern Klassen. 2. Aufl. Breslau: Graß, Barth u. Co. 1805. F. lehrte am Elisabetanum in Breslau. - In der »Beispielsammlung prosaischer Aufsätze«, die der Goetheaner Zauper seiner Redekunst beigibt, überwiegt ausnahmsweise sogar die klassische und romantische Prosa. Sie enthält Tieck, Goethe und Schiller (als Historiker) am häufigsten, dann Wackenroder, Novalis, Jean Paul, E. T. A. Hoffmann u. a. [Johann Stanislaus Zauper:] Praktische Anleitung zur Redekunst mit sorgfältig gewählten Beispielen für Schulen und zum Privatunterricht. Nebst einem Vorwort von C[arl] A[ugust] Böttiger. Dresden: Walther 1829.

5 Gustav Schwab: Die deutsche Prosa von Mosheim bis auf unsere Tage. Eine Mustersammlung mit Rücksicht auf höhere Lehr-Anstalten. Tl. 1. Stuttgart: Liesching 1843, S. 279. Nach Friedrich August Pischon (Handbuch der deutschen Prosa, in Beispielen von der frühesten bis zur jetzigen Zeit. $1 \mathrm{Tl}$., welcher die geschichtliche Prosa enthält. Berlin: Realschulbuchhandlg. 1818, S. XL) hat J. v. Müller damit »der Form und dem Stoffe nach " ein Werk geschaffen, von dem man sagt, »daß es kein vollendeteres in der neuern Litteratur giebt«.

$6 \mathrm{Zu}$ Heinse, Forster (»einer der Pfadfinder zum Verständnis der mittelalterlichen kirchlichen Baukunst «, Bd. 1, S. 210), A. W. Schlegel (das »Gemälde «-Gespräch als die »hervorragendste kunstliterarische Leistung " des älteren romantischen Kreises, S. 233), F. Schlegel und den in den Nachweisen genannten Kunsthistorikern s. Wilhelm Waetzoldt: Deutsche Kunsthistoriker. 2 Bde. Leipzig 1921-24. Für Heinse vgl. Arnold Winkler (Hg.): J. J. W. Heinse. Briefe aus der Düsseldorfer Gemäldegallerie 1776-1777. Mit einer Skizze der deutschen Geniezeit, des Lebens und der Werke Heinses und einer Entwicklungsübersicht der ästhetischen Grundbegriffe im 18. Jahrhundert (Textausgaben u. Untersuchungen zur Geschichte der Ästhetik 1) Leipzig u. Wien 1912; Manfred Dick: Der junge Heinse in seiner Zeit. Zum Verhältnis von Aufklärung und Religion im 18. Jh. München (1980), Kap. IX: Die Düsseldorfer Gemäldebriefe. Das Gemälde »Johannes in der Wüste «, heute in der Münchner Alten Pinakothek, wird Daniele da Volterra zugeschrieben. Abbildung bei Forster: Werke. Hg. v. der Deutschen Akademie der Wissenschaften zu Berlin. Bd. 9. Berlin 1958, nach S. 72. Úber Art und Wirkung der Forsterschen Kunstbeschreibungen handelt hier Gerhard Steiner S. 366-70.

7 Dazu Georg Jäger: Empfindsamkeit und Roman. Wortgeschichte, Theorie und Kritik im 18. und frühen 19. Jahrhundert (Studien zur Poetik u. Geschichte der Literatur 11) Stuttgart u. a. (1969), besonders S. 59-64; Günter Erning: Das Lesen und die Lesewut. Beiträge zu Fragen der Lesergeschichte; dargestellt am Beispiel der schwäbischen Provinz. Bad Heilbrunn/Obb. 1974, der die Motive der Lesesuchtkritik aber einseitig aus einer Gefährdung der vom 'ganzen Haus` repräsentierten Ordnung ableitet; Helmut Kreuzer: Gefährliche Lesesucht? Bemerkungen zu politischer Lektürekritik im ausgehenden 18. Jahıhundert. In: Leser und Lesen im 18. Jahrhundert. Colloquium der Arbeitsstelle Achtzehntes Jahrhundert Gesamthochschule Wuppertal, Schloß Lüntenbeck 24.-26. Oktober 1975 (Beiträge zur Geschichte der Literatur u. Kunst des 18. Jh.s 1) Heidelberg 1977, S. 62-75. - Die Romankritik wird in der Schule in Aufsätzen rekapituliert, vgl. Kap. 2.1.1. 
Spätere Beispiele: Georg Reinbeck: Sendschreiben an die geehrten Lehrer der Muttersprache in deutschen Gelehrtenschulen. Nebst sechs Beilagen etc. Stuttgart: Löflund u. Sohn 1832. 6. Beilage »Themate zu Aufsätzen «, S. 246: "Welches sind die Nachtheile und Vortheile des Romanenlesens, und welche von beiden sind überwiegend?«; Julius Rupp: Mustersammlung der Beredsamkeit und Aufgabensammlung für die oberen Klassen der Gymnasien und höheren Bürgerschulen. Abt. 1. Königsberg: Bon 1842, S. 280: »Ist die Schädlichkeit der Romanenlektüre ein Vorurtheil? «

8 Robert Heinrich Hiecke: Der deutsche Unterricht auf deutschen Gymnasien. Ein pädagogischer Versuch. Leipzig: Eisenach 1842, S. 69. „Durch Anleitung und Gewöhnung an ein verständiges und überlegtes Lesen guter und passender Bücher muß das Lesen schlechter verleidet und zur moralisch-geistigen Unmöglichkeit gemacht werden. «Úber die Polemik gegen die Belletristik auf Schulen orientiert: Der Deutschunterricht auf dem Gymnasium der Goethezeit. Eine Anthologie. Mit einer Einführung in den Problemkreis von Georg Jäger (Texte zum literarischen Leben um 1800, Bd. 2) Hildesheim 1977. Nachdruck von Carl August Böttiger: Ueber den Misbrauch [!] der Deutschen Lectüre auf Schulen und einigen Mitteln dagegen, 1787, und Nachwort S. 17-19. - Die Leihbibliothekslektüre von Schülern versuchte vor allem Preußen zu beschränken. Vgl. u. a. Circular-Rescript des Ministeriums des Innern und der Polizei [. . ], die polizeiliche Beaufsichtigung der Leihbibliotheken betreffend, vom 9. Aug. 1824; Circular-Rescript des Ministeriums der Geistlichen, Unterrichts- und Medizinal-Angelegenheiten [...], die Beaufsichtigung der Leihbibliotheken in Beziehung auf Gymnasien und Schulen betreffend, vom 16. Aug. 1824; Circulare des Consistoriums an sämmtliche Herren Direktoren und Rektoren der gelehrten Schulen der Provinz Brandenburg, die Theilnahme der Scholaren an Leih- und LeseBibliotheken betreffend, vom 26. Aug. 1824 (die Schüler erhalten Bücher aus Leihbibliotheken »nur gegen einen Erlaubnißschein ihrer Väter oder des Vorstehers des Gymnasii «, worin »die Titel der zu entleihenden Bücher jedesmal namhaft gemacht werden «). Verschärft durch Circular-Rescript des Ministeriums des Innern und der Polizei [...], die Ausschließung der Schüler der Gymnasien von der Theilnahme an Leihbibliotheken betreffend, vom 8. April 1825 (»ein unbedingtes allgemeines Verbot « der »Verabfolgung von Büchern an Gymnasiasten «). Annalen der Preußischen innern Staats-Verwaltung. Hg. v. Karl Albert von Kamptz. Bd. 8. Jg. 1824. H. 3, S. 872-75; H. 4, S. 1088-90 (Zitat S. 1090; ebenso Consistorium zu Cölln, 14. Sept. 1824, S. 1091-93); Bd. 9. Jg. 1825. H. 2, S. 393-94 (Zitat S. 394). Vgl. Georg Jäger: Die deutsche Leihbibliothek im 19. Jahrhundert. Verbreitung-Organisation-Verfall. In: IASL 2 (1977), S. 96-133; Alberto Martino: Die deutsche Leihbibliothek und ihr Publikum. In: Literatur in der sozialen Bewegung. Aufsätze und Forschungsberichte zum 19. Jahrhundert. Hg. v. A. M. Tübingen (1977), S. 1-26; Wolfgang von Ungern-Sternberg: Leihbibliothek und Zensur im 18. und 19. Jahrhundert. In: Die Leihbibliothek als Institution des literarischen Lebens im 18. und 19. Jahrhundert. Hg. v. Georg Jäger u. Jörg Schönert (Wolfenbütteler Schriften zur Geschichte des Buchwesens 3) Hamburg 1980, S. 255-310 (mit einem Problemaufriß und einer weiterführenden Bibliographie der Herausgeber).

9 [Friedrich Gottfried Wilhelm] Hertel: Ansichten über den Unterricht in der deutschen Sprache und den Vortrag der deutschen Literaturgeschichte auf Gymnasien. Pr. Gymnasium Zwickau 1834, S. 1-30. Hier S. 16. Vgl. Johann Heinrich Deinhardt: Der Gymnasialunterricht nach den wissenschaftlichen Anforderungen der jetzigen Zeit. Hamburg: Perthes 1837, S. 142: "Diese elenden Romanlesereien, die so furchtbar unter manchen Schülern eingerissen sind und alles gesunde kräftige Geistesleben niederdrücken und die Seele mit allerhand krankhaften und entnervenden Vorstellungen anfüllen und sie zu jeder angestrengten Thätigkeit unfähig machen, sie entspringen oft mit daher, daß der gewaltige Trieb des Jünglings nach Lectüre nicht auf eine vernünftige Art befriedigt worden ist. « In welchen Quantitäten das Lesefutter verschlungen wurde, zeigt der Heidelberger Historiker Schlosser (geboren 1776 in Jever, Ostfriesland). Als er nach Sekunda kam, wurde bei ihm »das Lesen eine Wuth«. Er durchlief »in Zeit von drei Jahren über viertausend Bücher «, die er sich aus einer Leihbibliothek seines Heimatortes besorgte. Georg Weber: Friedrich 
Christoph Schlosser der Historiker. Erinnerungsblätter aus seinem Leben und Wirken. Eine Festschrift [...]. Leipzig: Engelmann 1876. Schlossers Selbstbiographie (1826), S. 1-50; hier S. 11. Uber Schlossers Leseverhalten vgl. Karl-Heinz Haar: Die Bibliothek des Heidelberger Historikers Friedrich Christoph Schlosser (1776-1861). Entstehung, Inhalt und Geschichte einer Gelehrtenbibliothek. In: Bibliothek und Wissenschaft 8 (1972), S. 1-92. Gervinus machte eine ähnliche Phase "ausschweifendste[r] Lesewuth" durch, in der er die Bestände einer Leihbibliothek in Darmstadt verschlang. G[eorg] G[ottfried] Gervinus Leben. Von ihm selbst. 1860. Leipzig: Engelmann 1893, S. 38-39.

10 Heinrich August Erhard: Handbuch der teutschen Sprache etc. 2. Cursus. A. u. d. T.: Schauplatz teutscher Prosa etc. Abt. 1. Erfurt: Maring 1822. Vorrede, S. X.

11 Dazu Roderich Wais: Lyrikanthologien für den Deutschunterricht an höheren Schulen im 19. Jahrhundert. In: Die deutsche Anthologie. Hg. v. Joachim Bark u. Dietger Pforte (Studien zur Philosophie u. Literatur des 19. Jh.s 2) Bd. 2. Frankfurt/M. (1969), S. 267-97. Hier S. 277 Anm. 36 mit der Verteilung von Goethe und Schiller in acht Sammlungen. Von den ausgewerteten Anthologien bevorzugt zuerst Ph. Wackernagel (»Auswahl deutscher Gedichte«, 3. Aufl. 1838) Goethe vor Schiller (siehe jedoch meine Tabelle 18: Die Umwertung beginnt mit Follen, 1828/29, und Curtman, 1829; schon bei Eisenschmid, 1827-29, sind beide Autoren in gleichem, bei Reinbeck, 1824, in fast gleichem Umfang vertreten). Material zur Rezeption Goethes bei Wilhelm Schöppa: Goethes Eindringen in den deutschen Unterricht. In: Mitteilungen der Gesellschaft für deutsche Erziehungs- und Schulgeschichte. 20. Jg. 1910. 4. H., S. 271-85. Zwar hat sich »schon bis zur Mitte der zwanziger Jahre « »ein gewisser Goethekanon für die Schule « gebildet, doch scheint »ein Teil der Lesebuchschriftsteller Goethe noch nicht zu kennen « (S. 276/77). Zu Schiller s. Albert Ludwig: Schiller und die Schule. In: Mitteilungen der Gesellschaft für deutsche Erziehungs- und Schulgeschichte. 20. Jg. 1910. 2. H., S. 55-95 und Norbert Oellers: Schiller. Geschichte seiner Wirkung bis zu Goethes Tod, 1805-1832 (Bonner Arbeiten zur deutschen Literatur 15) Bonn 1967.

12 Alfred Kelletat: Die frühe Rezeption Hölderlins in Schule und Lesebuch (1830-1850). In: Abhandlungen aus der Pädagogischen Hochschule Berlin. Bd. III: Fachdidaktik und fächerübergreifender Unterricht. Red. Reinhard Dithmar u. Jörg Willer. Berlin (1976), S. 87-115. Hier S. 98. Die 3. Aufl. von 1838 analysiert Wais: Lyrikanthologien, S. 275-79. Wackernagel räumt jetzt der Klassik immerhin »etwa ein Zehntel seiner Sammlung « (27 Gedichte von Goethe, 10 von Schiller) ein (S. 277 mit Anm. 36).

13 Kelletat: Rezeption Hölderlins, S. 115. Es werden behandelt: Ph. Wackernagel, Auswahl deutscher Gedichte, 1832 (17 Texte); W. Wackernagel, Lesebuch, Tl. 2, 1836 (20); Schwab, Fünf Bücher, 1835 (12); Schwab, Deutsche Prosa, Tl. 2, 1843 (»Hyperion«); Heinrich Künzel, Drei Bücher deutscher Prosa in Sprach- und Stylproben von Ulphilas bis auf die Gegenwart, 1838 (»Hyperion «); Echtermeyer, Auswahl deutscher Gedichte, 1836 (1) und 1845 (17); Karl Goedeke, Elf Bücher deutscher Dichtung, Bd. 2, 1849 (18). Es fehlt die einen Wendepunkt in der Lesebuchentwicklung markierende Sammlung von Follen. Weiter können ergänzt werden: Uschold, Mustersammlung, 1835 (5 Texte); Mustersammlung (Bayern), Tl. 2, Abt. 1, 1847 (»Der Tod für's Vaterland«); Pischon, Denkmäler, Tl. 5, 1847 (6 Texte). Einen zusätzlichen Nachweis bei Peter-Martin Roeder (Zur Geschichte und Kritik des Lesebuchs der höheren Schule. Weinheim/Bergstr. 1961, S. 101) erwähnt schon Kelletat (Hermann Masius, Deutsches Lesebuch für höhere Unterrichtsanstalten, 1846, mit 4 Gedichten Hölderlins).

14 Franz Budde: Chrestomathie zur Geschichte der deutschen Sprache und Poesie für die obern Klassen der Gymnasien. Tl. 1. Münster: Theissing 1829. Vorrede, S. V-VI. In der Kleinschreibung folgt B. J. Grimm.

15 Georg Reinbeck: Handbuch der Sprachwissenschaft, mit besonderer Hinsicht auf die deutsche Sprache. Zum Gebrauche für die obern Klassen der Gymnasien und Lyceen verfaßt. Bd. 4. Essen: Bädeker 1828. Vorrede, S. V. Bei der Auswahl hat Verf. nicht so sehr »auf die Berühmtheit « der Autoren gesehen, »als auf die Zweckmäßigkeit[,] zum bestimmten Belege zu dienen« (ebd.). Über Reinbecks Haus als »Sammelpunkt des 
geistigen Lebens in Stuttgart«, den Erfolg seines Unterrichts und den Einfluß seiner Anthologien s. Anna Blos: Frauen in Schwaben. Fünfzehn Lebensbilder. Stuttgart 1929. Emilie Reinbeck-Hartmann, S. 110-13. Zur zeitgenössischen Gattungspoetik, die mit einer differenzierten, noch nicht auf drei Hauptgattungen reduzierten Systematik arbeitet, vgl. Georg Jäger: Das Gattungsproblem in der Ästhetik und Poetik von 1780 bis 1850. In: Zur Literatur der Restaurationsepoche 1815-1848. Hg. v. Jost Hermand u. Manfred Windfuhr. Stuttgart 1970, S. 371-404.

16 Heinrich Heine: Werke und Briefe (Hg. v. Hans Kaufmann) Bd. 4. Berlin u. Weimar 1961, S. 213, 216 (Rez. von Michael Beers »Struensee«).

17 Wilhelm Wackernagel: Deutsches Lesebuch. Tl. 2. A. u. d. T.: Proben der deutschen Poesie seit dem Jahre MD. Basel: Schweighauser 1836. Vorrede, S. YII.

18 Heinrich Bone: Deutsches Lesebuch für höhere Lehranstalten, zunächst für die unteren und mittleren Klassen der Gymnasien, mit Rücksicht auf schriftliche Arbeiten der Schüler. Köln: Dietz 1840. Einleitung, S. XXII. Uber den Unterricht Bones vgl. Carl Schurz: Lebenserinnerungen [Bd. 1]. Bis zum Jahre 1852. Berlin: Reimer 1906, S. 54-59. Schurz stand drei Jahre »unter der Leitung dieses ausgezeichneten Lehrers «, der ihn hochschätzte und sogar "zwei oder drei s seiner »eigenen kleinen Schulaufsätze in obiges Lesebuch aufnahm (S. 56).

$19 \mathrm{~K}$ [arl] E[duard] P[hilipp] Wackernagel: Auswahl deutscher Gedichte für höhere Schulen. 2., sehr verm. Ausg. Berlin: Duncker u. Humblot 1836. Vorrede zur zweiten Auflage, S. VI. Als Ordnungsprinzip dient »eine Klasseneintheilung der Gedichte nach ihrer äußeren Form « (ebd.), die mit dem geschichtlichen »Leben« des »Volkes « in Zusammenhang gebracht wird.

20 Bone: Lesebuch, S. XXII.

21 August Adolf Ludw[ig] Follen: Bildersaal deutscher Dichtung etc. Geordnete Stoffsammlung zum Behuf einer allgemeinen, poetischen und ästhetischen Schulbildung. Tl. 1. Winterthur: Steiner 1828. Vorrede, S. XI. Vgl. S. XI/XII (die Phantasie als »die Helferin und Vermittlerin alles Verstehens", ähnlich S. XIX) und S. XII (»das schöpferische Element «, wodurch der Mensch »ein Ebenbild des Schöpfers« wird).

22 Bone: Lesebuch, S. VI, mit gleicher Hervorhebung von "Phantasie" (begrifflose »Anschauung «) und »Gemüth «. B. stützt sich in seinem Dichtungsverständnis auf Worte von Goethe und Novalis (aus den Fragmenten); »am einflußreichsten für den Geist des Buches " seien »die Bibel, Goethe, Novalis und Claudius " gewesen (S. YXII). Von Novalis werden 11 Texte, darunter der Traum von der blauen Blume aus »Heinrich von Ofterdingen «, abgedruckt. Roeder (Geschichte und Kritik des Lesebuchs, S. 71-72) behandelt Bone als »das 'klassische Unterstufenlesebuch «, was aber allenfalls im Hinblick auf spätere Entwicklungen zutrifft. - Als Prototyp des »Gesinnungs-Lesebuchs «, bei dem es »in erster Linie nicht um Literatur, sondern um manipulative Gesinnungsbildung mit Hilfe von Literatur « (S. 194) gehe, wird von Hermann Helmers (Geschichte des deutschen Lescbuchs in Grundzügen. Stuttgart (1970), S. 194-98) Ph. Wackernagels »Deutsches Lesebuch " von 1843 (s. Bibliographie Bd. 2, Kap. 1.3.3) angesehen. Historisch kurzschlüssige Verbindungen mit dem Faschismus weist Kelletat (Rezeption Hölderlins, S. 99 Anm. 23) zurück. Über den Einfluß der Romantik auf das Lesebuch vgl. insgesamt Roeder, S. 82-90.

23 Schwab: Deutsche Prosa, Tl. 1. Vorwort, S. YII. Erning (Das Lesen und die Lesewut, S. 98) nennt das »Nationalbuch «, ein Schul- und zugleich Volksbuch, das Niethammer mit Goethe von 1808 bis 1811 plante, »eine Art säkularisierte Bibel von zeitloser Gültigkeit «. Dazu Gertrud Benker: Die Vermittlung von Volkslesestoff und Volksbildung in den bayerischen Lesebüchern vor 1900. In: Bayerisches Jahrbuch für Volkskunde 1970/71, S. 156-67. Hier S. 159-61.

$24 \mathrm{~K}$ [arl] E[duard] P[hilipp] Wackernagel: Auswahl deutscher Gedichte für höhere Schulen. Berlin: Duncker u. Humblot 1832. Vorrede, S. YIV. »Den Sinn für Schönheit kann nur die Schönheit bilden; wo diese nicht mächtig genug ist, wird sich auch jedes Reden über sie als unwirksam erweisen. (Ebd.) Ähnlich Follen, Bildersaal, TI. 1, S. Y YIY: Die Rhetorik als 
»ein Fabrikat des geschäftig nichtsthuenden Verstandes «, die nur »Gliederpuppen « erzeugt oder zur »Geschwätzigkeit " verleitet.

25 Ebd. S. XXX. Im Original »diese «.

26 (Andr[eas] Hieron[ymus] Mertens:) Auserlesene kleinere Gedichte aus den besten deutschen Dichtern zur Bildung jugendlicher Herzen und des Geschmackes. Augsburg: Eberhard Kletts Wittwe 1772, S. 192 Anm.; "vor ihm war Dunkelheit in den Schriften, nach ihm Schwulst«. Opitz wird »als der einzige Alte (ebd.) aufgenommen. Zu der Sammlung vgl. A. G. de Capua: Early Poetical Anthologies for Schools. A Contribution to the History of the Lyrical Anthology in Germany before 1770. In: Monatshefte für deutschen Unterricht, deutsche Sprache und Literatur 49 (1957), S. 337-52. Hier S. 351. Úber die Faktoren, welche die Beurteilung von Opitz bestimmen, s. Klaus Garber: Martin Opitz - »der Vater der deutschen Dichtung «. Eine kritische Studie zur Wissenschaftsgeschichte der Germanistik. Stuttgart 1976. Auf Fragen der empirischen Rezeption, wie in Anthologien, wird dabei kaum eingegangen.

27 Zur Frühgeschichte der Forschung s. Josef Körner: Nibelungenforschung der deutschen Romantik (Untersuchungen zur neueren Sprach- u. Literaturgeschichte. N. F. 9) Leipzig 1911. Für den Donauraum vgl. jetzt die gründliche Untersuchung von Fritz Peter Knapp: Die altdeutsche Dichtung als Gegenstand literarhistorischer Forschung in Österreich von den Brüdern Pez bis zu Friedrich Schlegels Wiener Vorlesungen im Jahre 1812. In: Die österreichische Literatur. Ihr Profil an der Wende vom 18. zum 19. Jahrhundert (1750-1830) (Die österreichische Literatur. Eine Dokumentation ihrer literarhistorischen Entwicklung, [Bd. 1]) Hg. v. Herbert Zeman. Tl. 2. Graz 1979, S. 697-734 (mit einer Fortsetzung bis ca. 1870 im folgenden Band). - Für die Rezeption in der Schule im Faktischen immer noch grundlegend: Otto Rudert: Die Entwicklung des mittelhochdeutschen Unterrichts. In: Zeitschrift für den deutschen Unterricht 29 (1915), S. 628-36, und Georg Schübel: Die Geschichte des mittelhochdeutschen Unterrichts. In: Zeitschrift für Deutschkunde 35 (1921), S. 319-37. Helmut Brackert, Hannelore Christ und Horst Holzschuh (Zur gesellschaftlichen Funktion mittelalterlicher Literatur in der Schule. Historischkritische Bestandsaufnahme. In: Mittelalterliche Texte im Unterricht. Hg. v. H. B., H. C. u. H. H. (Literatur in der Schule 1) München (1973), S. 11-69) reduzieren die sozialhistorische Fragestellung auf eine wenig differenzierte Ideologiekritik.

28 Hertel: Ansichten, S. 19. "Das rein Menschliche, was uns im Homerus entgegentritt und jedes Zeitalter, jede Nation ergreift und fesselt, das ist hier in unserm nationalen Epos nicht zu finden. « (Ebd.)

29 Christ. H. Hänle: Teutsches Handbuch für mittlere Classen der Gymnasien. 2. verb. Ausg. Frankfurt/M.: Andreä 1826. Úberschrift bei Abdruck eines Auszugs S. 247. Zit. nach der Besprechung in: Jahrbücher für Philologie und Pädagogik. Jg. 3. Bd. 3. 1828, S. 86-88. Hier S. 88.

30 K[arl] Dilthey: Zur Gymnasialreform. Pr. Gymnasium Darmstadt 1848, S. 15. Ähnlich schon Friedrich Schleiermacher: Erziehungslehre. Hg. v. C. Platz (Sämmtliche Werke. Abt. 3, Bd. 9; Literarischer Nachlaß, Bd. 7) Berlin 1849, S. 498: »die alte Literatur unseres Volkes« werde schwerlich »eine solche Allgemeingültigkeit « wie die römische und griechische erringen, "sondern immer mehr in das Gebiet des speziellen [!] fallen und mehr der eigentlichen Philologie vorbehalten bleiben «; August Spilleke: Ueber das Wesen der Bürgerschule. Pr. Friedrich-Wilhelms Gymnasium u. Realschule Berlin 1822, S. 57: das Nibelungenlied »keineswegs ein Nationalepos «, da ohne historischen Zusammenhang mit der Gegenwart, die in »Sitten, Ueberzeugungen, Gebräuchen « sowie in ihren kirchlichen und staatlichen Einrichtungen durch eine »Kluft « von der germanischen Zeit getrennt sei; C[aspar] Ch[ristoph] Gottlieb Wiß: Melanchthon oder Encyclopädie und Methodologie der Gymnasialstudien mit der nöthigsten Literatur. Lemgo: Meyer 1830, S. 29 Anm. 9: "Die Lesung altteutscher Werke und Gedichte, wie des Niebelungen-Liedes, steht in zu entferntem Zusammenhange mit der Bestimmung unserer Gymnasien, als daß man Zeit darauf verwenden könnte. "Ein Meinungsbild bei J. Müller: Bemerkungen über den teutschen Sprachunterricht auf Gymnasien im Allgemeinen und über die teutsche Sprache insbeson- 
dere. Pr. Gymnasium Glatz 1834, S. 11: Die Stimmen über altdeutschen Unterricht seien »noch sehr getheilt und den Lektionsverzeichnissen zufolge mehr dagegen, als dafür «.

31 Ebd.

32 Zum Zusammenhang von Rede und Republik Walter Jens: Von deutscher Rede. Reden und Aufsätze. München 1969. Titelaufsatz, S. 16-45. Vgl. die absolutistische Umkehrung des Topos, wonach die Rede den Staat nur in Zeiten der Demagogie und des Pöbels (Beispiel Griechenland) beherrsche. Programmatisch bei Johann Elias Schlegel: Rede, daß die vortheilhaftesten Umstände der Beredsamkeit, allemal mit einem verwirrten Zustande des gemeinen Wesens verknüpfet sind. In: [Johann Christoph Gottsched (Hg.):] Sammlung einiger Ausgesuchten Stücke, der Gesellschaft der freyen Künste zu Leipzig. Leipzig: Breitkopf 1754, S. 272-85. Außerhalb des Topos belegt die Politisierung der Rhetorik Hans-Wolf Jäger: Politische Kategorien in Poetik und Rhetorik der zweiten Hälfte des 18. Jahrhunderts (Texte Metzler 10) Stuttgart (1970).

33 Bibliothek Politischer Reden aus dem 18ten und 19ten Jahrhundert. 6 Bde. N. Ausg. Berlin: Voss 1845. Hier Bd. 1, Vorwort, S. VIII. Vgl. G. Friedr. Kolb (Das Staats-Lexikon. Encyklopädie der sämmtlichen Staatswissenschaften für alle Stände. Hg. v. Carl von Rotteck u. Carl Welcker. Bd. 11. Altona: Hammerich 1848. Artikel "parlamentarische Redekunst «, S. 378--89. Hier S. 381): Die Französische Revolution liefere »die frappantesten und gewaltigsten Beispiele von der unwiderstehbaren Macht, welche die Rede zu erlangen vermag «.

34 Knispel: Ueber die Nothwendigkeit, der oratorischen Ausbildung und besonders der des äußeren Vortrages eine erhöhete Fürsorge im Unterrichtswesen zu widmen. In: Allgemeine Schulzeitung. 21. Jg. 1844, Sp. 1361-72, 1377-81, 1385-89. Hier Sp. 1365/66. Ähnlich F[riedrich] W[ilhelm] Klumpp: Die gelehrten Schulen nach den Grundsätzen des wahren Humanismus und den Anforderungen der Zeit. Bd. 1. Stuttgart: Steinkopf 1829, S. 211; Joseph Kehrein: Sammlung deutscher Musterreden zum Gebrauche bei dem rhetorischen Unterrichte in Gymnasien und höhern Bildungsanstalten so wie zur Selbstbelehrung. H. 2. Mainz: Evler 1844. Vorwort, S. IV/V.

35 Verhandlungen der dritten Versammlung deutscher Philologen und Schulmänner in Gotha 1840. Gotha: Gläser 1841, S. 22-28. Hier S. 24. Zum Teil gleichlautend Friedrich Joachim Günther: Ueber den deutschen Unterricht auf Gymnasien. Essen: Bädeker 1841. „Die Redefertigkeit «, S. 207-74.

36 Hans Georg Nägeli, 1832. Zit. n. Friedrich Haupt: Mustersammlung der Beredsamkeit. Für die Schule und das Leben. Aarau: Sauerländer 1838. Vorwort, S. I X. »Der Volksrepräsentant sinkt ohne die Gabe der Beredsamkeit mehr oder weniger zur bedeutungslosen Nulle herab. « (S. VII)

37 Ebd. S. V. Vgl. W. A. Cormenin (Timon) [d. i. Louis Marie La Haye Vicomte de Cormenin ]: Das Buch der Redner. Leipzig: Weber 1843. An die Leser, S. III: »In einer Zeit, in welcher das Wort die Quelle aller Macht ist, in welcher der Staatsmann seine eigentliche Geltung erst auf der Tribüne erlangt, muß man, um einen Redner richtig zu beurtheilen, nicht allein sein politisches System, sondern auch die Vorzüge seiner Beredsamkeit zu würdigen verstehen."

38 Die deutsche Beredsamkeit und die Universitäten. In: (Augsburger) Allgemeine Zeitung 1847, Außerordentl. Beilage zu Nr. 363 vom 29. 12., S. 259-62. Hier S. 259. Der Verf. fordert Rednerschulen auf Universitäten. Ebenso: Wiener Zuschauer 1848, Nr. 58, 12. April, S. 462-63: Eine Schule der Redefreiheit! Unterz. A. V. M.

39 Für Baden s. Georg Jäger: Der Deutschunterricht auf Gymnasien 1780 bis 1850 . In: DV js 47 (1973), S. 120-47. Hier S. 134-35. »In der jetzigen Zeit der konstitutionellen Staaten «, so wird in der Volkskammer Badens in einem Kommissionsbericht über Schulangelegenheiten am 24.9. 1833 ausgeführt, »sei die Redekunst für die Führung von öffentlichen Verhandlungen ein notwendiges Handwerkszeug. Die Regierung habe daher mit Recht sDeclamation in den Lehrplan aufgenommen. "Werner Ruf: Der Neuhumanismus in Baden und seine Auswirkungen auf die Gelehrtenschulen. Phil. Diss. München 1961, S. 54. Vgl. den Direktor des Gymnasiums in Freiburg i. Br., Joseph Nikolaus Schmeisser: 
Theoretisch-praktisches Lehrbuch der Rhetorik. Tl. 1. Karlsruhe: Groos 1838. Vorwort, S. III/IV: „Durch die Errichtung ständischer Verfassungen [...] hat diese Kunst [die Rhetorik] auch in unserm Vaterlande einen neuen Schauplatz ihrer Thätigkeit gewonnen. [...] Auch an den Schranken der Gerichtssäle ertönt neuerdings das lebendige Wort zur Anklage des Verbrechens und zur Vertheidigung der Unschuld, wie es einst in Athen und in Rom gewirkt hat."

40 Haupt: Mustersammlung. Der Herausgeber ist »erster Lehrer, und Stellvertreter des Directors am Schullehrerseminar des Kantons Zürich " (Titelblatt). Zur Rede von Burke s. Adam Müller: Zwölf Reden über die Beredsamkeit und deren Verfall in Deutschland (1812). Nachwort von Walter Jens (Frankfurt/M. 1967), S. 110-14.

41 Karl Ludwig Kannegießer: Der deutsche Redner oder chronologisch geordnete Beispielund Mustersammlung der deutschen Beredsamkeit, von der ältesten bis auf die neueste Zeit. Leipzig: Hentze 1845. Vollständiger Titel s. Bibliographie Bd. 2; Kap. 1.3.3: für "Staatsbeamte, Landtagsdeputirte, Stadträthe, Stadtverordnete.

42 Rez. der 2. verb. u. verm. Aufl. 1854 von W[ilhelm] Assmann, in: Zeitschrift für das Gymnasialwesen 10 (1856), S. 470-73. Hier S. 472.

43 O[skar] L[udwig] B[ernhard] Wolff: Handbuch deutscher Beredsamkeit etc. Tl. 2: Die weltliche Beredsamkeit. Leipzig: Lorck 1846. Die »Bibliothek Politischer Reden « (1845) bestätigt, daß das Karlsruher Parlament als Hochburg politischer Rhetorik galt. Die Sammlung bringt 28 Beispiele aus Baden, 11 aus Hessen-Darmstadt, 7 aus Bayern und 5 aus Sachsen.

44 Dazu Helmut Heiber: Die Rhetorik der Paulskirche. Phil. Diss. F. U. Berlin 1953 (masch.); Dieter-W. Allhoff: Rhetorische Analyse der Reden und Debatten des ersten deutschen Parlamentes von 1848/49 (tuduv-Studien 3) München 1975. Noch nach dem Zusammenbruch der Revolution heißt es: »der mächtige Anlauf[,] den die deutsche Beredtsamkeit in den Tagen des rastlosen Ringens genommen hat «, mache »eine ausgebildete Theorie der Beredtsamkeit für das deutsche Volk zum unabweislichen Bedürfniß«. Blätter für literarische Unterhaltung 1851, Bd. 2, Nr. 123, S. 982 (Rez. von: Gorgias. Beredtsamkeit und Improvisation oder die Redekunst aus dem Stegreif vor den Gerichtsschranken, auf der Volksrednerbühne und auf der Kanzel. Deutsch, mit Rücksicht auf unsere Zustände und Bedürfnisse, von Fr. Teuscher. Weimar 1848. Unterz.: 80).

$45 \mathrm{Vgl}$. Lessings »Abhandlungen über die Fabel« (1759); Kap. V »Von einem besondern Nutzen der Fabeln in den Schulen «, nämlich den »heuristischen «, d. h. erfinderischen Nutzen. Neuausgabe Lessing: Fabeln. Abhandlungen über die Fabel. Hg. v. Heinz Rölleke (Universal-Bibliothek 27/28) Stuttgart (1970), S. 143-48, mit Zusammenstellung der Literatur S. 151-52.

46 Dazu Werner Hahl: Reflexion und Erzählung. Ein Problem der Romantheorie von der Spätaufklärung bis zum programmatischen Realismus (Studien zur Poetik u. Geschichte der Literatur 18) Stuttgart u. a. (1971) und Michael von Poser: Der abschweifende Erzähler. Rhetorische Tradition und deutscher Roman im achtzehnten Jahrhundert (Respublica Literaria 5) Bad Homburg v. d. H. u. a. (1969).

47 Zur Beschäftigung von Lehrern mit Klopstock s. S. 68 mit Anm. 48.

48 Dazu Ludwig Fertig: Die Hofmeister. Ein Beitrag zur Geschichte des Lehrerstandes und der bürgerlichen Intelligenz. Stuttgart (1979), mit Quellenauszügen.

49 Johann Heinrich Moritz Poppe: Technologisches Lexicon, oder genaue Beschreibung aller mechanischen Künste, Handwerke, Manufakturen und Fabriken, der dazu erforderlichen Handgriffe, Mittel, Werkzeuge und Maschinen, mit steter Rücksicht auf die Bedürfnisse der neuesten Zeit, die wichtigsten Entdeckungen, der dabey anzuwendenden geprüften chemischen und mechanischen Grundsätze, und einer vollständigen Literatur aller Zweige der Technologie, sammt Erklärung aller dort einschlagenden Kunstwörter, in alphabetischer Ordnung. 5 Bde. Stuttgart u. Tübingen: Cotta 1816-20.

50 Johann Friedrich Blumenbach, 1752-1840. Gemeint wohl: Handbuch der Naturgeschichte. 2 Tle. Göttingen: Dieterich 1779-80 (12. rechtmäßige Ausg. 1830; Nachdruck: 12. Ausg. Wien: Lechner 1832). 
51 Dazu Friedrich Sengle: Biedermeierzeit. Deutsche Literatur im Spannungsfeld zwischen Restauration und Revolution 1815 bis 1848 . Bd. 1. Stuttgart 1971. Probleme der Syntax, S. 545-93; grundlegend zur rhetorischen Sprachkultur der Zeit. Rudolf Wolfgang Müller: Rhetorische und syntaktische Interpunktion. Untersuchungen zur Pausenbezeichnung im antiken Latein. Phil. Diss. Tübingen 1964. Tl. 2, »Der rhetorische Charakter der lateinischen Interpunktion und ihr Verhältnis zur grammatischen Interpunktion «, S. 55-143, entwickelt noch für das 19. Jahrhundert fruchtbare Gesichtspunkte.

52 Johann Rudolf $W y \beta d$. Jüngere: Idyllen, Volkssagen, Legenden und Erzählungen aus der Schweiz. 2 Bde (Bd. 2 a. u. d. T.: Neue Idyllen etc.) Bern: Burgdorfer 1815-22.

53 Sammlung der Verordnungen und Vorschriften über die Verfassung und Einrichtung der Gymnasien. 3. Aufl. Wien: Schulbücher-Verschleiß bey St. Anna 1820, S. 108. Metrische Bearbeitungen gegebener Stoffe gehörten zu den Pflichtaufgaben österreichischer Gymnasiasten. „Merkt der Lehrer bey einem Schüler besondere Anlage zur Poesie, so kultivire er sie, und gebe ihm öfters Gelegenheit zu poetischen Ausarbeitungen." (S. 108) Eigene poetische Arbeiten nimmt dieser Lehrplan aber ausdrücklich von den Pflichtaufgaben aus.

54 Heinrich Viehoff: Eine Stufenfolgé metrischer Aufgaben für höhere Classen. In: Archiv für den Unterricht im Deutschen. 1. Jg. 1. H. 1843, S. 127-62. Hier S. 128.

55 Friedrich August Gotthold: Kleine Schriften über die deutsche Verskunst. Königsberg: Univ. buchhandlg. 1820. Entwurf zu einer Anweisung in der Verskunst zu unterrichten, S. 97-140. Hier S. 97.

56 Gotthold: Kleine Schriften. Zitate S. 109, 111-14. Ders.: Hephästion oder Anfangsgründe der griechischen römischen und deutschen Verskunst. 2. verb. Ausg. Königsberg: Bornträger 1824, S. 27. - Die 4. Beilage der »Kleinen Schriften«, S. 130-40, druckt »Metrische Versuche einiger Schüler des Friedrichskollegiums« ab.

57 Ebd. S. 113-14.

58 Johann Ferdinand Neigebaur: Die Preußischen Gymnasien und höheren Bürgerschulen. Eine Zusammenstellung der Verordnungen, welche den höheren Unterricht in diesen Anstalten umfassen. Berlin, Posen, Bromberg: Mittler 1835. Auszug aus dem Programm des Gymnasii zu Stralsund vom Jahre 1827, die Unterrichts-Gegenstände betreffend, S. 79 ff. Hier S. 81-82. Auf Sekunda »Uebung in freier Uebertragung deutscher oder griechischer Dichterstücke in lateinische Hexameter und ins elegische Versmaaß «. In Prima werden alle vierzehn Tage metrische UUbungen »in verschiedenen, besonders bei den Geübtern in Horazischen Versarten " geliefert. - Welches Ausmaß Versübungen in den alten Sprachen noch annehmen konnten, zeigt das Programm des Gymnasiums in Glogau über "Lateinische und griechische Metrik « (1 Wochenstunde) im Schuljahr 1835/36: In Prima wurde die Metrik »vollständig vorgetragen «, Oden des Horaz »mit Rücksicht auf Metrik gelesen, 20 metrische Aufgaben, abwechselnd aus beiden Sprachen eingeliefert « und $\$ 40$ metrische lateinische Extemporalien [d. h. schriftliche Schularbeiten] geschrieben « (S. 19). In Sekunda wurden eine »Elementar-Metrik « zweimal durchgenommen, »eine Erklärung der Metra des Horaz gegeben «, mehrere Oden von ihm »mit Rücksicht auf Metrik gelesen « und gleichfalls " 20 Aufgaben zu Hause bearbeitet, und 40 in den Lehrstunden geschrieben « (S. 21). In der letzten Klasse dieser Anstalt war noch 1848/49 das Deutschsprechen verboten! Dagobert von Gerhardt (Gerhard von Amyntor [Ps.]: Das Skizzenbuch meines Lebens. Tl. 1. Breslau: Schottlaender 1893, S. 39-44) charakterisiert sie als »Mönchsschule des Mittelalters« (S. 40).

59 Viehoff: Stufenfolge.

60 Heinrich Viehoff: Metrische Aufgaben für höhere Classen. In: Archiv für den Unterricht im Deutschen. 2. Jg. 4. H. 1844, S. 119-51.

61 Programme (Schul)Pforta 1841/42, 1846/47. Koberstein trug die Elemente der deutschen Verskunst 1841/42 "nach eigenem Hefte " vor. Eine Schilderung seines literarischen Einflusses auf die Schüler bei F[erdinand] Ranke: Rückerinnerungen an Schulpforte (1814-21). Halle: Waisenhaus 1874, S. 71-75.

62 Pr. Domgymnasium Naumburg 1841/42, S. VI-VII. Die folgenden Angaben sind ebenfalls aus den Jahresberichten gezogen. 
63 Das Programm des Lyceums in Rastatt 1830, das »Poetische und prosaische Versuche einiger Schüler der Poetik und Rhetorik « enthält, war durch die Fernleihe nicht aufzufinden.

64 Dazu Max Bucher, Werner Hahl, Georg Jäger u. Reinhard Wittmann: Realismus und Gründerzeit. Manifeste und Dokumente zur deutschen Literatur 1848-1880. 2 Bde. Stuttgart 1975/76. Besonders Bd. 1, S. 136-59; Bd. 2, S. 448-59, 501-16.

65 Rudolf Gottschall: Aus meiner Jugend. Erinnerungen. Berlin: Paetel 1898. Zitate S. 53, 68. Wiedergabe einer Szene aus »Cerigo« S. 55-58. Zu Gottschalls klassizistischer Literaturauffassung s. Helmuth Widhammer: Realismus und klassizistische Tradition. Zur Theorie der Literatur in Deutschland 1848-1860. Tübingen 1972. - Aus der gleichen Zeit können verglichen werden: die Schülerdichtungen von Carl Schurz (Lebenserinnerungen, Bd. 1, S. 65-67: eine historische Tragödie um den angelsächsischen König Edwy, eine romantische Ballade in Stanzen, lyrische Gedichte u. a.) und das ca. 1840/41 entstandene Jugenddrama von Friedrich Engels: Cola di Rienzi. Ein unbekannter dramatischer Entwurf. Bearb. u. eingel. v. Michael Knieriem (Wuppertal 1974). - Die Gedankenwelt von Georg Ebers (1837-98), Verfasser altägyptischer Romane, wurde durch intensiven klassischen Unterricht ganz mit »Vorstellungen aus dem Leben der Alten « (Die Geschichte meines Lebens. Vom Kind bis zum Manne. 2. Aufl. Stuttgart u. a.: Deutsche Verlagsanstalt 1893, S. 382) erfüllt. Gymnasialprodukte: ein »Weltdichtungsmonstrum « über das »Entstehen des kosmischen und menschlichen Lebens «, die Tragödie »Panthea und Abradat «, Aktusgedichte über die Erzählung des Herodot von Atys und Adrast sowie über das Leben Heinrichs des Vogelstellers u. a. (S. 324-25, 329-31, 381-83).

66 Robert Hamerling: Stationen meiner Lebenspilgerschaft. Hamburg: Actien-Gesellschaft 1889. Zitat S. 193. Die 1866 vollendeten »Märtyrer « liegen vollständig vor: Die Märtyrer. Ein Drama in fünf Acten. Hg. u. eingel. v. Michael M. Rabenlechner (Litteraturbilder der Gegenwart, Bd. VI) Dresden u. Leipzig 1901. Zur Charakteristik Hamerlings vgl. Richard Hamann u. Jost Hermand: Gründerzeit (Epochen deutscher Kultur von 1870 bis zur Gegenwart 1) (München 1971), S. 64: »ein Gründerzeitmensch reinsten Wassers «; Realismus und Gründerzeit, Bd. 1, S. 152-53 und Quellenbibliographie Nr. 820-29.

67 Gottschall: Aus meiner Jugend, S. 68. 


\section{Literatur}

Quellen und weitere Literatur zu einzelnen Ländern und Schulen s. Bibliographie Bd. 2

\subsection{Sozial- und Ideengeschichte}

Arnoldt, J[ohann] F[riedrich] J[ulius]: Fr. Aug. Wolf in seinem Verhältnisse zum Schulwesen und zur Pädagogik. 2 Bde. Braunschweig 1861-62.

Becker, Adolf: Der Neuhumanismus. Sein Ursprung und seine Entwicklung in Deutschland. Vacha 1924.

Bindseil, Heinrich Ernst: General-Register über die Verhandlungen der ersten fünfundzwanzig Versammlungen deutscher Philologen und Schulmänner 1838-1867. Leipzig 1869.

Blättner, Fritz: Das Gymnasium. Heidelberg 1960.

Blättner, Fritz: Philosophische Fakultät und Schule. Ein Beitrag zur Geschichte ihrer Beziehungen von 1750 bis 1850. Dargestellt am Beispiel der schleswig-holsteinischen Gelehrtenschulen und der Universität Kiel. In: Pädagogisches Denken in Geschichte und Gegenwart. Fs. Josef Dolch. Ratingen 1965, S. 73-89.

Böckel, Ernst: Hermann Köchly. Ein Bild seines Lebens und seiner Persönlichkeit. Heidelberg 1904.

Bollnow, Otto Friedrich: Die Pädagogik der deutschen Romantik. Von Arndt bis Fröbel. Stuttgart usw. (2. Aufl. 1967).

Brandau, Heinrich-Wilhelm: Die mittlere Bildung in Deutschland. Historisch-systematische Untersuchung einiger ihrer Probleme. (Göttinger Studien zur Pädagogik N.F. 2) Weinheim, Berlin (1959).

Bruford, Walter H[orace]: Die gesellschaftlichen Grundlagen der Goethezeit (Ullstein Buch 3142) (Frankfurt/M. usw. 1975).

Bruford, Walter Horace: Deutsche Kultur der Goethezeit (Handbuch der Kulturgeschichte, I. Abt.) Konstanz (1965).

Ermatinger, Emil: Deutsche Kultur im Zeitalter der Aufklärung. Bearb. v. Eugen Thurnher u. Paul Stapf. Einleitung v. Adam Wandruszka (Handbuch der Kulturgeschichte, I. Abt.) Frankfurt/M. (1969).

Fiedler, Ralph: Die klassische deutsche Bildungsidee. Ihre soziologischen Wurzeln und pädagogischen Folgen (Studien zur Soziologie des Bildungswesens 7) Weinheim 1972.

Gedanken zur Nationalerziehung aus dem Vormärz. Ausgew., eingel. u. erl. v. Helmut König (Erziehung u. Gesellschaft) Berlin 1959.

Geppert, Klaus: Die Theorie der Bildung im Werk des Novalis (EHS XI, Pädagogik 42) Bern usw. 1977.

Giese, Gerhardt: Quellen zur deutschen Schulgeschichte seit 1800 (Quellensammlung zur Kulturgeschichte 15) Göttingen (1961).

Grube, Kurt: Die Idee und Struktur einer reinmenschlichen Bildung. Ein Beitrag zum Philanthropinismus und Neuhumanismus (Pädagogik in Geschichte, Theorie u. Praxis 1) Halle 1934.

Herrlitz, Hans-Georg: Studium als Standesprivileg. Die Entstehung des Maturitätsproblems im 18. Jahrhundert. Lehrplan- und gesellschaftsgeschichtliche Untersuchungen (FAT 3005) (Frankfurt/M. 1973).

Jeismann, Karl-Ernst: Das preußische Gymnasium in Staat und Gesellschaft. Die Entstehung des Gymnasiums als Schule des Staates und der Gebildeten, 1787-1817 (Industrielle Welt 15) Stuttgart (1974). 
Kluge, Otto: Humanistische und neuhumanistische Bildungsziele in der Schulpädagogik des 18. Jahrhunderts. In: Zeitschrift für Geschichte der Erziehung und des Unterrichts 15 (1925), S. 36-101.

Knoll, Joachim H.: Johann Gottfried Christian Nonne. Ein Beitrag zur niederrheinischen Schulgeschichte am Beginn des 19. Jahrhunderts (Duisburger Forschungen. Beih. 14) Duisburg 1971.

König, Helmut: Zur Geschichte der Nationalerziehung in Deutschland im letzten Drittel des 18. Jahrhunderts (Monumenta Paedagogica 1) Berlin 1960 [Darin: Der Unterricht in der deutschen Sprache, S. 128-36].

König, Helmut: Zur Geschichte der bürgerlichen Nationalerziehung im Deutschland zwischen 1807 und 1815 (Monumenta Paedagogica 12-13) Berlin 1972-73.

Kraul, Margret: Gymnasium und Gesellschaft. Neuhumanistische Einheitsschule, städtische Gesellschaft und soziale Herkunft der Schüler (Studien zum Wandel von Gesellschaft $u$. Bildung im 19. Jh. 18) Göttingen 1980.

Kraul, Margret: Untersuchungen zur sozialen Struktur der Schülerschaft des preußischen Gymnasiums im Vormärz. In: Bildung und Erziehung 29 (1976), S. 509-19.

Lamprecht, Max: Die Einheitsschulidee bei Wilhelm von Humboldt und Johann Wilhelm Süvern. Phil. Diss. Jena 1922 [masch.].

Lassahn, Rudolf: Studien zur Wirkungsgeschichte Fichtes als Pädagoge. Heidelberg 1970.

Litt, Theodor: Das Bildungsideal der deutschen Klassik und die moderne Arbeitswelt (Kamps pädagogische Taschenbücher 3) 7. Aufl. Bochum o. J.

Loewe, Hans: Friedrich Thiersch. Ein Humanistenleben im Rahmen der Geistesgeschichte seiner Zeit. [Bd. 1:] Die Zeit des Reifens [mehr nicht erschienen]. München u. Berlin 1925.

Lundgreen, Peter: Die Bildungschancen beim Ưbergang von der »Gesamtschule « zum Schulsystem der Klassengesellschaft im 19. Jahrhundert. Úberlegungen zur Reichweite und Interpretationsmöglichkeit schulgeschichtlicher Befunde anläßlich des Buchs »Sozialstruktur und Schulsystem « von Detlef K. Müller. In: Zeitschrift für Pädagogik 24 (1978), S. 101-15.

Lundgreen, Peter: Quantifizierung in der Sozialgeschichte der Bildung. In: Vierteljahrsschrift für Sozial- und Wirtschaftsgeschichte 63 (1976), S. 433-53.

Lundgreen, Peter: Schulbildung und Frühindustriealisierung in Berlin/Preußen. Eine Einführung in den historischen und systematischen Zusammenhang von Schule und Wirtschaft. In: Untersuchungen zur Geschichte der frühen Industrialisierung vornehmlich im Wirtschaftsraum Berlin/Brandenburg. Hg. v. Otto Büsch (Einzelveröffentlichungen der Histor. Kommission zu Berlin 6) Berlin 1971, S. 562-610.

Menze, Clemens: Die Bildungsreform Wilhelm von Humboldts (Das Bildungsproblem in der Geschichte des europäischen Erziehungsdenkens 13) Hannover usw. (1975).

Menze, Clemens: Wilhelm von Humboldt und Christian Gottlob Heyne. Ratingen (1966).

Menze, Clemens: Die Individualität als Ausgangs- und Endpunkt des Humboldtschen Denkens [mit Diskussion]. In: Universalismus und Wissenschaft im Werk und Wirken der Brüder Humboldt. Hg. v. Klaus Hammacher. Frankfurt/M. 1976, S. 145-71.

Menze, Clemens: Wilhelm von Humboldts Lehre und Bild vom Menschen. Ratingen (1965).

Menze, Clemens: Die Verkehrung des Humboldtschen Gymnasiums von der Menschheitsschule zur Standesschule. In: Vierteljahrsschrift für wissenschaftliche Pädagogik 51 (1975), S. $125-45$.

Meyer, Ruth: Das Berechtigungswesen in seiner Bedeutung für Schule und Gesellschaft im 19. Jahrhundert. In: Zeitschrift für die gesamte Staatswissenschaft 124 (1968), S. 763-76.

Müller, Detlef K.: Sozialstruktur und Schulsystem. Aspekte zum Strukturwandel des Schulwesens im 19. Jahrhundert (Studien zum Wandel von Gesellschaft u. Bildung im 19. Jh. 7) Göttingen 1977.

O'Boyle, Lenore: Klassische Bildung und soziale Struktur in Deutschland zwischen 1800 und 1848. In: HZ 207 (1968), S. 584-608. Neudruck: Schule und Gesellschaft im 19. Jh. (s. dort), S. $19-43$.

O'Boyle, Lenore: The Problem of an Excess of Educated Men in Western Europe, 1800-1850. In: The Journal of Modern History 42 (1970), S. 471-95. 
Paetz, Wilhelm: Die Realschule in den ersten Jahrzehnten des neunzehnten Jahrhunderts. Wiss. Beil. zum Jahresbericht der Städt. Oberrealschule I zu Charlottenburg Ostern 1910.

Patrioten in Wort und Tat. Lehrer und Schüler, Professoren und Studenten im Befreiungskrieg. Ausgew., eingel. u. erl. v. Helmut König. Berlin 1963 (Reprint Berlin 1965).

Paulsen, Friedrich: Geschichte des gelehrten Unterrichts auf den deutschen Schulen und Universitäten vom Ausgang des Mittelalters bis zur Gegenwart. Mit besonderer Rücksicht auf den klassischen Unterricht. 3. erw. Aufl. hg. u. in einem Anhang fortgesetzt von Rudolf Lehmann. 2 Bde. Berlin u. Leipzig 1919-21.

Pinloche, A[uguste]: Geschichte des Philanthropinismus. Deutsche Bearbeitung von J[ohannes] Rauschenfels u. A. P. 2. Aufl. Leipzig 1914.

Preuß, Ulrich: Bildung und Bürokratie. Sozialhistorische Bedingungen in der ersten Hälfte des 19. Jahrhunderts. In: Der Staat 14 (1975), S. 371-96.

Programme zur bürgerlichen Nationalerziehung in der Revolution von 1848/49. Ausgew., eingel. u. erläutert v. Helmut König (Erziehung u. Gesellschaft) Berlin 1971.

Rethwisch, Conrad: Deutschlands höheres Schulwesen im neunzehnten Jahrhundert. Geschichtlicher Überblick im Auftrage des Königl. Preußischen Ministeriums der geistlichen, Unterrichts- und Medizinal-Angelegenheiten. Mit amtlichen Nachweisungen über den Besuch der höheren Lehranstalten des Deutschen Reiches. Berlin 1893 [Über die Entwicklung des Deutschunterrichts, S. 158-62].

Ringer, Fritz K.: Higher Education in Germany in the Nineteenth Century. In: Journal of Contemporary History 2 (1967), S. 123-38.

Ringer, Fritz K.: Education and Society in Modern Europe. Bloomington, Indiana, u. London 1979.

Roessler, Wilhelm: Die Entstehung des modernen Unterrichtswesens in Deutschland. Stuttgart (1961).

Schule und Gesellschaft im 19. Jahrhundert. Sozialgeschichte der Schule im Úbergang zur Industriegesellschaft. Hg. v. Ulrich Herrmann (Beltz-Studienbuch) Weinheim u. Basel 1977.

Schurr, Johannes: Schleiermachers Theorie der Erziehung. Interpretationen zur Pädagogikvorlesung von 1826. Düsseldorf (1975).

Schwarzmaier, Michael: Friedrich Immanuel Niethammer, ein bayerischer Schulreformator. Bd. 1 [mehr nicht erschienen]. Aalen 1974 (Reprint d. Ausg. 1937).

Sochatzky, Klaus: Das Neuhumanistische Gymnasium und die reinmenschliche Bildung. Zwei Schulreformversuche in ihrer weiterreichenden Bedeutung (Studien zum Wandel von Gesellschaft u. Bildung im 19. Jh. 6) Göttingen 1973.

Stach, Reinhard: Úber die Anfänge einer planmäßigen und naturgemäßen Denkerziehung in der Pädagogik der Aufklärung. In: Paedagogica Historica 13 (1973), S. 486-514.

Stach, Reinhard: Das Basedowsche Elementarwerk. In: Paedagogica Historica 14 (1974), S. 458-96.

Titze, Hartmut: Die Politisierung der Erziehung. Untersuchungen über die soziale und politische Funktion der Erziehung von der Aufklärung bis zum Hochkapitalismus (FAT 3002) (Frankfurt/M. 1973).

Weil, Hans: Die Entstehung des deutschen Bildungsprinzips (Schriften zur Philosophie u. Soziologie 4) Bonn 1930.

Wetzstein, O[tto]: Die geschichtliche Entwicklung des Realschulwesens in Deutschland. 5 Tle. Beil. zum Programm der Realschule (Realprogymnasium) zu Neustrelitz 1906-10.

Zorn, Wolfgang: Hochschule und höhere Schule in der deutschen Sozialgeschichte der Neuzeit. In: Spiegel der Geschichte. Festgabe für Max Braubach. Hg. v. Konrad Repgen u. Stephan Skalweit. Münster 1964, S. 321-39. 


\subsection{Rhetorik, Poetik, Literaturgeschichte}

Allhoff, Dieter-W.: Rhetorische Analyse der Reden und Debatten des ersten deutschen Parlamentes von 1848/49 (tuduv-Studien 3) München 1975.

Becker, Eva D[orothea]: >Klassiker in der deutschen Literaturgeschichtsschreibung zwischen 1780 und 1860. In: Zur Literatur der Restaurationsepoche 1815-1848. Hg. v. Jost Hermand u. Manfred Windfuhr. Stuttgart 1970, S. 349-70.

Borchmeyer, Dieter: Tragödie und Öffentlichkeit. Schillers Dramaturgie im Zusammenhang seiner ästhetisch-politischen Theorie und der rhetorischen Tradition. München 1973.

Braunbehrens, Volkmar: Nationalbildung und Nationalliteratur. Zur Rezeption der Literatur des 17. Jahrhunderts von Gottsched bis Gervinus. Berlin 1974.

Breuer, Dieter u. Günther Kopsch: Rhetoriklehrbücher des 16. bis 20. Jahrhunderts. Eine Bibliographie. In: Rhetorik. Hg. v. H. Schanze (s. dort), S. 217-355.

Brueggemann, Diethelm: Gellert, der gute Geschmack und die üblen Briefsteller. Zur Geschichte der Rhetorik in der Moderne. In: DVjs 45 (1971), S. 117-49.

Dockhorn, Klaus: Macht und Wirkung der Rhetorik. Vier Aufsätze zur Ideengeschichte der Vormoderne (Respublica Literaria 2) Bad Homburg v. d. H. usw. (1968).

Dockhorn, Klaus: Rhetorik und germanistische Literaturwissenschaft in Deutschland. In: Jahrbuch für Internationale Germanistik 3 (1971), S. 168-85.

Garber, Klaus: Martin Opitz - »der Vater der deutschen Dichtung «. Eine kritische Studie zur Wissenschaftsgeschichte der Germanistik. Stuttgart 1976.

Germanistik und deutsche Nation 1806-1848. Zur Konstitution bürgerlichen Bewußtseins. Hg. v. Jörg Jochen Müller (Literaturwissenschaft u. Sozialwissenschaften 2) Stuttgart (1974).

Goth, Joachim: Nietzsche und die Rhetorik (Untersuchungen zur deutschen Literaturgeschichte 5) Tübingen 1970.

Heiber, Helmut: Die Rhetorik der Paulskirche. Phil. Diss. F. U. Berlin 1953 [masch.].

Jäger, Georg: Das Gattungsproblem in der Ästhetik und Poetik von 1780 bis 1850. In: Zur Literatur der Restaurationsepoche 1815-1848. Hg. v. Jost Hermand u. Manfred Windfuhr. Stuttgart 1970, S. 371-404.

Jäger, Hans-Wolf: Politische Kategorien in Poetik und Rhetorik der zweiten Hälfte des 18. Jahrhunderts (Texte Metzler 10) Stuttgart 1970.

Jens, Walter: Von deutscher Rede. Reden und Aufsätze. München 1969.

Klassen, Rainer: Logik und Rhetorik der frühen Aufklärung. Phil. Diss. München 1973 (Druck Augsburg 1974).

Knoop, Gisela: Die Gesamtdarstellungen der deutschen Literatur bis zu Wilhelm Scherer. Phil. Diss. Münster 1952 [masch.].

Krause, Reinhard: Die Predigt der späten deutschen Aufklärung (1770-1805) (Arbeiten zur Theologie. II. Reihe, 5) Stuttgart 1965.

Linn, Marie-Luise: Studien zur deutschen Rhetorik und Stilistik im 19. Jahrhundert (Marburger Beiträge zur Germanistik 4) Marburg 1963.

Literaturgeschichte zwischen Revolution und Reaktion. Aus den Anfängen der Germanistik 1830-1870. Hg. v. Bernd Hüppauf (Frankfurt/M. 1972).

Úber Literaturgeschichtsschreibung. Die historisierende Methode des 19. Jahrhunderts in Programm und Kritik. Hg. v. Edgar Marsch (Wege der Forschung 382) Darmstadt 1975.

Meyen, Fritz: J. J. Eschenburg. 1743-1820. Kurzer Abriß seines Lebens und Schaffens nebst Bibliographie (Braunschweiger Werkstücke 20) Braunschweig 1957. - Dazu Ergänzungen und Korrekturen durch Hans Fromm: Bibliographie und deutsche Philologie. In: DVjs 39 (1959), S. 446-502. Hier S. 454/55.

Neumaier, Herbert: Der Konversationston in der frühen Biedermeierzeit 1815-1830. Phil. Diss. München 1972 (Druck Bergatreute 1974).

Nickisch, Reinhard M. G.: Gottsched und die deutsche Epistolographie des 18. Jahrhunderts. In: Euphorion 66 (1972), S. 365-82.

Nickisch, Reinhard M. G.: Karl Philipp Moritz als Stiltheoretiker. In: GRM N.F. 19 (1969), S. 262-69. 
Nickisch, Reinhard M. G.: Die Stilprinzipien in den deutschen Briefstellern des 17. und 18. Jahrhunderts. Mit einer Bibliographie zur Briefschreiblehre (1474-1800) (Palaestra 254) Göttingen 1969.

Reclam, Herta: Die Polenrede Robert Blums - rhetorisch erläutert. In: Wiss. Zeitschrift der Martin-Luther-Universität Halle-Wittenberg. Gesellschafts- u. sprachwiss. Reihe 5 (1955/ 56), S. 461-67.

Rhetorik. Beiträge zu ihrer Geschichte in Deutschland vom 16. bis 20. Jahrhundert. Hg. v. Helmut Schanze (Schwerpunkte Germanistik) (Frankfurt/M. 1974).

Rhetorik. Kritische Positionen zum Stand der Forschung. Hg. v. Heinrich F. Plett (Kritische Information 50) München 1977.

Sack, Karl Heinrich: Geschichte der Predigt in der deutschen evangelischen Kirche von Mosheim bis auf die letzten Jahre von Schleiermacher und Menken. 2. Ausg. Heidelberg 1866.

Schaub, Gerhard: Georg Büchner. Friedrich Ludwig Weidig. Der Hessische Landbote. Texte, Materialien, Kommentar (Reihe Hanser. Literatur-Kommentare 1) (München 1976).

Scherpe, Klaus R.: Gattungspoetik im 18. Jahrhundert. Historische Entwicklung von Gottsched bis Herder (Studien zur Allgemeinen u. Vergleichenden Literaturwissenschaft 2) Stuttgart (1968).

Schmidt, Hans Helfrid: Untersuchungen zum Stilideal des Lakonismus in der Biedermeierzeit 1830-1848. Thesis, Mc Gill Univ. Montreal, P. Q. 1972 [masch.].

Scholz, Paul: Wilhelm Jordans Reden in der Paulskirche. Studien zur parlamentarischen Beredsamkeit (Königsberger Deutsche Forschungen 7) Königsberg 1930.

Sengle, Friedrich: Biedermeierzeit. Deutsche Literatur im Spannungsfeld zwischen Restauration und Revolution 1815-1848. Bd. 1-3. Stuttgart 1971-80.

Sengle, Friedrich: Vorschläge zur Reform der literarischen Formenlehre (Dichtung u. Erkenntnis 1) 2. verb. Aufl. Stuttgart (1969).

Stötzer, Ursula: Deutsche Redekunst im 17. und 18. Jahrhundert. Halle 1962.

Ueding, Gert: Schillers Rhetorik. Idealistische Wirkungsästhetik und rhetorische Tradition (Studien zur deutschen Literatur 27) Tübingen 1971.

Weithase, Irmgard: Anschauungen über das Wesen der Sprechkunst von 1775-1825 (Germanische Studien 90) Berlin 1930.

Weithase, Irmgard: Zur Geschichte der gesprochenen deutschen Sprache. 2 Bde. Tübingen 1961.

Weithase, Irmgard: Die Geschichte der deutschen Vortragskunst im 19. Jahrhundert. Anschauungen über das Wesen der Sprechkunst vom Ausgang der deutschen Klassik bis zur Jahrhundertwende. Weimar 1940.

Weniger, Heinz: Die drei Stilcharaktere der Antike in ihrer geistesgeschichtlichen Bedeutung (Göttinger Studien zur Pädagogik 19) Langensalza usw. 1932.

Wiehe, Ernst: J. J. Eschenburgs Theorie der schönen Redekünste und die Poetik und Kunsttheorie der zweiten Hälfte des 18. Jahrhunderts. Phil. Diss. Leipzig 1924 [masch.].

Winkler, Christian: Elemente der Rede. Die Geschichte ihrer Theorie in Deutschland von 1750 bis 1850 (Bausteine zur Geschichte der deutschen Literatur 32) Halle 1931.

Wittsack, Walter: Studien zur Sprechkultur der Goethezeit. Berlin 1932.

Wychgram, Marianne: Quintilian in der deutschen und französischen Literatur des Barocks und der Aufklärung (Friedrich Manns Pädagogisches Magazin 803) Langensalza 1921.

\subsection{Geschichte des Sprach- und Literaturunterrichts}

Achelis, Otto: Der deutsche Unterricht an den Lateinschulen Schleswig-Holsteins in der vorpreußischen Zeit. In: Zeitschrift für Deutschkunde 43 (1929), S. 714-17.

Anemüller, B[ernhard]: Dramatische Aufführungen in den Schwarzburg-Rudolstädtischen 
Schulen vornemlich im 17. und 18. Jahrhundert. Ein Beitrag zur Geschichte der SchulComödie. Rudolstadt 1882.

Benker, Gertrud: Die Vermittlung von Volkslesestoff und Volksbildung in den bayerischen Lesebüchern vor 1900. In: Bayerisches Jahrbuch für Volkskunde 1970/71, S. 157-67.

Böhnke, Frieda: Die deutsche Dichtung in der Schule. Geschichte und Probleme 1750-1860. Phil. Diss. Frankfurt/M. 1965.

Bornmann, Fritz: Wilhelm Curtman als Vorkämpfer für moderne pädagogische Ideen (Pädagogisches Magazin 1025 = Philosophische u. pädagogische Schriften 6) Langensalza 1925 [Darin: Der deutsche Sprachunterricht, S. 14-17].

Bosse, Heinrich: Dichter kann man nicht bilden. Zur Veränderung der Schulrhetorik nach 1770. In: Jahrbuch für Internationale Germanistik 10 (1978), S. 80-125.

Brackert, Helmut, Hannelore Christ u. Horst Holzschuh: Zur gesellschaftlichen Funktion mittelalterlicher Literatur in der Schule. Historisch-kritische Bestandsaufnahme. In: Mittelalterliche Texte im Unterricht. Hg. v. H. B., H. C., H. H. (Literatur in der Schule 1) München (1973), S. 11-69.

Brandes, Wilhelm: Ein Aufsatzheft des jungen Raabe. In: Mitteilungen für die Gesellschaft der Freunde Wilhelm Raabes 3. Jg. 1913. Nr. 3, S. 69-77 [Schulaufsatzheft des Wolfenbütteler Obertertianers aus dem Winter 1847/48].

Breuer, Dieter: Schulrhetorik im 19. Jahrhundert. In: Rhetorik. Beiträge zu ihrer Geschichte in Deutschland vom 16.-20. Jahrhundert. Hg. v. Helmut Schanze (FAT 2095) (Frankfurt/M. 1974), S. 145-79.

Bukowski, Hermann: Der Schulaufsatz und die rhetorische Sprachschulung. Rhetorische Methoden und Aufgaben in der Institutio oratoria Quintilians und die Theorie des deutschen Schulaufsatzes. Phil. Diss. Kiel 1956 [masch.].

Burkhardt, Ursula: Germanistik in Südwestdeutschland. Die Geschichte einer Wissenschaft des 19. Jahrhunderts an den Universitäten Tübingen, Heidelberg und Freiburg (Contubernium 14) Tübingen 1976 [Darin: Germanistik und Deutschunterricht, S. 191-210].

de Capua, A. G.: Early Poetical Anthologies for Schools. A Contribution to the History of the Lyrical Anthology in Germany before 1770. In: Monatshefte für deutschen Unterricht, deutsche Sprache und Literatur 49 (1957), S. 337-52.

Der Deutschunterricht auf dem Gymnasium der Goethezeit. Eine Anthologie. Mit e.Einführung in den Problemkreis [...] v. Georg Jäger (Texte zum literarischen Leben um 1800, Bd. 2) Hildesheim 1977.

Dolch, Joseph: Lehrplan des Abendlandes. Zweieinhalb Jahrtausende seiner Geschichte. (2. Aufl.) Ratingen (1965).

Domandl, Moriz: Adalbert Stifters Lesebuch und die geistigen Strömungen zur Jahrhundertmitte (Schriftenreihe des Adalbert-Stifter-Instituts des Landes Oberösterreich 29) Linz 1976.

Enzinger, Moriz: Adalbert Stifters Studienjahre (1818-1830). Innsbruck (1950) [Gymnasium und Lyzeum der Benediktinerabtei Kremsmünster 1818-26].

Fiesel, Eva: Die Sprachphilosophie der deutschen Romantik. Tübingen 1927.

Frank, Horst Joachim: Geschichte des Deutschunterrichts. Von den Anfängen bis 1945 (München 1973).

Fritsch, Andreas: Sprache und Inhalt lateinischer Lehrbuchtexte. Ein unterrichtsgeschichtlicher Rückblick. In: Abhandlungen aus der Pädagogischen Hochschule Berlin. Bd. 3: Fachdidaktik und fächerübergreifender Unterricht. Red. Reinhard Dithmar u. Jörg Willer. Berlin (1976), S. 116-69.

Giesebrecht, Ludwig: Der Aufsatz in der Oberklasse Preussischer Gymnasien. In: Damaris (Stettin) 1861, S. 342-93 [geschichtl. Untersuchung].

Giesebrecht, Ludwig: Der deutsche Aufsatz in Prima. Eine geschichtliche Untersuchung. In: Zeitschrift für das Gymnasialwesen 10 (1856), S. 113-52.

Griessbach, Johannes: Die geschichtliche Entwicklung des altklassischen und deutschen Unterrichts an den Gymnasien im Königreich Bayern. Pr. Gymnasium Hof 1892 u. 1893.

Harth, Dietrich: Christian Wolffs Begründung des Exempel- und Fabelgebrauchs im Rahmen der Praktischen Philosophie. In: DVjs 52 (1978), S. 43-62. 
Hausenstein, Wilhelm: Zwei Schulaufsätze von Karl Ludwig Sand. In: Mannheimer Geschichtsblätter 8 (1907), Sp. 35-41 [Regensburger Gymnasialzeit 1812-13].

Helmers, Hermann: Geschichte des deutschen Lesebuchs in Grundzügen. Stuttgart (1970).

Hergt, Max: Beiträge zur Geschichte des deutschen Unterrichts an den humanistischen Gymnasien des Königreichs Bayern. 2 Tle. Pr. Theresien-Gymnasium München 1900 u. 1901, Wiss. Beil.

Herrlitz, Hans-Georg: Der Lektürekanon des Deutschunterrichts im Gymnasium. Ein Beitrag zur Geschichte der muttersprachlichen Schulliteratur. Heidelberg 1964.

Herrlitz, Hans-Georg u. Hagen Scheffler: Die deutsche Lektüre auf den humanistischen Gymnasien des 19. Jahrhunderts. Ausgewählte Ergebnisse einer statistischen Erhebung. In: Das Studienseminar Bd. 14, H. 1, 1969, S. 46-72.

Hirsch, Erhard: Klopstock und die Pädagogen des XVIII. und XIX. Jahrhunderts. In: Friedrich Gottlieb Klopstock. Werk und Wirkung. Hg. v. Hans-Georg Werner. Berlin 1978, S. 125-42.

Jäger, Georg: Der Deutschunterricht auf Gymnasien 1780 bis 1850. In: DVjs 47 (1973), S. $120-47$.

Jäger, Georg: Zur literarischen Gymnasialbildung in Österreich von der Aufklärung bis zum Vormärz. In: Die österreichische Literatur (s. dort), Tl. 1, S. 85-118.

Jäger, Georg: Humanismus und Realismus. Schulorganisation und Sprachunterricht 1770-1840. In: IASL 1 (1976), S. 146-59.

Jäger, Georg: Die gesellschaftliche Rolle des Sprach- und Literaturunterrichts auf der höheren Schule im Vormärz. In: Literatur in der sozialen Bewegung. Aufsätze und Forschungsberichte zum 19. Jahrhundert. Hg. v. Alberto Martino. Tübingen (1977), S. 93-129.

Jäger, Georg: Sozialstruktur und Sprachunterricht im deutschen Gymnasium zur Zeit des Vormärz. In: Zeitschrift für Pädagogik. 14. Beih. 1977, S. 189-202.

Kehrbach, Karl: Deutsche Sprache und Litteratur am Philanthropin in Dessau (1775-1793). In: Mitteilungen der Gesellschaft für deutsche Erziehungs- und Schulgeschichte 7 (1897), S. 333-59.

Keller, Fritz: Rhetorik in der Ordensschule. "Palatium rhetoricae « von Michael Denis: Ein didaktisches Epos - seine literarische Tradition, künstlerische Gestaltung und sein Verhältnis zum zeitgenössischen Rhetorikunterricht bei den Jesuiten. In: Die österreichische Literatur (s. dort), Tl. 1, S. 55-83.

Kelletat, Alfred: Die frühe Rezeption Hölderlins in Schule und Lesebuch (1830-1850). In: Abhandlungen aus der Pädagogischen Hochschule Berlin. Bd. 3: Fachdidaktik und fächerübergreifender Unterricht. Red. Reinhard Dithmar u. Jörg Willer. Berlin (1976). S. 87-115.

von König, Dominik: 'Nathan der Weises in der Schule. Ein Beitrag zur Wirkungsgeschichte Lessings. In: Lessing Yearbook 6 (1974), S. 108-38.

Kriebitzsch, Th[eodor]: Das Sprachstück und dessen Behandlung. In: Geschichte des deutschen Unterrichts in der Volksschule (Geschichte der Methodik des deutschen Volksschulunterrichts. Hg. v. C[arl] Kehr. 2. Aufl. 1. Bd.) Gotha 1889, S. 418-67.

Lattmann, Julius: Geschichte der Methodik des lateinischen Elementarunterrichts seit der Reformation. Eine specialistische Ergänzung zur Geschichte der Pädagogik. Göttingen 1896.

Lips, Bernhard: Oskar von Redwitz als Dichter der "Amaranth " (Münstersche Beiträge zur neueren Literaturgeschichte 9) Münster 1908 [Darin Abiturarbeit im Deutschen, Speyer 1841: »Schilderung eines Seesturmes«, S. 19-21].

Die österreichische Literatur. Ihr Profil an der Wende vom 18. zum 19. Jahrhundert (1750-1830) (Die österreichische Literatur. Eine Dokumentation ihrer literarhistorischen Entwicklung) Hg. v. Herbert Zeman. 2 Tle. Graz 1979.

Der Literaturunterricht. Bearb. v. Dietrich Boueke (Quellen zur Unterrichtslehre 14) Weinheim usw. 1971.

Ludwig, Albert: Schiller und die Schule. In: Mitteilungen der Gesellschft für deutsche Erziehungs- und Schulgeschichte 20 (1910), S. 55-95.

Ludwig, Albert: Aus der Vergangenheit des deutschen Unterrichts. In: Monatschrift für höhere Schulen 7 (1908), S. 303-13. 
Martens, Wolfgang: Drei Sammlungen von Schülerdichtungen aus dem Wiener Theresianum. In: Die österreichische Literatur (s. dort), Tl. 1, S. 1-22.

Matthias, Adolf: Geschichte des deutschen Unterrichts (Handbuch des deutschen Unterrichts an höheren Schulen. Bd. 1, Tl. 1) München 1907.

Menze, Clemens: Die Rolle der Ästhetik in Wilhelm von Humboldts Theorie der Bildung. In: Gegenwart und Tradition. Strukturen des Denkens. Fs. für Bernhard Lakebrink. Hg. v. Cornelio Fabro (Sammlung Rombach N.F. 1) Freiburg i. Br. (1969), S. 125-50.

Menze, Clemens: Der Úbergang von der ästhetisch-politischen zur literarisch-musischen Erziehung. Erörterungen über den Wandel des Bildungsdenkens zu Beginn des 19. Jahrhunderts. In: Vierteljahrsschrift für wissenschaftliche Pädagogik 47 (1971), S: 1-33.

Menze, Clemens: Úber den Zusammenhang von Sprache und Bildung in der Sprachphilosophie Wilhelm von Humboldts. In: Pädagogische Rundschau 18 (1964), S. 768-85.

Minor, J[acob]: Zwei Schulhefte Schillers. In: Zeitschrift für die österreichischen Gymnasien 39 (1888), S. 1057-82 [Karlsschule].

Morres, Eduard: Herders Ansichten über den deutschen Unterricht. In: Pädagogische Blätter für Lehrerbildung und Lehrerbildungsanstalten 32 (1903), S. 562-71.

Müller, Gisela: Das lateinische Ubungsbuch des 19. Jahrhunderts in Deutschland. Phil. Diss. Konstanz 1975 (Druck Zürich 1976).

Mundorf, Gerda: Die Muttersprache im pädagogischen Werk Herders (Hg.: Deutsches Pädagogisches Zentralinstitut) Berlin (Ost) 1956 [H.s Ansichten über die Muttersprache und sein Wirken für Verbesserung des deutschen Unterrichts].

Neuber, Wolfgang: Zur Dichtungstheorie der österreichischen Restauration. Die »Institutio ad Eloquentiam «. In: Die österreichische Literatur (s. dort), Tl. 1, S. 23-53.

Oberembt, Gert: Schülerlektüre und frühe Droste-Rezeption. Ein Beitrag zur literarischen Sozialisation im 19. Jahrhundert. In: Beiträge zur Droste-Forschung 4 (1976/77), S. 109-28.

Ockel, Eberhard: Rhetorik im Deutschunterricht. Untersuchungen zur didaktischen und methodischen Entwicklung mündlicher Kommunikation (Göppinger Arbeiten zur Germanistik 134) Göppingen 1974.

Oellers, Norbert: Schiller. Geschichte seiner Wirkung bis zu Goethes Tod, 1805-1832 (Bonner Arbeiten zur deutschen Literatur 15) Bonn 1967.

Pasternak, Franz: Die ästhetische Erziehung bei den Philanthropisten, mit Berücksichtigung der ästhetischen Strömungen ihrer Zeit. Phil. Diss. Halle-Wittenberg 1927.

Penzl, Herbert: J. Chr. Gottsched und die deutsche Sprache in Österreich. In: Michigan Germanic Studies 1 (1975), S. 141-51.

Peter, Hermann: G. E. Lessing und St. Afra. In: Deutsche Rundschau 26 (1881), S. 366-88 (Neudruck in: Mitteilungen des Vereins für Geschichte der Stadt Meißen. H. $25=$ Bd. 7 , H. 1, 1906, S. 34-63).

Peter, Hermann: Die Pflege der deutschen Poesie auf den sächsischen Fürstenschulen im zweiten Viertel des vorigen Jahrhunderts. In: Mitteilungen des Vereins für Geschichte der Stadt Meißen. Bd. 1, H. 3 (1884), S. 23-69 [Schülerdichtungen aus St. Afra; Dichterkränzchen in Pforta, mit Proben].

Peter, Hermann: Das Urkundliche über G. E. Lessings Aufenthalt auf der Landesschule St. Afra 1741-1746. In: Archiv für Litteraturgeschichte 10) (1881), S. 285-308 (Neudruck in: Mitteilungen des Vercins für Geschichte der Stadt Meißen. H. $25=$ Bd. 7, H. 1, 1906, S. 63-75).

Pick, August: Der Neuhumanismus und die deutsche Sprachpflege in den gelehrten Schulen der deutschen Länder. Phil. Diss. Frankfurt/M. 1927 (Druck Landau 1927).

Rabenlechner, Michael Maria: Hamerling als Schottengymnasiast. In: Festgabe zum 100jährigen Jubiläum des Schottengymnasiums. Wien 1907, S. 242-60 [Oktober 1844 bis August 1846].

Raumer, Rudolf von: Der Unterricht im Deutschen. In: Karl von Raumer: Geschichte der Pädagogik vom Wiederaufblühen klassischer Studien bis auf unsere Zeit. 3. Tl. 6. Aufl. Gütersloh 1897, S. 97-246.

Reichel, Eugen: Gottscheds Stellung in der Geschichte des deutschen Unterrichts- und Erzie- 
hungswesens. In: Mitteilungen der Gesellschaft für deutsche Erziehungs- und Schulgeschichte. 19. Jg. 1909. H. 2, S. 77-117.

Roeder, Peter-Martin: Zur Geschichte und Kritik des Lesebuchs der höheren Schule (Marburger Pädagogische Studien 2) Weinheim 1961.

Rudert, Otto: Die Entwicklung des mittelhochdeutschen Unterrichts. In: Zeitschrift für den deutschen Unterricht 29 (1915), S. 628-36.

Schaub, Gerhard: Georg Büchner und die Schulrhetorik. Untersuchungen und Quellen zu seinen Schülerarbeiten (Regensburger Beiträge zur deutschen Sprach- u. Literaturwissenschaft 3) Bern u. Frankfurt/M. 1975.

Schöppa, Wilhelm: Goethes Eindringen in den deutschen Unterricht. In: Mitteilungen der Gesellschaft für deutsche Erziehungs- und Schulgeschichte. 20. Jg. 1910, H. 4, S. 271-85.

Schübel, Georg: Die Geschichte des mittelhochdeutschen Unterrichts. In: Zeitschrift für Deutschkunde 35 (1921), S. 319-37.

Schumann, Joh[ann] Christ[oph] Gottlob: Gotthold Ephraim Lessings Schuljahre. Ein Beitrag zur Kultur-, Litteratur- und Schul-Geschichte. Trier 1884.

Schwartz, Paul: Zeitungslesen in preußischen Schulen. In: Zeitschrift für Geschichte der Erziehung und des Unterrichts 15 (1925), S. 109-17.

Theorien des Deutschunterrichts. Hg. v. Juliane Eckhardt u. Hermann Helmers (Wege der Forschung 541) Darmstadt 1980.

Toelle-Arnstadt, Max: Schultheater und Schüleraufführungen in Arnstadt (1545-1907). Arnstadt 1939.

Wais, Roderich: Lyrikanthologien für den Deutschunterricht an höheren Schulen im 19. Jahrhundert. In: Die deutsche Anthologie. Hg. v. Joachim Bark u. Dietger Pforte. Bd. 2 (Studien zur Philosophie u. Literatur des 19. Jh.s 2) Frankfurt/M. (1969), S. 267-97.

Wegener, Philipp: Zur Geschichte des deutschen Unterrichts. Beil. zum Jahresbericht des Gymnasiums und der Realschule zu Greifswald Ostern 1906.

Weigand, Georg: Karl Ferdinand Becker - ein hessischer Pädagoge und Sprachphilosoph des 19. Jahrhunderts (Frankfurter Beiträge zur Historischen Pädagogik) Frankfurt/M. usw. (1966) [Darin: A. Beckers 'Methode des Unterrichts in der deutschen Sprache`, S. 59-66; Beckers Einfluß auf die Entwicklung des muttersprachlichen Unterrichts, S. 66-71].

Welzig, Werner: Heine in deutschen Balladenanthologien. In: GRM N.F. 27 (1977), S. 315-28.

Welzig, Werner: Der Typus der deutschen Balladenanthologie (Österr. Akademie der Wiss. Phil.-Histor. Kl. Sitzungsberichte, Bd. 313) Wien 1977.

Wilisch, E[rich]: Das Ende der Zittauer Schulkomödie. In: Mitteilungen der Gesellschaft für Zittauer Geschichte. Nr. 4, 1907, S. 3-14.

Wilke, Christian Hartwig: Fabel als Instrument der Aufklärung. Untersuchung der Leistungsfähigkeit eines literarischen Typus. In: Basis 2 (1971), S. 71-102.

Windel, Rudolf: Aus Lehrbüchern für den deutschen Unterricht aus dem XVII. und YVIII. Jahrhundert. Ein Beitrag zur Geschichte des deutschen Unterrichts. In: Neue Jahrbücher für Pädagogik. 7. Jg. (Neue Jahrbücher für das klassische Altertum Geschichte und deutsche Literatur und für Pädagogik, Bd. 14) 1904, S. 391-410.

Wollenberg, Julius: Wie sah es auf Berliner Gymnasien in alten Zeiten mit dem Unterrichte im Deutschen aus? In: Zeitschrift für das Gymnasialwesen. 17. Jg. 1. Bd. 1863, S. 241-60. 


\section{Personenregister}

Nicht aufgenommen ist die Sekundärliteratur. Einmalige Nennungen, bloße Erwähnungen, Verweise sowie Literaturnachweise in den Anmerkungen sind nicht verzeichnet. - Hinweise auf Kurzbiographien kursiv. - Anonyma unter dem Werktitel.

Abbt, Thomas $101 \mathrm{f} ., 106 \mathrm{f}$.

Adelung, Johann Christoph 44, 47, 58, 61, $183 \mathrm{f}$.

Aesop $134 \mathrm{f} ., 137$

Alxinger, Johann Baptist v. 85, $91 \mathrm{f}$.

Ancillon, Friedrich 102, 107, $110 \mathrm{f}$.

Archenholz, Johann v. $98 \mathrm{f}$., 101, $104 \mathrm{f}$.

Arndt, Ernst Moritz 101, 115, $122 \mathrm{f}$.

Arnim, Achim v. 101,. 108, 110, 112, 115, 122,124

Auersperg, Anton Alexander v. s. Grün, Anastasius

Batteux, Charles 18, 54

Bernhardi, August Friedrich 28, 41 f., 149

Besser, Johann v. 8, 197

Blumauer, Johann Aloys 85, 92

Bodmer, Johann Jakob 88, 90 f., 110

Börne, Ludwig 101, 124

Boisserée, Sulpiz 101, 110, 112

Bone, Heinrich 118, 122 f., 181, 202

Bonitz, Hermann 70, 149

Bopp, Franz 100, 109f.

Brachmann, Louise 114, 116f.

Brandes, Johann Christian 91, 184

Braun, Alois $125 \mathrm{f}$.

Braun, Heinrich 10f., $54 \mathrm{f}$., 66, 149

Brederlow, C. G. Friedrich 94 f., 123

Breitinger, Johann Jakob 46, 11 (), 194

Brentano, Clemens 113, 115, 118, 122-24

Brockes, Barthold Heinrich 89f., 130, 197

Budde, Franz 123 f., 127

Bürger, Gottfried August 53, 61, 66, 92, 116, 179

Büsching, Anton Friedrich 16, 193

Buffon, Georg Louis Leclerc 97, 105

Burke, Edmund 98, 133

Calderon de la Barca, Pedro 60f.

Campe, Joachim Heinrich 97, 111

Canitz, Friedrich Rudolf Ludwig v. 18, 88 f., 91, 130, 197
Celsus 75, 165, 193

Cervantes Saavedra, Miguel de 60f., 199

Chamisso, Adalbert v. 93-95, 101, 105, 113, $115,118,124$

Cicero 4, 11, 75, 80-82, 112, 134, 161

Claudius, Matthias 92, 94, 101, 114, 118, 181, 202

Collin, Heinrich Joseph v. u. Matthäus Casimir v. 61, $91 \mathrm{f}$., 94

Cramer, Johann Andreas 8, 88, $91 \mathrm{f}$.

Creuzer, Friedrich 100 f., 107, 110, 112, 188

Cronegk, Johann Friedrich v. 88, 91

Curtman, Wilhelm Jakob Georg 115 f., 120, 122-24

Dach, Simon 127, 197

Deinhardt, Johann Heinrich 26, 30, 40 f., 149

Denis, Michael 80, 82, 85, 87-92, 149, 165

Dilthey, Karl 34 f., 149

Dusch, Johann Jakob 90, 165

Eberhard, Johann August 97, 99, 101, $109 \mathrm{f}$.

Echtermeyer, Theodor 118, 122

Edda 60, 179

Eichendorff, Joseph v. 94, 118, 122-24

Eisenschmid, Leonhard Martin 104 f., 107, $109 \mathrm{f} ., 115 \mathrm{f} ., 120,122 \mathrm{f}$.

Engel, Johann Jakob 15f., 60, 63-65, 91, 97-101, 105-07, 109-11, 132, 135, 140, 149, 184

Erhard, Heinrich August 99 f., 104 f., 107, $110,127,132$

Eschenburg, Johann Joachim 18f., 58, 61, 65

Eschenmayer, Karl August 100, 107

Falkmann, Christian Ferdinand (oder Friedrich) 114, 116f., 137-41

Fernow, Karl Ludwig $100 \mathrm{f},{ }, 110$

Fichte, Johann Gottlieb 99-102, 106 f., 115

Flemming, Paul 52, 127, 129, 197

Förster, Karl August 114, 116, 122 
Follen, August Adolf Ludwig 94 f., 115 f., 120 . 122 f., $149 f$., 201

Forster, Johann Georg 60, 98-101, 105 f., 109-11

Fouqué, Friedrich de la Motte 99-101, 124

Freiligrath, Ferdinand $93 \mathrm{f}$.

Fröhlich, Abraham Emanuel 94, 116-18

Gärtner, Karl Christian 8, 18

Garve, Christian 63f., 92, 97, 99-102, 106f., 110,161

Gedike, Friedrich 9, 15 f., 150

Gellert, Christian Fürchtegott 11, 80 f., 85, $88-92,99,101,107,110,114,116,118$, 126, 144, 161, 165, 181, 183f., 197

Gentz, Friedrich v. 94f., 98, 101, 112

Gerstenberg, Heinrich Wilhelm v. 88, 91

Gervinus, Georg Gottfried 85, 101 f., 112, 201

Gesner, Johann Matthias 14, 16, 150

Geßner, Salomon 80 f., 92 f., 99-101, 109 f., 114, 116, 126, $142 \mathrm{f} ., 165$

Gleim, Johann Wilhelm Ludwig 114, 116, 118

Goeckingk, Leopold Friedrich Günther v. $91 \mathrm{f}$.

Görres, Joseph v. 101, 109 f., 112 f., 123

Goethe, Johann Wolfgang 50, 52 f.f, 59-63, 67, 85 f., 91-102, 104-11, 114-18, $125 \mathrm{f}$., 132, 142, 144 f., 179, 181, 184, 195f., 199, $201 \mathrm{f}$.

Götzinger, Maximilian Wilhelm 38, 115, 118, $120,122,150$

Gottschall, Rudolf $144 \mathrm{f}$.

Gottsched, Johann Christoph 8, 46, 88 f., 194

Grabbe, Christian Dietrich 124, 144

Grillparzer, Franz 50, 92, 94, 124

Grimm, Jacob u. Wilhelm 94, 100-02, $108-13,115,123,143$

Grün, Anastasius 93-95, 179

Gudrun 179, 181

Günther, Joachim 37 f., 126, 133

Hagedorn, Friedrich v. 18, 88-91, 134, 137

Haller, Albrecht v. 18, 59f., 62, 90-92, 97 , $99,111,141$

Hamann, Johann Georg 101, 110

Hamerling, Robert 144-45, 194

Hammer-Purgstall, Joseph v. 101, $104 \mathrm{f}$.

Hardenberg, Friedrich v. s. Novalis

Haug, Friedrich $91 \mathrm{f}$.

Hebel, Johann Peter 93f., 101, 115, 118. 143

Heeren, Arnold Hermann Ludwig $98 \mathrm{f}$., $100-02,104,110$
Hegel, Georg Wilhelm Friedrich 29, 100 f., 107,110

Heine, Heinrich 94 f., 101, 115, 118, 124

Heinse, Wilhelm 61, 99-101, $105 \mathrm{f} ., 109 \mathrm{f}$.

Heinsius, Theodor 58, 61, 116, 122, 124, $126 \mathrm{f}$.

Herder, Johann Gottfried 53, 59-65, 92-94, 98-102, 107-11, 114, 116-18, 127, 132, 140,179

HeB, Ignaz Matthias v. 73-76, 150

Heydenreich, Karl Heinrich 63 f., 99 f., 107, 109

Heyne, Christian Gottlob 12, 16, 63 f., 99 f., 150

Hiecke, Robert Heinrich 33, 39-41, 98, $100 \mathrm{f} ., 104 \mathrm{f} ., 108-11,150$

Hippel, Theodor Gottlieb v. 101, 107

Hirschfeld, Christian Cay Lorenz 99, 105, 142

Hirzel, Heinrich 99, 105

Hölderlin, Friedrich 85 f., 94 f., 101, 114 f., $118,122,179,201$

Hölty, Ludwig Heinrich Christoph 61, 66, $91 \mathrm{f} ., 99,110,114,118,144$

Hoffmann, Ernst Theodor Amadeus 101, $113,115,124,199$

Homer, 45, 60, 67, 80, 110, 116, 135f., 179, 183,199

Horaz 4, 20, 80, 82, 135 f., 184

Hottinger, Johann Jacob 99, 109

Hufeland, Christoph Wilhelm $63 \mathrm{f}$.

Humboldt, Alexander v. 99-101, $105 \mathrm{f}$.

Humboldt, Wilhelm v. 12 f., 29 f., 100, 102, $104,108,110$

Iffland, August Wilhelm 91, 184

Immermann, Karl 101, 124, 126

Iselin, Isaak 98-99, 104

Jacobi, Friedrich Heinrich 59, 61, 63, 97, 99, $106 \mathrm{f}$.

Jacobi, Johann Georg 88, 94

Jacobs, Friedrich 53, 63 f., 100-02, 109-11, 186

Jahn, Friedrich Ludwig $101 \mathrm{f}$., 112

Jean Paul 93-95, 98-102, 105f., 108, 110f., $116,124,126,143,199$

Jerusalem, Johann Friedrich Wilhelm $63 \mathrm{f}$., $99,106 \mathrm{f}$.

Jung-Stilling, Johann Heinrich 99, 101, 111

Justi, Johann Heinrich Gottlob v. $11 \mathrm{f}$.

Kästner, Abraham Gotthelf 74, 91

Kannegießer, Karl Ludwig 105, 123, 132 f. 
Kant, Immanuel 98-101, 105-07

Kehrein, Joseph 125-27, 145, 189

Kerndörffer, Heinrich August 114-16, 120 , 122,126

Kerner, Justinus 93-95, 113, 115 f., 118

Kleist, Ewald v. 62f., 88-92, 116, 197

Kleist, Heinrich v. 95, 102, $123 \mathrm{f}$.

Kletke, Heinrich 98, 102, 104 f., 107 f., 110

Klinger, Friedrich Maximilian v. 102, 116

Klopstock, Friedrich Gottlieb 8, 52, 59 f., 62 f., $68,80,82$ f., 85, 87-92, 94, 97, 101, 110, $114,116,118,125 \mathrm{f} ., 135,137,140,144$, 184, 189-91, 197

Klumpp, Friedrich Wilhelm 26, 34, 37, 150, 175

Knebel, Karl Ludwig v. 101 f., $110 \mathrm{f}$.

Knigge, Adolph Frhr. v. 97, 100 f., $106 \mathrm{f}$.

Koberstein, August 39, 85, 143, 150, 206

Köchly, Hermann 33, 35-37, 42, $150 f$.

König, Johann Ulrich v. $89 \mathrm{f}$.

Körner, Christian Gottfried 100, 110, 115

Körner, Theodor 51, 61, 86, 93, 116, 122-24, $144,179,181$

Kopisch, August $118 \mathrm{f}$.

Kosegarten, Gotthard Ludwig Theobul 91, 116

Kotzebue, August v. 91, 184

Krug, Wilhelm Traugott 100, 107

Krummacher, Friedrich Adolf 92, 94, 100 , $102,114,116$

Lenau, Nikolaus 93-95, 126, 179

Leo, Heinrich $100 \mathrm{f} ., 104$

Lessing, Gotthold Ephraim 59, 61, 63, 66f., 80-82, 85, 89-92, 94, 97, 99-102, 107-11, 114, 116, 118, 126, 134f., 137, 181, 184

Lichtenberg, Georg Christoph 95, 116

Lichtwer, Magnus Gottfried 90 f., 116, 118

Livius 81,134

Logau, Friedrich v. 88-91, 129, 143

Lohenstein, Daniel Casper v. 88, 130

Luden, Heinrich 99f., 104

Ludwig I., Kg. v. Bayern 94, 118, 123

Macpherson, James s. Ossian

Manso, Johann Kaspar Friedrich 53, 99, 102, 109f., 186

Martial $80 \mathrm{f}$.

Marx, Gratian 71, 73-77, 79f., 85, 87 f., 151

Mastalier, Karl 85, 88, $91 \mathrm{f}$.

Matthisson, Friedrich v. 53, 61, 91 f., 99, 106, $114,116,126,144$

Meierotto, Johann Heinrich Ludwig $97 \mathrm{f} ., 151$
Meiners, Christoph 100, 105

Mela 75, 193

Mendelssohn, Moses 99, 101, 107, 110

Menzel, Wolfgang 101, 104

Mertens, Hieronymus Andreas 89, 91

Michaelis, Johann Benjamin 80, 82, 88, 91

Möser, Justus $98 \mathrm{f}$., $104 \mathrm{f}$.

Moritz, Karl Philipp 98-100, $105 \mathrm{f}$.

Mosheim, Johann Lorenz v. $106 \mathrm{f}$., 132

Müller, Adam 112, 133

Müller, Johannes v. 53, 59, 61-64, 98-102, 104 f., 199

Müller, Wilhelm 94, 109 f., 118

Mundt, Theodor 101, 110

Muret, Marc Antoine 80-82

Neander, Joachim 101, 107

Nepos, Cornelius 75, 189

Neuffer, Christian Ludwig $62 \mathrm{f}$., $93 \mathrm{f}$.

Nibelungenlied $53,60,68,112,127,144$,

$179,181,188,203$

Nicolai, Friedrich 97, 110

Niebuhr, Barthold Georg 99, 101, $104 \mathrm{f}$.

Niethammer, Friedrich Immanuel 12, 59, 67, $151,162,202$

Nikolay, Ludwig Heinrich v. 61, $91 \mathrm{f} ., 116 \mathrm{f}$.

Novalis $85,95,102,108,110,112 \mathrm{f} ., 115$, $118,122-24,145,199,202$

Ohlert, Albert Leopold Julius $25 \mathrm{f}$.

Oken, Lorenz 33, 110, 112

Opitz, Martin 8, 18, 52, 62, 88-90, 127, 129, 197, 203

Ossian 60, $87 \mathrm{f} ., 116$

Ovid 61, 81, 135f., 144f., 199

Passavant, Johann David 101, $109 \mathrm{f}$.

Pestalozzi, Johann Heinrich 101, 111

Pfeffel, Gottlieb Conrad 61, $91 \mathrm{f} .$. 114, 116, 118

Pfizer, Paul 101, 110

Phaedrus 80 f., 134 f., 137

Pichler, Karoline $91 \mathrm{f}$.

Pietsch, Johann Valentin 88, 197

Pischon, Friedrich August 104-11, $124 \mathrm{f}$., 128-32

Platen, August v. 93-95, 115, 118, 124, 179

Platner, Ernst 99, 107

Plautus 80, 82, 134

Plinius d. Ä. u. d. J. 75, 80 f., 165, 193

Podlaha, Wilhelm 86, 93-95

Posselt, Ernst Ludwig 58, 63f., 98-101, 104 


\section{Länderregister}

Baden 30, $47 \mathrm{f}$., $204 \mathrm{f}$.

Bayern 2, 7, $10 \mathrm{f}$, $31 \mathrm{f}$, $42 \mathrm{f}$., $47 \mathrm{f}$., 53-69, $71-73,160,171,173-75,182,205$

Hannover 24, 27, 168, 170

Hessen-Darmstadt 13, 23 f., 205

Hessen-Nassau 24

Mainz 9, 14 f., 17
Österreich 2, 7, $11 \mathrm{f} ., 32,43 \mathrm{f} ., 48,69-95,178$

Preußen 2, 7, 9, 13, 22 f., $27 \mathrm{f} ., 41,43-53$, $169 \mathrm{f}, 200$

Sachsen 13, 23, 27, 42, 163, 170 f., 177, 182-84, 205

Württemberg 13, 66, 164-66, 189

Zürich 19, 166 f., 171 


\section{Rolf Engelsing}

\section{Der Bürger als Leser}

\section{Lesergeschichte in Deutschland 1500-1800.}

1974. VI, 375 Seiten. Kartoniert DM 46,-

ISBN 3-476-00287-X

Eine Lesergeschichte, wie sie hier von Rolf Engelsing vorgelegt wird, hat sich stets der Aufgabe zu stellen, den individuellen Leseprozeß mit dem gesellschaftlichen zu konfrontieren. Mit der Einschränkung freilich, daß die Quellenlage diesen Doppelschritt überhaupt zuläßt. Engelsings Buch ist daher nicht als vollständige Lesergeschichte Deutschlands zu verstehen, sondern als Untersuchung, welche sich bewußt auf die regionalen Aspekte beschränkt, die eine norddeutsche protestantische Handelsstadt wie Bremen im Vergleich zum katholischen Süden Deutschlands von 1500 bis 1800 bietet. Seine Darstellung konzentriert sich auf das Bürgertum, schließt aber Seitenblicke auf andere soziale Gruppen ein. Unter der vorrangigen Betrachtung reproduktiver und produktiver Elemente des Leseverhaltens und der Lesewirkung kann Rolf Engelsings Buch als wichtiger Beitrag zur sozialwissenschaftlichen Aufarbeitung der bürgerlichen Kultur der Neuzeit gelten.

„Den Ausgangspunkt dieser Darstellung bildet das Bremer Bürgertum, doch Engelsing weiß mit Geschick dieses Modell zu einer spannenden Bildungsgeschichte von dreihundert Jahren auszudehnen, in der aus vielseitigem Quellenmaterial ebenso Leseverhalten des Bürgers wie die gesellschaftliche Entwicklung erschlossen wird.“

DIE ZEIT

\section{J.B.Metzler $\cdot$ Stuttgart}




\section{Rolf Engelsing}

\section{Analphabetentum und Lektüre}

\section{Zur Sozialgeschichte des Lesens}

in Deutschland

\section{zwischen feudaler und industrieller Gesellschaft.}

1973. XIV, 210 Seiten und 12 Abbildungen.

Kartoniert DM 46,-

ISBN 3-476-00271-3

Engelsing faßt den Gesamtkomplex Lesen für den Zeitraum vom Hochmittelalter bis zur Gegenwart zusammen. Er dokumentiert und untersucht die Bereiche Analphabetentum, Lektüre Buchdruck, Schul- und Volksbildung in Form eines sozialhistorischen Querschnitts. Der Schwerpunkt liegt dabei auf der pragmatischen Darbietung der Fakten, Materialien und Zahlen, die bisher in dieser Form - wenn überhaupt - nur für den Zeitraum seit der Aufklärung verfügbar waren. Zugleich kombiniert Engelsing die problemorientierte sozialwissenschaftliche Betrachtungsweise mit der buchwissenschaftlichen, die ihren Schwerpunkt in der angewandten Kulturkunde hat, was auch eine sachliche Erweiterung des Themas über den Aspekt des unmittelbar Aktuellen hinaus bedeutet. Der Band erfüllt so gleichermaßen den Anspruch einer exakten soziologischen Studie wie den eines Beitrags zur Geschichte der europäischen Kultur seit dem Mittelalter. Aufgrund des hier erstmals zusammengetragenen Quellenmaterials ist der Band grundlegend für jede weitere Beschäftigung, auch mit Einzelaspekten des Gegenstands. Er richtet sich gleichermaßen an den Kultursoziologen wie den Literaturwissenschaftler, an den Pädagogen wie den Historiker.

\section{J.B.Metzler $\cdot$ Stuttgart}

